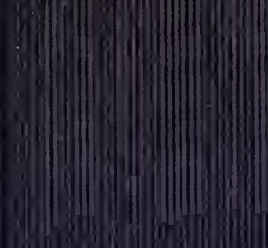




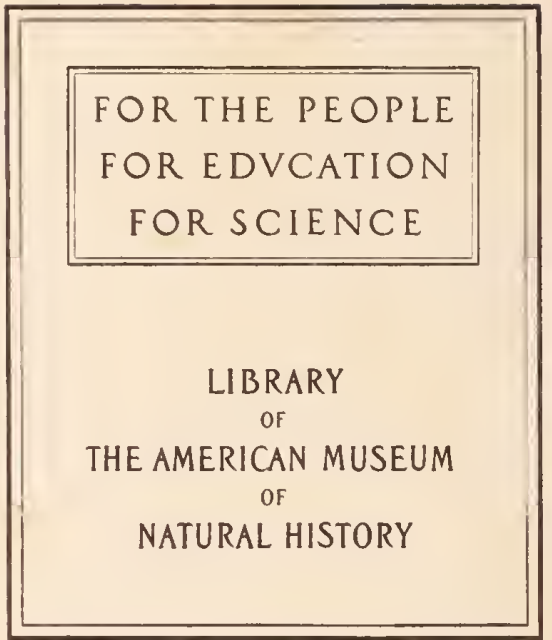






\section{DIE WIRBELTIERE}

Eine Übersicht

über die fossilen und lebenden Formen

\section{Dr. Otto Jaekel}

Professor an der Universität Greifswald

Mit 281 Abbildungen im Text

\section{Berlin}

Verlag von Gebrüder Borntraeger W 35 Schöneberger Ufer 12 a 


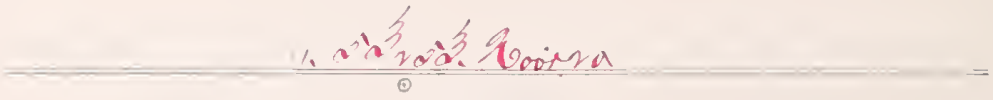

Alle Rechte,

insbesondere das Recht der Übersetzung in fremde Sprachen, vorbelalten

Copyright, 1911, by Gebrüder Borntraeger in Berlin 


\section{Vorwort}

Eine fernere Trennung der Wissenschaften der fossilen und der lebenden 'Tiere ist mit unseren Anschaunngen über die Entwicklung des organischen Lebens nicht melr in Einklang zu bringen. Die Notwendigkeit, die Ergebuisse der bisher getrennten Wissenschaften miteinander vergleichen und vereinen zu können, heischt auch im system eine Lösung. Wenn ich einen Versuch, die traditionelle Nauer zu übersteigen und einen Überblick über das ganze Gebiet zu erlangen, uit dem großen und formenreichen stamm der Wirbeltiere begann, so hoffe ich damit einerseits einem hier besonders zutage getreteneu Bedürfnis entgegenzukommen, andererseits aber bei der Größe dieses Gebietes und der vielseitigen Komplikationen seines fast unübersehbaren Inhaltes auf eine nachsichtige Aufnahme des Buches hoffen zu dürfen.

Besonderen Wert habe ich auf die Abbildungen gelegt. Eine klare Abbildung besagt mehr als zehn Seiten Text, und das Buch soll in erster Linie einen bequemen Überblick schaffen. Ich habe mich besonders bemüht, das paläontologische Vaterial durch nene Zeichmungen so klar zu stellen, daß es für den Zoologen und Anatomen wünschenswerte Aufschlïsse zum Vergleich mit den lebenden Formen und zur Klärung stammesgeschichtlicher Fragen liefert und eine Auswahl von Nachbildungen anderer Darstellungen wesentlich von diesem Gesichtspunkt getroffen. Von den lebenden Wirbeltieren sind zwar gute Abbildungen leichter zu beschaffen, aber auch wohl den meisten Forschern, namentlich aber dem weiteren Kreise von Interessenten nicht so leicht zugänglich, daß ihre reichliche Datbietung nicht willkommen sein dürfte. Den Herren Prof. Matschie und Dr. Pappenheim am Berliner zoologischen Museum bin ich für freundliche Hilfe bei der Auswahl ron Figuren lebender Säugetiere und Knochenfische zu besonderem Danke verpflichtet. Der Verlagsbuchhandlung aber wird der Leser mit mir dankbar sein, daß sie die Mittel für die Herstellung der zahlreichen Figuren uneingeschränkt zur Verfügnug stellte. 



\section{In halt. *)}

Seite

Vorwort . . . . . . . . . . . . . . . . . . III

Einleitung . . . . . . . . . . . . . . . . . . 1

Umfang des Wirbeltierstammes . . . . . . . . . . . . . 8

Znrechnung der Tunicaten

Einteilnng der typischeu Wirbeltiere

Die geologischen Zeiträume . . . . . . . . . . . . . . 16

1. Unterstamm Protetrapoda . . . . . . . . . 17-24

Klasse Tunicata . . . . . . . . . . . . . . . . . 17

Ordnung Appendiculati . . . . . . . . . . . . . . . 19

" Ascidii . . . . . . . . . . . . 20

$"$ Salpi . . . . . . . . . . . . . . 22

2. Unterstamm Eotetrapoda . . . . . . . . . . 25-99

I. Klasse Malacostomata c . . . . . . . . . . . . . . . 29

1. Unterklassc Palaeostraci . . . . . . . . . . . 31

Ordnmug Heterostraci . . . . . . . . . . . . . . . 32

Goniaspidi . . . . . . . . . . . . 33

" Anaspidi . . . . . . . . . . . . . . 37

"Pterichthyi . . . . . . . . . . . 37

2. Unterklasse Cyclostomata . . . . . . . . . 38

Ordmung Palaeospondyli . . . . . . . . . . . . 39

Hypospondyli . . . . . . . . . . . . 39

$"$ Myxini . . . . . . . . . . . . . . 40

$"$ Petromyzontes . . . . . . . . . . . 40

3. Unterklasse Leptocardia . . . . . . . . . . . . 41

II. Klasse Hypostomata . . . . . . . . . . . . . . . . . 43

1. Unterklasse Placorlermata . . . . . . . . . . 44

Ordnnng Ptychostei . . . . . . . . . . . . . 46

Coccostei . . . . . . . . . . . . . . 47

2. Unterklasse Chondrostei . . . . . . . . . . . . . 49

Ordnung Sturioni . . . . . . . . . . . . 51

"Polyodonti . . . . . . . . . . 51

\#) Um diese Inhaltsangabe übersichtlich zu erhalten, sind Unterorduungen nicht aufgefiihrt und die phylogenetischen Bezeichnungszusätze wie „Nebcn"klasse, „Haupt"ordnung usw. fortgelassen. Klassen sind also hier ebenso wie Ordnungen nur als solche bezeichnet. 
3. Unterklasse Placodea . . . . . . . . . . . . . . . . . . . .

Ordnung Holocephali . . . . . . . . . . . . . 52

Selachii . . . . . . . . . . . . 5 5

III. Klasse Teleostomata . . . . . . . . . . . . . . . . 66

1. Unterklasse Proostea . . . . . . . . . . . . 70

2. Unterklasse Holostea . . . . . . . . . . . . 73

Ordnnng Cyclolepidoti . . . . . . . . . . . . 75

Dipnoi . . . . . . . . . . . . . . 77

Osteolepidoti . . . . . . . . . . . 79

Polypteri . . . . . . . . . . . . 8 80

Heterocerci . . . . . . . . . . . . 80

Platysomi . . . . . . . . . . . . . 81

Lepidostei . . . . . . . . . . . . . . . . . 82

Pycnodonti . . . . . . . . . . . . . 83

Belonostomi . . . . . . . . . . . . . 84

Amii . . . . . . . . . . . . . . . 84

Eugnathi . . . . . . . . . . . . . . 85

Belonorhynchi . . . . . . . . . . . 86

3. Unterklasse Teleostea . . . . . . . . . . . . . 87

Orinung Malacopteri . . . . . . . . . . . . . 88

Ostarioplysi . . . . . . . . . . . . . 89

$"$ Apodes . . . . . . . . . . . . . . . 91

" Symbranchii . . . . . . . . . . . . . 91

" Haplomi . . . . . . . . . . . . . . . . 92

" Heteromi . . . . . . . . . . . . . . . 92

" Catosteomi . . . . . . . . . . . . . . . 93

" Anacanthini . . . . . . . . . . . . . 95

"Acanthopteri . . . . . . . . . . . 95

Opisthomi . . . . . . . . . . . . . 98

"Perlicnlati . . . . . . . . . . . . . 98

" Plectognathi . . . . . . . . . . . . 98

3. Cnterstamm Tetrapoda . . . . . . . . 100-24.

I. Klasse Hemispondyla . . . . . . . . . . . . . . . 106

Ordnung Branchiosanri . . . . . . . . . . . . . 109

Plagiosterni . . . . . . . . . . . 109

Sclerocephali . . . . . . . . . . . 110

Acanthostomi . . . . . . . . . . . 114

Trematocephali . . . . . . . . . . 114

II. Klasse Miosauria . . . . . . . . . . . . . . . . . . 115

1. Unterklasse Microsauria . . . . . . . . . . . . 117

Ordnnng Haplosanri . . . . . . . . . . . . . 118

Urosanri . . . . . . . . . . . . 118

Aistopodi . . . . . . . . . . . . . 119

Nectridei . . . . . . . . . . . . . . 119

2. Unterklasse Cotylosauria . . . . . . . . . . . 121

Ordnung Pareiasauri . . . . . . . . . . . . . 122

Datheosauri . . . . . . . . . . . . 124 
III. Klasse Amphibia

?Ordnung Lysorophi

Ordnung Gymnophioni

"Urodeli . . . . . . . . . . . . . . . . 129

Anuri

IV. Klasse Reptilia

1. Unterklasse Archaeosamia . . . . . . . . . . . 130

Ordnung Gephyrostegi . . . . . . . . . . . . . 137

Procolophonii . . . . . . . . . . . . 138

"Mesosauri . . . . . . . . . . . . 139

"Ichthyosauri . . . . . . . . . . . . . 140

2. Unterliasse Holosauria . . . . . . . . . . . . 141

Urilnung Protorosauri . . . . . . . . . . . . . . 142

$"$ Rlynchosauri . . . . . . . . . . . . . 146

" Champsosami . . . . . . . . . . . . 147

" Sauropterygii . . . . . . . . . . . . 147

$"$ Placodonti . . . . . . . . . . . . 150

" Lyogmathi . . . . . . . . . . . . . . 152

3. Unterklasse Hyperosania . . . . . . . . . . . 155

Ordnung Dinosanri . . . . . . . . . . . . . . . 157

Loricati . . . . . . . . . . . . . . . 162

Pterosauri

V. Klasse Ares . . . . . . . . . . . . . . . . . . 167

1. Unterklasse Archornithes . . . . . . . . . . . . 170

2. Tuterklasse Neornitlies . . . . . . . . . . . . . 170

Ordunng Odontolcae . . . . . . . . . . . . . 174

Alectromorpliae . . . . . . . . . . . 175

" Ratitae . . . . . . . . . . . . . . 175

$"$ Pelargomorphae . . . . . . . . . . . . 177

n Colymbomorphat . . . . . . . . . . . . 178

" Coraciomorpliae . . . . . . . . . . . . . 179

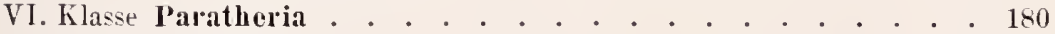

Ordnung Therapsidi . . . . . . . . . . . . 182

$"$ Testudinati . . . . . . . . . . . . 183

"Anomodonti. . . . . . . . . . . . . 189

" Theriodonti . . . . . . . . . . . . 193

"Monotremati . . . . . . . . . . . 195

VII. Klasse Mammalia . . . . . . . . . . . . . . . . . . 197

1. Unterklasse Miotheria . . . . . . . . . . . 204

Ordmung Haplodonti . . . . . . . . . . . . . . 204

" Multituberculati . . . . . . . . . . . 207

$"$ Diprotodonti . . . . . . . . . . . . 209

2. Unterklasse Mesotheria . . . . . . . . . . . . 209

Ordnung Insectivori . . . . . . . . . . . . . . . . 209

Chiropteri . . . . . . . . . . . . . . 211

Galeopitheri . . . . . . . . . . . . 213

Prosimiat . . . . . . . . . . . . . . 213

Simiae . . . . . . . . . . . 216 


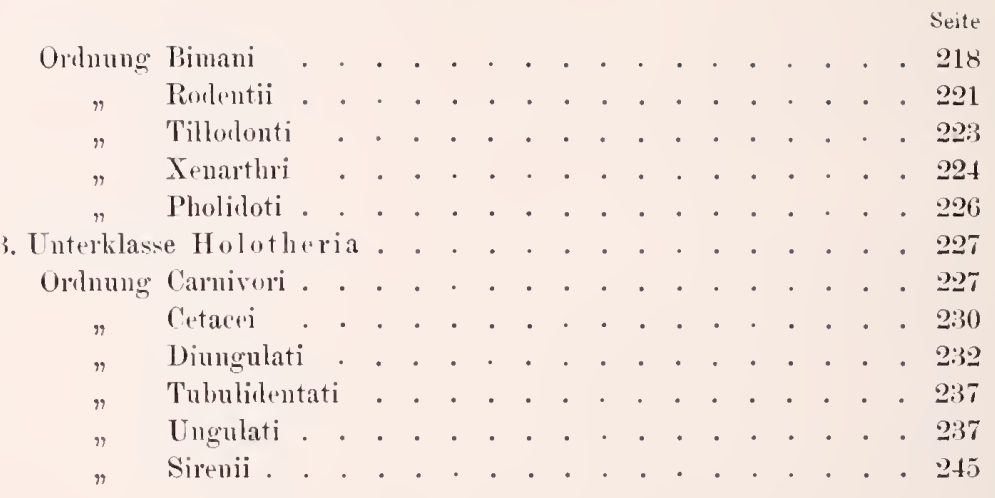


Das System ist nns hente nicht mehr wie zu Linnés Zeiten das Endziel naturwissenschaftlicher Forschung, sondern ein notwendiges Übel, ein praktisches Bedïrfnis vor allem für das Gedächtnis, das sich fiir die Einzelheiten in der Menge Kategorien schaffen muB, Überblick nicht zu verlieren. Was mo heute in seiner ganzen Bedeutung zum Bewußtsein gekommen ist, und alles andere in der Wissenschaft nur als Mittel zum Zweck erscheinen läßt, ist die Klarlegung der stammesgeschichtlichen Entwicklung. In ihr ist alles enthalten, fiir sie ist jedes Einzelne bedentsam, ans ilıren Problemen ergibt sich die leitende Fragestellung für die Behandlungsweise jedes biontologischen Stoffes. Das System ist eine Ansdrucksform der Stammesgeschichte, und manche meinen wohl hente noch Stammesgeschichte und System so in Einklang bringen zı können, daß aus ihrer Kongrıenz ein „natürliches System" resultiere. Aber ein System kann nicht natïrlich sein, da die natürlichen Fäden der Verwandtschaft keine präzisen Alogrenzungen erlauben. In der sogenannten Logik des Systems liegt seine Unnatilr.

Das Ideal des Systems ist eine kurze Definition der Abteilungen, eine scharfe Gegeniiberstellung der Unterabteilungen, nnd dem formalen Schönheitsbedïrfnis des Systems entspricht eine möglichst gleichmäßige Abwägnng des Inhaltes der gegensätzlichen Abteile. Mit dem letzten Postulat hat man zuerst gebrochen. Indem Haeckel z. B. Amphioxus, die einzelne Form, als "Acrania" allen ïbrigen Wirbeltieren, den „Craniota“ gleichwertig gegenüberstellte, stieb er zwar die Systematiker vom alten Schlage arg vor den Kopf, aber er glanbte wenigstens damit den natïrlichen Entwicklungswegen gerecht geworden zn sein. Anch andere haben sich nicht geschent, dem morphologischen Prinzip jede andere Riicksicht zu opfern. Indem z. B. Edw. Cope innerhalb der Cranioten dem Besitz oder Mangel eines Unterkiefers die größte Bedentung zumaß, stellte er die Cyclostomen und einige fossile Fische als "Agnatha" allen iibrigen als "Gnathostomata" gegeniiber. Das waren 
Übertreibungen des Wertes anatonischer Anffassungen, die sich mit dem System nicht vertrngen mnd die schließlich einen geradezn chaotischen Znstand des Systems eingeleitet haben. Die ältere Auffassmng, daß die Cyclostomen von Hanse ans keinen Unterkiefer besaßen, ist unhaltbar geworden, er ist bei ihnen nur verkïmmert; bei alten Fischformen, denen Bashford Dean noch kürzlich den Unterkiefer absprach, ist er ohne Frage nachweisbar. Es war also mindestens sehr voreilig, anf eine morphologische Anffassung eine systematische Einheit anfzubanen, die nmm wie ein Kartenhans zerfällt. Davor sollte und mnß ein Srstem sichergestellt sein. Wie man unreife Hypothesen nicht gleich einem breiten Publikum anftischen soll, so darf man anch unklare stammesgeschichtliche Ideen nicht gleich in ein "System" formen. Die Neignng vieler Phylogenetiker, jede entwicklnngsgeschichtliche Anfassmng durch eine Ändermng des systems zn besiegeln, hätte dem letzteren allein schon jeden festen Halt nehmen müssen, aber das Unheil ist dadnrch noch wesentlich verschärft worden, daß sich diese neneren srstematischen Versuche auf ganz verschiedenen WTegen selbstïndig nebeneinander her bewegten.

Die unselige Trennung der fossilen von den lebenden Organismen hat sich anch anf das system erstreckt, trotzdem dieses letztere nach der Anffassme aller anf der Stanmesgeschichte beruhen soll. Aber dem Zoologen, dem Embryologen, dem Anatomen sind eben andere Inomente maßgebend wie dem Paläontologen, und so macht jeder sein System. ohne anf das Arbeitsmaterial des anderen volle Rücksicht zu nehmen. Verschiedene Autoren wie Flower, Weber haben sich in ihren Systemen der Sängetiere bemüht, das fossile Laterial wenigstens nebenbei zu erwïhnen oder gar systematisch zu berïcksichtigen, dassethe haben Cope, Zittel, W. K. Gregory n. a. vom paläontologischen Standpnnkt in einzehnen thteilnngen rersucht nnd ihre dabei gewonnenen Prinzipien anf das lebende Material auszudehnen gesucht, aber einheitliche gleichsimnige Bearbeitungen fossiler und lebender Formen gilht es noch kaum, ebenso wie, wenigstens in Europa, noch allgemein die lebenden Formen und ihre ansgestorbenen Vorfahren gewissenhaft anf verschierlene Mnseen verteilt werden: die lebenden Bären und Rhinozeronten in das eine, die dihnvialen nnd tertiären in ein anderes, damit man nur ja nicht in Versuchumg gerate, beide miteinander zu vergleichen und Beobachtungen an den einen znr Beurteihng der anderen zn verwerten! -

Es ist nnlenglbar, daß die fossilen Formen größtenteils nnr mangelhaft bekannt sind, nnd daß es recht schwierig ist, sich ein eigenes Urteil ïber solche oft nur als Unika bekannte Formen zn bilden. Andererseits ist die Arbeit des Paläontologen an sich schon so musag- 
bar mühsam und zeitraubend, daß el sich mit der meist sehr großen Menge der lebenden Formen schwer abfinden kann und es daher selten wagt, auch ïber die rezenten Formen ein abschließendes Crteil zu fällen. Geschieht es abel wirklich hier und da, so pflegen sich die Zoologen und namentlich die Museumsbeamten als die Hauptrertreter der systematik solchen Torschlägen ron paläontologischer seite gegenüber schon deshalb ablehnend zu rerhalten. Weil die Repräsentanten der ausgestorbenen Abteilungen gar nicht in ihr Departement gehören.

So haben wir hente nebeneinander zoologische, auf sehr rexschiedenen didaktischen. morphologischen oder embryologischen Gesichtspunkten aufgebaute systeme und paläontologische, die nur nebenher das lebende Material berücksichtigen. DaB dies auf die Dauer ein unhaltbarer Zustand ist, wird allgemein empfunden, aber die Hindernisse und Schwieriokeiten seiner Abstellung haben mus bisher ron einer einheitlichen Behandlung des unbestritten einheitlichen stoffes abgehalten. Wenn ich den Versuch wage, gerade auf dem äuBerst komplizierten Gebiet der Wirbeltierkunde eine g-leichsinnige Übersicht über die lebenden und ausgestorbenenen Klassen und Ordnungen zu geben, so liegt das zunächst daran, daß hier das Bedürfnis nach einev Klärung am meisten empfunden wird. Aber auch zufällige praktische Momente sprachen für einen solchen Entschluß. Die Absicht, in der ron mir geplanten Stammesgeschichte der Tiere die Darstellung der Wirbeltiere durch eine allgemeine Besprechung ihrer Organisation einzuleiten, nötigt mich, die systematischen Namen, die ich darin anwenden muB, rorher zu erläutern. Würde ich nun ein solches Srstem dem ersten Heft unserer Stammeso'eschichte einfügen, so wïrde ich dadurch die anderen Mitarbeiter an diesem Teile und mich selbst für das ganze Terk auf dieses Syrstem und damit auch auf eine stammesgeschichte im rorans festlegen. Das erscheint nicht angängig, und so entschloB ich mich im Einvernehmen mit der Verlagsbuchhandlung der .stammesgeschichte*, eine kurz gefaßte Übersicht über die Klassen und Ordnungen der Tirbeltiere roranzuschicken. Hierauf kann ich mich dann belufen, ohne meine Mitarbeiter und mich selbst für die ganze Folge unserer stammesgeschichtlichen Darlegungen endgültig zu binden. Der rorliegende Tersuch wird naturgemäß zunächst mangelhaft ausfallen, aber wie ich hoffe. viele Amregungen zu Terbesserungen hervorrufen und hierdurch unsere Kenntnisse auf diesem Gebiete in rascherem Tempo erweitern, sodaß auch dadurch ständige Änderungen dieses Srstems unausbleiblich rerden. - Noch einige Worte über den Tersuch der Durchführung. 
.Te mehr in museren Kenntnissen die Stammesoeschichte an 7nsammenhang gewinnt, muso aussichtsloser ist es, scharfe systematische Kategorien abzugremzen. Das ist für die Stammesgeschichte höchst erfrenlich, aber es wäle der Tod jedes Systems, wenn die historische Entwickhng immer gerade (orthogenetische oder besser ..engenetische“) Wege ginge, und wenn nicht einige Unstände den systematischen Abgrenzingen zngute kämen.

Wem Formen ihre Lebensweise durch äußere Momente bedingt änderten, oder wenn einzelne Spezialisierungsprozesse tiefgehende spannungen in der Harmonie der Teile bewirkten, dann erfolgen ans Jugendstadien herans T'mschläge der Organisation, nelu oder weniger plötzliche Ändernngen der Fntwicklung, die ich als Metakinese bezeichnet und begrïndet habe ${ }^{1}$ ). Solche Änderungen schaffen scharfe Grenzen. Anch da, wo sich die Tmbildnngen etwas langsamer und nngleichnäßig in großem Kreise vollzogen, sind die nen entstandenen Typen als Versuchsformen nener Korrelationsverhältnisse ar'm an Individuen und Arten und deshalb auch äußerst selten fossil erhalten.

Neue, aus . Ingendstadien entsprungene Formenkreise sind also in der Regel scharf gegen ihre Torfahren abgegrenzt und deshalb systematisch gnt zu sondern. Weun abel', wie es hier und da geschah, die Unbildungen ruckweise oder in mehreren Formenreihen nebeneinander erfolgten, so können solche Versuchs- und Übergangsformen erhalten sein. Sie sind dann meist sehr verschiedenartig, da die alte Korrelation in die Brïche ging, und nene Harmonien noch keine traditionelle Konstanz erlangten. Würde man mu solche in wesentlichen, später ganz konstanten Organisationsverhältnissen weit aberrierenden Formen ebenso bewerten, wie die festen Rahmen der Organisation der groben Massen späterer Generationen, so würden wir weder ein klares Bild der Stammesgeschichte noch des systems bekomnen können. Eine rein formelle morphologische Terwendung solcher 'Typen im System ist also nicht angängig. Mit scharfen Grenzen nnd logischen Gegensätzen ist iiber solche Hindernisse nicht hinwegzukommen. Wenn aber das System einen lediglich praktischen Zweck verfolgt, und uns eine Übersicht ïber die großen Züge der Stammesgeschichte nnd den Grad der Terwandtschaft bieten soll, dann liindert nus doch nichts, jene Übergangsformen als solche aucl in System gesondert zu behandeln, indem wir den systematischen Abteilnngen solche Versnchs- oder Torformen roransschicken und duch einen Zusatz als extravagante Vertreter der Abteilıng kennzeichnen.

1) Über verschiedene Wege phylogenetischer Entwickelung. G. Fischer, Jena 1902. 
Dasselbe gilt von den letzten Dekadenten. Auch ihre Organisation geht schlieBlich aus Raud und Band und keine Definition will nehr für sie passen. Sollen wir auch sie morphologisch den großen Abteilungen gleichstellen? Sollen wir wenigen Ausnahmen zu Liebe die wichtigsten Kennzeichen der großen Masse aus deren Definition fortlassen? Diese Dekadenten verhalten sich gegenüber dem Stamme wie einzelne pathologische Individuen immerhalb der Art. Wie wir auch diese im Artbegriff unberïcksichtigt lassen, so können wir auch jene dekadenten und aberranten Typen dem System nebenbei ansschlieben, ohne sie in der Definition und Gliederung der Stämme maBgeblich zu berücksichtigen. Es geuïgt den Definitionen ein ,bei normaler Ausbildung" oder dergleichen einzufïgen, um jene Formen trotz ihrer Abweichungen ihren natiurlichen Terwandtschaftskreisen einordnen zu können.

Schwieriger läßt sich in der Definition zum Ausdruck bringen, daß ein wichtiges Merkmal einer Abteilung sich erst innerhalb derselben ansbildet. Es kann schließlich zu dem wichtigsten Kennzeichen des ganzen Formentypus werden, und deswegen in dessen Definition nicht übergangen werden, aber es ist nicht ein festes, sondern ein flüssiges, ein werdendes Merkmal nnd muB anch sprachlich als solches rermerkt werden. Die systematische Terwertung solcher Eigenschaften wird in der Regel erschwert, weil sie sich oft in verschiedenen Abteilungen nebeneinander entwickeln, aber in den Formenreihen der einzelnen auf sehr verschiedener Ausbildungsstufe stehen.

Man tut am besten solche Figenschaften als genetische besonders hervorzuheben, wie z. B. innerhalb der Klasse der sängetiere eine fortschreitende Ausbildung des Lebendiggebärens und der Plazentalbildung, oder bei den Knochenfischen einer Terknöcherung der Wirbelkörper, bei den Ganoiden einer Regulierung der Schwanzflossenbildung, bei den Unpaarhufern die Verorößerung der Mittelzehe. Was ron den werdenden Merkmalen gesagt war, gilt ebenso ron verschwindenden Eigenschaften, wie z. B. von der Existenz der 2. Gliedmaßenpaare der Wirbeltiere, die wohl hier und da rerkïmmern, aber deren Existenz trotzdem für den Typus der Wirbeltiere eines der wichtigsten Kennzeichen bleibt.

Unter solchen Konzessionen an die natiuliche Stammesgeschichte leidet freilich die Präzision der Definitionen, aber diese sind doch nicht zum Auswendiglernen für Schulkinder, wie Linnés Zahl der Staubgefäße und Stempel, sondern sie sind Hilfsmittel für das Verständnis der für eine Abteilung und ihre Entwicklung wesentlichen Charakterzïge.

Was nun schließlich die Gegenüberstellungen im system betrifft, so ist die schärfe logischer Gegensätze hier durchaus unnatürlich. Ich kann sagen, es gibt runde und es gibt nichtrunde Tische, wenn ich 
aber die letzteren positir charakterisieren will, z. B. als eckige Tische, so komme ich sofort in Konflikt mit den ovalen. So ist es anch in der Natur. Prinzipiell lassen sich natiirlich Gegensätze anf ja und nein formen, aber die Natur spottet solcher Schablonen. Trotz alleden ist dies doch in der Praxis lange nicht so schlimm als es hiernach erscheinen könnte. Die Natur und die Lebensbedingungen sind allerdings so mannigfaltig. daß man meinen könnte, daß die Organismen darauf in der mannigfaltigsten Weise reagieren könnten, aber offenbar stehen einer bestimmten Organisation, wie sie doch in jedem Typus rorliegt, in jedem Falle mur wenige Wege zur Ampassmng und spezialisiermng offen. Wie wir in unsern praktischen Ltensilien und ITaschinen wie z. B. den Luftschiffen oder Dampfern sehr bald auf wenige meist nur einen oder zwei, selten mehrere Typen abkommen, weil eben nnter gegebenen Verhältnisse nur wenige Lösungen des Problems gangbar sind, so führen ron jedem Punkte doch meist nur einer oder zwei Wege nach Rom. Das ist unser Vorteil auch im Sistem der Organismen. Jede Ahteilung zerfällt, abgesehen ron etwa rorhandenen Versuchsformen, in der Regel nur in wenige Unterabteilungen, sodaß praktisch in der Regel das zu erreichen ist, was die Systematiker ron jeher als Rahmen des Systems wiinschten. Die Richtungen der Entwickhng charakterisieren sich in der Regel sowoll morphologisch wie anch nach der Menge ilner Vertreter in eine Hauptreihe und eine oder wenige Nebenreihen. Bringen wir, wo es klar rorliegt. auch diese Momente im system zum Ansdruck, bezeichnen wir also beispielsweise in einer Klasse oder Unterklasse die eine Ordnung als Hauptordnung, die andere als Tebenordnung bezw. als erste oder zweite Nebenordnung, so wird dadurch das System als solches nicht beeinträchtigt, aber der natïrlichen Entwicklung in selır zweckmäßig klärender Weise Rechnung getragen.

Der Gegensatz zwischen Phylogenie und System prägte sich ror allem darin ans, daß die gleichwertigen Ahteilungen im system in eine Reihe geordnet wurden, während im Stammbaum eine heterotome Verzweigung als Norm herrschte. Indem wir nun die seitwälts rom Hanptstanme abgezweigten Abteilungen ans der Hanptreihe als Nebenklasse, Nebenordmung usw. heransriicken, und in der serialen Aneinanderreilung den phyletischen Zusammenhang durch fortlaufende Zahlen zum Ausdruck bringen, gelingt es uns, in einfachster form eine klare Raumtiefe in das Srstem lineinzutragen. AnBerdem können wir Plrasen der phryletischen Entwicklung als Stufen bezeichnen und damit numittelbar der Stammesgeschichte Rechnung tragen. Gegebenenfalls kömen wir eine Torstufe, Hanpt- und Oberstufe unterscheiden. Wir laben nun beispielsweise in einer Klasse folgende Anordnung getroffen: 
Erste Stufe erentuell als [nterklasse.

I. Hauptordnung

I $c$ Nebenordnung

3

$\gamma=$

II. Hauptordnung

III. Hauptordnung

IIT 6 Yehenordnung

\begin{tabular}{|c|}
\hline \multirow[b]{2}{*}{$\cdot$} \\
\hline \\
\hline \\
\hline
\end{tabular}

Zweite stufe als Cnterklasse.

IV. Hauptordnung

TT ${ }^{\prime}$ Nebenordnung

Dritte Stufe als Lnterklasse.

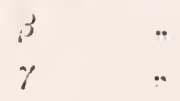

V. Hauptordnung

Ta Nebenordnung

YT. Hauptordnung

VT $\iota_{1}$ Nebenordnung:

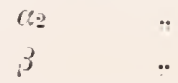

Bei der Einschachtelung der Abteilungen ineinander hat es natiurlich keinen Zweck, leere Schachteln zu rerwenden, also beispielsweise zu sagen, eine Klasse besteht nur ans einer Lnterklasse, diese aus einer Ordnung, diese wieder aus einer Lnterordnung, wenn alle diese nur durch eine Familie oder eine noch kleinere Einheit tatsächlich repräsentiert sind. Warum sollen wir nicht unter Cmständen eine Familie oder gar einen einzelnen Typus einem groß gewordenen Formenkreise gleichwertig gegenüberstellen, aber dann anch kurz sagen Lnterklasse. Gattung usw. Dadurch rereinfacht sich das Srstem doch in durchans zwangloser und zweckmäßiger Weise.

Die rorher aufgestellten Prinzipien der Kombination sistematischer Anordnungen mit der natïrlichen Entwickelungsgeschichte habe ich zuerst praktisch ausprobiert bei den Pelmatozoen, deren Stammesoeschichte mir jetzt so klar rorzuliegen scheint, daß ich für die obigen Gesichtspunkte einen zurerlässigen Maßstab zu haben glaube. Aus der noch äußerst lïckenhaften und vielfach sehr unsicheren Phylogenie der Wirbeltiere hätten sich diese Prinzipien kanm gewinnen lassen. Ich erwähne 
das nur, weil ich noch nicht in der Lage war, die Stammesgeschichte der Pelmatozoen ${ }^{1}$ ) zu Ende zu führen und meine Bestimmtheit in jenen theoretischen Fragen aus der Stammesgeschichte der Wirbeltiere allein kamm rechtfertigen könnte.

Das System habe ich bis zn den Ordnungen mud Unterordnungen durchgefïhrt und, wo ich nene Groppierungen vormahm oder neue $\mathrm{Ab}$ teilungen einführte, gelegentlich anch Fanilien oder Gattungen angeführt. Eine knrz gefaßte Übersicht ïber das Ganze kann natïrlich nicht erschöpfend für spezialisten werden. Unsichere paläontologische Funde habe ich im allgemeinen gar nicht berücksichtigt, mm den Wert des sicheren Materiales nicht herabzudrïicken. Durch Beigabe vieler Abbildungen, mamentlich der weniger bekannten Formen der Vorzeit, hoffe ich, im Verein mit der Verlagsbuchhandlnng allen Lesern nützhich zı sein. Der Wunsch, durch die Velschiedenheit der Abbildungen innerhalb der einzelnen Typen ein Gesamtbild ihrer Organisation zu bieten, ließ sich leider auf dem engen Raum nicht durchführen. So bemïhte ich mich, wenigstens von den Hanpttypen die äußere Form und die phylogenetisch und systematisch wichtigsten skeletteile zur Darstellnug zu bringen. Wo nicht Bezug auf andere Autoren genommen ist, sind die Figuren von mir gezeichnet oder photographiert.

\section{Der Umfang des Wirbeltierstammes}

\section{a) Die Zurechnung der Tunicaten}

Nachdem die Feststelhngen Kowalewskys²) ïber die Embryonalentwicklung der Ascidien allgemein Anerkennung erfuhren, könmen wir nns nicht mehr länger gegen die Tatsache sträuben, daß die Tunicaten mit den Wirbeltieren verwandt sein müssen. Da man zienlich allgemein nur mit aufsteigenden Entwickelungsprozessen rechnete, so glanbten freilich viele, daß uns die Niedrigkeit der Organisation der Tunicaten damn anch nötige, sie als Urformen des Wirbeltierstammes anzmsehen. Das ist aber durchaus unnötig und wäre jedenfalls im höchsten Maße unwahtscheinlich.

Neben den in mehr oder weniger gerader Linie fortschreitenden Entwicklungsprozessen, die ich frïher im AnschlnB an einen Ansdruck

1) Verlag von'Jul. Springer, Berlin, Band I, 1899.

2) A. Kowalewsky: Entwicklungsgeschichte der einfachen Ascidien. (Mém.) Acad. St. Pétersbourg ( $)$. Tom. X 1 sitif. 
Eimers als orthogenetisch bezeichnete und die ich num wegen verschiedener Hißverständnisse, die die Erweiterung des Eimerschen Begriffs mit sich brachte, als engenetische Prozesse bezcichnen möchte, finden sich unverkennbare Nenerungsvorgänge der phyletischen Entwicklung derart, daß die Deszendenten unter die Entwicklungshöhe ihrer Vorfahren in ganzen oder in einzelnen organen heruntersinken. Solche auf einer "Epistase“, einem Stillstand oder einem fortlaufenden Rïckschritt bertuhenden Entwickehungserscheinungen möchte ich als miogenetische bezeichnen. Sie geheu natürlich im einzehnen Individumm von dessen Jugend oder Embryonalstadium aus und können un so tiefere Rïckschritte bewirken, je friiher die hemmenden Momente auf den Organismus einwirken. Engenetische und miogenetische Prozesse gehen im einzelnen Organismus gewöhnlich nebeneinander her, so daß in jedem Typus die Organe aul sehr verschiedener Entwickhungshöhe stehen.

Spannungen in der individuellen Ausbildung der einzehnen Organe können nun in frïhen Entwickhungsphasen zu plötzlichen Ungestaltungen fïhren. Korschinsky verwandte für solche bei Pflanzen von ihm zuerst beobachtete Erscheinungen den leider bereits in der \%oologie verbratichten Ausdruck Heterogenesis. de Vries schlug für ähnliche Ausschlïge die ebenfalls und zwar in der Paläontologie verbranchte Bezeichnung Mutationen vor. So sah ich mich zu einer nenen Bezeichnung für diese Fälle genötigt und nannte alle diese aus der Ontogenie abznleitenden Umschläge der individuellen Entwicklung "Metakinesen". Um nun eine Einheitlichkeit in der Bezeichmmng dieser Entwicklungsvorgänge durchzuführen, schlage ich vor, solche durchgreifenden Unformungen gegenüber den in ihrer bisharigen Richtung fortschreitenden Prozessell als paragenetische zu bezeichnen. Der Reiz zu solchen Umgestaltungen kann von imneren Momenten (Funktionsund Reizstärkungen, Korrelationsverschiebungen, Störungen einzelner Organe) ansgehen oder in äußeren Umständen eine entscheidende Anregung gefunden haben. Da nun solche Unformungen im Gebiet der Pathologie und der Mißbildungen tatsächlich vorkommen, wie sie von de Vries u. a. auch normal gezüchtet sind, so kommen wir ohne ihre Annahme anch in der Phylogenie nicht mehr ans, wie ich nannentlich an der Stammesgeschichte der Pelmatozoen zu erweisen suchte, und auch an der Phylogenie der Tunicaten exemplizierte. (V. internat. Zool. Kongr. Berlin 1901 Verhandl. S. 1058.) Paragenesen können aufwärts oder abwärts führen, je nachdem ihr Ergebnis dem Organismus als Ganzem Fortschritte sichert oder nicht.

Durch eine dekadente Paragenese schien mir nummehr die phylogenetische Beziehung der Tunicaten zu den Wirbeltieren ihre naheliegende Erklärung zu finden. Wie verschiedene Arthropoden-Typen 
dureh sessilität tief von ihrer Organisationshöhe lepuntersanken und durchgreifende Umformungen erfuhren. so wird rermutlich anch die Sessilität an der Degeneration der Ascidien bedeutenden Anteil gohabt haben. Dadurch werlen bei ihnen einerseits Organe anf miogenetischen $\Pi^{\top}$ ege zu ataristisch niederen Stufen zurïckgefülnt sein, so daß $n$ s ilue 'Träger jetzt ..prinuitirer” erscheinen als ilue rertebraten Vorfahren nnd andererseits wird die Miogenese anderen funktionell wichtigen Organen nene Spezialisiernngsprozesse ermöglicht haben. Die Torfaluren, der Ascidien miissen schon allein wegen i.urer embryonalen WrirbelsäulenAnlage echte Wirheltiere gewesen sein, nnd deshalb nüssen wir die Tunicaten auch als einen Seitenstanu der Wirbeltiere anfassen.

Bei den sogenamnten ,Hemichordata"; den wmmartigen Balanoglossus und seinen enteropnensten Verwandten. ferner Cephalodiscus nud Phoronis scheinen nur noch zu wenig Grïnde für eine direkte Beziehung zu delu Tirbeltierstamm zu sprechen, als daß wir hier von denselben melu als eine Notiz nehmen könnten. Sie soheinen mir zunächst nur für die Frage nach den Torfahren der. Wirbeltiele beaclitenswert und werden vielleicht noch eine wichtige Rolle spielen, wenn wir einual das rerwandtschaftliche Terhältuis der episonatiden Torfahren zu den ron dort aus metakinetisch reränderten Echinodermen likarer stellen können. Die letzteren haben sich wohl in ähnlicher Weise ron den Torfahren der Wibltiere seitlich abgezweigt, wie die Tunicaten ron deren frïlen, aber bereits rertebrat ansoperägten Entwicklungsplasen. Hier scheiden wir also die letzterwähnten Typen aus.

\section{b) Die Einteilung der typischen Wirbeltiere}

Die hisher übliche Einteilung der echten Wirbeltiere in die fünf gleichwertigen Klassen der Fische, Amphibien, Reptilien, Tögel nud Sïngetiere rerband sich mit der Vorstellung, daB alle etwa in gleichem V'erhälnis verwandt und die Fische die Vorfahren aller übrigen seien. Nin ist wohl unleugbar. daB die rierfüßigen Landwirbeltiele, die Tetrapoden, eine genetische Einheit bilden, aber die Beziehmngen der Fische zu den Tetrapoden sind trotz aller daranf gerichteten Bemühmngen noch dnrchaus nuklar geblieben.

Wie ich selıon in einer älteren schrift ${ }^{1}$ ) zu begründen snchte. stößt die bisher übliche Auffassung der Fische als Stamuformen der Tetrapoden anf sehr große schwierigkeiten. Die Zahl, Form und Stellung der parigen Giliednaßen bleibt nnverständlich, "renn wir sie ron dem

1) Ther die Stammformen der Wirbeltiere. (Sitz.-Ber. d. Ges. naturf. Freunde zu Berlin 1896 S. 116.) 
Typus der Fische herleiten sollen ${ }^{1}$ ). Die Schwimmblase der Fische kann nur ein Rndiment aber nicht der primäre Ansgangspnnkt der parigen Lnngen sein ${ }^{2}$ ). Der Schultergirtel sehr primitiver Fischtypen wie Acanthodes zeigt einen Ban, der nur als modifizierter TetrapodenSchnltergintel verständlich ist ${ }^{3}$ ). Die Existenz einer wohl ausgebildeten Beckenanlage bei sehr alten Fischformen (Coccosteidae) dentet unmittelbar anf eine frïlıere Ansbildung der hinteren Extremitäten als tragende Gliedmaßen. Die Sondernng einer Halsregion, die nur ans dem Landleben zn rerstehen ist, findet sich bei älteren Fischtypen und rerschwindet bei den jüngeren mit deren steigender Anpassung an das Wasserleben. Ans diesen und anderen Gründen erscheint es richtiger, die unmittelbaren Vorfahren der Fische in Landwirbeltieren zn suchen, wenn anch keineswegs geleugnet werden soll, daß deren Vorfahren einmal Wasserbewohner waren. Unter einer solchen Voraussetznng erklären sich viele Eigentümlichkeiten niederer Organisation bei den Fischen als frïhe nnd deshalb tiefe Riickschläge zu den Vorfahren des ganzen Wirbeltierstammes.

Daß uns die damit supponierten älteren landbewohnenden Wirbeltiere, wirkliche ,Eotetrapoda" noch nicht ïberliefert sind, findet sein Analogon in der äußerst mangelhaften Erhaltung oder dem rollständigen Fehlen anderer sicher voranszusetzender Landbewohner wie silurischer Insekten und Landpflanzen. Auch sie treten uns wie die Tetrapoden erst in Karbon nnd zwar hier sofort in großer Mannigfaltigkeit entgegen.

Es ist nicht ansgeschlossen, daß verschiedene in ilmer Entwicklung verschieden hoch stehende Eotetrapoda zum Wasserleben ïbergingen, ebenso wie dies später mit zahlreichen Vertretern der Reptilien, Tögel und Sängetiere der Fall war. Würde sich eine solche Möglichkeit begrïnden lassen, so würde man den Begriff der Fische als stammesgeschichtlicher und systematischer Einheit fallen lassen mïssen, wie dies ja anch hier und da schon beziiglich des Amphiosus und der Cyclostomen angenommen wurde. Zu einer solchen Anffassmng scheint mir indes das vorliegende stammesgeschichtliche Material nicht ansreichend. Es scheint viehmehr zweckmäßig, die Fische zunächst weiter als Einheit zu behalten, da ihre Vertreter zum mindesten in den meisten Organisations-

1) O. Jaekel: İber Bau und Entstehung der paarigeu Extremitäten. Sitz.-Ber. der Kgl. Akad. d. Wiss. Berlin 1909 s. 719.

2) Neue Funde von Placoderm im Devon von Wildungen bestätigen diese Auffassung. Bei zwei neuen Coccosteiden finde ich Schwimmblasen erhalten, deren innerer Bau dem der Dipnoer ähnelt und daher für ihre Funktion als Lunge spricht.

3) Über die Gliederung des primären Schultergürtels von Acanthodes. Congrès zoolog. internat. Berlin 1901. G. Fischer. 1902. S. 610 . 
verhältnissen wesentlich nnter den Tetrapoden stehen und sich rermutlich ron deren Vorfalnen abgezweigt haben, lange bevor dieser die Organisationshöhe der Tetrapoden erreichten. Andererseits sind nuleugbare Beziehungen zwischen rerschiedenen Klassen der Fische nachweisbar, Beziehmoen, denen man eine phylogenetische Bedentung nicht wohl absprechen kam.

Im System erweist sich jedenfalls die Znsammenfassung, der Fische ans praktischen Gründen als zweckmäBig. mnd merläßlich, zumal der habituelle 'Trpus der Fische soviele Kennzeichen gegenuber den Tetrapoden bietet, daß dren heidrersitige Definitionen dadurch sehr erleichtert werden.

Ite bisherigon Klassen von Tetrapoden sind unzweifelhaft phylogenetisch eng miteinander relknüpf, so dab wir sie als einen Unterstamm der Wirheltiere anfassen nud den Fischen als Einheit gegenüberstellen miissen. Dip dritte Einheit gagenïber Tetrapoden und Fischen bilden dann die Tunicaten.

Narll dem Gesagten scheint mir also folgende erste Zerlegung des Wirbeltierstammes angebracht.

A

Tunicate
B

Pisces
C

Tetrapoda

Die einer solchen Einteilung zugrunde liegenden phylogenetischen Verhältnisse sind nitht ganz einfach darzulegen. Ich möchte zunächst mit der Aneinanderruliumg einiger stufen versuchen. den Entwicklungsgang des Wirbeltierstammes anf Grund seinel historischen Daten in folgender Weise zum Ausdruck zu bringen.

Vorstnfe: Bilaterale Episomatiden mit vornständigem IInnd, einheitlichem Darmtraktus, mit einem ösophagealen, segmentierten Atemramm. mit parigen schizopoden Glisdmaßen, einem metameren Nervenlängstanm nnd rincr mehrteiligen, im Anschluß an die vorderen simmesorgane erfolgten, metaneren Gehirnbildung. Hiervon gehen aus die

\section{Tertelleritu,}

nnd zwar als erste stufe: Weiche nicht erhaltungsfähige und deshalb fossil kaum anffindbar. Trformen mit den Eigenscliaften der Torstufe, mit der Reduktion der Gliedmaßen anf zwei Paare. Vergröberung und Konzentration der vorderen Ganglienpare zu einem geschlossenen Gehirn, Verlegung des Mnndes auf die dem Gehirn abgewendete seite. die nun zur Ventralseite wird, während Rückemmark und Tirbelsänle, die z. T. zu dessen schutze dient, dorsal zu liegen konmen. Die anch embryonal 
noch seitlich angelegten Gliedmaßen rïcken an die nntere ventrale seite. Der Rücken stärkt sich und bildet im Anschluß an den Schutz des Rückenmarks und die Bildung der Myotome und Rippen eine immere Längsstuitze als Wirbelsäule.

Ton den Etappen dieses normalen und jedenfalls sehr langen Entwicklungsprozesses in der Hauptreihe zweigten sich Wasserformen ab, ron denen wohl die überwiegende Mehrzahl spurlos zugrunde gegangen ist. Vermutlich haben sich die Tunicaten schon von solchen Typen abgezweigt, indem sie sessil wurden und damit ror allem die Grundlagen der Episomatiden-Organisation aufgaben. Es blieben ihnen ans der "Vorstufe* vor allem der ösophageale metamere Atemraum, der Darntraktus und die Fortpflanzung in bilateral netamer gebauten Embryonen. Aus der ersten Stufe behielten sie das rertikal regulierte Lageverhältnis der inneren Längsorgane zueinander und die embryonal in Chordaform erfolgende Anlage der Wirbelsäule.

Eine zweite Stufe der Hauptrichtung der Wirbeltierentwickelung: wiurde die Organisationen gefestigt haben, die uns schon innerhalb der Fische als primitive Kennzeichen aller Wirbeltiere entgegentreten, also vor allem der knorpligen Embryomalanlage der immeren Skeletteile, die Ausbildung einer vermutlich in 8 Metameren erfolgten Gehirnkapsel, die Konsolidierung der parigen simesorgane am Kopf, Nasen, Augen, Olıren, die Verschmelzung des hinteren Kopfabschnittes zur Occipitalregion, die Aushildnng eines Schulter- und Beckengeriistes, die typische Gliederung der Gliedmaßen in einen einheitlichen Oberteil, einen zweiteilig gestiitzten Mittelteil nud einen handförmig gegabelten in den Radien geg'liederten Unterteil, der L'mbildung metamerer peripherer Stïtzleisten zu Rippen, der homologen stiicke des hinteren occipitalen Kopfabschnittes zll vierteilig gegliederten Kiemenbögen. Auch die Anlage der Weichteile und inneren Organe muB sich zu dem Typus der Tirbeltiere konsolidiert haben, so vor allem die Tmbildnng der metameren Muskulatur in die nenen am Organismus entstandenen Funktionsbezirke, so namentlich an den paarigen Gliedmaßen, ferner die Konzentration der urogenitalen Organe in der abdominalen Region. Schließlich muß sich auch die Haut außen in schmppenartige Bezirke metamer und dorsoventral gesondert haben.

Das sind naturgemäß ans dev unerschöpflichen Fülle der mannigfaltigen Organisationsverhältnisse des Wirbeltiertypus nur wenige Punkte, die aber fül nnsere morphologische Beurteilung des Stammes besondere Bedeutung erlangt haben. Es kommt mir nur darauf an, anzudenten, daß die Wirbeltiere iluren Typus in dieser sehr langen, fossil auch noch nicht kontrollierbaren Stufe so weit konsolidiert hatten, daß die in das Wasser zurückgegangenen Fische denselben zwar in vielen anffälligen 
Punkten modifizieren und gelegentlich sogar abschwächen konnten, daß sich aber in seiner Richtung die Hauptentwicklung der Wirbeltiere bewegte, und zu einer dritten, der Tetrapodenstufe, ïberleitete. Ton jener zweiten stufe nun hahen sich seitlich abgezweigt und durch Übergang ins Wasser zu Fischen umgebildet drei grobe Formenkreise, deren direkter genetischer Konnex nicht nachweisbar ist. Es ist nicht nur möglich. sondern wahrscheinlich, daß die Fische keine genetische Einheit bilden, sondern daß sich ihre Klassen selbständig von jenen Eotetrapoden der zweiten Stufen abgezweigt haben.

Die dritte Stufe der Wirbeltierentwicklung enthält die höchstentwickelten Typen, die wir als Tetrapoden zu bezeichnen pflegen. Es sind das in der älteren Auffassung die Amphihien, Reptilien, Vögel nud Säugetiere. Nicht alle sind wirkliehe Tetrapoden, d. h. vierfüBige Landbewohner. Viele Truen - mehr als ein Dutzend - sind zum Wasserlehen iibergegangen, sodaß sie zu Schwimmtieren, zu "Pterygopoden" oder .. Teopoden" wurden, und zwei von diesen haben in ihrom ganzen Hahitus vollkommen den Charakter von Fischen angenommen. Es sind das unter den Reptilien die Ichthyosauria und unter den Sängetieren die Wale. Aber trotzdem hetrachten wir sie nicht als Fische, weil sie ihre Herkunft von "Tetrapoden" nicht verlengnen köınen und weil die Fische eben einer ïlteren primitiveren Entwicklungsphase der Wirbeltiere entstammten. Tetrapoden ist also ein Stufenbegriff, ehenso wie Fische. Wïhrend wir aber unter Fischen nur Schwimmtiere verstehen, haben wir den Begriff der Tetrapoden erweitert, sodaß er auch Fisehtypen einschliebt. Darin liegt eine Dissonanz, die wir im systematischen Teile berücksichtigen müssen.

Die dritte Stufe der Wirbeltierentwicklung, die wir also als Tetrapoden bezeichnen, läßt sich etwa in folgender Weise charakterisieren: Tetrapoden sind Lungenatmer mit dentlich abgesondertem Kopf, Hals und Rumpf mit schizopoden in der Regel fünfzehigen Gliedmaßen, mit durchgehenden Nasengängen (Choanen), paarigen Angen und echten Ohren, knöeherıem Innenskelett, festem Hinterhauptsgelenk, mit der Epiphyse in der Parietalregion. Schultergiirtel verknöchert, Becken melıteilig, primär an der Wirbelsäule (Sacrum) befestigt. Wirbelsäule deutlich in Wirbel gegliedert; jeder derselben aus oberen Bögen und Wirbelkörper bestehend. Rippen einfach, meist zweiköpfig. Der Bhıtkreislauf steht auf einer wesentlich höheren Stufe als bei den niederen Formen. Ein Herz und ein komplizierter Blutkreislanf ist immer ausgebildet. Auch das Gehirn ist scharf von dem Rückenmark gesondert. Das Branchialskelett bleibt dem Kopf untergeordnet.

Diese dritte Wirbeltierstufe läßt uns die Entwicklung des Stanmes in der Hauptreihe ziemlich klar übersehen. Die Microsaurier, die 
Paratheria und die sängetiere stellen diese Hauptentwicklungsphasen dar, die sich in direkter Linie aneinander reilten. Freilich geschah dies nicht so. wie das öfters selbst noch ron modernen Phylogenetikern aufgefaßt wurde, daß die höheren Ḱlassen an das Ende, sondern daß sie in der Regel an den Ausgangspunkt der vorhergehenden Klasse anknüpften, daß also eine Stufe nicht mit ihrem ganzen lnhalt in den Entwicklungsgang einznziehen ist, sondern nur wie die Äste eines Stammes mit ihren Ansatzpunkten. Die Reptilien betrachte ich ebenso wie die Hemispondyla und Amphibia als Nebenreihe, ron der wieder die Tögel ihren Ansgang nahmen.

Phylogenetisch würde sich hiernach die Entfaltung des Wirbeltierstanmes in folgenden Etappen vollzogen haben:

Vorstufe Episomatida

\section{Verterrota}

Hauptrichtung

Nebenrichtungen

I. Stufe Protetrapoda

fossil noch nubekannt

Tunicata

II. Stufe Eotetrapoda

fossil noch unbekannte

Landwirbeltiere

$\begin{aligned} & \text { Malacostomata } \\ & \text { Hypostomata } \\ & \text { Teleostomata }\end{aligned} \mid \stackrel{\Xi}{3}$

III. Stufe Tetrapoda

Microsania

Paratheria

Mammalia

Hemispondyla
Amphibia
Reptitia
Aves

Die Zeiträmme, in denen Wirbeltiere die erste und zweite Stufe durchliefen, dïrften sehr lang gewesen sein, an Daner wahrscheinlich den Zeitraum der dritten Stufe noch überschritten haben, einfach deshalb, weil die Verändernngen der Organisation in diesen Stufen ein selır holes Maß erreichten. Wenn für die Entwicklung dieser zwei Stufen nur die beiden ersten Formationen das Kambrinm und Silur zeitlich zur Verfügmng standen, so dürfen wir doch nicht iibersehen, daß diese ältesten Formationen sehr viel größere geologische Zeiträume nmspannten als die später folgenden. Die Maximalmächtigkeit kambrischer Erdschichten wird auf 3000 Meter geschätzt, die des Silnr anf 6000 Meter, d. h. ebensoviel wie für alle mesozoischen und neozoischen Formationen zusammengenommen. Dieses Zeitverhältnis entspräche etwa dem Мaß der morphologischen Wandlungen in den genannten Stufen. 
Die geologischen Zeiträume, in denen die Entwicklung der Wirbeltiere erfolgte, sind in Kürze folgende:

Neozoikum
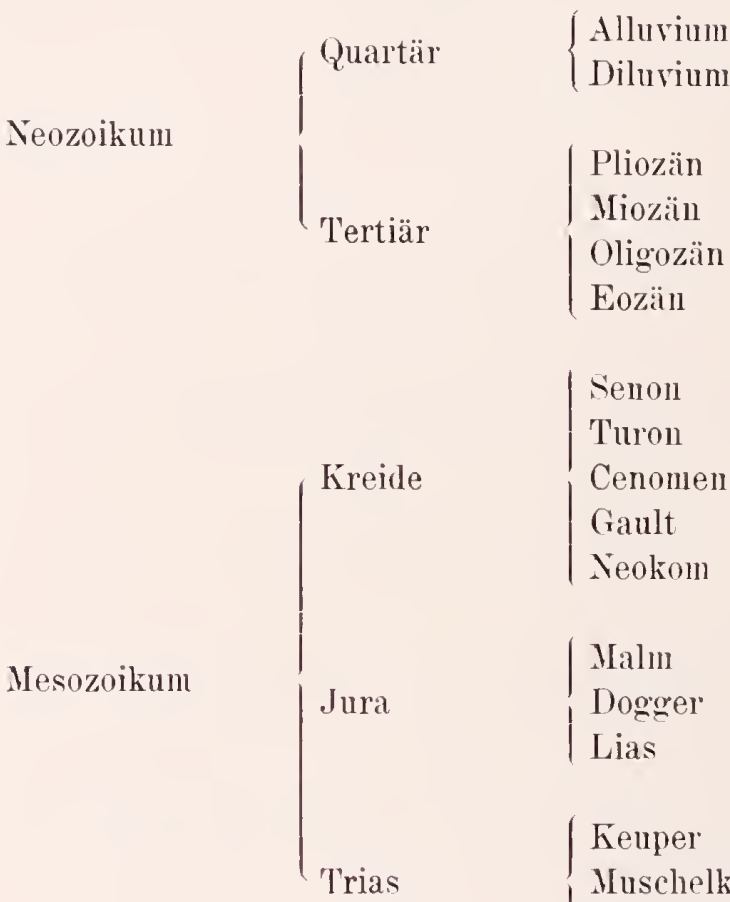

$\mid \begin{aligned} & \text { Senon } \\ & \text { Turon } \\ & \text { Cenomen } \\ & \text { Gault } \\ & \text { Neokom }\end{aligned}$

Malm

Dogger

Lias

Keuper

Muschelkalk

Buntsandstein

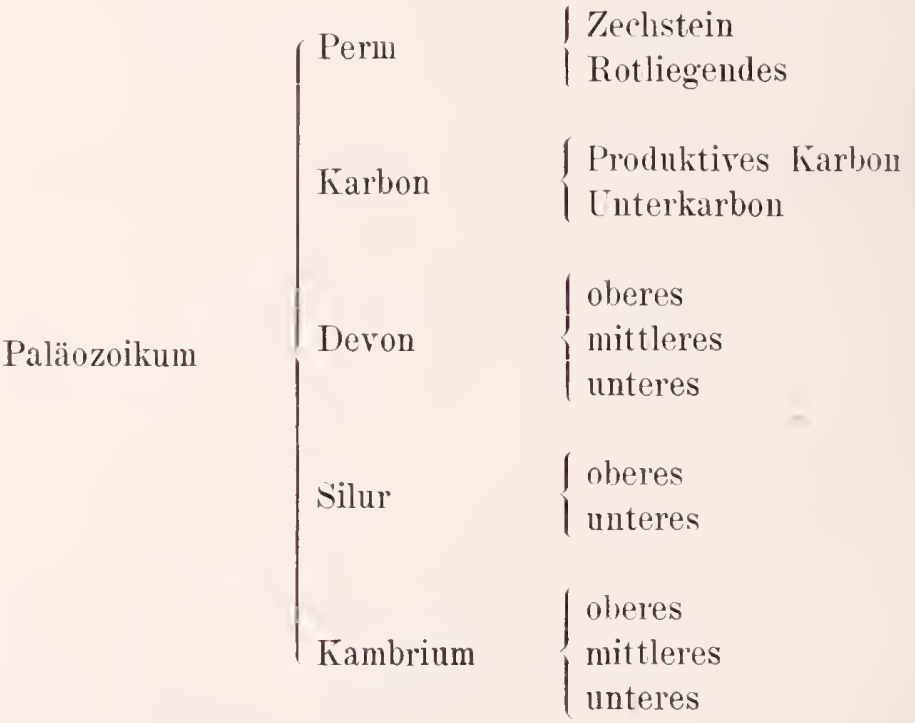




\section{A. 'Tunicata, Manteltiere, Lam. 1816}

Nebenklasse der ersten Wirbeltierstufe

Wie schon oben angedeutet wurde, müssen wir Vorfahren der bisher bekannten Wirbeltiere voraussetzen, die gegenüber wirbellosen Episomatiden nur durch die elementarsten Eigenschaften des Wirbeltierstammes charakterisiert sein mochten. Es sind das außer der Gliederung eines metameren axialen Körpers mit vorn gelegenem Mund, hinten ventral gelegenem After mit einem dorsalen, metamer gebauten Nervenlängsstamm vor allem folgende Eigenschaften gewesen: Eine Konzentration pariger Sinnesorgane und entsprechender Ganglienpaare im Kopf, die Ausbildung des vordersten Darmabschnittes (Oesophagus) als Atemraum, die Ausbildung einer das Rückenmark dorsal und ventral umfassenden skelettbildung, die zur Bildung eines inneren bindegewebigen Axenskelettes führte. Dazu dürfte getreten sein die Konzentration der urspriünglich metamer angelegten Sekretionsorgane, besouders der Fortpflanzungsorgane.

Ob sich bei solchen Urformen die segmentale Skelettbildung schon soweit erhärtet hatte, daß sie Kalksalze ausschied und die Formen damit fossil erhaltbar machte, erscheint fraglich. Jedenfalls kennen wir noch keinen Vertreter eines solchen einfachsten Wirbeltiertypus, und werden seine Erhaltung um so weniger erhoffen können, als die Stammformen vermutlich auf dem Lande entstanden waren. Am Anfang neuer Klassen stelit, wie ich früher erläuterte, vor allem ein durchgreifender Wechsel der Lebensbedingungen. Da wir nun die Vorfahren der Wirbeltiere schon wegen ihrer vielfach vortretenden Kiemenatmung im Tasser snchen miissen, so ist wahrscheinlich, daß sie ihre neuen Eigenschaften, wie die Konstanz ihrer zwei Beimpaare durch den Übergang zum Landleben erwarben. Daß von einem solchen eine Rückkehr zum Wasserleben umso leichter war, je früher sie stammesgeschichtlich erfolgte, bedarf keiner Begründung, ebenso wenig wie das, daß solche Formen auch die neu erworbenen Landtiereigenschaften vollständiger abstreiften, als dies bei späteren Nachfolgern der Fall war. 
Die einzigen Formen, die wir von dieser stnfe ableiten könnten, sind die Thuicaten. Oh diese sich aber schon hier oder erst von Dekadenten einer höheren Wirbeltierstnfe abgezweigt haben, bleibt fraglich. Die Wahrscheinlichkeit spricht wohl aber dafïr, daß sie sich hier abzweigten, da ihre Organisation so tief unter der der Fische, den Dekadenten der zweiten stufe, steht.

Die rorgenannten supponierten Anlagen finclen wir, wenn anch in verschiedenem Grade degeneriert, bei den 'Tunicaten wieder, wo sie allerdings größtenteils in Jngendstadien zurïckgedrängt sind. Die Sessilität dieser Formen erklärt wohl ansreichend die tiefe Dekadenz und Tnubildung dieses Typus, vor allem die Aufgabe der Symmetrieverhältnisse, die dmreh die freie und axiale Bewegung des Episomatidenkörpers hedingt waren. Dementsprechend blieben anch von den Sinnesorganen, die auf die Toraustelhng des Mundes eingerichtet waren, nur fragliche Rudimente übrig, während dre bilateral gebante selowanz wenigstens bei den .Jugendformen als Lokomotionsorgan in Gebrauch blieb. Als ganz aberrante Dekadenten anfgefaßt, stören nun die Tunicaten weder das phylogenetische noch das systematische Bild dieser ersten Entwicklungsstnfe. In System prägen wir diese Auffassung durch den Bugriff der "Nebenklasse" ans.

Definition: Degenerierte kleine freischwinnende oder sessile, einzelne oder zu Kolonien vereinigte Meeresbewohner, deren Köper mit einem vorubbrebenden oder daucraden Mantel ans Cellulose (T'nnicia) umhïllt ist. Ein Mund dient als passive Einfuhröfnung für Meerwasser, das ein mit Wimperll ausgestatteter Branchialranm des oesophagus einsangt, und das nach Passage eines Darmtraktus dureb einen After wieder ausgestoben wird. Der Atemranm ist mit einer wimpernden Hypobranchialrinue versehen. Die Nerran bilden ein sogenanntes Cerebralganglion, an das nnpare sinnesorgane allesehlossen werden. Ein Herz sorgt für die Blutzirkulation.

Die Fortpflanzung erfolgt lermaphoditiseh dureh Fier oder Sprossen oder Embryoketten, die z. T', einen Generationswerhsel verursaclien.

bie. Jngendformen enden meist in einen Schwanz, der einen Axialstrang (Urochorda), einen axialen Ansläufel des Zentralnervensystems, und Andrutungen metamerer Muskelanlagen enthäl und auch im Lageverhältnis der Organe dem Organisationsplan der Wirbeltiere entspricht.

In wieweit sich in einzelnen Organisationsverhälnissen engere Beziehmngen zu den Wirbeltieren ergeben werden, steht noch dalin. Jedenfalls wird man dio Mantelbildnng und die damit im Znsammenhang 
stehende Bildnng eines Peribranchialranmes bei eimem Vergleich mit dem Tirbeltierkörper außer acht lassen müssen, denn sie scheint eine Neubildung. die durch die Sessilität veranlaßt war, nnd die den eigentlichen Vertebraten-Körper nur umhüllte, während ihre eigentïmliche Fortpflanzmng wohl als sekundäre Folge ihrer Koloniebildnng anznsehen ist.

Die folgende systematische Übersicht stützt sich im wesentlichen auf W. A. Herdman's Bearbeitung der 'Thnicaten in dem Sammelwerk The Cambridge National Hystory, dem anch die meisten Abbildungen für diese Klasse entnonmen sind.

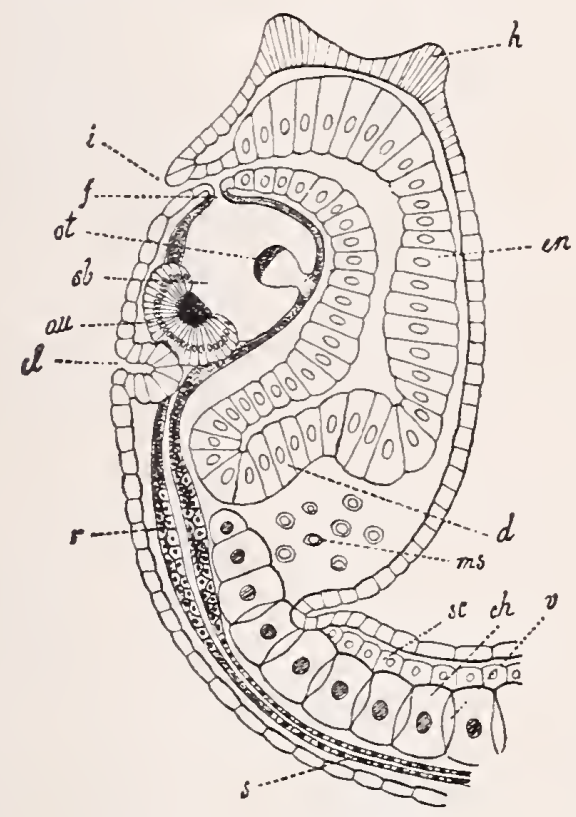

Fig. 1.

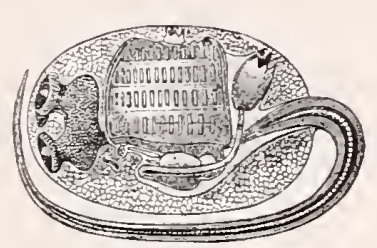

Fig. ?.

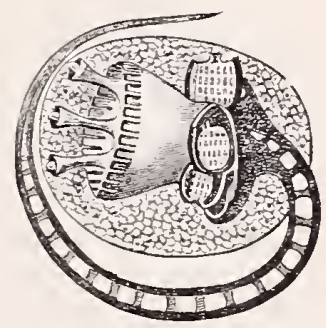

Fig. 3 .

Fig. 1. Embryo von Ascidia mammillata, Längsschnitt, Seitenansicht (nach Kowalewsky, aus Korschelt n. Heider, Entwicklungsgeschichte).

Au Auge, ch Chorda, el Cloakenbläschen, d Darmkanal, en Entodermsack, $F$ Flimmergrube, $h$ Haftpapillen, $i$ Mund, ot Otolith, $r$ Rumpf-, $s$ Schwanzabschnitt des Rückenmarkes, $S b$ Sinnesblase, sc subchordaler Entodermstrang.

Fig. 2. Embryom von Distaplia, Fig. 3 von Diplosomoides (2 und 3 nach Herdman).

\section{Hamptordnung Appendiculati.}

Sehr kleine geschwänzte, frei schmimmende Tmnicaten, mit schnell entwickelter. leicht abgestoßener und ergänzter Kapsel als Mantelbildung. Der branchiale Teil des Oesophagus mit zwei rentralen Kiemenspalten. An ein großes dorsales (cerebrales) Ganglion schließt sich ein 
Nervenstrang, der im Schwanz begleitet wird ron einer axialen skelettanlage, der Lrochorda. Die Muskeln des Schwanzes mit Andeutungen metamerer Gliederung. Anus an der Ventralseite. Fortpflanzung durch einzelne Keimzellen. An das cerebrale Ganglion sind ein Bewregungen empfindender .Otocyst" und ein Pigmentfleck als Simnesorgane angeschlossen. Die Ordnung enthält nn zwei kleine Formenkreise winziger, meist pelagisch lebender Formen, deren Größe einige Millimeter nicht iihersteigt. Sie sind der wenigst degenerierte, der Wirbeltierorganisation noch am nächsten stehende Typus der Thunicaten, an den sich deren übrige Formenkreise wenigstens mit ihren Jugendformen anschließen. Vielleicht sind aber die Appendiculati selbst nur persistente Jugendformen spezialisierterer T'unicaten.

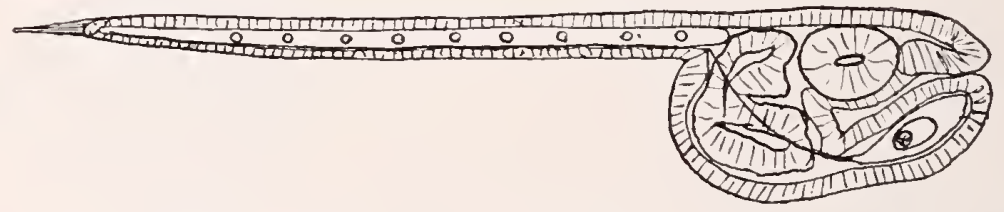

Fig. 4. Appendicularia. Jugendform im Längsschnitt mit dem Mund und dem daran angeschlossenen Branchialraum des Oesophagus. Darüber die Otocyste. Im hinteren Teil des Rumpfes Querschnitte durch den Darm. (Nach R. Goldschmidt in Kemnas Referat.)

\section{Nebenordnung I Ascidii}

Größere meist sessile 'Tunicaten, die nur in der Jugend noch eine Schwanz- und Chordabildung besitzen und in erwachsenen Zustande ganz von einem trpischen Cellulose-Mantel umhüllt sind. Ihr Branchialsack kommuniziert durch zahlreiche Spältchen mit einem Peribranchialraum, der sich in das Atrium nud den Mund öfnet.

Dieser Formenkreis bildet mit seiner charakteristischen Mantelund Branchialbildung den Typus der Klasse und umschließt einerseits sessile Formen, die einfach oder zusammengesetzt sein liönnen, und koloniate freilebende Formen, die den Übergang zu der zweiten Nebenordnung den salpen bilden.

Ian teilt sie ein in

\section{Unterordnung Monascidii}

einfache sessile Individuen, die ganz isoliert sind und sich einzeln fortpflanzen oder durch eine Art Wruzelgeflecht miteinander verbunden sind und sich dann durch Sprossen vermehren.

Die sehr formenreiche Unterordnung unfaßt mehr als 500 Arten. Hierhin gehören die einfachen ganz isolierten Ascidien, die Cynthien, die Molguliden und die durch Wurzelkanäle rerbundenen Clavelliniden. 


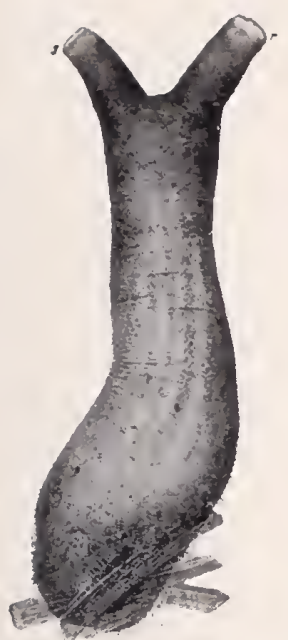

Fig. 5.

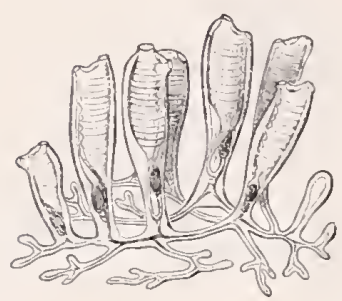

Fig. 6.

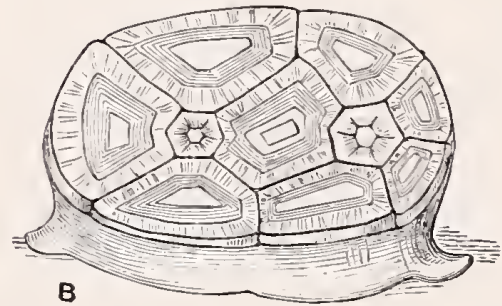

Fig. 8.

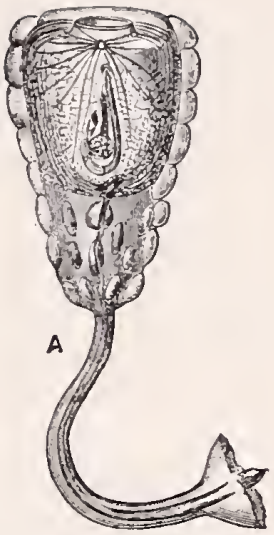

Fig. 7 .

Fig. 5. Ascidia canina, Nittelmeer, $1 / 2$ nat. Größe (nach Kupffer).

Fig. 6. Clavellina lepadiformis, Nordsee (nach Herdman) $2 / 3$ nat. Größe.

Fig. 7 . Hypobythius calycodes Moseley im Nord-Pacifik.

Fig. 8. Chelyosoma macleayanum (nach Herdman) mit eigentïmlicher Deckelbildung.

\section{Unterordnung Synascidii}

Sessile durch Sprossung fortpflanzende Asciden, die zu Kolonien vereinigt und durch eine gemeinsame Schalenmasse umhüllt sind. Sie

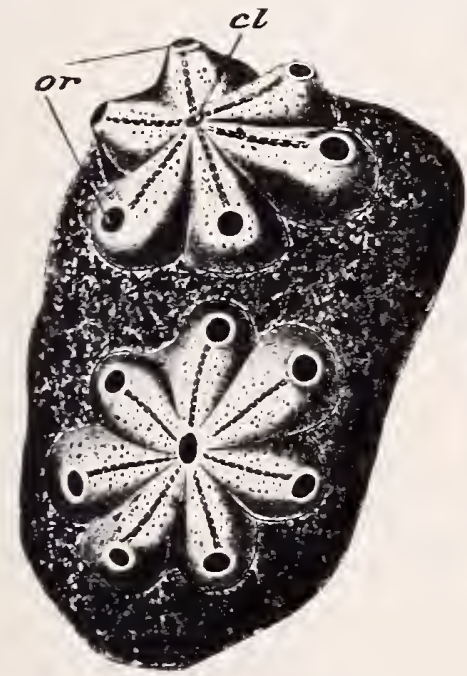

Fig. 9. Eine Kolonie mit zwei Individuen von Botryllus violacens (nach Nilne Edwards).

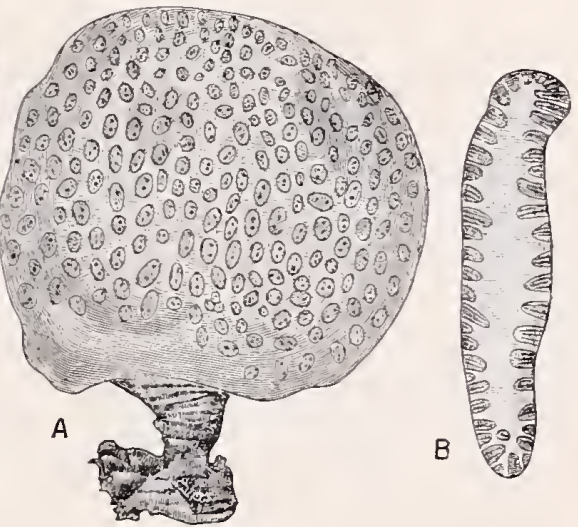

Fig. 10. Goodsiria placenta Herdm., links ein ganzer Stock mit zahlreichen Individuen, $B$ Querschnitt durch den Stock (nach Herdman) $1 / 2$ nat. Gröle. 
umfassen die .merosomen“ Distomatidae, Coelocormidae, Diplosomatidae, Polyclinidae und die ,holosomen" Botryllidae. Polystyelidae.

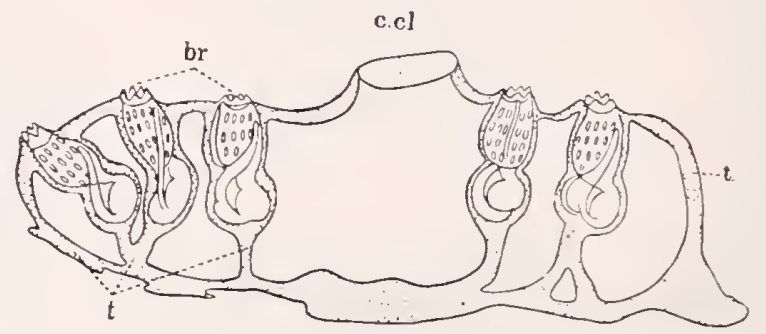

Fig. 11. Schnitt durch eine Kolonie ron Diplosoma, mit 5 Einzeltieren und gemeinsames. Kloake (ccl), br Branchialöffnungen (nach Herdman).

3. Unterordmng Centrascidii nom. nor. (Luciae Herdman).

Freischwimmende, pelagisch lebende Kolonien ron zylindrischer Tasenform, in denen die Einzeltiere ihren Branchialsack nach außen und ihr Atrium in einen gemeinsamen Innenraum öfnen. Den Trpus dieser zentralisierten Kolonien bilden die Pyrosomen, die durch ihr Phosphoreszieren ansgezeichnet sind, nnd dadnrch die Benennumg Lnciae rerälaBten. Die Kolonien werden bis $4 \mathrm{~m}$ lang.
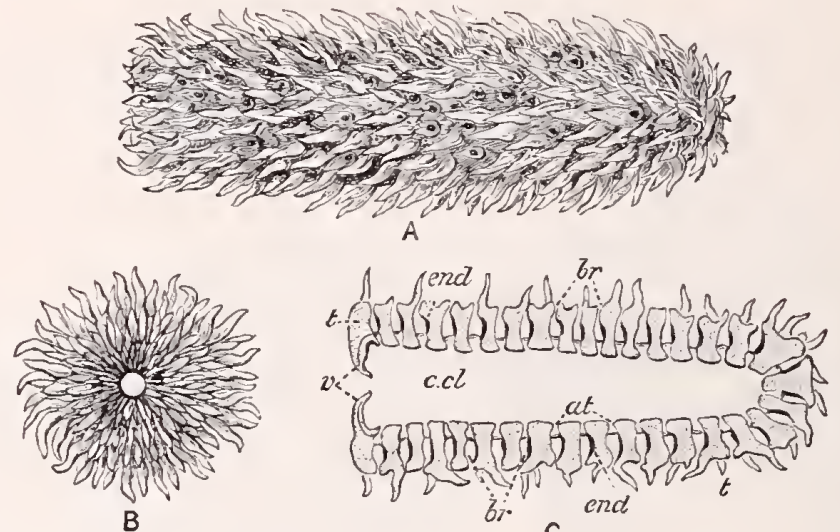

C

Fig. 12. Darstellung einer Kolonie von Pyrosoma. A ron der Seite, $B$ von dem gemeinsamen Atrium aus, $C$ im Längsschnitt nach Herdman).

Nebenordmung II Salpi ('Thaliaceae, Salpen).

Kleine, frei schwimmende, einzelne oder koloniate, pelagische Tunicaten, deren gerundeter Einzelkörper ganz von einem danernden durchsichtigen Mantel umhüllt ist, dessen muskulöse Kontraktionen Wasser ausstoßen und dadurch eine Lokomotion bewirken. Ein Peribranchialraum ist vorhanden, unit dem der Branchialsack durch spalten kommmniziert, und in 
den anch der Anus mïndet. Die Fortpflanzıng erfolgt durch sogenaunte Stolonen, die einen schon von dem Dichter Chamisso beobachteten Generationswechsel veranlassen. Aus den Stolonen der Einzelindividuen entstehen die salpenketten, die wieder in Einzelindividnen zerfallen. Auf Grund ihrer Inskelbildnng lassen sich zwei Etappen der Spezialisierung nnterscheiden, die erste charakterisiert durch die weniger vollkommene Ringmuskulatur von Salja, die andere durch die Bildung vollstïndiger Mnskelringe bei Doliohum und seinen Verwandten. Die Träger der ersteren erscheinen danach und in ihrer einfacheren Fortpflanzung als die primitiveren, während sie in der Larvenentwicklung ohne Schwanzbildung nud der Koloniehildung spezialisierter sind.

\section{Unterordnung Cyclomyarii}

mit vollständigen Ringmuskeln, selbständigem Branchial- nnd Peribranchialıaun, ohne Koloniebildung der erwachsenen Formen. Der Körper ist tommenförmig und weist in der Jugend noch eine Schwanzbildung auf.

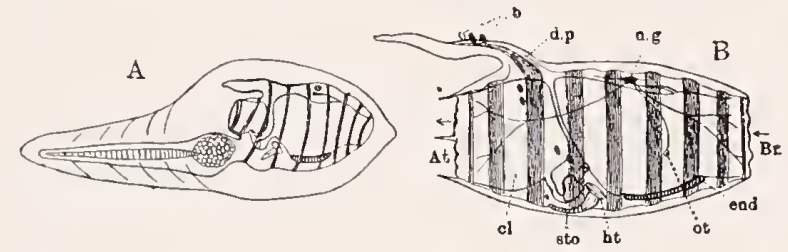

Fig. 13. Jugendstadien von Doliolum (nach Uljanin und Barrois aus Herdman). At Atrium, $B r$ Branchialöffnung, ng Ganglion; Ot Otocyst, en endostyl, Dp Dorsalfortsatz, ht Herz, st Stolo prolifer, $b$ Embryonen.

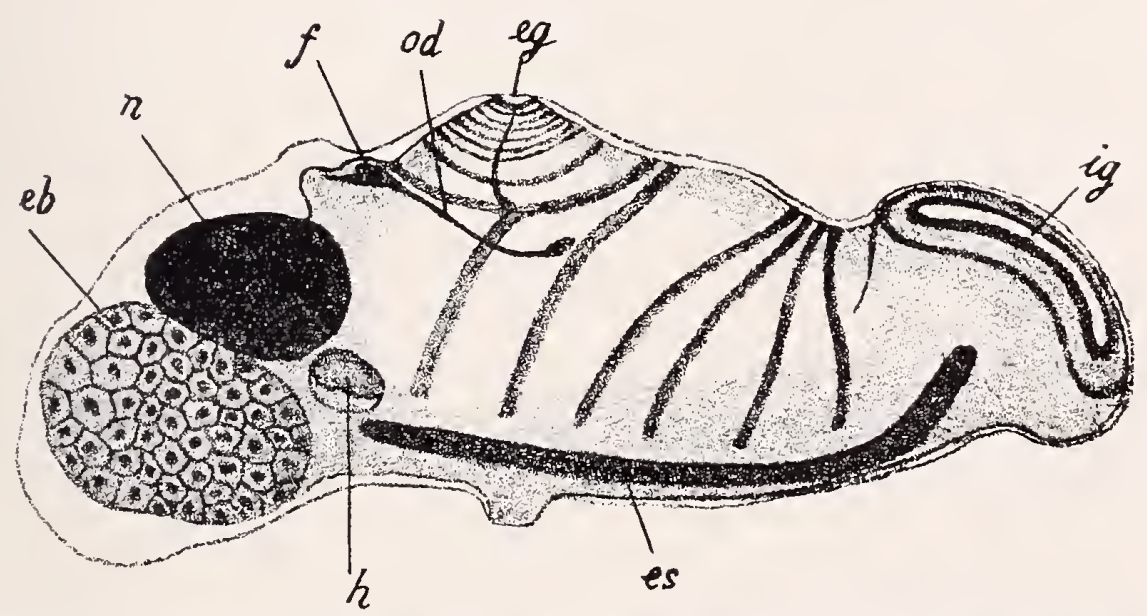

Fig. 14. Salpa maxima, junges Kettenindividuum (nach K. Heider). Eb Elaeoblast, $n$ Nucleus, $h$ Herz, $f$ Eifollikel, od Oviduct, ig Ingestionsöffnung, eg Egestionsöffnung, es Endostyl, darüber die Muskelbänder. 
Cnterorhumg Hemimyarii

mit unvollständigen Ringmuskeln, Branchial- und Peribranchialranm einheitlich, an den Enden des Tieres im Hund und After müudend. Aus dem Stolo bilden sich danernde Kolonien, deren Einzeltiere ilure Embryonen zeitweise durch eine Placenta ernähuren.

Hierher gehört nur die Gattung salpa (s. Fig. 14).

Fossile Tunicaten sind uns bisher noch unbekannt. Da sie keine erhaltungsfähigen Hartgebilde besitzen, ist höchstens durch gelegentliche Alformung eine Erhaltung wenigstens ilırer äußeren Form denkhar.

Aus dem Perm von sicilien liegen mir einige becherförmige Kalkausgiisse vor, deren kolbig verdickte Oberseite dieselbe sonderhare Felderung zeigt wie die beckelbildung des Fig. 8 abgebildeten Chelyosona macleayanum. Trotz der auffallenden Ähnlichkeit mit dieser For'm trage ich doch Bedentien, jene fossilen Reste als Ascidien anzusehen, da sich solche äußeren Formverhältnisse anch anderwärts wiederholen köınten, und die gentunte lehende Form gerade in dieser Deckelbildnng einen ganz isolierten und aberranten Typus darstellt. Daß G. Steinmann die Ascidien von fossilen Bivalven und die Salpen ron fossilen Brachiopoden herleitete, brancht wohl nur noch als Kinriosum erwälunt zn werden, nachdem er uns die indiskutablen ... Grundlagen" seiner' absonderlichen Ideen in extenso enthüllt laat. 


\section{B. Pisces, Fische}

\section{als Nebenstamm der zweiten Wirbeltierstufe}

Würden wir das system rein auf stamnesgeschichtlichen Grundsätzen aufführen, so würden, wie oben bemerkt wurde. die Fische in einer zweiten Stufe der Wirbeltierentwicklung nur die ins Trasser übergegangenen Typen umschließen und bei deren fraglicher Zusammengehörigkeit als systematischer Begriff hinfällig sein. Er würde stammesgeschichtlich ebensowenig Trert haben, wie etwa eine srstematische Zusammenfassung der Ichthyosaurier und Tale innerhalb der Tetrapodenstufe oder aller Flugwirbeltiere in eine Einheit.

Übertrïge man nun aber eine solche stanmesgeschichtliche Volstellung der ..Fische" auf das Srstem, so wären wir genötigt, für die rerschiedenen Typen oder Klassen dieser stufe einen Namen in Anwendung zu bringen, der für seine bisher allein bekannten Repräsentanten gar nicht passen würde. Der stammesgeschichtlich nächst liegende Name Eotetrapoda wäre auf Landtiere basiert, die tatsächlich noch nicht gefunden sind, die es also für uns noch nicht gibt. Derartige irreale Größen, wie sie E. Haeckel in seinen srstemen rielfach rerwendete, haben sich bisher nirgends eingebürgert. Das Srstem will konkret sein. Tir behalten also den alten Tamen Fische so lange, bis deren vierfüßige Vorfahren gefunden werden, und begnügen uns damit, ihn als zrreiten Nebenstamm zu bezeichnen und ihn dadurch in einen gewissen Unterschied gegen den .Hauptstamm“ der Tetrapoden zu bringen.

Die Lückenhaftigkeit der stammesgeschichtlichen Überlieferung legt zumeist darin, daß viele Organismen überhaupt keine erhaltungsfähigen Teile besaßen, andererseits darin, daß die Kadaver auch der erhaltungsfähigen Organismen durch reichlichen Luft- und Bakterienzutritt spurlos rerwesten. Bei den typischen Wirbeltieren mit ihren erhaltungsfähigen äußeren oder imneren Skeletteilen kommt nur das letztgenannte Moment in Betracht und rerursacht, daß die Landtiere in viel gröBerem Laße spurlos verschwanden als die Wasserbewolner, und die weitaus orößte Zahl aller fossilen Wirbeltiere aquatile Typen sind. Mit den Insekten 
und don Pflanzen ergeht os uns ganz analog; anch sie treten nus wie die Landwirbeltiere häufig erst in der Steinkolnlenformation, nucl zwar hier bereits in goroBer Organisationshöhe und Mannigfaltigkeit entgegen. Thre Wurzeln müssen also in älteren Erdschichten gesucht werden. und daß Fische nicht die Stanmformen der Trtrapoden sein kïnnen, wnde ancl hiter wieder herrorgehoben.

Die älteren Fischformen sind allem Anschein nach anfangs süßwasser- und Utferhewohner gewesen. Das gilt sogar noch ron den ältesten Haiformen. Wo sich ihre Reste in marinen Ablagerungen fanden. sind sie - von einigen Ansnahmen abgesehen - nicht melur im normalen Zusammenhang ihres hörvers enthalten, sondern in einzelne Skeletteile zerstrent. Sie sind dort niclit in sitn eingebettet, sondern ins Meer rerschleppt durch fließendes Wasser nud die Fhutströmungen, oder durch andere Organismen, die sie zerlegten nud in 'Teilen darontrugen. Die Fundstätten dej älteren Fischreste sind sogenannte Bonebeds. d. l. Uferbänke nit abgerollten Wirbeltierknochen, dann die sogenannten "Oldred"-Sandsteine. die zunächst noch reine Cferablagermngen sind. In Salzwasser wurden die Fische exst später heinisch: das winderbar reiche Fischlager in Oberderon ron Wildungen scheint eine erste antochthone marine Fanna ron Placodermen zn bieten. Andere Fische sind hier nur vereinzelt eingeschleppt. Marine holocephalenartige Formen erschienen bisher erst in Lnterkarbon, marine Selachier ebenfalls. Anch die 'Teleostomen waren zmnïchst Uferbewohner, nud zwar wahrscheinlich in Flïssen und Landseen, erst in Oherderon scheinen sie das Meer erobert zn haben: in die großen Tiefen der Ozeane sind sie narlnweislich wohl erst in der Kreideformation eingedrnngen.

Verfolgt man die Eigenschaften der Fiscle riokwärts in deren stammesooschichtlicher Entwicklung, so ergehen sich viele, unserer bislerigen Anfassung dianetral gegenüberstehende 'Tatsachen. Ich nuß mich in dieser Hinsicht luier anf wenige Andentnngen beschränken.

Als älteste Fischformen erscheinen Tỵen, die den Eindruck persistirter, fuBloser Kaulquabben machen, die sich bei ihrer Anpassung an das Wasserleben zunächst durch eine selur verschiedenartig spezialisierte Panzerhildung schützten. In dem Maße, wie sie im Wasser heimisch wurden und zur Offensive ïbergehen komnten, muBten sie nit zunehmender Beweglichkeit den num hinderlich wewordenen Panzer in zweckmäbig gelagerte Teilstiicke zerlegen. Diese Zerlegung erfolgte zunächst in sehr mannigfaltiger Weise. Indem aher dann die Trilstücke in engeren Konnex nit dem Muskelsistem traten, wurden sie durch dessen im ganzen gleichartige Anlage in ähnlicher Weise geordnet, so daß sich schließlich anf sehr verschiedenen Wege ähnliche Gliedernngen 
auch im Hautskelett ergeben und dieses der Organisation der Tetrapoden nïher riicken.

Diese uns vorliegenden Übereinstimmungen in Hantskelett beruhen also auf Analogien, nicht anf Homologien, wohl aber anf einer gewissen Einheitlichkeit des mrsprünglichen Trirbeltiertypus, den wir in dieser Stufe als Eotetrapodentypus bezeichneten.

Die skelettbildungen, die bei älteren Vertretern einzelner Klassen noch typische Knochenstruktur besitzen, rerlieren dessen Charakter und bleiber entweder in einem knorpligen Embryonalzustand (Placoidei oder Knorpelfische) oder nehnen wie bei Teleostiern einen chondroiden Clarakter all.

Die parigen Gliedmaßen sind bei den ältesten Typen (auch noch bei den lebenden Dipnoern) axial gebaut, bei den juingeren Typen actinal. Bei alten Fischtypen finden sich grobe Beckenanlagen, die anf eine frïhere Stiitzfunktion der hinteren Gliedmaßen weisen. Die Kiemen sind ursprïnglich wie bei den Tetrapoden dem Kopf untergeordnet und in geringer Zahl (4) vorhanden. Erst später rücken sie in die Halsregion und vermehren sich. Die hintere schädelgrenze rerliert erst allmälılich an Schärfe, die Skelettstruktır des Schwanzes riickt allmählich nach vol'n ror und rerwischt die hintere Rumpfgrenze, die Rippen treten dann gegenüber den unteren Bögen zurück. Alle älteren Fische waren wahrscheinlich Lungenfische. Die schwimublase entstand aus verkïmmernden Lungen. Aus dem Deron liegen jetzt einige Placodernen ror, deren schwimmblase die rielen Einfaltungen der Wand zeigt, wie sie für die Lunge der Dipnoer charakteristisch ist. Die Bezahmung der Haifische erscheint nicht primitir, sondern als Resultat einer allmählichen Zerlegung plattiger Kieferknochen. die zur Gebißfunktion spezialisiert waren.

Die Fische sind bisher nur nach den Kennzeichen der lebenden geordnet worden. Formenreihen sind bisher nur in sehr geringen Maße aufgestellt, und die genetischen Beziehungen der gröBeren Abteilnngen zueinander erscheinen überans nnklar nnd unsicher. Seit Artedi gewannen allmählich einzelne natïrliche (iruppen feste Gestalt. Bei ihm erscheinen zuerst die Acanthopterygier und Malacopterygier unter den sogenamten Knochenfischen. Curier und Valenciennes sondern Knorpel- und Knochenfische. Bei Jol. Miiller tauchen die Leptocardier, Cyclostomen und Dipnoer auf neben den Ganoiden und 'T'eleostostier'ı, die schon rorher den Cliarakter von Einheiten angenommen latten. Ton paläontologischer seite werden dann neue Gruppen linzugefügt, so namentlich die Placodermen und später die 
uralten Ostracodermen, die kleine aber merkwürdige Gruppe der Acanthodier u, a. Schließlich sind folgende Formenkreise als selbständige Einheiten anerkannt worken:

die Leptocardier oder Acranier,

die Marsipobranchier oder Cyclostomen,

die Ostracodermen,

die Placodermen,

die selachier und Holocephalen, die als Placoidei, Elasmobranchier oder Plagiostomen zusammengefaßt wurlen, die Ganoiden,

die Teleostiel',

die Dipnoel.

C̈ber die gegenseitigen Beziehungen dieser Gruplen gingen die Meinnugen sehr weit anseinander. Einige wie Amphioxus als .. Ar"anier", die Cyclostonen als .. Agnatla" wurden ron einzelnen Antoren allen übrigen Wirbeltieren, andere wie die Dipnoer allen iibrigen Fischen als gleichwertig gegenühergestellt. Anch über kleinere Gruppen wie die Acanthodier gingen die systematischen Ansichten weit ansemander, während andere wie die Störe trotz anfälliger Unterschiede gegeniiber den Ganoiden allgemein bei diesen belassen wn'den.

Oh die Fische überhaupt eine geschlossene phyletische Einheit bilden wie die Lrnterstänme der Tetrapoden und Thnicaten. ist wie gesagt fraglich. Wie ich seit $1896 \mathrm{in}$ rewschiedenen Schriften zu begüunlen suchte, kann ich die Fische nicht für primitive Wirbeltiere, keinesfalls aber als stammformen der Tetrapoden anselen. Ilue Organisation, namentlich die ihrer ältesten Vertreter und die Entwicklungstendenzen ihrer jüngeren Verwandten werden nur rerstindlich unter der Annalume, daß sie ron Landwirbeltieren abstammen und die Fischform ebenso sekundial als Ampassung an das schwimmleben erwarben, wie später die Tchthyosaurier, Wale und andere Wasserbewohner. Die Niedrigkeit ihrer (Organisation beluht einerseits auf miogenetischen (epistatischen) Rïckbihdungen, andererseits darauf, daß sie eben von Landwirbeltieren abstammen, die primitiver waren als die, die wir bisher kennen. Beide Momente sind jetzt nach so langer Verkettnng in endlosen Formenreilen kaum mehr auseinanderzulegen. Bei dieser Auffassung liegt natürlich die schlubfolgernng nahe, daß der Übergang solcher Urtetrapoden ins Wasser wiederholt nnd anf selbständigen Wegen erfolgte, ebenso wie die Ichthyosaurier und Cetaceen nnverkennbar selbständige Typen darstellen. Die Konvergenz nußte dabei umso gründlicher in die Erscheinung treten, je älter und primitiver die betreffenden 'Typen waren; und je weniger gefestigt demgemäß der Typus der Wirbeltiere in cler hetreffenclen \%eit war. 
ITenn danach auch die Einheit der Fische als Unterstamm der Wirbeltiere durchans fraglich erscheint, so werden wir ihn im praktischen system doch weiter als Einheit behandeln mïssen, da wir zu seiner stammesgeschichtlichen Zerleg'ung kamm ausreichende Grundlagen finden werden. Daß wir sie in einer ersten Stufe der Wirbeltiere nur als Nebenklasse ansehen können, wurde schon vorher S. 11 begründet. In systematischer Hinsicht läßt sich eine .Einheit“ der Fische auf folgende Merkmale stïtzen.

Definition: Kiemenatmende kaltblitige Wirbeltiere ohne deutliche Abgrenzung einer Hals- und Schwanzregion, mit flossenförmigen paraxial gegliederten GliedmaBen, in dep Regel mit medialem Flossenbesatz. Nasen vorn gelegen, meist ohne Ganmengang. Ohren zu statischen Organen umgebildet. Großhirn klein, Epiphyse nach vorn gerichtet, Epidyse [wenn vorhanden] in den Frontalien gelegen. Beckengürtel verkümmert, in oder an Stelle der Wirbelsäule häufig eine persistierende Chorda. Rnmpfmuskulatmo metamer gegliedert. Meist schupiges oder plattiges Hantskelett.

Anßerdem zeigen die lebenden Fische noch eine Anzahl gemeinsamer Merkmale in ihren Weichteilen, wie einfachen Ban des Herzens, einfacheren Verlanf des GefäBsystentes usw., ïber deren Vorhandensein bei fossilen Formen kein sicheres Crteil abzugehen ist. Die Cmbildung der Lungen zur Schwimmblase trifft nur für einen Teil der Formen zı.

Die Fische finden sich rom Untersilur bis zur Gegenwart. Viele Gruppen sind ansgestorben.

Folgende Abteilnngen scheinen mir einen hohen Grad von Selbständigkeit zu beanspruchen nnd sind deshalb zum Range ron Klassen erhoben. An den Copeschen Namen der 'Teleostomata anknïpfend habe ich sie als I. Malacostomata, II. Hypostomata und III. Teleostomata bezeichnet. Sie bilden drei Stufen des Organisationsfortschittes. Die beiden ersten könmen phyletisch rerbunden sein. für die dritte Klasse scheint mir dies unwahrscheinlich.

\section{Klasse MaIacostomata m., Weichmänler}

Definition: Niederste Fischtypen, für die anscheinend eine weiche, wahrscheinlich zahnlose nnd saugartige Ausbildung des Mundes das aufälligste Kennzeichen bildet. Die paarigen GliedmaBen sind ganz oder teilweise rückgebildet, die medialen Flossen stehen auf sehr niedriger stufe. Der Kientendarn erlangt in seitlichen runden Öffnnngen eine 
Kommunikation mit der Anßenwelt. Thre Lebensweise wurde z. T. parasitisch und hat dann zu starker Rückbildung ihrer gesamten ()rganisation geführt.

Die hipl zusammengefaßten Fischtypen scheinen auf den ersten Blick ziemlich heterogen zu sein und sind anch deshalb schwer unter einen Hut zu bringen, weil von den fossilen meist nur ein stark entwickeltes Hautskelett bekannt ist, bei den lebenden aber ein schwach ansgebildetes Innenskelett rorliegt. Trotzdem sind beide Typen nicht nur durch die Niedrigkeit ihrer Organisation einander nahe gebracht, sondern anch dmech eine Anzahl positiver Merkmale miteinander verkniipft. \%u ersteren rechne ich die Persistenz ihres embryonalen Knorpelskelettes, die Erhaltung einer Epiphysenöfnung („Epidyse“) nnd die geringe Finfaltung ihrer umparen Flossen, zu letzteren die zahnlose, sangartige Ausbildung ihres Mundes, die Mündung der Kiemen in seitlichen, kleinen, runden Löchern, die Lnterdrïckung der parrigen Gliedmaben und die Existenz eines ror den Angen gelegenen unparen Simnesorganes, das von Kupfer hei Cyclostomen als Riechplakode bezeichnet wurde. Wenn diese Eigenschaften auch nicht für alle Vertreter der Klasse bezeichnend sind, so zeigen sie doch durch ihr Erscheinen bei Vertretern der beiderlei Typen, daß zwischen diesen direkte rerwandtschaftliche Bezielungen bestehen muBten. Ob diese durch die gleichwertige Zusammenstellung der drei Typen, der uralten Palaeostraci, del' Cyclostomen und des Amphioxus riehtig wiedergegeben sind, wird kilum anzunehmen sein, aber bestimmte Klarheit werden wir hierüber kanm gewinnen kömnen und nus mit der Zusammenstellung des Ähnlichen begnïgen mïssen. Fossile Cyclostomen sind seit dem Devon bekinnt, aber in nachpalapozoischen schichten nicht mehr erhalten, offenbar weil ihr skelett auf immer tieferer stufe zuriekblieb. Tou der dritten Lnterklasse, den Acraniern orler Leptocardiern, sind nach ihrem ganzen Körperznstand fossile Reste nicht bekanut und auch kaum zu erhoffell.

Anch den Mangel der paragen GliedmaBen bei den ältesten und rerschiedenen jüngeren Palaeostraken kann ich nicht für prinär halten, ebensowenig wie bei den Crelostomen und Leptocardiern, und glaube für die sekundäre Lnterdrïckung derselben gerade in der umfassenden nngegliederten Skeletthiille der Palaeostraken eine Erkliirung zu finden. Die von Patten diesen ältesten Formen in ten willkürlichsten Kombinationen rekonstruierten Gliedmaßen sind ron keiner Seite bestätigt worden und wohl ohne Frage abzulehnen.

Die skelettbildung selbst erfolgt bei den Heterostraci noch ohne selbständige Knochenzellen, die erst bei den jüngeren Formen (Cephalaspiden) in das Knochengewebe anfgenommen werden. Bei den Heter- 
ostraci erfolgt die skelettbildnng nnter Bildnng langer feiner Faltungen der Epidermis (Fig. 15) und zerlegt sich bei ihren jiingeren Nachkommen (Fig. 16) in gefaltete schmpenartige Felder. Bei anderen (Fig. 20) sind gröbere Falten auf einem Rïckenschilde angelegt und anscheinend von Anfang an in einzelnen Ossifikationszentren erhärtet, in denen sich dann nach hinten eine segmentale Gliederumg bemerkbar macht, die die Schmppensegmentation des Hinterleibes anbahnt. Wieder bei anderen, den Coelolepiden oder Thelodonten. ist die Skelettbildnng anf die Ansbildıng einzelner Plättchen oder Dornen (Lanarkia) beschränkt. Ich möchte glauben, daß anch diese auf kleine Einzelfaltmngen der Epidermis zurückznführen sind. und daß diese sowohl ihre Rantenstellung zueinander wie auch ihre Sockelbildung erst sekundär erworben haben. Die Malacostomata umfassen hiernach drei Ordnungen. eine fossile. die die ältesten Wirbeltiere enthält, und zwei, die noch lebende Tertreter anfweisen.

\section{Stufe als Unterklasse †Palaeostraci m.}

Bilaterale Fische, deren Kopf und rorderer Teil der Rumpfregion einheitlich gepanzert ist, deren Hinterleib plattig bis schmppenartig. skelettiert ist und z. T. eine Rïckenflosse ansbildet. Die paarigen Gliedmaßen fehlen ganz, bei einigen sind die vorderen in Form gepanzerter Paddeln ansgebildet. Die Angen sind klein, seitlich gelegen oder bei Bodenformen dorsal zusammengerïckt. Mundteile unverknöchert, bei den ältesten Formen wohl rorstiilpbar als Sangmund wie bei Amphibienlarven. Untersilur bis Oberderon.

Die Palaeostraci zeigen in ihrer äuBeren Erscheinung - wie ein Blick auf die folgenden Figuren lehrt - so anffallende Unterschiede, daß man über ihre engere Terwantschaft in Zweifel kommen kann. Andererseits zeigen sich aher doch wieder Zwischenformen zwischen den sehr nngleichen Extremen, wie z. B. Tremataspis zwischen den Cyathaspliden und den Cephalaspiden, dab man ihre Verwandtschaft kamm bezweifeln kann. Wir werden kamm ammehmen diurfen, daß die bisher bekannten Formen die Mannigfaltigkeit dieser ältesten Typen irgendrie erschöpfen, und eine Klärung ihrer verwandtschaftlichen Beziehnngen erst von weiteren Funden erhoffen duirfen.

Die Skelettbildung umschließt bei den ältesten Formen alle Organe bis anf den Mund und die Angen. Anch die Epiphyse ist bei diesen Formen durch einen dünnen, besonders sknlpturierten Buckel des einheitlichen Rückenschildes abgeschlossen. Bei den jüngeren Formen, den Tremataspidi und Goniaspidi, ist eine Epidyse wieder hergestellt. Dasselbe gilt auch ron anderen Organen, so mamentlich von einer vorderen muaren Riechplacode. den parigen kleinen Ohröfnnngen, die wohl 
mit den sogenannten spritzlöchern der selachier zu identifizieren sind, einer vermmtlich respiratorischen öffnmng über der Rantengrube des Gehirns (Fig. 19), mnd den seitlichen Kiemenöfmmngen, die bei den ältesten Formen fehlen, bei den jüngeren aber ähnlich wie bei den Cyclostomen als Serien kleiner seitlicher (̈)fmmngen erkennbar sind. Bei den Heterostraci glaubte ich früher für die Kiemen, von deren Stützen hogige Eindriicke bei Palaeaspis an der Innenfläche des Rückenschildes zn beobachten sind, seitliche Öffnmngen unter der schmalen Seitemplatte annehmen zn sollen. Es scheint mir aber jetzt wahrscheinlicher, dab die Kiementaschen dieser Formen blinde seitliche Ausstïlpungen des Oesophagns waren, mnd dab sie also ein Entwicklungsstarlinm repräsentierten, wie es bisher bei Wirbeltieren noch nicht beobachtet ist, wie es aber in der Embryonalanlage des Schlundes anch der höheren Wirbeltiere noch als Ausgangsstadium anzmmelmen ist.

\section{Hauptordmmog + Heterostraci Lankester}

Kanlquabbenfömige kleine Fische mit walzem undem oder flachem „Cephalothorax", aus großem Rïckenschild, schmalen Seitenschildern und Banchschild, mit seithichen Angen, ohne änBere Kiemenlöcher, ohne paarige Ghedmaßen.

'Typus Palaeaspis, ferner Crathaspis, Tolypaspis aus dem mittleren baltischen Obersilur, Pteraspis aus dem mnteren Devon. Diese gruppieren sich in zwei Cnterorrmmngen.

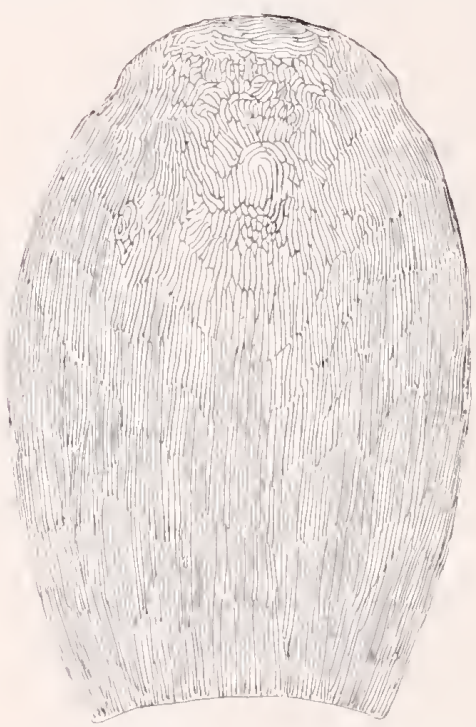

Fig. 15. Rückenpanzer von Palaeaspis integer Kunth, aus dem schwedischen Obersilur. Vergrößert ${ }^{3 / 2}$.

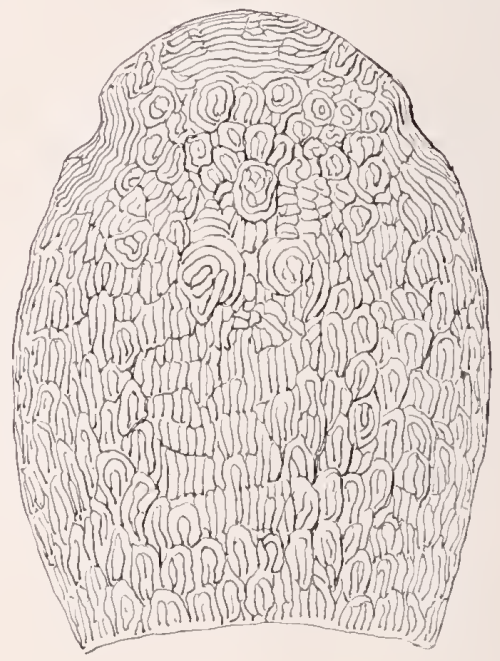

Fig. 16. Dasselbe Panzerstück von Tolypaspis Schmidti Rohon. Obersilur von Oesel. Größe $3 / 2$. 


\section{Unterordnung † Palaeaspidi}

mit einfachem, nicht gegliedertem, vorn abgestumpften, bei der ältesten Fol'm (Palaeaspis) walzenrunden Vorderkörper, ohne Rostralbildung und ohne Rïckenstachel, mit langen feinen Längsleisten auf den großen Panzerplatten (Fig. 15), die dann zn schuppenartigen Bezirken zerlegt werden (Fig. 16). Über der Epiphyse bildet die Schale einen hügeligen Bezirk.

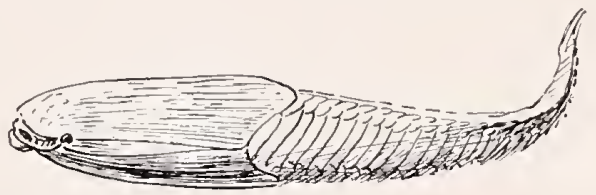

Fig. 17. Palaeaspis integer Kunth sp. Rekonstruktiou. 1/2 nat. Größe.

\section{Unterordnung †Pteraspidi.}

Der Rïckenpanzer alogeflacht und in 5 Felder zerlegt, vor'n zu einem Rostıum verlängert, hinten in einen Riickenstachel ausgezogen. Skulptur-Längsstreifen sehr fein und durchlaufend. Schuppige Plättchen des Hinterleibes klein quadratisch. Im Unterderon weit rerbreitet.

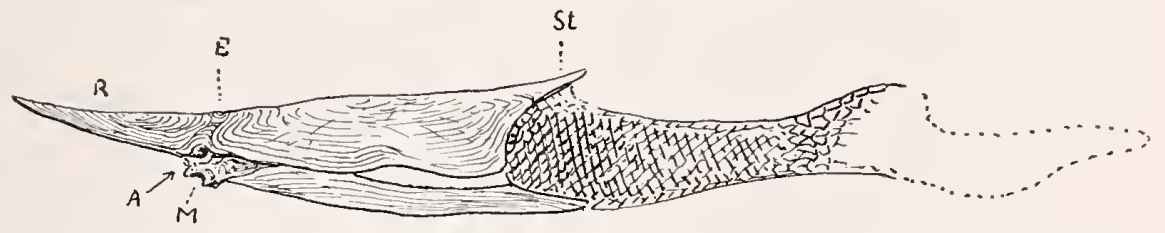

Fig. 18. Rekonstruktion von Pteraspis aus dem untersten Devon von Nordeuropa. $1 / 2$ nat. Größe. $R$ Rostrum, $E$ Lage der Epiphyse, St Nackenstachel, $\boldsymbol{A}$ Auge, $\boldsymbol{M}$ Mund.

\section{Ordnung † Goniaspidi.}

Bodenfische mit flachem Vorderkörper, der in einen einheitlichen, oder in Platten oder Dornen zerlegten Panzer gehüllt ist. Dieser ist durch seitlich und riickwärts vorspringende Ecken charakterisiert. 4-5 paarige Kiemenlöcher an der Unterseite. Augen meist dorsal brillenartig zusammengerückt. Vordere Gliedmaßen nur vereinzelt als gepanzerte dicke Paddeln ausgebildet. Rückenlinie mit Dachschuppen, Rïckenflosse und Schwanzflosse öfters nachgewiesen. Hierher gehören die obersilurischen Tremataspiden (Fig. 19), die Cephalaspiden, die Ateleaspiden, die Psammosteiden, Drepanaspiden und die Thelodonten, deren Panzer in Dornen anfgelöst ist.

Bei den devonischen Cephalaspiden sind vordere Gliednaßen als dicke, schuppenbedeckte Paddeln erkennbar (Fig. 21).

Die Goniaspiden bilden eine formenreiche Gruppe, die sich in vier Unterordnung'en zerlegen läßt. 


\section{Unterordnung tTremataspidi.}

Rücken- nnd Brnstpanzer flach und glatt. Angen dorsal brillenartig znsammengerückt, mit zwischen ihnen gelegener Epidyse, davor gelegener Riechplacode, dahinter gelegener Rautengrube, die wohl zum direkten Gasanstansch des Gehirns diente, paarigen kleinen Ohröfnungen. Die physiologische Bedeutung seitlicher Gruben ist noch nicht anfgeklärt. Auf der Unterseite kleine postorale Platten, dahinter ein großes Scliild, vor demselben jederseits eine schräge Reihe von Kiemenlöchern. Hinterleib mit kleinen, rektangulären, schmppenähnlichen Hautplatten. Obersilur.

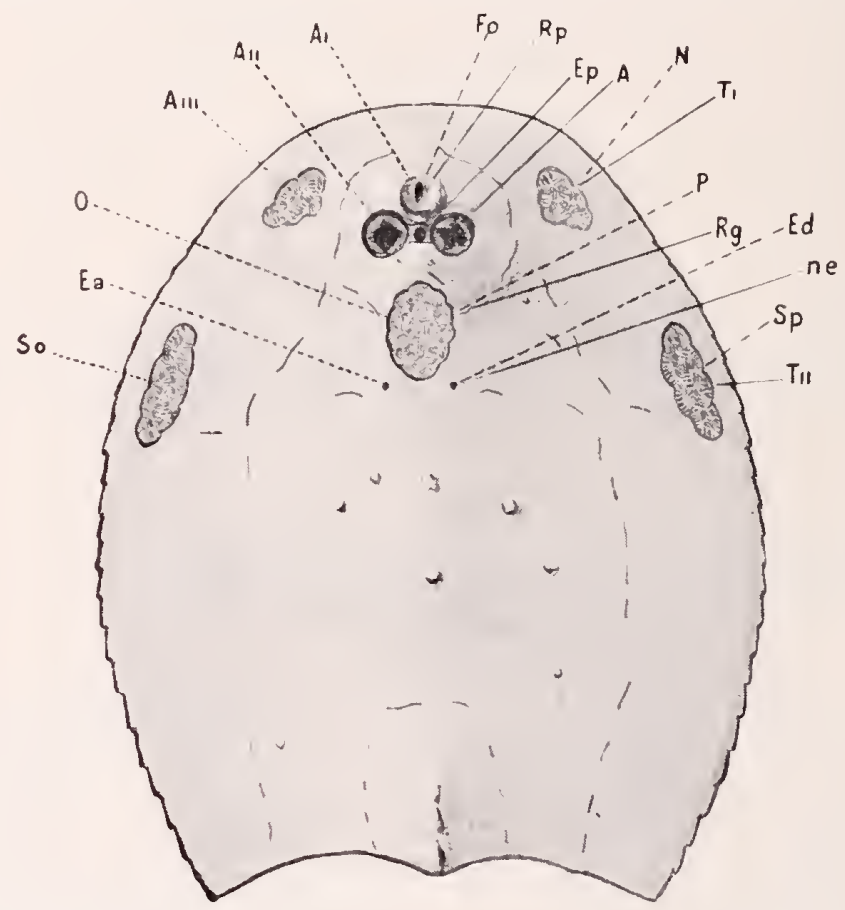

Fig. 19. Tremataspis Schrenki F. Schmidt aus dem Obersilur von Oesel. Dopp. Größe. Vorn median die unpaare Riechgrube, dahinter die Augen, zwischen ihnen in der Bräcke das kleine Epiphysenloch. Dahinter median die ovale respiratorische Rantengrube, dahinter beiderseits die feinen Ohröffnungen. Beiderseits am Rande zwei Gruben, die vielleicht zur Aufnalme von Tentakeln dienten. (Nach Jaekel.)

\section{Unterordnnng †Cephalaspidi.}

Wie vorige, aber Rückenpanzer breit, mit Seitenrändern, die hinten eckig auslaufen („Cornna“), in einzelne kleine schuppenähnliche Bezirke gegliedert. Die Unterseite mit kleinen Plättchen vorn und zwei paarigen größeren dahinter. Vor denselben die Kiemenlöcher. Eine Rückenflosse. Sclıwanzende aufgebogen mit ventralem Flossenbesatz. Obersilur und Unterdevon. 


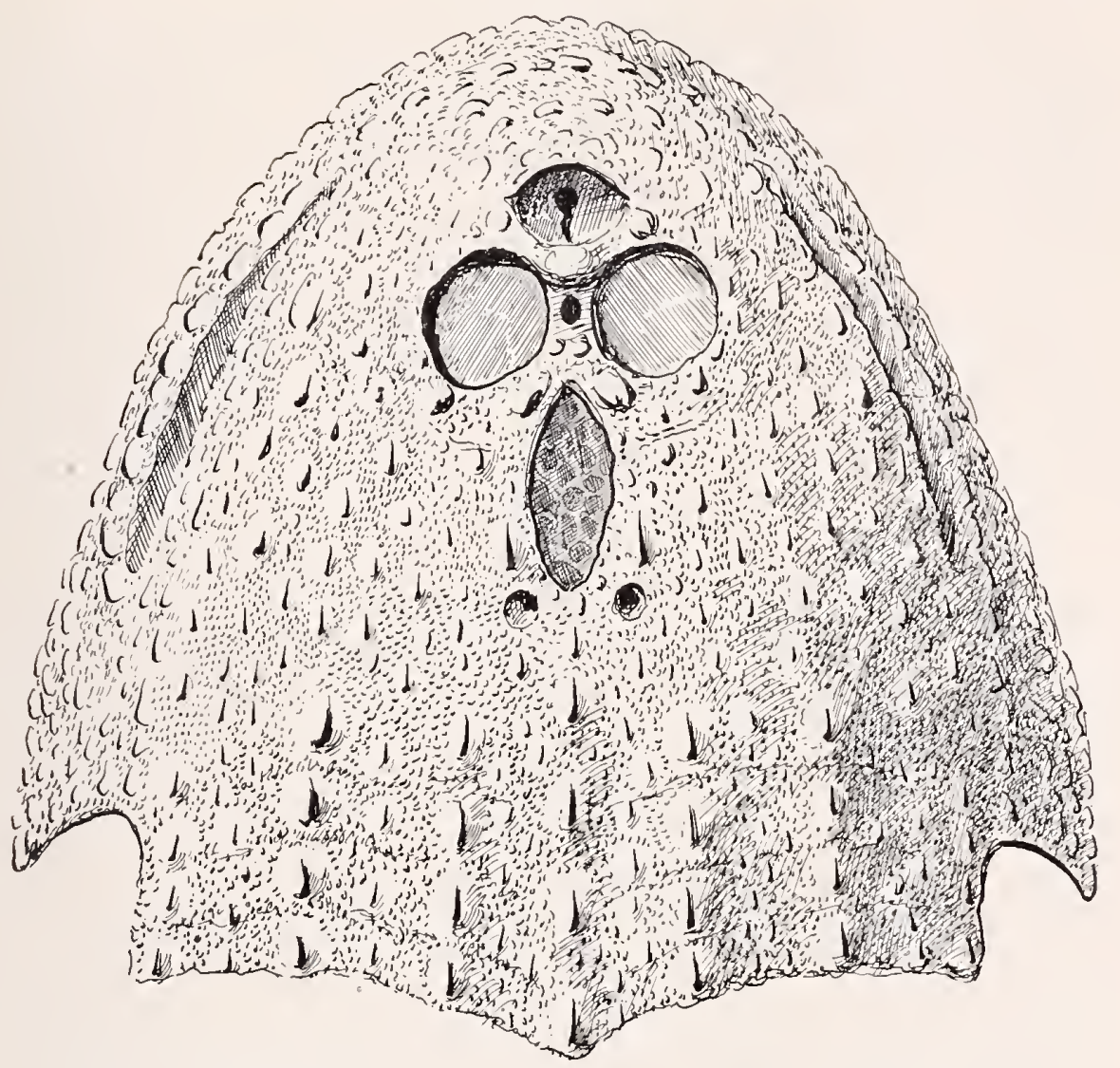

Fig. 20, Rückenschild von Thyestes verrucosus F. Schmidt. Obersilur Oesel. 5-fache Vergrößerung, vergl. Erklärung zu Fig. 19.

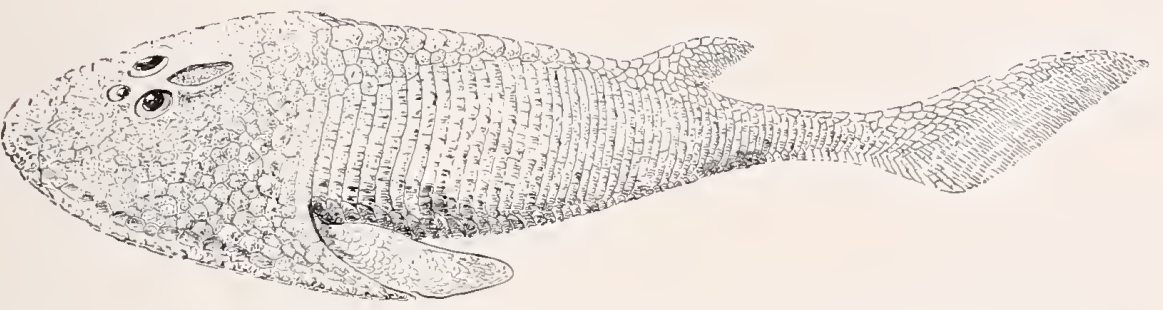

Fig. 21. Rekonstruktion von Cephalaspis Murchisoni Ag. Unterdevon von England. $1 / 2$ nat. Größe.

\section{Unterordnung †Drepanaspidi.}

Ähnlich den vorigen, aber mit großen medialen Platten auf der Ober- und Unterseite des Kopfumpfpanzers. Öffnungen der Sinnesorgane unklar. Paarflossen fehlen. Unterdevon, Rheinland. 
Hierher gehören wohl auch die Psammosteiden des russischen Devons, deren Forderkörper bei einigen Formen in einen großen walzenrunden, bei anderen in einen flacheren Panzer gehïllt war, der anch die charakteristischen Seitenecken der Goniaspiden aufweist.

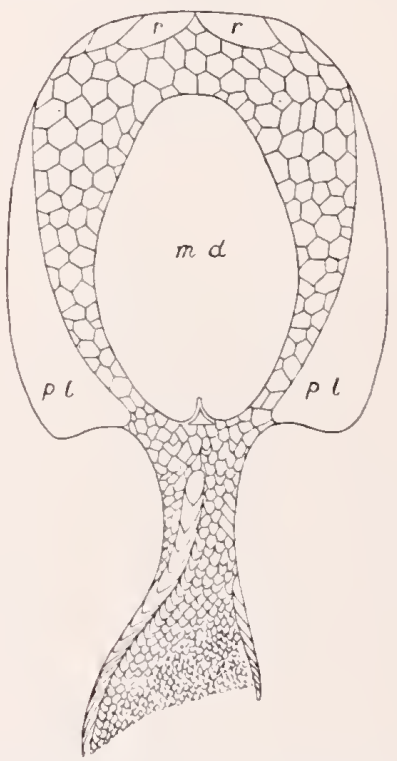

Fig. 22. Drepanaspis gemündenensis Schlüter. Unteres Devon, Rheinland (nach Traquair) ${ }^{1 / 4}$ nat. Gröbe.

4. Vunterordnung tThelodonti.

Vorderkïrper verbreitert und seitlich in Hinterecken ansgezogen. Der Hinterleib fischförmig mit epicerker Endflosse. Die Hant mit einzelnen isolierten Dornen (Lanarkia im obersten Silur) oder mit breiteren eng gestellten, mit einem sockel versehenen Dornsehüppchen besetzt (Thelodus, Coelolepis).

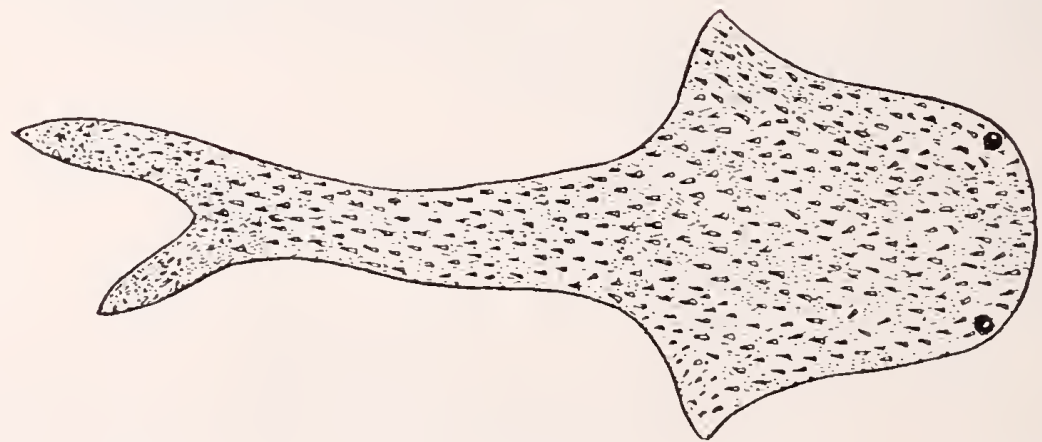

Fig. 23. Thelodus scoticus Traquair. Oberstes Silur von Schottland (nach Traquair). 


\section{Is. Ordnmng † Anaspidi Traquair.}

Die durch Birkenia und wahrscheinlich auch Lasanius im obersten Silur Schottlands repräsentierte Gruppe ist noch nnvollständig bekannt und anscheinend von ihrem Beschreiber R. H. Traquair verkehrt gestellt, derart daß Riicken und Banchseite miteinander vertauscht sind. So gestellt war die stellung der Kiemenlöcher und die Lage der großen medialen Dornemplatten zu schwer verständlich.

Körper fischförmig mit (?) lıypocerker Endflosse, mit walzenförnigem Vorderleib. Kopf mit skulpturierten Platten bedeckt. Augen seitlich. Kiemenlöcher jederseits in einer nach der ventralen Mittellinie konvergierenden Reihe. Rumpf und Hinterleib mit spindelförmigen Plättchen bedeckt.

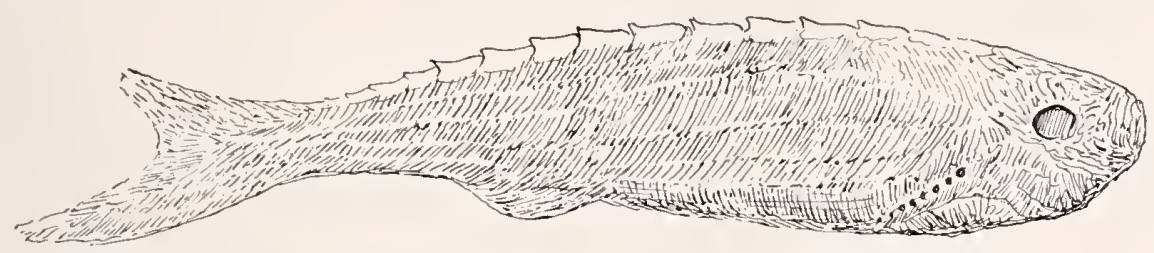

Fig. 24. Birkenia elegans Traquair. Oberstes Silur, Schottland. Restauriert. Vergrößert $3 / 2$.

\section{Nebenordnung + Pterichthyi.}

Die gewöhnlich mit den Coccosteiden und anderen panzertragenden Fischen des Devons als Placodermata vereinigten Asterolepiden oder Pterichthyer bilden einen der orginellsten Wirbeltiertypen, dessen systematische Beurteilung daher auch die mannigfaltigsten Ansichten hervorrief. Es sind knöchern gepanzerte Malacostomen mit kleinem Kopf, brillenartig zusanmengerückten Augen, hreitem gebißlosem Mundspalt, großem aus dorsalen seitlichen und ventralen Platten gebildeten Rumpfpanzer, an dessen Vorderrand seitliche Eckstacheln vortreten nnd z. T'. zu beweglichen „Ruderorganen" spezialisiert sind. Paarige Gliedmaßen fehlen; der Hinterleib ist mit eckigen Plättehen bedeckt, und mit unpaaren Flossen versehen. Kiemenlöcher fehlen. Wahrscheinlich lagen die Kiemen unter dem Kopfschild und öfneten sich in den Spalt des Skelettes vor dem Halspanzer. Der Hinterleib ist nicht, wie dies bisher dargestellt wurde, mit echten Deckschmpen, sondern mit breiten Plättchen bedeckt, die sich z. T. in einen steilen Dorn erhoben.

Der wesentliche Pnnkt in der Beurteilung dieses Typus war die Klarstellung, daß die sogenannten Ruderorgane nicht den "Armen" bezw. vorderen Gliedmaßen anderer Wirbeltiere entsprechen, sondern den seitlichen Panzerecken der Goniaspiden homolog sind. Es sind also abgegliederte, passiv beweglich gewordene Seitenstacheln des Panzers. 
An eine starke aktive Beweglichkeit, etwa zur Nahrungsaufnahme, ist dabei nicht zu denken. Durch die Abgliederung des Kopfpanzers von dem Rumpfpanzer entfernen sich đie Pterichthyi ron allen übrigen Palaeostraken und bilden dadurch einen Übergang zu den Coccosteiden unter den Hypostomen. Die gleichartige Gliederung ihres Bauchpanzers mit dem der Coccostei (Fig. 33) wäre als reine Analogie schwer verständlich.

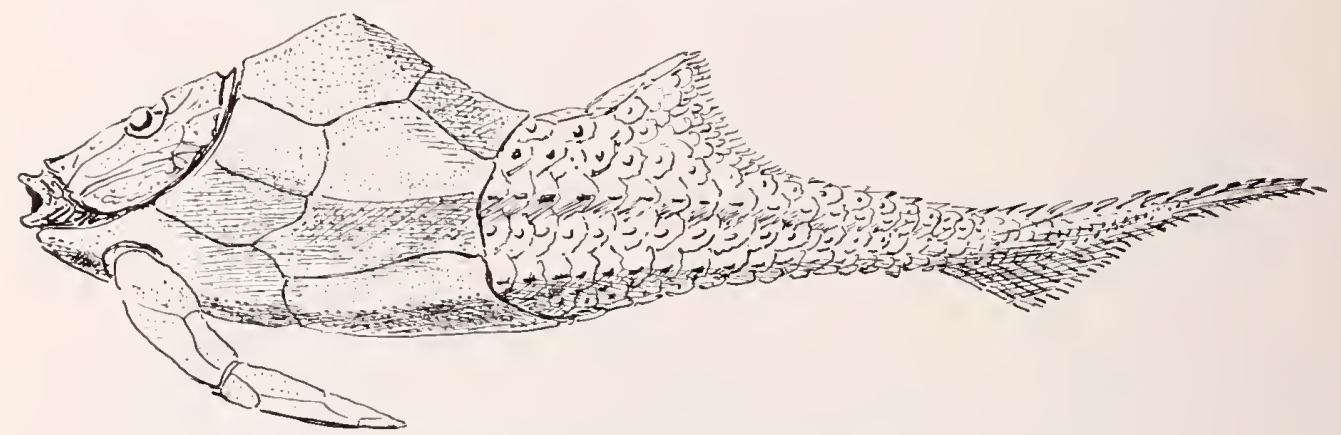

Fig. 25. l'terichthys Milleri Ag. aus dem Mitteldevon von Schottland. Restauriert in $2 / 3$ nat. Größe.

Hierhin gehören als weniger spezialisierte Formen die

Unterordnung + Acanthaspidi

mit großen, aber noch unbeweglichen seitenstacheln, und die

\section{Unterordnumg +Asterolepidi}

mit hohem Rmmpfpanzer nnd beweglichen Seitenstacheln. Pterichthys, Asterolepis, Microbrachium und Bothriolepis, die in mittel- und oberdevonischen Schichten der nördlichen Hemisphräre verbreitet sind.

Unterklasse Cyclostomata, Rundmäuler.

(Marsipobranchia Joh. Mïller, Monorhina Haeckel.)

Nackthäntige Malacostomen ohne paarige Flossen mit komprimiertem Ruderschwanz und wenig differenziertem medialen Flossensaum. Mund znm Saugen eingerichtet mit hornigen Lippen- und Zungenzähnen aber rückgebildeten Kiefern. Skelett bei den älteren Typen noch zusammenhängend verkalkt, dann mit prismatischer Kalkinkrustation, dann knorplig oder nur membranös. Kiemen bentelförmig, 6-14 seitliche rnnde Kiemenöfnungen, die bei endoparasitärer Lage des Vorderkörpers in eine hintere öffnung zusanmengezogen sein können (Myxine). Nasengrnbe einfach, dorsal, vor den Augen gelegen (monorhin), z. T. durch einen Gaumengang in die 
Mundhöhle mündend (Hyperotreta), z. 'T'. blind geschlossen (Hyperoartia). Die fossilen Formen lassen die Auffassung der $\mathrm{Cy}$ clostomen als Degenerationsreihe nicht im Zweifel.

\section{Ordnung † Palaeospondyli.}

Tnnenskelett verknöchert, am Mund mit fingerförmigen Fortsätzen versehen, dahinter mit verwachsenen kranialen Visceralbögen, Wirbelkörper gesondert, die oberen Bögen mit Dornfortsätzen versehen. Schwanz epicerk mit Flossenträgern in der niedrigen schwanzflosse. Devon.

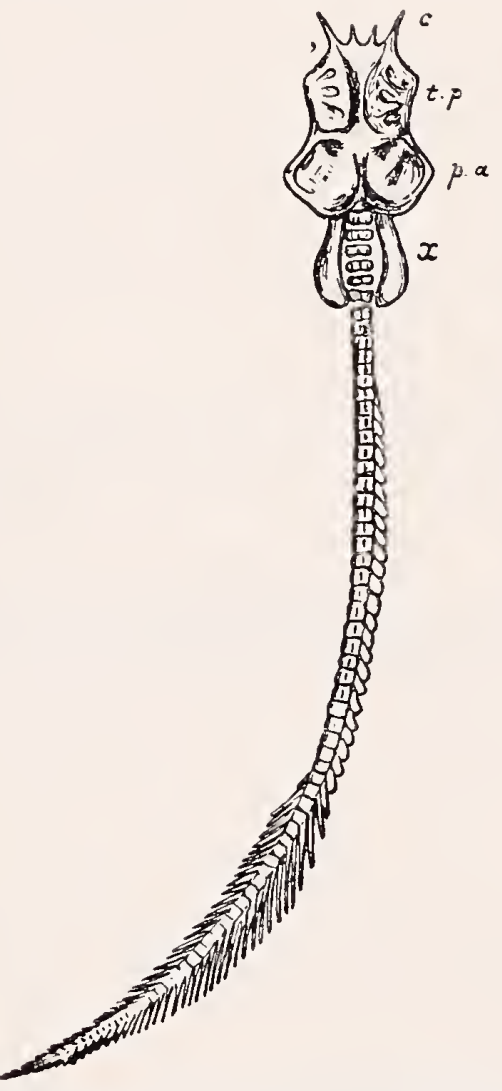

Fig. 26. Palaeospondylus gunni Traquair. Mitteldevon, Schottland. 3/1 (nach Traquair).

\section{Ordnung † Hypospondyli.}

Skelett prismatisch inkrustiert, am Iundrande mit Lippenfortsätzen, mit drei Schädelregionen, deren vordere mit Mundbögen, deren hintere mit einer geringen Zahıl - anscheinend vier - Kiemenbögen versehen ist. Wirbelkörper in paarigen Hypocentren verkalkt. Obere Bögen in paarige 
Hälften zerlegt, die sechs (?) vorderen dem hopf zugewandt. Dorsale und ventrale Flossensäume dureh Flossentrïger gestiitzt. Bisher nur eine Form, die ich als nene Gattumg einführe (Fig. 27).

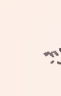
-

Fig. 27. Hypospondylus bohemicus n. g. n. sp. Gaskohle Nürschan, Bühmen. 3/2. Rekonstruierte Seitenansicht.

\section{Ordunng Myxini.}

Die Nasengrube dureh einen Gang mit der Mundhöhle verbunden („Hyperotreta“). Vier Paare ron Mundtentakeln. Infolge parasitischer Einbohrung des Vorderkörpers in andere Fische sind die äußeren Kiemenlöcher in eine rïckwärts geschobene Öffnung vereinigt, nach innen miinden die Kiementaschen direkt in den ()esophagus. Angen rudimentär. Ohr mit einem Bogengang. Hienher die lehenden Gattungen Myxine, Homea (= Bdellostoma) nnd Macrophthalmia.

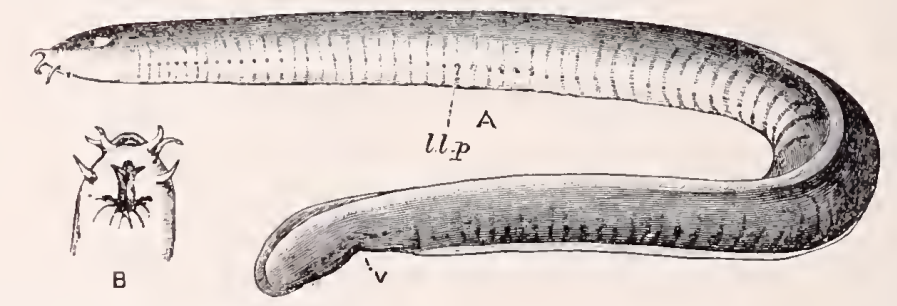

Fig. 28. Myxine glutinosa, lebend, Nordsee (nach Boulenger). $l l p$ seitliche Öffnung der Schleimsäckchen, $v$ After, $B$ der Mund von unten gesehen.

4. Ordnung Petromyzontes, Lampreten, Neunaugen.

Aalförmig, z. T. zicmlich groß; mit geschlossener Nasengrube (.,Hyperoartia“), einem Kranz von Cirren an Mundrand und zahbeichen Hornzähnen im Mund und anf der Zunge. Sieben Kiemenoffnungen

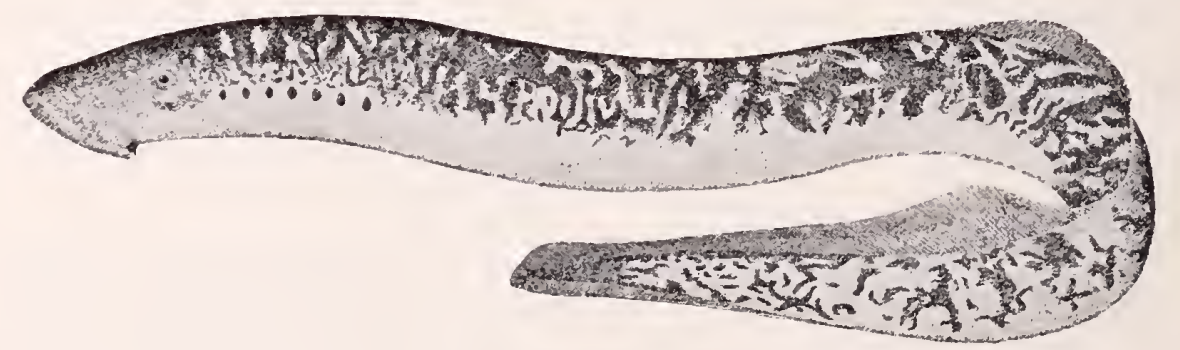

Fig. 29. Petromyzon marinus, lebend. Atlantic. 1/3 (nach Jordan u. Evermann). 
jederscits. Innen jedelseits ein gemeinsamer hiemenkanal, der in die Ohrhöhle mïndet. Nund mit zwei halbkreisförmigen Kanälen. Augen normal entwickelt.

Hierher die fast ïherall verbreitete Gattung Petromyzon.

\section{Unterklasse Leptocardi J Joh. Müller.}

(Acrania Haeckel, Cephalochordata Boul.)

Kleine nackthäntige, fischförmige. marine Malacostomen ohne dentich differenzierte Flossen, ohne parige Angen mud Ohren, ohne deutlich differenzierten Gehirnabschnitt des Rückenmarkes, ohne Wirbelbildnng an der Cholda, ohne Herz, mit weichem, cirrenbesetztem Mnnd, mit metameren Urnieren und Geuitalorganen, mit paarigen, einzeln nach den Seiten geöfneten Kiementaschen am Oesophagns, mit einfacher Leber am Darm. mit pulsierender ventraler Aorta, mit linlisseitig gelegenem After. AnBerdem ist vom Ectoderm ein Peribranchialranm gebildet, dessen Atrinm die Crmieren- und Genitalkanäle anfuimmt und in einem hinteren Atrioporus geöfnet ist. Der definitive Mund ist nach von Tijhe nicht der der Wirbeltiere, sondern entspricht deren linker Ohrspalte. Die Chorda ist bis znr spitze des Rostrnms verlängert.

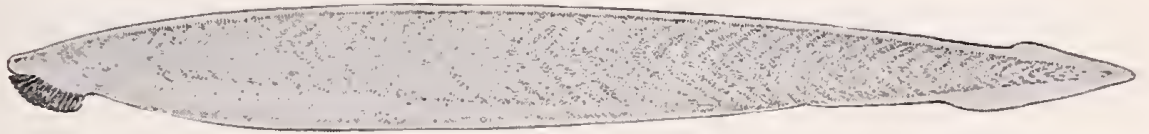

Fig. 30. Branchiostoma (Amphioxus) lanceolatum Pallas, lebend Mittelmeer. 2/1 (nach Jordan u, Evermann).

Amphioxns bezw. die beiden Gattnngen Branchiostoma (Costa) und Asymmetron (Andrews) sind muzweifelhaft die niederst organisierten Wirbeltiere und bieten in einer Menge von Organisationsverhältnissen äußerst einfache Znstände, die schon an sich für die Entwicklungsgeschichte der Wirbeltiere von größter theoretischer Bedentung sind. Die Metamerie ihrer Crnieren- mnd Genitalorgane knïpft noch an die episomatiden Vorfahren der Wirbeltiere an, die Anshildung ihres Schlnndes als Atemraum, die pnlsierende Tätigkeit der ventralen Aorta sind vielleicht nnmittelbar aus niederen Lrzuständen herrorgegangen. Andere Terhältnisse köunen dagegen nmmöglich primitiv sein. Die besonders im Jugendstadinm stärker herrortretende Unsymmetrie der beiden Körperhälften, die spätere Verlagernug der Kiemen, des Mundes mnd Afters beweisen unmittelbar, daß die Vorfahren ron Amphioxns lange Zeit nnter ganz 
absonderlichen Lebensrerlältnissen existiert haben müssen. Die Unsymmetrie und die Verlagerung wichtiger Organe sprechen entschieden fiir eine Anlreftung, die in der Sessilität der 'Tnnicaten ihr Analogon fände. Durch eine Auheftung wïrde sich auch das Felılen der paarigen Kopfsimesorgane erklären und die geringe Entfaltung des Gehirus durch Verkïmmerung jener Sinnesorgane und der freien Mundfunktionen verständlich werden. Die alleinige Entwicklnng einer Chorda und den Mangel ron Ossifikationen kann ich ebenfalls nicht melu als primitiv anselıen. Die Chorda ist mir ebenso nur ein ontogenetisches Hilfsmittel der Wirbelbildung wie der Knorpel für das sonstige Innenskelett. Ihre Existenz setzt demnach eine rorherige feste Skelettbildung voraus. Ihr Unterbleiben in der Ontogenie würde sich ebenfalls durch eine sessile oder parasitische Lebensweise an einfachsten erklären.

Anch die Nenbildung des Peribranchialraumes, der an die entsprechenden Bildnngen bei 'T'unicaten erinnert, ist mit einer freien, für die stammformen der Wribbeltiere als einzig möglicher Weg zu löherer Entwicklıng zn supponierenden, freien Bewegungsweise nicht in Einklang zu bringen. Daß die Chorda bis an die Spitze des Rostrums vorgewachsen ist, beweist, daß die bei allen Wirbeltieren seiner Ausdehnumg mach rorn hinderliche Hypophyse umgangen sein muB, und ist also anch ein Beweis für die paramorphe Verlagerung der Kopforgane.

Die Bedeutung, die vou zoologischer und anatomischer Seite Amphioxus in stammesgeschichtlicher Hinsicht beigenessen wurde, scheint hielnach, wie ich schon seit vielen Jahren betont habe, nicht gerechtfertigt. Erst hätte die Uroeschichte rou Amphioxns in pliysiologischer Beziehung klarer gestellt werlen miissen, ehe man die Niedrigkeit seiner Organisationsverhältnisse für primitiv erklärte; diese Vorbedingung ist aber in keiner Weise erfüllt worden. Die Beantwortung der diesbezüglichen Fragen kanu nu dahin führen, daB die Leptocardier vor allew in vielen Verhälnissen anf niedrigste Stufen zurückgesunken sind, dab ihnen aber die Folgen einer paragenetischen Aushildung ihrer Vorfahren überall in dell Gliedern stecken.

Indem wir num die Leptocardier als degenerierteste Malacostomen auffassen und sie stammesgeschichtlich durch cyclostontenartige Stadien von älteren normal gebanten bilatęralen Vorfahren ableiten, schließen wir sie einerseits an die ältesten und niedersten Wirbeltiertypen an, und tragen andererseits ihrer Aberanz in vielen Organen Reclunng. 


\section{Klasse Hypostomata n. nom.}

Fische mit plattigem oder dornigem Hautskelett oder nackter Haut, deren Mund an der Unterseite des Kopfes gelegen und mit Zahubildungen versehen ist, die entweder Deckknochen sind oder frei dem Knorpel aufsitzen. Kiemen durch Bogen gestiitzt unter dem Kopf gelegen oder sekundär in die Halsregion gerückt, mit gemeinsamen oder gesonderten Kiemenspalten. Beide Gliedmaßenpare wohl ausgebildet, die hinteren z. 'T. noch größer als die vorderen, mit knorpligem Innenskelett. Unpare Flossen mannigfaltig ausgebildet. Schwanz epicerk. Gehirn und Simnesorgane wohl entwickelt. Epidyse verwachsen. Wirbelsäule normal gegliedert, aber mit persistierender Chorda. Innenskelett knorplig, z. T. zusammenhängend oder prismatisch verkalkt. Vom Devon bis jetzt.

Die Herkunft der Hypostomen, die durch ilrren bezahnten, stets an der Unterseite gelegenen Mund und durch den Mangel echter Schuppen in erster Linie charakterisiert sind, ist noch unsicher. Sie können aus primitiven Nalacostomen herrorgegangen sein, wobei nicht ganz ausgeschlossen ist, daß die Placodermata und die Selachier aus rerschiedenen Formenkreisen der Malacostomen entstanden. Es ist aber auch möglich, daß die Hypostomen direkt von vierfüBigen Landwirbeltieren ausgegangen sind.

Die Zusammenfassung der hier vereinigten Fischtypen ist neu, scheint mir aber nach eingehenden über 20 Jahre zurïckreichenden Forschungen stammesgeschichtlich noch am meisten gerechtfertigt zu sein. Über die systematische Bewertung des gegenseitigen Verhältnisses der einzelnen Gruppen kann man vollends verschiedener Meinung sein. Mir erscheint folgende Anordnung unseren tatsïchlichen Kenntnissen und den praktischen Bedürfnissen eines „Systems“ am besten angepaßt.

1. Unterklasse Placodermata

Ordnung Ptychostei

. Coccostei

2. Unterklasse Chondrostei Störe.

3. Unterklasse Placoidei Agassiz

Ordnung Holocephala

$"$ Selachia. 


\section{Unterklasse Placodermata.}

Hypostomata mit dickem, knöchernem, plattig gegliedertem meist tuberkuliertem Kopf-nnd Halspanzer, dessen hinterer Ansschnitt znr Anfuahme der vorderen Parflossen diente. Mund mit Kieferknochen, anf denen sich ofter's stephanodonte Zähne anshilden. Becken bisweilen wohl entwickelt. Kiemen unter dem Kopfskelett. Innenskelett kuorplig, aber meist zusammenhängend oberfächlich verkalkt.

Die Besonderheiten iluer Skelettbildung beruhen vor allem anf der festen Umhüllung des Kopfes und Halses durch echte Deckknochen, nnd auf der scharfen sonderung dieser beiden Körperabschnitte. Ilese ist nicht nur in diagnostischer Hinsicht bedeutsam gegeniiber der znsammenhängenden Panzermng des Kopfes und Nackens hei den Palaeostraken, somderu auch stammesgeschichtlich wichtig, weil sich diese Sonderung eincl Halsregion spätel bei den Fischen ganz verliert, und ilne Ansprägnng bei so alten Fischformen auf eine frühere physiologische Selbständigkeit des Kopfes hinweist.

Die Gliderung des Kopfskelettes ist in ganz anderer Weise erfolgt als bei den Teleostomen nnd Tetrapoden. In Schädeldath sind nmo die Parietalia paarig, die iibrigen medialen sehädeldachknochen unpar. Das Oecipitale smperius ist besonders kräftig als Stiitzpunkt der Nackenmuskulatnr. das Rostıum ïber Nase und Mnnd hänfig weit verlängert.

Die Nasenlöcher sind klein, paarig untel dem Rostrun zusammengedrängt, wahrseheinlich noch mit der Mundhöhle in Verbindung. Die Bezahnung ist stephanodont, 1. h. auf eine Kerbung der Deckknochen besehränkt. In einigen Fällen sind diese Deckknochen zn einem Sichneiderand zugeschärft (llynchodont), in anderen sind sie als Kaupolster spezialisiert.

Die Kiemen liegen in normaler Zahl d. h. vier zwischen gegliederten Knorpelbögen, unter der Schläfenregion des Kopfpanzers. Znr Beschreibung des diesbezüglichen Materiales bin ich leidel noch nicht gekommen. Die Wasserausfuhr erfolgte wahrscheinlich einzeh aus den Kiemen durch einen spalt, der beiderseits zwischen dem Kopfschild und dem Halspanzer nachweisbar ist. Ein eigentlicher Opercularapparat existiert noch nicht.

Die vorderen Glietmaben waren, soweit ich nach einem Coccosteiden mrteilen kann, mit gegliederter, knorpeliger Hauptachse versehen und in diesem axialen Teile mit Schmppen bedeckt. Eine tiefe, von hinten erfolgte Einbnehtnng in den Halspanzer markiert aber üherall die Stelle der vorderen Parflossen. Dieser Halspanzer wird damit zum dermalen Schnlterapparat. der ans einer gö̈ßeren Zahl ron Platten zusammen- 
gesetzt und auf der Bauchseite weit nach hinten ausgedehnt ist. I)ic innere Beckenanlage, die sonst bei den Fischen größtenteils verkümmert ist, war hier z. T. noch groß und anscheinend an der Wirbelsäule angehängt. Diese starke Entwickhnng des Beckens dentet darauf, daß bei den Vorfahren der Placodelmen die hinteren Gliedmaßen eine stïrkere Leistung ausübten. Da eine solche bei schwimmender Lebensweise ausgeschlossen ist, die hinteren Paarflossen anch bei Fischformen klein blieben, verkiimmern oder weit nach rorn verschoben werden, so ist wohl als eine solche stärkere Funktion nur ein Tragen oder ein Schieben des Körpers d. h. eine tetrapode Bewegung desselben rorauszusetzen. Der Schwanz zeigt ventral eine immere Platte, die wohl als Stiitzpunkt einer Analflosse diente. Ein ventrales Caudalsegel und eine lange Dorsalis waren vorhanden, rermutlich davor anch eine kleine Nackenflosse hinter dem dorsale .Nuchale", da dieses und eine innere Stiitzplatte die gleiche Ausbildung zeigen, wie die entsprechenden Teile ron Holocephalen.

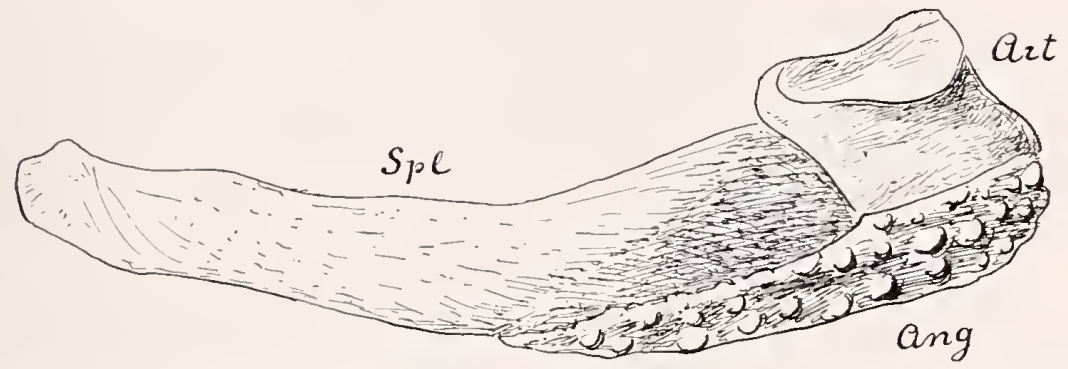

Fig. 31. Unterkieferast von Pholidosteus Friedeli Jaekel, aus dem Oberdevon von Wildungen. Außenseite. Art Das knorplig angelegte, perichondral rerknöcherte Articulare. Spl Splemiale. Ang Angulare. (Nach Jaekel.) $\% / 1$.

I)ie morphologische und systematische Beurteilnng der Placodermen war großen Schwankungen unterworfen. Zunächst wegen ihres Panzers für schildkrötenartige Wesen gehalten, wurden sie bald daranf als Fische erkannt, aber doch bis in die neueste Zeit sehr versehieden beurteilt. Meist mit den rorher besprochenen malacostomen Palaeostraken in engeren Konnex gebracht, wurden sie noch ron A. Smith Troodward als nächste Verwandte der Dipnoer betrachtet, ron Bashford Dean aber von allen übrigen Wirbeltieren abgesondert, weil ihm schien, daf sie eines Unterkiefers entbehrten. Diese Anffassung war irrig. wie der vorstehend abgebildete Unterkiefer beweist. Derselbe besitzt ein knorpliges, außen schwach rerknöchertes Gelenkstïck, das dem Meckelschen Knorpel bezw. dem Articulare anderer Trirbeltiere homolog ist. Unten und innen rorn sind diesem inneren Skelettstück, das das Kiefergelenk bildet, zwei Deckknochen angefügt, deren inneres vorderes als 
Splemiale, deren hinteres dem Angulare verglichen werden kann. Der Besitz eines echten T'nterkiefers befreit die Placodermen von dem Verdacht, in einem tieferen Gegensatz zn allen Wirbeltieren zu stehen. Thre Fischnatur kommt nicht nur in ihrer änberen Körperform, sondern anch in vielen Einzelheiten ihres Skelettbanes zum Ansdrnck. Von ihrel Tirbelsäule verknöchern nur die oberen und mnteren Bögen. Die unpaaren Flossen haben skelettierte Flossenträger, was bei Tetrapoden nie rorkonmt, ihr Kiemenapparat weist normal entwickelte Kiemenbögen anf, ihre Epiphyse liegt in der Frontalregion. Thre Lmingen sind als sackförmige schwimmblase ansgebildet. Das sind alles Eigenschaften, die wir bei anderen Wirbeltieren als den Fischen noch nicht kennen. Andererseits bilden sie imerhalb der Fische einen sehr eigenartigen Typus.

Die Mannigfaltigkeit der Formen bedarf noch weiterer Anfklärnng. Zunächst lassen sich folgende Ordmungen einigermaßen sicherstellen.

\section{fOrdnung Ptychostei.}

Kleine, dünn und meist faltig sknlpturierte Panzerfische mit gesondertem Kopfskelett, das dorsal nud besonders in der Occipitalregion ziemlich laug ist, keine Rostrabildung anfweist und ron den seitlich gelegenen Augenhöhlen nuterbrochen ist. Wechselnde (bei den Coccostei fellende) Platten in der Mitte des Kopfdaches.

\section{† Interordnung Phlyctaenaspi}

mit zwei Paaren medialer schädelplatten vor dem Supra-occipitale. Unterdevon.

\section{†Unterordnung Petalichthyi}

mit drei medialen Platten in der Mittelachse des Schädeldaches. Trenal-

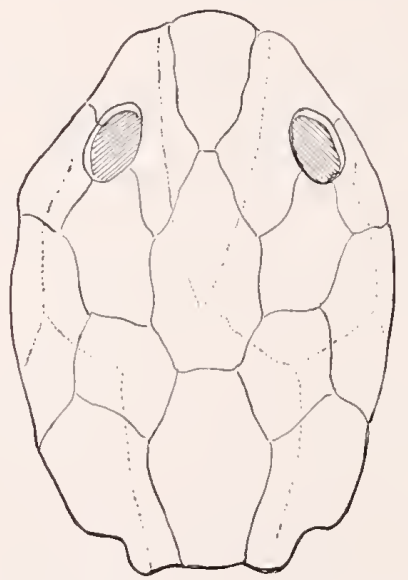

Fig. 32. Macropetalichthys prumiensis Kayser. Mitteldevon. Eifel. $1 / 3$ nat. Größe. 
kanäle durch Reihen von Sinnesgrübchen ersetzt. Macropetalichthys, Mesopetalichthys im Mitteldevon.

\section{fOrdnung Coccostei.}

Kopf ziemlich groß, Nasenlöcher unter dem Rostrum gelegen. Augen seitlich mit vierteiligem Scleroticalring. Unterkiefer mit großem zum Kanen benutzten Dentale, den vomerale und palatinale Zahnplatten gegenüberstehen. Nacken mit einer großen Platte (Nuchale) bedeckt, die auf der Wirbelsäule reitet. Kehl-Brustpanzer aus vier seitlichen

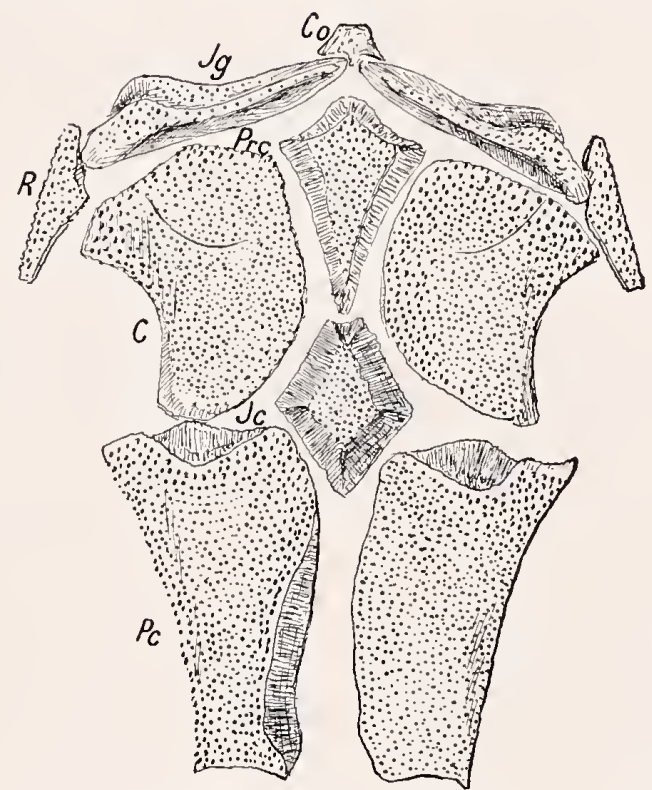

Fig. 33. Brustpanzer von Coccosteus decipiens Ag. Mitteldevon. Schottland. Mit mehreren Paaren seitlicher und medialer Hautplatten. Etwas verkleinert. (Nach Jaekel.)

und zwei medianen Platten gebildet. 4 oder 5 Kiemenbögen nnter der Wangenregion des Kopfes. Halspanzer mit vier seitlichen Platten, die jederseits eine Art von Schulterskelett bilden.

Hierhin gehören die z. T. selır formemreichen, dem Mittel- und Oberdevon angehörigen Unterordnungen:

\section{†Unterordnung Homostei.}

Ziemlich stark anwachsende Formen wit flachem Schädeldach, dorsal gerichteten voш Seitenrand etwas abgerückten Augen und sehr langer Occipitalregion. Homosteus Assm. im Oberdevon. Nordeuropa.

$$
\text { †Unterordnung Coccostei. }
$$

Schädeldach mit seitlich gestellten Augen und wit mäßig langer 
Occipitalregion. Halspanzer ans einem dorsalen Nuchale, vier Seitenplatten und zwei unteren Platten jederseits, oft mit seitlichem Eckstachel, zum 'T'eil mit spitzer Rostralbildung. Gebiß aus einem kanenden Teil des Spleniale, des Tomer und der Palatina gebildet. Beckenanlage bisweilen noch ziemlich groß. Soweit bekannt, ist eine Dorsalflosse hinter dem Nuchale und eine Analflosse vorhanden. Der Schwanz ist lang, epicerk und mit einem durclı Flossenträger gestützten Flossensaun versehen. Hierhin gehören zahlreiche Formenkreise im Mittel- und namentlich im Oberderon. Der eine Fundort Wildungen bei Kassel hat allein mehr als 60 Arten geliefert, die sich auf 5 Familien verteilen. Die wichtigsten sind die Familien Coccosteidae, Dinichthyidae, Platyosteidae (inkl. Mylostoma), Leptosteidae, Anchenosteidae.

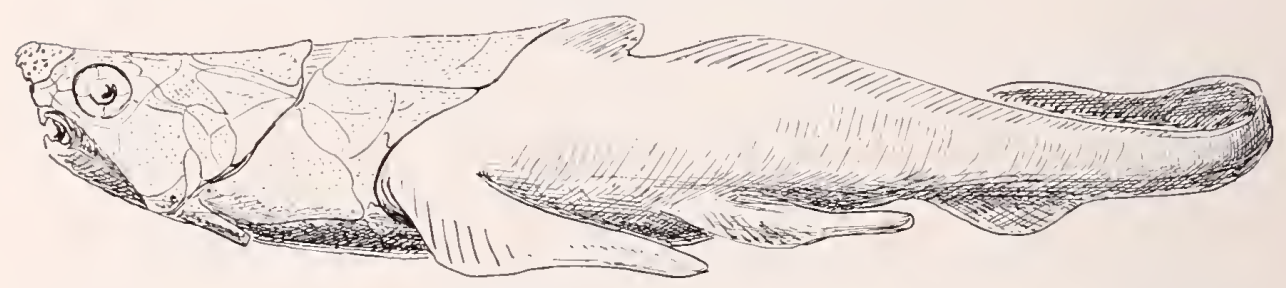

Fig. 34. Coccosteus decipiens Ag. Restaurierte Gesamtansicht. Mitteldevon. Schottland.

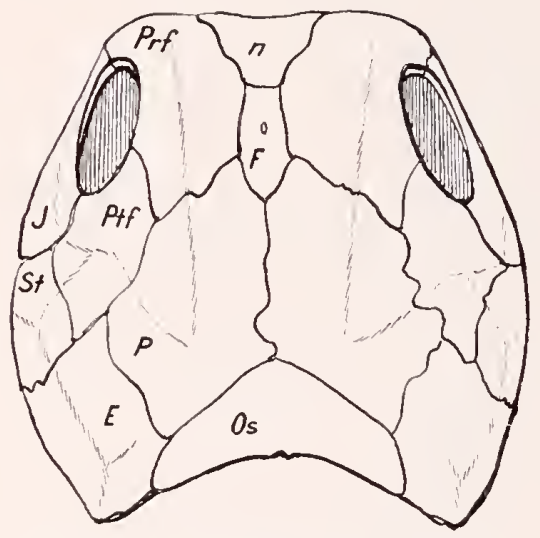

Fig. 35. Pachyosteus bulla Jkl. Oberdevon von Wildungen. Schädeldach. $1 / 2$ nat. Größe. (Nach Jaekel.)

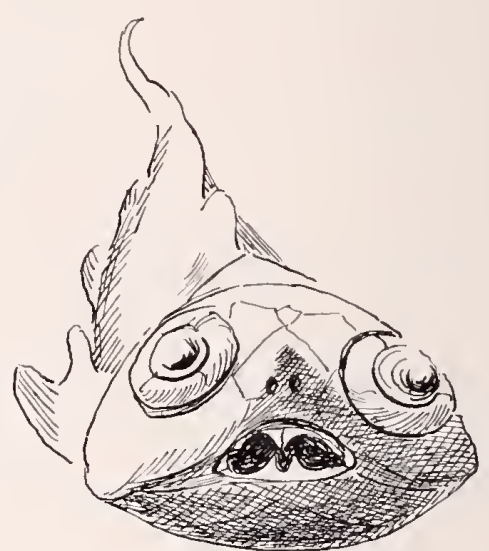

Fig. 36. Rhinosteus Traquairi Jkl. Vorderansicht mit Nasen und Mund. $1 / 2$ nat. Größe. Restauriert.

\section{Lnterordnumg †Heterostei m.}

GroBe Formen mit breitem Schädel, kleinen seitlichen Augen und sehr verkiirztem Halspanzer. Heterosteus Assmus im Oberdevon von Estlland bedarf noch sehr näherer Klärung. 


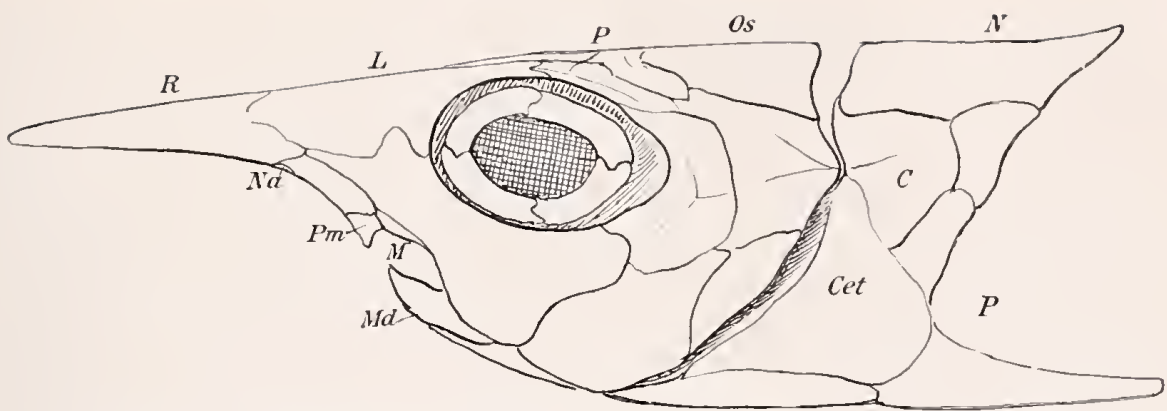

Fig. 37. Oxyosteus, ein Coccosteer aus dem Oberdevon ron Wildungen.

Seitenansicht des Panzers. $1 / 2$ nat. Größe.

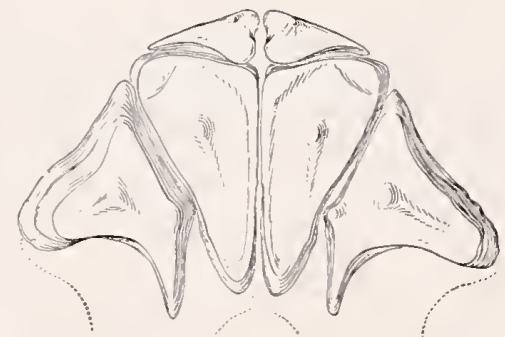

Fig. 38. Gebiß von Mylostoma variabilis Newt. Unterkarbon. Ohio U. S. A. 1/4. (Nach Eastman).

\section{Unterklasse Chondrostei, Störe.}

Die bisher wegen ihres Knorpelskelettes zu den Ganoiden gestellten Störe schließen sich phylogenetisch im Devon unmittelbar an die Placodermen an. Auch ihre heute noch lebenden Formen lassen sich diesem Formenkreise an besten beiordnen. Es sind normal geformte Schwinmer mit langem Kopf, actinal gebanten Parflossen, epicerker Schwanzflosse, mit skulpturierten Plattenreihen in der Hant, mit zahnlosem Schneidegebiß, kleinem Kiemendeckel, großem Schultergïrtel mit ansgebreitetem, vorn eingebogenen dermalen Schulterskelett.

Die Störe schließen sich nicht nur in ihrem eigenartigen Plattenskelett an die Placodermen an, sondern anch in der Gliederung ihres Schultergürtels, der sich Platte für Platte auf den der Placodermen zurückführen läßt, fermer durch ihr Gebiß, das aus zugeschärften Deckknocken der Mundbogenstïcke besteht und durch die Gliederung ihres Schädeldaches, in den wie bei Placodermen die unpaaren medialen Elemente überwiegen. Die Unterbringung ihrer Kiemen unter dem Kopfskelett ist wohl als primitiv aufzufassen, während sie in der Ausbildung ihrer Schwimmblase, der actinalen Struktur ihrer Paarflossen 
und einiger anderer Eigenschaften die Speziahisierungshöhe der Teleostomen erreichten. Demgegenüber bleiben sie in der epistatischen Erhaltung des Knorpels in ihrem Innenskelett, dem Mangel echter Schuppen, der Lage und Form ihres Mundes und dessen Bezahnung echte Hypostomen, entfernen sich aber von deren Mitgliedern durch die höhere Lage der Nasenlöcher, die hier nicht unter, sondern an der Seite des Rostrums gelegen sind. Die Pterygopodien der Placoiden fehlen. In zwei Beckenflossen eines devonischen Rhynchodonten ist aber die metapterygiale Skelettachse noch wesentlich stärker ausgebildet als bei den lebenden Stören. Im Schädel persistiert der Knorpel in weitem Unfange nnd läBt es nur zn einer schwachen Knochenbildung konmen. Während diese im hinteren Teil des Schädels noch dem Typus der Placodermen nahe steht, nimmt die knorplige Ausbildung eines Rostrums größeren T'mfang an, und läßt nur eine Terknöcherung in kleinen unregelmäßig gesonderten Bezirken zu. Vielleicht hängt mit dieser eigenartigen Rostrabbildung, die bei den Polyodonten sehr spezialisiert ist, anch die gegenüber den anderen Hypostomen anfällige Terlagerung der Nasen zusammen.

Hierher gehören die devonischen Rhynchodonten, die bisher zu den Holocephalen gestellt wurden, aber in Gebiß und Schultergiurtel eine typische Zwischenstellung zwischen Placodermen und jüngeren Stören einnehmen. Ferner gehört hierher als echter Stör Chondrosteus ans. dem englischen Jura, aber meines Erachtens nicht Belonorliynchus und seine Terwandten, die von A. Smith Woodward ebenfalls hierher gerechnet wurden, dazu schließlich die jetzt verbreiteten $z$. T. recht groß gewordenen Nachkommen, die zumeist in Flüssen leben, Acipenseriden nnd Polyodonten oder Löffelstöre. Beide Typen weisen recht erhebliche Differenzen auf, so daß man sie wohl zum Range von Ordnungen erheben kann. Die Störe stellen nicht nur den älteren, sondern meines Erachtens anch den primitiven Trous dar. Die von Boulenger hervor-

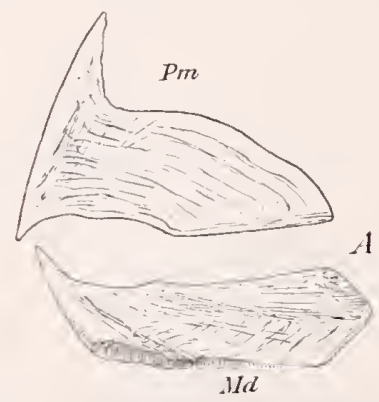

Fig. 39. Rhamphodus tetrodon Jkl. Gebiß. Oberdevon von Wildungen. 1/2. (Nach Jaekel.) Pm obere praemaxillare, $I$ Id untere mandibulare Zahnplatte. 
gehobene Annäherung der Polyodonten an den Typus der Selachier fasse ich lediglich als Degenerationserscheinung auf.

\section{Hauptordnung Sturii Störe.}

Rostrun zugespitzt, bei den lebenden unten mit Cirren versehen, Schädeldach geschlossen. Mund klein und rorstreckbar. Vor den Brustflossen ist eine Hantplatte (Spinale) zu einem Stachel ungeformt, der bei den lebenden beweglich eingelenkt ist. Haut mit Reihen isolierter gedornter Platten und kleineren mmegelmäßigen Plättchen besetzt. Hierhin gehören die devonischen Rhynchodonten, wahrscheinlich ein triassischer Typus aus Spitzbergen, und die lebenden Acipenseriden.

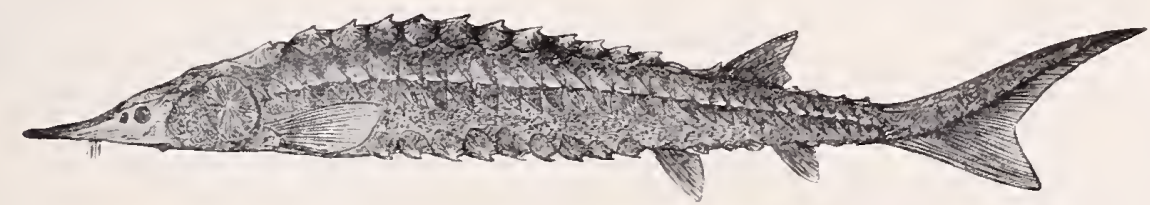

Fig. 40. Acipenser sturio L. der Stör. Lebend. Südrußland. 1/20. (Nach Nitsche.)

\section{Nebenordnung Polyodonti, Löffelstöre.}

Mit breitem löffelförmigem Rostrum ohne Cirren, mit großem Mund, rudimentärem Gebiß, unterbrochenem Schädeldach nnd stark reduziertem Hautskelett; Haut fast nackt. Brustflossenstacheln fehlen. Hierhin stelle ich die jurassischen Chondrosteiden und die lebenden Polyodonten mit Polyodon und Psephurus.

\section{Unterklasse Placoidlea Agassiz.}

Hypostomata ohne äußere Kopforenze, ohne zusammenhängendes Plattenskelett, mit glatter oder dornenbesetzter Haut. Paarige Flossen stets vorhanden in normaler Stellung, die hinteren bei den Männchen immer mit den sogenannten Pterygopodien versehen. Unpaare Flossen meist wohl entwickelt, Flossen meist mit einem Saum von Hornfäden. Nasenkapseln getrennt, innen geschlossen. Oberkieferapparat zu einem Palatoquadratum verschmolzen. Dieses und die Mandibel mit Zahnplatten oder einzelnen Zähnen besetzt. 4-6 Kiemen mit äußeren Kiemenspalten. Schwimmblase fehlt. Spiralklappen im Enddarm.

Dieser die Holocephalen und Selachier umfassende Formenkreis deckt sich mit den Bezeichnungen Chondropterygier, Plagiostomen, Selachier und Elasmobranchier, soweit diese im weiteren Sinne gebraucht, d. h. auch anf die Holocephalen bezogen wurden. Da der Inhalt dieser Namen aber sehr wechselte und nun gegenüber den anderen Hypostomen keine spezifisch charakteristischen Eigeuschaften betonte, glaubte ich, den 
alten fon Louis Agassiz gegebenen Namen Placoidei wieder anfnehmen zn sollen, wenn er auch keine besonders auffällige Eigenheit gegenüber den anderen Tertretern der Klasse hervorhebt.

Die Holocephalen stehen den Placodermen in vieler Beziehung nahe und diuften aus ihnen herrorgegangen sein. Ihr Gebiß, die Autostylie ihres Oberkiefers, die Zahl, Lage und Ausmündung ilırer Kiemen und riele andere Eigenschaften sind primitiv gegenüber den entsprechenden durch Dekadenz rereinfachten oder spezialisierten Velhältnissen der Selachier.

\section{Hauptordnung Holocephala, Chimaeren.}

Es sind zwar höchst wahrscheinlich alle bisher besprochenen Hypostomata "holocephal“ gewesen, insofern ihr Oberkieferapparat mit dem Schädel rerwachsen war, aber da sich der darauf gegründete Name für diese Ordnung ganz fest eingebürgert hat, möchte ich ihn nicht aufgeben. Der Inhalt der Ordung muß nicht merheblich geändert werden. Einerseits gehören die bisher hierher gerechneten Rhynchodonten zweifellos zu den Chondrostei, wo sie nun hier iluen Platz gefunden haben. Andererseits sind rerschiedene fossile Typen hier einzureihen, die frïher zu den Selachiern gestellt wuden, und denen ich bisher eine Stellung zwischen heiden Ordnungen zugewiesen hatte, die Deltodonten und Cochliodonten. Soweit wir wissen, sind auch diese wie die jüngeren Chimären durch folgende Merkmale ansgezeichnet:

Definition: Bodenhewohnende Placoideen mit wenigen, nicht wechselnden ,statodonten“, ron innen nachwachsenden Zahnplatten, die aus Deckknochen der Kieferteile hervorgingen und wesentlich zum Zermalmen und Kanen von Weichtieren benutzt wurden. Ihr Palatoquadratum ist mit der Schädelkapsel fest rerwachsen, nicht auf den Hyoidbogen gestïtzt. Kiemen hinter dem Kopf, in einen gemeinsamen Spalt ausmündend. Stachelbildungen am Kopf und auf dem Nacken. Die Wirbelsänle der Chimären zeigt lingförmige sekundär vermelute Wirbelbildungen. Eine Analflosse fehlt, Schwanzflosse schwach ansgehildet. Die jüngeren Formen sind z. T. mit einem langen Rostrum versehen. Thre Eikapseln, die sich seit dem Jura kanm verändert haben, sind mit einer auffällig gefalteten Seitenleiste rersehen.

Tom Devon bis zur Gegenwart. Hauptverbreitung im Karbon.

†Unterorduung Trachyacanthi Jaekel.

Zahuplatten ohne spezialisierte Kaubuckel („tritoral areas") mit gleichmäBiger Vasodentinstruktu („Palodentin“). Kopf ohne Rostralbildung, seitlich mit Stacheln und Platten bewehrt. Hierhin gehören 
die Trachyacanthiden mit dreieckigen flachen Zahnplatten und stacheln und Buckeln auf der Rückenseite und den Seitenflächen des Kopfes. Karbon und Perm (Fig. $41-45$ ).

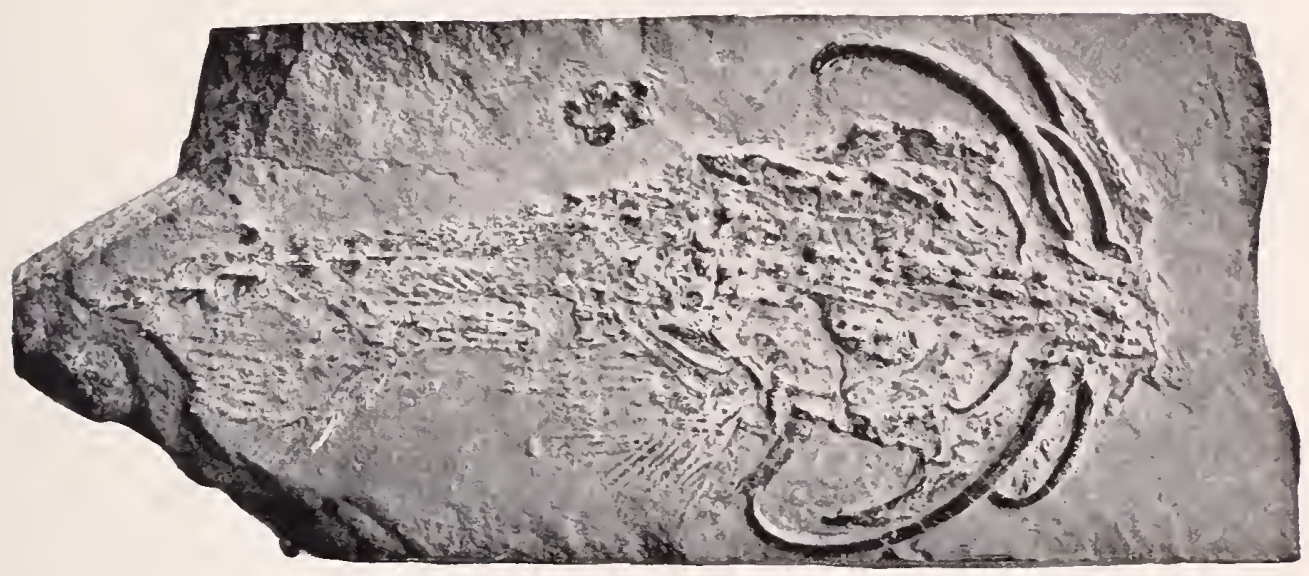

Fig. 41. Menaspis armata Ew. ob. Perm (Kupferschiefer) aus Thüringen, ein Vertreter der Trachyacanthiden. $2 / 3$.

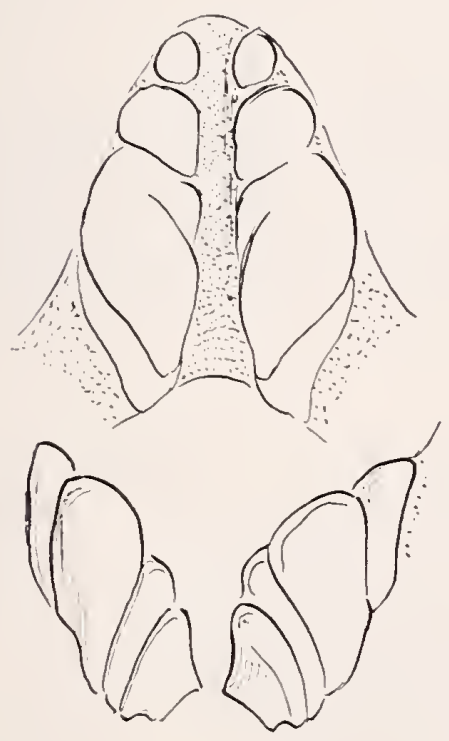

Fig. 42. Obere und untere Gebi@platten von Cochliodus contortus Ag. Mariner Kohlenkalk, England. 1/1.
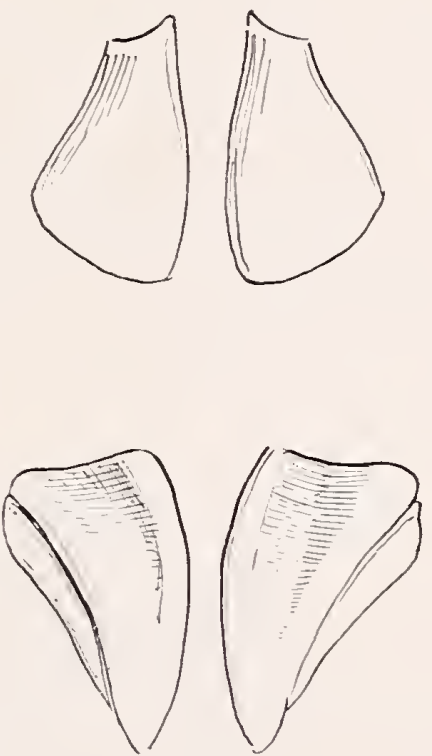

Fig. 43. Menaspis armata Ewald. Kupferschiefer des Perm, Thüringen. Gebiß des Ober- und Cnterkiefers. $2 / 1$. 


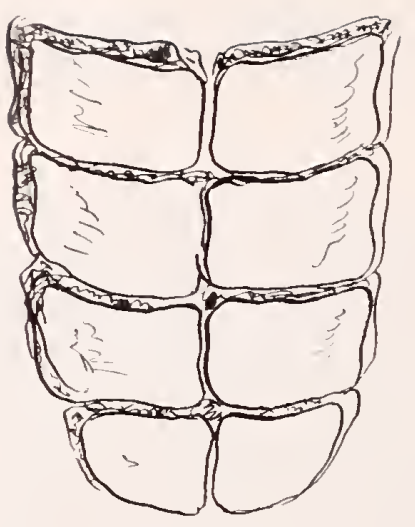

Fig. 44. Psammodus porosus Ag.

Zahnplatten (kombiniert).

Kohlenkalk. England.

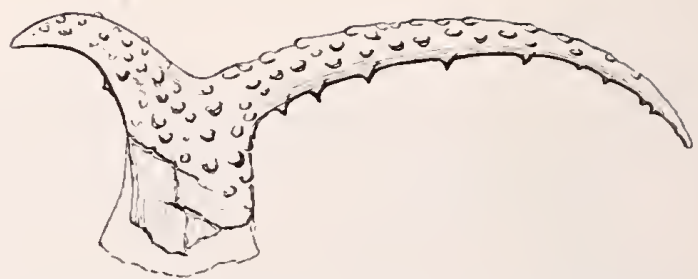

Fig. 45. Seitenstacheln eines Trachyacanthiden (Cladacanthus paradoxus Ag.). Kohlenkalk, Irland. (Nach Jaekel.)

Unterordmuge Chimaeri.

Chimären in engeren Sinne mit strukturell differenzierten Kauplatten, medialem Rostral- und Nackenstachel, öfters mit langem Rostrum reisehen. Haut fast ganz nackt.

Hierhin gehören die jurassischen Myriacanthiden als Übergangstypus von Trachyacanthen zu Cyphodonten, mit mehreren Paaren muschelförmiger gewölhter Zahnplatten, großen medialen Stoßzähnen im Unterkiefer mit seitlichen Dütenplatten am Kopf. Rostral- und Nackenstachel. Myriacanthus und Chimaeropsis.

Weiter gehören hierher die durch starke Rostralbildung, langen Rostralstachel und grobe Ausbreitung der Pectorales ausgezeichneten Squalorajiden, sowie die bekannteren Familien der jüngeren mesozoisehen, tertiären und lebenden Chimären, die durch zwei nbere und ein unteres Paar von Zahmplatten, kleinen Rostralstachel, großen Nackenstachel und nackte Haut ansgezeichnet sind.

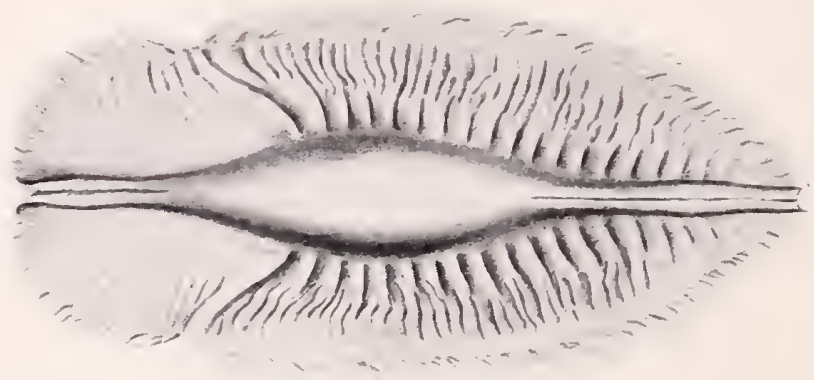

Fig. 46. Eikapsel ron Callorhynchus. Lebend, ebenso schon in der Juraformation. 

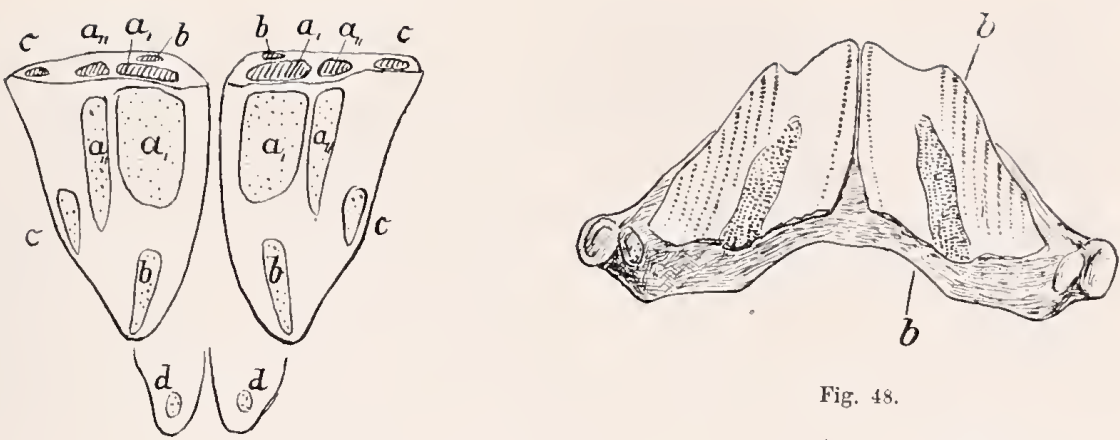

Fig. 48 .

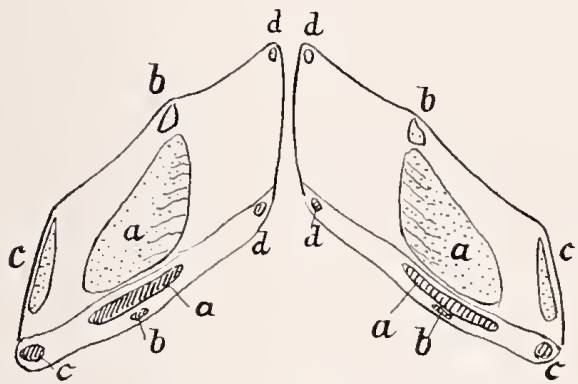

Fig. 47. Gebiß von Ischyodus aelensis (Qu) Jura. Württemberg. 1/2. (Nach Jaekel.)

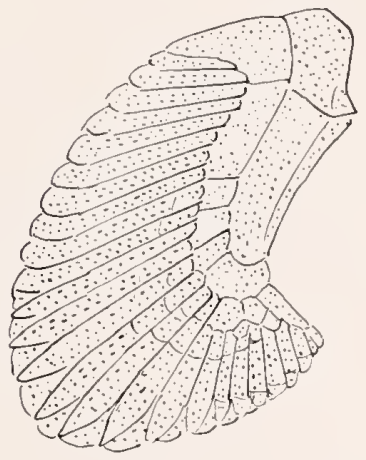

Fig. 49 .

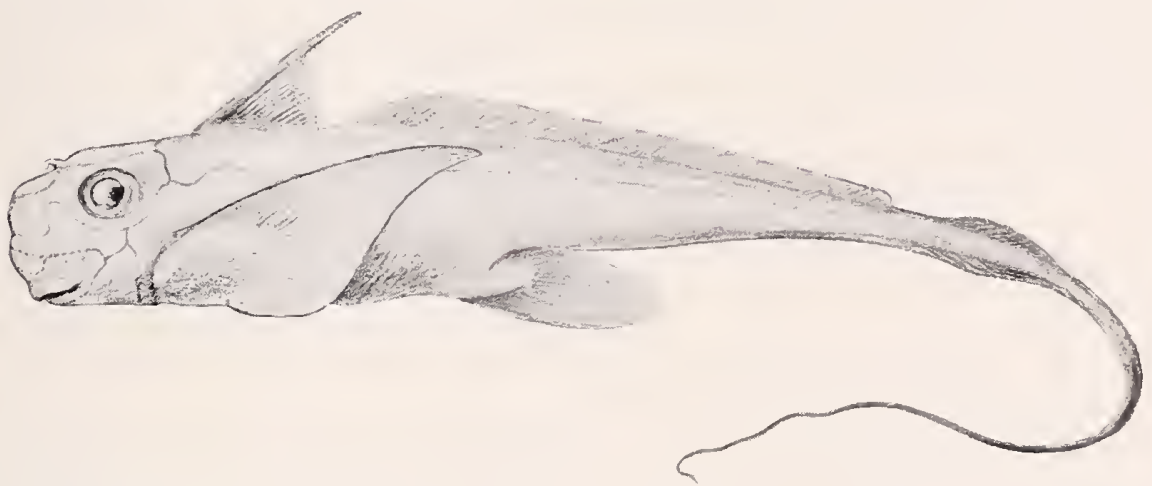

Fig. 48-50. Chimaera monstrosa. Lebend, Atlantis. $501 / 5$ nat. Größe; 48 Unterkiefer $4 / 3$ mit den beiden Zahnplatten; 49 Brustflossenskelett.

\section{Nebenordming Selachii Cuv.}

Placoidea, deren Zahnplatten in Einzelzähne zerlegt sind, die sich an Innenrande der Kiefer ersetzen und iiber den Kiefer rïickend in der Regel die älteren verdrängen. Ihr Palatoquadratum ist nur lose mit dem Schädel verbunden und meist auf den Hyoidbogen gestützt. Kiemen ursprïnglich von einem Kiemendeckel bedeckt, später direkt iı 
Spalten ausmündend, bei jüngeren degenerierten Typen anf 5 und 6 vermehrt, die letzte Kieme wird noch von einem 5, 6 oder 7 cm-Bogen gestïtzt. Stachelbildungen auf dorsale Flossenstacheln beschränkt, oder Dornen anf dem Schwanze zn Stacheln verlängert. Wirbelsänle vertebral gegliedert. Tirbelkörper mit intervertebralen Chordaresten, bei jüngeren Typen meist sanduhrörmig verkalkt. Hant meist mit rhombisch geordneten Dornen bedeckt, selten nackt odel mit Buckeln besetzt. Plattige Bildnngen fehlen in der Hant rollständig, ebenso Knochenzellen in allen Skeletteilen, die meist mit prismatischen Kalkköruchen inkrustieren.

Tom Devon bis jetzt sehr verbreitet und formenreich.

Das Gebiß bildet anch fiir die fossilen Formen das beste Kennzeichen zur systematischen Gliedernng, während die bisher für maßgebend gehaltene Körperform sich mehrfach konvergent wiederholt. Es gibt nicht weniger als vier verschiedene Rochentypen, die selbständig durch Anpassung an das Bodenlehen entstanden.

\section{†. Unterordnnmg Statodonti ul.}

Plnmpe, z. 'T'. rochenförmige Bodenbewohner mit Kaugebiß, dessen Zälıne z. T. noch nicht in regelmäßige Längsreilıen auf den Kiefern geordnet sind. Die meist plattigen, aus Vasodentin gebildeten Zähne vermelren sich an der Innenfläche des Kiefers, fallen aber an deren Außenrand nicht aus, sodaß sie zeitlebens perennieren, d. h. statodont sind. Karbon und Perni.
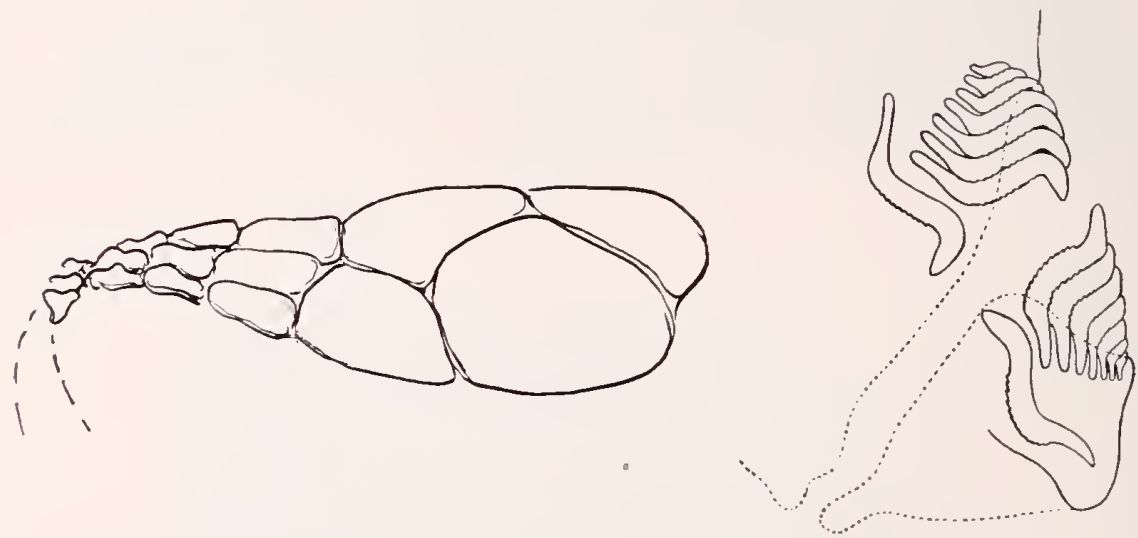

Fig. 51. Bezahnungsform von Psephodus magnus Ag. aus dem englischen Karbon. Restauriert. Links die Symphyse mit den kleinen Vorderzähnen, rechts großen hinteren Kauzähnen. $2 / 3$.
Fig. 52. Medianschnitt durch das Gebiß von Janassa aus dem Perm. Die älteren kleineren Zähne dienen den jüngeren, größer nachgewachsenen als Unterlage. (Nach Jaekel.) 
Hierhin gehören die Formen, die einen allmählichen Übergang von den Gebißformen der ältesten Holocephalen zu der typischen .lyodonten " Bezahnung der jüngeren Selachier darbieten. Bei dem beistehend abgebildeten Psephodus ist der Hauptkauzahn noch über die ganze Breite des Kiefers ausgedehnt und wächst an dessen Innenrand danernd nach, während die ïbrige Kanfläche in Einzelzähne zerlegt ist. Bei anderen reguliert sich die Gebißform derart, daß alle Zähne ersetzt werden nnd in Quer- und Längsreihen geordnet sind (Fig. 57). In einem Formenkreise spezialisiert sich der Ersatz ohne gleichzeitigen Zahwwechsel zu der sonderbarsten Gebißform, die wohl je existiert hat, indem die Zähme in der Symphysenreihe bei schnellem Ersatz aufeinander geschoben in spiraler Drehung aus dem Unterkiefer herausrücken (Edestidae).

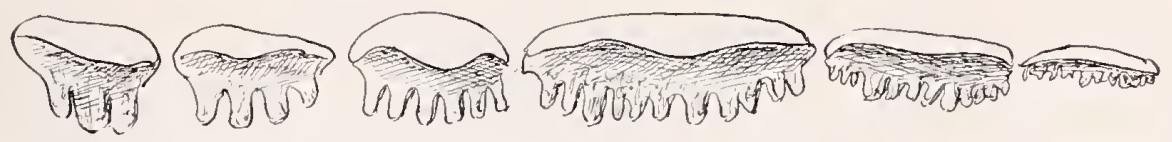

Fig. 53. Zähne eines Petalodonten, Polyrhizodus, die vermutlich alle zu einer Gebifform gehören. Kohlenkalk, Irland. 2/s.

\section{Unterordnung Cestracionti.}

Plumpe haiförmige Bodenbewohner ohne Rostrum, deren bohnenförmige meist bergig gekerbte Zähne in regelmäßige Quer- und Längs-

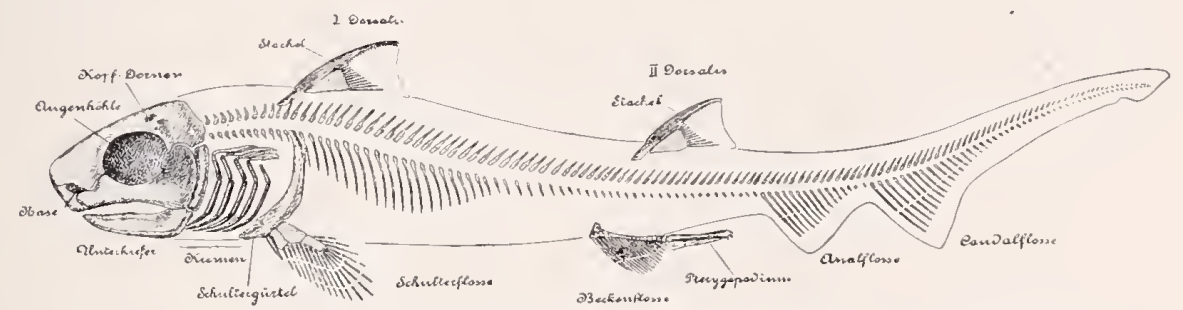

Fig. 54. Skelett von Polyacrodus aus dem Lias. Restauriert. (Nach Jaekel.)

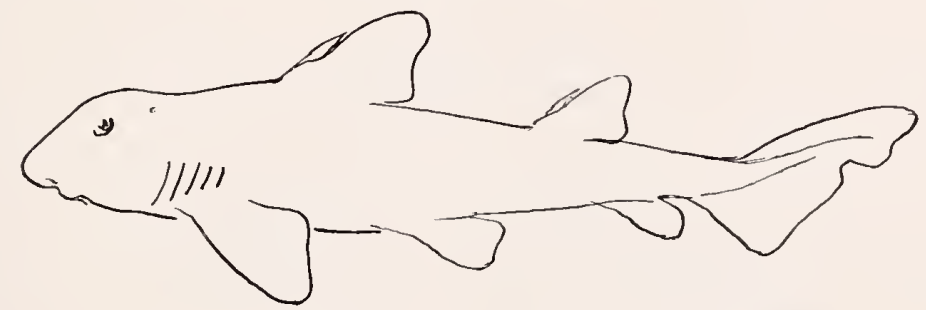

Fig. 55. Heterodontus (= Cestracion) Philippi, Südsee.

reihen geordnet sind und am Außenrande ausfallen. Das Palatoquadratun ist in ganzer Länge mit der Schädelkapsel verbunden. An- 
scheinend sind 2 Dorsalflossen mit Flossenstacheln und eine Analflosse typisch. Karbon bis jetzt.

Hierher gehören namentlich folgende besonders im Mesozoicum verbreiteten Formenkreise. Familie Orodontidae Karbon, Acrodon-

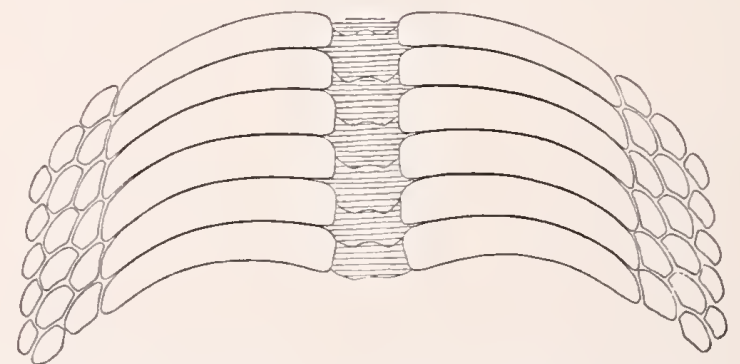

Fig. 56. Bdellodus bollensis Quenstedt. Unterkiefer-Gebiß. Ober-Lias. Württemberg. $1_{12}^{1 / 2}$ nat. Größe.

tidae, Perm bis Jura, Hỵbodontidae Carbon bis Kreide, Cestraciontidae Jura bis jetzt. Ferner die Ptychodontidae der Kreide mit ihrem breiteren Mahlgebiß und ihren sonderbar skulpturierten Zähnen.

\section{Lnterordung Centrobati Jkl.}

Rochenförmige Nachkommen der Cestracioniden ohne Rostrum, mit Stacheln auf dem peitschenförmigen Schwanz. Ihre sehr ausgebreiteten Brustflossen stoben vor dem Kopf zusammen. Ihre Zähne sind ans Vasodontin.
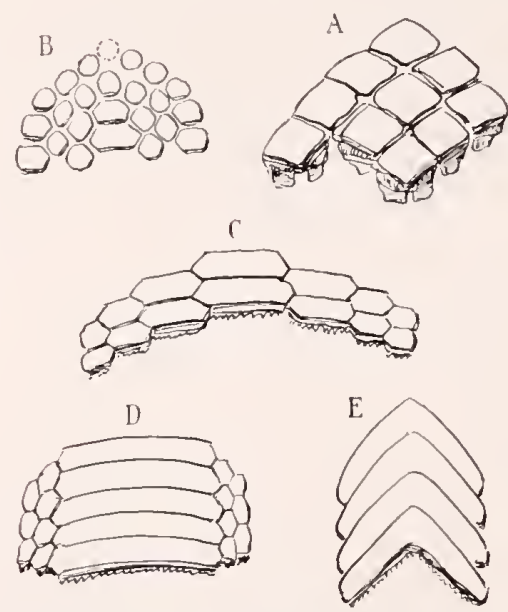

Fig. 57. Gebißformen der Centrobatiden, $A$ Rhombodus aus der obersten Kreide, $B$ embryonale Bezahnung von Myliobatis aquila, $C$ Zygobatis (Rhinoptera), $D$ Myliobatis, $E$ Aetobatis narinari. 
Hierhin gehören die in der oberen Kreide einsetzenden Familien der Trygoniden und Myliobatiden, denen sich als Nachkommen der letzteren, die riesigen im Gebiß degenerierten Ceratopteriden anschließen. (Fig. 57 bis 59.)

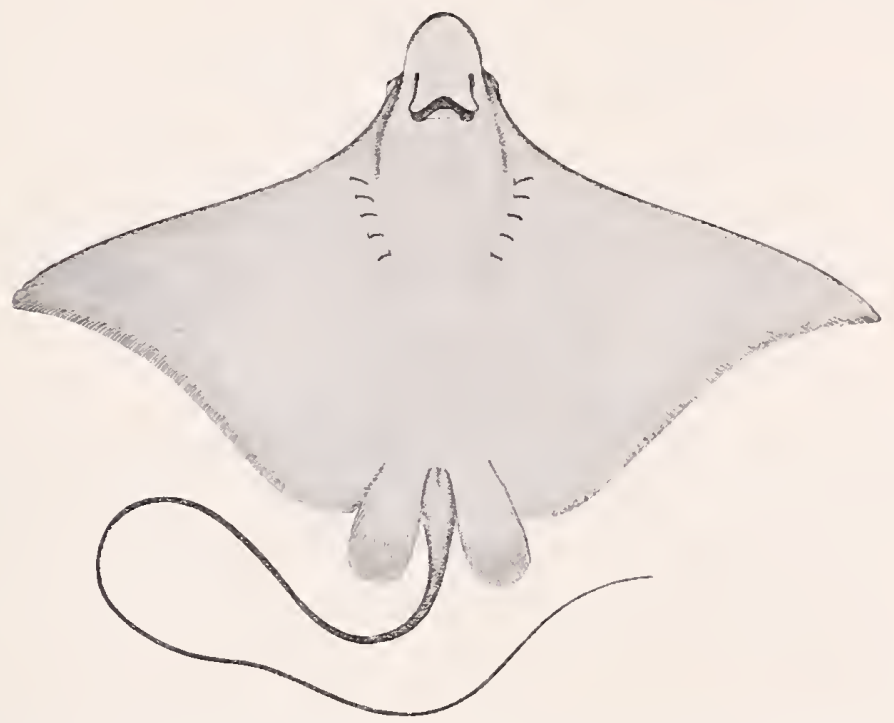

Fig. 58. Aetobatis narinari. Lebend. (Nach Jordan u. Evermann.)
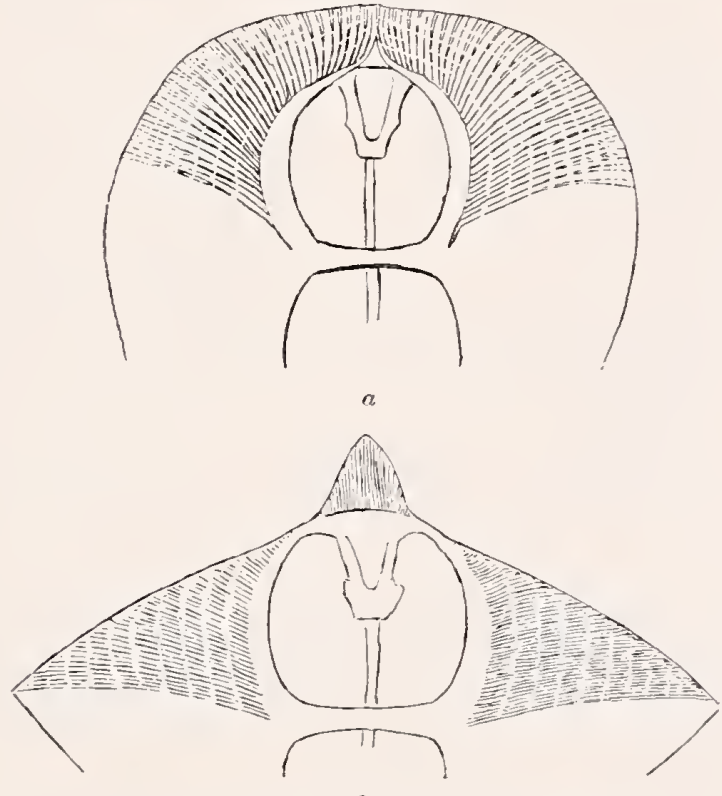

$b$

Fig. 59. Der vordere Zusammenschluß der Brustflossen, a bei Trygon, $b$ bei Myliobatis. (Nach Jaekel.) 


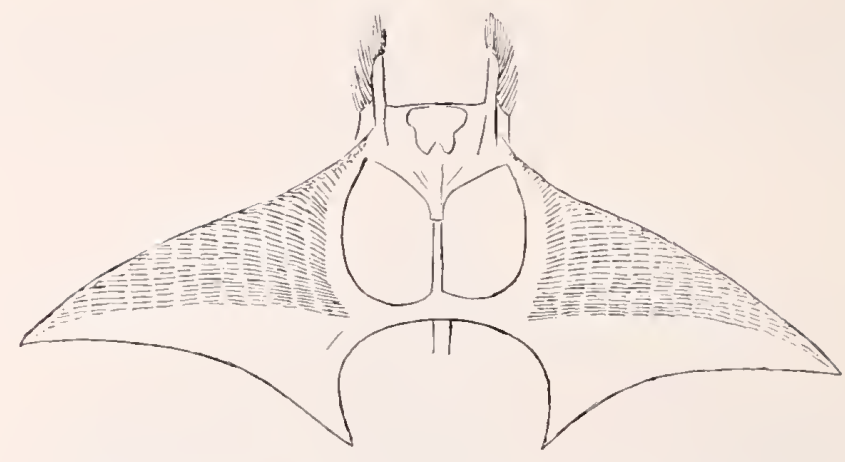

c

Fig. 59c. Zerlegung der "Kopfflosse" bei Ceratoptera.

4. Unterordnung Palaeosquali m.

Haiförmige Selachier ohne Rostralbildung. Zähne nit breitenı einwärts gewendeten Sockel und anßenständigen Spitzen. Rückenstacheln fehlen. Die Paarflossen der älteren Formen mit axialer Hauptachse. Analflosse vorhanden, schwanzflosse wenig spezialisiert. Palatoquadratum vor und hinter den Orbita befestigt. Devon bis jetzt.

Hierher gehören die Familien der Cladodonten, Plemracanthiden, und die lebende Chlanydoselache. Ton diesen sind die Cladodonten als älteste, gut bekannte Haie besonders ausgezeichnet durch lange,

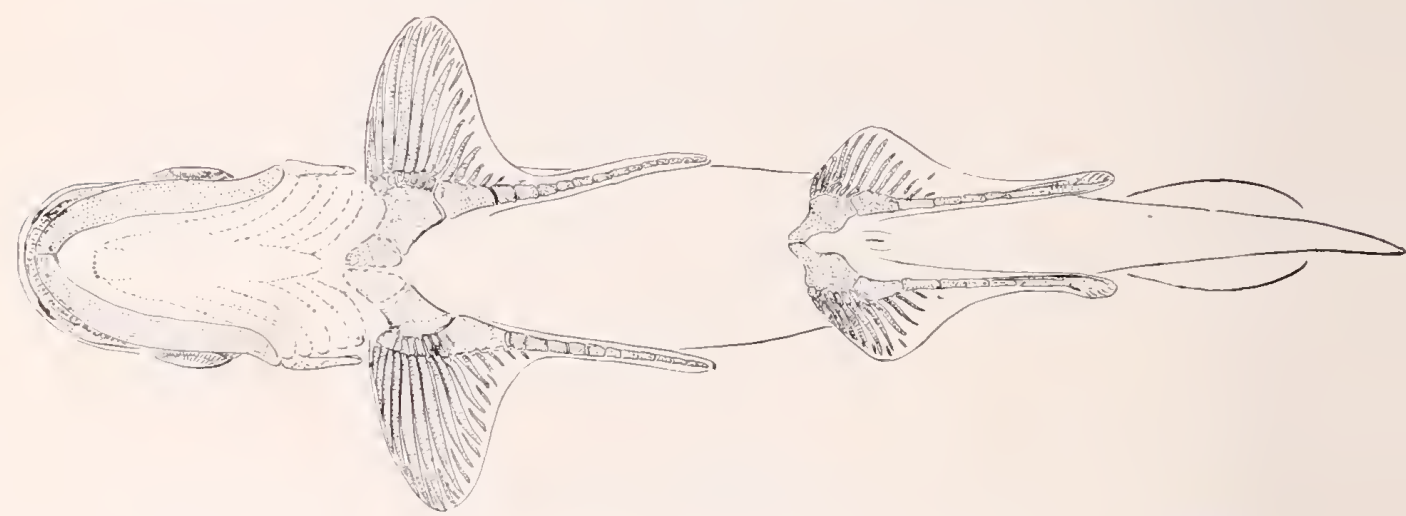

Fig. 60. Cladodus. Unterseite rekonstruiert. Karbon. (Nach Jaekel.) 1/8 nat. Größe.

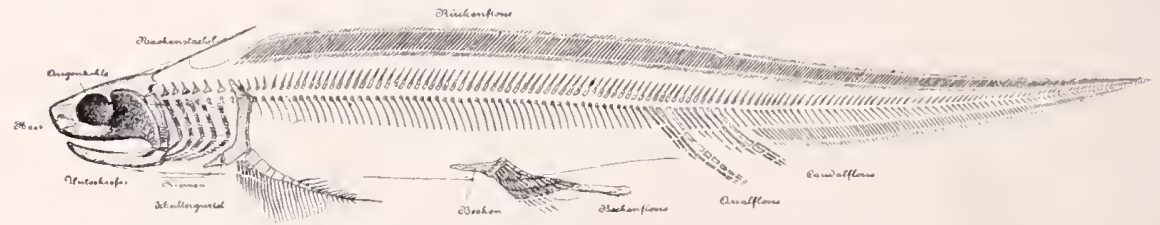

Fig. 61. Pleuracanthus sessilis Jordan sp. Unt. Perm. Saarbrücken. Restauriert. (Nach Jaekel.) 1/4 nat. Größe. 
den Pterygopodien der Bauchflossen entsprechende metapterygiale Läng'sachsen und durch einen mehrkränzigen Skleroticalring. Bei den karbonischen und permischen Pleuracanthiden sind die Torderflossen archipterygial, d. h. mit rorderen und hinteren Nebenstrahlen an einer Hanptachse, ein Kiemendeckel bedeckte die Kiemen, am Hinterkopf saß ein zweiseitig gedornter stachel auf.

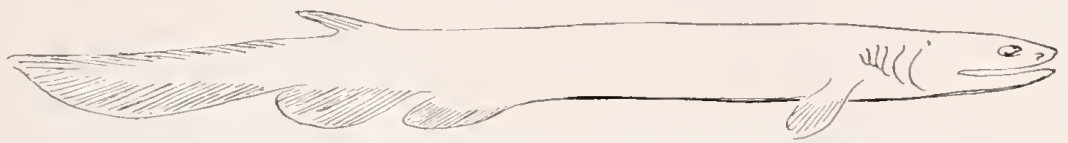

Fig. 62. Chlamydoselache anguineus. Lebend, Pacific. 1/s nat. Größe.

\section{Unterordnung Rhinae.}

Rochenförmige Bodenfische mit ausgebreiteten, aber nicht mit dem Kopf rerwachsenen Schulterflossen, ohme Rostrum, mit einer äußeren Zahnspitze auf einwärts ausgebreiteter Turzel. Ohne Analflosse. Rïckenflossen anf den Schwanz, der mit steifer Endflosse rersehen ist. Seit dem oberen Jura kaum rerändert. Rhina (Squatiua, Meerengel) bis zur Gegenwart.

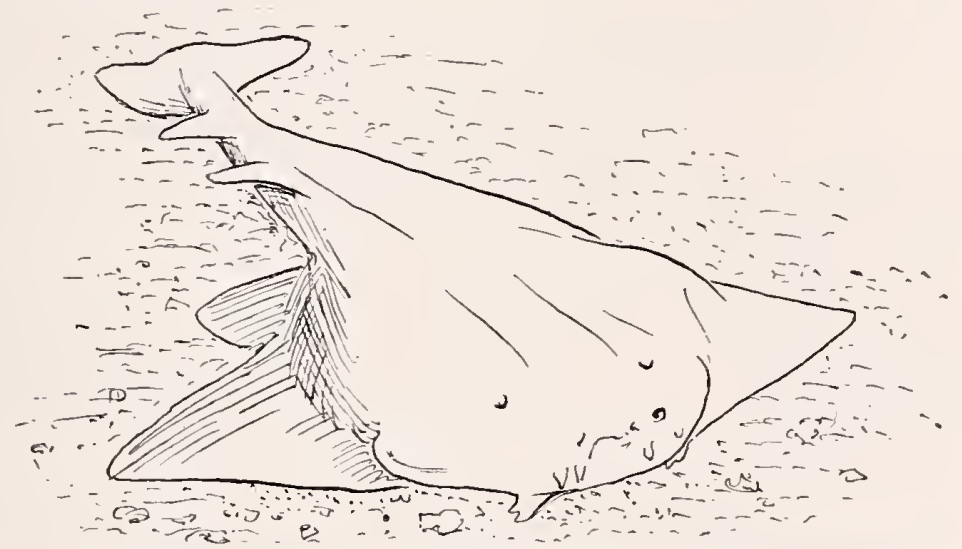

Fig. 63. Rlina squatina, lebend, Nordsee. Nach der Natur gezeichnet. 1/20.

\section{Unterordnung Notidani.}

Spindelförmige Haie mit 6 oder 7 Kiemenspalten vor den Schulterflossen, schwacher Rostralbildung, mit einer Rücken- und Analflosse. Zähne mehrspitzig, im Unterkiefer schneidend. Wirbelsäule schwach verkalkt.

Hierhin gehören zahlreiche fossile Formen seit dem Jura nnd die lebenden Gattungen Hexanchus, Notorhynchus (Heptanchus, Notidanns). 


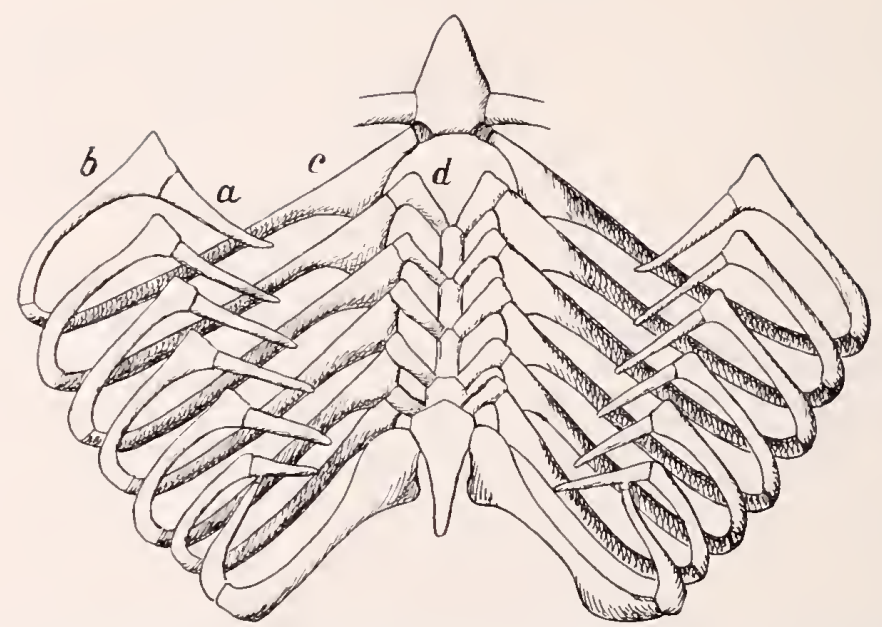

Fig. 64. Kiemengerüst von Notorhynchus (Heptanchus) von oben gesehen. (Nach Gegenbaur.)

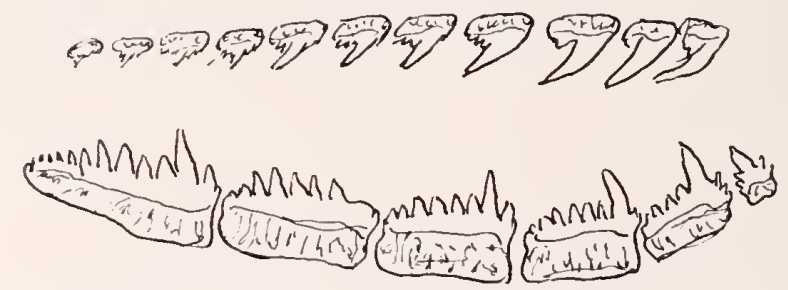

Fig. 65. Gebiß der rechten Kieferäste von Notorhynchus (Heptanchus) cinereus; aus dem Atlantischen Ozean.

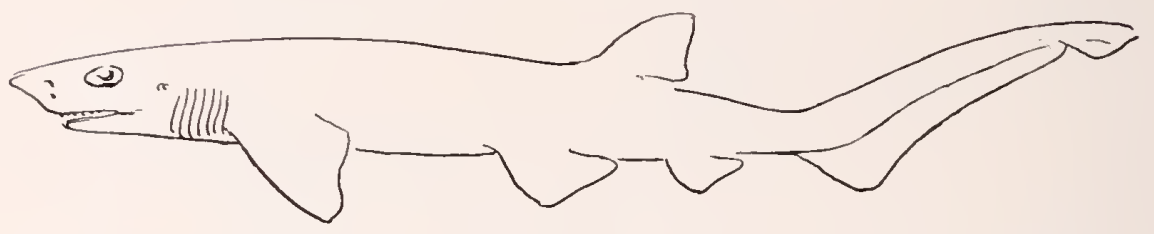

Fig. 66. Notorhynchus Heptanchus, Notidanus) maculatus. Lebend. Pacific.

\section{Unterordnung Spinacidi.}

spindelförmige Haie mit einfachem Rostrum, 5 Kiemenspalten, 2 Dorsales, die meist mit Flossenstacheln besetzt sind, ohne Analflosse. Gebiß mannigfaltig, im Unterkiefer schneidend, Zähne meist einspitzig.

Hierhin gehören die Spinacidae mit Squalus acanthias, die Echinorhinidae mit eigenartigen Stachelplättchen auf dem Rücken und mehrspitzigen Zähnen und die Pristiophoridae mit langem Rostrum, dessen Seitenränder mit verschieden großen Hautzälnnen besetzt sind. 


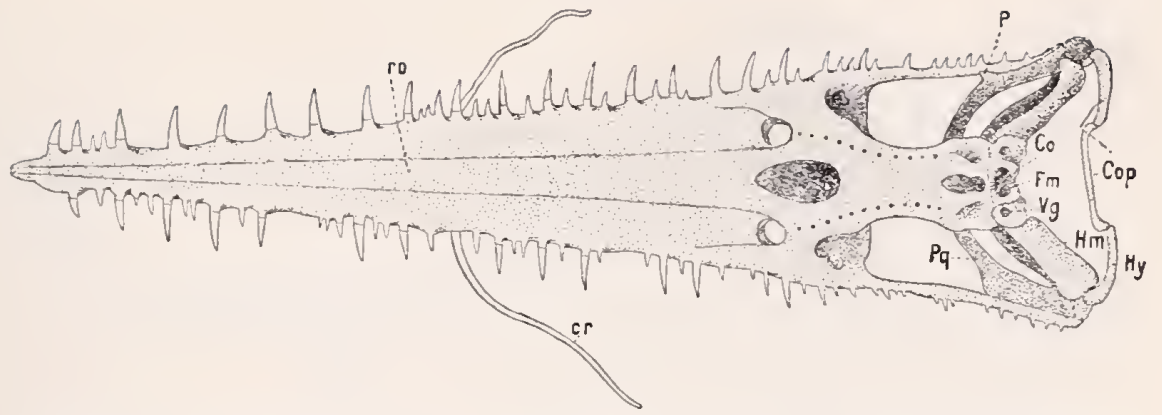

Fig. 67. Schädel des lebenden Pristiophorus cirratus. (Nach Jaekel.) Südsee.

\section{Unterordnung Trirostri.}

Haiförmig mit 5 Kiemenspalten, dreiteiligem Rostralknorpel. 2 Dorsales ohne Stacheln, Analis vorhanden, Schwanzflosse meist spezialisiert. Zähne mit scharfer innen aufragender Hauptspitze. Hoch entwickelte Raubfische. Jura bis jetzt. Familie Scyllidae. Scylliolamnidae, Lamnidae, Carcharidae, Mustelidae.

Diese durch ihre dreiteilige Rostralbildung charakterisierte Gruppe umfaßt die gegenwäıtig sehr formemreichen typischen Haie, unter denen die Scylliden den ältesten, seit dem Jura bekannten Typus bilden. Ihr

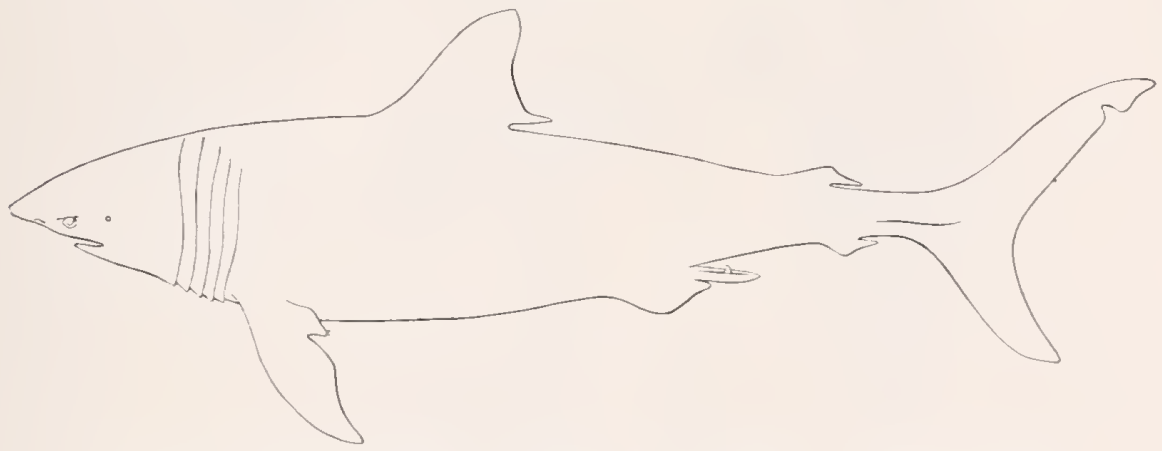

Fig. 68. Selache maxima. Lebend, Cuv. Atlantik. 1/120 nat. Gröbe.

(Nach einem Exempl. des Brit. Mus.) Arktische Meere.

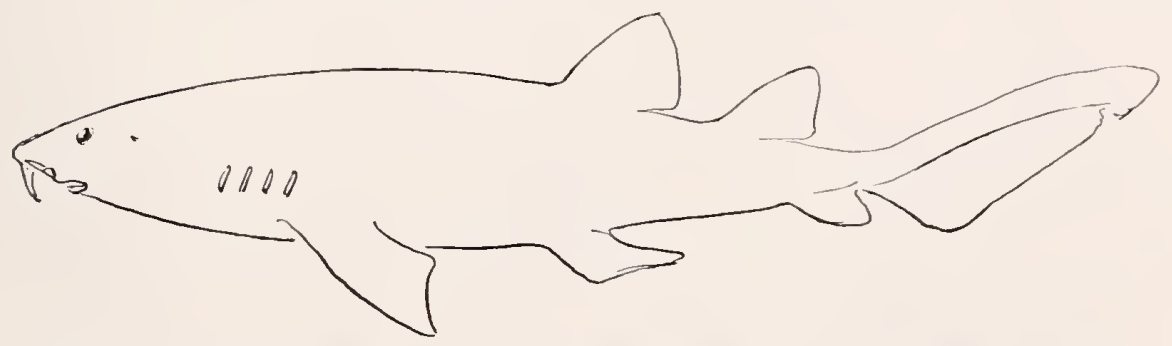

Fig. 69. Ginglymostoma cirratum gm. L. sp. Lebend. 1/8 nat. Größe. Atlantic. 
unteres scluwanzsegel ist noch schwach, während es in den höher entwickelten Formen der Lamniden und Carchariden dem oberen Schwanzende gleichförmig wird (Fig. 68). Einen hemerkenswerten Typus bildet unter den Carchariden der Hammerhai (Fig. 70) mit seinem sonderbar verbreiterten Kopf.

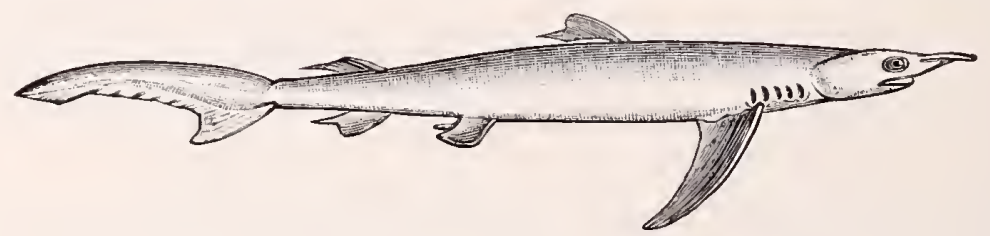

Fig. 70. Carcharias glaucus, der Blauhai. Etwa $1 / 30$. (Nach Müller u. Henle.)
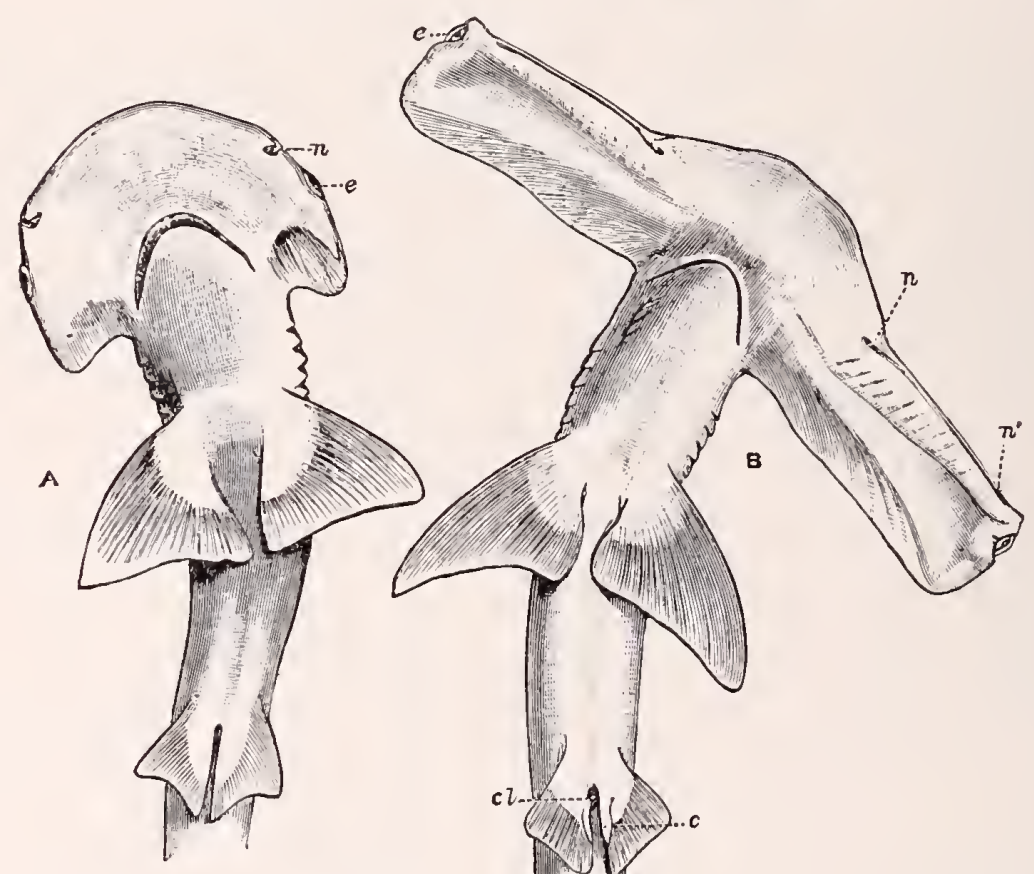

Fig. 71. Kopf des Hammerhai Zygaena malleus im Jugendstadium $(\boldsymbol{A})$ und $\mathrm{im}$ erwachsenen Zustand $(B)$. (Nach Boulenger.) Südliche Meere.

\section{Unterordnung Rhinoraji Jkl.}

Rochen mit 5 ventral gelegenen Kienenlöchern nit weit ausgebreiteten, voru durch ein löffelförmiges Rostrum getrennten Brustflossen; Zähne klein pulpodentinös, zweiwurzelig. 2 Rückenflossen auf dem Schwanz, keine Analis, Schwanzflosse anfangs wohl entwickelt, später oft rïckgebildet. Oberer Jura bis jetzt.

Familie Rhinobatidae, Pristidae, Torpedinidae, Rajidae, Cyclobaedait. 


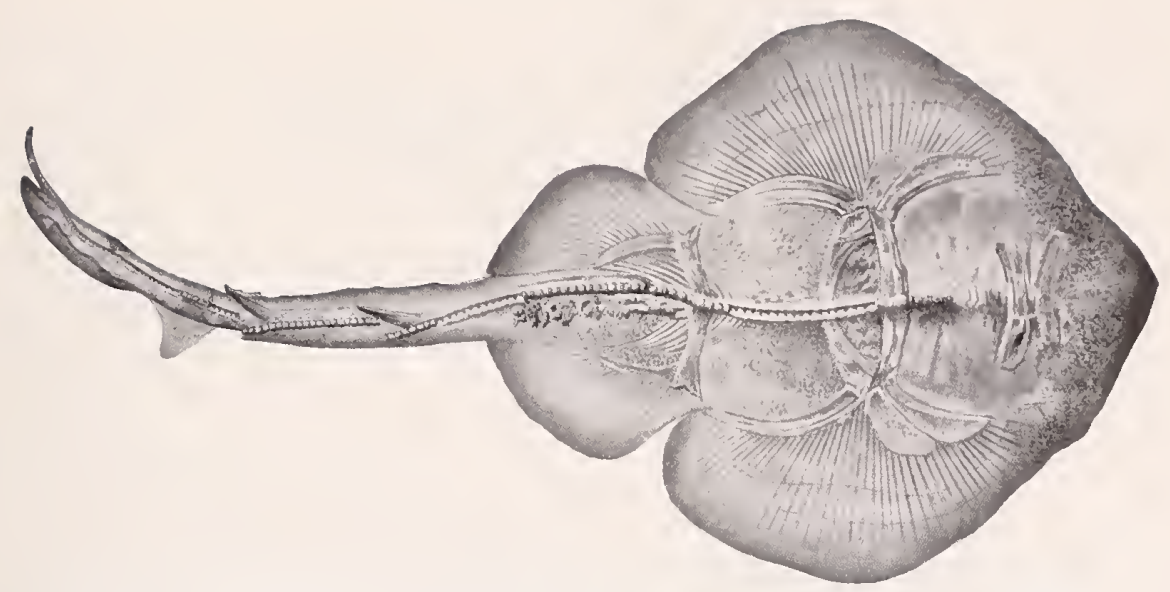

Fig. 72. Belemnobatis, ein Rhinobatide mit Flossenstacheln an den kaudalen Rückenflossen. Aus dem oberen Jura von Cirin. (Nach Thiollière.)

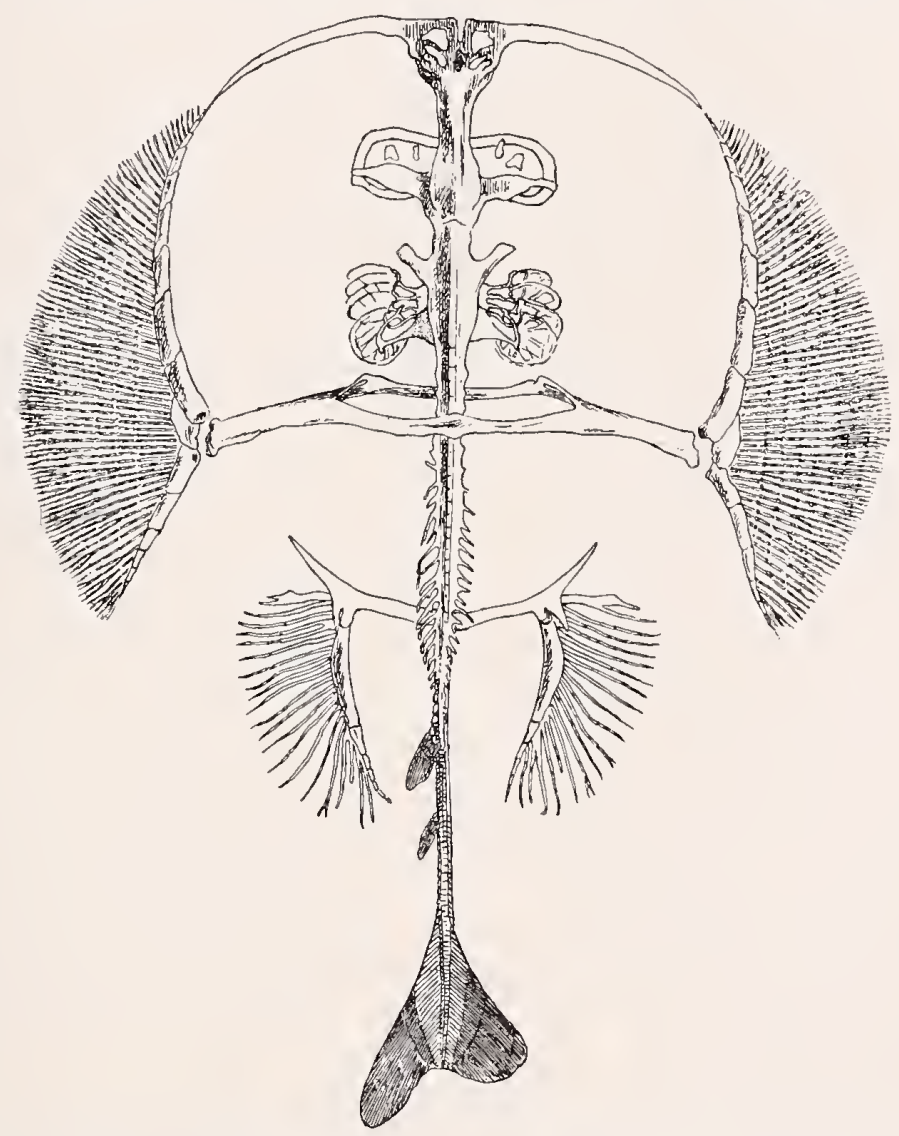

Fig. 73. Skelett von Torpedo, deren Schulterflossen durch die elektrischen Organe weit auseinandergedrängt sind. (Nach Jaekel.) 


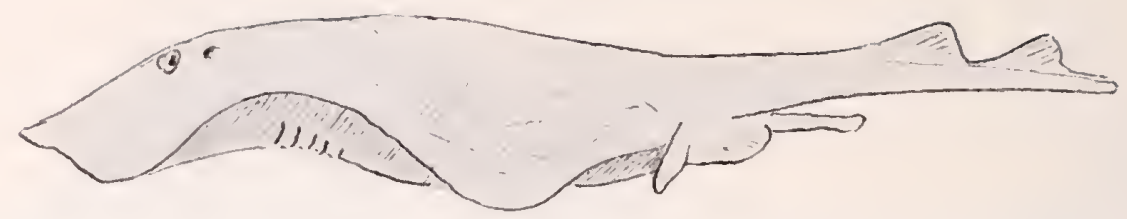

Fig. 7t. Die Schwimmbewegung einer lebenden Raja. Unter der wellig bewegten Brustflosse die 5 Kiemenspalten, an den Beckenflossen vorn der Lauffinger, hinten die genitalen Pterygopodien.

\section{Stufe. Klasse Teleostomata Cope.}

Die Teleostomata, unter denen Edward Cope die Ganoiden mud 'Teleostier zusammenfaßte, sind wohl begriindet durch den phylogenetischen Znsammenhang der genannten Abteilungen, deren Verwandtschaft schon in dem System Joh. Müllers lervortritt. Nicht um die terminale Lage des Hundes, die ihren Namen veranlaßt hat, sondern eine ganze Summe anderer Eigenschaften unterscheidet diese Klasse von den vorher genannten Malacostomen und Hypostomen. In erster Linie scheint mir die Form typischer schnppen bemerkenswert, die mit ilnem Hinterrand wie die Ziegel eines Daches die beiden folgenden Schuppen flach iiberlagern, mit denen sie in rhombischer Stellung ihrer Zentren alternieren. Dann ist ihre Verknöcherung in viel höherer Weise spezialisiert als bei den übrigen Fischen, aber die starken Wandlnngen, die sie in der Phylogenie der verschiedenen Gruppen erfährt, schränken die systematische Verwertung dieses Momentes für die ganze Klasse erheblich ein. In einem Punkte aber liefert diese höhere Spezialisiernng des Skelettes ein wichtiges Merkmal, nämlich in der acrodonten Bezahnumg der Kieferknochen. Anßerdem kommt es bei den Teleostomen zwar vielfach zu einer teilweisen miogenetischen Persistenz des Knorpels, aber niemals zu dessen eigenartigen Kalkinkrustationen, wie sie bei Cyclostomen nnd vor allem bei selachiern auftraten. Wir mïssen aber in Ange behalten, daß echte Verknöchernng sich sowohl bei älteren Malacostomen (z. B. Cephalaspis, Pterichthys) wie auch bei Hypostomen (Placodermi) fand, und daß sich ein knöchernes Innenskelett auch nicht erst später bei den Teleostiern entwickelte, sondern bereits bei deronischen Ganoiden vorhanden war, daß es viehmehr bei diesen mit der Znnahme ihrer Hantpanzerung verloren ging und dadurch einer Persistenz des Knorpels rielfach Platz machte.

Vier Kiemen sind von fünf Kiemenbögen gestützt und von einem Apparat beweglicher Kiemendeckel geschintzt, die den Raum hinter und unter dem Kopf einnehmen. Dieses Verhältnis ist fest konsolidiert, 
während bei älteren Typen die Kiemen aus dieser primären Lage in die Halsregion verschoben und dort in ihrer Zahl bisweilen erheblich vermehrt sind. In diesen und anderen Punkten besteht also keine direkte Beziehung der Teleostomen zu den älteren Fischtypen. Das spricht für eine selbständige Entstehung der Teleostomen aus Landtieren, ebenso wie die Gliederung des Schädelskelettes, die vielmehr der der ältesten Tetrapoden als der der Placodermen ähnelt. Ton einer engeren Homologie einzelner Elemente wird aber auch hier keine Rede sein können. Dagegen spricht nicht nur die Schwierigkeit, eine Homologie der einzelnen Elemente durchzuführen, sondern vor allem die diesbezügliche Verschiedenheit der ältesten Teleostomen-Typen untereinander.

Die Dipnoer sind wegen der lungenartigen Ausbildunng ihrer Schwimmblase und wegen des axialen Baues ihrer Paarflossen zunächst für eine ganz eigenartige Gruppe ron Fischen gehalten, ja sogar zwischen Fische und Tetrapoden als Übergangstypus gestellt worden. Diese Auffassung kann man jetzt, nachden wir deren ältere Vorfahren kennen, und die Organisation der Ganoiden zum Vergleich heranziehen können, unbedenklich aufgeben. Die ältesten Dipnoer sind von primitivsten rundscluppigen Ganoiden kaum zu trennen, sie haben sich aber von diesen schnell selbständig abgezweigt und deren primitive Organisation in vielen Punkten bis zur Gegenwart erhalten. Eigenartig bleibt von Anfang an ihre breite Gaumenbezahnung, wenn auch typische Kieferrandzähne älteren Dipnoern nicht fremd sind. In ihrer gesanten Organisation sind sie allerdings seit devonischer Zeit, wie zuerst L. Dollo zeigte, unter ihren Ganoidenzustand heruntergesunken. Wenn wir alles berïcksichtigen, können wir nicht umbin, die Dipnoer in engsten Konnex mit den älteren rundschuppigen Ganoiden zu bringen, zumal auch deren älteste Typen wohl als Lungenfische im physiologischen Sinne aufzufassen sind.

Etwas anders liegen die Verhältnisse bezïglich der sehr alten Gruppe der Acanthodier, die schon im Obersilur erscheinen, dort noch ganoidenartig aussehen und dann im Laufe des Paläozoikums in verschiedenen Punkten nahezı bis zur Organisationsstufe der Selachier degenerieren. Für sie ist ein unmittelbarer oder auch nur allgemeiner Anschluß an älteste Ganoiden historisch nicht mehr nachweisbar, immerhin fühıt uns die ganze Tendenz ihrer Entwicklung rückwärts zu Ganoiden und zu keinem anderen 'Typus der bisher bekannten Fische. So scheint es richtig, sie den Teleostomen einznordnen, ihnen aber innerhalb dieser Klasse eine selbständige Nebenstellung anzuweisen. Sie mögen sich von mbekannten Ahnen der Teleostonten abgezweigt haben, so daß wir sie als primitive Nebenordnung einer präsumierten ersten Hauptordnung ansehen können. Bei jeder anderen Gliederung hätte man bei der 
fehlenden Rammtiefe des alten Systems die Acanthodier den iibrigen Teleostomen als gleichwertige Unterklasse gegenüberstellen müssen.

Die systematische Einteilung der typischen Teleostonen in Ganoiden und Teleostier ist manchen Bedenken begegnet, die z. T. auf noch unïberwindlichen schwierigkeiten fußen. Verschiedene innere Merkmale, die man znr Trennung der lebenden Ganoiden und Teleostier verwandte, sind nicht nur stammesgeschichtlich an den fossilen gar nicht zu lrontrollieren, sondern auch innerhalb der lebenden Formen nicht mehr durchführbar. Die spezifische Gliedernng des Skelettbanes aber, die sich überall als der sicherste und allein branchbare Boden systenatischer Gliederungen der Wirbeltiere erwiesen hat, läbt uns hier leider anch noch vielfach im Stich. Der Unstand, daß die Erhaltung der Gesantform der fossilen Fischskelette deren ungefähre Vergleichung mit anderen und lebenden in der Regel leicht ermöglichte, und dadurch ihrer geologischen Verwendnng als Leitfossilien Genüge leistete, hatte zur Folge, dalb wir nns nm die Einzelheiten ihres Skelettbaues, namentlich ihrer Schädelanatomie, noch sehr wenig bekinnmert haben. Einige Autoren, wio mamentlich R. H. Traquair, O. M. Reis und A. Smith-Woodward haben in ihren Beschreibnngen fossiler Fische einen Anfang damit gemacht, aber ron einer befriedigenden Kenntuis kann nur erst bei sehr wenigen Formen gesprochen werken. So fehlt nun zmmeist eine solide Grundlage für phylogenetische Konstrnktionen. Dazu komnt die fast unübersehbare Menge lebender Teleostier, die fast $95^{\circ} \%$ aller lebenden Fische ansmathen nnd sich seit der oberen Kreide bei der Eroberung des tieferen Meeres teilweise zn höchst absonderlichen Gestalten spezialisiert haben.

Verschiedene Faktoren komplizieren das Verhältuis der Ganoiden zu den Teleostiern. Daß die letzteren aus den ersteren hervorgingen, ist wohl niemandem mehr zweifelhaft, und daß die Rïckbildung des Hautskelettes sowie die gleichzeitige Kräftigung des Innenskelettes für den Paläontologen das wesentliche Moment in diesem Umbildnngsprozeß bedentet, dürfte anch kaum zweifelhaft sein. Die Frage ist nur, ob dieser Übergang von Ganoiden zu Teleostiern nur an einer oder an mehreren Stellen erfolgte. Naturgemäß wïrden die letzteren nur dann eine phyletisch-systematische Finheit bilden, wenn der Übergang nur in einem Formenkreise erfolgte. Daß dieser Formenkieis Familien und vielleicht sogar eine ganze Ordnung unfassen könnte, wïrde die ïbliche Fassung des Begriffes monophyletischer Einheiten nicht alterieren, denn eine "Phyle" läßt sich systematisch etwa als Ordunng auffassen. Gehen wir nun die Ordnungen der "Ganoiden" dnrch, so kann von diesen wohl nur die Ordnung der actinopteren Eckschmpper als Ansgangspunkt der' Teleostier in Betracht kommen. 
Die miogenetische Reduktion des Schuppenpanzers anf die ältere und einfachere Form dümner Rundschuppen ist anscheinend selbständig an mehreren Stellen erfolgt, ich erinnere an die Familie der Amiaden, Belonorhynchiden, an die Eugnathiden, Catmiden und an die Pholidophoriden und deren Beziehung zn den Oligopleuriden.

Nun scheint indes, dab sowohl die Belonorhynchiden wie auch die Amiaden ohne weitere Nachkommenschaft ansstarben, und dab es keine erheblichen Schwierigkeiten bereitet, ihre Formenreihen bei den Ganoiden zu belassen, obwohl sich ihre letzten Endglieder in der Richtung der Teleostier vom Typus der Ganoiden entfernten. Dann bleibt aber nur ein verhältnismäßig enger Kreis übrig, aus dem die ältesten Malacopterygier hervorgingen; es sind das die Familien der Pholidophoriden, Caturiden, Eugnathiden und Oligopleuriden, die mit der Riickbildung des Ganoidenpanzers die Verknöcherıng der Wirbelsäule verbanden. Bei dieser Sachlage scheint mir aber die Anfrechterhaltung der alten Abteilungen der Teleostier als Unterklasse der T'eleostomata gerechtfertigt.

Die bisherigen phylogenetischen Grindlagen der Entwicklnng der Teleostomen würden dann etwa in folgendem System einen kurzen Ausdruck finden:

Klasse Teleostomata Cope.

I. Vorstufe. Unterklasse Proostea m. Nebenordnung Acanthodi.

II. Hauptstufe. Unterklasse Holostea m. (Vorphase Crossopterygii Huxley.)

1. Hauptordnung Cyclolepidi

2. $" \quad$ Osteolepidi
Nebenordnung $1 \propto$ Dipnoi

$1 \beta$ Coelacanthi

" $1 \%$ Onychodonti

. $\quad 2 \Leftrightarrow$ Polypteri

(Hanptphase Actinopterygii Smith-Woodward.)

3. Hauptordnung Heterocerci

4.

5.

Lepidoti

Amii
Nebenordnung $3 a$ Pycnodonti

$3 \beta$ Belonorhynchi 4 Aspidorhynchi

$4 \beta$ Lepidostei

$\pm \gamma$ Belonorhynchi

III. Oberstufe. Unterklasse Teleostea Joh. Müller.

1. Hauptordnung Malacopteri Nebenordnung Ostariophysi

Symbranchii

. Apodes 
2. Hamptordnung Haplomi

3. Acanthopterygii
Nebenordnung 2a Heteromi

$2 \beta$ Catosteomi

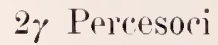

3 Opisthomi

$3 \beta$ Peliculati

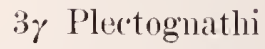

Bei vorstehenden Gesichtspunkten ergiht sich folgende Definition del Teleostomen:

Fische mit echten dachziegelartig übergreifenden Schuppen, mit voruständigem Mund, mit acrodonten Zähnen anf den Deckknochen der Kiefer. Innenskelett meist verknöchert. 4 Kiemen zwischen 5 Kiemenbögen, von einem Apparat von Kiemendeckeln bedeckt, unter diesen einzeln geoffnet. Beide Paarlossen meist wohl entwickelt, die hinteren öfters nach vorn verschoben oder rürkgebildet. Flossenskelett ursprünglich mehl axial, später ganz actinal gebaut. Schädeldachknochen wohl gesondert, in der Regel parig.

\section{Vorstufe. Cnterklasse Proostea m.}

Die Acanthodier, die bisher den einzigen Bestandteil dieser Stufe bilden, lassen sich den höher organisierten Ganoiden nicht muterordnen. Ihre Organisation weicht fast in allen Verhältnissen nicht nnwesentlich von der der höheren Teleostomen ah und steht namenthich auch in dem Mangel von Kinochenzellen anf der tiefsten Stnfe der Teleostomen. Darauf wurde ihr Name „Proostea" basiert. Innerhalb einer solchen ersten oder Torstnfe erscheinen aber die Acanthodier nicht als primitiver 'l'ypus, von dem etwa die Ganoiden abgeleitet werden könnten, sondern als ein abernanter Seitenzweig, der auch in der Folge durch Degeneration so tief unter die Organisationsstufe del Klasse heruntersank, daß es nicht wunderbar ist, daB einzelne Autoren auf Grund des Studinms dieser letzten Dekadenten die ganze Ordnung mit den niedriger organisierten Selachiern in systematische Beziehnng bringen wollten.

Die älteren Formen erweisen sich aber deutlich als ganoidenähnliche Teleostomen, vor allem dureh ihr gesamtes Hautskelett mud ihre Flossenbildung. In letzterer erreichten sie sogar schnell eine höhere stufe als die älteren Ganoiden.

Bei dieser abseitigen Spezialisierung der Acanthodier ist es kaum möglich, die Vorstufe, ans der sie stammen, näher zu präzisieren, aber einige Organisationsverhältnisse möchte ich doch unter diesem Gesichtspunkt hervorheben. 
Die paarigen Gliedmaßen sind als Flossen wohl ausgebildet. Bei einem 'Typus kommen aber seriale paarige Anhänge vor, die zwar nur durch ihr stachelartiges Dermalskelett den Paarflossen naheriicken, aber doch als Rudimente bezw. epistatische Rückschläge zu der Anlage einę gröBeren Zahl metamerer Gliedmaßen aufgefaßt werden könnten. Der innere Schultergïrtel ron Acanthodes weist eine vierteilige Zusammensetzung auf, deren Teile man entsprechend denen der Tetrapoden als Suprascapulare, Scapulare, Coracoid und Praecoracoid bezeichnen kann. Die Form und manche Besonderheit dieser Teile erinnert durchans an die primitiven Formen des Tetrapoden-schultergiurtels. Da der innere Schultergürtel bei den übrigen Fischen ganz andere Wege der Differenzierung einschägt, ist die tetrapodenartige Ausbildung desselben bei

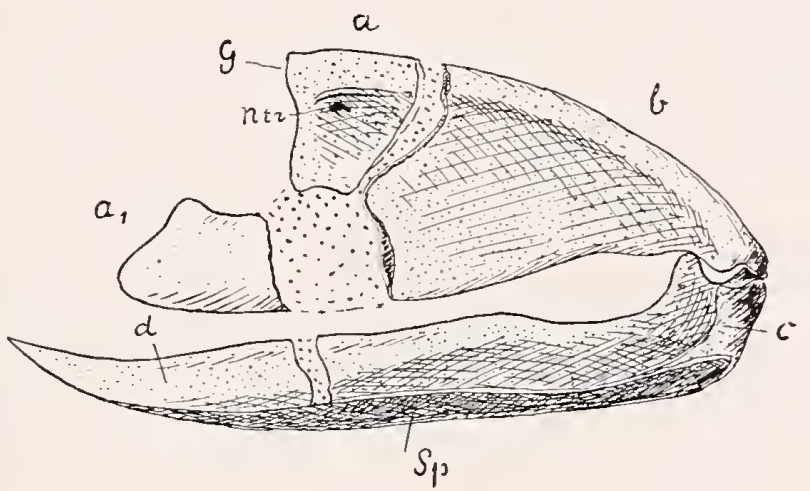

Fig. 75. Mundskelett von Acanthodes Bronni Goldfuß aus dem unteren Perm von Lebach b. Saarbrücken. Nat. Größe. (Nach Jaekel.) $a-d$ die vier Stücke des primären Mundbogens, $G$ das Gelenk an der Postorbitalecke, Ntr Nervenloch, $a_{1}$ die primäre Unterlage des Maxillare und des Palatinums anderer Wirbeltiere, $S p$ ein rudimentäres Spleniale.

einem so niedrigen Teleostomentypus nicht zu unterschätzen. Zu einer planmäBigen histologischen Untersuchung des Skelettbautes der Acanthodier bin ich leider noch nicht gekommen und wage deshalb auch daribber noch kein Urteil abzugeben, ob der Nangel echter Knochenkörperchen bei den jüngsten Acanthodiern als primär anzusehen ist. Beachtenswert ist jedenfalls, daß bei den älteren Formen ein Hautskelett wohl entwickelt ist, auch die Schuppen wirkliche Deckschuppen sind, während sie später zu rhomboidischen Kleinschuppen reduziert sind. Die Mundbogenteile zeigen noch eine sehr primitive Ausbildung und namentlich eine vierteilige Gliederung des Mundbogens (Fig. 75), die den sekundären Charakter des sogenannten Palatoquadratums dokumentiert. 


\section{Nebenordumng Acanthodi.}

MäBig große kleinschuppige Teleostomen mit epicerkem Schwanz, langen, in der Regel längsgefurchten. Stacheln vor den Rumpfflossen, mit weiter Mundspalte, vierteiligem Mnndbngen, teilweise mit acrodonten oder stephanodonten Zähmen, neist unbezahnt. Augen mit vierteiligem Scleroticalring, sonstige Deckknochen schwach entwickelt, bei den jüngeren Formen meist rïckgebildet. Innerer Schnltergïrtel vierteilig, tetrapodenartig geformt. Zwei Seitenlinien am Rnmpf, z. T. mit dorsalen Kommissuren.

Die meisten Eigenschaften dieser kleinen, aber sehr eigenartigen Gruppe ältester Fischtypen waren in degenerativer Wandlung begriffen, so daß sie kanm in eine feste Definition zu fassen sind. Die ältesten Acanthodier stehen alten Ganoiden relativ nahe, die jüngeren degenerieren so, daß sie schließlich in manchen Punkten Selachiern ähnlich werden. Die älteren sind Rundschmper, die jüngeren Kkleinschmper. Bei älteren Formen mit echten Deckknochen finden sich anch acrodonte Zähne.

\section{Unterordnnug Diplacantli.}

2 Dorsalflossen. Schmppen relativ groß, gerundet, übergreifend. Stacheln vor allen Rumpfflossen. Schädeldeckknochen wohl entwickelt, zahlreich. Kiemenregion und Schnltergiirtel z. T. mit Deckknochen, z. T. stachelartige Bildungen an der Banchseite in biserialer metamerer Anordnung. Ohersilur bis Devon. Fam. Ischnacanthidae, Diplacanthidae.

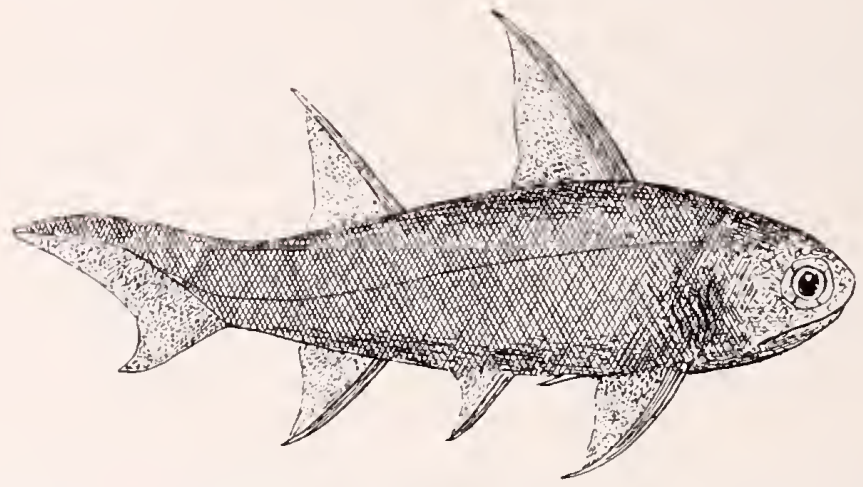

Fig. 76. Diplacanthus striatus Agassiz. Mitteldevon von Schottland. Nat. Größe. (Nach Traquair.)

\section{Unterordnung Acanthodi.}

1 Dorsalflosse. Derunalskelett am Kopf und Schultergürtel größtenteils rückgebildet. Hierher gehören die Acanthodier mit Chiracanthus und Acanthodes (Fig. 75) und die Acanthodopsidae mit stephanodonter Bezalnung (Acanthodopsis im englischen Karbon). 


\section{Stufe. Unterklasse Holostea m.}

Die zweite Stnfe der Teleostomen-Entwicklung kann man, da sie eine zienlich klare geschlossene Einheit bildet, auch als systematische Einheit auffassen. Sie deckt sich nicht ganz mit Joh. Müllers Begriff der Ganoiden, da einerseits die Grenzen gegen die Teleostier hier etwas anders gezogen sind, und andererseits die sogenannten Knorpelganoiden, die Störe, ganz von den Ganoiden getrennt wurden. Thre Benenmung Holostea steht in Einklang mit den Bezeichnungen der beiden anderen gleichwertigen Abteilungen, den Proostea und Teleostea und ist basiert auf das typische Kennzeichen der Unterklasse, der echten Verknöcherung, die ja bei den Acanthodiern fehlte, und bei den Teleostomen nachträglich elastischeren Folmen der skelettbildung wich.

Die Schuppen sind echte Deckschuppen, aber selten noch auf der primitiven Stufe diuner Rundschuppen, sondern meist verdickt, eckig geformt, durch Zapfen in vertikalen Reihen miteinander verbunden und auBen mit Schmelz bedeckt. Derselbe ist typischer, scharf rom Dentin gesonderter prismatisch strukturierter Schmelz, der aber in mehreren, bisweilen zahhreichen Schichten abgelagert ist. Diese Schmelzbedeckung des Hautskelettes ist von allen Wirbeltieren allein für die Holostea typisch. Den früher zu den Ganoiden gestellten Stören fehlt dieselbe auf den sogenannten Schupuen. So wäre nach Ausscheidung der letzteren der Name Ganoiden für den Kreis in seinem jetzigen Unfang besonders typiseh. Die Zähne sind acrodont und in der Regel auch noch wenigstens teilweise mit Schmelz überzogen. Allerdings setzt hierin ein Umbildungsprozeß ein, der bei den Teleostiern dann alloemeine Bedeutung erlangt zn haben scheint. Bei älteren Holostea findet sich sogar eine labyrinthoide Einfaltung des Zahnkegels, die aufällig an die entsprechende Ausbildung der Zähne von Labyrinthodonten erinnert. Man bezeichnet hier die ganz analoge, wenn nicht homologe Ausbildung als .,dendrodont".

Während fïr die Mehrzahl der Holostei die epicerke Ausbildung des Schwanzes, l. h. die Aufbiegung des Wirbelsäulenendes in ein oberes Schwanzsegel typisch ist, findet sich bei einigen Typen cine horizontale Streckung der Wirbelsäulenachse und eine gleichmäßige Entwicklung eines oberen und unteren Schwanzsegels an der zweckmäßigsten Druckstelle, nämlich etwas vor dem Schwanzende. Daraus entstehen dann Flossentypen, bei denen das Schwanzende median aus einer oben und unten symmetrischen Flossenbildung himausragt und als "Pinselflosse" bezeichnet wurde. Fiir derartige 'Typen diurfte der Name Diplocerci zutreffender sein. Aus einer Reluktion der Druckleistung des Schwanzendes und einer indifferenten Seitenbewegung des ganzen 
Körpers auf schlaumigem Boden resultiert daun in mehreren Fällen ein amphicerlier schwanztypus, der den niedrigen Schwanzflossenbildungen schwimmender Tetrapoden ähnlich wird.

Als Ausdruck von Stufen del Entwicklnug kann man namentlich die crossopterygiale und die actinopterygiale Ausbildung der Paarflossen nnd die heterocerke sowie die homocerke Anshildung des Schwanzes betrachten. Die crossopterrgiale Flossenhildnng ist der natiirliche Ansgangspnnkt mnd das Anfangsstadium aller älteren Fischtypen und zwar nicht nur der "Crossopterygier", wogegen sich die Verkïrzung der Flossenachse auf verschiedenen leider historisch schwer kontrollierbaren Wegen rollzog. Die starke Heterocerkie permischer Ganoiden besitzt gegenïher triassischen und jurassischen Nachkommen nur eine graduelle und für die einzehen Formenreihen rerschiedene Bedentung. Auch die T'erknöchernug der Wirbelsïule bildet nicht so einfache Gegensätze, wie man früher ammahn. Einerseits zeigen schon devonische Ganoiden verknöcherte Wirbelkörper, andererseits erhalten noch jurassische Typen die Chorda in weitem Lmfange, obwohl sie in allen übrigen Verhältnissen zn Teleostiern geworden sind. Die Intensität der Verknöcherıng der Wrirbel hängt ror allen von der Energie der Bewegung ab, die allerdings durch die Gesantform des Körpers in verschiedene Bahnen geleitet sein kann. Ein unmittelbarer Zusammenhang besteht dabei nicht zwischen der Kräftignng der Wirbelsänle und der Rückbildung des Hantskelettes. Das letztere kann wie bei den Caturiden reduziert sein, olne taß die V'erknöchernng der Wirbel eintrat, und ebenso kann ungekehrt der Hautpanzer noch kuaftig ansgebildet sein, und doch gleichzeitig wie bei einigen Pholidophoriden die Wirbelsäule rerknöcher’n.

Bei dieser Sachlage kommen wir in einzelnen Fällen in Konflikt, oh win Formen noch den Ganoiden oder schon den Teleostiern zuzählen sollen. Es betrifft diese Frage namentlich die Pholidophoriden, Pachycormiden, Belonorhynchiden und Amiaden. Es scheint mir nun zweckmäßig, diejenigen Formenkreise bei den Ganoiden zu belassen, die sich zwar in inen Endformen den 'T'eleostiern näheru, aber' keine weitere Entwicklung in deren Typus erfahren haben, also namentlich die Amiaden, Pholidophoriden, Belonorhynchiden. Andererseits stehen Formen wie die Pachreormiden nnd Caturiden den Teleostiern schon sehr nahe, wemn anch die Ansbildnng ihrer Wirbelsänle, ihre Schwanzbildung und andere Merkmale die Entwicklnngsstnfe der Teleostier noch nicht klar zum Ausdruck bringen.

Bei dieser Einteilung winden die Teleostier mit zwei nahe rerwandten Trpen aus den Lepidoti hervorgehen, einerseits ans kiäftigen Raubfischen, den Caturiden, andererseits mit harmloseren herdenförmig 
lebenden Leptolepiden, die sich als "physostome“ Malacopterygii in die Familien der Clupeiden, Salmoniden nnd andere fortsetzen und zu besonderen Nebenordnungen der Ostariophysi, Symbranchii und Apodes spezialisieren. Innerhalb der einzelnen Formenreihen wïrde ich die Grenze da ziehen, wo der kräftige Panzer rhombischer Eckschuppen verloren geht und an seiner Stelle wieder die ältere und primitivere Form dünner Rundschuppen persistiert. Hiernach erhalten die Ganoiden eine leidlich scharfe Lmgrenzung.

Hiernach sind die Holostea spindelförmige Teleostomen mit verkalkten meist schmelzbedeckten Schuppen, normal gestellten Paarflosssn, mit breitem Mnnd, der fast immer mit maxillären Randzähnen besetzt ist. Schwanz in der Regel epicerk mit terminaler (selten praeterminaler diplocerker) Endflosse. Wirbel vielfach unverknöchert. Bulbus arteriosus des Herzens mit wenigstens 3 Klappenreihen. Enddarm mit Spiralfalten. Schädel stegal, d. h. von einem geschlossenen Panzer von Hantknochen umh ïllt. Nasen am Vorderrand. Augen anfangs weit vorn, meist ziemlich klein. Kiemendeckel meist wohl entwickelt, mäBig groß. Nasengruben in der Regel blind geschlossen, ohne Choanen nach der Mnndhöhle.

\section{Phase Crossopterygii, Quastenflosser, Huxley.}

Als eine erste Stufe der Ganoidenorganisation hat man Formenkreise zusammengefaßt, für die von Huxley der Name Crossopterygier gegeben wurde. Er umfaßt Formen mit Quastenflossen, d. h. Flossen, in denen ein axialer, mit Schuppen bedeckter Teil dentlich markiert ist. Indem wir die Dipnoer wieder hier anschließen, gewinnt dieser Name nnd die anf ihn begrïndete Abteilnng wenigstens als Phase wieder nene Berechtigung.

\section{$\uparrow$ 1. Hauptordnung Cyclolepidi.}

Rundschuppige Ganoiden mit breitem Mund, spitzen meist dendrodonten Zähnen, axopterygialen Paarflossen, bauchständigen Beckenflossen, 2 Rückenflossen und einer Analflosse. Schwanz diplocerk oder epicerk. Im geschlossenen Schädeldach kleine Frontalia mit Epidyse, große Parietalia und ein einfaches Occipitale superins. 2 große Jugularplatten. Schulterskelett mit großen skulpturierten Cleithren. Devon bis Kreide.

\section{† a) Unterordnmo Holoptychii}

mit langer Flossenachse, großen runzlig skulpturierten Schuppen, dendrodonten Zähnen und langer Schwanzachse. Oberdevon. Karbon. Fam. Holoptychidae, Grroptychidae, Rhizodontidae. 


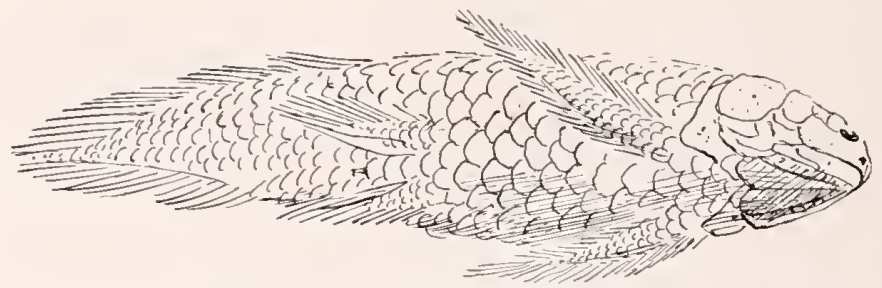

Fig. 77. Glyptolepis leptopterus Ag. aus dem Mitteldevon von Schottland, schräg von unten gesehen. $1 / 2$ nat. Größe.

\section{$\doteqdot$ b) Unterordnung Diplocerci}

mit dorsaler und rentraler Flossenbildung ror dem amphicerk umrandeten Schwanzende. Flossenachse kurz und breit. Flossenstrahlen stärker entwickelt. Fam. Eusthenopteridae, Oberderon. Fan. Coelacanthidae, Deron bis Kreide.

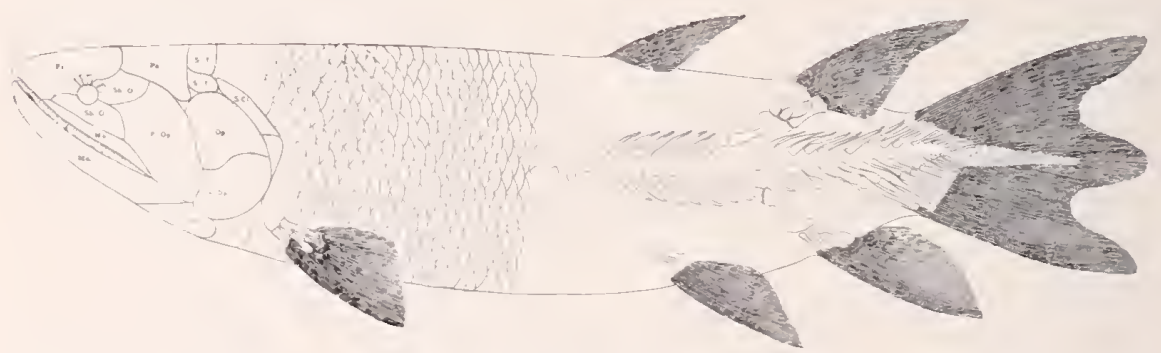

Fig. 78. Eusthenopteron Foordi Whiteaves. Oberdevon. Scaumenac Bay. Kanada. 1/3. (Nach Whiteaves.)

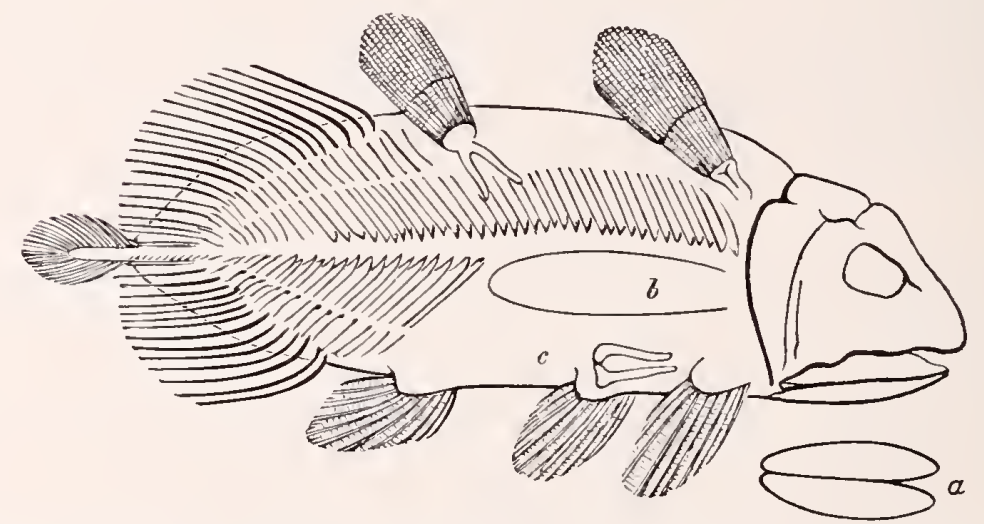

Fig. 79. Skelett eines Coelacanthiden (Undina) aus dem oberen Jura von Solnhofen, Bayern. (Nach A. Smith-Woodward.)

$\dagger$ c) Unterordnung Onychodonti.

Invollständig nur in Schädelskelett bekannte Formen mit großen 
sichelförmig gekrimmten Zahmreihen auf den Praemaxillen und der Symphyse des Unterkiefers. Schupuen klein, ziemlich diinn. Deron.

\section{Nebenordnung Dipnoa, Lungenfische.}

Spindelförmige am Ende komprimierte sïßwasserbewohner mit stumpfem Kopf, ventral unter dem Vorderrand gelegenen Nasen, mit großen, runden Blattschuppen, axoptergialen Parflossen, knorpligem, oberflächlich verkalktem Innenskelett. Der unpare Flossensaum meist wenig differenziert, seine Strahlen reiten auf je einem Bogenstücke der diplocoelen Wirbel. Schwanzflosse heterocerk oder amphicerk (gephyrocerk, Dollo). Oberkiefer am Cranium angeschlossen. Gebiß selten noch aus einer Zahnreihe am Kieferrand, meist mit einem Paar Tomerzähnen, immer mit je zwei breiten, radial gezahnten oder gefalteten Zahnplatten, die regetarischer Nahrung angepaßt und rasodentinös strukturiert sind im Gaumen und Unterkiefer. Die Lunge noch nicht zu einer Schwimmblase vereinfacht und zeitweise in voller Atemfunktion. \& Kiemen von einem großen Kiemendeckel bedeckt. Deron bis jetzt, immer selten, aber in Süßwasserschichten weit rerbreitet.

Die älteren Formen stehen, wie zuerst Dollo betonte, in ihrer Flossenform und wohl auch in ihrer ganzen Organisation auf höherer Stufe als die jüngeren und besonders die lebenden Vertreter. Die Zahnplatten verlieren die Einzelhöcker, die ihnen ursprïnglich aufsaßen und in die sie auch gelegentlich zerfallen, und spezialisieren dafür ihre Kaufläche durch korrespondierende Flächenwellung.

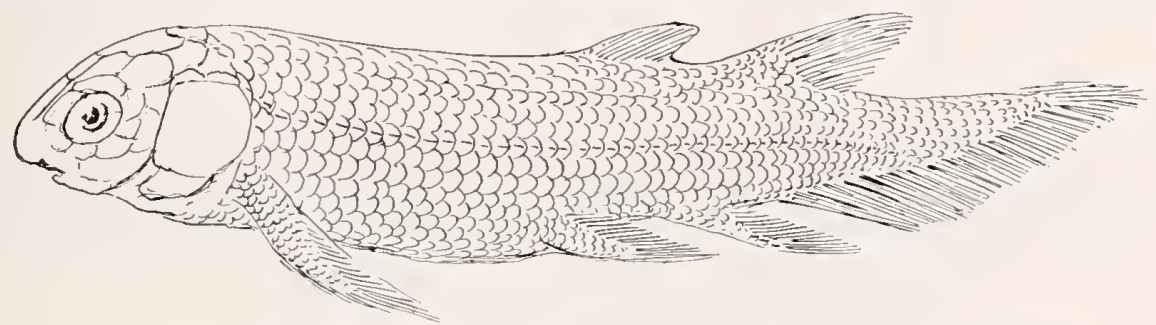

Fig. 80. Dipterus valenciennesi Sedg. u. Murch. Mitteldevon. Schottland.

\section{Unterordnung Dipteri.}

Schwanz heterocerk, ron den beiden Dorsalflossen und der Analflosse scharf gesondert. Kopf vorn breit deprimiert, ganz mit Deckknochen bedeckt. Zahnplatten mit vielen Höckern. Biseriale Paarflossen mit langer beschuppter Achse. Deron. Fam. Dipteridae im Devon.

Nebenreihe Uronemi.

Kopf breit mit geschlossenem Schädeldach. Zahnplatten breit, in 
irregnlär' gestellte Einzelhöcker zerlegt. Schwanz amphicerk. Lronemus, Karbon; Conchopoma, Perm.

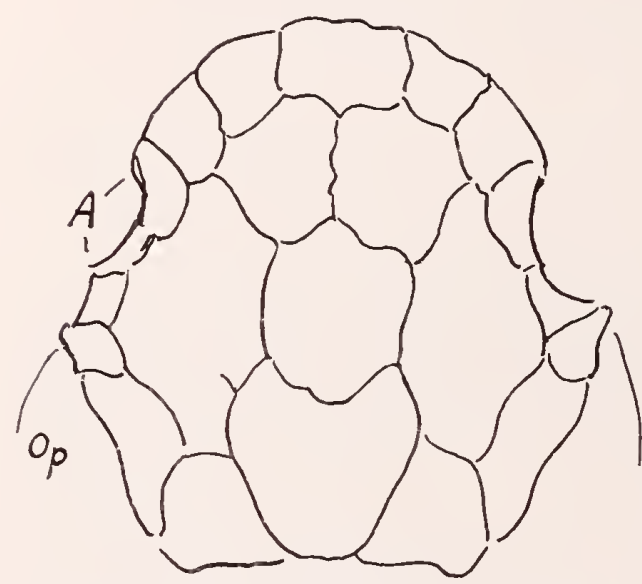

Fig. 81. Schädeldach von Conchopoma gadiforme Kner. Unt. Perm. Lebach, Saarbrücken. 1/1. Restauriert.
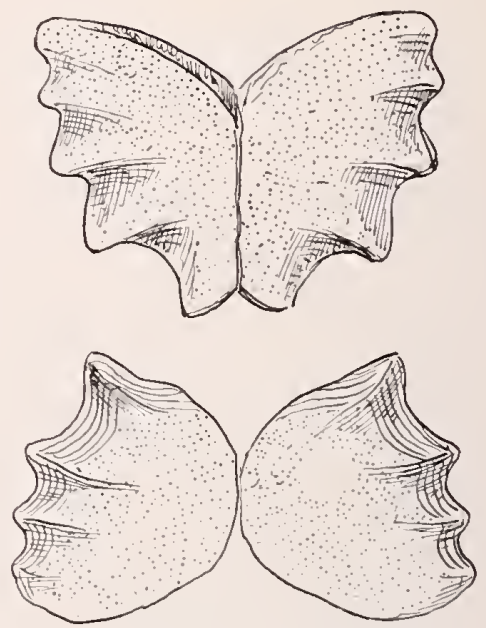

Fig. 82. Zahnplatten von Ceratodus Sturi Teller. Obere Trias. Lunz, Österreich. 1/2.

\section{Unterordnung Ceratodonti.}

Schwanz und Rürkenflossen verwachsen. Zahmplatten groß, z. T. mit gekerl,ten Radialleisten. Kopfknochen an Zahl verringert. Paarflossen biserial. Fam. Phaneropleuridae, Devon. Ctenodontidae, Sagenodontidae, Karbon, Perm. Ceratodontidae, Trias bis jetzt.

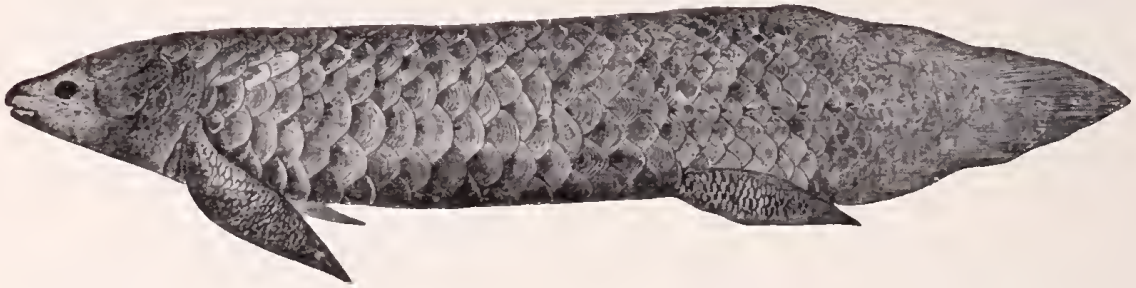

Fig. 83. Neoceratodus Forsterei Günther, sp. Australien. 1/ø. (Nach Boulenger.)

Unterordnung Protopteri.

Körper lang, walzenförmig. Paarflossen lang mit reduzierten Seitenstrahlen. Unpaare Flossen kontinuierlich, einen amphicerken Saum bildend. Schnppen klein nud schwach. Kopf nicht breiter als hoch. Kopfknochen sehr rerringert. Zahmplatten glatt mit wenigen tiefen Falten. Lepidosirenidae. 


\section{Hauptordnung Osteolepidi.}

Ganoiden ron normaler, gestreckter oder komprimierter Form. mit eckigen. durch Zapfen verbmndenen schuppen, die mit einer glatten, von Poren durchsetzten schmelzlage bedeckt sind. Thr schwanz ist epicerk oder isocerk, ilme Paarflossen mit kurzer Achse. Ihr Kiemendeckelapparat wohl entwickelt. Ihre zahlreichen Zühne zugespitzt, meist dendrodont. 2 große Jugnlaria. Parietalia lang. Frontalia mit Epidyse. Paarflossen mit kmrzer beschmpter Achse. Flossenstrahlen ans kleinen Schuppenreihen gebildet. 2 Rückenflossen.

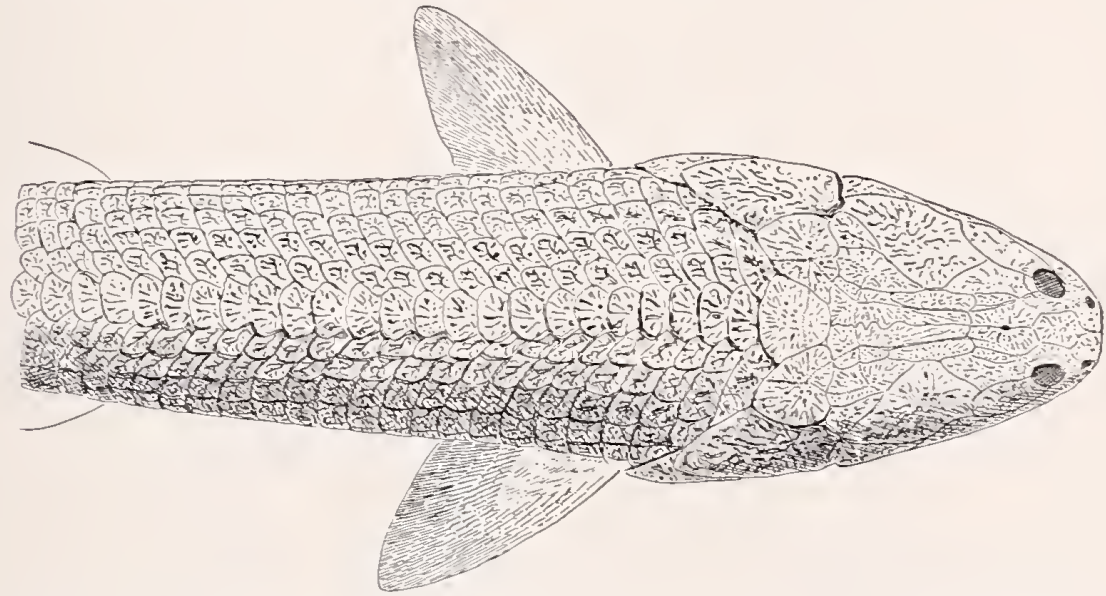

Fig. 84. Glyptopomus Kinnairdi. Oberderon von Schottland. Wenig verkleinert.

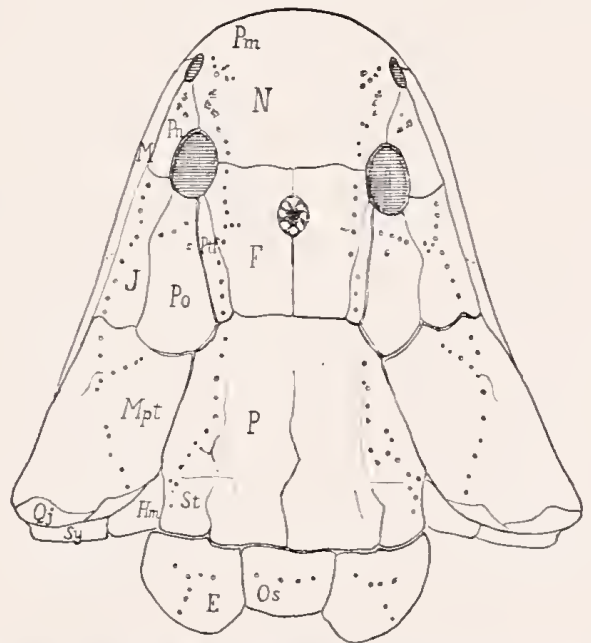

Fig. 85. Kopf von Osteolepis. Nat. Größe. Mit den rorn gelegenen Yasen. den Augen und dem von einem "Scleroticalring" geschiutzten Scheitelauge in den Frontalia $(F)$. (Nach Jaekel.) 
Hiermnter fasse ich nur paläozoische Formen zusammen, die im Deron und Karbon rerbreitet sind. die Glyptoponiden, Osteolepiden, Megalichthyiden. Die sehr spezialisierten Polypteriden der Gegenwart scheide ich ans.

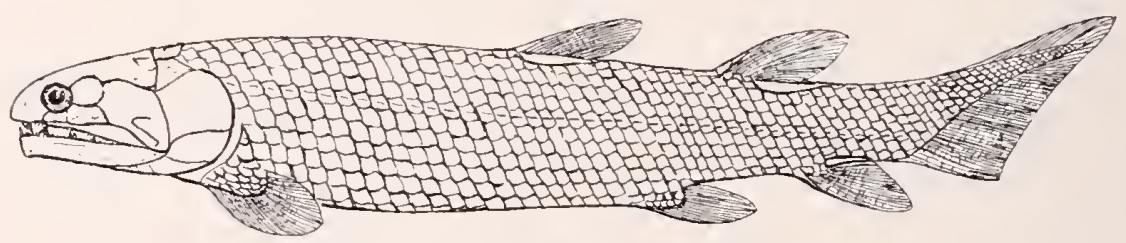

Fig. 86. Osteolepis macrolepidotus Ag. Mittel-Devon von Schottland. 1/2 nat. Größe. (Nach Traquair.)

\section{Nebenordunng Polypteri.}

Tralzenförmig gestreckte Fische mit mäßig dicken Eckschmpen, kurzen Achsen in den Parflossen, deren hinteres Par verschwinden kann. Rückenflossen in eine Anzahl kleiner Segel aufgelöst, die durch große Fulcra gestiitzt sind. Scluwanzfosse änBerlich homocerk, hinten gerundet. Hierher die lebenden Polypterus und Calamoichthys.

\section{Hamptordnumg Heterocerci (= Palaeoniscidae Smith-Woodward).}

Normal geformte Holostei mit langer epicerker schwanzachse, mit eckigen gefalzten Schuppen, mit actinopterygialen Paarflossen, einer Dorsalis, einer Analis, meist mit Fnlcren vor den Flossen. Kiemendeckel ziemlich klein, Deckknochen der Palatoqmadratregion zu einer Einheit verbunden. Schnltergïrtel mit Infraclaviculis. Zähne klein, in der Regel spitz. Mundspalte weit.

Die Palaeonisciden bilden einen Übergangstypns von Osteolepisartigen Vorfahren zn den großen dickschuppigen Ganoiden des Mesozoiknms. Sie scheinen eine formenreiche aber einheitliche Gruppe zn bilden, doch darf man nicht ïhersehen, daß ihre anffälligsten Eigenschaften wie namentlich inre Heterocerkie nur eine typische Dmrchgangsstation, also eine Stnfe anf dem Wege zur höheren Entwickinng der Ganoiden, aber keine selbständige Entwicklungsrichtıng darstellt. Inuch Einstellung in die Hanptreihe der Holostea snchte ich dieses Verhältnis znm Ansdruck zu bringen. Smith-Woodward hat die Palaeonisciden mit den Chondrostei (Stören) rereinigt. Nachdem wir die letzteren ganz von den Holostea (Ganoidea) getrennt haben, ist eine engere Beziehung zn den Palaeonisciden hier nicht diskutabel, und die Ähnlichkeit in ihrer äußeren Form lediglich als Parallelismms der Ent- 
wicklnng angesehen. Hierhin gehört als Unterordnung Microlepidoti die Gattung Cheirolepis (Fig. 87) mit winzigen rhombischen Schuppen. Durch die letzteren und ihre Körperfor'm erinnert sie an die Acan-

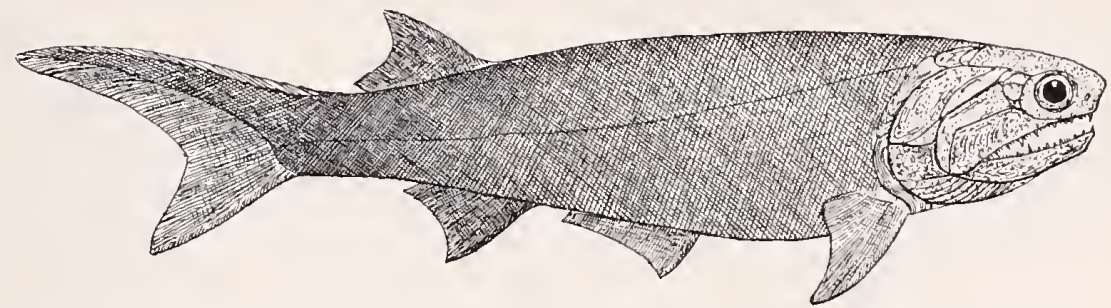

Fig. 87. Cheirolepis Trailli Agassiz. Mittel-Devon. Schottland. 2/2 nat. Größe. (Nach Traquair.)

thodier. Traquair hält es indes für ausgeschlossen, daß hier eine genetische Beziehmng bestehen könnte. Die normale Unterordnung bilden die Palaeonisci des Karbon, Perm und der Trias, die alle durch

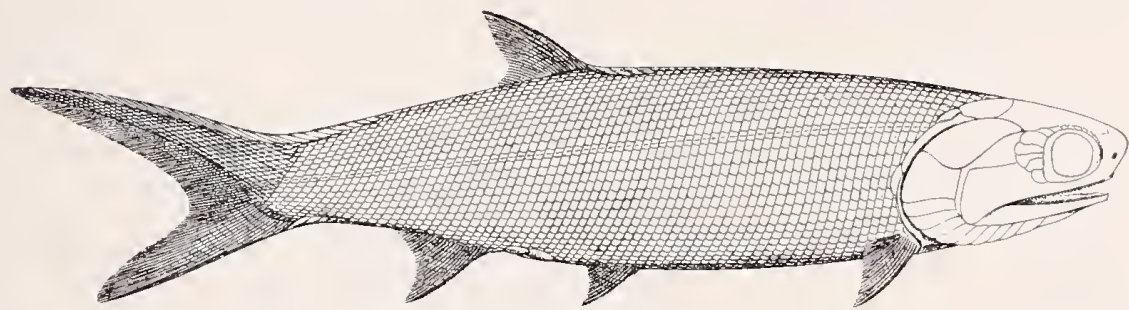

Fig. 88. Palaeoniscus Freieslebeni Ag. Oberes Perm. Deutschland. 1/2 nat. Größe. (Nach Traquair.)

größere Eckschuppen ansgezeichnet sind. Palaeoniscus und Amblypterus sind mit zahlreichen anderen Gattungen die weit verbreiteten Vertreter im Perm Enropas.

\section{Nebenordnung +Platysomi Traquair.}

Komprimierte im Umriß rhombische Formen mit vertikal verlängerten Falzschuppen, epicerkem Schwanz, langer Dorsalis und Analis mit kleinen Schulterflossen, kleinen oder rückgebildeten Beckenflossen. Kiemendeckel und Schädelbau wie bei Palaeonisciden. Zähne stumpf griffelförmig oder kuglig.

Diese in Karbon nnd Perm verbreiteten Deszendenten der $\mathrm{Pa}$ laeonisciden sind wohl Tiefwasserbewolner gewesen. Sie umfassen zahlreiche Gattungen, die noch eine Sonderıng in einzelne Formenkreise erlauben würden. 


\section{Hanptordnming Lepidostei Huxl.}

Spindelförmige, selten komprimierte Ganoiden mit kräftigen rhombischen, in schrägen Vertikalreihen verfalzten Schmelzschnppen, mit knızer, aus dem oberen schwanzsegel größtenteils zurückgezogener

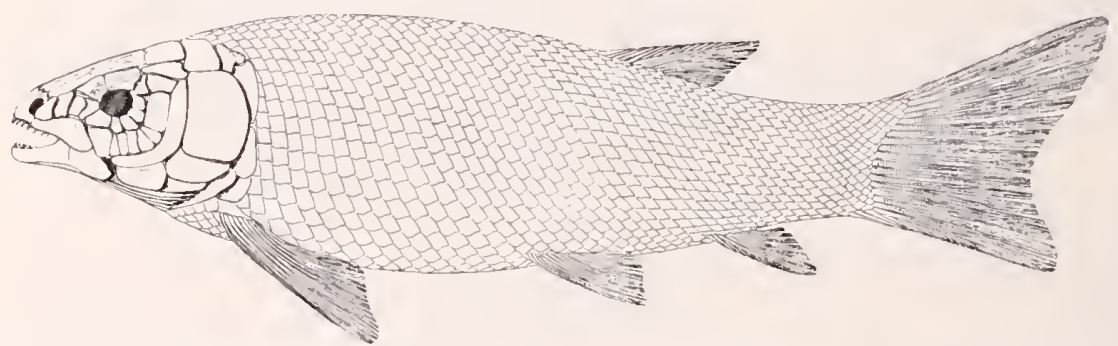

Fig. 89. Lepidotus elvensis Blainville. Oberer Lias. Holzmaden. Wiurtt. 1/5 nat. Größe.

Schwanzachse. Flossen actinopterygial, oft mit Fulcren besetzt. Banchflossen kiein. normal gestellt, eine Dorsal- nnd Analflosse. Gebiß mit. griffelförmigen (stylodonten) oder stumpfen (splärodonten) Zälnen.

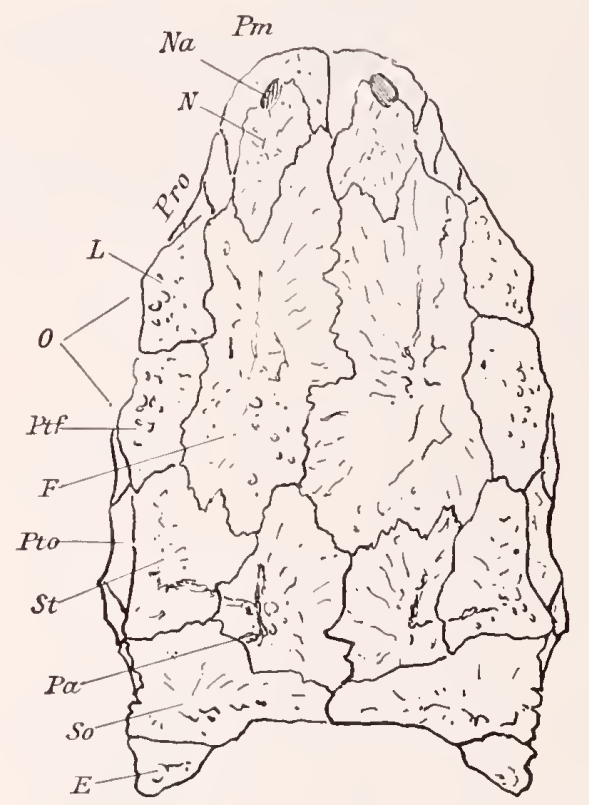

Fig. 90. Schädeldach von Lepidotus elvensis Blainv. Oberer Lias. Holzmaden, Württ.

Operenlarapparat groß und normal ansgebildet. Thas Auge von Cirenmorbitalplatten nmgeben.

Lepidotus ist der stattlichste, verbreitetste und bestbekannte Vertreter eines großen Formenkreises mesozoischer und einiger jüngerer 
Ganoiden, die durch ihre glänzenden schmelzbedeckten großen rhombischen Schuppen, die äußerlich fast homocerke Form ilıer Schwanzflosse gekennzeichnet sind. Ihr Gebiß ist verschiedenen Lebensweisen angepaßt, meist mit stmmpen, mit Tecodentin bedeckten Kauzähnen rersehell.

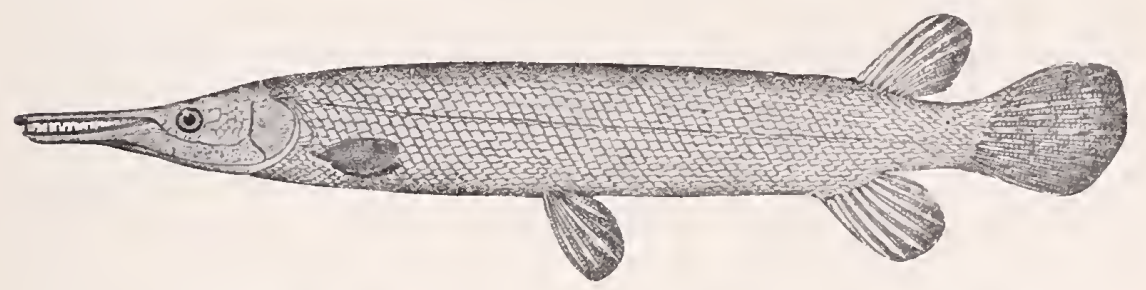

Fig. 91. Lepidosteus osseus. Lebend in den Flüssen von Nordamerika. 1/4.

(Nach Jordan u. Evermann.)

Zu den Lepidostei stellte ich anßer den Catopteridae, Semionotidae, Lepidotidae (Fig. 89) auch die Pholidophoridae und die lebenden Lepidosteidae (Fig. 91). Bei den Pholidophoriden zeigen sich Übergänge einerseits zn den aberranten Aspidorhynchi, anderseits zu den Trissopiden, die schon dem Kreise der Teleostier angehören.

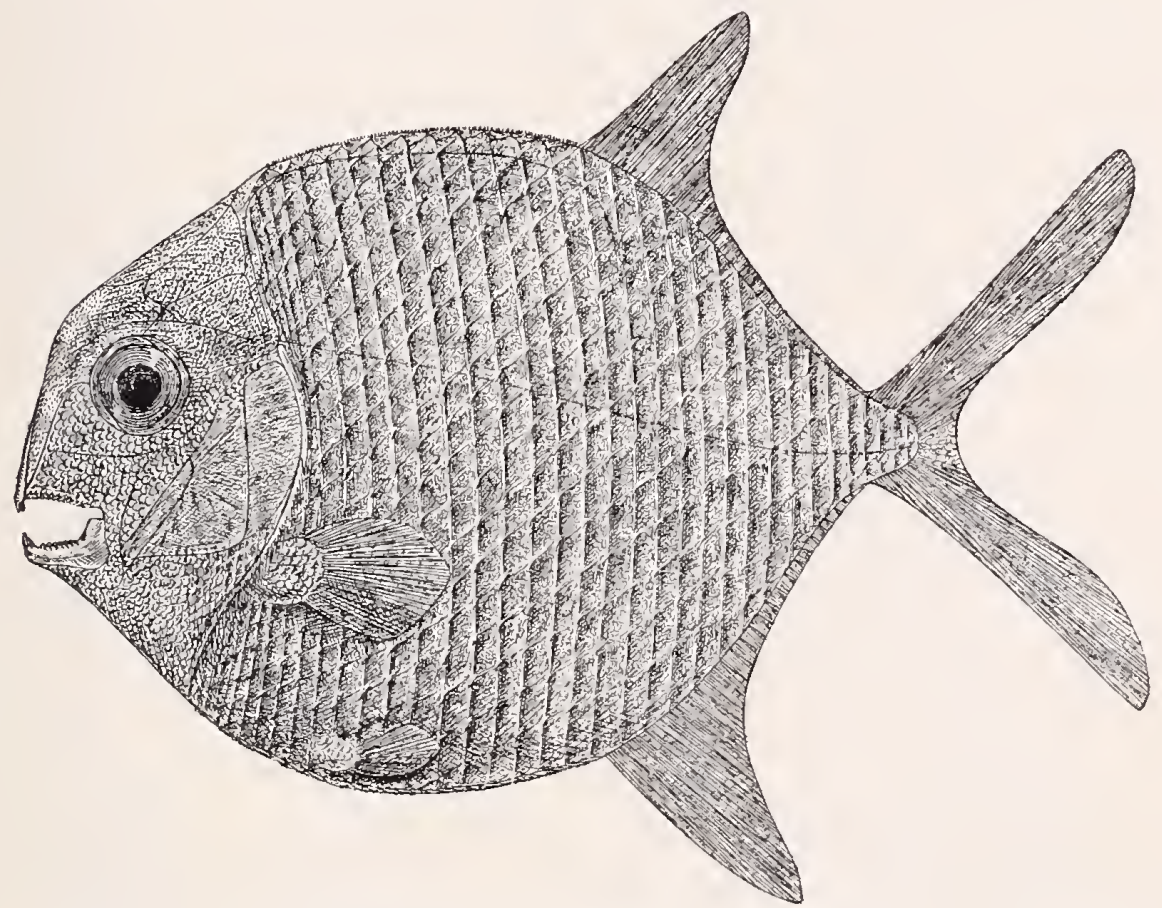

Fig. 92. Gyrodus hexagonus Blainv. sp. Oberer Jura Solnhofen. $2 / 3$ nat. Größe. Ein Vertreter der Pycnodonten. (Nach P. Hennig.) 


\section{Vebenordnung †Pycnodonti.}

Komprimierte. im Lmriß orale Eckschmpler mit dümnen, aber noch skulpturierten schuppen, die in Tertikalreihen fest rerfalzt sind. Brnstflossen mit kurzer beschmpter Achse. Beckenflossen klein oder ganz ritkkgebildet. Die Dorsal- nud Analflosse lang, die Schwanzflosse isocerk mit kurzer epicerker Schwanzachse. Gebiß ans schlanken Torderzähnen mnd dicken Kauzähnen gebildet, die sich anf Vomer, Palatina nnd Dentale rerteilen. Maxille unbezahnt. Die Parietalia durch das Occipitale smperins getrennt. Snb- nud Interoperculum fehlen. Augenring zweiteilig: Wirbelsäule aus ca. 30 Wirbeln gebildet. Obere Bögen in der simmetrieebene flächig verbreitet. Flossenträger doppelt so zahlreich als die oberen Bögen. Intestinalregion dnrch eine verknöcherte Scheidewand hinten alogeschlossen (wesentlich nach P. Hennig). Fam. Gyrodontidae (Fig. 92) Trias bis Kreide. Fam. Prenodontidae Deron bis Tertiär.

\section{Tebenordmng + Belonostomi.}

Langestreckte Fische mit langem, zugespitztem Rostrum, mit rertikal rerlängerten seitenschuppen nnd mehreren Reihen rhombischer Rïcken- nnd Banchschnppen. Brust- und Banchflossen klein, actinopterygial. Analflosse und eine Rückenflosse. Schwanzflosse isocerk gespalten. Operculnm groß. Unterkiefer mit einem abgegliederten bezahnten Praedentale. Praemaxille mit großen, Maxille mit kleinen spitzen Zähnen. Parietalia rerwachsen. Ringwirbel von der Chorda durchzogen. I heser Kreis deckt sich mit den Rhynchodontidae Zittels, und den Aspidorhynchidae simith-Woodwards. Der Name der rerbreitetsten Form Belonostomus scheint mir die beste Benennung für den ganzen Formenkreis zu geben. der in Jura nnd Kreide bekannt ist.

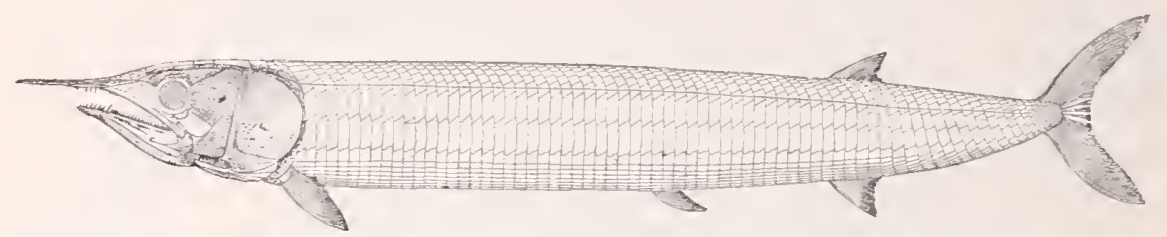

Fig. 93. Aspidorhynchus acutirostris L. Ag. Oberer Jura. Solnhofen, Bayern. $1 / 5$ nat. Gröbe. (Restauriert ron P. ABmann.)

\section{Nebenordnung Amii.}

Kileine oder mäßig große normal geformte Raubfische mit weitem Iaul nit normal gestellten Flossen, die meist rorn ron schwachen Fnlcren bedeckt sind, mit mäßig dicken schmelzbedeckten crcloidischen Deckschnppen. Schädel ganz in kräftige schmelzbedeckte Ḱnochen ge- 
hiillt, Opereularapparat wohl ausgebildet. Wirbel schwach verknöchert, z. T. hemispondyl, von der Chorda durchzogen. Eine große Kelıl- (Jugular-) Platte ist vorhanden.

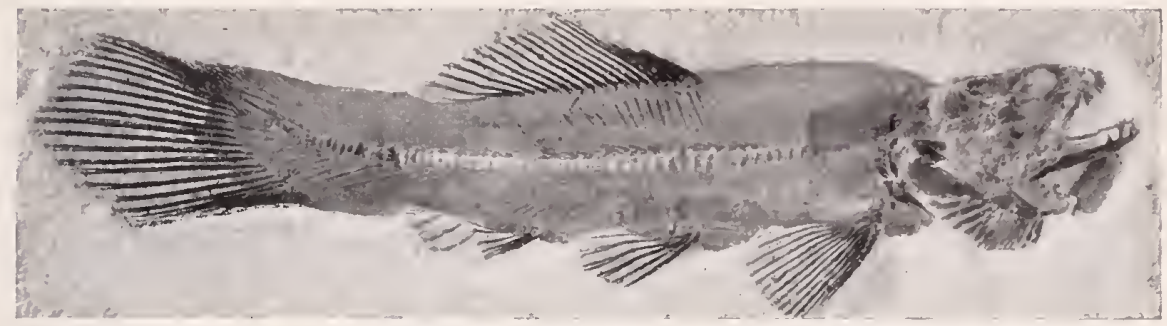

Fig. 94. Megalurus elegantissimus Wagn. Ob. Jura. Solnhofen. $2 / 3$.

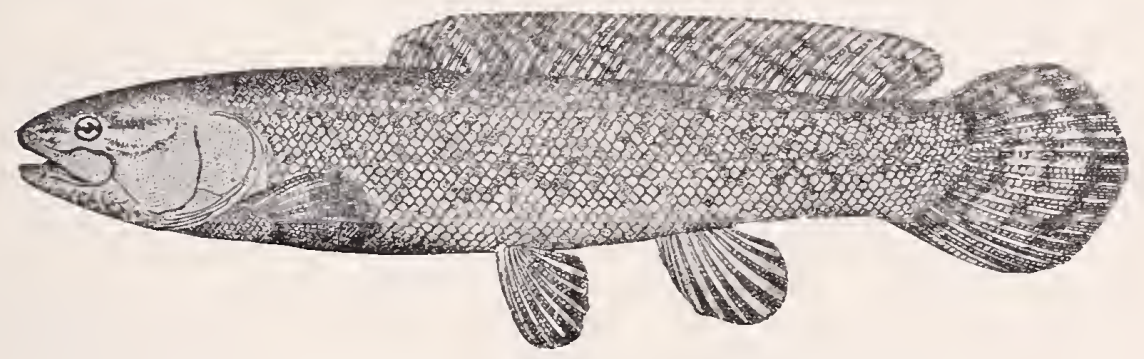

Fig. 95. Amia calva lebend in Flüssen Nordamerikas. 1/4.

\section{Hauptordnumg † Eugnathi.}

Spindelförmige Raubfische mit großem Maul, kleinen und verdünnten, bisweilen gerundeten Schuppen. deren Schmelzbelag z. T. verschwindet. Schwanz isocerk, meist gespalten. Zälne spitz kegelförmig. Wirbel

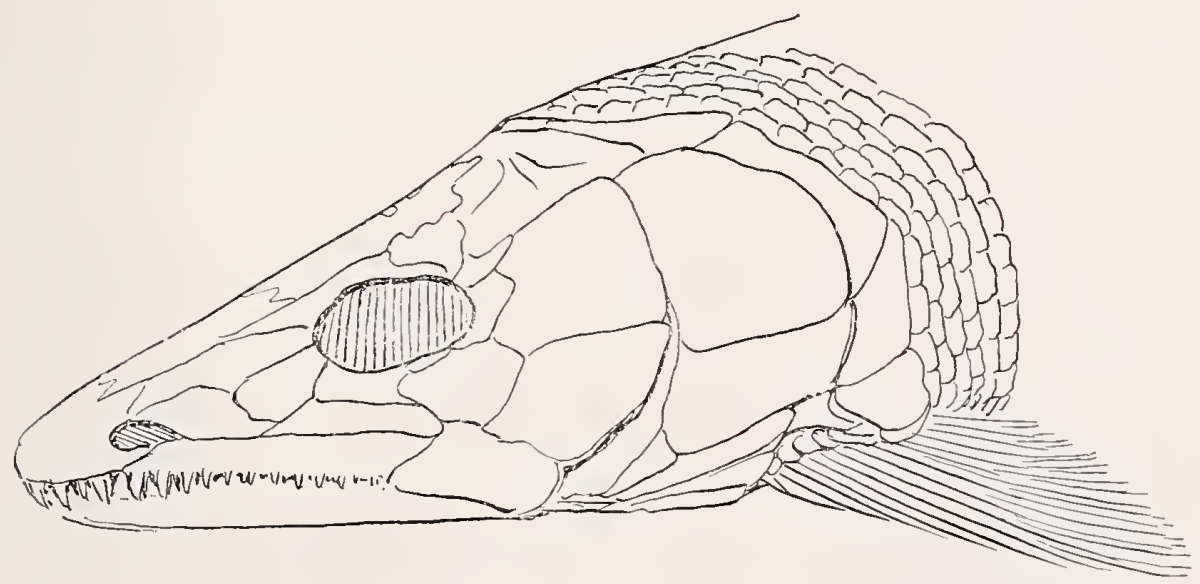

Fig. 96. Eugnathus orthosthomus Ag. Unter Lias. Südengland. 
meist noch nnverknöchert, bisweilen ans Hohlringen oder aus Hall wirbeln zusammengesetzt. Fulcra ror den Flossen meist wohl entwickelt. Dieser Formenkreis, der etwa der Familie der Saurodontidae Zittels entspricht, gelıt wahnscheinlich wie die Lepidosteiden direlit von den Palaeonisciden

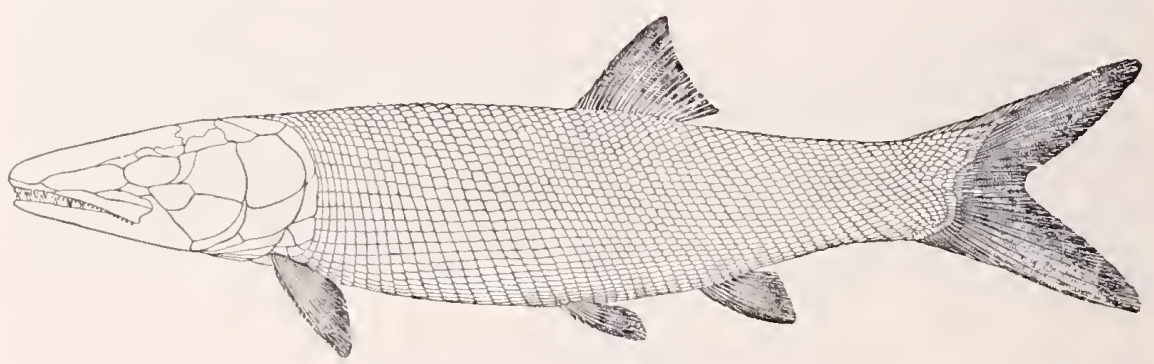

Fig. 97. Engnathus orthostomus Agassiz (Restauration von A. Smith Woodward). Unt. Lias. Südengland.

ans, und könnte schon einen Teil triadischer Catopteriden und Semionitiden umfassen. Besser bekannt sind erst die Formen des Jura, die Eugnathidae, Catmidae, die z. 'T'. sehr großen Pachycormidae, wïhrend die Oligopleuridae schon zn den T'eleostiern gestellt sind.

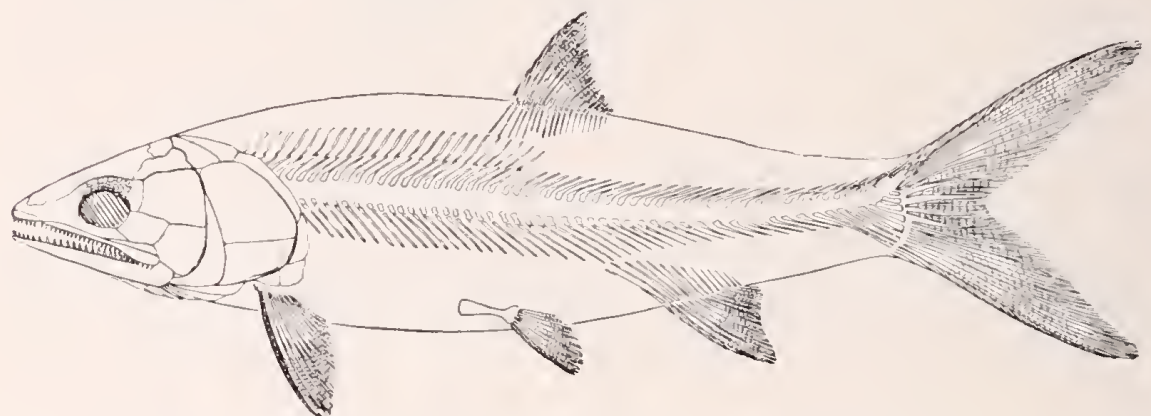

Fig. 98. Caturus furcatus Ag. Ob. Jura, Solnhofen. 1/8 Restauration von A. Smith Toodward unter Weglassung des Scliuppenpanzers.

\section{Nebenordnung † Belonorhynchi.}

Schlanke marine Tliefwasser-Fische mit scharf zugespitzem Kopf, langem Mundspalt, spitzen Zïlmen mit 'Tecodentin-Kappe, einer Dorsalis, einer Analis, einer scheinbar isocerken Schwanzfosse. Paarflossen actinal gebaut. Tirbel nuverknöchert. Schmppenpanzer zu einigen isolierten Längsreihen reduziert. Die auf die triassischen Gattnngen Belonorhynchns und Samichthys basierte Ordnnng ist noch nicht anfgeklärt. Ihre Vertreter stehen ganz ahseits von den übrigen Holostea und scheinen eine selbständige Entwicklung in der Richtung der Teleostier-Organisation eingeschlagen zn haben. Smith Woodward brachte sie mit den Stören 
in Konnex wohl wegen ihrer sonderbaren schuppenreihen. Ihr ganzer Schädelbau mnd ihre Bezahnung schließen allein schon diese Möglichlieit aus. Wir werden sie volläufig am besten als Nebenordmung der Holostei und vielleicht am ehesten als aberrante Terwandte der Pachycormiden auffassen.

\section{Stufe. Unterklasse 'Teleostea.}

Die 'Teleostier oder Knochenfische sind gegenïber den Holostea oder Ganoiden durch allgemeine Kräftignng und durchgehende holospondyle Verknöcherung der Wirbelkörper ansgezeichnet. In der stärkeren Ansbildung des Innenskelettes kommt ilme große Schwimmenergie und damit ihre aktivere Anpassung an das Wasserlehen zum morphologischen Ausdruck. Mit der Zunahme ihrer Beweglichkeit tritt eine Redultion des Panzers ein. Die dicken schmelzbedeckten Ganoidschuppen werden zı dïnnen elastischen Blattschnppen, die nicht in der Struktwr wohl aber in der Form einen Rückschlag zn den Rundschuppen der ältesten 'Teleostomen darstellen. Das Ende der Wirbelsänle zieht sich ans dem Schwanze zurïck, in dem Maße wie dieser znr Endflosse gekräftigt worde. Ihre Flossen sind durchans aktinal gebant, eine Struktmr; die schon bei den höheren Holostei rorgebildet wurde. Der anfangs stegale Schädelbau wird in der Wangenregion gelockert und mnterbrochen. Der Oberkieferrand gibt seine primäle Struktur auf, indem bei vielen Formen die Maxille aus dem bezahnten Oberkieferrand ausgeschaltet wird, nnd die Praemaxillen ihre Funktion ïbernehmen.

Die Supraoccipitalia drängen die Parietalia bei den spezialisierteren Formen auseinander. Anch die Beckenflossen geben oft ihre prinäre Normalstellung auf. Der Name der Cnterklasse bedentet, daß ihve Terknöcherung vollkommen sei, ist aber insofern unzntreffend, als die Teleostier die echte Knochenbildnng wieder anfgaben und sich dafür eine viel einfachere, histologisch weniger spezialisierte Art der Knochen- und Schuppenbildnng zu eigen machten.

Definition: Innenskelett rerknöchert, Wirbelkörper bei einigen hemispondyl, sonst normal diplocoel, Schwanzbildnng in der.Jugend epicerk dann homocerk. Haut mit dïnnen elastischen, in der Regel cycloidischen, selten verwachsenen oder rïckgebildeten Schuppen bedeckt. Paarflossen durchans actinopterygial, Banchflossen häufig naclı vorn verschoben, bisweilen rïckgebildet. Kiemen meist durch einen unfangreichen Operkularapparat bedeckt. Bulbus arteriosus mit zwei Klappenreihen. Sehnerven gekrenzt. Darm ohne Spiralklappe. 
Einige dieser Kennzeichen sind nur an den lebenden Formen nachweishar nnt werden sich erst almählich in deren Phylogenie entwickelt haben. Thre geologische Verbreitumg reicht von der T'rias bis zur Gegenwart. Seit der Kreide sind sie in allen Gewässern verbreitet.

Die neneste systematische Bearbutung der fossilen 'Teleostier verdanken wir A. Smith Woodward, der in seinem Katalog der fossilen Fische des britischen Musenus das überans schwer zn benrteilende Material zum ersten Mal nach neneren zoologischen Gesichtspunkten duchoearbeitet hat. Systeme der lebenden Fische sind mehrfach anfgestellt und vielfach modifiziert worden. Tch habe mich in folgenden größtenteils an das von Boulenger gehalten, den im bitischen Musenm jedenfalls das großßte Material von Fischen der Jetztzeit vorlag, und der sich auch benuihte, das Systen der fossilen Fische von A. Smith Woodward mit den der lebenden in Einklang zu bringen. Inden ich nich wesentlich auf die genanuten Antoren stïtzte, habe ich den fossilen und lebenden Formen in gleicher Weise Rechnung zu tragen gesucht, und nur in wenig P’unkten, so namentlich in der Abgrenzung der 'Teleostier ron den Canoiden und der allgemeinen Gliederung des Systems rigene Anschaungen zum Ausdruck gehracht.

Wenn sich anch ferner die Malacopterygii und Acanthopterygii nicht in vollen Wert ihnes Tamens anfrecht erhalten lassen, so bilden sie doeh gnte und mit Recht eingebïrgerte Gruppen, die ich nicht fallen lassen wollte. Thre prinnitiven Vertreter scheinen die Ansgangspunkte für eine Anzahl kleinerer Gruppen zu bilden, die ich diesen Ordnungen als Tebenordnungen angereiht habe. Es scheint, daß zwischen diesen beiden Hanptkreisen eine dritte Abteilnng sich relativ frül selbständig machte und dann anch ihrerseits zum Ansgangspunkt nener Nebenordnungen wurde. Es ergeben sich darans muter den bisher zu den Teleostiern gestellten Fornen drei Hamptabteilungen, die aber eine gemeinsanle Definition kam gestatten, weil die genannten Nebenordunngen sich größtenteils so weit von dem Typus ihrer Stammgruppe entfernen, daß sie mit diesen wohl phylogenetisch aber nicht definitorisch in Zusammenhang gebracht werden können. (System siehe Seite 69.)

\section{Hauptordnung Malacopteri s. str. Bonlenger.}

Typische, wenig spezialisierte Teleostier, deren Flossen normal gestellt sind und besonderer vorderer stacheln entbehren, deren Wirbel verknöchern, deren Schwanz scheinbar ganz homocerk ist, deren Lnftblase mit den Schlnndrohr in Verbindung bleibt. Schultergïrtel mit Mesocoracoid, am Schädel angelüngt. Opercularapparat wohl ausgebildet. 
Hierhin gehören nach G. A. Boulenger 21 Familien, von denen ich aber die Pholidophoriden mit ihren typischen dicken Ganoidschuppen sowie die Catulden und Engnathiden bei den Ganoiden heließ, während

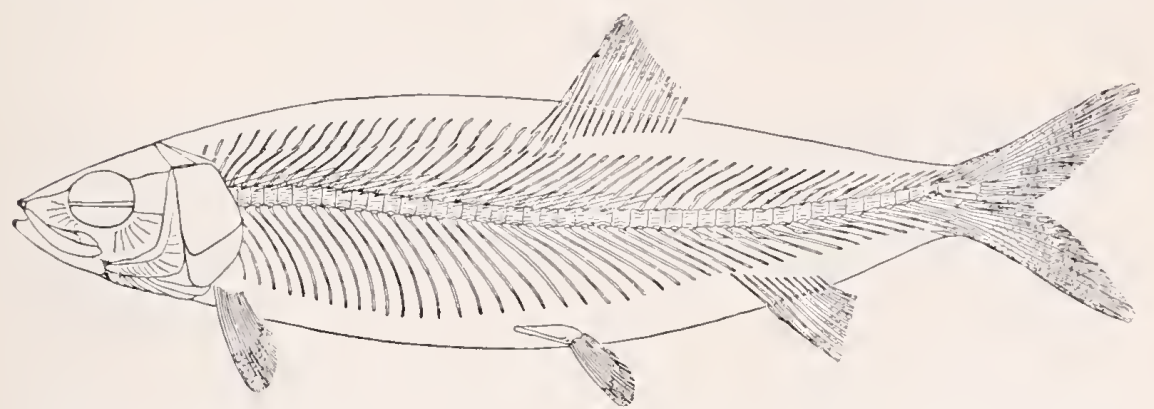

Fig. 99. Leptolepis dubius Blainv. Oberer Jura. Solnhofen. 2/3 nat. Größe. Restauration ohne Sehuppen. (Nach A. Smith-Woodward.)

die rundschmppigen Oligoplemiden und Archaeomeniden trotz ihrer Fulcren vor den Riickenflossen in die vorliegende Ordnung gestellt

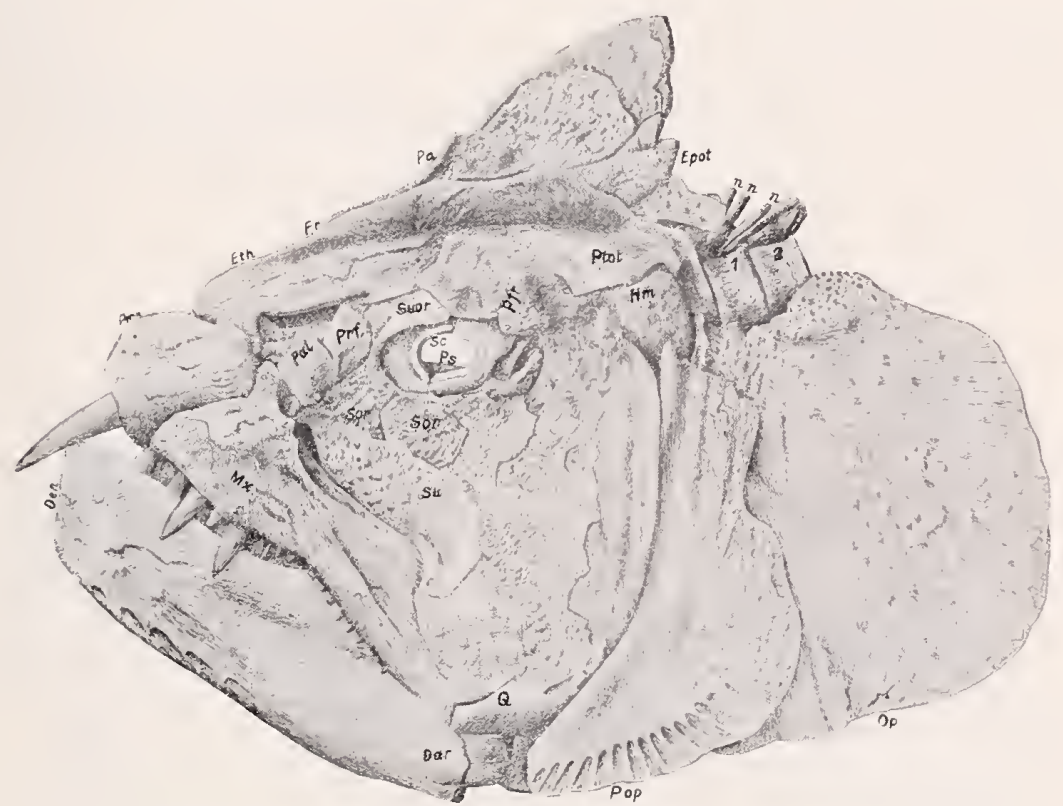

Fig. 100. Xiphactinus audax Leidy. Schädel. Obere Kreide. Kansas. 1/6 nat. Größe. (Nach Alb. Steward.)

wurden. Es bleiben darin anferdem die Familien der jurassischen nnd cretaceischen Leptolepidae, die Elopidae, Albulidae, Mormyridae, Hyodontidae, Notopteridae, Osteoglossidae, Pantodontidae, Ctenothrissidae, 
Phractolaenidae, die cretaceischen Saurodontidae, die seit der miteren Kreide bekannten, z. 'T'. riesengroßen Chirocentridae (Fig. 101), dann die ehenfalls seit der Kreide bekannten und seitdem inmer hänfigeren Heringe, die Clupeidae, damn die Lachse, die Salmonidae, die Alepocephalidae, Stomiatidae, fonorhynchidae mud die Cromeriidae.

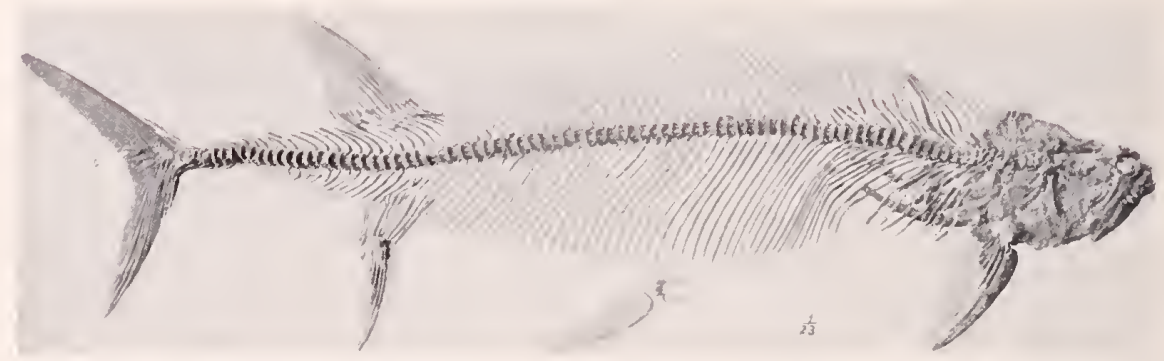

Fig. 101. Portheus molossus Cope. Obere Kreide. Kansas. 1/20. (Nach Osborn.)

1 r Nebenordnming Ostariophysi s. str. Boulenger.

Wie vorige, aber die vordersten 4 Wirbel dnrch besondere kleine Kunchen (Webersche Kuöchel) rerbunden, bisweilen ein einheitlich rerwachsener volderster Strahl an Brust- und Rückenflosse. Dieser anscheinend eng numgrenzte Formenkreis entstammit offenbar den Malacopterygia. Er umfaßt die Familien der Characinidae, del Gymnotidae, mit dem elektrischen Aal Gymnotus electricus, die Cyprinidae, die Silnidae oder Wrelse, die ein altes Geschlecht bilden (Fig. 102), ferner die Loricariidae und Aspredinidae.

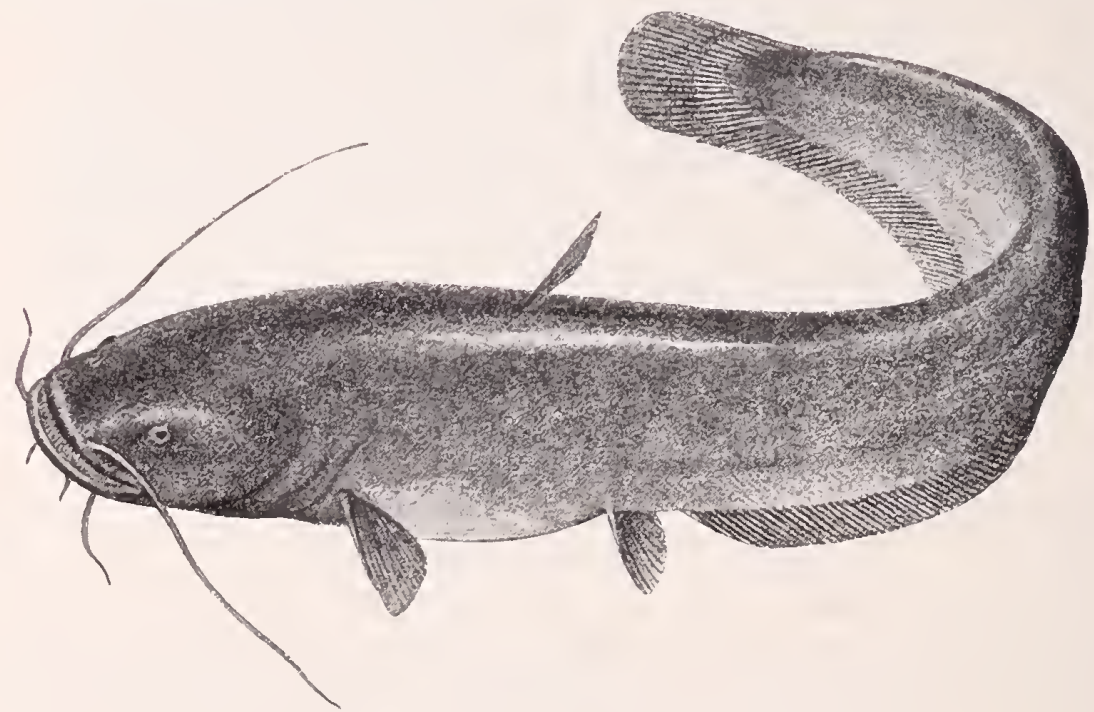

Fig. 102. Silurus glanis L., der Wels unserer Sülbwasser. 


\section{$1 \beta$ Nebenordnung Aporles.}

Schuppenlose Aale, ohne Bauchflossen, ohne Praemaxillen, öfters auch ohne Maxillen. Opercularapparat rückgebildet, Verbindung des Schultergiurtels mit dem schädel gelöst. Sonst den Malacopterygiern

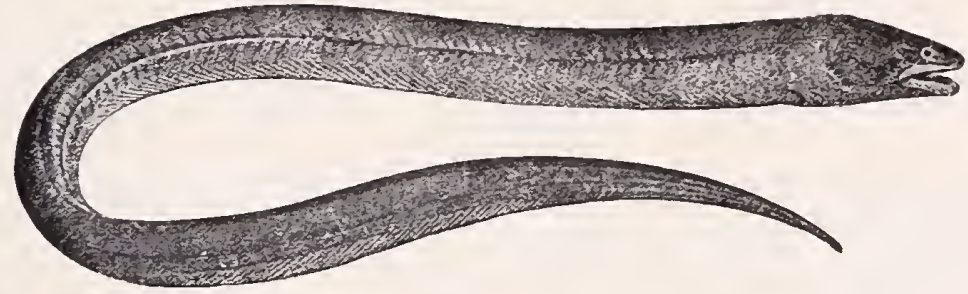

Fig. 103. Muraena macrura Bleeker. Indischer Ozean. (Nach Day.)

ähnlich. Einige Tiefseeformen sehr aberrant wie Fig. 104. Kreide bis jetzt. Boulenger zählt folgende Familien anf: Anguillidae, Nemichthyidae, Synaptobranchidae, Saccopharyngidae, Muraenidae.

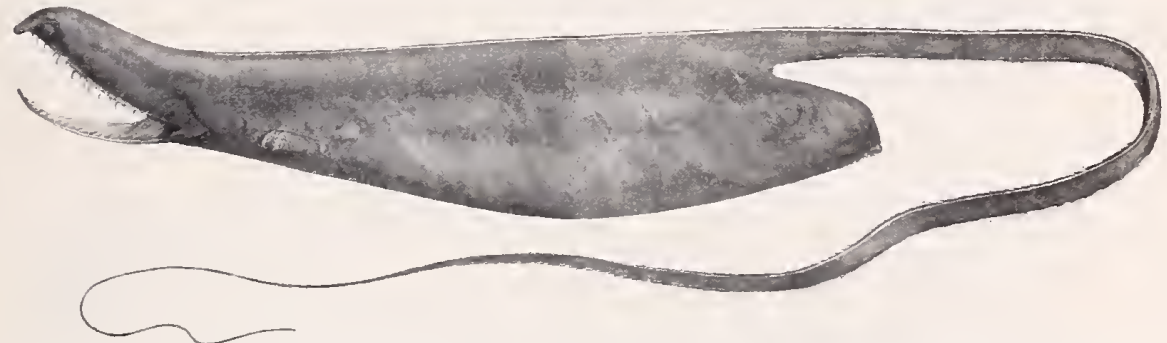

Fig. 104. Saccopharynx ampullaceus Harwood, eine lebende Tiefseeform des Atlantik. (Nach Günther.)

\section{$1 \gamma$ Nebenordnung Symbranchii.}

Aalartige Fische ohne Paarflossen, ohne Schwimmblase mit einfacher rückwärts geschobener Kiemenöffnung, sonst wie die Malacopte-

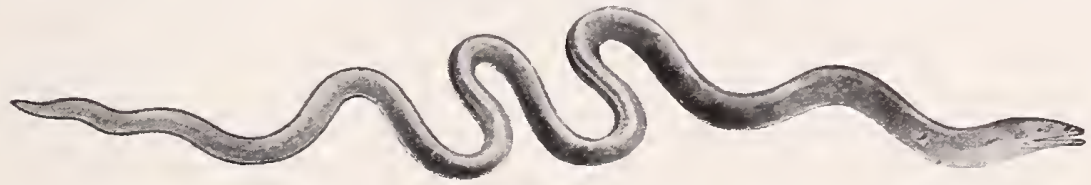

Fig. 105. Symbranchus bengalensis Mc Clell. Indischer Ozean.

rygii, ron denen sie vermutlich auch abstammen. Thre Vertreter sind seit dem Eocän bekannt. Fam. Symbranchidae, Amphipnoidae. 


\section{உ. Hauptordnung Haplomi Bonlenger.}

Ähnlich den Malacoptergiern, aber ohne Mesocoracoid. Flossen bisweilen mit einigen starren strahlen. Die Haplomi sind nach Boulenger einerseits mit den Dalacopterygiern verwandt, von denen sie abstammen diurften, anderseits mit den dcanthopterygiarn. Sie umfassen

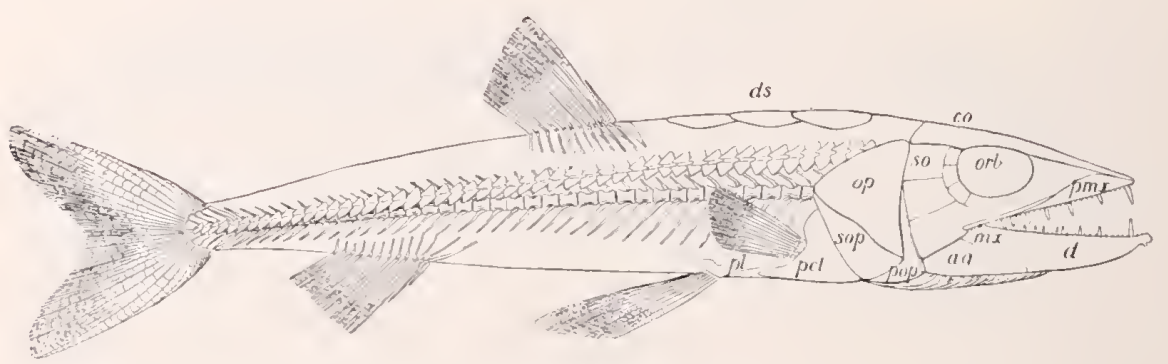

Fig. 106. Eurypholis bossieri Pirtet. Obere Kreide. Hakel, Syrien. 2/3. (Nach A. Smith-Woodward.)

nach Boulenger die Familien der Galaxiidae, Haplochitonidae, die in der Kreide läufigen $†$ Enchodontidae, die ihnen verwandten Esocidae (Heclte), die Dalliidae, Scopolidae, Alepidosanridae, Cetominidae, †Chirothricidae, Kneridae, Cyprinodontidae, Amblyopsidae, Stephanoberycidae, Percopsidae.

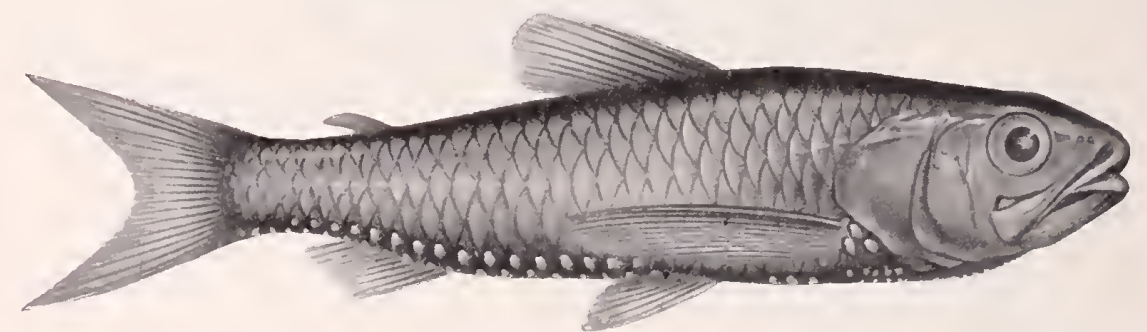

Fig 107. Neoscopelus macrolepidotus Johns. Indischer Ozean. (Nach A. Brauer.)

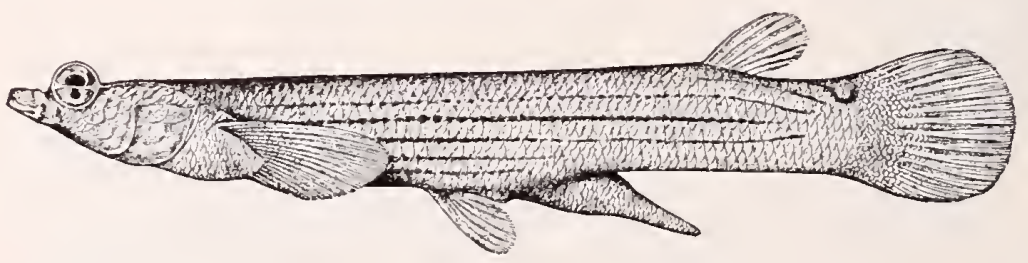

Fig. 108. Anableps tetrophthalmus mit zerlegter Pupille, um mit dem oberen Teil über Wasser, mit dem anderen unter Wasser zu sehen. (Nach Boulenger.)

\section{2r Nebenordnung Heteromi Boulenger.}

Schwimmblase ohne Schlundgang, Parietalia normal verbunden. Opercularia wohl entwickelt. schultergürtel an schädel angehïngt, 
ohne Mesocoracoid. Bauchflossen meist normal gestellt, bisweilen riickgebildet. Hierhin die cretaceische Familie Dercetidae, bei denen Sm.Troodward noch eine Gliederung der schwanzlosse nachwies, die Halosauridae und Notacanthidae, die in der Tiefsee leben, ferner die zwischen diesen beiden Familien stehenden Lipogenyidae und der eigentümliche Fierasfer, der parasitisch in Holothurien lebt (Fig. 109).

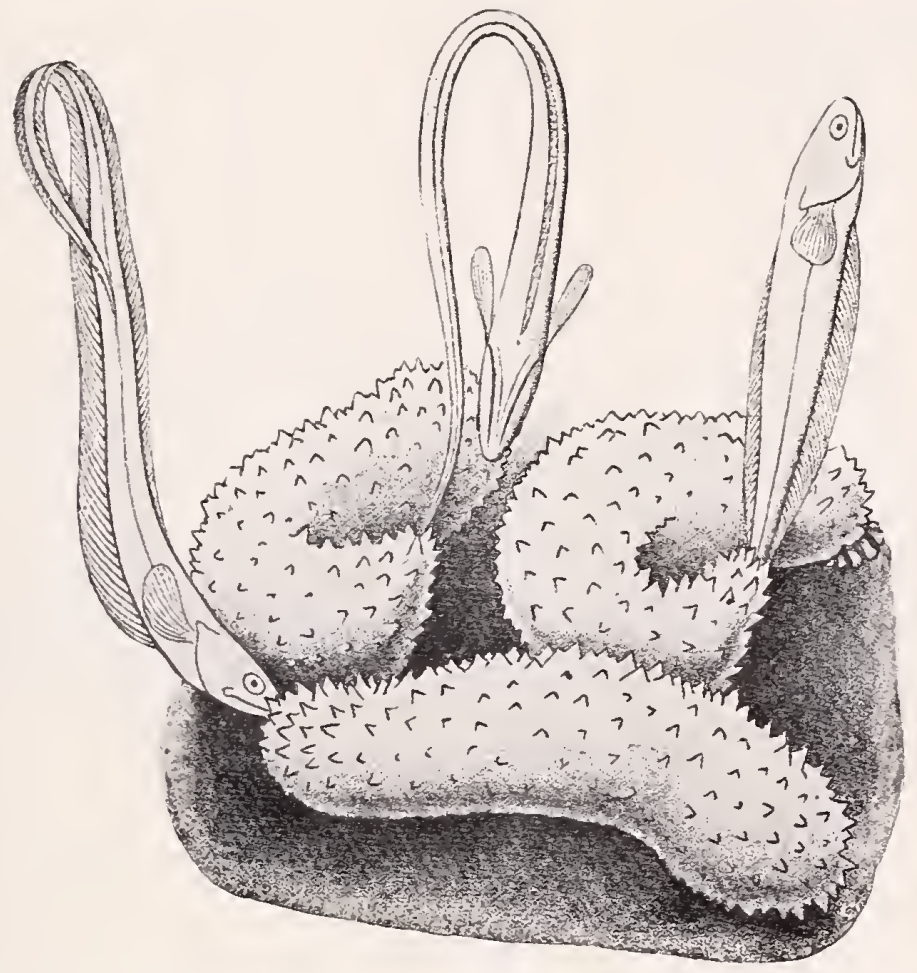

Fig. 109. Individuen von Fierasfer acus in Exemplaren von Holothurien lebend. Golf von Neapel. (Nach Emery.)

\section{Nebenordnung Catosteomi Boulenger.}

Schwimmblase ohne offenen Schlundgang oder ganz rückgebildet. Parietalia getrennt und bisweilen rückgebildet. Schultergürtel am Schädel angehängt, kein Mesocoracoid, Coracoid sehr groß. Maxillaria zumeist rom IIundrand ausgeschlossen. Bauchflossen bauchständig oder rückgebildet. In dieser Nebenordnung sind die älteren Gruppen der Lophobranchii und Hemibranchii von A. Smith-Toodward rereinigt. Boulenger gab ihr den Namen Catosteomi. Fam. Lamprididae, die gesondert stehen, dann die weit verbreiteten Stichlinge oder Gastrosteidae, die Aulorhynchidae, die ausgestorbenen Protosyngnathidae, die Aulostomatidae, die Fistulariidae (Fig. 110), Centriscidae, Amphisilidae, und die 
frïher wegen ilırer „Büschelkiemen“ als Lophobranchii bezeichneten Solenostomidae, Syngnathidae und Pegasidae.

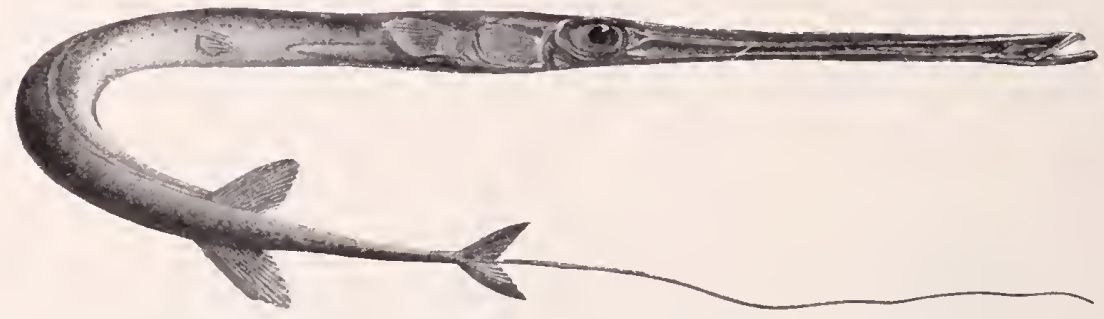

Fig. 110. Fistularia serrata Cuv. Indischer Ozean. (Nach Day.)

$2 \gamma$ Tebenordnung Percesoces Boulenger.

Schwimmblase ohne schlnndgang oder ganz rückgebildet. Parietalia getrennt. Schulterbogen am Schädel ohne Mesocoracoid. Banch-

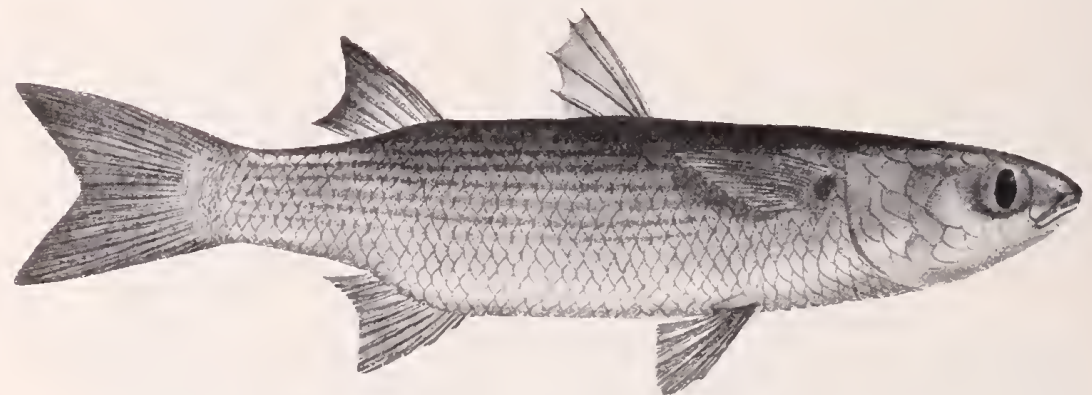

Fig. 111. Mugil oeur Forsk. Indischer Ozean. (Nach Day.)

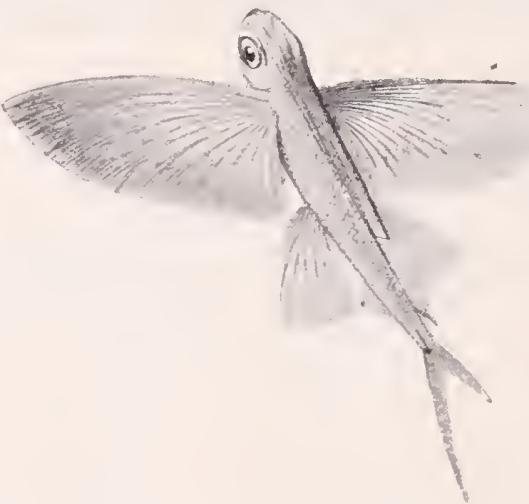

Fig. 112. Exocetus, in Flugstellung. Tropische Meere. (Nach Ahlborn.)

flossen bauchstïndig, Becken nicht fest mit dem Schultergürtel verbunden. Diese Formen nehmen eine Zwischenstellung zwischen den 
Haplomi und den Acanthopterygiem ein. Fam. Sicombresocidae (Fig. 112), Ammodytidae, Atheriniidae. Mugilidae, Polynemidae, Chiasmodontidae, Sphyraenidae. Tetragonuridae, Stromateidae, Icosteidae, Ophiocephalidae. Anabantidae.

$2 \delta$ Tebenordnung Anacanthini Joh. Mïller.

Schwimmblase ohne Schlundoang. Parietalia getrennt. Schultergiurtel an schädel angehängt, ohne imneres skelet. Baurhflossen weit nach voru gerïckt. Flossen ohne Stachehn, das schranzende dorsal und ventral lang umsäumend (Macruriden) oder in zwei dorsale und eine ventrale Hilfsflosse spezialisiert (Gadidae). Fam. Macrmidae, Gadidae, Muraenolepidae.

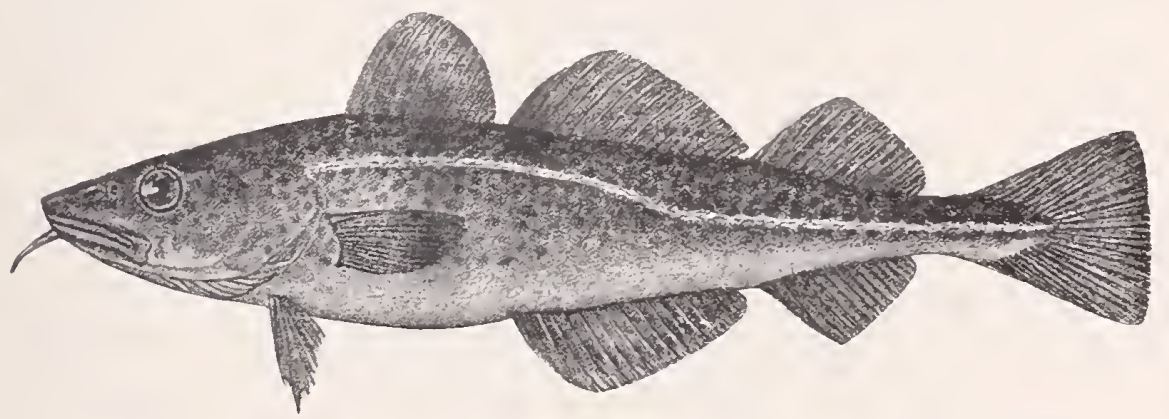

Fig. 113. Gadus morrhua, der Dorsch. Lebend Nordsee. (Nach Benecke.)

\section{Hauptordnung Acanthopterygii Cuv.}

Schwimmblase in der Regel abgeschlossen. Kiemendeckel wohl ausgebildet. Schnltergürtel am Schädel angehängt. Ventralflossen weit vorn. Die Maxillen vou dem bezahnten Mundrand ausgeschlossen. Die stachelartige angegliederte Ausbildung der vorderen Strahlen der Rücken- und Afterflosse ist wohl für die überwiegende Mehrzahl, aber nicht für alle Tertreter dieser äußerst formenreichen tbteilung charakteristisch.

Die große Formenmenge wird in eine Anzahl von Unterordmungen zerlegt: 1. die barschartigen Perciformes, die in (ler Kreide erscheinen und im Eocän schon sehr formenreich sind. Fig. 114 gibt einen der ältesten Typen wieder. Ton den 36 Familien, die diese Lnterordnung umfaßt, seien erwähnt die Beryciden, Serraniden, Sciaeniden, Perciden, Spariden, Chaetodontiden, Acanthmiden, Labriden und Scariden.

Eine zweite Unterordnung bilden die scombriformes. Ton den Terwandten der Makrelen, die sich von diesen Typen nach sehr verschiedenen Richtungen entfernt haben, seien erwähnt die Carangiden, mit ihren vorstreckbaren Praemaxillen, die Scombriden, Trichiuriden, Siphiiden (Schwertfische) und Coryphaeniden. 


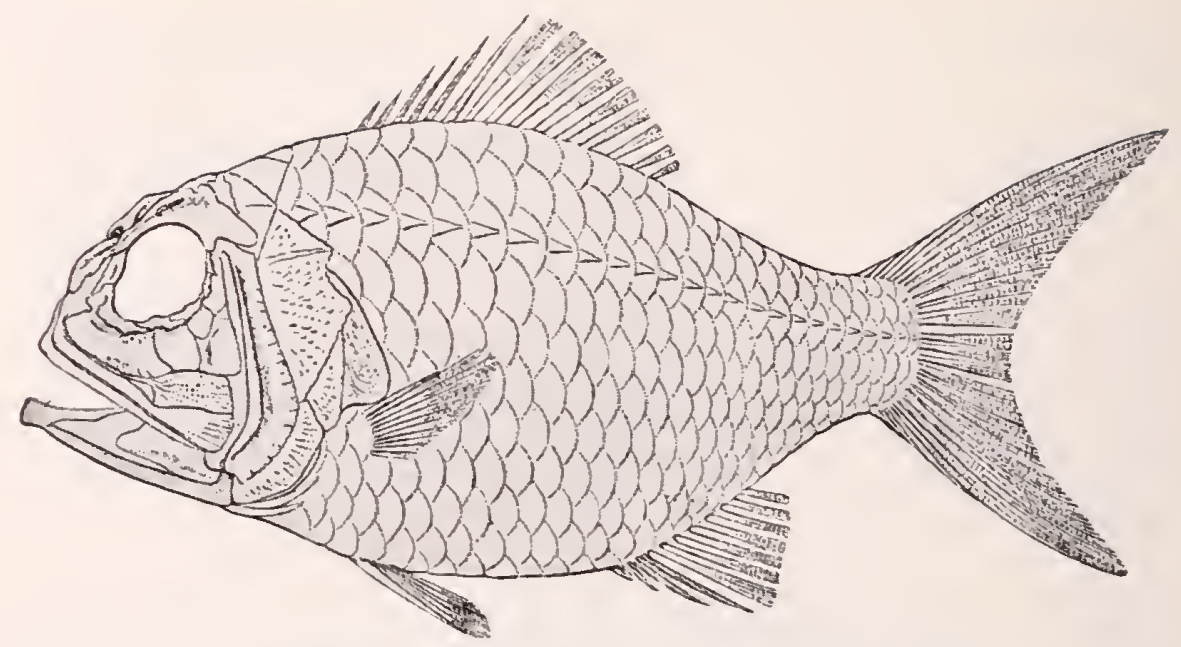

Fig. 11. Hoplopteryx lewesiensis. Obere Kreide. Süd-England. (Nach A. Smith-Woodward.)

Die dritte Unterordnung der Zeaeformes schließt sich mit ihrem stark komprimierten rhombischen Körper an den bekannten Zeus faher an, zu dessen V'orfahren die in Fì. 115 abgebildete Form aus dem Eocän

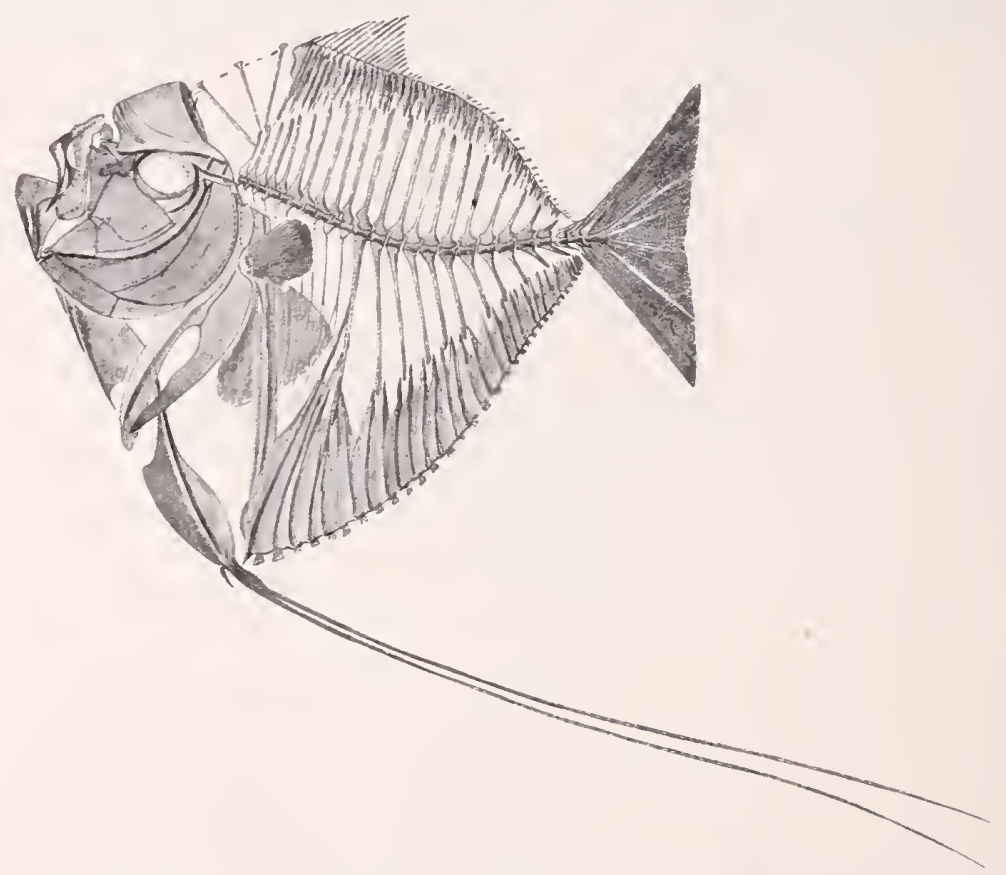

Fig. 115. Mene rhombeus Volta sp. Alt-Tertiär (Eocän). Mt. Bolca. 1/2 nat. Größe. (Nach Cramer.) 
des beriilmmten Fischfundortes Mt. Bolca gehört. Eine Aberranz führt bei extremen Formen zu einer Asymmetrie. Dahin gehören die tertiären Amphisiliden und die weit verbreiteten Plattfische oder Schollen, die als Pleuronectiden bezeichnet werden.

Weitere Unterordnungen repräsentieren die lebenden Kurtiden, Gobiiden, Echeneiden, die letzteren unter der Bezeichnung Discocephali. Eine größere Gruppe bilden die Scleroparei, Cuviers alte Acanthopterygii mit Panzeraugen, allerdings mit Ausschluß der Stichlinge. Die zahlreichen Familien sind durch Übergänge miteinander verbunden; von bekannteren seien erwähnt die Scorpaeniden, die Cottiden mit dem bekannten Cottus gobio, die Cyclopteriden mit Cyclopterus lumpus, die Trigliden, die mit ihren langen abgegliederten vorderen Brustflossenstrahlen auf das Ufer krabbeln, und die Dactylopteriden, von denen Fig. 116 den typischen Flugfisch darstellt.

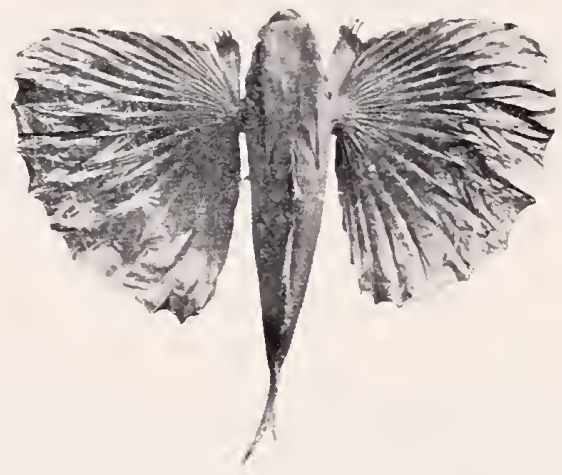

Fig. 116. Dactylopterus volitans, ein Flugfisch tropischer Meere.

15 Familien umfaßt dann die Unterordnung der Jugulares mit ihren kehlständigen Bauchflossen nnd ihrer geschlossenen Blase, denen eine Knochenstütze für das Praeoperculum fehlt. Hierhin gehören die Trachiniden, die glotzängigen Uranoscopiden, die formenreichen Blenniiden (Fig. 117), die Zoarciden und Ophidiiden.

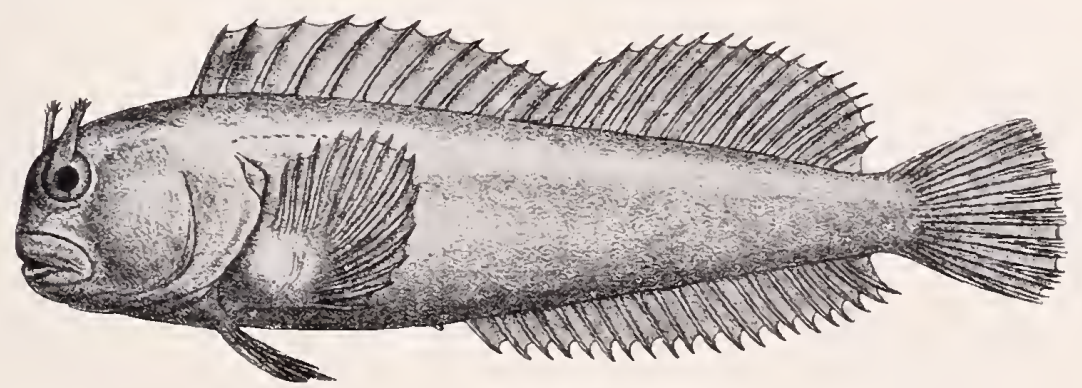

Fig. 117. Blennius sordidus Benn. (Nach Günther.) 
Eine letzte Uuterordnung der Acanthopterygii bilden noch die Taeniosomi, die zu langer Bandform gestreckt und komprimiert sind, die Trachypteriden nud die Lophotiden.

\section{3، Nebenordnung Opisthomi Cope.}

Schwimmblase geschlossen, Kiemendeckel unter der Haut, Parietalia getremnt, Schultergiurtel weit rom Schädel entfernt an der Wirbelsänle angehüngt. Bauchflossen fehlen.

Die einzige hierher gehörige Familie der Mastacembeliden stammt vermntlich von den Blenniiden ab.

\section{$3 \beta$ Nebenordnung Pediculati aut.}

Die durch ihre armartige Ausbildung der Brustflossen aufällige, in sich geschlossene Grmpue ist ausgezeichnet durch geschlossene Blase, verdecktes Operculum, getremnte Parietalia, mangelnde Rippen, mangelndes Mesocoracoid und die Verwachsuug der Kiemenspalten zu einer an

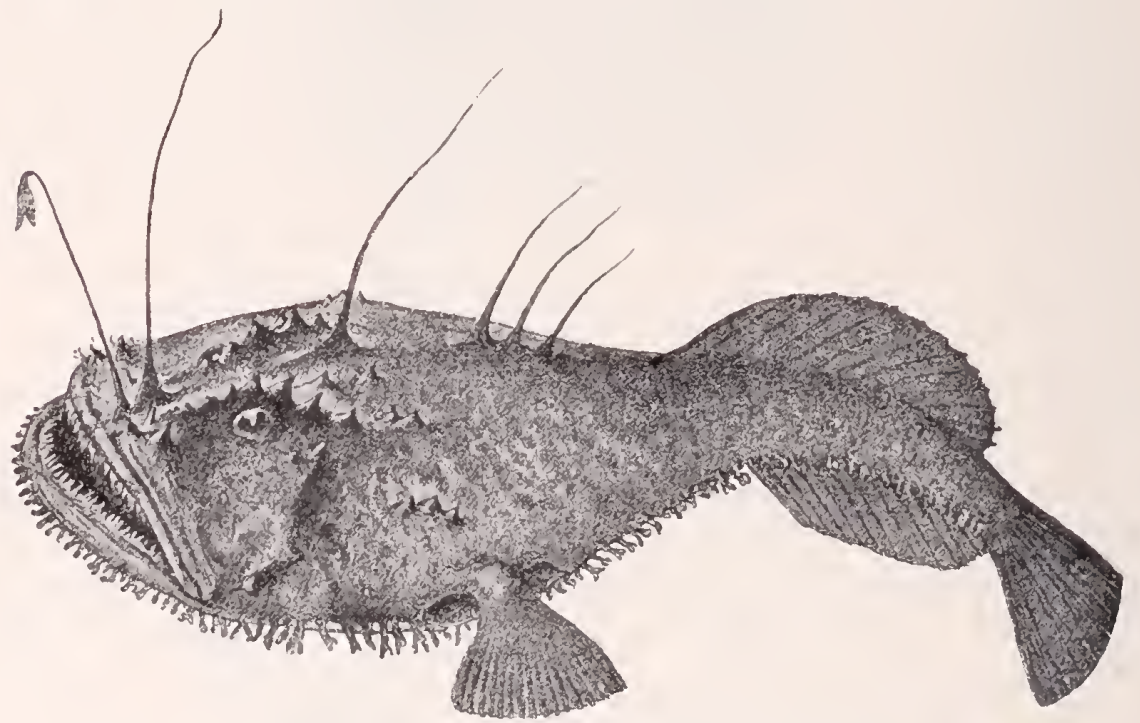

Fig. 118. Lophius piscatorius L. Küsten Europas. (Nach Renecke.)

der Brustflossenhasis gelegenen kleinen Öfnung. Die Hant eutbeht der schuppen, ist aher mit Dornen mud Stacheln bewehrt. Hirrhin gehört der hekannte Lophius (Fig. 118) und die Familien der Ceratiidae, Antemaridae, Gigantactinidae und Malthidae.

\section{3y Nehenordnung Plectognathi Cuvier.}

Absonderlich spezialisierte Nachkommen der Acanthopterygier, deren sehwimmblase ahgeschlossen ist, deren Parietalia durch die 
Supraoccipitalia getrennt sind. Maxillaria und Praemaxillaria sind meist verwachsen. Schultergïrtel am Schädel befestigt, ohne Mesocoracoid. Ventralflossen brustständig, redıziert. Hautpanzer zu festen Platten und Stacheln spezialisiert.

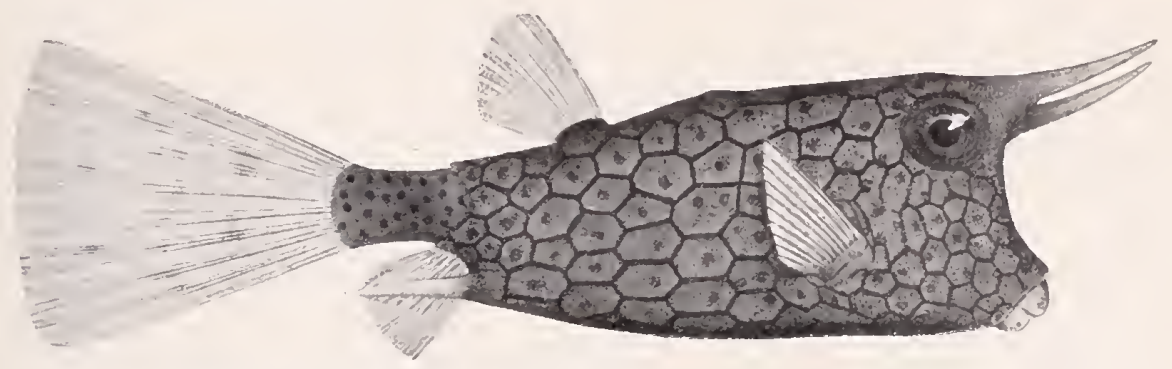

Fig. 119. Ostracion cornutus L. Atlantic. (Nach Günther.)

\section{Unterordnung Sclerodermi}

mit senkrechter Supraclavicula, und einfach stachelförmigen obereu Wirbelbögen. Hierhin gehören die Triacanthiden, Triodontiden, Balistiden und die Ostracioniden, von denen die letzteren schon im älteren Tertiär typische Vertreter aufweisen. Kiemendeckel (Opercularia) reduziert. Wirbelsäule verkïrzt. Rippen fehlen.

\section{Unterordnung Gymnodontes}

mit schräger, fast horizontaler Supraclavicula, die vorderen Wirbel mit besonders gestalteten zweispaltigen oberen Bögen. Sie umfassen die Familien der Tetrodontiden, die schon im Alttertiär gefundenen Diodontidae mit ibrem eigentümlich spezialisierten Gebiß und die sonderbare Gattung Hola, den sogenannten schwimmenden Kopf, der riesige Dimensionen erreicht. 


\section{Tetrapoda.}

\section{Hauptstamm der Oberstufe der Wirbeltiere.}

Der Name Tetrapoden ist zwar mehrfach zusammenfassend für die vierfüßigen Wirbeltiere gebraucht, aber bisher nicht zul einer systematischen Einheit gegeniiber den Fischen und T'unicaten erhoben worden. Die Berechtignng einer solchen Einheit ergibt sich ans den S. 11 nnd 14 erörterten Beziehungen der Fische zn den höheren Klassen der Wirbeltiere. So lange man die Fische als Stammformen derselben und die Amphibien als ilıren Übergang zu den typischen Landbewohnern ansah, lag zu einer Zusammenfassung der Landbewolner kein unmittelbarer Anlaß vor. Nachden wir aber die Tunicaten und Fische als Seitenstämme älterer Stufen der Wirbeltierentwicklung auffaßten, müssen wir notgedrungen die Tetrapoden anch systematisch von ilınen ablösen. Daß sie nun stanmesgeschichtlich eine Einlıeit bilden, kann wohl kaum bezweifelt werden. Dazu sind ihre morphologischen Beziehungen untereinander viel zu innige, als daß wir an ihrer gemeinsamen Abkunft zweifeln könnten. In allen ihren Organisationsverhältıissen ergaben sich gemeinsame Grundzüge, und es gibt wohl kaum eine Anlage in ihrem Körper, in dem einzelne Typen engere Bezielıungen zu den Fischtypen als $\mathrm{zn}$ den anderen Ḱlassen vierfüßiger Landtiere anfwiesen. Ans der unerschöpflichen Menge enger Beziehungen ihrer genamnten Organisation lassen sich etwa folgende Pnnkte als Definition hervorheben:

Tetrapoden sind Lungenatmer, normal mit gesondertem Kopf, Hals und Rumpf, mit axialen, in der Regel fünfzehigen GliedmaBen, mit durcligehenden Nasengängen (Choanen), paarigen Augen und echten Ohren, knöchernem Innenskelett, festem Hinterhauptsgelenk, mit der Epiphyse in der Parietalregion. Schultergïrtel verknöchert, mehrteilig, Becken primär an der Wirbelsänle (Sacrum) befestigt. Wirbelsäule deutlich in Wirbel gegliedert; jeder derselben in obere Bögen und Wirbelkörper geteilt. Rippen einfach, meist zweiköpfig. Der 
Blutkreislauf steht auf einer wesentlich höheren stufe als bei den niederen Formen. Ein Herz ist immer ausgebildet. Auch das Gehirn ist scharf ron dem Rückenmark gesondert. Das Branchialskelett bleibt dem Kopf untergeordnet.

\section{Die Gruppierung der Klassen.}

Nachdem im Anfang des 19. Jahrhunderts die Amphibien als besondere Klasse allmählich von den Reptilien getrennt waren, denen sie Linné, Cuviel u. a. noch als Ordnung eingefügt hatten, ist an den vier Klassen von Tetrapoden: Amphibia, Reptilia, Ares, Mammalia, kaum geriittelt worden, trotzdem allmählich eine große Anzahl fossiler Tetrapoden bekannt wurden, die sich in jenes System nicht recht einfügen wollten. Namentlich lernte man in Karbon, Perm und in der Trias Formen kennen, die Merkmale von Amphibien und Reptilien vereinigten. Während Burmeister 1850 diese Erkenntnis klar herrorhob, behandelten die andern die zweifelhaften Formen nur von dem Gesichtspunkt, ob man sie besser den Amphibien oder Reptilien unterordne. SchlieBlich einigte man sich darin, fast alle jene Formen den Amphibien zuzuzählen, weil man bei einigen Jugendformen ihrer Vertreter Kiemenbögen beobachtet hatte.

Innerhalb der Amphibia stellte R. Owen 1861 für jene alten Typen zwei Ordnungen auf, die er als Ganocephali und Labyrinthodonti bezeichnete. Die ersteren umfaßten sehr verschiedene paläozoische Gattungen, die letzteren jene großen Formen der Trias, die durch ihre Faltenzähne gekennzeichnet waren. Cope faßte diese und einige kleine karbonische Formen, die inzwischen ron Dawson als Microsauria beschrieben worden waren, als .,Stegocephali“ zusammen. Der Name war richtig gewählt, denn alle diese Formen waren in auffälligster Teise durch ein geschlossenes Schädeldach charakterisiert, das keinerlei Andeutungen von Durchbrïchen in der hinteren Schädelregion erkennen lieB. Von Cope und allen folgenden Autoren sind dann diese Stegocephali als Unterabteilung der Amphibien aufgefaßt nnd mit den Urodelen und Anuren als Ordnung auf eine Stufe gestellt worden.

Die speziellere Finteilung der Stegocephala durch Cope suchte dann namentlich Zittel ${ }^{1}$ ) zu bessern, der bei ihnen drei Unterordnungen, der Lepospondyli (Hiilsenwirbler), der Temnospondyli (Schnittwirbler) und der Stereospondyli (Vollwirbler) unterschied. Leider trug anch diese Einteilung nur gewissen Differenzen, nicht aber den gegenseitigen Beziehungen dieser Formen Rechnung, und alle wurden als echte Amphibien betrachtet. Daß Hermann Credner gelegentlich der Beschreibung 
der permischen Tetrapoden des Planenschen Grmndes jene Stegocephalen und einige primitive Reptiltypen als Eotetrapoda zusammenfaßte, hat eine Änderung des ganzen Systems nicht herbeigeführt, da in seinen Eotetrapoda noch heterogenere Typen zusammengefaßt waren als in Copes Stegocephalen.

Georg Banr ${ }^{1}$ ), der 1896 eine kleine phylogenetische Studie über die Stegocephalen schrieb, sagt ,The Stegocephali are rertebrates, with gills in the young stages and lungs in the adult, und are therefore placed among the Batrachia." Dieses Merkmal allein kann aber hente nicht mehr als entscheidend für diese Zıgehörigkeit gelten. Wir kennen jetzt sogar rerschiedene Batrachier, deren Entwickhng olue das Larvenstadinm der Kanlquappe und infolgedessen auch ohne Kiemenbildung vor sich geht. Mit mehr Recht legen wir wohl jetzt allgemein das Hauptgewicht auf den Ban des Schädels. Charakteristisch für die Amphibien scheinen daran namentlich eine relativ geringe Zahl von Knochen, der doppelte Condylus occipitalis, ein großes Parasplenoid, ein großer Schädeldnrchbruch in der postorbitalen Region und der Mangel dentlich ausgeprägter Epiotikalecken. AuBerdem sind dïnne Tirbel und kurze einköpfige Rippen für die Amphibien typisch.

Für die Reptilien dagegen kann als typisch gelten in Schädel der Besitz mindestens eines Paares ron Dnrchbrïchen in der Schläfeuregion, ein einfacher, in jedem Falle basioccipitaler Condyhs, ein schwaches Hervortreten der paroccipitalen schädelecke, eine schwache Ausbildung des Parasphenoids, eine reiche Entfaltung ron Knochen im Schädelban eine breite Ansbildung der Pterygoiden, ein pterygopalatinaler Gammen und eine kräftige Ausbildung aller Knochen in ganzen Skelettbant. Viele sonstige Differeuzen scheinen in ihrem phyletischen Entwicklnngsgange schwankend und deshalb in systematischer Hinsicht weniger wesentlich zu sein.

Daß rach diesen wohl allgemein anerkannten Gesichtspnnkten eine glatte Einreihnng auch nur eines einzigen der ältesten Tetrapoden in die Amphibien oder Reptilien nicht möglich war, sonderu ihre Znteilung zu einer dieser Klassen nnr dnrch einseitige Betonnng einzelner Merkmale möglich wnrde, bedarf keiner näheren Begründmmg.

Seit einer langen Reihe ron Jahren hatte ich mich bemïht, vor allem den anatomischen Ban jener älteren Formen klarer zu stellen, um für ihre stammesgeschichtliche Benrteilung eine solidere Grundlage zu gewinnen. In zwei Schriften (\%ool. Anz. 1909 nnd 1910) suchte ich die hierans gewonnenen Gesichtspunkte, die nnir für die systematische 
Beurteilung der ältesten Tetrapoden leitend schienen, zur Diskussion zu stellen. Bereichert wurde diese Darlegung durch die interessanten Funde karbonischer Tetrapoden, ron denen uns soeben B. Williston kurze Berichte gegeben hat ${ }^{1}$ ).

Den Bemühungen, die ältesten 'Tetrapoden entweder den Anplibien oder den Reptilien einzureihen, steht vor allem der Lmstand entgegen, daß sie ein geschlossenes stegales (Jkl.) Schädeldach besitzen ${ }^{2}$ ). Auch die ältesten, bestimmt ausgeprägten Reptilien lassen uns nicht in Zweifel darüber, daß sie von „Stegocephalen“, d. h. wie ich mich vorsichtiger ausdrücken will, ron Torfahren mit stegalem Schädeldach abstammen.

Ein Blick auf die im folgenden gegebenen Schädelbilder überzengt wohl zunächst davon, daß man die stegalen Formen schon wegen ihres Schädelbaues weder den Amphibien noch den Reptilien zurechnen kann. Nun war der nächstliegende Aısweg aus diesem Dilemma, alle jene älteren Fornıen nit stegalem Schädelbau als eine besondere Klasse der Tetrapoden, eben als Stegocephalia zusammenfassen. Zieht man aber die Differenzen ihres Schädelbanes und andere Organisationsverhält-

1) S. W. Williston, "The oldest known Reptile "Isodectes punctulatus" Cope. Journ. of Geology Vol. XVI. Nr. 5. 1908. Chicago. - Derselbe, Lysorophus a permian uredole. (Biol. Bull. Vol. XV. Nr. 5. Oct. 1908. p. 229.)

$\left.{ }^{2}\right)$ Gaup hat in seiner Schrift Beiträge zur Morphologie des Schädels III, Zur vergleichenden Schläfengegend am knöchernen Wirbeltierschädel. Morphol. Arbeiten, herausgegeb. v. Gust. Schwalbe, IV (1), S. 121, den Gegensatz zwischen dem geschlossenen Schädeldach eines Stegocephalen und dem mit Jochbögen konstruierten Schädeltypus der höheren Tetrapoden scharf hervorgehoben und ersteren als stegokrotaph, letzteren als zygokrotaph bezeichnet. Das sind unangenehme Wortbildungen, die namentlich in den terminologischen Kombinationen, wie "Monozygokrotaph" fast unaussprechlich werden. Das allein schreckt wohl schon ab diese Bezeichnungen zu übernehmen, indes bestimmt mich dazu auch ein sachlicher Grund. G. Baur sowohl wie E. Gaupp verwenden den Begriff des geschlossenen Schädeldaches (stegokrotaph Gaupp) ebenso für Stegocephalen wie für Schildkröten rom Typus der Chelone. Das sind aber total verschiedene Schädelbildungen. Gegenüber dem doch primär geschlossenen StegocephalenSchädel ist der der Cheloniden äußerst spezialisiert und im besonderen die Überdachung der Schläfenregion in dem vorher zygokrotaphischen Schädel lediglich durch eine kaudane Ausbreitung der Parietalia zustande gekommen. Bei diesbezüglicher Verwendnng würde der Bezeichnung stegokrotaph nur noch eine habituelle, aber keinerlei morphologische Bedeutung mehr zukommen.

Ich habe demgegenüber den Schädeltypus der Stegocephalen, bei dem die Schläfenregion vollständig durch ihre spezifischen Deckknochen überdacht ist, als "stegal", alle andern, in denen das Dach unterbrochen und zwischen diesen "Durchbrüchen" oder Gruben und Lücken, durch Joche oder Brücken gestützt ist, als "zygal" bezeichnet. Daraus ergeben sich dann die einfachen Bezeichnungen monozygal und dizygal für die beiden Hauptformen des Reptilienschädels. Wenn man für die Überdachungsart der Schläfenregion der Cheloniden eine besondere Bezeichnung für nötig hält, so könnte man dafür wohl das Wort „tegal" bilden. 
nisse in Betracht, so können wir unmöglich alle jene Formen unter einen Hut bringerr.

Daß die Stegocephalie als prinuär anzusehen ist, dafür spricht die nnverkennbare Tatsache, daß auch alle Typen von Fischschädeln von stegalen Schädeldächern ausgehen (vgl. die Schädelbilder der ältesten Fische). Ein gewisser Parallelismus in der Gliederung des Schädeldaches bei Fischen und Tetrapoden läßt sich dabei nicht übersehen. Anch bei den Fischen finden sich sehr verschiedene Gliederungsarten des stegalen Schädeldaches. Man denke dabei z. B. an das Schädeldach der Plakodermen, der Störe, der Ganoiden und der Dipnoer. Bei diesen glaube ich jetzt den Nachweis erbringen zı können, daß der primitive $A$ msgangspunkt aller dieser Schädelformen ein eiuheitliches Dach war, das erst unter dem Zng und der Spannnng der ïberdachten Kopfteile in Regionen und bestimmte Knochenplatten zerlegt wurde. Die prinzipielle Übereinstimmung in der Anlage der überdachten Kopfteile hat dann über den wichtigen und konstanteren 'Teilen bestimmte Elemente zur Selbständigkeit gebracht, während sich in andern stärkere Abweichnngen des inneren Banes anch in der Bildnng des Schädeldaches geltend machten.

Die Frage ist nun, ob nicht auch hier bei den "Stegocephalen" analoge Verhältnisse vorliegen. Ich betone, daß es sich dabei nur $\mathrm{mm}$ Analogien handehn kam, denn einen Fischschädeltypus, aus dem wir die Stegocephalen-Schädel direkt ableiten könnten, gibt es trotz G. Baurs entgegengesetzter Annahme ${ }^{1}$ ) meines Erachtens nicht. Gewisse Ähnlichkeiten, wie sie namentlich die Crossopterygier unter den älteren Ganoiden zeigen, sind doch noch lange keine Übereinstimmungen und erklären sich eben aus einer ähnlichen Einwirkung der inneren Kopfteile anf das Schädeldach und durch die prinzipielle Einheitlichkeit der Organisation des Wirbeltierkörpers. Schon der Umstand, daß das Scheitelloch bei allen Fischen in der Region der Frontalia liegt, beweist allein schon einen durchgreifenden Gegensatz in der Schädelbiłdnng der Fische und der Tetrapoden.

Ist aber das Schädeldach der ältesten Tetrapoden erst sekmndär dırch die darunter gelegenen Schädelelenente, sowie durch die Homoplasie gleichwertiger metamerer Skelettbildungen wie der oberen Bögen und der Schädeldachknochen (Nasalia, Frontahia, Parietalia, Supraoccipitalia) gegliedert worden, dann ist es begreiflich, daß wir zunächst große Differenzen in der Sondermng des stegalen Schädeldaches finden. In diesen wïrden z. T'. die Differenzen zum Ausdruck kommen, die lange

1) G. Baur, The stegocephali a phylogenetic study. Anat. Anz. XII. 22. 1896. 
vor der Differenzierung des schädeldaches in den innelen Organen, vorhanden waren. Lange getrennt entwickelte Reihen als Vorfahren der bis jetzt ältesten Tetrapoden müssen wir sowieso annehmen, da die Mannigfaltigkeit der ältesten Formen aus dem Karbon auch in andern Organisationsverhältnissen sonst keine Erklärung finden könnte.

Schon die Rücksicht auf die Mannigfaltigkeit del ältesten Schädel legt es nahe, die Stegocephalie als ein Durchgangsstadium der Schädelbildung aller Folmenreihen älterer Wirbeltiere anzusehen und den Schwerpunkt ihrer systematischen Verwertung in der spezifischen Gliederung der stegalen Schädelformen zu suchen.

Geben wir damit die Vorstellung auf, daß die Stegocephala innerbalb der Tetrapoden ein geschlossener Formenkreis seien, so gewinnen außer den Differenzen der stegalen Schädelformen vor allem die tiefgreifenden Unterschiede in der Wirbelbildung der paläozoischen Tetrapoden erhöhte Bedeutung. Schon frïhere Autoren und namentlich Zitte ${ }^{1}$ ) haben diesen Differenzen großen Wert in systematischer Hinsicht beigemessen, dieselben aber doch nicht zur Sonderung höherer Einheiten für ausreichend erachtet. Allerdings waren damals auch die ziemlich komplizierten Verhältnisse des Tirbelbaues der ältesten Tetrapoden noch nicht genügend aufgeklärt.

Wir können offenbar auch innerhalb der Tetrapoden Stufen der historischen und organisatorischen Entwicklung erkemnen. Auf der höchsten Stufe stehen unverkennbar die Säugetiere. Wir werden sie an das Ende der Entwicklung stellen müssen und die zu ihrer Organisation führende Richtung als die Hauptrichtung der Tetrapoden-Entwicklung ansehen dürfen. Ihnen stehen offenbar als ummittelbare Vorfahren voran die hier als Paratherien bezeichneten Formen, die den ältesten Reptilien so nahe stehen, daß man sie bisher sogar mit diesen vereinigte. Die Reptilien schieben sich nur mit ilıren ältesten Vertretern zwischen die Paratheria und deren Vorfahren ein, die wir hier als Miosaurier bezeichnet haben, wie ja ïberhaupt die Entwicklung zu nenen höheren Formen in der Regel nicht die ganze Stufe der nächst niederen durchläuft, sondern ron Typen derselben ausgeht, die noch in Terden begriffen sind, die ilıre Organisation noch nicht auf ein bestimmtes Verhältnis aller Teile festgelegt haben. Die Miosaurier bilden also die erste Etappe dieser Hauptrichtung, die wir damit festgelegt haben. Eine Seitenrichtung ron den Reptilien aus schlugen als Klasse die Vögel

1) K. v. Zittel: Handbuch der Paläontologie, Bd. III, S. 34 \%. 
ein; darïber ist niemand mehr im Zweifel. Das gleiche scheint mir aber anch ron den Amphibien zu gelten und wahrscheinlich anch ron den Hemispondyla. Den Ausgangspunkt der beideu letzteren kennen wir noch nicht. Der der Amphibien dürfte vielleicht bei Microsanriern liegen. Der der Hemispondylen dürfte vor der uns bekannten Entwicklungsgeschichte der Tetrapoden zu suchen sein, d. h. wir müßten nnbekannte ältere Tetrapoden als ihre Yorfahren voraussetzen. Das ergilt das folgende Bild:

Tetrapoda.

Hauptklassen

I. Stufe ? Vorklasse

II. Stufe Miosauria
Nebenklassen

I 6 Stufe Hemispondyla

IIr Stufe Amphibia

II $\beta$ Stufe Reptilia

II 32 Stufe Aves

\section{Stufe Paratheria}

IV. Stufe II ammalia

Innerhalb des Lnterstammes der Tetrapoda kennen wir wie gesagt die ältesten Vertreter noch nicht, aber schon die bis jetzt als älteste bekannten Formen nötigen zu einer Erweiterung des bisherigen Systems der Landwirbeltiere.

\section{Nebenklasse Hemispondyla Jaekel 1909.}

Als eine Klasse für sich erweisen sich zunïclıst die Formen, deren Wirbel nicht in toto, sondern in Teilstücken verknöcherten, oder in nnverknöchertem Zustande persistierten. Alle diese faßte ich als Hemispondyla nor. cl. zusammen. Ihre typischen Vertreter sind die Formen mit temnospondylem und embolomerem Wirbelbau, vor allem der bekannte Archegosaurus. An dieser Form ließen sich sämtliche Wirbelossifikationen von rorn nach hinten verfolgen und zeigen ${ }^{1}$ ), daß die T'eilstiicke der Wirbel in den rerschiedenen Körperregionen sehr verschieden ausgebildet sind und Typen der Wirbelbildung umfassen, die man früher anf Grund einzelner Beobachtungen rerschiedenen Formenkreisen als Typen zuschrieb. Die Figuren 120, A-F erläutern diese an demselben Individnum beobachteten Differenzen. Typisch für diese Wirbelbildung ist die Znsammensetzung ans zwei Abschnitten, einem vorderen, eimheitlichen, dessen Ossifikationszentrum

1) Jaekel, Über die Organisation von Archegosaurus Zeitschrift d. deutsch. geol. Gesellsch. 1896. Heft 3. S. 511. 
basal gelegen ist, dem "Hypozentrum" Gaudrys, und einem hinteren Abschnitt, in dem jederseits zwei dorsal "gelegene Ossifikationszentren ("Plenızentra“) typisch sind, aber im hinteren Teil des Körpers jederseits in ein oberes und ein unteres Stück zerfallen (Fig. 120, D). Im hinteren Teil des Schwanzes nnterbleibt die Ossifikation dieser hinteren Stïcke bereits in einer Region, wo die vorderen Hypozentra noch zwei schwache basale Ossifikationen anfweisen (Fig. 120, F). Weiter hinten kommen anch diese nicht mehr zur Ansbildung, sodaß hier die Chorda ohne Ossifikation blieb.

Während bei Formen wie Acanthostoma und den Branchiosauren die Chorda fast in ganzer Länge auf diesem Stadium persistierte, verstärkte sich bei andern die Verknöcherung der Hypozentra, so daß die
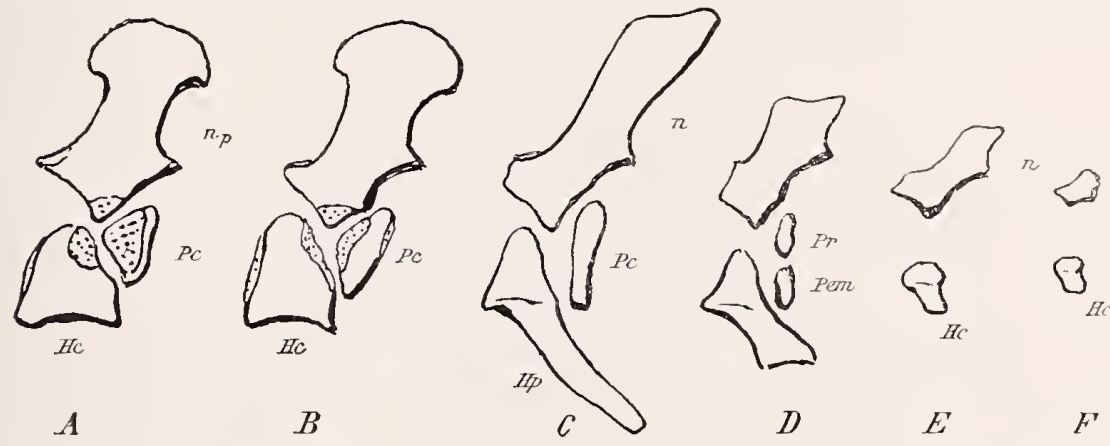

Fig. 120. Die hemispondylen Wirbelformen von Archegosaurus decheni Goldf. aus dem unteren Perm von Lebach bei Saarbrücken. Rekonstruiert. Die beiden ersten sind Rumpf-, die folgenden Schwanzwirbel. Hc, Hypozentrum; Pc, Pleurozentren; $n p, n$, Neurapophysen; Hp, Hämapophysen. (Nach Jaekel.)

Pleurozentren wenigstens innerhalb der Rumpfregion an den Oberrand der Chordascheide verdrängt werden und hier als kleine keilförmige Stücke verkümmerten. Es sind das Formen, die man bisher als Stereospondyli oder Vollwirbler bezeichnete, und deren Hypozentrum man irrtümlich für den normalen Wirbelkörper hielt, während es nur deren vorderen Abschnitt vorstellt. Die hemispondyle Wirbelbildung steht, wie ich an anderer Stelle ${ }^{1}$ ) erlänterte, mit der embryonalen Wirbelbildung von Sphenodon in inniger ataristischer Beziehung, bietet aber doch in ihrer ganzen phylogenetischen Selbständigkeit und ihrer später ansgeprägten eigenartigen Weiterentwicklung (der sogenannten Stereospondyli) keinen Konnex mit der normalen Wirbelausbildung der ïbrigen Tetrapoden. Schon ihre Wirbelbildung bedingt also die Selbständigkeit

1) Über die Pildung der ersten Halswirbel und die Wirbelbildung im allgemeinen.

Juli. Protokoll d. deutsch. geol. Ges. Bd, 56. 1904. S. 109. 
dieser Klasse, die in der Trias mit den Riesenformen der sogenannten Labyrinthodonten ihren Kulminationspmnkt und zugleich auch ihr Ende erreichte.

Definition: siißwasserbewohnende, vermutlich rückgebildete, Salamander oder krokodilförmige Tetrapoden mit kmrzem Hals, zwei schwach gebanten Schreitbeinen, deren rorderes (wohl primär) 4, deren hinteres 5 Zehen aufweist, mit komprimiertem, mäßig langem Rnderschwanz. Wirbelkörper aus Hypozentrmm nnd 2 Pleurozentren gebildet, die aber rielfach knorpelig persistierten. Schädel in der Regel stegal, hei kräftiger

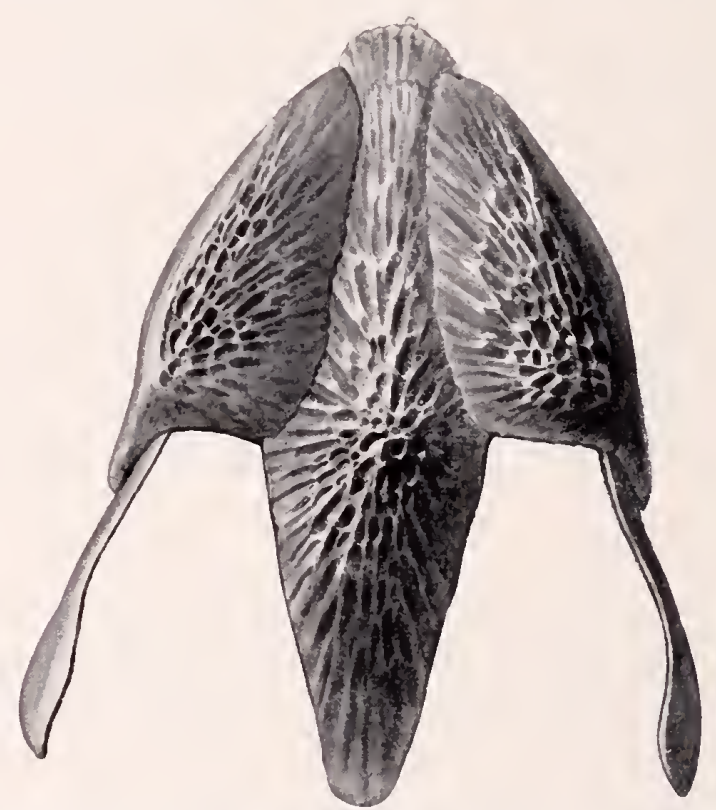

Fig. 121. Schultergürtel von Archegosaurus decheni Goldf. In der Mitte die Interclavicula, vorn beiderseits die Claviculae, dahinter seitlich die löffelförmigen Cleithra, den AuBenrand der dreieckigen Scapularia bedeckend. Unteres Perm von Lebach bei Saarbrücken. Größe etwa $1 / 2$.

Verknöchernng mit Tremalkanälen, in der Schläfenregion mit allen bei Tetrapoden vorkommenden Deckknochen, nur ansnahmsweise mit einem Durchbruch in der oberen Schläfenregion. Zähne kegelförmig, an der Basis gefaltet, auf den Vomera, Palatina nnd Transversa eine innere Zahnreihe bildend. Gaumen craniopalatin, mit schmalem Parasphenoid, großen Gammendurchbrüchen, vorn gelegenen Choanen und Intermaxillargruben. Condyli occipitales seitlich gestellt, frei vorragend, lä̈nfig unverknöchert. Rippen einköpfig, Bauchrippen schmppig, große Schuppen bisweilen ïher die ganze Haut verteilt. Claviculae und Interclavicula sehr große skmlpturierte Platten bildend; Cleithra löffelförmig; Scapulare 
breit, Coracoid in der Regel knorpelig. Becken meist mit knorpeligen Ossa pubis und schlankem Ilium an einer Sacralrippe aufgehängt. Lebensdauer voln Karbon bis zur oberen Trias.

In der Gruppierung der Formenkreise wird man die Branchiosauriden zwar hinsichtlich ihrer Organisationshöhe auf die niederste Stufe stellen miüssen, man wird sie aber schon wegen ilırer Dekadenz nicht an den Ausgangspunkt der übrigen stellen können. Ihre landbewohnenden Vorfahren müssen schon in der Fuß- und Wirbelbildung eine wesentlich straffere Organisation besessen haben. Mir scheint, daß wir den relatir kleinen Formenkreis am richtigsten in folgender Weise gliedern können:

1. Stufe mit breiten flachen Schädeln, großen Augenhöhlen, kurzer Nasalregion, ausgebreiteter Interclavicula, mäßig langem Schwanz, Körper ganz mit großen, dünnen, radial skulpturierten Schuppen bedeckt.

\section{I c Nebenordnung Branchiosauri.}

Salamanderähnliche, meist kleine Süßwasserbewohner mit breitem, flachen, stegalem Schädeldach mit sehr großen Orbitae, relativ großem Parasphenoid, breiter, gernndeter Interclaricula, mit schwacher Wirbelrerknöcherung, schwach entwickelten Füßen, komprimiertem Rnderschwanz, schuppiger Haut. Zehenformel 2.2.3.3 bezw. 2.2.3.4.3.

Hierhin rechne ich:

Familie Branchiosauridae, klein mit halbkreisförmigem, glattem Schädeldach, unverknöcherten Wirbelstiicken, Karbon Nordamerika und Perm Europa (Apateon - Protriton - Branchiosaurus, Pelosaurns).

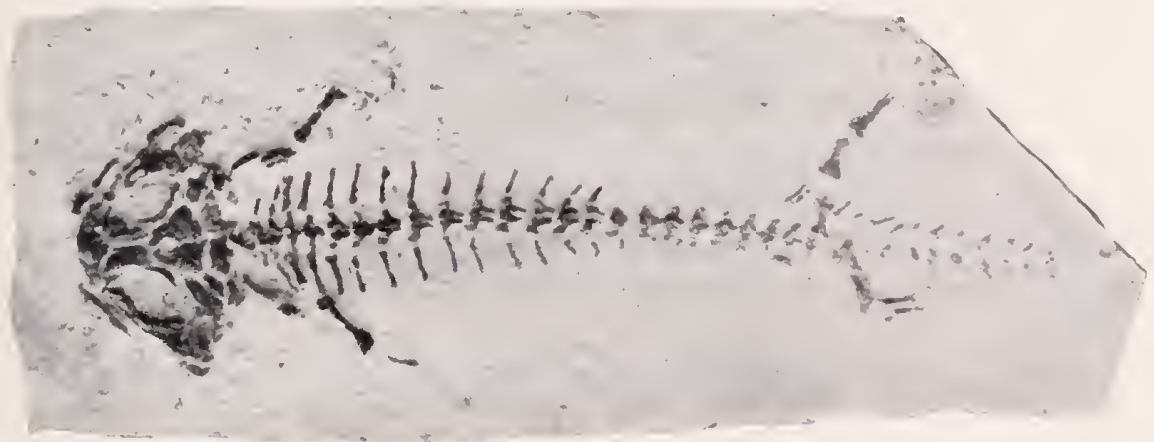

Fig. 122. Apateon pedestris H. v. Meyer. Ein Branchiosauride aus dem unteren Perm von Odershausen in der Pfalz. 3/2. Rückenseite.

\section{If Nebenordnung Plagiosterni.}

In der oberen Trias Württembergs entdeckte Eb. Fraas kürzlich einen nenen Typus mit sehr breitem halbkreisförmigen Schädel, der in 
seinem Bau den Sclerocephalen ziemlich fremdartig gegeniibersteht und sich wohl am besten als spezialisierter Nachkomme primitiver Vertreter der ersten Stmfe auffassen läßt.

Große Vierfüßler mit sehr breitem Kopf, vorn gelegenen Nasen und Augen, mit breiter Basis des Parasphenoids mud geschlossener innerer Zahnreihe auf Vomer, Palatina und Transversa. Condyli verknöchert. Claviculae und Interclaviculae sehr verbreitert. Keuper Stuttgarts.

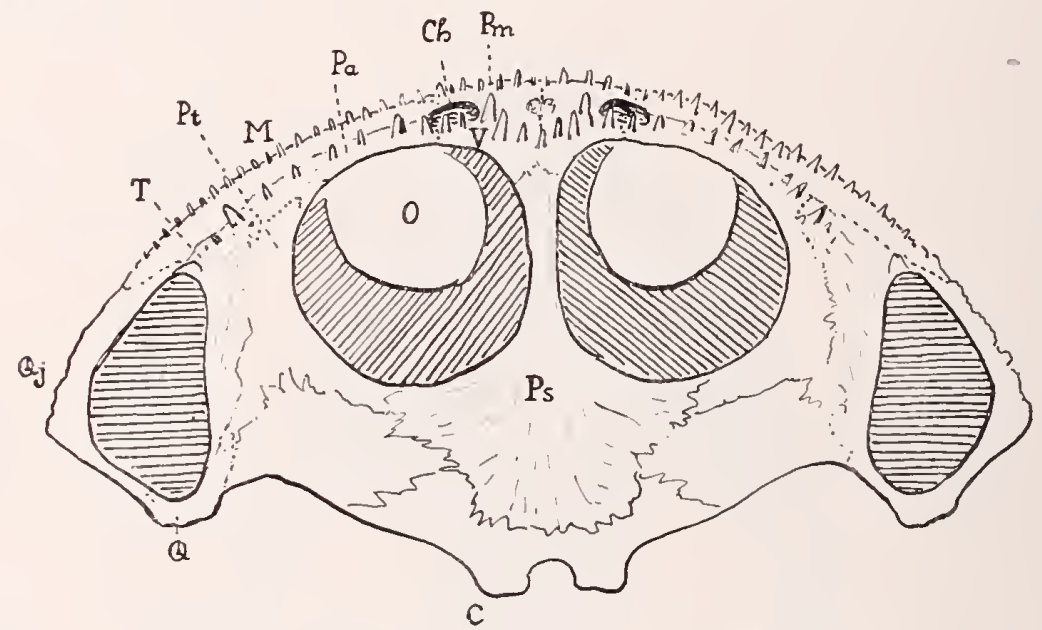

Fig. 123. Gaumeufläche des Schädels von Plagiosternum. Mittlerer Keuper Württembergs. Nach dem Original im Stuttgarter Naturalien-Kabinett mit freundlicher Erlaubnis von Prof. Eb. Fraas in 1/3 nat. Größe gezeichnet. Pm Praemaxillen, Ch Choanen, $V$ Tomer, Pa Palatina, $I$ Maxillare, Pt Pterygoidea, $T$ Transversa, $O$ Orbita, $Q j$ Quadratojugale, $Q$ Quadratum mit Kiefergelenk, Ps Parasphenoid, $C$ Condyli.

2. Stufe. Stattliche Formen mit großem, kräftig radial skulpturierten, vorn verjüngtem Schädel, mit mäßig großen. Augenhöhlen, relativ kleinem Parasphenoid nnd rhombischer Interclaricula. Wirbelkörper aus einem vorderen basalen Hypozentrum und zwei dorsalen hinteren Pleurozentren mindestens in der Hals- und Rumpfregion kräftig verkinöchert.

\section{Hauptordnung Sclerocephali.}

Krokodilförmige, meist ziemlich große Süßwasserbewohner mit kräftig skulpturiertem, stegalem, vorn verjüngtem Schädeldach mit mäßig großen oder kleinen Orbita, schmalem Parasphenoid, rhombischer Interclavicnla, skulpturierten Claviculae, schmalen Cleithra mit blattförmigen Gastralien (sogenannten Bauchrippen) mit stark gefalteten „labyrinthodonten" Zälmen, mit verknöcherten Wirbelteilen, kräftigem Ruderschíanz, mäßig kräftigen Schreitbeinen mit kurzem breitem Humerus, ziemlich 
schlankem Femur mit freien spitz endenden Zehen und soweit bekannt der Phalangenformel rorn 2.3.4.?, hinten 2.3.4.5.4.

Familie Sclerocephalidae mit vorn verjüngtem Schädeldach, längeren Zahnreihen auf den inneren Kieferknochen, mit offenem Ohrausschnitt, halbringförmigen Hypozentren und wohlentwickelten Pleurozentren mit

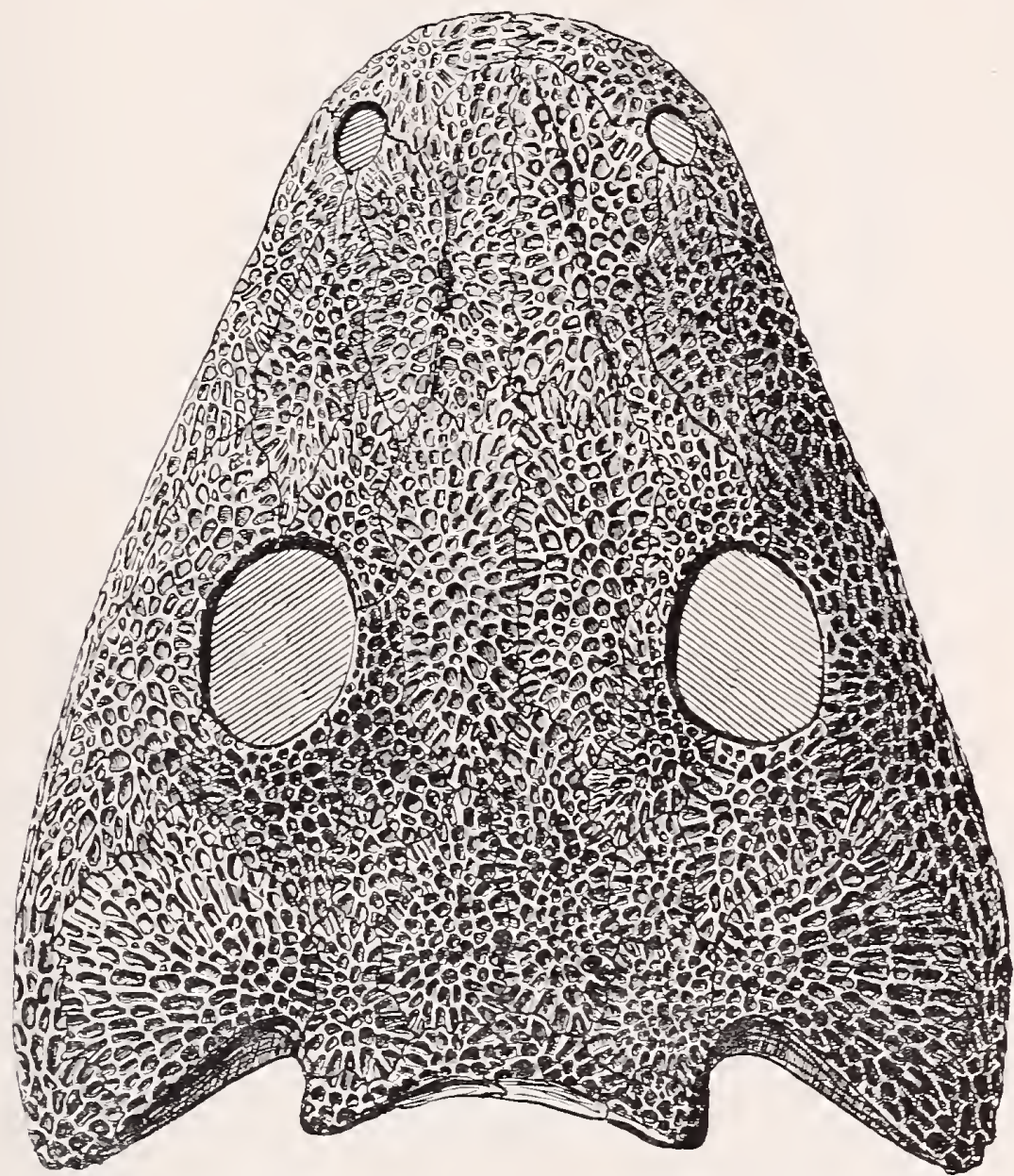

Fig. 124. Schädeldach eines Hemispondylen (rgl. Chelydosaurus vranii Fritsch) aus dem obersten Karbon (Gaskohle) von Nürschan, Böhmen. 1/2 nat. Größe.

unverknöcherten Coracoiden und Ossa pubis. Anthracosaurus im Karbon, im Perm: Sclerocephalus Goldf., Chelydosaurus, Archegosaurus. Hierher die Familie der Wicropholidae in Südafrika, die Cochleosauridae, die Eryopidae in Texas, wie obige, aber groB, mit dickem Schädel, je einem Zahn auf den inmeren Kieferknochen, mit stark ossifizierten Schulter- und Beckenknochen, normal verknöcherten Wirbelteilen. Erỵops 
im Perm ron Texas. Hierher ferner die Riesenformen der Trias, die wegen ihrer komplizierten Zühne als Lybyrinthodonten znsammengefaßt
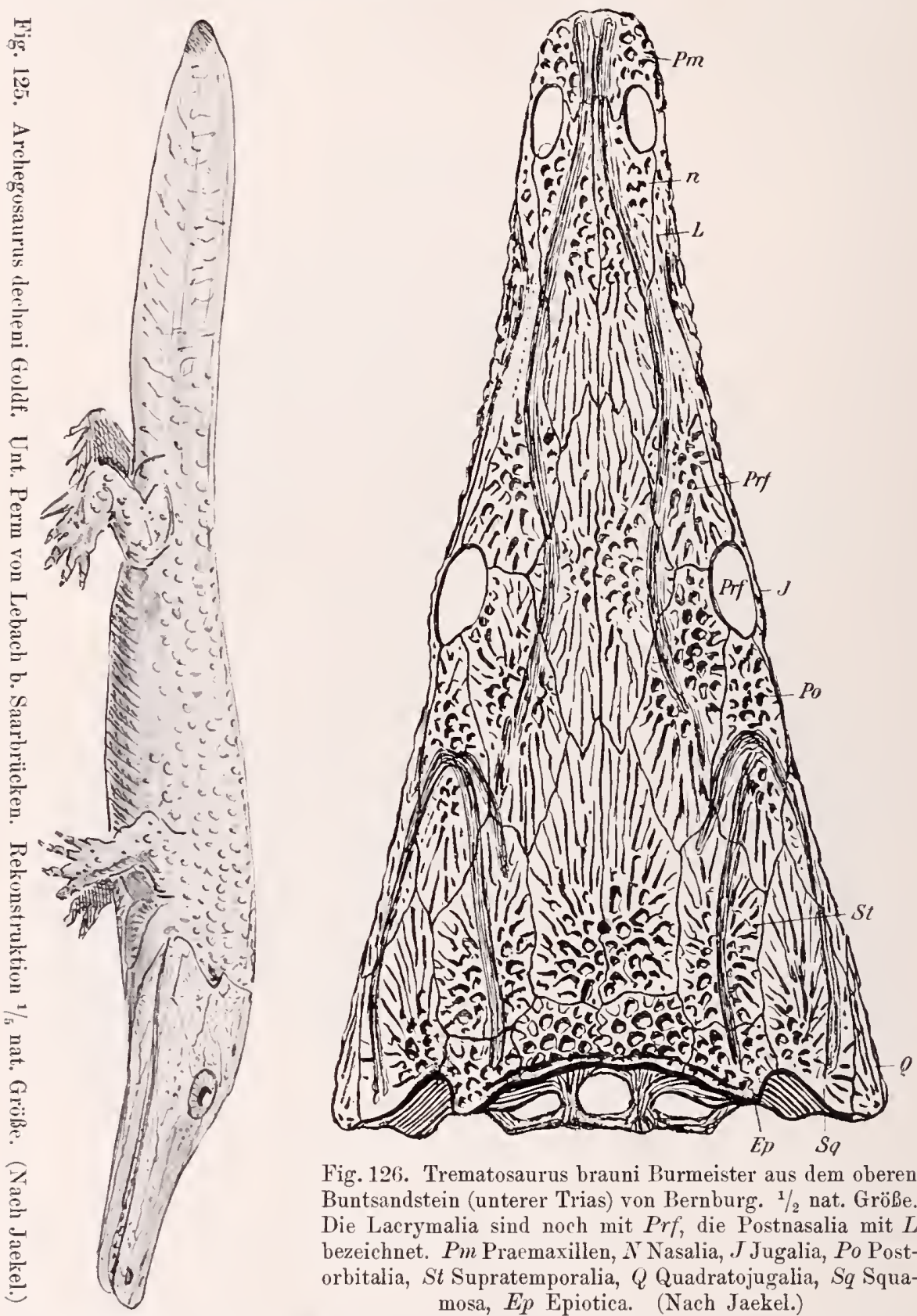

Fig. 126. Trematosaurus brauni Burmeister aus dem oberen Buntsandstein (unterer Trias) von Bernburg. 1/2 nat. Größe. Die Lacrymalia sind noch mit Prf, die Postnasalia mit $L$ bezeichnet. $P m$ Praemaxillen, $N$ Nasalia, J Jugalia, $P o$ Postorbitalia, St Supratemporalia, $Q$ Quadratojugalia, $S q$ Squamosa, Ep Epiotica. (Nach Jaekel.)

wmrden, nnd zwar die Metopiadae mit dem riesigen Metopias diagnosticus des wiirttembergischen Keupers, die Capitosauridae mit flachem Schädel, 


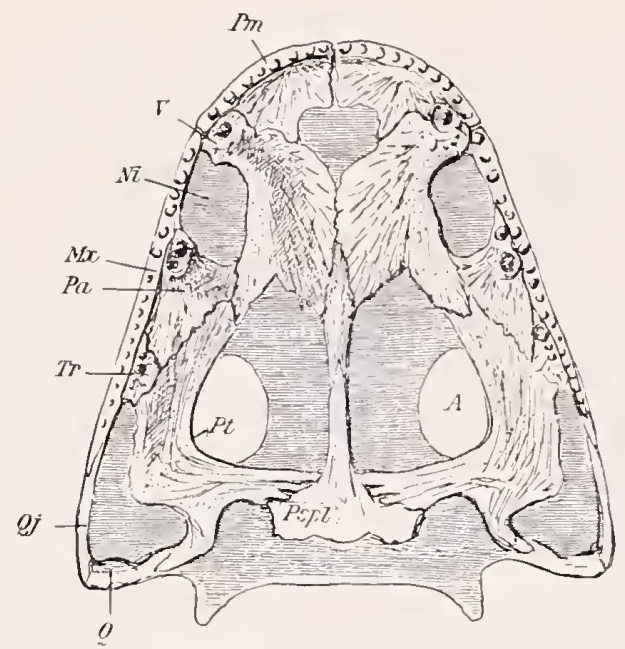

Fig. 127. Gaumenfläche von Acanthostoma vorax Cred. Größe $2 / 3$ (nach Jaekel). Pm, Prämaxillen; V, Vomer; Ni, Choanen; $M x$, Maxillaria; $P a$, Palatina; Tr, Transversa; $P t$, Pterygoidea; $Q j$, Quadratojugalia; $Q$, Quadrata und Kiefergelenk; Psph, Parasphenoid.

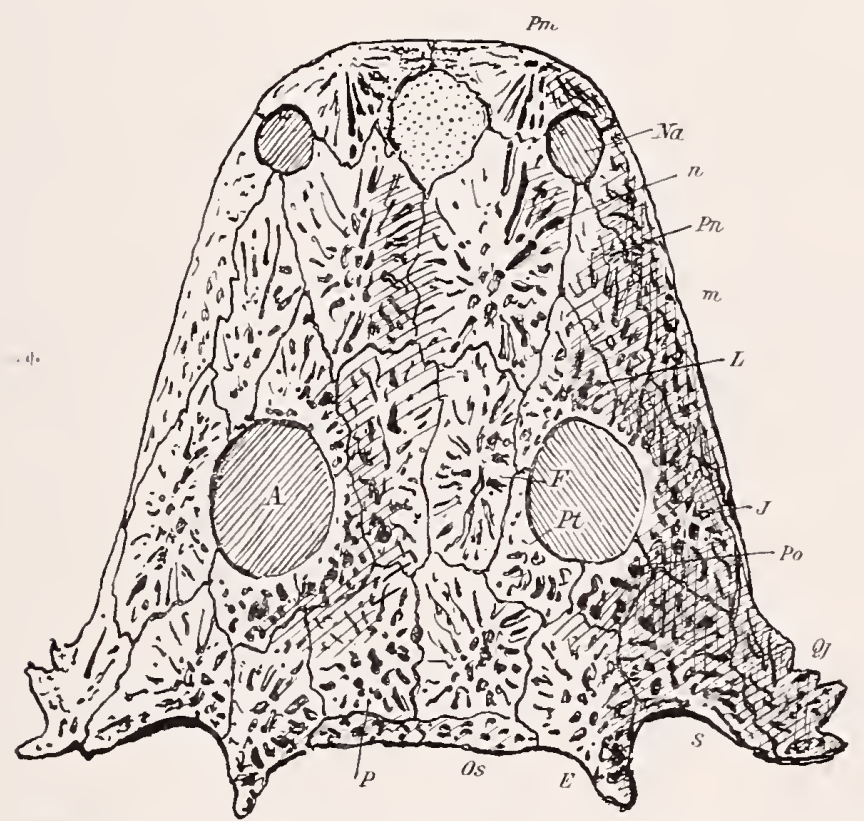

Fig. 128. Schädeldach von Acanthostoma vorax Cred. Nat. Größe. Unteres Perm von Nieder-Häßlich b. Dresden. Orig. Geol. Pal. Inst. Leipzig. Na Nasenöffnungen, Pm Praemaxillaria, $M$ Naxillaria, $N$ Nasalia, L Lacrymalia, Pn Postnasalia, $F$ Frontalia, Pt Postfrontalia, Po Postorbitalia, J Jugalia, $P$ Parietalia, St Supratemporalia, Os Supraoccipitalia, S Squamosa, Qj Quadratojugalia. 
weit zuriickliegenden kleinen Augen, und der Tendenz den Ohreingang durch Verlängerung der Epiotikalecken zu nmwachsen. Hypozentra groß, die Chorda dorsal umfassend, Pleurozentra reduziert. Interclavicula breit. Innere Zahnreihen normal ausgebildet. Capitosanrus im Buntsandstein und Cyclotosanrus in Keuper.

\section{II $\bullet$ Nebenordnung † Acanthostomi in.}

Schädel kräftig, vorn verjüngt, hinten aufgewölbt, mit mäßig großen Angenhöhlen, großer Präfrontallücke, und großer Vomerlücke, großen Palatina nnd wohl ausgebildeten Transversa. Die Gaumenknochen tragen wenige innere Zähne am Kieferrand. Hierhin gehört als Typus Acanthostoma (Fig. 127 u. 128), fermer Dasyceps in englischen Karbon.

3. Stufe. Schädel kräftig, im hinteren Teil vorgewölbt mit einem eigenartigen Schläfendurchbruch.

\section{Hauptordnung †'Trematocephali.}

Krokodilähnliche Formen mit kräftig skulpturiertem vorn verjüngtem hinten aufgewölbtem Schädeldach, das in der Schläfenregion jederseits einen einfachen Durchbruch aufweist. Es ist sehr bemerkenswert, daß sich auch innerhalb dieser typischen Hemispondylen ein Schläfendurchbruch einstellte, daß er aber offenbar in ganz anderer Weise erfolgte als bei den Paratheria und Säugetieren. Schrittbeine ziemlich kräftig. Bisher nur einige Formen im Perm von Texas durch Williston beschrieben.

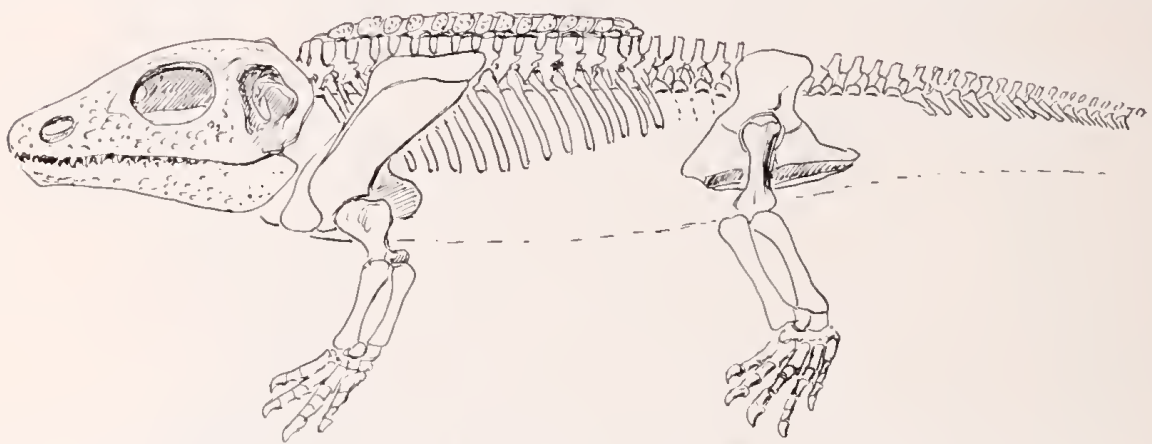

Fig. 129. ('acops aspidophorus Will. Skelett nach Willistons Abbildung gezeichnet. $1 / 4^{\text {. }}$ Perm von Texas.

Das phylogenetische Verhältnis der Hemispondylen ist nicht leicht zn bemrteilen. Wären sie die ältesten Tetrapoden, so würde man sie wohl als deren ursprünglichste Vertreter ansehen müssen. Das ist aber nicht der Fall, da ihnen die Mehrzahl der Microsaurier im Karbon vorangeht, und sie erst im Perm weitere Verbreitung erlangen. Thre 
zweifellos sekundäre Anpassung an das Wasserleben erklärt einen großen Teil ihrer niederen Organisation und läßt diese und namentlich auch die Hemispondylie, die sekundär auch bei Ganoiden auftrat, als epistatische Hemmungen ontogenetischer Bildungsprozesse erscheinen.

Bei dieser Auffassung läßt sich auch die stammesgeschichtliche Aufeinanderfolge ihrer Formenkreise an leichtesten verstehen. Die Branchiosauriden, die mit einer einzigen Form schon im Karbon von Ohio auftraten, wären die zunächst am stärksten gehemmten Typen, während durch unmittelbare Anpassung an das Wasserleben die kräftigeren Formen, die in der jüngeren Trias mit fast meterlangen Schädeln riesige Dimensionen erlangten, während die Trematocephali mit ihrem Schläfendurchbruch auf eigenem Entwicklungswege die höchste Organisationsstufe erreichten. Als Vorfahren anderer Tetrapoden können die Hemispondyla schon wegen ihrer Wirbelbildung nicht in Betracht kommen.

Alle übrigen Tetrapoden haben einheitlich ossifizierte, also vollständige "holospondyle" Wirbelkörper, in denen die beiden primären Urwirbelstücke zu einer neuen Einheit miteinander verschmolzen sind; sie bilden auch darin eine höhere Stufe der Wirbeltierentwicklung.

\section{II. † Miosauria nom. nov.}

Hauptklasse der zweiten Stnfe.

Die Notwendigkeit, die Stegocephalen mit vollständigen „holospondylen" Wirbeln einerseits von den Hemispondyla, andererseits von den Amphibia und Reptilia abzulösen, fülurte mich dazu, den von Dawson als Microsaurier bezeichneten Formenkreis zum Range einer Klasse zu erheben. (Zool. Anz. 1909 S. 209.) Nachdem nun aber dieser Sammelpunkt für indifferente alte Tetrapodentypen geschaffen ist, die sich noch nach keiner der späteren stammesgeschichtlichen Richtungen festgelegt haben, wird es sehr schwierig, sie systematisch und diagnostisch von denjenigen Formen abzulösen, die eine gewisse Spezialisierung im Sinne der Reptilien, Paratherien oder Amphibien erfahren haben, aber in ihren wesentlichen Eigenschaften und diagnostischen Kennzeichen doch noch dem Typus der Microsauria angehören. Es sind das vor allem die Cotylosanrier und einige vereinzelte Typen, die teils den Reptilien, teils den Amphibien zugezählt werden.

Nun wäre der einfachste Ausweg, diese als Unterabteilungen der Klasse der Microsauria einzureihen, aber das scheint aus zwei Gründen untunlich. Erstens sind diese Formen z. T. so groß geworden, daß der Name Microsauria nicht mehr für sie paßt, und zweitens ist dieser Kreis 
ron Dawson, seinem Begrinder, eben erheblich enger gefaßt und auf die Formen beschränkt worden, die auch von mir als Microsaurier bezeichnet wnrden. Es erscheint hiernach doch richtiger, die Microsaurier in bisherigen sinne zn belassen, sie aber als Unterklasse aufznfassen nnd sie mit einer zweiten Unterklasse, den Cotylosania, in eine Klasse zu vereinigen. Für diese wäre der Name Miosanria geeignet, da bei ihren Tertretern die Samiercharaktere noch nicht ansgeprägt sind, sie also eine Vorstufe zu den höheren Formenkreisen bilden. Dnrch die Ablösung der Cotylosauria von den Reptilien und Paratherien gewinnen diese sehr viel an systematischer Schärfe.

Fiur die Miosamria als Klasse ergibt sich mun folgende Definition: Kurzhalsige, shwerfällige, vierfüBige oder fußlose Kriechoder Schwimmtiere mit stegalem Schädeldach, einfachem, meist schwach bezalntem Gaumen, indifferenten acrodonten Kegelzähnen am Kieferrand, doppelten oderdreiteiligen Hinterhautsgelenken, meluteilig zusammengesetztem Unterkiefer. Wirbel holospondyl und diplocoel, mit kräftigen Querfortsätzen nud wohl ausgebildeten Rippen im ganzen Bereich des Halses mnd Rmmpfes. Fiiße kurz, schwerfällig, mit noch unbestimmter Zehenformel. Schultergürel mit wohl ausgebildeten Deckknochen. Ein bis zwei Sacralwirbel dienen znl Befestigung des Beckens. Als Hantskelett ist z. T. noch ein gleichmäßiges dïnnes šchuppenkleid vorhanden, hei höheren Formen kommen gröBere aber veleinzelte Bnckel in der Haut nnd Gastralia vor. Terbreitet im Karbon, Perm nnd in der Trias.

Dieser Kreis holospondyler, stegocephaler Tetrapoden ist immer noch so formenreich, daß vielleicht später seine weitere Zerlegung notwendig werden wird. Bei nnsrer noch recht nangelhaften Kenntnis ihres Skelettbaues scheint mir aber schon ein wesentlicher Fortschritt darin zu liegen, daß wir seine Tertreter klar von den Hemispondyla, den Reptilia nud den Amphibia loslösen. Es gehören hierher zunächst ältere Formen ans dem produktiven Oberkarbon von Ohio, Irland und aus der sogenannten Gaskohle von Nïrschan in Böhmen. Die von Linton in Olino sind von Edw. Cope ${ }^{1}$ ), die von Kilkenny in Irland von Huxley ${ }^{2}$ ) und die ans Bölnmen von Ant. Fritsch ${ }^{3}$ ) monographiseh bearbeitet worden. Ihr Erhaltungszustand muß als änßerst giinstig be-

1) Edw. D. Cope: Synopsis of the extinct Batrachia from the coal measures. (Rep. Geol. Survey of Ohio. Vol. II. Columbus 1875. p. 349).

2) Th. Huxley: Description of Vertebrate-Remains from the Jarrow Colliery, Kilkenny. Transact. R. Irish Acad. Dublin 1866.

3) Ant. Fritseh: Die Fauna der Gaskohle und der Kalksteine der Permformation Böhmens. Prag 1883 u. folg. 
zeichnet werden, da in der Regel rollständige Skelette rorliegen. Leider waren namentlich in älterer Zeit die Präparations- und Cntersuchungsmethoden in der Paläontologie noch zu mangelhaft, $11 m$ eine endgültige Klarstellung des zumeist recht fremdartigen Skelettbaues zu ermöglichen. Für die jüngeren und spezialisierten Formen kommen wesentlich die Arbeiten ron Cope, F. Broili ${ }^{1}$ ), Jaekel ${ }^{2}$ ), S. Williston über die nordamerikanischen, die ron H. G. Seele $y^{3}$ ) und E. F. Newton ${ }^{4}$ ) über die englischen, und die ron F. r. Huene ${ }^{5}$ ) über die zentraleuropäischen Formell in Betracht.

\section{Stufe. Unterklasse Microsauria Dawson.}

(Lepospondyli Zittel, Holospondyli Jkl.)

Kleine kurzhalsige, Land oder SüBwasser bewohnende, Eidechsen oder schlangenartige Tetrapoden mit stegalen, rerschieden zusammengesetztem Schädeldach. diplocölen ${ }^{6}$ ) Mirbelkörpern. Wohl entwickelten Zrgapophrsen und Querfortsätzen, meist zweiköpfigen Rippen. Extremitäten zum Teil als LauffüBe wohl rerknöchert, zum Teil rückgebildet oder ganz fehlend. Historische Terbreitung in Karbon und Perm.

Der ron Zittel gegebene Sanie Lepospondsla bedentet Hülsenwirbel, besagt aber damit nichts Tesentliches und Charakteristisches für diesen Kreis, insofern auch bei Amphibien ähnliche dünne Hülsenwirbel rorkommen und die spezialisierterer Microsaurier nicht mehr als hiilsenförmig bezeichnet werden können. Der ron mir im Kolleg gebrauchte und ron Herrn K. Schwarz auch in der Literatur eingeführte ${ }^{\top}$, Name Holospondyla bedentet nur einen Gegensatz zn den Hemispondyla

1) Ferd. Broili: Permische Stegocephalen und Peptilien aus Texas (Paläont. LI). Stuttgart 1904 .

2) O. Jaekel: L̈ber Ceraterpeton, Diceratosaurus und Diplocaulus (Yeues Jahrb. f. Mineral. 1903, I, S. 109).

3) H. G. Seeley: Pareiasaurus bombideus (Owen) and the significance of its affinities to amphibians, reptiles and mammals. Phil. Transact. Roy. Soc. London 1888 und 1891.

${ }^{7}$ E. T. Newton: On some Reptiles from the Elginsandstone. Phil. Transact. Roy. Soc. London 1893.

5) F. v. Huene: Übersicht über die Reptilien der europäischen Trias. (Paläontograph.) Jena 1902.

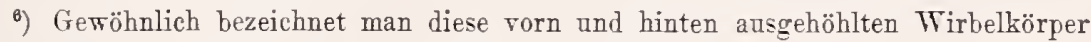
als „amphicöl“. Amphi bezieht sich aber auf den Umfang, amphicöl könnte also nur die seitliche Einbuchtung von Wirbelkörpern bedeuten.

i) Hugo Schwarz: Über die Wirbelsäule und die Rippen holospondฐler Stegocephalen (Lepospondyli Zitt.). Beitr. z. Paläont. and Geolog. Österreich-Lngarns und des Orients. Wien 1908. Bd. XXI. S. 63. 
und hatte nur Sinn, solange diese Abteilnngen immerhalb der Stegocephala unterschieden wurden. Der Name Microsamia, den Dawson allerdings nur für einen 'Teil dieser Formen gebranchte, deutet wenigstens ein sehr charakteristisches Merkmal, die geringe Größe dieser ältesten Tetrapoden an.

Die Microsaurier stellen nur eine kurze, schnell ausgestorbene Entwicklungsreihe dar, von der sich allerdings einige Typen als Nebenordnungen separierten.

In die Hauptreihe gehören offenbar die landbewohnenden vierfüßigen, salamander- oder eidechsenartigen alten Haplosauri, während sich die zum Schwimmen aptierten Urosauri, die schlangenförnigen Aistopodi und die breitköpfigen Nectridei ziemlich weit von dem normalen Typus entfernt haben und selbständige Nebenordnungen bilden.

\section{Hauptordnung Haplosauri in.}

Salamander- oder eidechsenartige Formen mit vier als Geh- oder Schwimmfüßen ausgebildeten fünfzehigen Extremitäten, mit dreieckigem Kopf, kurzem Hals, langem Rumpf, langem, einfach skelettierten Schwanz, langen zweiköpfigen Rippen.

Hierher gehören als Familien die Hylononridae und die Microbrachidae (einschlieBlich Limnerpeton). (Fig. 130 1. 131.)

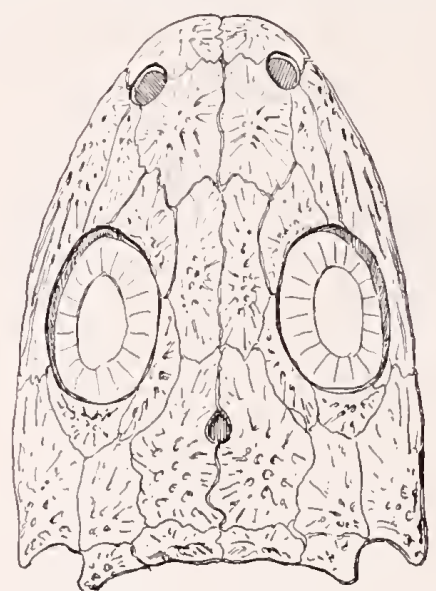

Fig. 130. Schädel eines sehr primitiven. Haplosauriers aus den unterpermischen Sübwasserkalken von Niederhäßlich bei Dresden. $2 / 1$.

I $\alpha$ Nebenordnung Urosauri in.

Schlanke eidechsenartige Formen mit langem, seitlich komprimiertem kräftig skelettierten Ruderschwanz. Füße zum Teil rückgebildet. Hierher gehören als Repräsentanten selbständiger Unterordnungen die Scincosanridae mit Sauravus (Fig. 132), Urocordylidae und Ophiderpetondidae. 


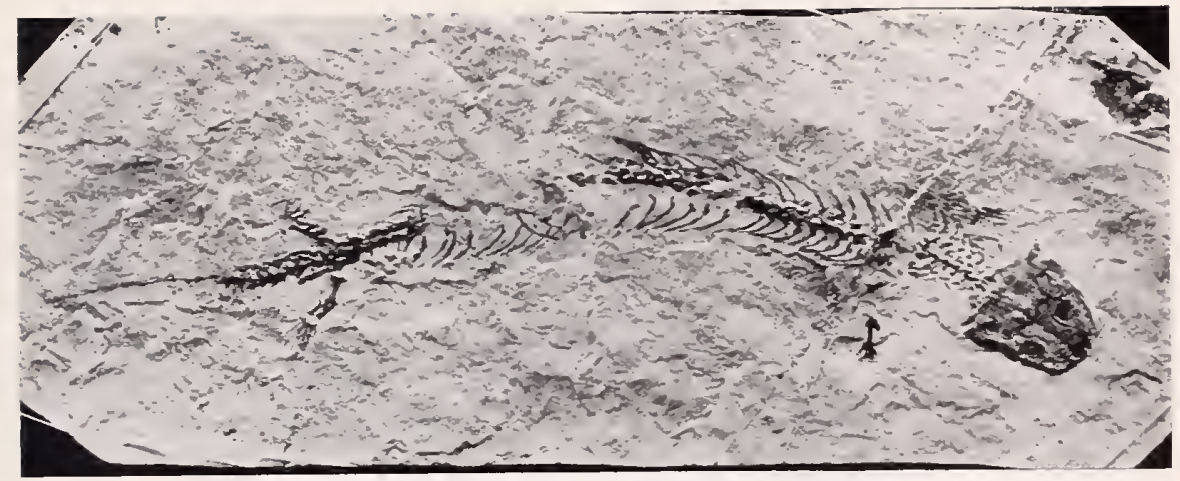

Fig. 131. Microbrachis pelecani Fritsch. Nat. Größe. Schädel etwas breit gedrückt, mit deutlichen Augenhöhlen, sehr kleinen Vorderbeinen am 8. Wirbel bei $\rightarrow$, und unverknöchrten Schwanzwirbeln. Oberstes Karbon. Nürschan, Böhmen. (Orig. Museum Berlin.)

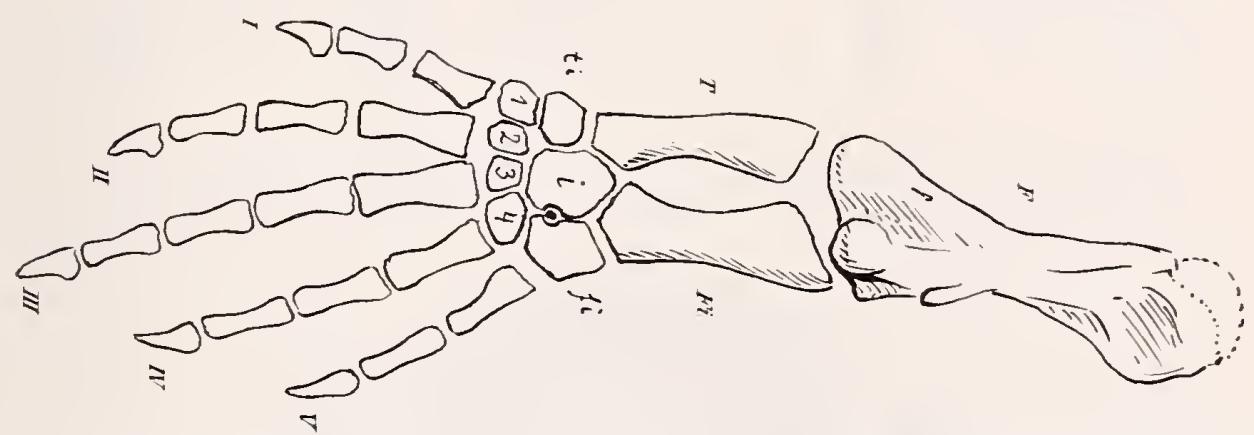

Fig. 132. Linker Fuf von Scincosaurus crassus Fritsch mit einem vollständig verknöcherten

Tarsus. Größe $/ 1$. Oberstes Karbon. Nürschan, Böhmen. (Orig. Museum Berlin).

\section{I $\beta$ Nebenordnung Aistopodi Miall.}

Fußlose, schlangenartige, langgestreckte Formen mit einfach gebauten Wirbeln, spitzem Kopf, einfachen einköpfigen Rippen.

Hierher gehören die Dolichosauridae und Molgophidae.

\section{I $\gamma$ Nebenordnung Nectridei Miall.}

Salamanderartige Vierfüßler mit breitem, durch kleinen Mund und wenig Knochen der Schläfenregion ausgezeichnetem Schädel, kurzem Hals und Rumpf, langem peitschenförmigen Schwanz mit einfachen, bis zum Ende verknöcherten Wirbeln.

Hierher die drei, wohl Familien repräsentierenden Gattungen Diceratosaurus Jkl., Ceraterpeton Huxley und Diplocaulus Cope. (Fig. 133, 134 u. 135.) 


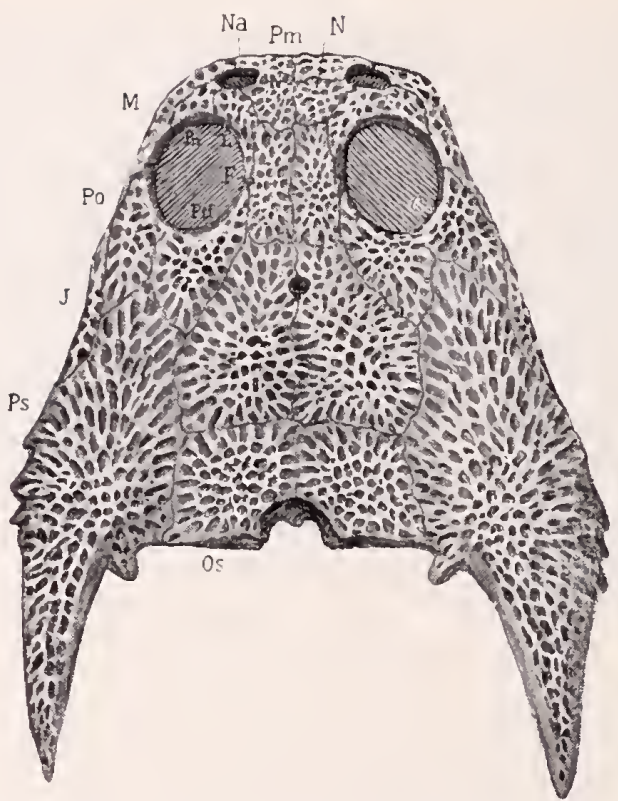

Fig. 133. Diceratosaurus punctolineatus Cope sp. Schädeldach. Oberes Karbon. Linton, Ohio. 21/2:1. (Nach Jaekel.)

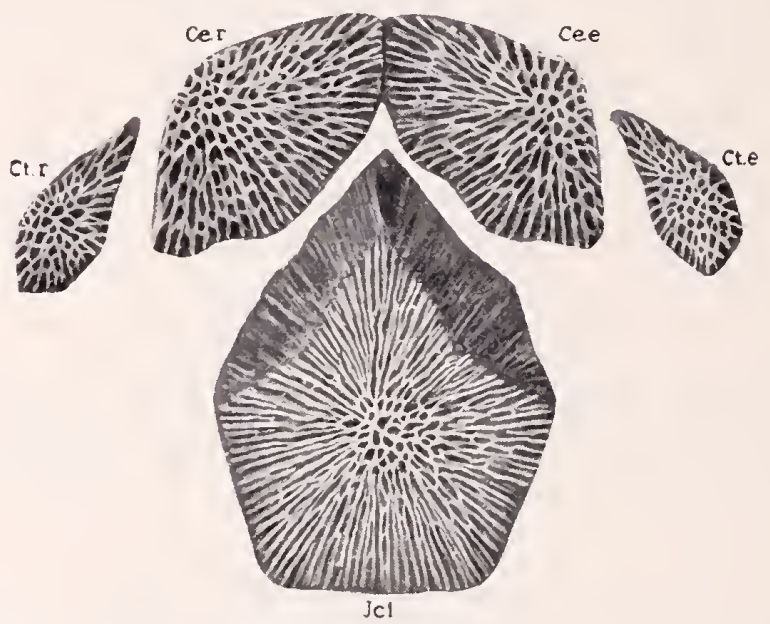

Fig. 134. Dermales Schulterskelett derselben Art, vorn die großen Clavicula, daneben die Cleithra, unten die Interclavicula. Alle sind skulpturierte Deckknochen. 2/1. (Nach Jaekel.)

Voll diesen vier Ordnungen scheinen mir die sehr spezialisierten Ordnungen der Urosauri und Nectridei im Palaeozoicum ausgestorben zu sein. Die Haplosauri scheineu dagegen den Ausgangspunkt der Cotylosauria zu bilden. Ob die Aistopodi ausgestorben sind oder vielleicht 
mit den Gynnophionen in Beziehung zu bringen sind, bedarf weiterer Entdeckungen vollständig erhaltener Formen.

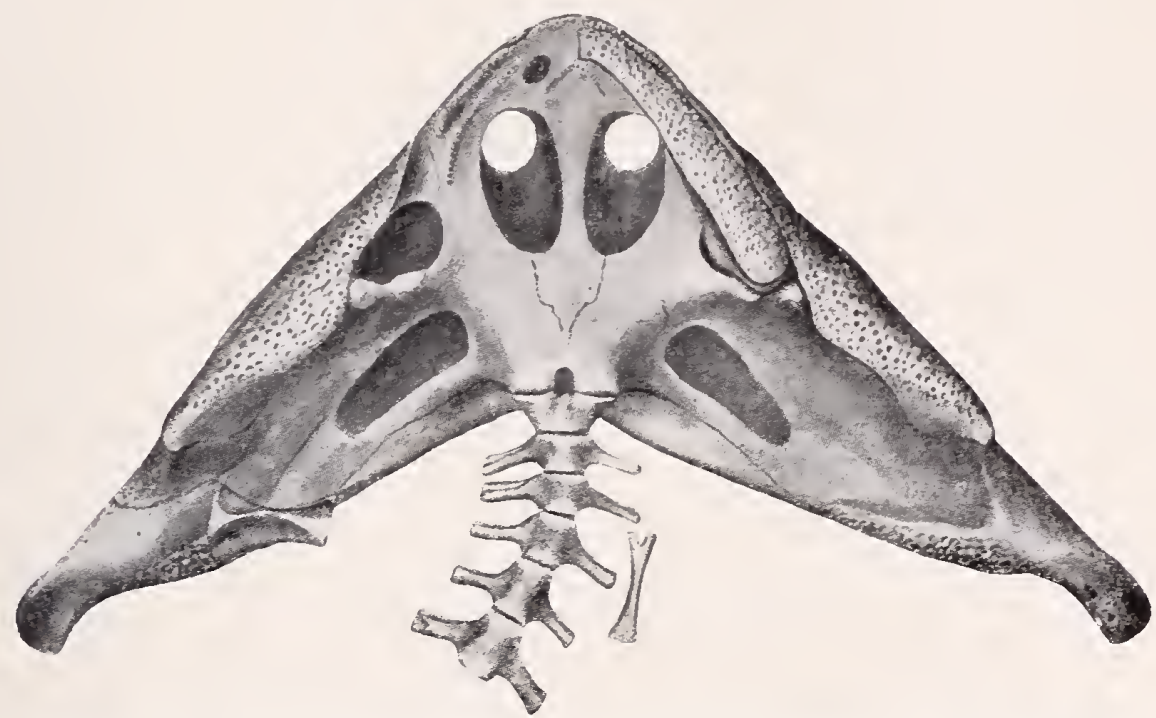

Fig. 135. Diplocaulus magnicornis Cope. Unterseite des Schädels und der ersten Wirbel, auf der rechten Seite mit einem Unterkieferast. Perm von Texas. ${ }^{1}$ s. (Nach S. Williston.)

\section{Stufe. Unterklasse Cotylosauria Cope.}

Es erscheint mir zweckmäBig, die Cotylosaurier im simne der meisten Autoren d. h. mit Einschlnß der Pareiasaurier, hier als Oberstufe den Nicrosauriern anzuschließen, da sie sich, wie schon H. F. Osborn betonte, noch nicht klar nach den beiden Richtungen der Reptilien oder der Paratheria-Mammalia entschieden haben. Durch ihr stegales Schädeldach ordnen sie sich den alten Typen unter, erheben sich aber ïber dieselben nicht nur durch ihre steigende Körpergröße, sondern auch durch Spezialisierung ihres Schädels. der Gliedmaßen und der Schwanzbildung. Anch eine Halsbildung macht sich bei ihnen geltend und nähert ihre Körperform dadurch den löheren Typen. Ihr Schädeldach beginnt sich im sinne seiner Inskulierung zu formen nnd die Bezahnung verschiedener Nahrung anzupassen.

Die Cotylosaurier werden dadurch zur Stammgruppe ältester Reptiltypen, ror allem aber der Paratheria, die sich in gerader Linie aus ihnen entwickelten.

Den Ausgangspunkt dieser Unterklasse der Cotylosauria bilden allem Anschein nach Formen, die den systematisch noch einfacheren Microsauriern angehören und als deren primitive Tertreter ror der Schwelle von Crreptilien und Paratherien stehen. Scharfe Grenzen gibt 
es hier erfreulicherweise nicht mehr, und es ist schließlich in das Belieben des einzelnen Forschers gestellt, ob er einen solchen Grenztypus schon den Reptilien oder den Paratherien zuweisen will. Die Formen aus der Verwandtschaft von Datheosaurus aus den Perm von Schlesien scheinen sowohl in der Gesantform des Körpers, wie auch der Länge des Rumpfes und Schwanzes deu Reptilien schon sehr nahe zu stehen. Weniger primitiv als Datheosaurus aus den schlesischen unteren Perm scheinen Pariotichus und Labidosaurus aus dem oberen Perm von Texas zu sein.

Definition: Cotylosauria sind höher organisierte Miosauria, deren Schädel sich durch Kontraktion der präorbitalen Region und durch Brïckenbildung in der Schläfenregion im Sinne der höheren Tetrapoden zu formen beginnt. Ihr Parasphenoid wird rerkleinert, ihr Hinterhauptsgelenk bildet in der Regel das Basioccipitale im Condylus stärker aus und führt dadurch zur Bildung eines tripartiten Condylus. Die vordere Lage der äuBeren und inneren Nasenlöcher bleibt bestehen, ebenso eine primitive Bezahnung, die auch auf die inneren Gaumenkuchen ausgedehnt bleibt. Der Schultergiirtel nimnt den bogigen Habitus der Reptilien an, bewahrt aber in der Regel noch die Cleithra. Die Wirbelkörper sind meist kräftig verknöchert, behalten aber den diplocoelen Charakter. Im Becken bleiben die ventralen Knochen bis zur Symphyse flächig ausgebreitet. Die Gliedmaßen werden kräftiger musuliert, so daß sich die Knochen spezialisieren, namentlich die Oberarmknochen an den Enden ausbreiten. Die Zehenformel bleibt unsicher und anscheinend noch uicht fest bestimmt.

Innerhalb der Cotylosauria lassen sich wohl jetzt schon zwei Richtungen auseinander halten, deren eine zll den Reptilien, deren andere zu den Paratherien und damit zu den Säugetieren ïberleitet. Für die letzteren ergibt sich als Ordnungsname der im gleichen engeren Sinne schon mehrfach gebrauchte Name "Pareiasauri", um deren Typus sich zweckmäßig die bisher bekannten Vertreter dieses Typus scharen. Die reptilienartigen Formen lassen sich etwa 1 m Datheosaurus gruppieren. Die in der Richtung zu den Säugetieren führende Ordnung werden wir als Hauptordnung, die zu den Reptilien führende als Nebenordnung auffassen können.

\section{Hauptordnung Pareiasauri Seeley.}

Der für diesen Formenkreis synonym gebrauchte Name Copes Cotylosauria war viel weiter und enthält in der späteren Fassung der 
Autoren allem Anschein nach sehr verschiedenartige Formen, während die Pareiasauri Seeleys an den Typus der vorliegenden Unterordnung ankniipften, und einen wesentlich engeren Kreis umfassen. Für diese gilt folgende Definition:

Pareiasauri sind schwerfällige z. T. ziemlich große Paratherier mit geschlossenem „stegalem" Schädeldach, ohne Schläfendurchbrüche und ohne echte Jochbogenbildung. Ihre Nasenlöcher sind getremnt. Ihr Gaumen ist nahezı "craniopalatin", ihr Hinterhauptcondylus konzentriert unter starker Beteiligung des Basioccipitale. Ihr Unterkiefer weist noch alle primitiven Deckknochen, aber einen schwachen Coronoidprozeß auf. Ihr Schultergürtel zeigt außer Claviculis und Interclaricula z. T. noch Cleithra als obere Deckknochen. Die Scapula besitzt ein "Acromion". Ihr Becken ist "bisacral" d. h. an zwei Wirbeln angehängt, die unteren Beckenknochen (Pubis und Ischium) sind ventral in langer Symphyse verbunden. Die Zehenformel ist noch nicht klargestellt, nähert sich aber dem Typus 2.3.3.3.3. Alle Wirbel tragen Rippen. Hals und Schwanz sind kurz, die oberen Bögen der Rumpfregion sind breit und kräftig verknöchert, die Dornfortsätze kurz.

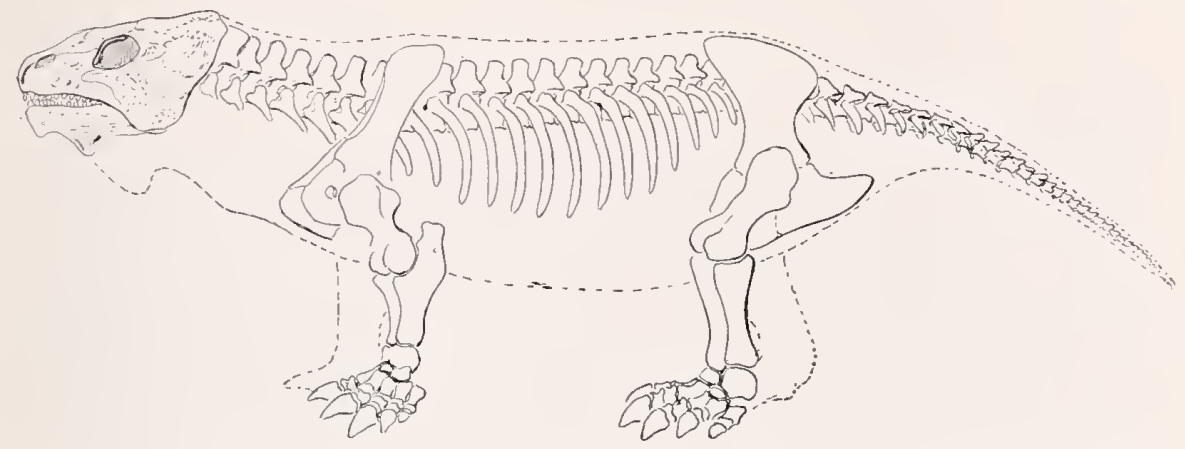

Fig. 136. Pareiasaurus Beani Seeley. Skelett rekonstruiert. Oberes Perm, Südafrika. (Nach Jaekel.)

Diese Form und Sclerosaurus armatus (Aristodesmus Rütimeyeri) aus dem Buntsandstein von Basel biłden mit ihrem höheren, vorn abgestutztem Kopf und ihren großen Stacheln an Kopf eine besondere Familie der Pareiasauri. Ferner gehören hierher die Diadectidae mit dem noch fraglichen Empedias und mit Chilomys. Bei diesem letzteren sind die hinteren Backzähne schon stark nach innen ausgedehnt und die bei Pareiasaurus noch vorhandene innere Bezahnung des Gaumens speziell der Pterygoiden ist verschwunden. 


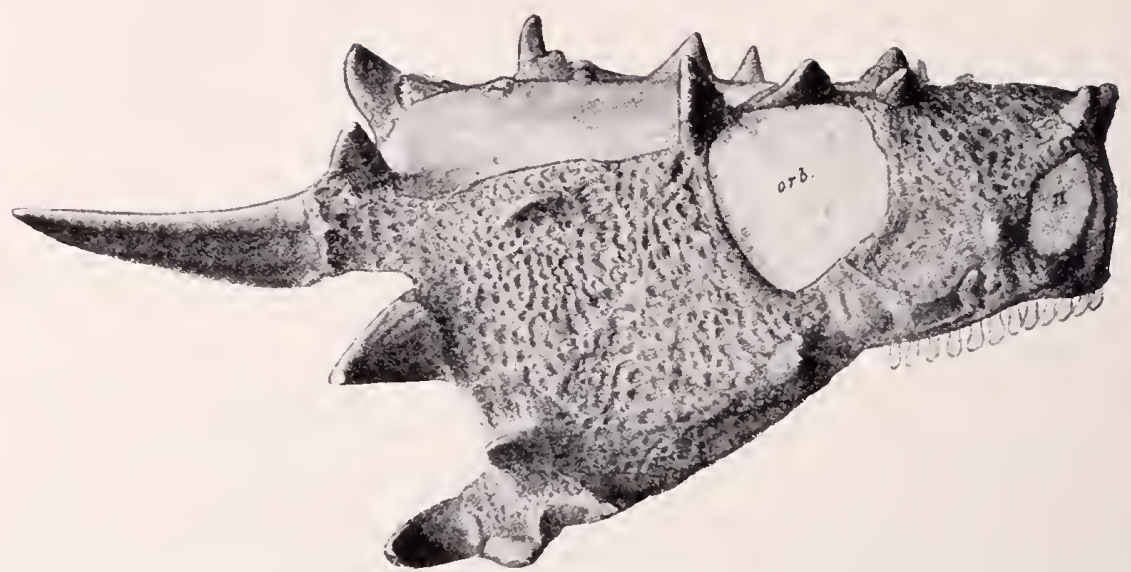

Fig. 137. Seitenansicht des Schädels von Elginia mirabilis Newt. vermutlich aus unteren Triasschichten des "neuen roten Sandstein" Schottlands. 1/2. (Nach Newton.)

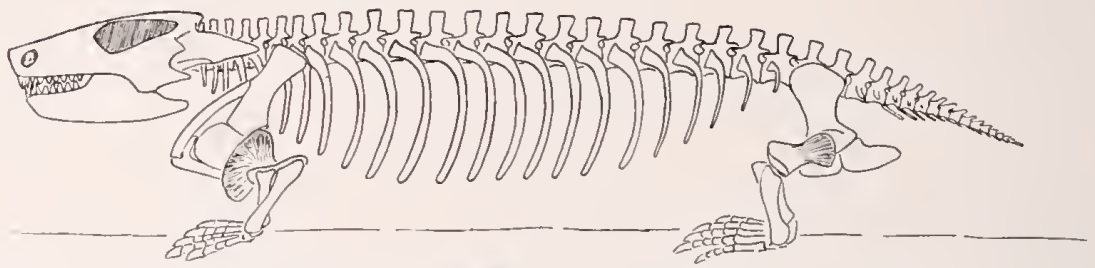

Fig. 138. Sclerosanrus armatns von Meyer. Ans Bnntsandstein. Riehen bei Basel. 1/3. (Restauration von F. v. Hnene.)

\section{Nebenordnung Datheosauri.}

Eidechsenartige, mäßig große Vierfüßler, mit stegalem, dickem Schädeldach, vorn gelegenen Nasenlöchern, mäßig großen Augenhöhlen,

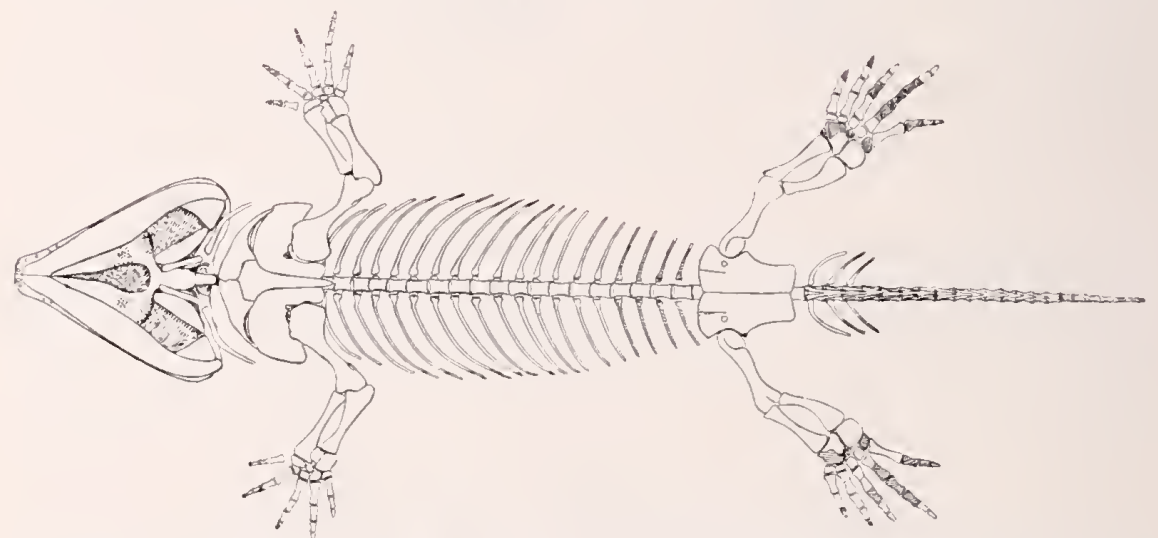

Fig. 139. Pariotichus laticeps Williston. Perm von Texas. Restanrierte Ansicht der Unterseite des Skelettes. 1/4. (Nach Williston.) 
C. Tetrapoda. Miosauria
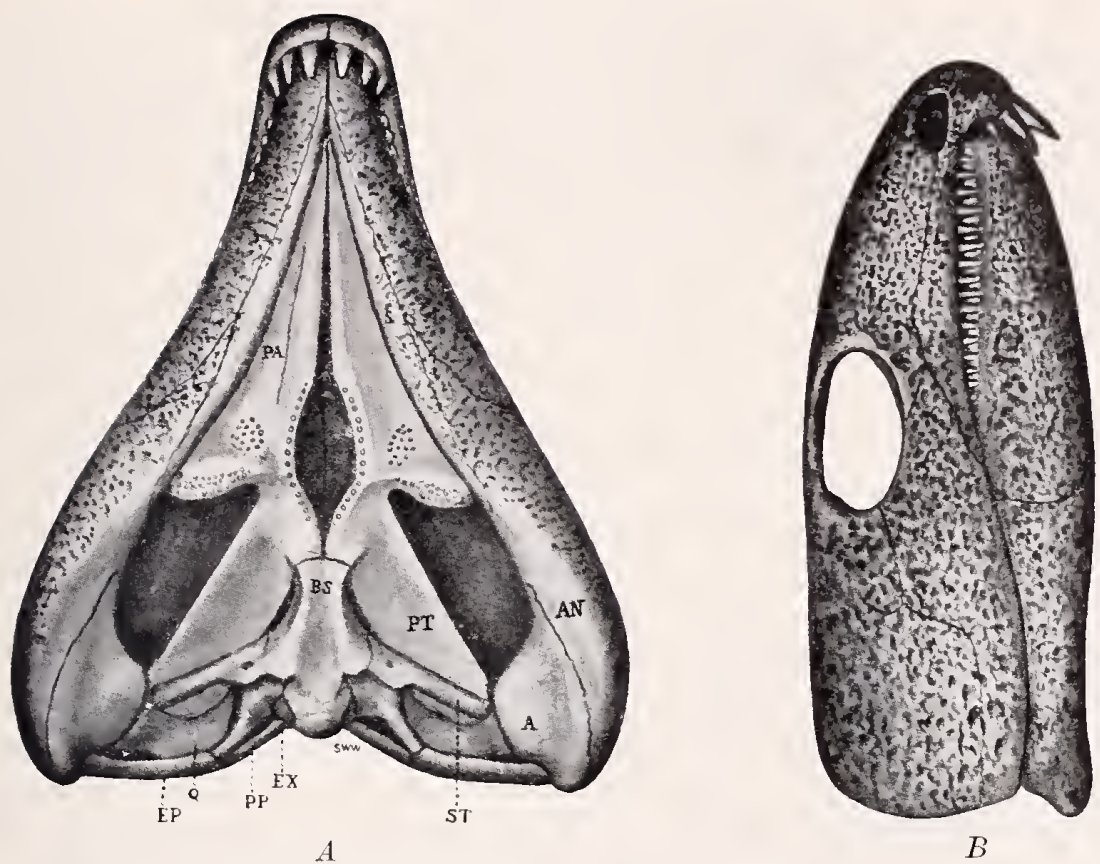

Fig. 140. Labidosaurus hamatus Cope. $A$ von der Gaumenfläche, $B$ von der Seite gesehen. Oberes Perm Texas. 2/3. (Nach Williston.)

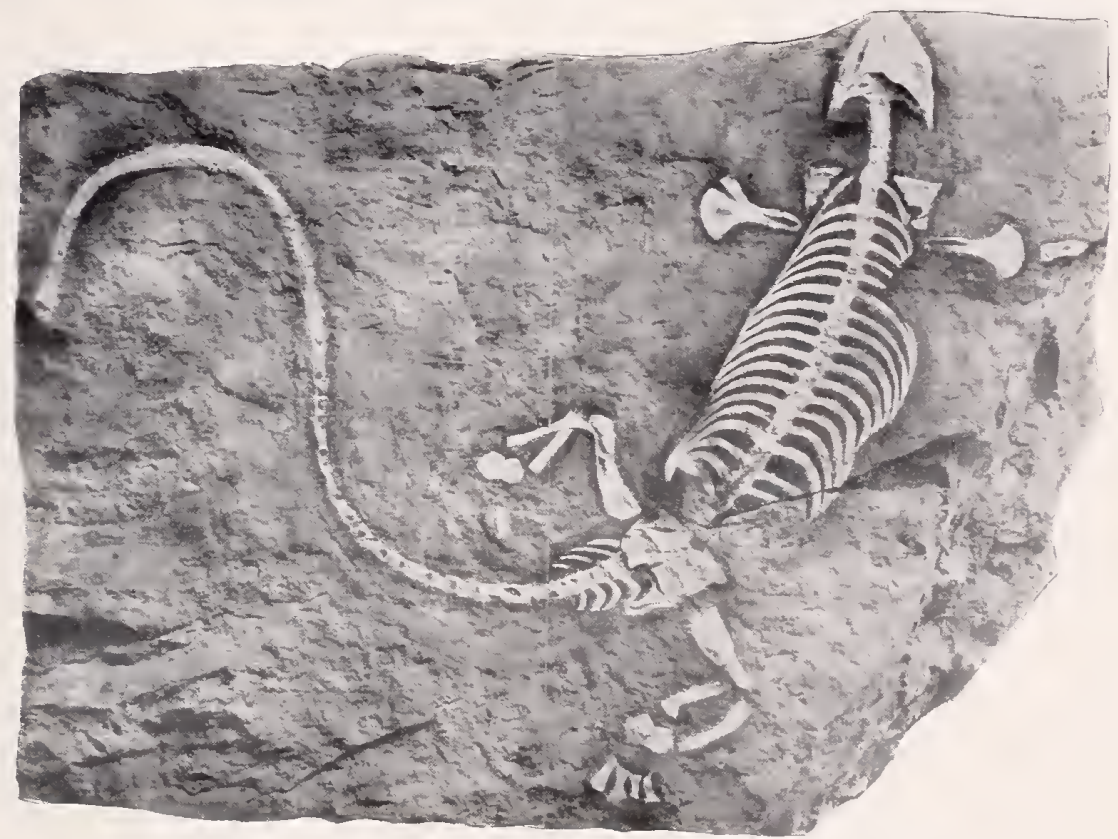

Fig. 141. Datheosaurus macrurus Schröder. Unteres Perm. Neurode, Schlesien. 1/4. (Nach Schröder.) 
mit starken Vorderzähnen, großen bezahnten Pterygoiden, einfachem Condylus, kurzen, indifferenten Beinen, mit biplatem Humerus, anscheinend reptilienartiger Zehenzalıl. Rippen gleichförmig ausgebildet. Hierhin gehören die Datheosamriden, Labidosauriden und andere weniger vollständig bekannte Typen, wie Isodectes.

\section{Nebenklasse Amphibia (Blainville 1818).}

Das Merkmal, das Blainville in erster Linie veranlaßte, die Amphibien von den Reptilien abzutrennen, war die amphibische LebensWeise zwischen den beiden Elementen des Wassers und der Luft, die Atmung ihrer Jugendformen durch Kiemen, die der erwachsenen durch Lungen. Darauf beruhte auch ihre phylogenetische Beurteilung, man hielt sie für die Übergangsformen der Fische zu den landbewohnenden Tetrapoden. Seitdem nun durch v. Mehely u. a. Amphibien bekannt wurden, die sich ohne jenes bisher charakteristisch erschienene Larvenstadium direkt rom Ei zur fertigen luftatmenden Landform entwickeln, miissen wir notgedrungen nach anderen Kennzeichen zur Charakteristik der Amphibien suchen, und ihre bisherige entwicklungsgeschichtliche Beurteilung einer Revision unterziehen.

Durch die hier erfolgte Ablösung vieler fossiler Typen, die bisher den Amphibien untergeordnet wurden, wie der Hemispondyla und VicroSauria, sind die Amphibia wesentlich auf die Formenkreise der lebenden Typen und deren unmittelbare Vorfahren beschränkt. Diese Formenkreise sind wohl umgrenzt und gegenwärtig scharf voneinander gesondert, die Urodela, die Anura und die Gymnophiona oder Coecilia.

Charakteristisch ist für diese Anphibien außer ihrer zumeist aquatischen Ontogenie ihre holospondyle Wirbelbildung, der doppelte Condylus am Hinterhaupt, das große Parasphenoid, der große einfache Durchbruch in der Schläfenregion, der Mangel deutlicher Epiotikalecken, die einköpfigen kurzen Rippen und die Anhängung des Beckens an einem einzigen Wirbel.

Die historische Entwicklung dieser Formenkreise ist noch ganz dunkel. Die Frösche, die sich als spezialisierteste Formen erweisen, schienen bisher erst im Tertiär aufzutreten. Nun wird uns ein nener Fund eines echten Frosches in oberen Jura Spaniens durch A. Smith Woodward bestätigt. Ebenso isoliert ist noch das älteste Vorkommen eines Urodelen (Hylaeobatrachus) in der unteren Kreide, dem Iguanodontenlager ron Belgien. Fossile Gymmophionen sind noch nicht 
mit Sicherheit festgestellt, und doch möchten wir glauhen, daß diese Blindwühler ein sehr alter 'Typus der Amphibien sein mübten. Die Möglichkeiten einer fossilen Erhaltung von Amphibien sind offenbar gering, so daß nur besonders günstige Unrstände die gelegentliche Erhaltung einzelner Individnen ermöglichten und deren geologische Verbreitnng kein Bild von der historischen Entwicklnng der Klasse bieten kann. Ganz nnklar erscheint namentlich die verwandtschaftliche Stellung der Gymnophionen, die vielleicht noch mit paläozoischen Mierosauriern in nnmittelbarem Konnex stehen. Der vou J. Williston vor knrzem genauer beschriebene Lysorophus aus der oberen Steinkohlenformation von Ohio U.S. A. mag seiner Kiemen wegen zll den "Amphibien" gehören und erinnert anch im Schädelban an Gynmophionen. Amphibien sind hiernach:

Holospondyle meist kleine Land- oder Sïßwasserbewohner mit breitem, flachen Kopf, dessen primäres Schädeldach Schläfen und Wangenregion frei läBt. Paroccipitalecken fehlen. Gaumen craniopalatin. Parasplenoid lnd Pterygoidea in der Ganmenfläche sehr ausgebreitet. Postpalatine Ganmenlïcken grob. 2 Condyli occipitales. Zähne meist in einer Reihe auf den Kiefern, bisweilen rückgebildet. Rippen einköpfig kurz. Füße vorn mit 4 Zehen nnd 2.2.3.3 oder 1.2.3.3 Phalangen, hinten mit 5 Zehen nnd 2.2.3.4.3 oder 2.2.3.3 Phalangen. Entwicklung meist im Wasser unter Bildung eines fußlosen Larvenstadiums.

Die Formenkreise der Amphibien sind in phylogenetischer Hinsicht noch ganz ungeklärt. Die folgende Gruppierung mnB daher als provisorisch bezeichnet werden nud soll in erster Linie dem formalen Bedürfnis zn Hilfe kommen.
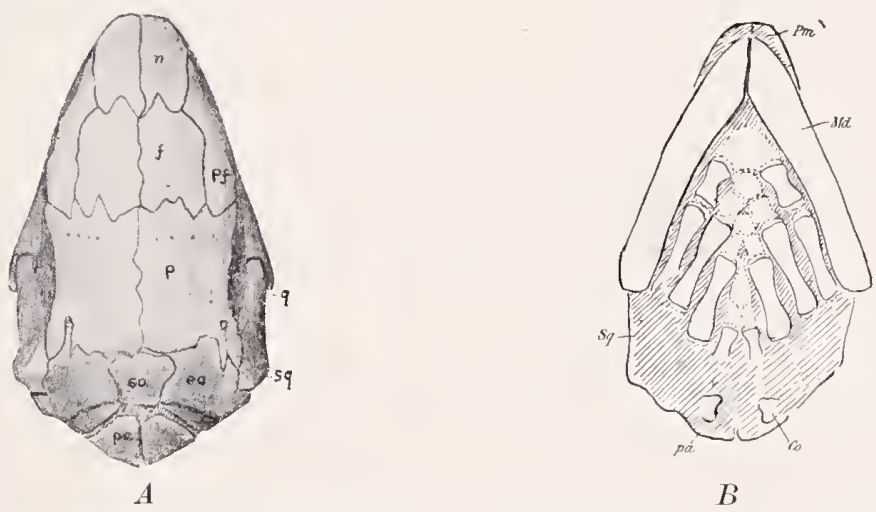

Fig. 142. Lysorophus tricarinatus Cope. Perm von Illinois. $\% 1 . A$ Oberseite des Schädels (nach Williston), $B$ Unterseite mit den Kiemenbögen. Restauriert. 
I. Stufe. Paläozoische Formen mit stegalem Schädeldach mit persistenten Kiemen. Hierhin stelle ich als Hauptordnnng den jetzt von Williston genauer beschriebenen Lysorophns (Fig. 142).

Eine zweifelhafte Stellmng nehmen die Gymnophionen ein. Die Zoologen betrachteten sie gewöhnlich als Nachkommen der Urodelen, aber manche Homente sprechen dafïr, daß sie einen älteren Typus darstellen und etwa an die Ordnung der Lysorophi als Nebenordnung anzuschließen seien. Daß sie fossil nicht erhalten sind, erklärt sich ans ilırer Lebensweise in humosem Boden, der ilırer Erhaltung keinerlei Aussichten bietet.

I a Nebenordnnng Gymnophiona (Coeciliae, Apoda), Blindwiihler.

Fußlose. Wnrmförmige Amphibien mit unterirdischer Lebensweise, verknöcherten Angen, großem Paraphenoid, muterbrochenem Oberkieferrand. Haut weich mit rudimentären Schnppen (Fig. 143).
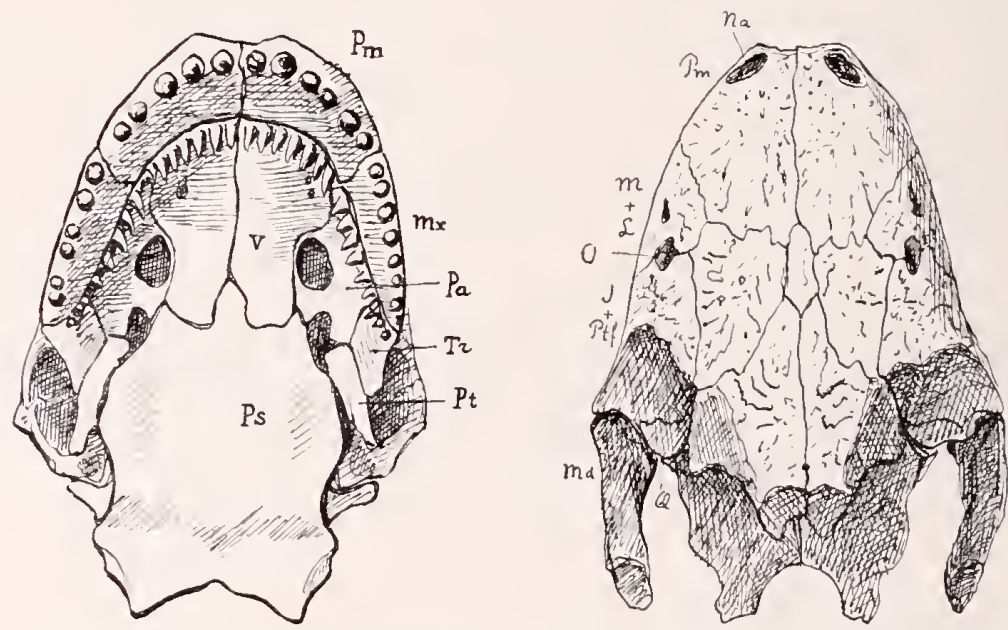

Fig. 143. Schädel eines lebenden Gymnophionen von der Unter- und Oberseite. Ps Parasphenoid, $v$ Vomer, Pm Praemaxillen, mx Maxillen, Pa Palatina, Tr Transversa, Pt Pterygoidea. - Na Nasenlöcher, O Orbita, L Lacrymale, Q Quadratum, $J+$ Ptf Jugale und Postfrontale, $M d$ Hinterende der Mandibel.

II. Stufe. In dieser fasse ich die Urodelen in der Hauptordnung, die Anmen in der Nebenordunng zusammen.

Diese zweite Stnfe der Amphibienentwickhnng ist gekennzeichnet durch flachen, in der schläfenregion durchbrochenen Schädel, sehr großes Parasphenoid, amphicöle oder hemicöle Wirhelkörper, knrze Rippen, reichliche Erhaltung vom Knorpel im skelett. 
II. Hauptordnnng Urodela oder Caudata Dumeril.

Vierfüßige geschwänzte Amphibien mit breitem Kopf, walzenförmigem langem Rumpf, komprimiertem Ruderschwanz. Gliedmaßen klein oder teilweise rürkgebildet. Schädel mit großem Parasphenoid,

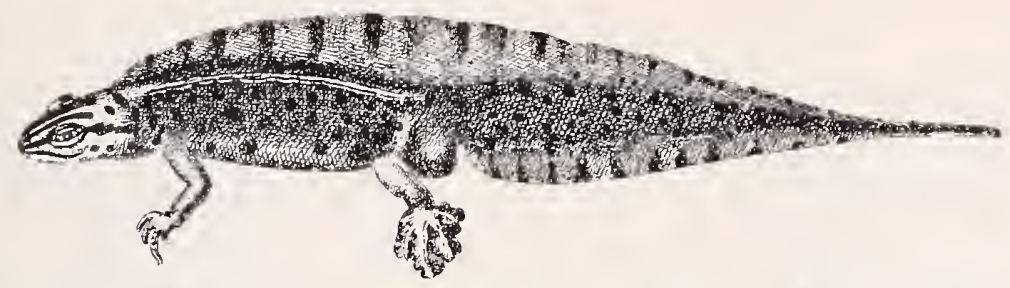

Fig. 144. Molge vulgaris L. var. Kapelana von Mehely. Männchen in der Wassertracht aus Nordungarn. 1/2. (Nach L. von Mehely.)

breiten Pterygoidea und weiten Orbita. Kieferrand zwischen den Maxillen nnd dem Quadratum weit unterbrochen.

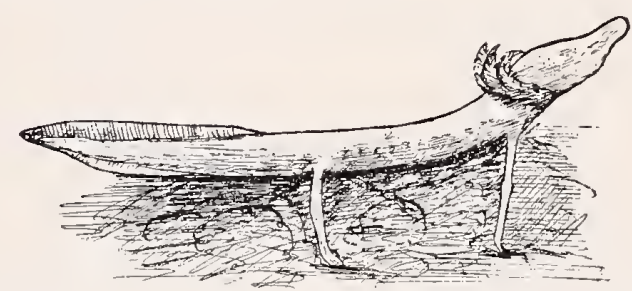

Fig. 145. Typhlomolge rathbuni. 1/2. Eine blinde in einem $60 \mathrm{~m}$ tiefen Brunnen in Texas entdeckte Form. (Nach Blackford aus Versluys.)

Daß die früheren Unterordnungen der Perennibranchiaten und Cryptobranchia oder Derotremen stammesgeschichtlich nicht haltbar sind,

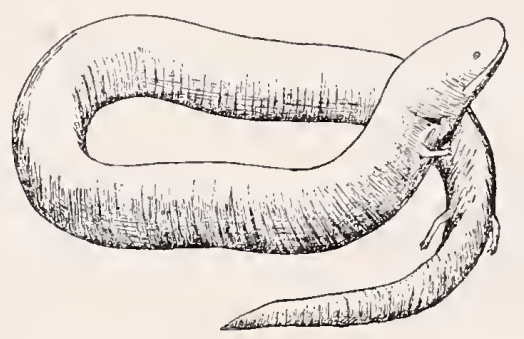

Fig. 146. Amphiuma means aus Brehm. (Nach Versluys.)

bedarf keines Hinweises mehr, seitdem die Persistenz der Embryonalkiemen als epistatische Hemmung der Ontogenie von Derotremen erkanut ist. 
If Nebenordnung Anura, Ecaudata, Frösche.

Schwanzlose, vierfüßige Amphibien mit sehr kurzem Rumpf, rückwärts verschobenen langen Ilia und einen dem Becken eingelagerten Prgostyl, dem verwachsenen Schwanzende der Wirbelsäule.

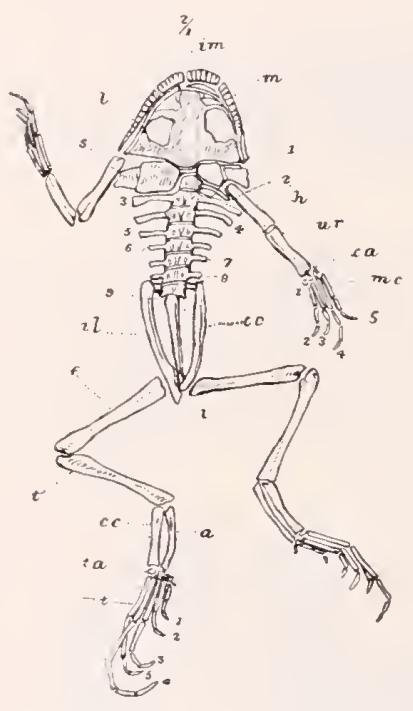

Fig. 147. Oxyglossus pusillus Owen sp. Ein fossiler Frosch aus dem Tertiär von Bombay. $1 / 2$. (Xach Stolitzka.)

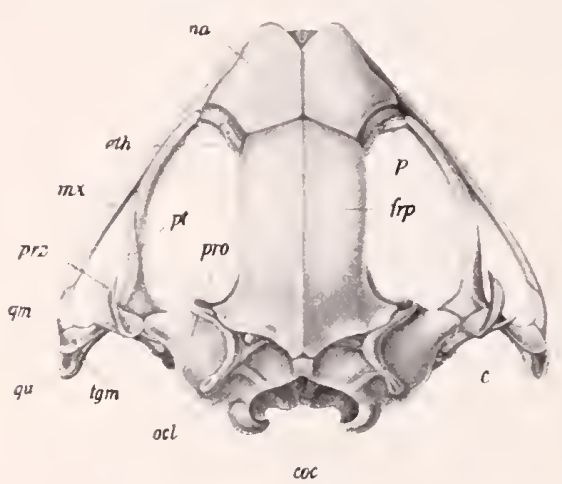

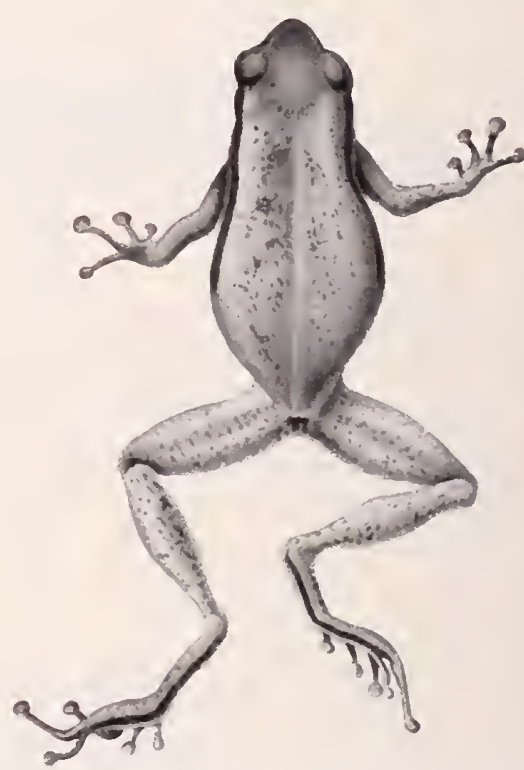

Fig. 148. Phrynixalus biroi. von Mehely von Neu-Guinea. Ein direkt olne Larvenstadium entwickelter Landfrosch. Nach L. v. Mehely.)

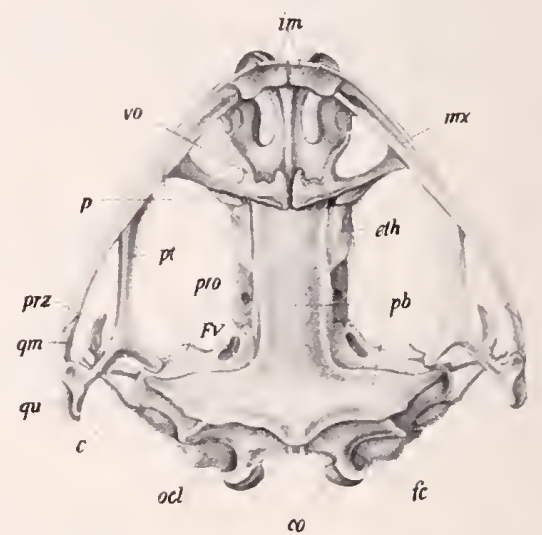

Fig. 149. Copiula oxyrhina Blgr. Ein Landfrosch von Nen-Guinea.

Scliädel von oben und von unten. 4/2. (Nach L. v. Mehely.) 


\section{Nebenklasse Reptilia (restr. Jaekel 1910).}

Das System der Reptilien wurde immer schwieriger, je melır Vertreter ansgestorhener Formenkreise bekannt wurden. Mit den wenigen iiberlebenden 'Typen war man früher schnell fertig geworden, aber die Paläontologie lehrte allmählich eine solche Fülle älterer Formen kennen, die sich den lebenden nicht einordnen ließen, daß man sich zunächst zur Aufstellung einer großen Zahl neter Ordnungen imnerhalb der Klasse genötigt sah. Natnrgemäß standen diese untereinander in sehr verschieden engen Beziehungen, aber es schien sehr schwierig, sie in größere Einheiten innerhalb der Klasse zusammenzıfassen. Einen entscheidenden Fortschritt in diesen Studien bedentete der Versuch H. F. Osborns ${ }^{1}$, alle Reptilien nach dem Vorhandensein eines einfachen oder zweier Jochbögen in Synapsida und Diapsida zu teilen. Aber einerseits verringerten Modifikationen in der Ausbildung der Bögen den diagnostischen Wert dieser Einteilung, und andererseits versagte das Prinzip gegenüber älteren Formen, die sich sozusagen auf keine jener beiden Richtungen festgelegt hatten.

In zwei Schriften, der einen „Über das System der Reptilien"2), einer zweiten "Über die Paratheria, eine neue Klasse von Tetrapoden“") habe ich versucht, diese schwierigkeiten zu beseitigen, indem ich einerseits die echten Synapsida von den Reptilien ganz lostrennte und als Paratheria in engere Beziehung zu den Mammalia brachte, andererseits einen Teil der bisher als Synapsida betrachteten Typen als ursprünglich diapsid erweisen konnte, und nun den diapsiden Ban des Schädels, den einfachen Condylus, die volle Ansbildung der postdentalen Elemente des Unterkiefers und die Phalangenformel 2.3.4.5.3-4 als die primären Haupteigenschaften aller Reptilien hinstellen konnte.

Die nun als echte Reptilien übrigbleibenden Formenkreise umfassen also die Diapsida im simne Osborns, und von dessen Synapsida die Samropterygii und Placodonti. Die Diapsida wurden von Osborn in folgender Weise gegliedert:

I. Diaptosauria: 1. Protorosanria, 2. Pelyeosanria, 3. Rhynchosauria, 4. Procolophonia, 5. Proganosauria, 6. Choristodera, 7. Rhynchocephalia.

1) The Reptilian subclasses Diapsida and Synapsida etc. (Mem. Am. Mus. Nat. Hist. Vol. 1, pt. 8.)

2) Zool. Anz. XXXV 11.

8) Ebenda XXXVI 6/7. 
11. Phytosauria: 1. Belodontia, 2. Aetosamia.

III. Ichthyosauria.

IV. rrocodilia.

V. Dimosauria: 1. Theropoda, 2. Cetiosauria, 3. Orthopoda.

VI. Squamata: 1. Lacertilia, 2. Mesosamria, 3. Ophidia.

VIF. Pterosantia.

Die gesperten Nanen reprïsentieren Superorders, die anderen Orders. Da beide aber hier einander gleichstehen, ist es zu beanstanden, daß sie im System rerschiedene Rangbezeichnung erhalten haben. Fs lassen sich abcr gegen obige Einteilung anch insofern Einwände erheben, als die Reihenfolge natürliche Gruppen auseinanderzieht, wie namentlich die Phytosanri, I hinosanri nnd Crocodili, die sicher eine phyletische Einheit bilden. Auch sind nun die Nothosauri, Placodonti und Plesiosami in diesen Formonkreis eimzureihen.

Tieses System der Reptilien suchte ich dann gegenüber der Osbornschen Einteilung zu modifizieren, indem ich folgende Formenkreise als diapside oder als echte Reptilia zusammenfaBte.

$$
\text { Ordnungen: } \quad \text { Unterklassen: }
$$

1. Protorosauri

2. Naosauri

3. Procolophonii

4. Sphenodonti

5. Rhynchosami

6. Champsosauri

1. Mesosauri

2. Ichthyosauri

3. Samopterygii

t. Placodonti

1. Lacerti

2. Mosasauri

3. Ophidii

1. Dinosauri

2. Crocodili

3. Pterosami

I. Archaeosauria

If. Enaliosanria

[H. Lyognatha

IV. Hyperosauria

WTas die Benennung der Abteilungen betrifft, so waren die der kleineren Einheiten, die als Ordnnngen gelten können, im ganzen festgelegt. Einige der älteren Namen, wie z. B. Rhynchocephalen, hatte 
ich fallen lassen, weil sie in sehr verschiedenem sinne velwendet worden waren und ihrem sprachlichen Sinne nach für die wenigsten ihrer Vertretel paßten. In allgemeinen erschienen diese Ordnungen anch insofern gleichwertig, als ihre Vertreter in der Tat morphologische 'Typen von anuähernd gleicher Bedeutung repräsentieren. Thre Wortbildung war insoferu einheitlich geregelt, als alle anf i oder ii endigen. Daß ihr Inhalt an einzelnen Formen sehr verschieden ist, ist selbstrerständlich: wähıend die Dinosauri, Crocodili, Lacerti und Ophidii ein ganzes Heer von Fornen enthalten, bestehen andere, wie z. B. die Mesosauri, Placodonti, Champsosami, nur aus wenigen Gattungen und Arten.

Fïr die Klasse in diesem engeren Sinne läßt sich nun folgende Diagnose aufstellen.

Reptilien sind luftatmende, wechselblïtige, beschuppte, geranzerte oder nackthäntige Tetrapoden, die Eier legen oder lebendige Junge produzieren.

Ihre Skeletteile sind größtenteils verknöchert, auch die Enden ihrer Fußknochen. Thre Wirbel sind lolospondyl an beiden oder einer der Endflächen vertieft. Thre Rippen sind lang, zwei- oder einköpfig, in der ganzen Rumpfregion, der Hals- und vorderen Schwanzregion wohl entwickelt, im Schwanz durch parige untere Bögen ergänzt, die interzentral gestellt sind und bisweilen besoudere Stiicke (sog. Interzentren) als Stïtzpunkte haben.

Der Schädel ist anßer bei einigen primitiven Typen diapsid, aber der untere (Wangen-) Bogen kamn verkümmern. Die Nasenlöcher sind getrennt, öfters zurückgeschoben, die Choanen ebenfalls getrennt im vorderen Teil der Ganmenfläche (nur die Krokiodilier sind in der Nasenbildung abweichend spezialisiert). Vomera, Transversa und Pterygoidea sind wohl entwickelt und anfangs bezahnt, die letzteren halten in großer Ausdehnung wud meist median verbunden die „pterygopalatine“ Gammenfläche zusanmen. Das Parasphenoid ist klein, eine Bulla tympanica fehlt. Das Hinterhauptsgelenk bildet ein einfacher Condylus unter dem Foranen magnum. Das Kiefergelenk wird nur vom Quadratum gebildet. Der Unterkiefer ist mit zwei vorderen und zwei hinteren Deckknochen bedeckt ind weist an Kronfortsatz 1 oder 2 Complementaria anf. An Cranium sind immer selbständige Prämaxillen und öfter anch besondere Postnasalia vorhanden, die Angenhöhlen vollkommen umgrenzt, hinten durch ein Postfrontale und Postorbitale geschlossen. Die obere oder Schläfengrube von den letzteren, dem Parietale und Squamosum, die untere oder Wangengrube von den Postorbitale, Jugale, Squamosnm und Quadratojngale umgeben; letzteres kann mit dem unteren ("Wangen“-) Bogen verkümmern. Besondere „Epiotica“ sind öfter's noch ïber den Occipitalia lateralia ansgebildet. 
Die Zähne sind einspitzig, kegel-, meißel-, spatel- oder säbelförmig, ans Pulpodentin mit schmelzbelag, acrodont, pleurodont oder bothrodont ohue geschlossene W'uzeln befestigt, und werden meist dnrch laterale, selten durch rertikale Verdiängung ersetzt.

Der Schultergürtel ist rierteilig, Smprascapulare und Prälcoracoid persistieren öfters knorpelig; bogige Claviculae und eine riickwärts verlängerte Interclavicula (Episternum) sind meist vollanden. Der Humerus weist häufig ein Foramen ulnare (entepicondyloidemm), seltener auch ein Foramen radiale (ectepicondyloideum) auf. Die Ulua neist kräftig, ehenso wie die Fibnla ursprünglich dominierend. Fußnurzeln ron den fast immer selhständigen Metapodien getrennt. Zehen meist vollzählig, bisweilen eine, selten zwei reduziert. Die Phalangenformel ist 2.3.4.5.4-3, wird aher bei schwinmformen gesteigert. Die Endphalangen sind bei den Landbewohnern mit großen, nicht retraktilen Krallen besetzt.

Das Becken ist primär an \& Sacralwirbeln befestigt, die aber bei hüpfenden Formen rermeht werden. Das Becken zeigt in der Regel eine lange ventrale symplysse nnd einen Einschnitt oder ein Foramen obturatorium in dem meist flächig ansoehreiteten Os pubis.

Stabförmige Gastralia (sogenannte Banchrippen) sind bei allen älteren Gruppen vorhanden, werden aber bei jüngeren rückgebildet.

Der schwanz ist nicht scharf rom Rumpfe gesondert, in der Regel lang, mit iuterzentralen Hämapophỵsen.

Der After liegt in der Banchfläche.

Fossil vielleicht schon rom Karbon, sicher rom Perm lis zur Gegenwalt.

Die wesentlichsten dieser Merkma le ergeben folgende kurze Definition:

Körper gestreclit, meist mit langem Sehwanz und Hals. Haut oft plattig oder sehuppig gepanzert. Schädel diapsid, die Wangenbrïcke hisweilen verkümmert. Gaumen pterygopalatin. Condylus einfach hasioccipital. Schultergiitel mehrteilig, meist mit Claviculis nud Interclavicula (Episternum). Becken primär an 2 Wirbeln befostigt: seine Elemente gesondert. Im MittelfuB dominieren Ulua und Fibula. FuBgelenk intertarsal. Zehenformel llolmal 2.3.4.5.4-3.

Die Gliederung der Klasse in die oben genannten Unterabteilungen scheint zunächst in einem Punkte noch benerkenswerte Schwierigkeiten zu bieten, das ist die Stellung der Ichthyosamrier und Mesosamier. Die ersteren sind so eigenartig spezialisiert, daß sie einen geschlossenen Typus für sich zu bilden scheinen. Anderseits ist die morphologische Bedentung ihrer Jochbogenbildung noch unklar. Wir wissen nicht, ob ihre Wangenregion psendosynapsid ist wie bei den Plesiosauriern und 
Placodonten. oder ob sie mindestens epistatisch auf einen Lrzustaud zurückgreift. indem ein seitlicher mterer Dnrchbruch der schäfenregion iiberhanpt noch nicht ansgebildet war. Jedenfalls scheinen die Ichthrosamier anch in diesem Punkte mit den Mesosauriern zu harmonieren, und wenn wir diese als nächste Terwandte der Ichthrosaurier ansehen, so wird sich wohl bei den jetzigen stande mserer Kenntnisse gegen eine derartige Anordnung nicht riel sagen lassen. Eine ancestrale Beziehnng zu den Nothosamiern als ältesten Enaliosauriern elscheint jedenfalls fraglicher als je. nachdem wir in Anarosanlus einen sehr primitiren Yothosaurier kennen gelernt haben. (Jaekel, Zool. Anz. 1910, S. 326. Fig. 1.) Ausgeschlossen erscheint anch nicht, dab sich die Ichthrosamier ron dinocephalen Paratherien abzweigten. T'm dieser Frage aber näher zu treten, müssen wir rolerst weitere Kenntnisse ïber die Organisation jener noch wenig anfokekärten Dinocephalen abwarten.

schwierig ist anch ferner die Frage einer stufenweisen Gruppierung aller Ordnnngen. Weil wir dabei neue Tege der Anordnung einschlagen müssen. Zunächst sind wir wohl alle darüber einig. daB die Dinosaurer die höchste stufe der normalen Reptilentwicklung darstellen, nnd daß die Pterosaurier sich ron dort als spezialisierte Trpen seitwärts abzmeigten. Ebenso dürten wir darïber einig sein. daB als ältere stufe trpischer Reptilorganisation stammesgeschichtlich nur die Formen un Palaeohatteria und Protorosanxus in Betracht kommen können. Damit sind Wenigstens zwei Etappen der Hauptentwicklung, festgelegt. Wir werden anch dariber nicht im Zweifel sein. daß Formenkreise wie die Rhynchosauri. Enaliosami, Champsosami Ordnnngen sind. die sich seitwärts ron der Hauptrichtung abgezweigt haben. Auch das ist klargestellt. daß die Eidechsen. Mosasanrier nnd Schlangen eine phyletische Einheit bilden, nnd daß in dieser die Mosasanrier und Schlangen die aberranten, die Eidechsen die normaler entwichelten Trpen sind. Aber nun entsteht die Frage, ob wir diese Eidechsen als Hauptordnung einreihen sollen, oder als aberrante Jebenordnung ansehen. Es scheint, daß es nicht zweifelhaft sein kann. daß anch ihre Erformen nicht zu den Dinosanriern überoeleitet haben, sondern daß deren Ausgangspunkt bei weniger spezialisierten Trpen zu suchen ist. Schon die Rückbildung des nuteren Tangenbogens rerweist die Eidechsen und ihren ganzen Terrandtschaftskreis in eine seitemichtung. Ich glaubte aber bei der nun getroffenen Anordnung in drei stufen als Tnterklassen. Ton einer gleichwertigen Behandlung dieses Formenkreises als Cnterklasse absehen zn missen nnd habe sie als Tebenordnung Lrognathi den .. Holosauria“ untergeordnet. schwierigkeiten bereiteten anch die sogenannten Rhynchocephalen, deren Hanptrertreter die sphenodonten und die Rhrnchosanier sind. Während die letzteren als 
selbständige Nebenordnung aufgefaßt sind, habe ich die Sphenodonten als Unterordnung den Protorosanriern eingereiht.

Eine schwer zu präzisierende Stellung nehmen die Procolophonii, die Mesosaturi und die Ichthyosauri in einer solchen Stufenreihe ein. Ihre Schädelbildung, speziell der Hangel eines nnteren Schläfen- oder Wangendurchbruchs scheint sie ans dem Kreise der Reptilien in deren neuer Fassung anszuschlieBen, und doch gehören sie ihrer ganzen Organisation nach unverkennbar hierher. Mir scheint num, daß der Mangel eines unteren Schädeldurchbruches bei ihnen auf Urzustände zurïckreicht, in denen diese Durchbrüche noch nicht ganz fertig waren, in denen sich zunächst der obere Durchbruch gebildet hatte, aber die Wangenregion noch geschlossen bhieb. Wenn wir num nnverkemubare Stammformen der Reptilien wie Gephyrostegus schon in deren Kreis als Vorformen aufnehmen, würde uns damit eine Vorstufe oder erste Stufe der Reptilienentwicklung gegeben sein, an die wir in Seitenrichtungen die Procolophonii, Mesosauri und Ichthyosanri anschließen, und von der wir in der Hauptrichtung der Reptilienentwicklung die Protorosauri als zweite stufe ableiten kömnen. Das ergibt folgende Gruppierung der Ordnungen:

I. Stufe (Vorstufe) drchaeosanria als Unterklasse.

Hauptordnungen:

I. Gephyrostegi
Nebenordnungen:

I c Procolophonii

I $\beta$ Mesosauri

I\% Ichthyosauri

II. Stufe Holosauria als II. Unterklasse.

II. Protorosauri

II $\_$Rhynchocephati

II Es Enaliosauri

II $\gamma$ Cliampsosanri

II $\delta$ Lyognathi

HI. Stufe als Hyperosauria als III. Unterklasse.

III. Dinosauri

III " Crocodili

III $\beta$ Aetosauri

III $\gamma$ Pterosanri

\section{Stufe als Unterklasse Archaeosauria.}

Niedrig organisierte Reptilien mit den primitiven Merkmalen der Klasse: allen primären Schädelknochen, einem Hinterhauptscondylus, pterygopalatinen Ganmen, Ausbildung freier Rippen in der ganzen Halsund Rumpfregion, Ausbildung von Banchrippen, mit Claviculis und 
Tförmiger Interclavicula, 2 Sacralwirbeln, mit der Phalangenformel 2.3.4.5.4, die allerdings wie anch sonst bei vorgeschrittener Anpassung an das Wasserleben ïberschritten wird. Wirbel diplocöl. Schwanz lang. Noch nicht fertig ausgebildet ist die Brïckenbildung in der Schläfenregion und die Ausbildıng zweier Schläfendmrchbrüche.

Eine präzise Abgrenzung einer solchen Vor- und Durchgangsstufe läßt sich natürlich nicht gewimnen. Die normale Übergangsreihe muß Formen umfassen, die zwischen den Miosauriern, den typischen Reptilien (Holosauria) und den ältesten Paratherien eine vermittelnde Stellıng einnehmen. Eine solche Position wurde bisher den Cotylosauriern zugeschrieben, die eiust von Edward Cope aufgestellt wurden, und denen der Verwandtschaftskreis des siidafrikanischen Pareiasaurus zugerechnet wurde, für den Seeley auch den Namen Pareiasauria aufstellte. Wie bei Besprechung der Miosauria begründet wurde, scheint es angebracht, daß man diesen die Copeschen Cotylosanria einordnet. Sie enthielten in den Datheosamiern Formen, die dem Anfang der Reptilien-Entwicklung sehr nahe rücken, andere, die sich nach keiner dieser beiden Richtungen festgelegt haben. Da nun solche Übergangsund Zwischenformen in dem einen Merkmal mehr nach dieser, in dem andern mehr nach jener seite inklinieren, so wird natiirlich ïber die genaue Stellung der einzelnen Form kaum eine volle Einigung zu erzielen sein. Der Charakter der Zwischenform kommt durch solche Kontroverse nur noch klarer zum Ausdruck.

Als Formen der Hanptreihe werden wir solche anffassen, in denen die Organisation sich in der Richtung der Reptilien spezialisierte, aber nach keiner Seitenrichtung anffallend abwich. Das ist anscheinend der Fall bei einer Anzahl von permischen Typen, bei denen temporale Schädeldurchbrïche entstehen, aber noch keine feste Form erlangt haben, ja sogar nach Case anf den beiden Seiten eines Schädels verschieden sein können. Leider sind diese noch nicht genügend anfgeklärt, um hier eine klare systematische Stellıng zu finden. Solchen Typen werden andere als Nebenordnungen angeschlossen, nämlich die Procolophonii Siidafrikas und die aquatischen Typen der Mesosaurier und der Tchthyosalurier.

\section{Hauptordnung Gephyrostegi.}

Im Schädel sind zwar noch alle Elemente des sogenannten Stegocephalen-Typus rorhanden, aber der Schädel hat nicht nur die höhere Form und leichtere Struktur des Reptilschädels angenommen, sondern verstärkt sich auch in der Richtung der späteren Jochbögen und verdïnnt die temporalen Zwischenregionen bis zum teilweisen Durchbruch. Bei Gephyrostegus selbst sind diese Stellen nur verdünut oder entbehren 
der Skuptur (Fig. 150) und kennzeichnen dadurch die stellen der späteren Durchbritche. Stammesgeschichtlich sind solche Ansgangsformen wie der in Fig. 150 abgebildete Gephyrostegus den Rejtilien zuzurechnen, systematisch könnte man sie wegen ihres Schädelbaues noch den Miosamier'n zuzählen.

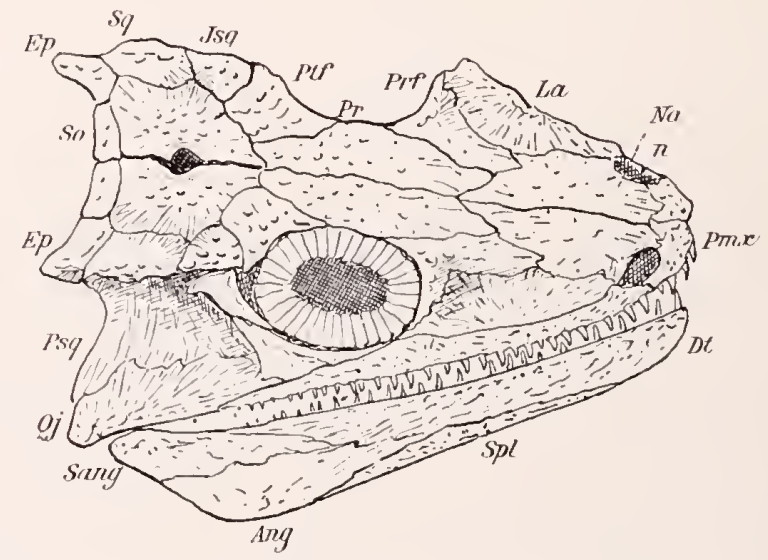

Fig. 150. Seitenansicht eines schief zusammengedrückten Schädels von Gephyrostegus bohemicus Jkl. aus dem obersten Karbon von Nürschan in Böhmen. $2 / 3$ nat. Größe. (Nach Jaekel.)

Bei anderen permischen Formen scheinen wis gesagt echte Durchbrüche erfolgt zu sein, aber noch keine morphologische nnd crbliche Konstanz erlangt zu haben. Termutlich werden mus die Untersuchungen ron Case hier bald nene Formen näher kennen lemen.

\section{Ta Nebenordmung Procolophonii Seeley.}

Kleine vierfüßige Landtiere mit kurzem, hinten velneitertem schädel, der noch alle primären Schädelelemente nnd die seitlichen Schädelecken der Occipitahegion und ein großes Scheitelloch (Epidyse) enthält. Die Nasen liegen weit vorn, die Angenhöhlen sind sehr groß und nach hinten ausgedehnt, so daß hinter ihnen nur ein kleines schläfenloch Platz findet, das offenbar zusammengedrängt ist. Ganmenfläche mit vielen Durchbrüchen. P'teryoidea ziemlich groß aber nicht in der Fläche verbroitet, Tomera, Transversa nnd Parasphenoid wohl ausgebildet. Tomer und Pteryooid mit kleinen /ähnen besetzt: größere komprimierte auf dem äuBeren Kieferrand. Coracoid und Procoracoid getremt. Claviculae und lange Interclavicnla, Pubis mit Foramen obturatorimm. Zehenformel typisch 2.3.4.5.4. Handwurzel mit zwei Centralien, Pisifonne und 4 distalen Carpalien. Fnßwurzel primitir mit 4 distalen Tarsalien. Wirbel diplocöl und durchbohrt ron der Chorda. 
Interzentra im Hals und vorderen Schwanz. Die genanere ron Broom zu erwartende Beschreibung des einzigen Typus Procolophon trigoniceps Owen ans dem Perm von Suidafrika steht noch aus.

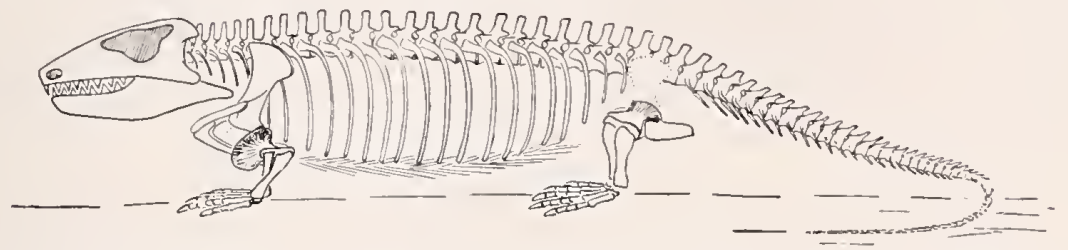

Fig. 151. Koiloskiosaurus coburgiensis v. Huene, ein Procolophonier aus dem mittleren Buntsandstein von Koburg. Rekonstruktion $1 / 3$. (Nach F. r. Huene.)

\section{3 Tebenordnung Mesosauri (Proganosauri Baur).}

Die Mesosaturier (Mesosaurus und Stereosternum) sind leider im Schädelbau noch nicht genïgend aufgeklïrt, aber nach allem, was nus

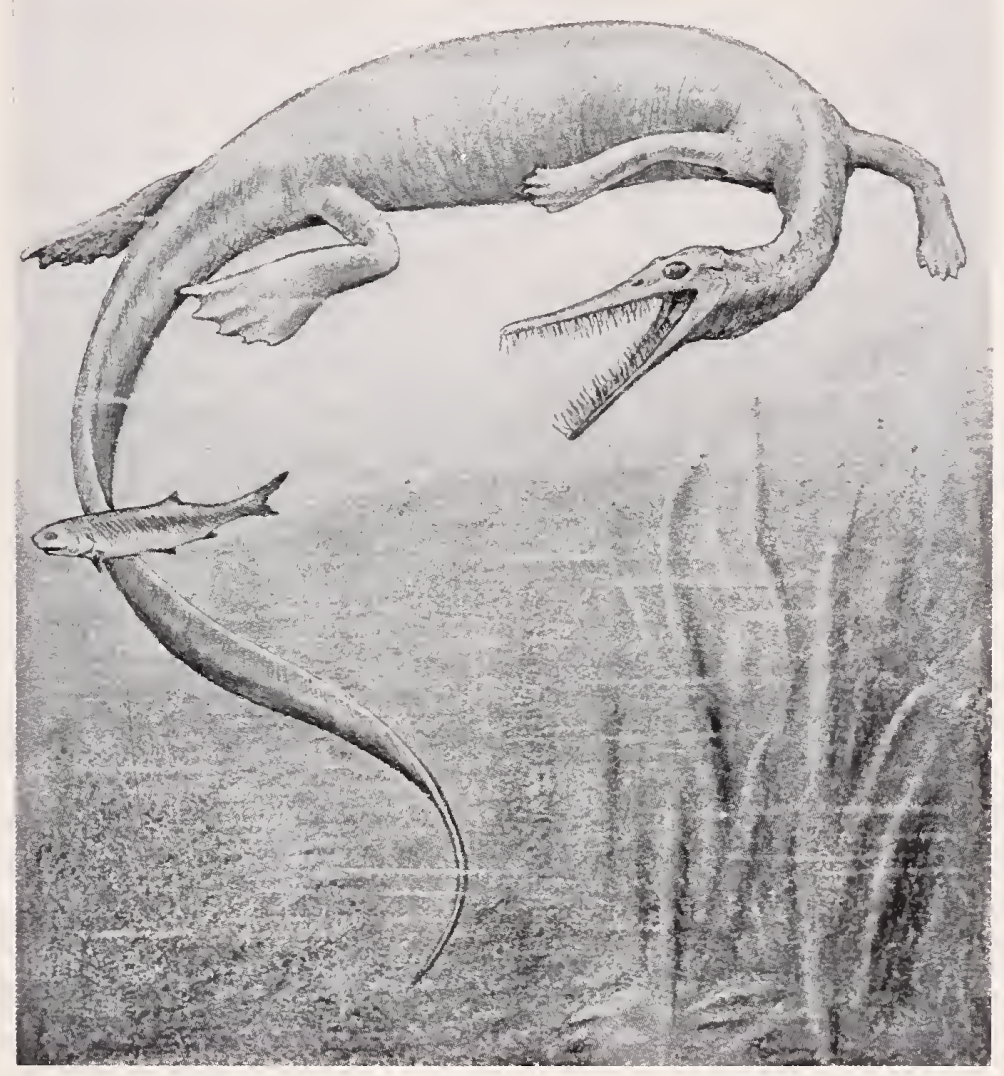

Fig. 152. Mesosaurus brasiliensis McGregor. Oberes Perm von Süd-Brasilien.

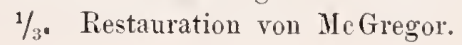


rom Skelett rorliegt, scheinen sie eine ancestrale Stellung sowohl den Ichthyosamiern wie den Nothosanriern gegenüber einzmnehmen. Daß ihre Abkmft ron Palaeohatteria-artigen Formen so direkt anzmnehmeu ist, wie dies gewöhnlich geschieht, ist mir zwcifelhaft; im Schädelban entfernen sich beide Formen sicher ziemlich weit roneinander, und es erscheint im besonderen fraglich, ob bei den Mesosanriern ïberhaupt schon ein unterer schläfen- oder ."Wangen"-Durchbruch ansgebildet war. Es sind:

Langgestreckte vierfiißige Schwimmformen mit langem zugespitztem, scharf bezahntem Kopf, mit rückwïrts gerückten Nasen. großen Angen mnd oberen Schläfengruben. Ob Wangengruben vorhanden waren, ist fraglich. Zähne lang, zugespitzt, schwach gekrümmit, in Alveolen befestigt. Schulter und Beckengürtel ventral flächig ansgebreitet. Hmmerus oben schlank, unten verbreitert mit Foramen ulnare. Vordere Fulbwurzel mit 3 proximalen, 4 distalen. Hinterfuß mit 2 proximalen, 5 distalen Knochen. Zehenformel 2.3.4.5.4. Wirbel rerdickt, diplocöl. Rippen dick einköpfig. Schwanz ling im vorderem Teil mit langen Qnerfortsïtzen, im mittleren Teil gebrochen mit langen unteren Bögen und Dornfortsätzen. Dünne Bauchrippen sind vorhanden. Die Ordnnng bernht anf zwei Formen: Sterensternmm in oberen Perm von Südbrasilien und Mesosaurus in gleichartigen Schichten Südafrikas mid Sïdanerikas.

\section{Iy Nebenordnumg Ichthyosauri Blainville (Ichthyopterygia Owen).}

Die Ichthyosauri sind dmrch Verlängermng ihrer Schnanze, die Vergrößerung ihrer Angen, die Terkürzung ihres Halses und ihrer Wirbel und die Flossenform ihrer Fïße ausgezeichnet, in denen sie starke Hyperphalangie und teilweise Hyperdactylie bis zn zehn Zehen erreicht habeu. Zu ihrer allmählichen Anpassung an die Fischform gehört die

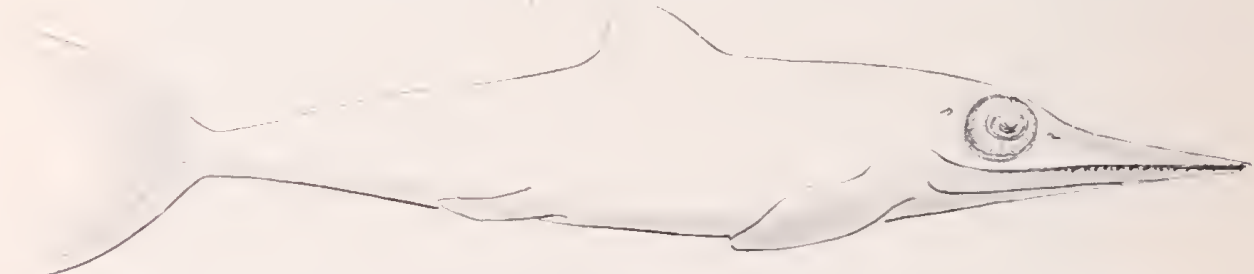

Fig. 153. Rekonstruktion der äußeren Form von Ichthyosaurus. (Nach Jaekel.)

Rednktion der hinteren Gliedmaßen und des Beckens, die Ansbildung einer hrpocerken Schwanzflosse und einer Iorsalflosse. Innerhalh dieses Formenkreises, der in der Trias mit indifferenteren Formen einsetzt und mit zahnlosen Riesenformen in IIalm- und Kreideschichten auslänft, machen sich zwei hesonders anffallende divergente Entwicklungsrich- 
tungen goeltend, indem die einen ihre Brustflossen unter sehr starker Hyperphalangie in die Länge ausdehnen und unter Reduktion der Zehenzahl rerschmälern, die andern ihre Brustflossen kurz und breit formen und bis fünf überzählige Finger produzieren. Eine befriedigende Gliederung dieses enggeschlossenen, aber' formenreichen Typus hat sich noch nicht durchführen lassen.

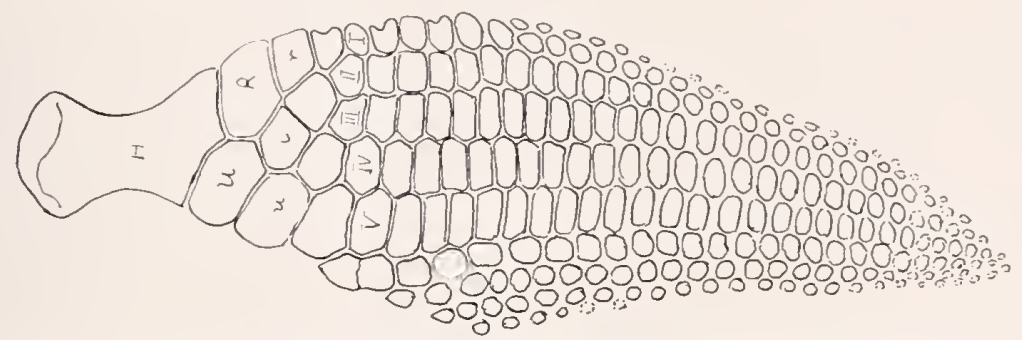

Fig. 154. Rechter Arm rou Ichthyosaurus communis Con. var. hyperdactyla m. Unterer Lias von Lyme Regis, Engl. (Nach einem Exemplar des Stuttgarter Museums.)

\section{Stufe als Unterklasse Holosauria.}

Die Reptilcharaktere sind hier voll ausgeprägt, die beiden schädeldurchbrüche. die bei der älteren Stufe noch z. T. fehlten, sind hier ausgebildet und bei einigen aberranten Typen (Enaliosauri, Lepidosanri) ist der untere Bogen wieder rückgebildet. Wird dann bei stärkerer Kaufunktion der übrig gebliebene obere stark angespannt und verdickt, so erscheint er wie der einfache "synapside* Jochbogen der Paratherien, ist aber seiner Genese nach .pseudosynapsid“. Die Abweichnngen ron der Hauptrichtung erfolgen einerseits durch Anpassungen an das Wasserleben, andererseits aber auch durch die kriechende Lebensweise wie bei den Schlangen.

Definition: Kletter-, Lauf- oder Schwimmtiere meist mit normalen Füben und mäßig langem Hals, langem Schwanz, mit einfach gebautem, rom verjüngtem Kopf, mit mindestens einem oberen, meist aber zwei schläfendurchbrichen, einfach kegelförmigen, stephanodont, acrodont, selten bothrodont befestigten, z. T. noch in der Gaumenfläche verbreiteten Zähnen, einfachem Condỵlus occipitalis. Tirbelkörper zuerst diplocöl und amphicöl ${ }^{1}$ ), öfter Subzentren ${ }^{2}$ ) vorhanden. Hium lang, in der Regel an 2 Sacralrippen befestigt. Rippen meist zweiköpfig, nur bei resschiedenen Wasserbewohnern vereinfacht. Interclaricula nit

1) "Diplocöl", vorn und hinten ausgehöhlt, „amphicöl" (Jkl.) im Umfang hohl, d. h. eingesenkt.

2) Die bald als Hypozentra, bald als Interzentra bezeichneten kleinen basalen Zwischenstiicke, denen ich eine primäre Bedeutung abspreche. 
Stermalprozels. Dümne stahföruige Gastralia ${ }^{1}$ ) vorhanden. Humerus mit Foramen uhnare ${ }^{2}$. Zwei proximale Carpalia mnd Tarsalia. Normale Plaalangenzalıl 2.3.4.5.4.

Perm lis jetzt. Znmeist in der nördlichen Hemisphäre.

\section{Hamptordnung Protorosami seeley.}

Drfinition: Bämme oder Felsen hewohnende Klettertiere von Katzen- oder Hundegröße mit langen Halswibeln nnd langem sehwanz. Wirbel tief diplocöl. Subzentralia vorhanden. Zïhne schlank, bothrodont, nicht anf die Kieferändel beschünkt. Humerus proximal und distal sehr verbreitert. Zehenzahl normal. ¿ sacralwirbel. Palaeohatteria Credn. im nnteren Perm bei Inesden. Haptodus Gandry vou

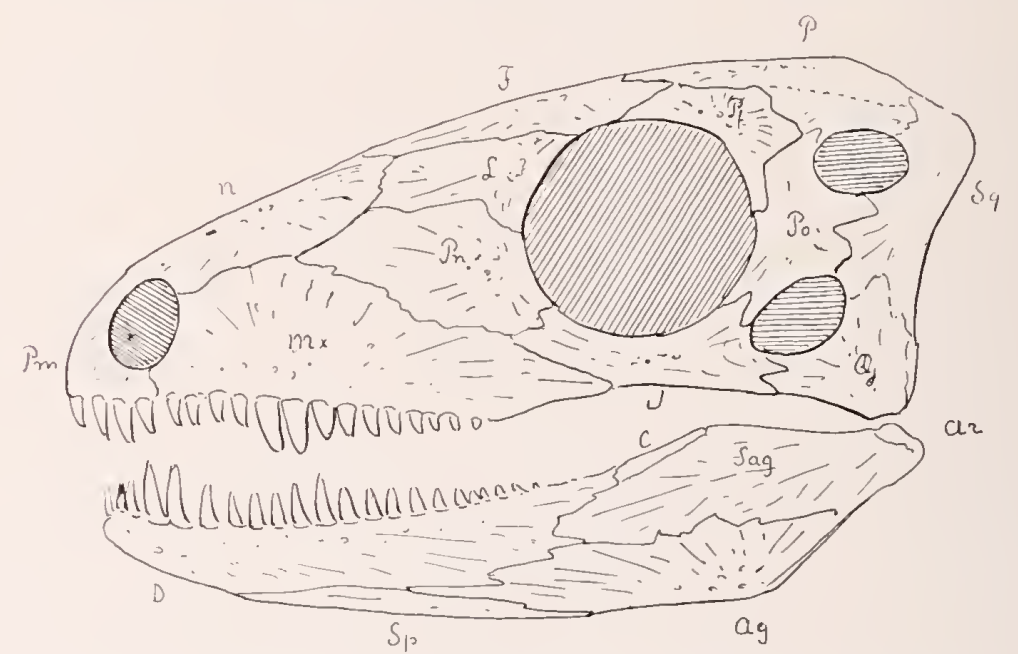

Fig. 155. Schädel von Palaeohatteria longicaudata Cred aus dem mittleren Rotliegenden (mittl. Perm) von Niederhäßlich bei Dresden (neue Rekonstruktion in nat. Größe auf Grund des Originalmateriales).

$P m$ Praemaxillen, $I x$ Maxillen, $N$ Nasalia, $F$ Frontalia, $P$ Parietalia,

$L$ Lacrymalia, Pn Postnasale, Pf Postfrontalia, Po Postorbitalia, $S$ Squamosa, J Jugalia, Qj Quadratojugalia, D Dentale, Sp Spleniale, C Complementare, Sag Supraangulare, Ag Angulare, Ar Articulare.

Antun, Kadaliosanuins Crd, in oberen Lagen des nnteren Perm bei Iresden, Protorosamus H. v. M. im oberen Perm sind Tertreter dieses Formenkreises, der leider noch insofern mangelhaft bekannt ist, als der Schädel dieser Formen noch nicht in allen Teilen klargestellt ist. Dadurcli, dab mir Herr Geheimrat Prof. Dr. H. Credner sein kostbares

1) Gastralia von Voeltzkow für die sogenannten Bauchrippen vorgeschlagen.

2) Foramen „uhnare" für F. entepicondyloideum. 
Material sächsischer Paläohatterien zur erneuten Untersuchmo g’ütigst anvertrant hat, konnte ich wenigstens eine kleine Terbessernng der Darstelhnng des Schädels ron Palaeohatteria bringen (Fig. 155).

Iie Protosani als prinitirste und einfachste Archaeosauria gingen wahrscheinlich ohne scharfe Grenze ans Miosanriern wie Gephrrostegus

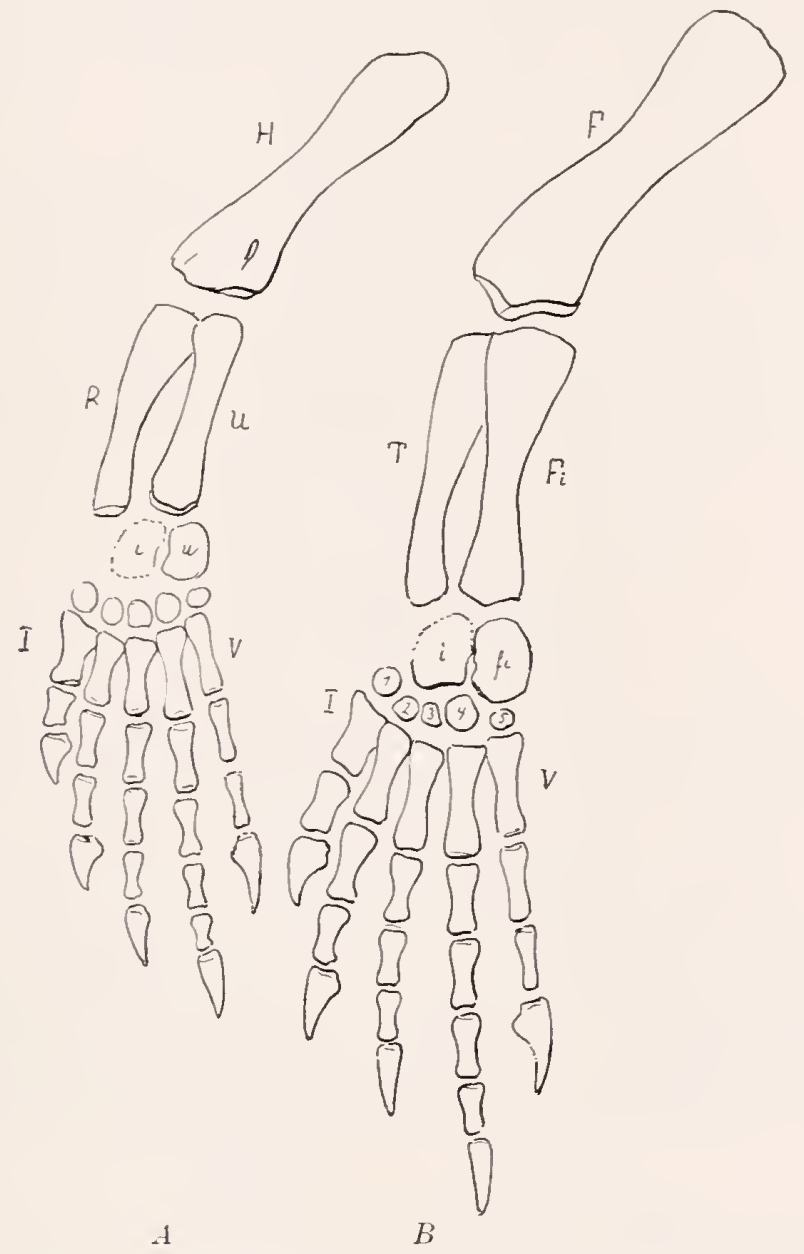

Fig. 156. Gliedmaßenskelett von Palaeohatteria longicandata Cred.

A Vorder-, B Hinterfuß. (Nach Jaekel.)

herror, bei dem an der Stelle der schläfen- und Tangengruben wohl Terdünnungen. aber noch keine Durchbrüche der schädelwand vorhanden waren.

An Anfang der Ordnung steht Palaeohatteria aus dem unteren Perm, der in jeder Beziehung den Typus eines normalen, aber noch sehr primitiven Reptilis darbietet. Der Schädel ist ziemlich hoch. 2 Schädel- 
durchbriche sind rorhanden, aber der untere noch sehr klein und in Terhältnis zu den ihn umrahmenden Knochen noch nicht ganz reguliert.

An Palaeohatteria schlossen sich andere Formen, wie Kadaliosaurus, Aphelosaurus, Protorosaurus im oberen Perm, der größer, in seiner Skelettiel'ung wesentlich fortgeschritten und besonder's in seinem Halse riel beweglicher gewrorden ist. Ton derartigen Formen des obersten Paläozoikum sind wahrscheinlich die meisten jüngeren Reptiltypen ausgegangen, so auch die

\section{Unterordnumg Naosauri (Pelycosauria Cope).}

Die Naosaur, die ron Edw. Cope znerst unter dem Namen Pelycosauria mit den Theriodontiern und damit den Paratherien in nächste Beziehung gebracht wuden, haben sich mehr und nehr als ummittelbare Terwandte der ältesten Protorosauri, speziell von Formen wie Palaeohatteria erwiesen, mit der sie auch ränmlich und zeitlich zusanmen anftreten. Sie haben sich offenbar durch einseitige Spezialisierung ilurer

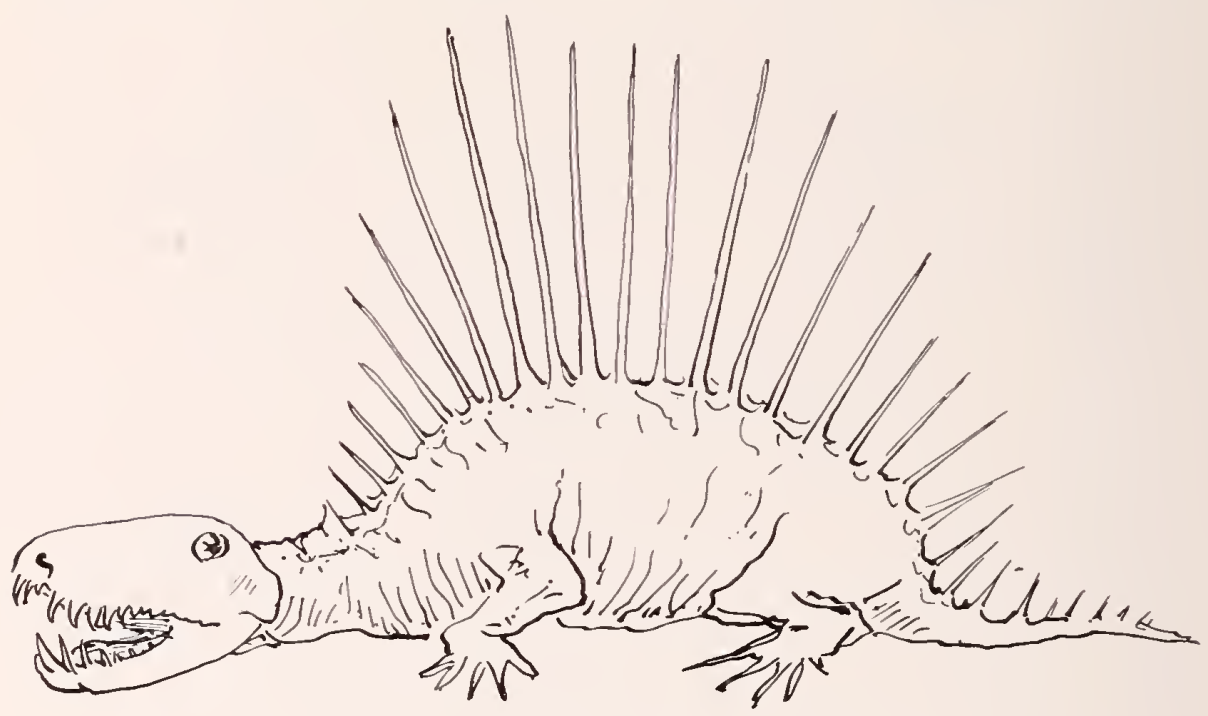

Fig. 157. Dimetrodon Cope. Perm von Texas. (Umrißfigur nach Jaekel.)

GebiBform und ihrel Rückenstacheln seitwärts abgezweigt, aber meines Erachtens nicht so weit, daß wir sie nicht als Unterordnung bei den Protorosauriern halten könnten. Formen wie die Poliosauriden, speziell Theropleura stehen Palaeoliatteria noch so nahe, daß man sie deren Familie angliedern könute. Die Spezialisiermng des Gebisses und der Dornfortsätze bleibt dann fül die übrigen Naosani charakteristisch. Das klärt die Definition dieses Formenkreises. Es sind stark an- 
wachsende rierfüBige Protorosanrier mit stark verlängerten aus dem Rücken spitz rortretenden Dornfortsätzen der Rumpfregion und stark rergrößerten säbelförmigen Hauzähnen im vorderen Teil der Maxille, der sich nach unten aushiegt. Der schwanz und Hals rerkiurzt sich in dem Maße ilner Spezialisiermo:

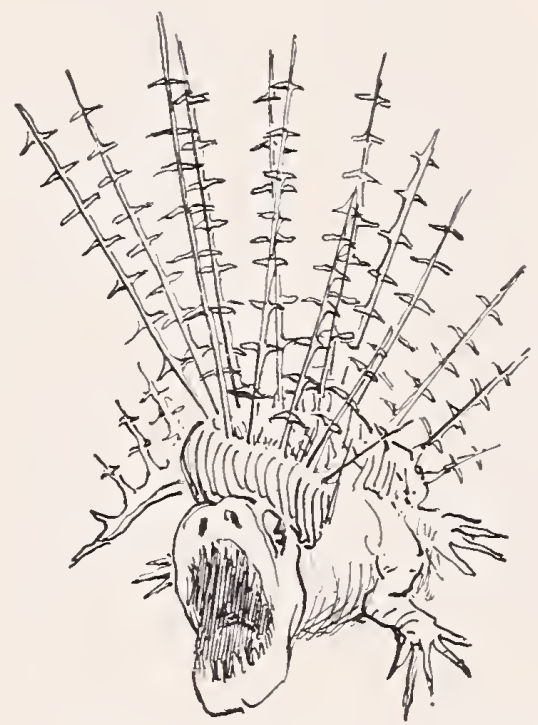

Fig. 158. Naosaurus Credneri Jkl. mittl. Rotliegendes.

Niederhäßlich bei Dresden. Rekonstruktion. (Nach Jaekel.)

Die Riickendornen wurden frïher so dargestellt, als ob sie durch eine Haut bis zum Ende verbunden waren. Damn hätten sie aber dem Organismus keinen Nutzen gewährt und ihn nur ungehener belastet und in seiner Beweglichkeit behindert. Daher scheinen mil obige Rekonstruktionen, in denen diese stacheln als Schutzwehr frei herausragen, dem Charakter ihrer Spezialisierung besser gerecht zu werden.

\section{Tnterordnung sphenodonti.}

Stephanodont bezahnte Rhynchocephalen. die als Landtiere Kletterfüße besitzen, oder im Tasser zu Krokodil- oder Protensähnlichen Schwimmformen umgebildet sind. Schädel hoch gewölbt. zierlich gebaut, mit Zähnen auf den Gaumenknochen und einreihiger Bezahnung der Kieferränder. Hierhin gehören der triadische Polysphenodon mit bezahnten Pteryooiden, die Homoeosauriden des Jura, die Proteusund Samranodontenartigen jurassischen Anguisauriden mit ihrem langen komprimierten Hinterleib und rudimentären, weit nach vorn gerïckten Gliedmaßen, und der lebende sphenodon ron Neu-Seland. 


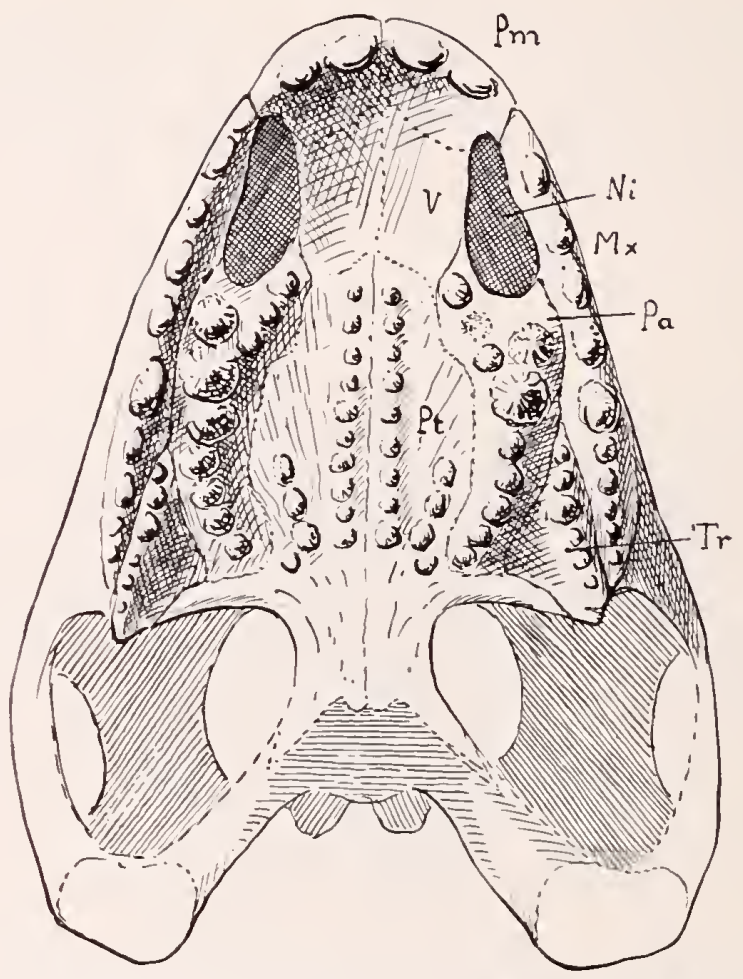

Fig. 159. Gaumenfläche des Schädels von Polysphenodon Mülleri Jaekel. Mittl. Keuper von Fallersleben. Hannover. $4 / 1$.

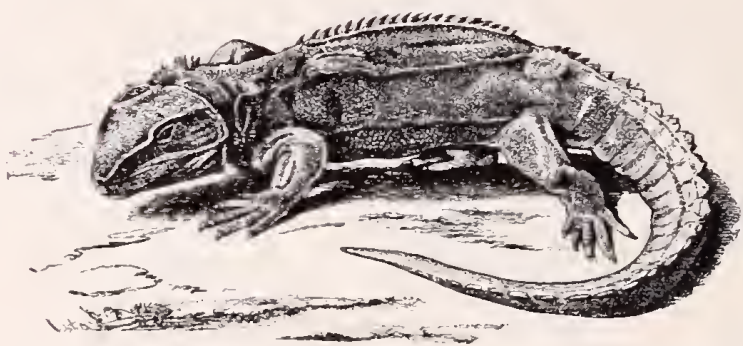

Fig. 160. Sphenodon punctatum lebend in Neu-Seeland. (Nach Haacke.)

\section{II a Nebenordnung Rhynchosauri Osborn.}

Mittelgroße schwerfällige Vierfüßler mit kurzen Gliedmaßen, diplocölen Wirbehn, deren kräftig verknöcherter Schädel zum Kanen von Huscheln aptiert ist. Die Kieferränder sind zahnlos, die Prämaxillen und die vordersten Teile des Unterkiefers schnabelartig verlïngert, wahrscheinlich mit Hornschnabel. Pterygoidea, wahrscheinlich auch Palatina mit dicht gedrängten acrodonten Höckerzähnen gepflastert. Nasen 
vorn. Augenhöhlen in der vorderen Hälfte des Schädels. Schläfengruben groß, Wangengruben klein; walırscheinlich auch hintere Durchbrüche vorhanden. Rhynchosaurus und Hyperodapedon. Beide in der unteren Trias von England, letztere auch aus Indien.

\section{II $\beta$ Nebenordnung Champsosauri (Choristodera Cope).}

Krokodilförmige Wasserbewohner, mit lang zugespitztem Schädel, vorngelegenen Nasenlöchern, normal entwickelten Schläfen und Wangenbögen und je zwei Durchbrüchen jederseits. Zähne acrodont, spitz, kegelförmig, innen gefaltet, Unterkiefer ohne Coronoidprozeß. Einige Interzentra an den Halswirbel und der Axis. 26 präsacrale Wirbel, 2 sacrale, Schwanz lang. Rippen vorne am Hals zweiköpfig, danach einköpfig, sehr nuassiv. Schultergürtel nit breiten, durchbohrten Coracoiden, großen Claviculis und gestielter Interclavicula. Ilia klein. Pubis und Ischia ausgebreitet. Humerus distal ausgebreitet, mäßig lang mit Incisura radialis. Zehenformel nornal. 2 Gattungen: Champsosaurus, obere Kreide Amerikas, Simoedosaurus, unterstes Tertiär Belgiens.

\section{II $\gamma$ Nebenordnung Sauropterygii Owen.}

Marine Schwimmformen, mit langen Hals, flossenartigen Füßen, schmalem, flachem Kopf mit verlängerter Schnauze, zurïckgeschobenen Nasen, mäßig kleinen Augen, in der Regel mit großen Schläfengruben und großer Epidyse, Wangenbogen verkïnmert, Postorbitalbogen bisweilen sehr gekräftigt. In dem pterygopalatinen Gaumen sind die Pterygoidea sehr ausgebreitet und unbezahnt. Transversa (Ectopterygoidea) vorhanden. Zähne einfach, mit rundem Quersclinitt und Längsleisten. Schnlter und Beckengürtel in der Ventralfläche sehr ausgebreitet. Scapulare und Ilium klein. Humerus nit rückgebildetem Foramen ulnare. Wirbel massiv, Rippen vorn zweiköpfig, im Rumpf einköpfig. Interzentra fehlen. Hierher gehören die Nothosauriden der Trias und die Plesiosamiden des Jura und der Kreideformation.

\section{Unterordnung Nothosauri m.}

Schlanke Wasserbewohner mit kleinen zum Schwinmuen wenig veränderten Gliedmaßen, mit ziemlich schlankem Humerus und Femur, langem Hals mit zirka 20 Wirbeln, und mäßig langem Schwanz. Gaumen unbezahnt mit median zusammenstoßenden Pterygoiden, volm getrennt gelegenen Choanen und breiten Transversa. Schläfenbrïicke dïnn, von Wangenbogen nur ein maxillarer Zipfel erhalten. Das Hinterhaupt fällt hinter einer parietalen Querleiste ab, die Paroccipitalia (Epiotica) 
gesondert von den Exoccipitalien. Wirbel kompalit sehwach amphicöl, Rippen einköpfig, Gastralia zahlreich, stabförmig. ihre Mittelreihe winklig gebogen. Schultergurtel nur rentral ansgedehnt, und dort in einen vorderen clavicularen und einen hinteren coracoidalen Bogen zerlegt, ebenso im Becken ein pubicaler und ischialer Bogen gebildet. In der Trias Deutschlands und der Alpen rerbreitet.

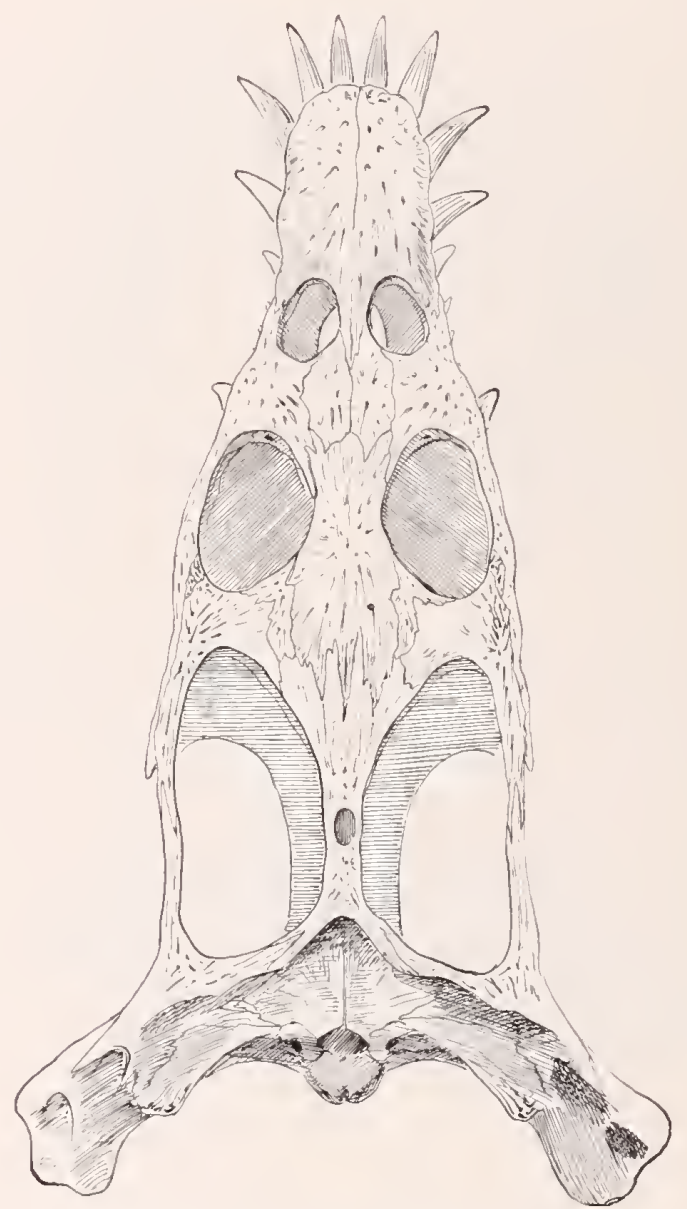

Fig. 161. Oberseite des Schädels von Nothosaurus (Cymatosaurus) cf. friedericianus v. Fritsch. Unterer Muschelkalk, Mühlhausen, Thüringen. $2 / 3$.

Hierher gehören die Anarosanridae mit kleinem schläfendurchıruch, die Simosanridae mit breitem Schädel (Fig. 162), die Nothnsantridae (Fig. 161) mit langen Schlïfendurchlhrüchen und die Pistosannidae mit schmal verjïngter schnanzenregion. 


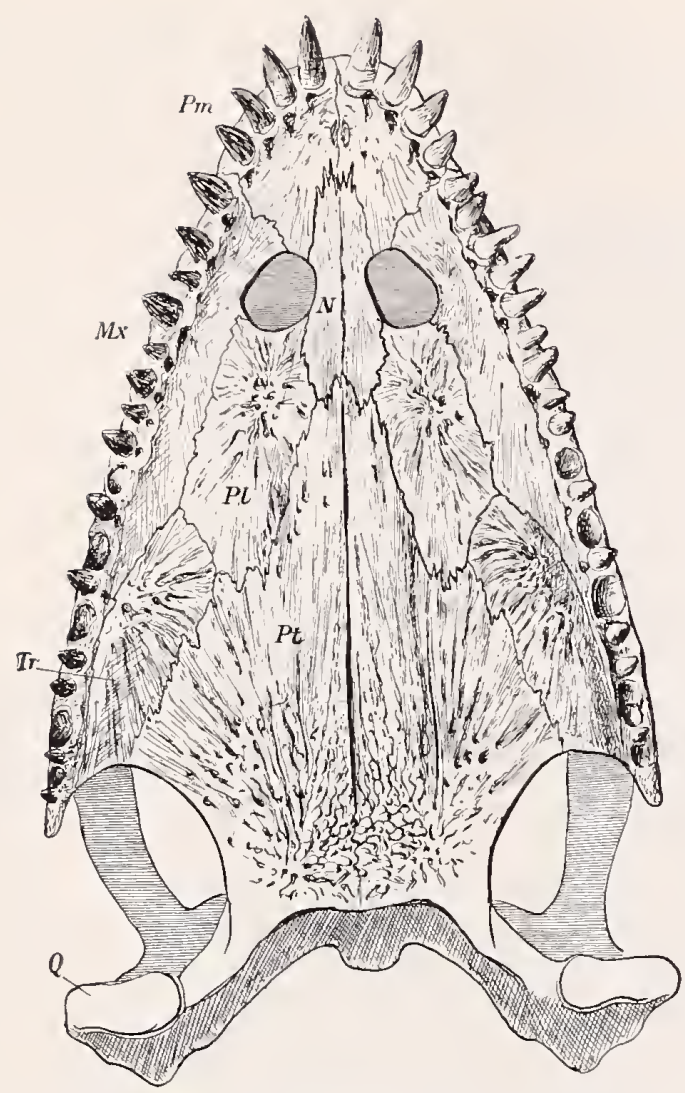

Fig. 162. Gaumenfläche von Simosaurus guilelmi. Oberer Muschelkalk, Württemberg. 1/2. (Nach Jaekel.)

2. Unterordnung Plesiosani.

Große strandhewohnende Meerestiere mit großen zu Flossen umgeformten Gliedmaßen, kurzem Rumpf und Schwanz. Schädel mit großen, schlanken Raubzähnen und kräftigem Schläfenbogen. Schulter- und

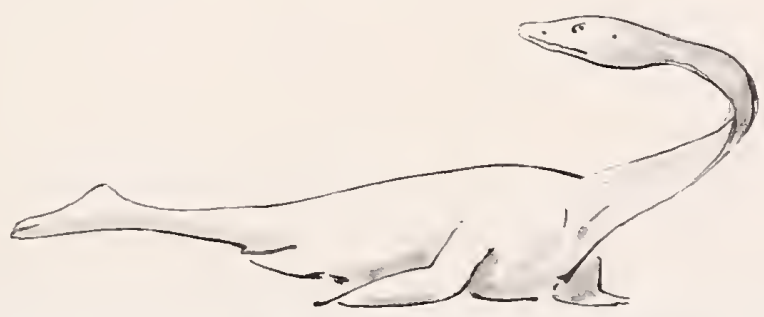

Fig. 163. Restauration eines jurassischen Plesiosaurus mit kleinem Kopf und langem Hals in liegender Stellung. (Nach Jaekel.) 
Beckengerüst rentral, in der Fläche sehr ausgebreitet, Gastralia stabförmig, mehrreihig ohne winklig gebogene Mittehreihe. In Trias, Jnra und Kreide weit verbreitet.

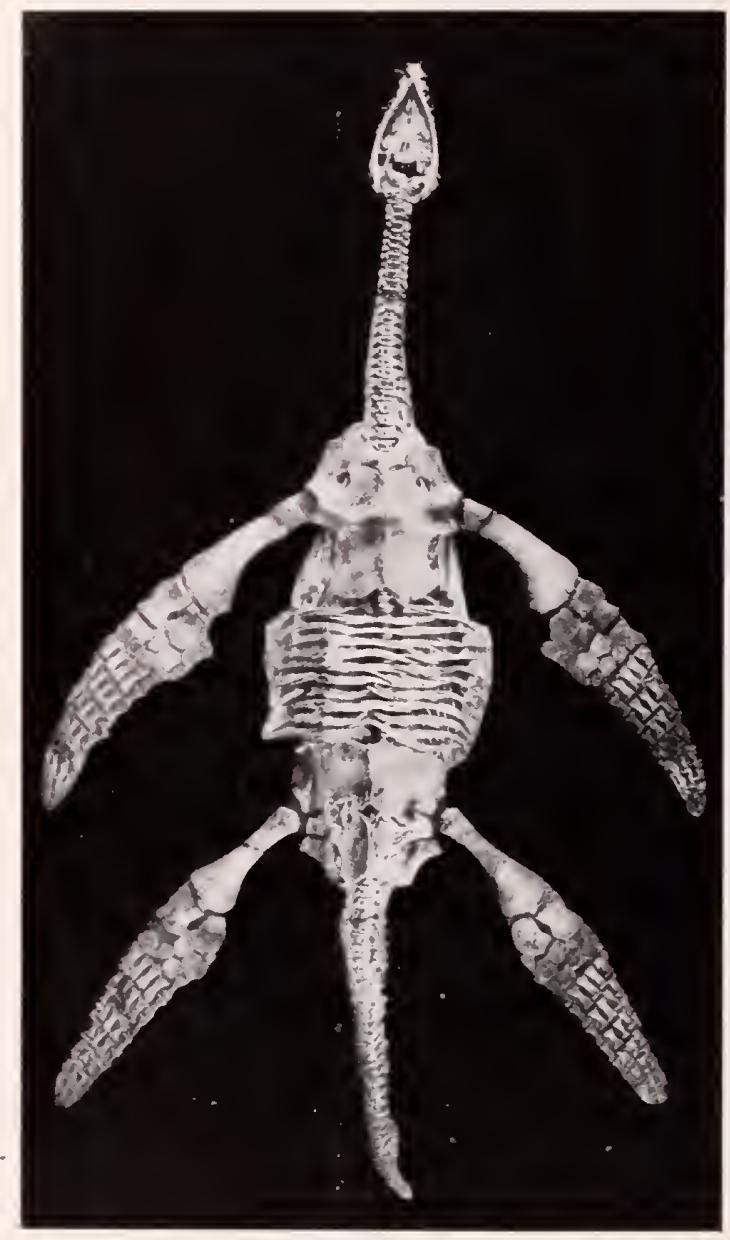

Fig. 164. Thaumatosaurus victor E. Fraas. Oberer Lias; Holzmaden, Württ. Bauchseite. (Nach Fraas.)

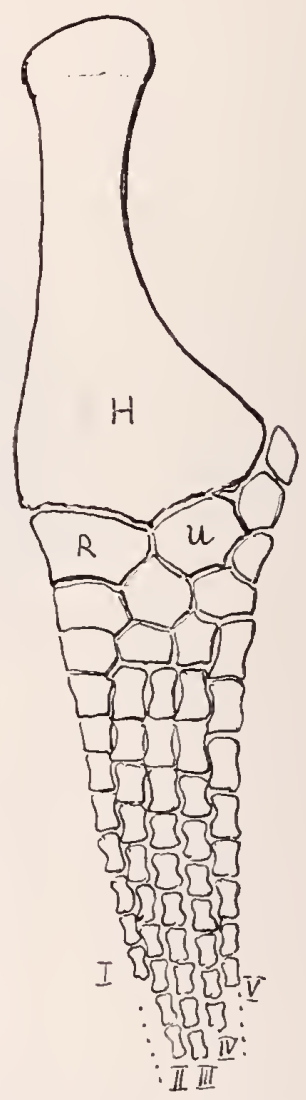

Fig. 165. Armskelett ron Polycotylus latipinnis Cope eines Plesiosauriers der nordamerikanischen Kreide.

(Nacl Williston)

\section{N Nebenordung Placodonti v. Meyer.}

Marine IInschelfresser, deren Gebiß nnd schïdel der Mnschelnahrung angepaßt ist, mit großen breiten Kanzïhnen auf den vereinigten Palatinen. Choanen ror den Palatina in einer Grnbe rereinigt. Jochbogen kräftig. Unterkiefer mit großem Kronfortsatz. Rumpf mit 
dorsalem Buckelpanzer, Bauchrippen dick rerwachsen. Die sehr eigenartigen Formen, Placodus, Cyamodus und Placochelys, sind mit den Nothosauriem eng verwandt, aber ganz einseitig spezialisiert. Mit ihrem Panzer und ganzem Habitus erinnern sie äußerlich an den Schildkrötentypus der Dermocheḷ̂den.

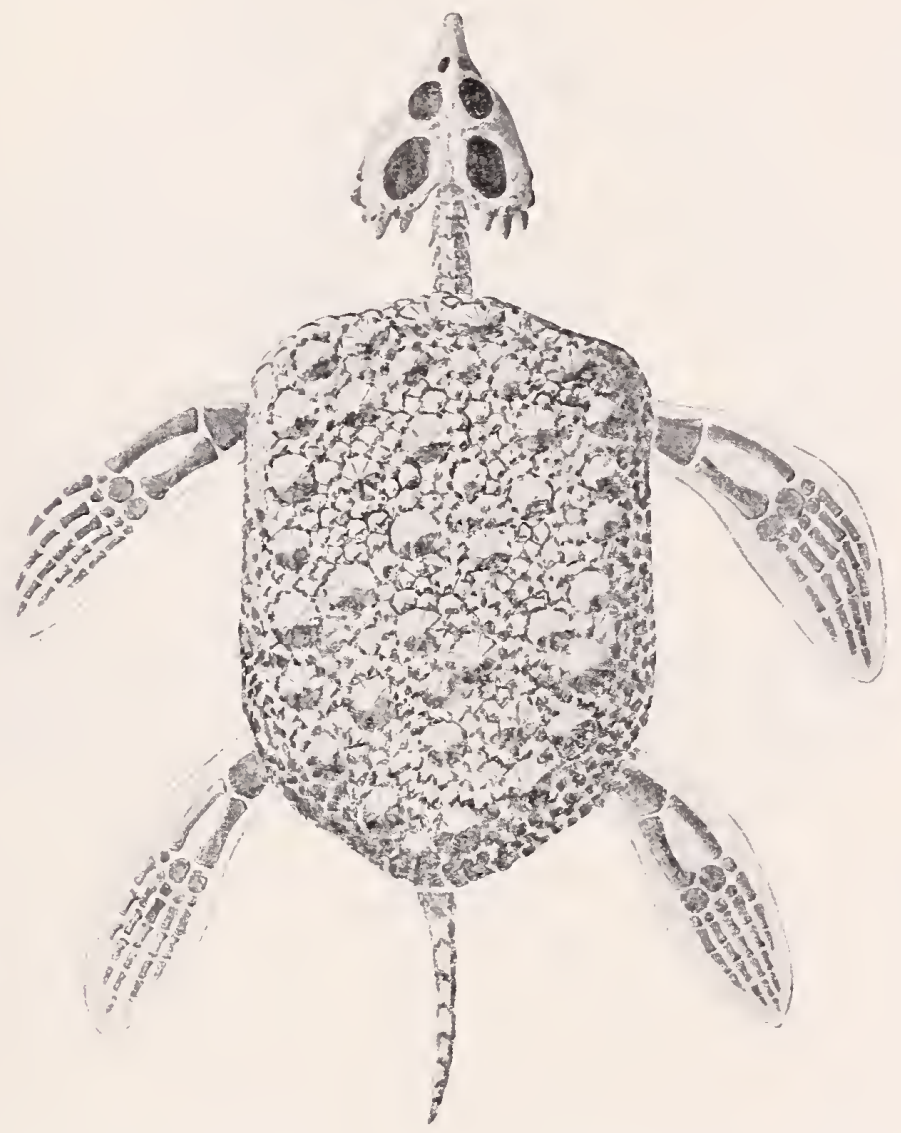

Fig. 166. Rekonstruiertes Skelett von Placochelys placodonta Jkl. Obere Trias. Vesprem, Ungarn. 1/8. (Nach Jaekel.)

Durch die kräftige Panzerung des Rückens und der Bauchseite erinnert Placochelys an die lebende Dermochelys. Innerhalb der Ordnung konzentriert sich die Bezahmung auf den Palatina und verkümmert auf den Prämaxillen und dem vorderen Teil des Unterkiefers. Auch die maxilläre Zahnreihe erfährt eine Reduktion ron 5 auf 3 Zähne. Placodus und Cyanrodus im germanischen Muschelkalk, Placochelys im Keuper Ungarns. 


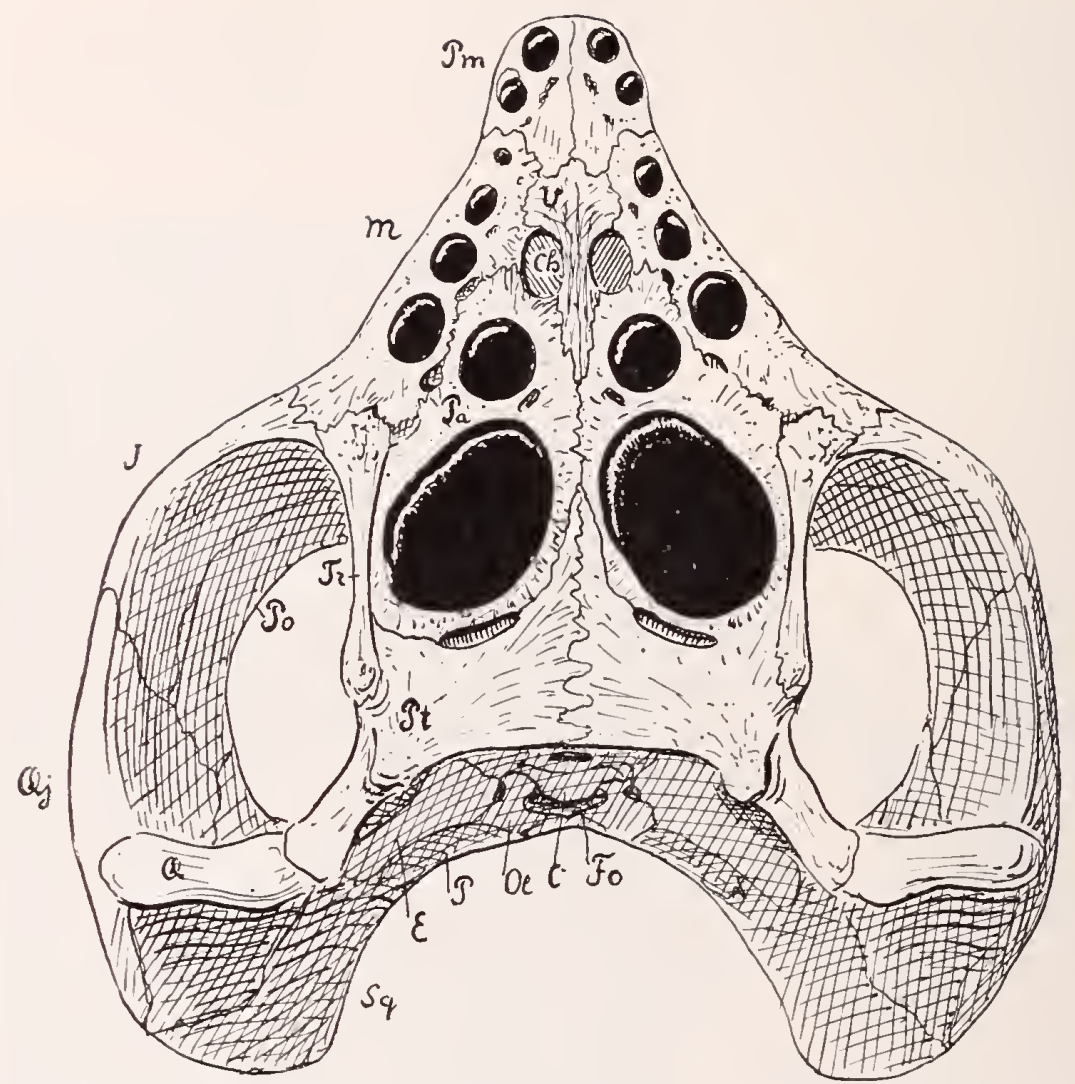

Fig. 167. Gaumenfläche des Schädels von Cyamodus tarnovitzensis Gür. mit großen, schwarzen Kauzähnen. Mittl. Trias (unt. Muschelkalk), Oberschlesien. ${ }^{2 /}$. (Nach Jaekel.)

II $\varepsilon$ Nebenordnung Lyoguathi Jaekel (Synamata, Lepidosamia, streptostylical).

Die engen Beziehungen der hier znsammengefabten Formen Lacerti (Fidechsen), (Ophidii (Achlangen) und Mosasanri (Pythonomorpha Cope) sind seit längerer \%eit festgestellt und allgenein anerkannt. Das anffälligste gemreinsane Kennzeichen der lebenden Formen, die Beschupunng ist an fossilen kanm zu kontrollieren nnd nicht ansschlieBlich für diesen Kreis typisch. Morphologisch wichtiger ist aber die allel gemeinsame Lockerung des Kiefergelenkes durch gelenkige Ablösmng des Kieferstieles (Syuamosum, Quadratum) von der Schädelkapsel. Danach hatte ich diese von Fibloringer mit dem sprachlich recht schweren Namen Streptostylica bezeichneten Formenkreise als .Lyognatha“ zusammengefaßit. 


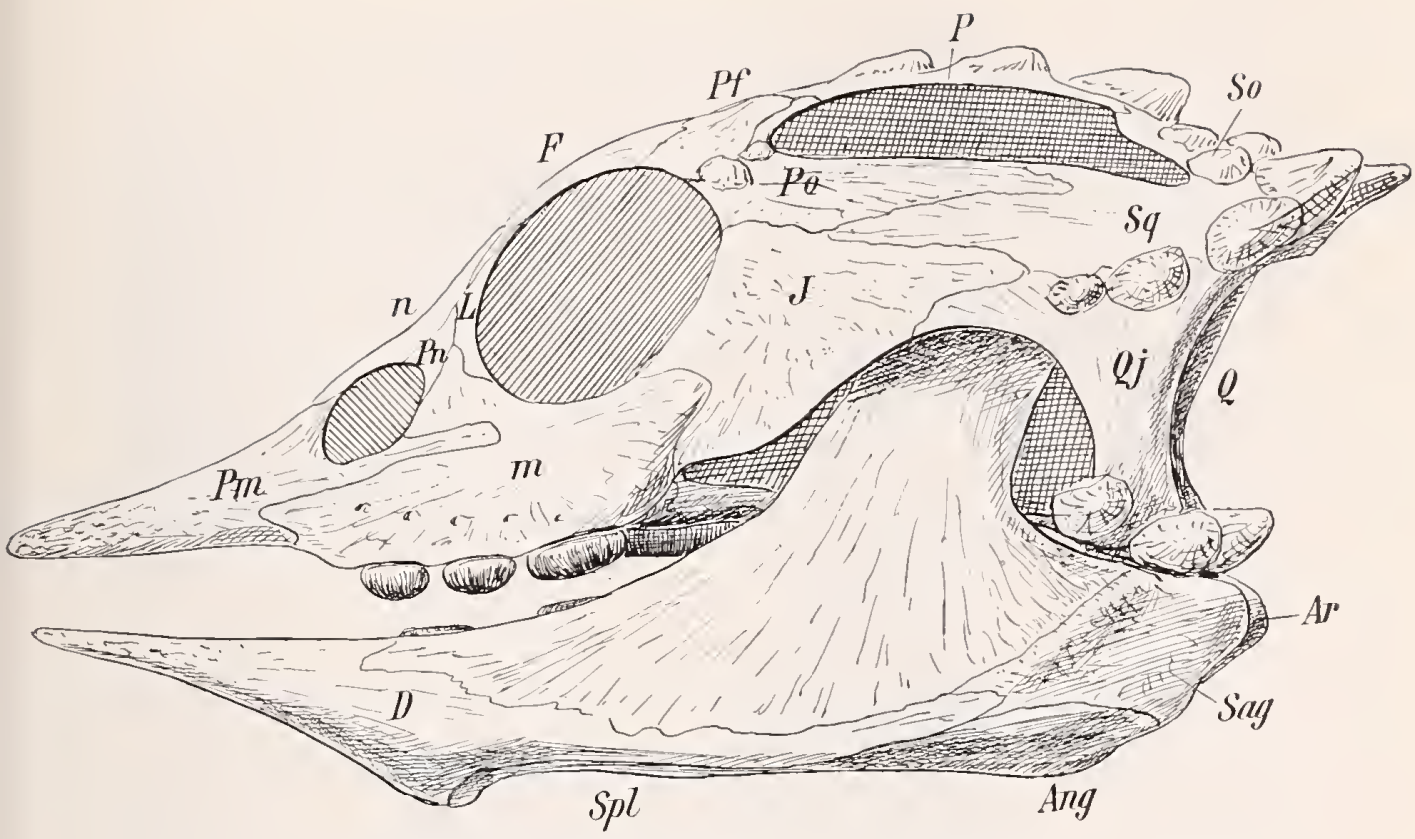

Fig. 168. Schädel von Placochelys plucodontı Jkl. in Seitenansicht. Interer Keuper von Vesprem, Ungarn. $1 / 2$ nat. Größe. Pm, Prämaxillare; $M$, Maxillare; $P n$, Postnasale: $L$, Lacrymale: Pf, Postfrontale; Po. Postorbitale: $P$. Parietale; So, Supraoccipitale; $S q$, Squamosum; $Q j$, Quadrato-jugale; $Q$, Quadratum; $J$, Jugale; $D$, Dentale; Spl. Spleniale, dariber das Complementare als Kronfortsatz; Ing. Angulare; Sag, Supra angulare; Ar, Articulare.

Definition: Kleine bis große langgeschwänzte Kriech-, Kletteroder Schwimmtiere mit vorn verjüngtem Kopf, kleinen vorn gelegenen Nasenlöchern, rïickgebildeten Wangeubogen, beweglichem Kieferstiel, konischen, meist glatten, akrodonten, bothrodonten oder plemrodonten Zähnen, die nicht auf die Kieferränder beschränkt sind. Gaumenfläche sehr durchbrochen, die Pterygoidea durch die Palatina von den Vomera getrennt. Wirbel diplocïl oder procöl, mit Zygosphen und Zygantrum. Rippen einköpfig. Bei normaler Funktion der Extrentitüten Schultergürtel mit wohlentwickelten Präcoracoidea und Scapularia, Füße normal ausgebildet, bei Mosasamiern zu Flossen nmgebildet und mit überzähligen Zehen versehen, bei Ophidiern rïckgebildet.

Die hierher gehörigen Ordnnngen sind bekannt und bediurfen im Rahmen dieser Aufzähl̉ung keiner weitereu Erlänterung. Ihre Eiuteilung auf Grund der Zungenbildung, die bei den lebenden nahe liegt, ist gegenüber den fossilen undurchführbar. 
Unterordnung Lacerti, Eidechsen.

Kleine, vierfüßige, krallentragende Klettertiere, mit kurzem Hals, langem Rumpf und walzenförmigem Schwanz, Kopf mäßig verlängert, ziemlich hoch gewölbt, oben mit Hautplatten bedeckt. Bezahnung auf die Kieferränder beschränkt, acrodont oder pleurodont.

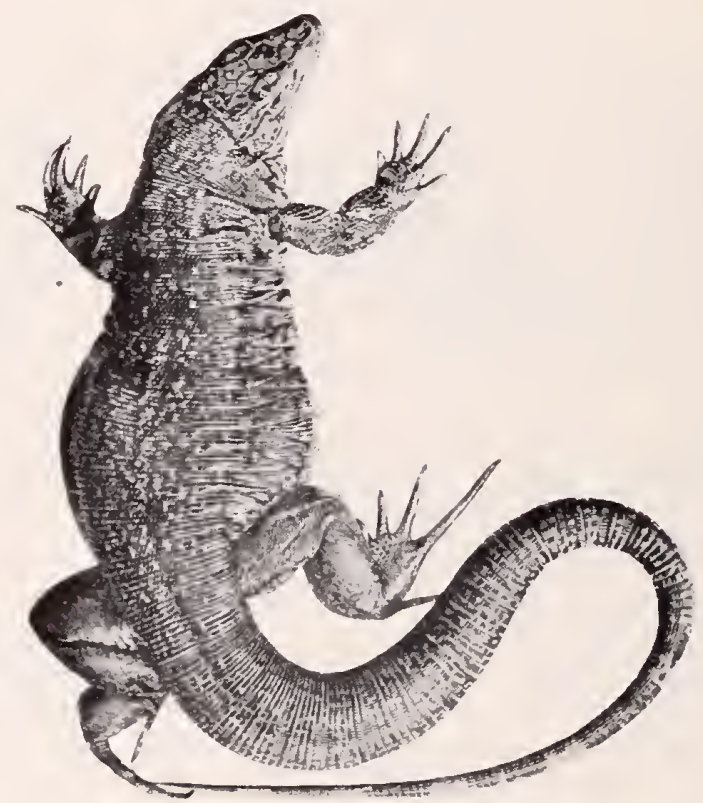

Fig. 169. Körperform einer lebenden Eidechse, Lacerta. (Nach einer Photographie.)

†Unterordnung Mosasauri (Pythonomorpha Cope).

Große marine schwimmformen, deren Füße zu kurzen breiten fünfzehigen Flossen umgebildet sind. Schwanz zum Schwimmorgan komprimiert. schädel mit großen thecodonten Zähnen, großer Epiphyse.

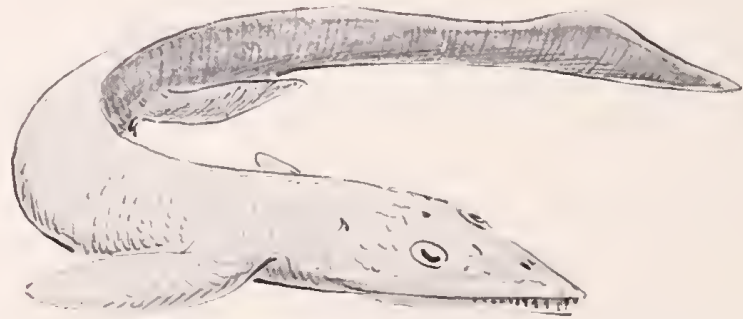

Fig. 170. Rekonstruktion eines Mosasauriers aus der oberen Kreide. $1 /{ }_{00}$. (Nach Jaekel.) 
Thre stammformen sind raranidenartige Formen ans der unteren Kreide der Adriagebiete. Torkommen in der Kreideformation Europas und Nordamerikas.

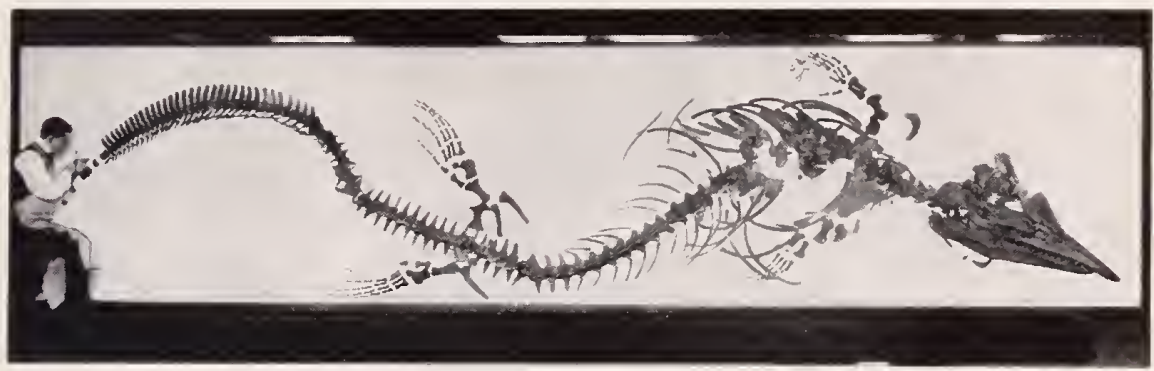

Fig. 171. Skelett von Tylosaurns aus der oberen Kreide von Kansas. (Nach Osborn.)

Cnterordnung Ophidii, Schlangen.

Fußlose, walzenförmige Kriechtiere, ohıe Schulter und Beckengerïst, mit selu beweglichen Kieferknochen und stark bezahnten Vomera und Pterygoidea. Fossil seit der oberen Kreide. Jetzt sehr verbreitet z. T. in Wasser.

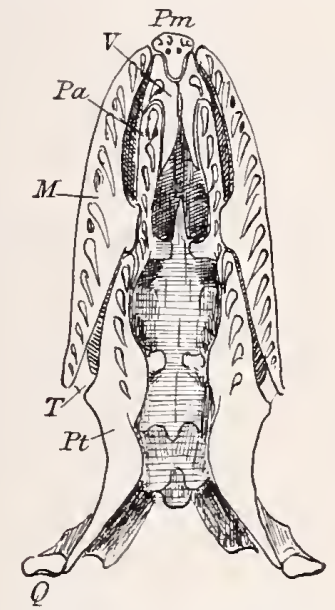

Fig. 172. Gaumenfläche des Schädels von Python.

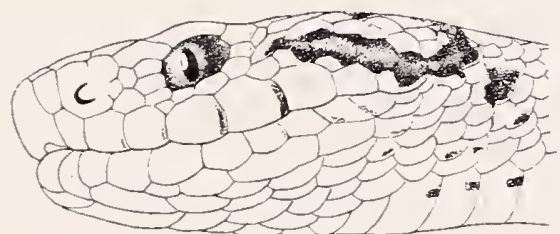

Fig. 173. Kopf einer lebenden Schlange Vipera ursinii Bonaparte, Ungarn. (Nach von Mehely.)

3. Stufe. †Cnterklasse Hyperosauria Jaekel. (Archosauria Cope z. T., Archosauria Fürbringer).

Die hier vereinigten For'menkreise sind bereits von Fürbringer zusammengefaßt und einheitlich benannt worden. Derselbe nahn wenig- 
stens für die gloich Winheit den Nanen Arohosamria anf. den Edw. Cope aber nicht nur liur diese Formentreise. sondern vor allem für die Neosania oder Pelyrosamia gegeben hatte. Von einer systematischen Verbindung dieser Formenkreise kann hente wohl keim. Rede mahr sein. Damit fällt aber auch der so verbrauchte Name Archosauria. Für den hier zusammengefaßten emgeren Formenkeis war eime neur Benenmug deshallh schwierig. weil ihre Lebensweise nud Organisation mach sehr verschiedenen Richtungen auseinander geht. Ein alle auszeichnendes anffälliges Merkmal. wie es die "Lyognatha" besitzen, ist bei ihmen anscheinend nicht vorhanden. ofler wenigstens ist ein solehes, vielleicht nnr weil es im system hisher nicht henötigt wurde, noch nicht fest gestellt. So schien min ein indifferenter Name wie ..Hyperosauria " der beste Austreg aus dieser čchwierigkeit. Das Hyper bedenter einerseits einen Höhengrad der Anshildung gegenüber den andern, was hier offenhar zutrifft und kamn anderseits auch auf das ökologisele Niveau bezogen werden, insofern diese Typen zumeist edhte Landhawohner sind und ein Teil sogar zu Flugtieren geworden ist. Auch auf die z. T. riesige Größenentwirklumg kann das .Hyper" bezogen werden.

Definition: Kleine his riesengrobe hochentwickelte Reptilien nit

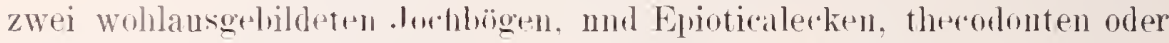

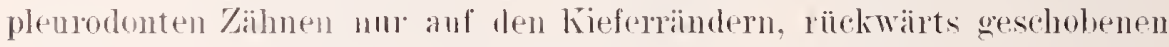
Choanen. vorn oder meit zuräckliegenden Nasenlöchern. Ejidyse meist ritckgebildet. Cntertiefer mit sehwachem Kronfortsatz und meist mit großel Fentestra externa.

Wirbel lang. diplocïl odter procoil. stets an den seiten rerdünnt, mit den Precessus transwersi verwachsen. Riplen zwriköpfig, schlank. Gastralia öfters rïckgebildet. Sacrnm mit zwei oder einer gröberen /abl

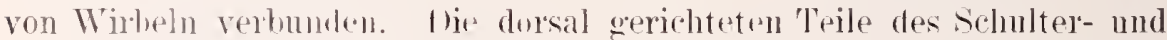

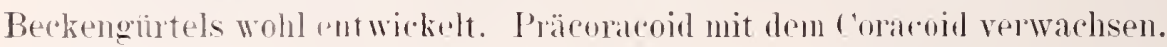
Dermale Teile des rolultergintels rückgehildet. Os pubis schlank, öters mit Processus ischiations (lostpulis). Fible mit normalen Zehenzahlen. Trials bis jetzt.

I)ieser Formenklojs nimmt vielleicht seinen Ansgangsumbt von permischen Formen wie Deuterosamus und Rhopalodon. Fs ist wahrscheinlich. dab der südafrikanische Erythosnchus zn den primitiven Vertretern dieser Lnterklasse geeört. Herr v. Hnene lat für ihn kiirzlich einen Ordnumgsnamen aufgestellt. dem ich aber zunädsst nur einen provisorischen Wert zumesse, da mir wichtige Punkte seiner Organisation moch nicht genigend geklärt erscheinen. In der Beckenbildung, die ich nach dem Lomboner Exemplar gezeichnet habe (Fig. 17f), muB man jedenfalls auf eine men Verbintlung mit den Jinosamiern schlieben, 


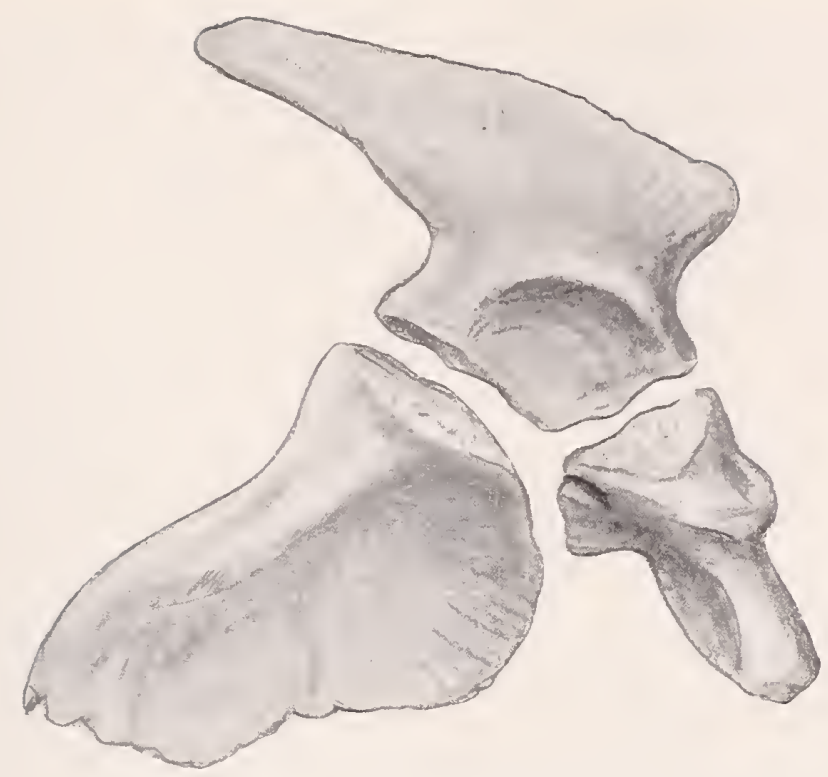

Fig. 17. Recken von Erythosuchus africanus Broom. Trias südafrika. \%/6.

ebenso nach den Rumpfwirbeln. Sicher gohionn hielher folgende Ordnungen :

\section{Hauptorduung † Diuosauri iwen.}

Ausgestorbene langhalsige, langgeschwänzte Landbewohnel mit zwei typischen Jochbogen, vorderen kleineren, hinteren größeren Lauffüßen und langem schwanz. Die Naseulöcher getrennt im vorderen Teil der Schnauze.

Die Dinosaurier bilden eine natürliche. scharf ungrenzte Abteilung, die sich vermutlich in der untersten Trias ron Proterosauriern abgezweigt hat, und ihrerseits durch die Belodonten mit den Krokodiliern und andererseits mit den Pterosauriern verwandt ist.

Die Gliederung der Dinosaurier war ron Marsh in ganz richtige Wege geleitet worden, indem er die Theropoden, samopoden und Orthopoden als natioliche Abteilungen der Ordnung unterschier. Die Namen waren indessen nicht sehr gut gewählt, denn „säugetierbeine“, wie der Name besagt, haben die Theropoden nicht gehabt. sie konnten wohl wie die Känguruhs anf den Hinterbeinen hüpfen, aber das taten die Orthopoden ebenfalls, deren Benennung danach renigstens für die Hinterbeine zutrifft; aber sauropod blieben alle drei Trpen. insofern ilue Beine den Reptilhabitus ins Prinzip bewahrten, höchstens \%. T. rogelartig wurden. Auch die Bezeichnung Praedentata für die an der Schnauzenspitze gerade nicht bezahnten, sonderu mit Hornschnäbeln versehenen Orthopoden 
aus der Terwandtschaft der Ignanodonten war nicht simgemäb. Indem Seeley daun 1887 die Dinosamier anf Grund der Ausbildung ihres Os pubis in Samischia und Onnithischia zerlegte, und unter ersteren die 'Theropoden und Samopoden und unter letzteren die Orthopoden verstand. vertiefte er die systematische Gliederung, nur daß die Namen weder phonetisch noch sprachlich gut gebildet waren, und sachlich an das wenig clarakteristische Ischium statt an das markante Pubis anknïpften. Ich habe daher muter Aufrechterhaltmng der Seeleyschen Einteilung seine Gruppen in Praepubici nud Postpubici umgetanft. Diese Namen sollten besagen, daß bei den ersteren das Pnbis wesentlich nach vorn, bei den anderen anch nach hinten ansgedehnt ist. Nun hat aber Herr v. Hnene die Meinnng vertreten, daß das Pubis der Ornithisehia in seinen rïckwärts gewendeten Hauptteil dem ganzen Pubis der übrigen Samrier entspräche nnd also kein besonderes „Postpubis" sei. Diesen Einwand glanbe ich in einer besonderen studie ïber das Becken der Dinosanrier widerlegen zı können mud halte deshalb an meinem Vorschlage fest, die beiden Hauptabteilnngen der Dinosamier als Prapubica nnd Postpubica zu bezeichnen. Der Ansdruck .,Prae"pubici erscheint deshalb gerechtfertigt, weil sich das Pubis dieser Dinosanrier ganz nngewöhnlich weit nach vorn ausgedehnt hat. Besondere Elemente sollen weder mit dem "Prae"- noch mit dem "Post"pnbis gemeint sein, sondern nur starke V'erlängermngen in den angedeuteten Richtumgen. In beiden Abteilnngen gehen die schwerfälligeren, also auch die übermäßig großen Formen wieder zu der schwerfälligen Cangart anf vier Beinen über. Eine hierauf gegründete Hanpteinteilung war also nicht angebracht. Anch die Erhebung der Hinterfüße auf die Zehen hat nur sekundäre Bedentmug. Wir teilen also:

\section{Unterordnung Praepubici Jkl. (= Saurischia Seeley).}

Hiipfende oder kriechende Fleisch- oder Pflanzenfresser mit spitzen Einzelzähnen, mit vorwärts verlängerten Pubisknochen.

Diese Abteilung unfaßt nun einerseits die hüpfenden Ranbdinosamrier mit säbelförmigen, fein gezähnelten Raffähnen und kräftigen Krallen. die Megalosanri. zweitens die ebenfalls hïpfenden, aber etwas schwerfälligeren Formen der Trias- nnd Juraformation, die sich mit kleinerem Kopf, langem Hals und meißelförmigen spitz gekerbten Einzelzähnen, mit einigen kräftigen Krallen an den $3-4$ inneren Zehen wohl einer omnivoren, wenn nicht schon frugivoren Lebensweise angepaßt hatten. Etwa 25 Skelette dieser Formen sind jetzt in der oberen Trias vou Halberstadt entdeckt nnd werden nach der Präparation wohl ein ziemlich klares Bild der Organisation dieser älteren Typen liefern (Gresslyosamridae 11. a.). 

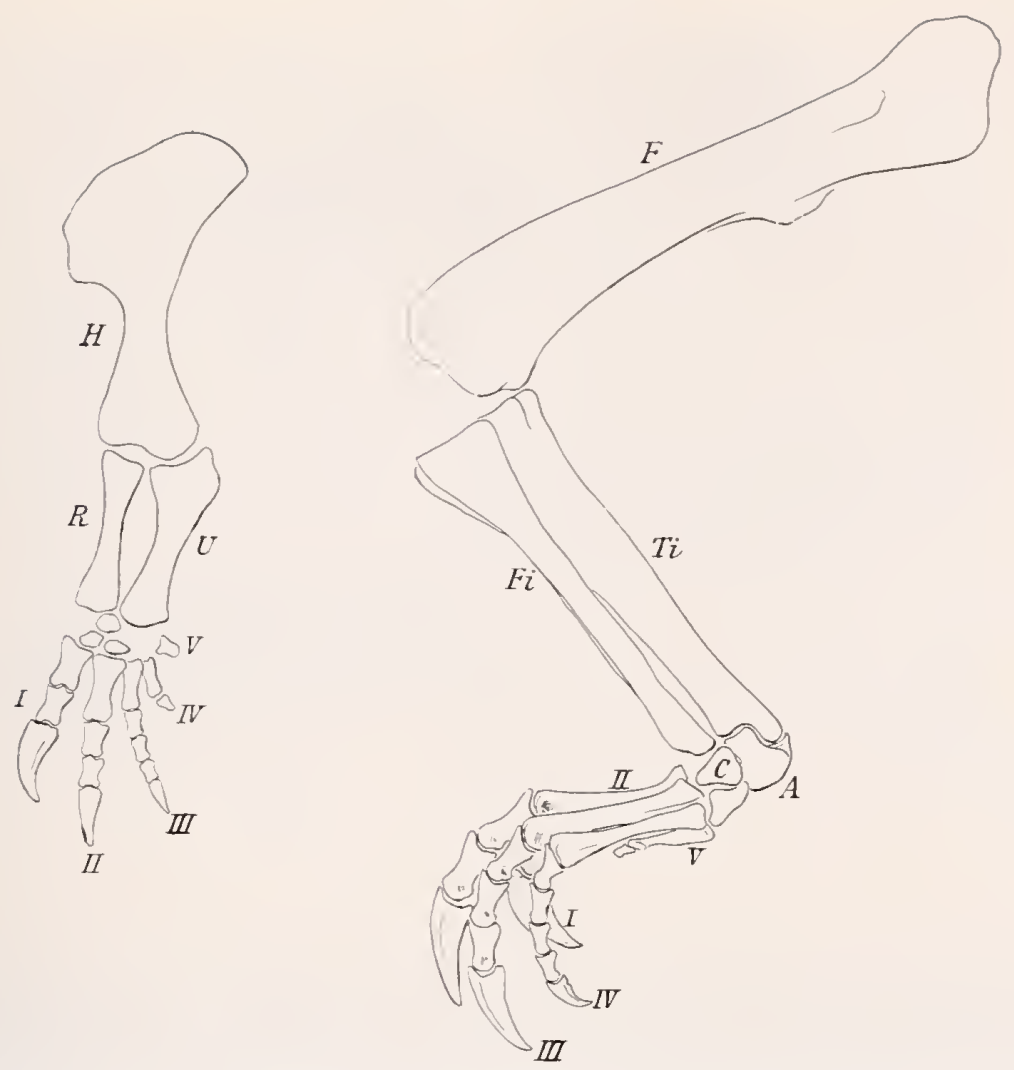

Fig. 175. Vorder- und Hinterfub eines Dinosauriers (Greßlyosaurus Torgeri n. sp.) aus dem Keuper von Halberstadt im gleichen GröBenverhältnis 1/12 verkleinert.

Einen dritten Kreis bilden die sogenannten Samropoden, die Riesenformen, deren Last den Körper mieder zur stärkeren Benutzung der vorderen Gliedmaßen drängte, und diese wieder in normaler Größe entwickeln ließ. Ihre Zehenglieder sind kïrzer geworden, nur ihre imneren Finger noch mit großen Krallen besetzt. Thre Zähne konzentrieren sich auf den rordersten Teil der Schnauze. Ihre Pubis öffnen sich nach unten und werden zu beilförmigen Spangen. Atlantosauriden, Camarosauriden. Brontosauriden nnd Diplodociden.

II. Unterordnung Postpubici c. (Orthopoda Marsh, Ornithischia Seeley). Inscheln oder Pflanzen fressende Dinosaurier mit großem Kopf und mehr oder weniger zusammengedrängten Kauzähnen, mit rückwärts verlängertem Pubis in dem rogelartigen Becken,

a) erecti anfrecht gehende Formen mit mäßig großem Kopf, Scelidosauridae als Trurzel mit meißelförmigen Eckzälınen, Iguanodontidae (Praedentata Marsh) mit Hornschnäbeln au vorderen Schnauzenende nnd mit mehrreihigem Zahnpflaster dahinter (Fig. 177), Hadrosauridae, 


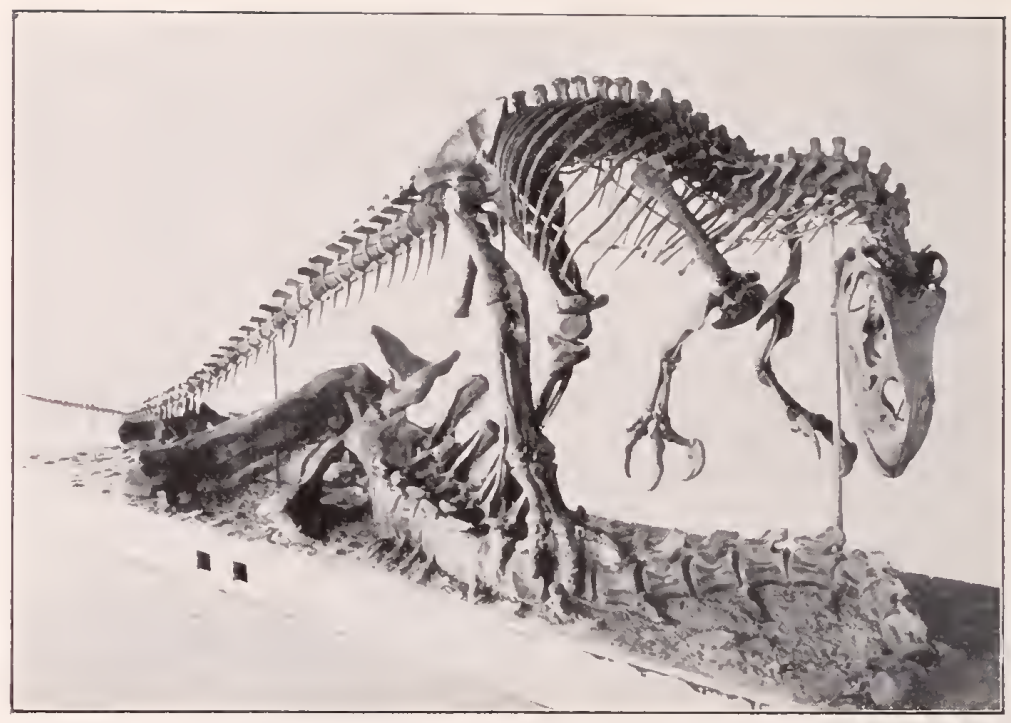

Fig. 176. Allo-aurus agilis Marsh, ein Raublinosanrier des oberen Jura ron Kolorarlo. Restauriertes Slinlett. ${ }^{1}{ }_{20}$. (Nach einer Photographie des Natural History Museum in New-York.)

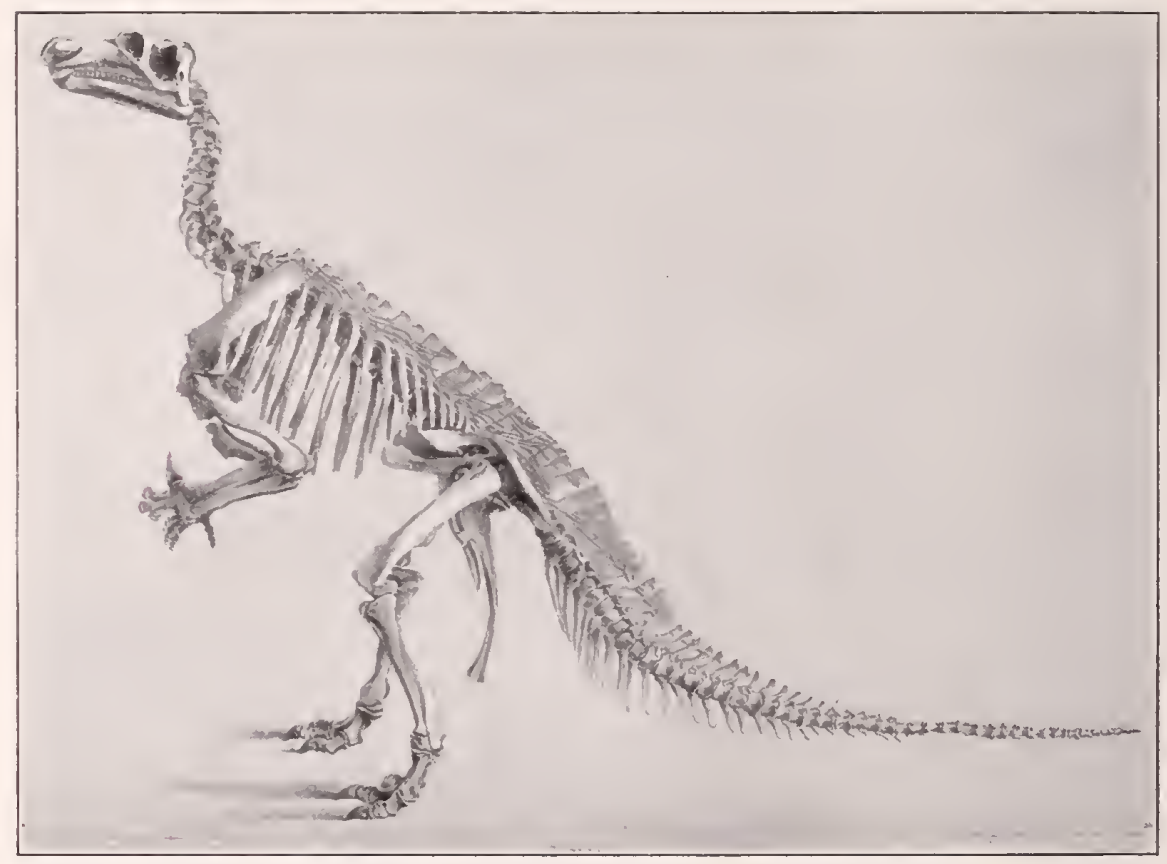

Fig. 17.. Skelett rou Iguanodon bernissartensis Boulenger. Lnterste Kreide. Bernissart, Belgien. $1 / 60^{\circ}$ Nach Dollo.) 
b) caduci schwerfallige, z. T. gepanzerte, niedergedrickte Formen mit den stegosauridae (Fig. 178) und deu Ceratopsidae (Fig. 179 u. 180 ).

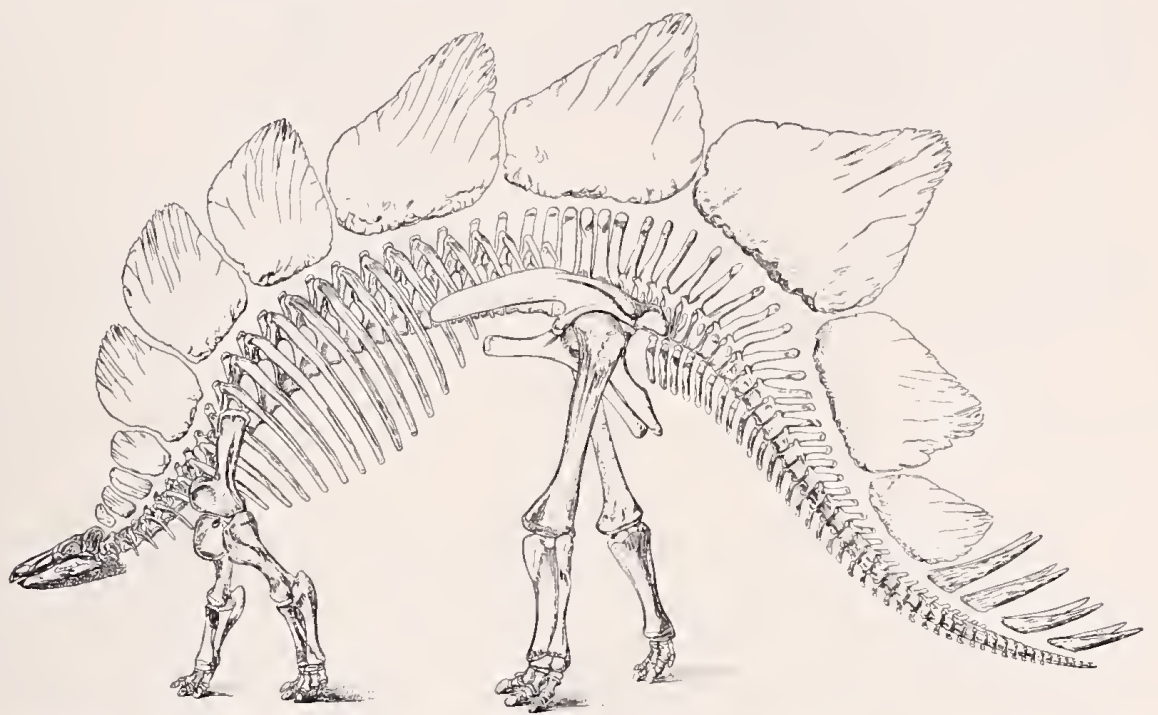

Fig. 178. Stegosaurus ungulatus Marsh. Oberer Jura, Kolorado. Rekoustruktion des Skelettes. 1/60. (Nach Marsh.)

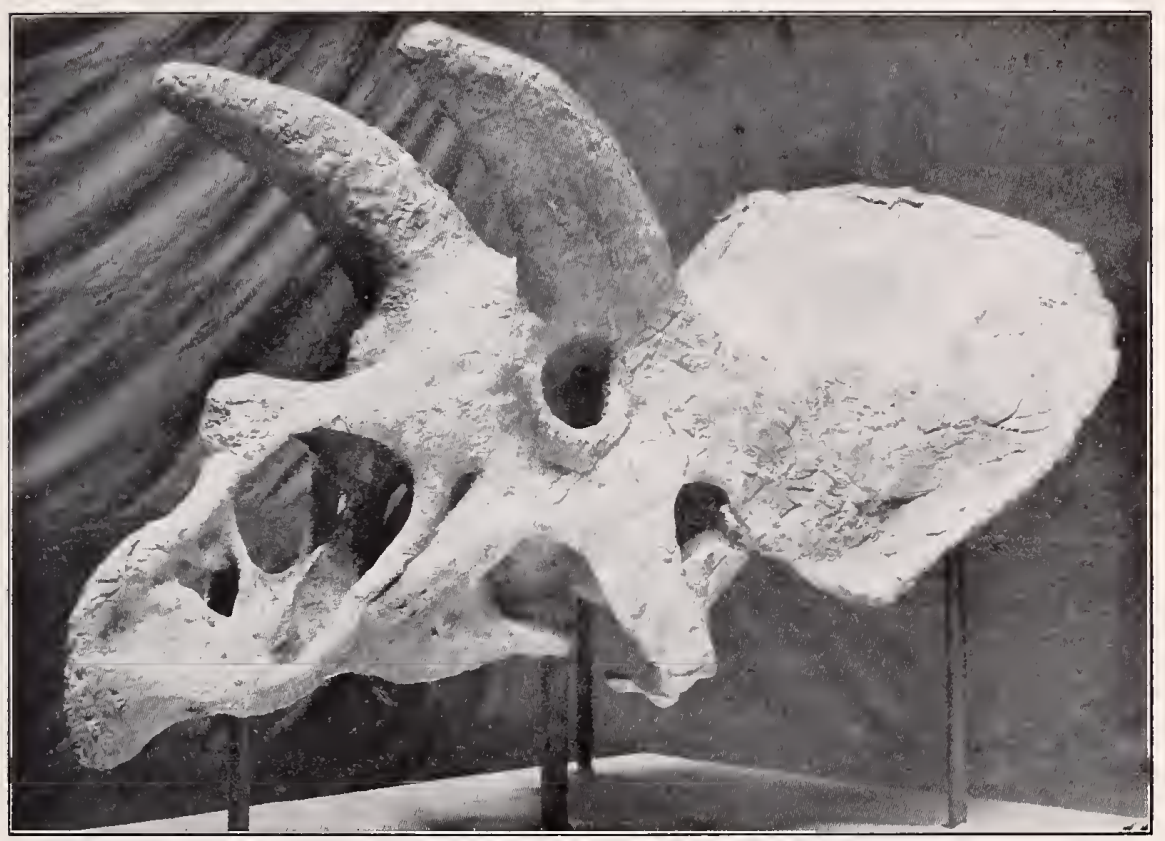

Fig. 179. Triceratops flabellatus Marsh. Schädel schräg von vorn gesehen, mit großen horntragenden Stirnzapfeu hinter den Augen. 1/20. Oberste Kreide vou Montana, U.S. A. (Nach einer Photographie des Field Columbian Museum.) 


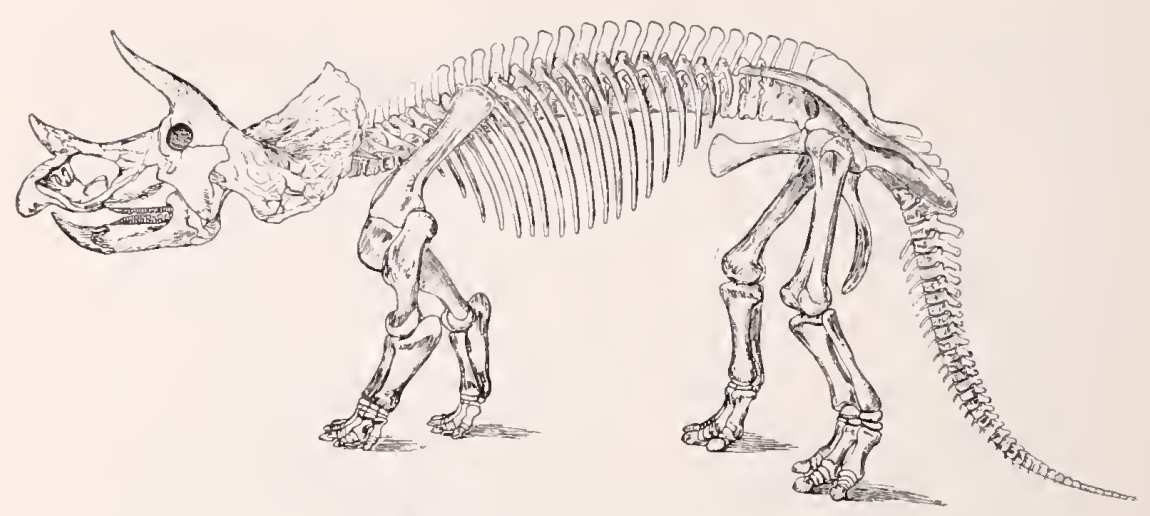

Fig. 180. Triceratops prorsus Marsh. Obere Kreide, Montana. Restauriertes Skelett. 1/70. (Nach Marsh).

II a Nebenordnung Loricati (Crocodilia im weiteren Sinne).

So nahe anch die große Mehrzahl der fossilen Krokodile den lebenden steht, so haben doch einige ilner älteren Typen vornehmich durch abweichende Stellmng ihrer änßeren Nasenlöcher nnd indifferente Anshildnng ihres Ganmendaches einer Einordnung in das System Schwierigkeiten bereitet. Da sich diese, die Belodonten und Aetosanria, aber in ihrer Gesamtform und speziell ihrer Panzerung so eng an die Krokodile anschließen, scheint es mir in Anschnß an Huxley zweckmäßig, sie wieder mit den echten Krokodilen zu vereinigen. Nur muß man dann im Gegensatz zu Huxley, jenen aberranten Formen gegenïber alle echten Krokodile, also auch seine Mesosuchia in eine Einheit zusammenfassen. Innerhalb der letzteren scheint mir der Gegensatz der Krokodile nnd Gaviale anch bei den fossilen Formen dnrchführbar. Eime besondere Gruppe unter den echten Krokodilen bilden die marinen Schwimmformen, für die E. Fraas den Namen Thalattosuchia anfgestellt hatte. Die Ansbildnng des Rostrums bietet bei diesen wie bei den vorhergenannten echten Krokodilen einen bequemen Anlaltspunkt anch für ihre systematische Bezeichnumg.

Definition: Langgestreckte Wasserformen, mit langem, großem Schädel, kuzem Hals und lingem Schwanz. GliedmaBen kur, als Schreitbeine oder SchwimmfüBe ansgebildet. Haut in der Regel mit Längsreihen knöcherner, grubig sknlptnrierter Platten gepanzert. Zähne gleichartig kegelförmig, oft mit vorderer und hinterer Kante, thecodont befestigt. Schädel kräftig verknöchert.

Die geologische Verbreitung beginnt in der nnteren 'Trias mit Mesorhinns Fraasi Jkl. und damit mit den Belodonten, deren änBere Nasen weit zuriekgeschoben sind und die Choanen mit sich weit riickwärts gezogen haben. Bei den echten Crocodilien ist diese rïiekwiirtige 
Lage der Choanen zu einer eigenartigen „anlopalatinen" (Jaekel) Gaumenbildung spezialisiert, die äußeren Nasen aber sind ganz weit nach vorn zusammengeschoben. Eine phyletisch zweifelhafte Stellung nehmen die Aetosaurier ein, deren Schädelban (Fig. 183) dem der Dinosanrier und Pterosaurier (Fig. 185) sehr nahe steht.

\section{Unterordnung +Belodonti (Parasuchia Huxl.),}

mit langer, dicht bezahnter Schnauze, weit rückwärts gelegenen änßeren Nasenlöchern, großen Antorbitalgruben, noch nicht vereinigten Palatina und Pterygoidea. Panzerung zumeist aus breiten Platten gebildet.

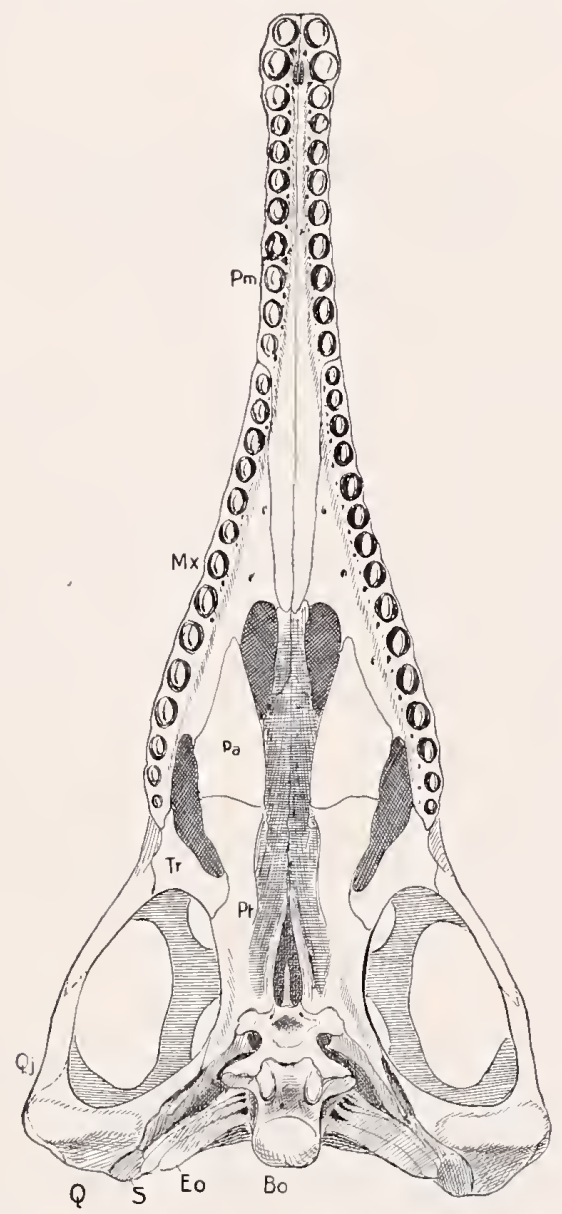

Fig. 181. Mesorhinus Fraasi Jaekel, der älteste Belodont. Gaumenfläche. 1/4. Mittl. Buntsandstein, Bernburg. (Nach Jaekel.)

Hierher gehört der oben genannte Mesorhinms als Typus einer Familie. 
Vertreter jüngerer Fanilien sind Belodon mit rerdickter, Mystriosuchus mit sehr schlanker Schnauze. Beide im Keuper Europas und Aruerikas.

2. Unterordnung Crocodili (Mesosuchia †Eusuchia Huxley).

Schädel dick, grubig skulpturiert, ohne Antorbitalgruben, nit diumer P'ostorbitalbrücke, kleinen Augen und Schläfengruben. Äußere Nasen ganz vorn an der schnauzenspitze vereinigt, imnere durch Vereinigung der Palatina (Mesosuchia) und später auch durch Vereinigung der Pterygoidea (Eusuchia) weit zurückgeschoben und fest überdacht (aulopalatiner Gaunentypus Jaekels.)

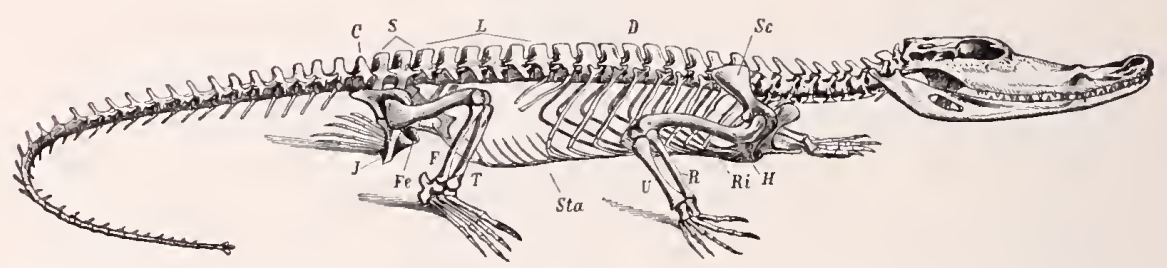

Fig. 18.2. Skelett des lebenden Nilkrokodils Crocodilus vulgaris Cur. (Nach ClauB.)

Hierler gehören als ,longirostri“ die †Teleosauridae, †Pholidosauridae, †Tomistomidae und die noch überlebenden Gaviale südasiatischer Fliisse, ferner als ,acutirostri“" (Thalattosuchia E. Fraas) die jurassischen Metriorhynchidae und Geosauridae und schließlich die strandbewohnenden ,brevirostri" †Atoposauridae, fGoniopholidae, und die Crocodilidae (inkl. Alligator).

3. L'nterordnung t Aetosauri (Pseudosuchia Huxley)

mit normal gesteliten Naseulöchern, großen Antorbitalgruben und großen Augenhöhlen.

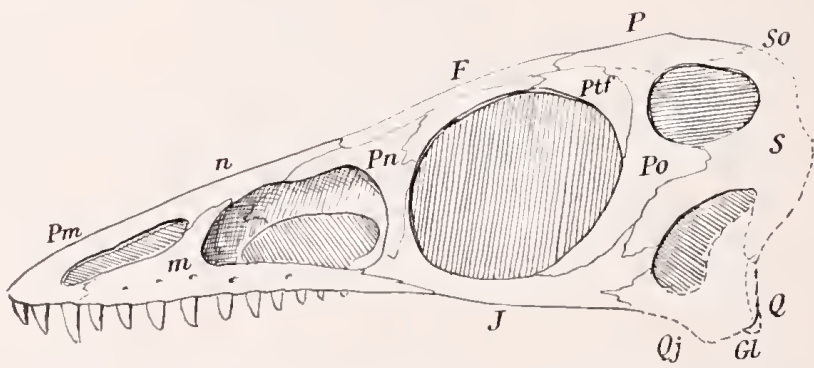

Fig. 183. Neue Rekonstruktion des Schädels von Aetosaurus ferratus 0. Fraas.

Mittl. Keuper, Stuttgart. (Nach den Originalen im Stuttgarter Museum.) 


\section{II $\beta$ Nebenordnung +Pterosauri Kaup.}

Fein und hohl skelettierte Flugtiere mit nackter Haut, deren Arme durch Verlängerung des letzten Fingers zu Flugorganen umgebildet sind. Schädel zugespitzt, mit Hornscheiden rorn, und großen schlanken Raffzähnen dahinter, mit zurückliegenden Nasenlöchern, großen Antorbital- und kleinen Temporalgruben. Angen groß mit sclerotikalring. Präsacrale Wirbel meist procöl. Die die Pterosaurier' charakterisierende Flügelhildung erfolgt durch Verlängerung der vier Glieder des vermutlich vierten Fingers, der fünfte scheint riickgebildet. Der erste bis dritte sind in normaler Weise gegliedert (2.3.4) und mit großen Endkrallen rersehen (Fig. 184). Am Hinterfuß scheint an den vier vorthandenen Zehen die Normalzahl 2.3.4.5 die Regel zu sein.

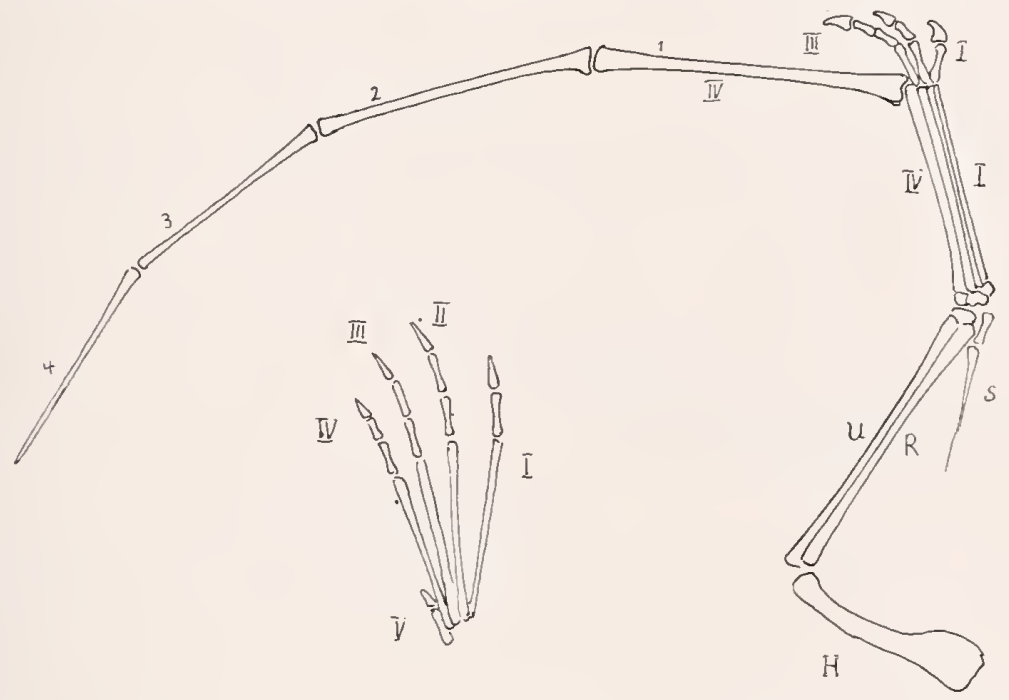

Fig. 184. Gliederung des Armes und des Hinterfußes eines oberjurassischen Pterodactylus des Berliner Museums. $H$ Humerus, $R$ Radius, $U$ Llna, $C$ proximale und distale Carpalia, I-IV die vier Finger, $S$ Sehnenverknöcherung der Flügelbildung. 1/1 .

Die Fußgliederung 2.3.3.3.1 erscheint hier abnorm.

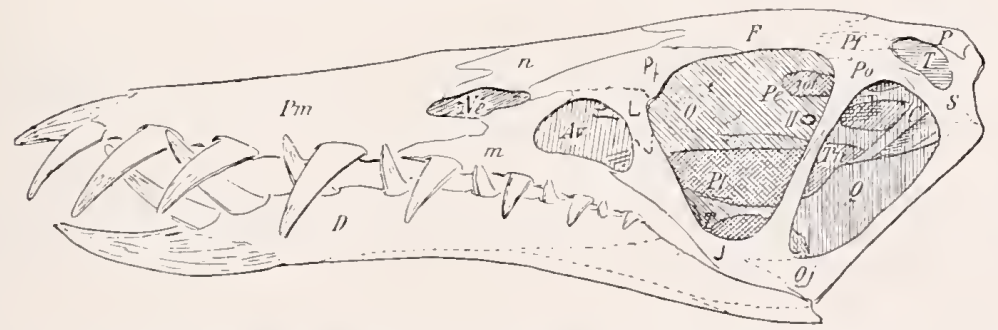

Fig. 185. Rekonstruktion des Schädels von Rhamphorhynchus.

Ne Nasen, $A v$ Antorbitalgrube, O Orbita, $T$ Temporalgrube, darunter die Wangengrube.

$3 / 4$. (Nach Jaekel.) 


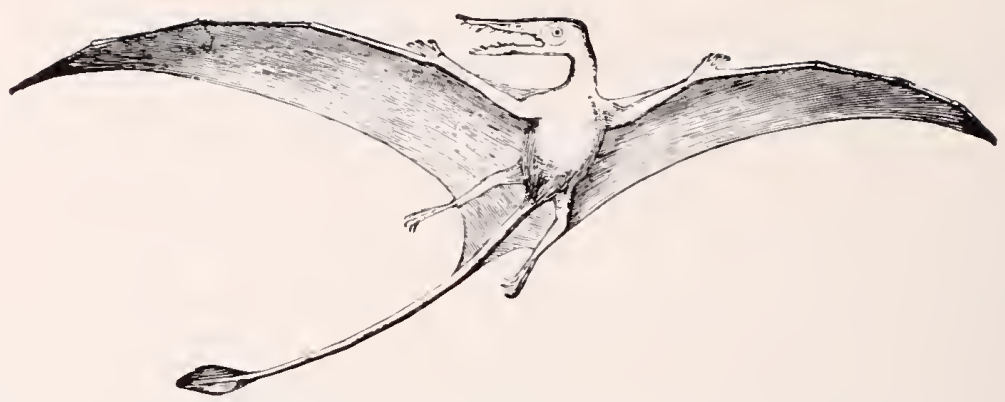

Fig. 186. Rekonstruktion von Rhamphorhynchus aus dem oberen Jura von Solnhofen in Bayern. 3/4. (Nach Marsh.)

Die Pterosaurier sind wohl Nachkommen kleiner postpubicaler Dinosaurier. Die Bezeichnung ihrer 2 Hanptgruppen scheint mir am einfachsten anf Grund ilurer Schwanzform zu erfolgen.

a) longicandati (Pterodermata Seeley). Rhamplorynchidae.

b) brevicaudati (Ornithochiroidea Seeley). Pterodactylidae, Pteranodontidae.

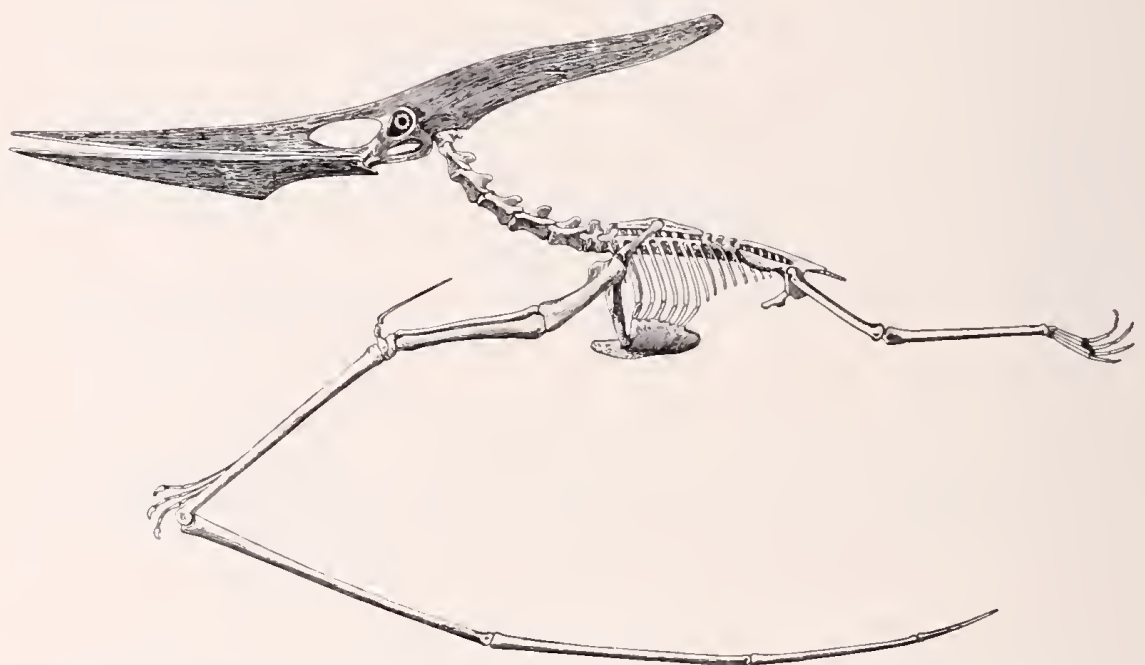

Fig. 187. Rekonstruktion des Skelettes von Pteranodon in seitlicher Ansicht, ohne die rechtsseitigen Gliedmaßen. Obere Kreide, Kansas. (Nach Eaton.)

Ihre altesten Reste fanden sich in der oheren Trias, sie starben in der oberen Kreide Amerikas mit zahnlosen Riesenformen ron 8 m Spannbreite aus (Fig. 187). 


\section{Nebenklasse Aves, Vögel.}

Befiederte warmblïtige Zweifübler, deren Arme dureh Federbesatz unter Rückbildung des Handskelettes zu Flügeln ungebildet sind, deren Kopf in der Regel zugespitzt und zahnlos mit Hornschnäbeln versehen ist, mit pterygopalatinem Gaumen, einfachem occipitalem Condylus, mit langem Ilium, vielen Wirbeln im Sacrum und langem Postpubicalprozeb ror dem Ischium, deren Füße mit Krallen besetzt sind, deren fiinfte Zehe obliteriert ist und deren Metatarsalia miteinander und dem Tarsus verschmolzen, deren Entwicklung im Ei unter Bildung eines Amnions erfolgt.

Durch ilı Flugvermögen und die besondere Anpassung ihres Körpers an diese Funktion sind die Vögel seit alter Zeit so scharf umgrenzt, daß kein ernst zu nehmender Systematiker an ihrer Einheit und Selbständigkeit gezweifelt hat. Auch darïber ist nach der Erkenntnis des natürlichen Zusammenhanges der Organismen sofort Einigkeit erzielt worden, daß die Vögel als nächstverwandte und spezialisierte Nachkommen von Reptilien aufzufassen sind. Meinungsverschiedenheiten bestanden nur darïber, ob man Übergangsformen von Reptilien zu den Vögeln den letzteren glatt unterordnen solle, oder ob man sie wegen des Mangels einzelner typischer Kennzeichen der heutigen Vögel von deren Einheit ausschließen solle. Engenetische Vorformen trennen wir hente ron ihren unmittelbaren Nachkommen nicht mehr gern ab und haben dazu vollends keine Veranlassung mehr unter den hier befolgten systematischen Gesichtspunkten. Übergangstypen oder Vorformen wie Archaeopteryx ordnen wir also den Vögeln unter, zumal ilıre Mängel gegenïber den typischen Vogelcharakteren als unmittelbare Vorstufen derselben ınd damit der höheren Organisation der jüngeren Vögel erscheinen. Wir folgen in ïbrigen dem Systeme M. Fürbringers in dessen übersichtlicher Zusammenfassung in Bronns Klassen und Ordnungen des Tierreiches durch Hans Gadow.

Stufen der Entwicklung der Klasse ergeben sich nach unserer noch sehr mangelhaften Kenntnis fossiler Vorfahren einerseits aus der Rückbildung des ursprïnglichen langen Reptilschwanzes, andererseits aus der Rückbildung der Zähne und der freien Finger an den Flügeln.

Die Verkürzung des Reptilschwanzes beruht offenbar auf der 'Tendenz, das Endstener an den schwimmenden Körper heranzuziehen und findet sein Analogon in der Schiffahrt, in der unmittelbaren An- 
fïgung des Steners an das Boot gegenüber der primitiveren Herausstreckung eines freien Ruders. Jie Verkiurzung des Vogelschwanzes wird sich alluählich vollzogen haben, aber bei unserer diurftigen Kenntnis älterer Vogelformen steht uns der lange "Blattschwanz" von Archaeopteryx und der kurze .. Fücherschwanz" der jüugeren Vögel znnächst noch muremittelt gegeniiber. Dieser Gegensatz läßt sich systematisch sehr gut ansnïzen, aber wir dürfen uns nicht verhehlen, dab es im simne unseres Systems nur ein Stufenuntersehied ist.

lie Benrteilung der Flïgelbildung ist insofern noch unklar, ats wir nicht wissen, welche Finger das definitive distale Fliigelskelett znsammensetzen. Nach den menesten Beobachtungen einciseits an Embryonalstadien lebender Vägel (vgl. Barfurth Anat. Anz. 1911), andererscits an menen Dinosaulerfunden ron Habberstadt scheint mir liamm mehr zweifelhaft, daß der erste nud zweitr Finger reduziert werden, der dritte mit schwacher Beteilignng des vierten nnd fiuften das eigentliche Fingerskelett des Flügels bildet (vergl. Fig. 175 mul 189).

Hiernach wïrde Archaeopteryx noch das Dinosamrierstadium reprïsenticren, aber auch darin mm graduell von den jüngeren Vügeln muterschieden sein. da bei diesen embryonale mol anormale Atarismen den genetischen Zusammenhang mit dem Archaeopteryxstadium doknmentielen wimden.

In der Bezahmung ist der C̈hergang ein allmählicher, insofern noch rerschiedene Kreidevögel echte Zähne besitzen. Ina dieser stufenweise Ïbergang aber in verschiedenen Reihen der Vögel getrennt und wahrseheinlich verschieden schnell erfolgte, läßt er sich schwerer als die oben genamten Herkmale systematisch verwerten. Nicht nur die Löfelform und thecodonte Befestigung der Zähne, sondern anch die Hornschnabelbildung findet ihre nächste Beziehung hei den Dinosanriern und ihren den Vögehn physiologisch nahestehenden Nachkommen, den Ptelosamiern.

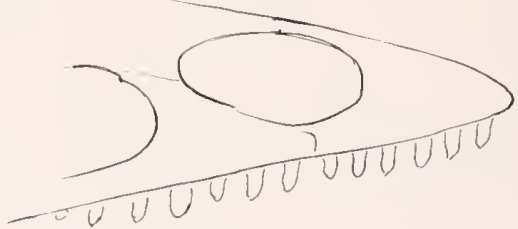

Fig. 1st. Bezalmung des Oberkiefers von Archaeopteryx

(Nach dem Berliner Exemplar.) Vergröherung 2/1.

Auf Grund dieser Monente ist zunächst eine Hanpteinteilung vorgeschlagen in Alcholnithes ('alus oder Aleharolnithes Gadow (= Salll'urae Haeckel) für Archaeopteryx nnd eine alle übrigen jüngeren Vögel 
mmfassende Abteilung Neornithes Gadow (= Ornithurae Haeckel). Wir können beide phrlogenetisch als Vor- und Hauptstufe, systematisch als Unterklassen auffassen. Als anderes Finteilungsprinzip wurle der Besitz oder Mangel eines Kieles auf dem Brustbein (Sternum) betrachtet und danach die Vögel in gekielte (Carinatae) und ungekielte (Ratitae) geteilt. Die frïher gelegentlich geäußerte Meinmo, daß die mngekiviten als auf niederer Vogelstufe stehend die primitiveren seien, ist wohl kanm meht diskntabel. Es kaun keinem Zweifel nnterliegen. daB die Tögel ihre eigentiumliche Organisation, vor allem die Umbildnng ihres Armskelettes, nicht durch Laufen, sondern durch Flattern md Fliegen d. h. durch Druckberegungen der rorderen Gliedmaßen auf die Luft erlangt haben, und daß also Lanftiere mit rückgebildeten Flügeln nnmöglich primitiv sein können. Ratiten müssen also eine Seitenrichtung der typischen Vogelentwicklnng darstellen. M. Fiùbinger führte deshalb für sie die Bezeichnnng .,Denteraptenornithes“ ein, nm durch diesen leider fast manssprechlichen Namen anzudenten, daß sie ihre Organisation erst sekundär erwarben und von Hanse aus echte Vögel waren. Es bleibt nur die Frage, ob eine solche Anfgabe der Flngtätigkeit nnd der Übergang zum Lanfen einmal oder ofters erfolgte, ob demgemäß die Ratiten eine systematische Einheit bilden. Fürbringer und Gadow fülurten nun eine so große Zahl gemeinsamer Charaktere aller Ratiten anf, daB man sie wohl für einen phylogenetisch geschlossenen Typus lialten kann. Seine Stellung und Bedeutung würden wir dann durch den Begriff einer Nebenordnung der zweiten oder Hanptstufe zum Ausdruck bringen. Nach Fürbringers Aufassumg sind sie als Dekadenten einer Gruppe von Formen anzusehen, die die Crypturiformes, Gruiformes und Galliformes enthält. Gadow vereinigt sie mit diesen zu einem ..Kreis A ", während er in einen . Kreis B* die Columbiformes, Ardeiformes und Anseriformes stellt, und ron deren Vorfahren den alten Trpus Hesperornis der nordamerikanischen Kreide ableitet. So ergeben sich für ihn innerhall) seiner Neornithen zwei Hauptabteilungen A und B mit je zwei Unterabteilungen. In der systematischen Anfreihnng der Formenkreise hat damn aber Gadow eine ron obigen abweichende Anordnung getroffen, indem er die ron ihm anerkannten Beziehnngen innerhalb seiner Kreise A und B nicht weiter berïcksichtigt und den Ratitae und dem Typus rou Hesperornis (als Odontolcae Marsh) die sämtlichen typischen Vögel als Carinati gegeniiberstellt. Anch das scheint mir nicht zweckmäBig. daß ex die Reihenfolge der Neornithes mit den aberranten Ratitae und Odontolcae einleitet. Durch die hier durchgeführte Sonderung rom Haupt- nnd Nebenordnungen glaube ich nicht nu dem System, sondern auch der phylogenetischen Auffassmug Fürbringers und Gadows näher gerückt zu sein. Da wir alle Vögel für primäre 
Carinaten halten, mïssen wir freilich diesen Begriff als systematische Eimheit fallen lassen. Das ergiht folgende Gliedermng der Klasse:

A. Vorstufe als Unterklasse Archornithes Carus mit Archaeopteryx als einzigem Tipus einer Hauptordnung.

B. Hauptstufe als Lnterklasse Neornithes Gadow.

Hauptordnungen:

I. Colymbomorphae

II. Pelargomorphae

III. Alectoromorphae

IT. Coraciomorphae
Nebenordnungen:

Tr Odontolcae

IIIr Ratitae

\section{A. Vorstufe. Unterklasse Archornithes Gadow} (Saurmae Haeckel, Archaeornithes Gadow).

Langgeschwïnzte, bezalnte Tögel mit freien krallenbesetzten Fingern an den befiederten Flügeln.

AnBel diesen systematisch wichtigsten Merkmalen sind noch eine Reihe anderer atavistisch bedeutungsvoll, so namentlich die Diplocölie der Wirbel, die Selbständigkeit der Halsrippen, der Mangel von Processus nncinati an den Rumpfrippen, die Selbständigkeit der Beckenknochen, die geringe Größe des Iliums, die zweiseitige Befiederung des Schwanzes. Anch die große Zahl ron scleralplatten (etwa 11) in Auge kntipft an Reptilienzustände an.

Einziger Typus Archaeopteryx lithographica H. v. Herer (macrura Owen, Siemensi Dames) im oberen .Juma von Solnhofen in Bayern.

Die sistematische Bedentung von Archaeopteryx berult nicht nur daranf, daß sie eine ganze Anzahl typischer Reptilienmerkmale innerhalb der Vogelklasse anfweist, sondern daß sie sich allem Anschein nach von dem Hanptwege der Vogelentwicklung sehr wenig entfernt hatte, und deshalb als direkte Lrform der Vïgel er'scheint. Sie repräsentiert also in muserem system die Hanptordnung der Vorstufe. (Fig. 188 u. 189).

B. Hauptstufe als Unterklasse Neornithes Gadow.

Die vordersten Finger rückgebildet, die folgenden im Flügel verkümmert. Ihre IIetacarpalien miteinander verwachsen. Die Zahl der schwanzwirbel anf 13 oder weniger reduziert, die letzten $5-6$ in der Regel zu einem Pygostyl verwachsen. Die Hetatarsalia mit dem Tarsus fest zn einem Tarsometatarsus versehmolzen.

Durch die Terkürzung des Schwanzes zn einem Fächerschwanz nnd die totale Cmbildung des Armes zum Fliigel unter der vollen Anfgabe der primären Gliederung des Handskelettes kommt in dieser 


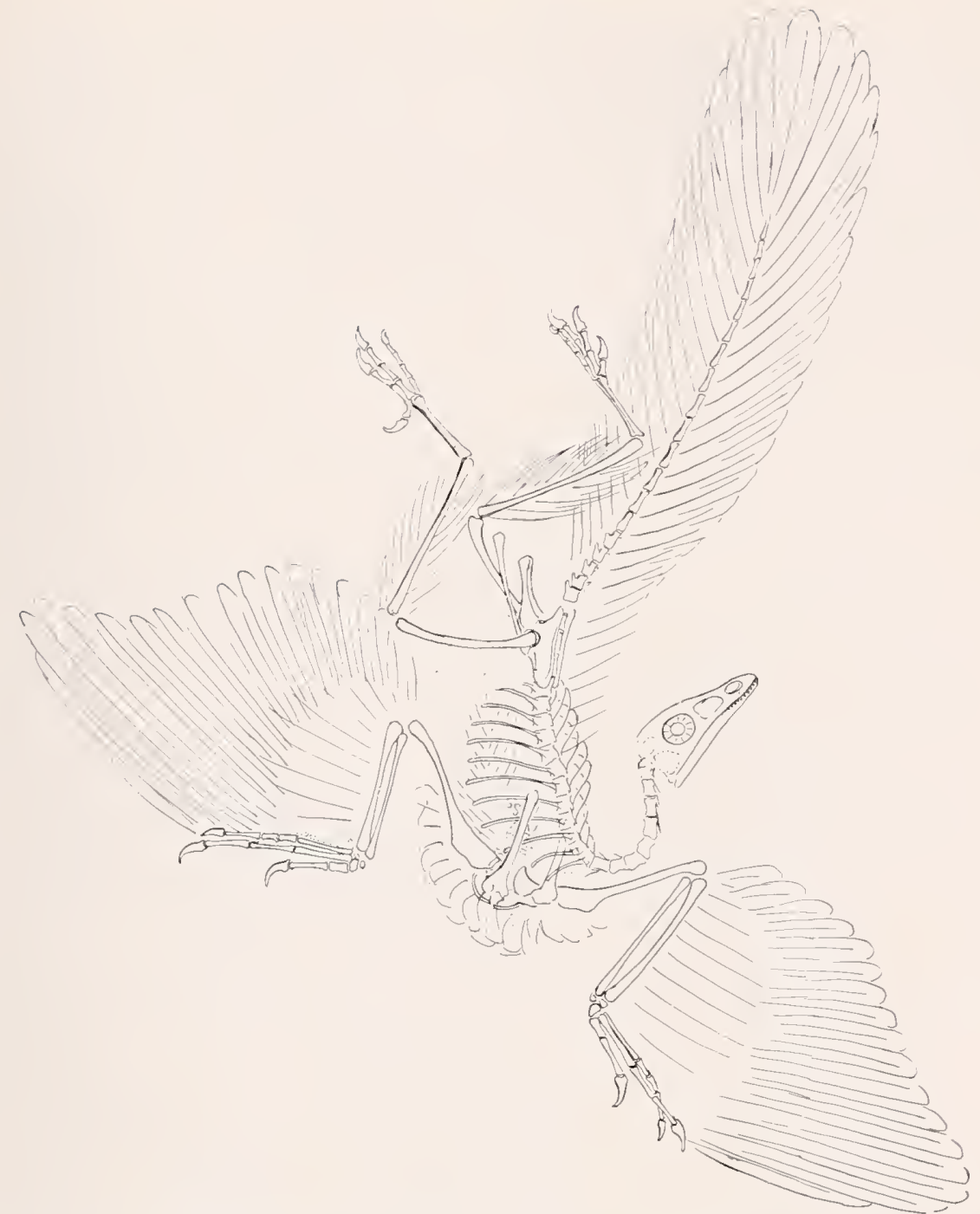

Fig. 189. Archaeopteryx lithographica. Oberer Jura. Solnhofen. 1/4 nat. Größe. Neue Rekonstruktion in der Form des Berliner Exemplares. Die Zehen der Hinterfüße sind teilweise ergänzt auf Grund des Londoner Exemplares. An dem rechten Arm ist die dritte Zehe in normale Lage versetzt und die von mir vermuteten Finger IV und V mit punktierten Linien eingetrageu.

höheren Stufe der Typus der Vögel erst voll zum Ausdruck. Die Vertreter dieser als Unterklasse auffaßbaren Stufe sind seit der oberen Kreide bekannt und seit dem Tertiär allmählich so zahlreich geworden, daß sie an Artenmenge alle übrigen Tetrapoden in den Schatten stellen. Thre systematische Gliederung wurde schon oben kurz berührt. Wir können offenbar die Odontolcae und Ratitae nicht als primitive 
Vogeltypen anffassen, dem die Erlernung des Fluges, der den Körper der Vögel erst zur Ausbildung brachte, mußte notgedrungen zunächst carinate Typen hervorrufen und in der Normalentwicklung erhalten. Schwache Flieger, Laufvögel, mïssen also entartete Vogeltypen sein. Anch der Übergang zur Schwinm- und gar zur Tauchbewegung liegt außerhalb der Norm der Vogelentwicklung. Lanfvögel wie die Ratitae und Tanchvögel wie die Odontolcae, Sphenisci n. a. werden damit in Nebenreihen gerïckt, wïhrend als normale Lebensweise das Leben auf Bämmen anzusehen ist und demgemäß Bambewohner die Hauptrichtung der Entwicklung der Klasse bestimmen. Nun entsteht die Frage, ob wir die Ratitae und Odontolcae von bekannten Banntypen ableiten kömnen, oder ob sie älteren ansgestorbenen und noch unbekannten Typen entstammten. In diesem Falle kïme in Frage, ob wir

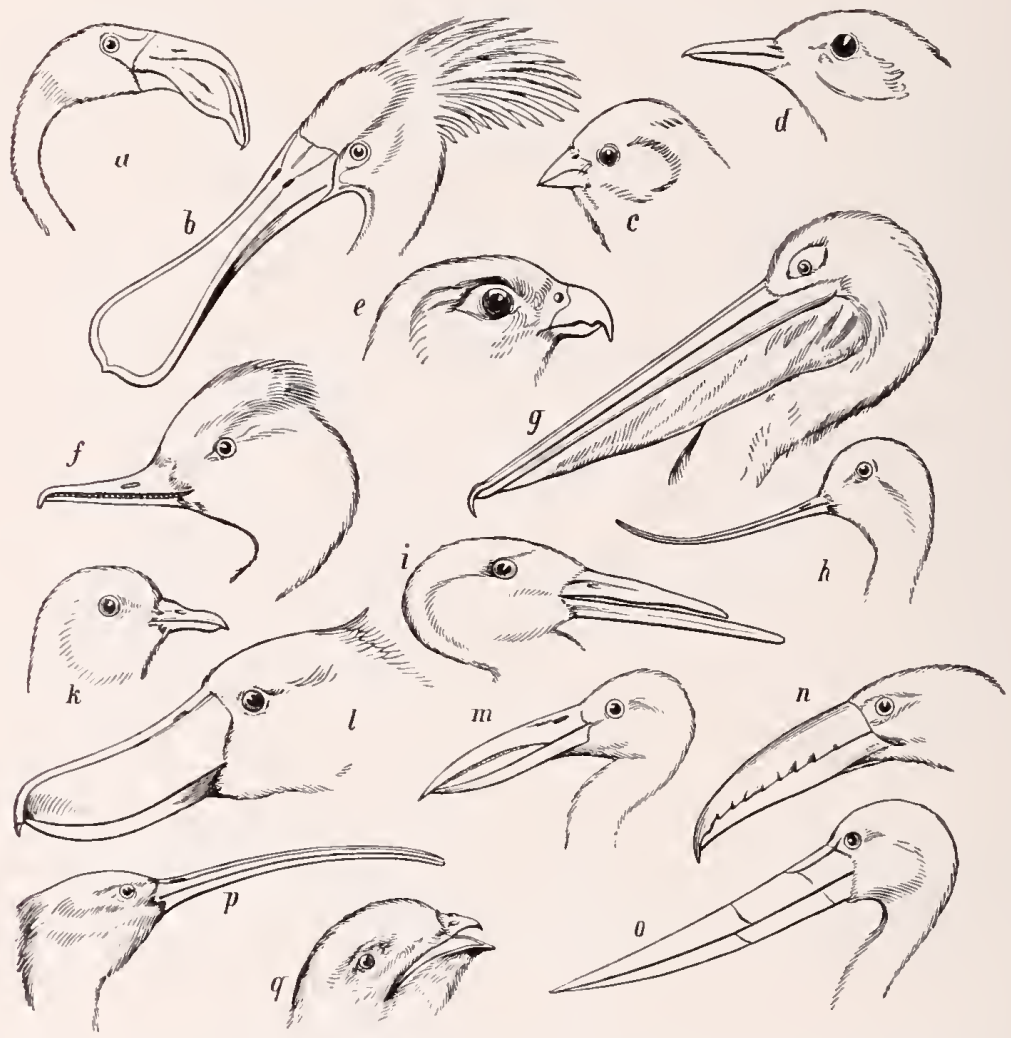

Fig. 190. Kópfformen: a Phoenicopterus antiquorum, $b$ Platalea leucorodia, $c$ Emberiza citrinella, $d$ Turdus cyanus, $e$ Falco candicans, $f$ Mergus merganser, $g$ Pelecanus perspicillatus, $h$ Recurvirostra avocetta, $i$ Rhynchops nigra, $k$ Columba livia, $l$ Balaeniceps rex, $m$ Anastomus coromandelianus, $n$ Pteroglossus discolor, o Mycteria senegalensis, $p$ Falcinellus igneus, $q$ Cypselus apus. (Nach verschiedenen Autoren aus Clauß.) 
sie einer niederen stufe unterordnen. Da nun, wie öfters betont wurde, die Chancen der Erhaltung von Landtieren und besonders Taldhewohnern sehr ungiunstig sind, aber mit der Nähe des Wassers zunehmen, so erklärt sich, daß auch hier bei den Vögeln vorwiegend Wasser- und Lferbewohner fossil erhalten sind, und uns also die Stammesentwicklung in der Hanptreihe entzogen ist. Archaeopteryx, der wohl wirklich ein "Lrvogel" war, machte darin eine selu bemerkenswerte Ausnahme; aus späterer Zeit kommt dann als wichtigerer 'Typus nur Ichthyornis aus der Kreide von Texas in Betracht, aber anch diese steht nach Fürbringer und Gadow den Colymbi. rezenten Tauchrögeln, sehr nahe und kann nicht ohne weiteres als Stammform der Ratitae oder ron Hesperornis als Typus der Odontolcae gelten. Demnach werden wir uns die Unterklasse der Neornithes wohl zweckmäßig in der Weise gliedern, daß die Ratiten und Hesperornis als Nebenordnungen, und zwar die Odontolcae als Nebenordnung einer bisher noch unbekanuten primitiveren Hauptordnung, also in einer tieferen Stufe als die ibrigen Neornithen anfgefaßt werden. In den Hauptordnungen würden dann die Banmrögel in der Hanptrichtung, die Wasserrögel in Nebenrichtungen einzustellen sein. In übrigen stiutzt sich die systematische Einteilung vorwiegend auf die Kopfform und Schädelbilduug, deren Differenzierung nachstehende Übersicht anschaulich macht. Sie beruht wesentlich auf den Terschiedenheiten animalischer und vegetabilischer Ernährung und deren zahllosen Modifikationen.

Hauptordnungen:

II. Alectoromorphae

Crypturi

Turnices

Galli-Gluifor'mes

Columbae-Charadriiformes

III. Pelargomorphae

Falconiformes

Ciconiiformes

Anseriformes

IV. Colymbomorphae

Ichthyornithes

Colymbiformes

sphenisciformes

Procellariiformes

T. Coraciomorphae

Cuculiformes

Coraciiformes

Passeriformes
Nebenordnungen:

Ic Odontoleae

II $\beta$ Ratitae 


\section{I e Nebenordnung Odontolcae Marsh.}

I)iese wesentlich auf Hesperornis aus der oberen Kreide von Texas basierte Ordnung enthält Wasservögel, die sich offenbar nicht der Schwimmbewegung angepaßt hatten, sondern nur als Lanfvögel am Ufer lehten. Nur so erklärt sich, daß ihr Sternum den Kiel verlor, der später dam nur den landbewohnenden Laufrögeln, den „Ratiten“ im engeren simne verloren ging, während die späteren spezialisierten Wasservägel das schwimmen im und unter Wasser erlernten und besonders als "Taucher" den Kiel anf dem Brustbein für die schwimmbewegung der vorderen Gliedmaßen ebenso ben̈̈tigten, wie vorher für das Fliegen.

Definition: Uferbewohnende Laufrögel, mit kiellosem Brustbein, bezahnten Kiefern, deren Zähne in Rinnen (Typus ,taphrodont") befestigt sind.

Hesperornis in der oberen Kreide rou Nordamerika, während Enaliornis in der oberen Kreide Südenglands noch unvollständig bekannt ist. Falls sie ein gekieltes Sternum besaß, könnte sie als Vorfahr von Hesperornis und der Colymbiformes eine Hauptordnung der ersten Stnfe repräsentiereı.

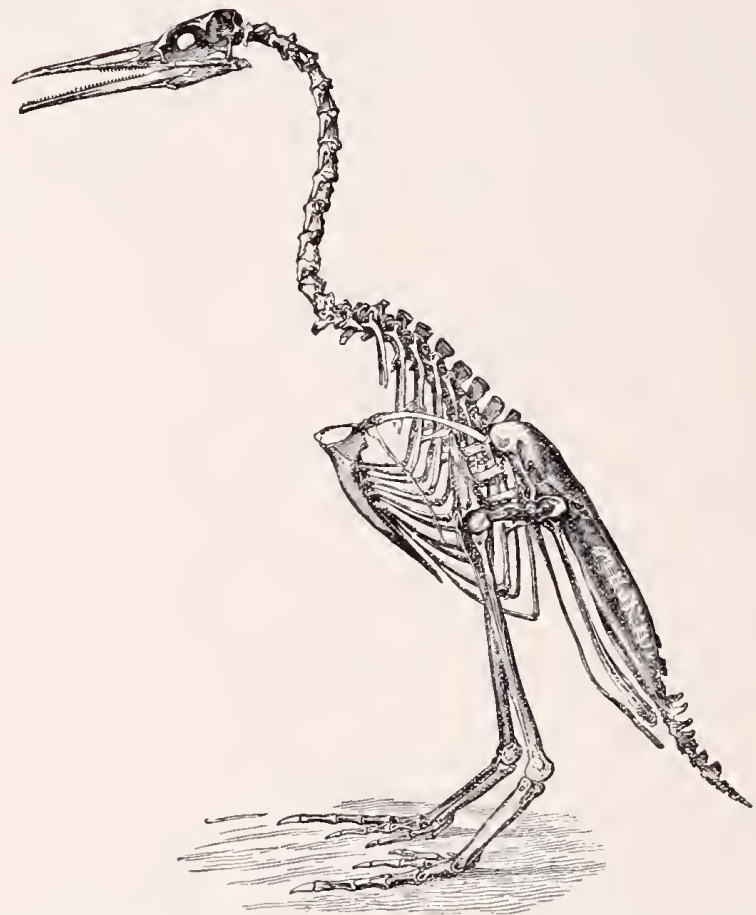

Fig. 191. Skelett von Hesperornis regalis Marsh aus der oberen Kreide von Texas. Restauration von O. C. Marsh in $1 / 10$ nat. Gröle. (Nach Marsh.) 


\section{Hauptordnung Alectromorphae Gadow.}

Diese Ordnung, deren mesozoische Vorfahren leider noch unbekannt sind, enthält in den Crypturi niedrig organisierte Formen, deren Schwanzende noch nicht zu einem Pygostyl verwachsen ist und dadurch an die „Saururae" d. h. an Archaeopteryx anknipft. Ton diesen Crypturi gehen die Turnices aus, ferner die Hühner und die Gruiformes, sowie die Tauben und die Charadriformes. Von den primitiven cretaceischen Torfahren der Crypturi könnten nach Gadow die Ratiten abstammen.

\section{Unterordnung Crypturi ('Tinamiformes Gadow).}

Nestflïchtende Carinaten mit Incisura ischiatica und unverwachsenen letzten Wirbeln. Schnabel lang, Flïgel lang, Schwanz kurz ohne Pygostyl. Typus: Timamus (Crypturus) major Gray, das brasilische Steißhuhn.

\section{Unterordnung 'T'urnices.}

Wachtelähnliche nestfliichtende Landvögel mit reduziertem Hallıx, mit großem Vomer, 14-15 Halswirbeln.

\section{Unterordnung Galli, Hïhner.}

Vierzehige Landvögel mit schizognathem Schädel, großer spina und seitlichen Fortsätzen am Sterum.

\section{Unterordnung Gruiformes, Kraniche.}

Sumpfvögel mit Vomer und schizognathem Kiefer, diskreten Rückenwirbelu, getrennten Coracoiden, ohne echten Kropf. Hierhin gehören die Rallidae, Gruidae u. a.

\section{Unterordnumg Charadriformes Gadow.}

Diese die Tauben und Möven enthaltende Gruppe ist u. a. durch schizognathen Kiefer, n-förnige Furcula und kurze Spina ansgezeichnet.

\section{Nebenordnung Ratitae.}

Landbewohnende nestflïchtende Laufvögel mit riickgebildeten Flügeln und Brustkiel, Quadıatum mit einfachem oberen Gelenkhöcker. Coracoid getrennt, mit der Scapula stumpfwinklig verwachsen. Schwanzende in der Regel mit getrennten Wirbelı. Penis am Skelett muskuliert. Dunen fehlen.

Hierhin gehören die Strauße, Struthiones, Rheae, Casnarii, der kleine lebende Apteryx und der riesige fossile Dinornis Neuseelands, die Aepyornis ron Madagaskar und benachbarten Inseln, ferner die Stereornithes, fossile Riesenvögel, wie Phorolhacos ans Südamerika. 


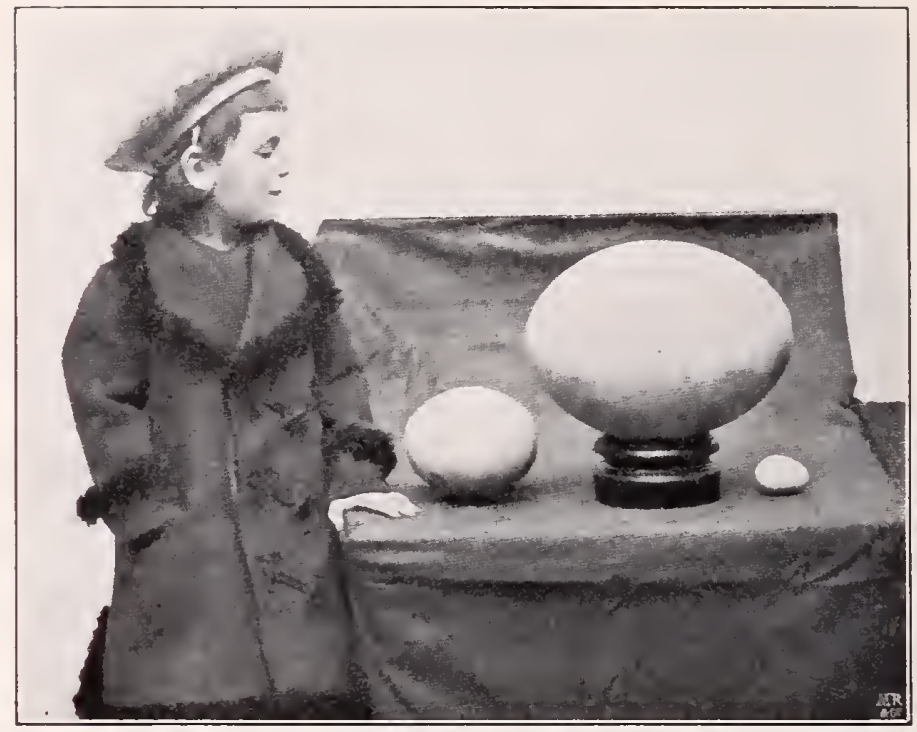

Fig. 192. Eier links vom Strauß, in der Mitte von Aepyornis, rechts rom Haushuhn.

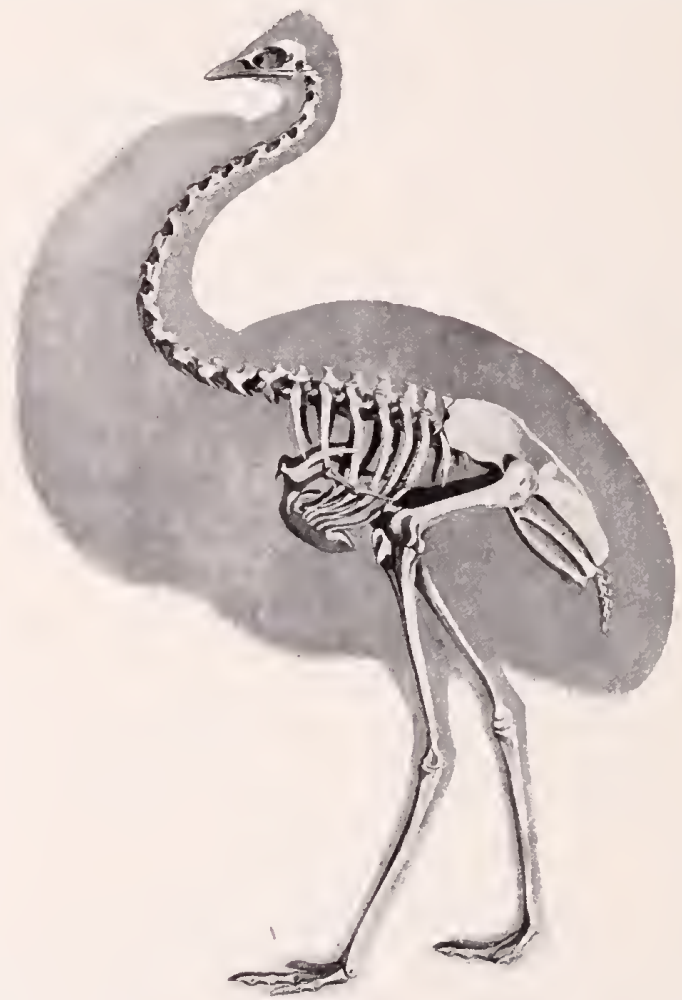

Fig. 193. Der australische Kasuar, Casuarius novae Hollandiae. Skelett und UmriB. 1/10. (Nach Pander und d'Alton.) 


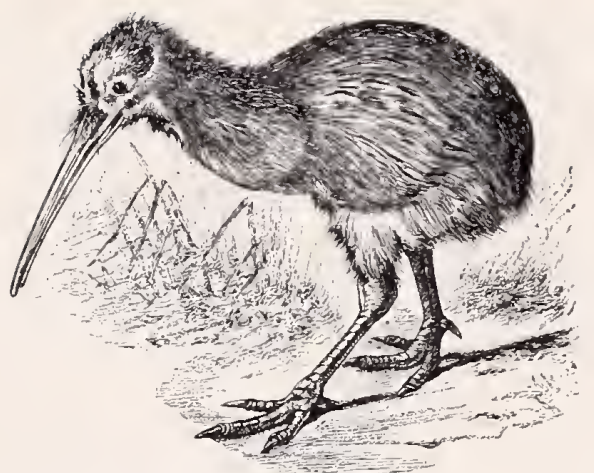

Fig. 194. Apteryx australis. Der Kiwi Australiens. 1/4. (Nach Haacke.)

\section{Hauptordmung Pelargomorphae Gadow.}

Die Abteilung Gadows umfaBt die Falken, Enten und Störche, die in sich wieder eine große Zahl ron Formen enthalten und wegen deren Divergenz kaum präzis definiert werden können.

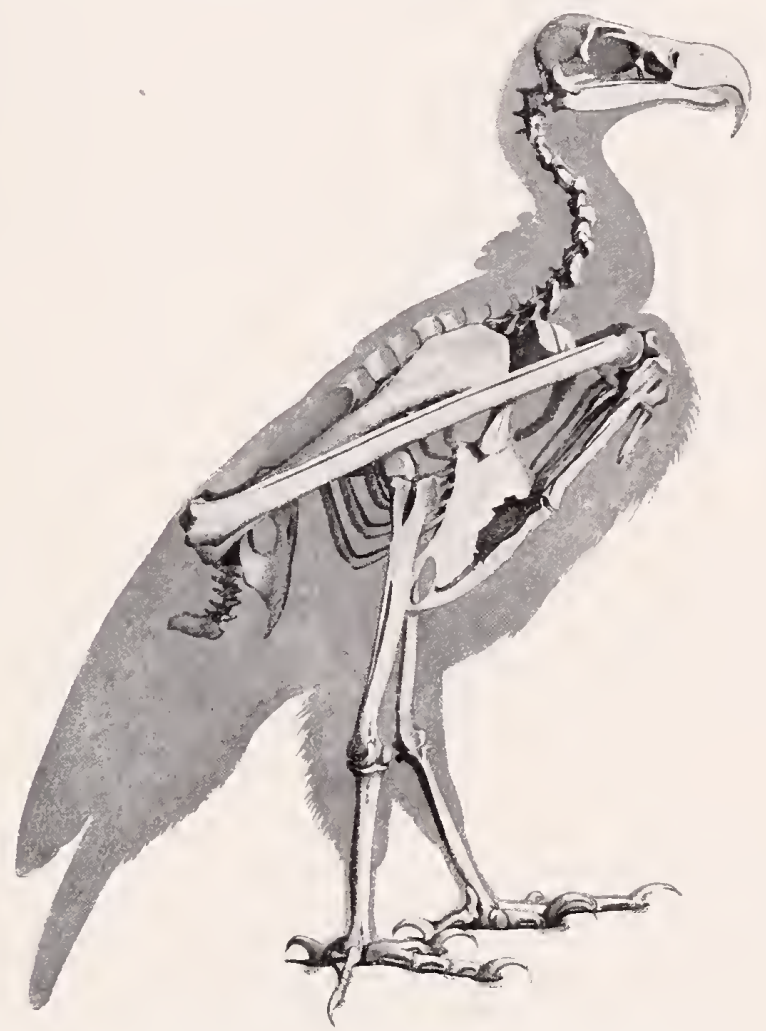

Fig. 195. Skelett und Körperumriß eines Geiers, Vultur ? niger. 1/4. Lebend. Europa. (Nach Pander und d'Alton.) 
Unterordnnng Falconiformes, Tagraubvögel.

Caruivore, nesthockende, desmognathe Raubrögel mit lakigem Oberschnabel, enthalten die Cathartidae nnd die Accipitres.

Unterordnumg Anseriformes Gadow.

I)esmognathe Nestflïchter mit vollständigen Basipterygoidfortsätzen, einem Paar sternotrarhealer Muskeln und rerstülpbarem Penis. Hierhin die siidamerikanischen Pelamedeae und die fast kosmopolitischen echiten Entell.

Unterordnmog Ciconiiformes Gadow

die Steganopoden, Ardeae (Reiler), Ciconiae und Phoenicopteri enthalten und durch echtes Nestkleid, rollständigen Vomer nnd desmognathe Kieferbildung ansgezeichnet sind.

\section{Hauptordnung Colymbomorphae Gadow (= Podicipitiformes Fürbringer).}

In diesem Formenkreis veremigt Gadow die Tchthyornithes, Colymbiformes, sphenisciformes nnd Procellariiformes, die nnn hier den Charakter von Unterordnnngen erhalten muibten. Eine Definition für diese Colymbonorphae hat Gadow nicht gegeben. Vou den genannten sind nur die ältesten, die Ichthyornithen normal gebildete Flngvögel,

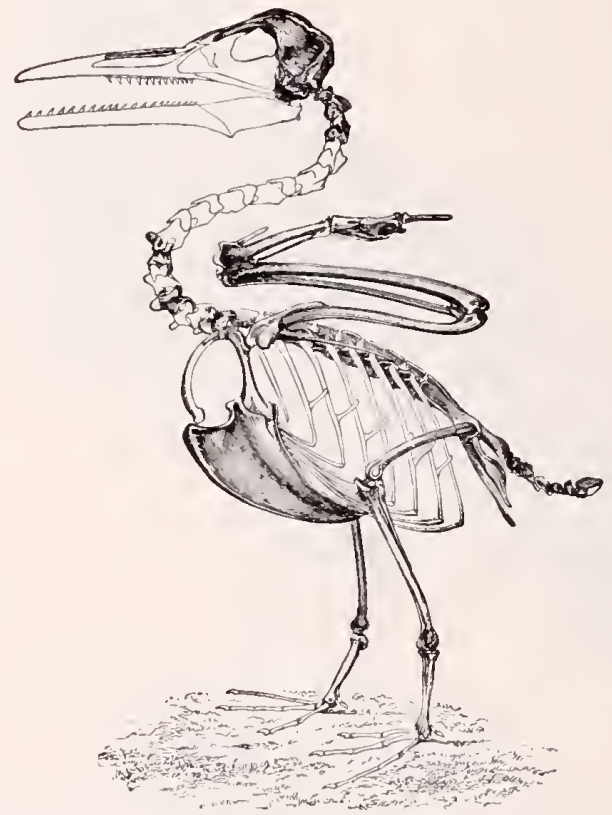

Fig. 196. Ichthyornis dispar Marsh aus der oberen Kreide von Texas. 1/s. (Restauration von Marsh.) 
während die ïbrigen dem Leben im ITasser angepaßt sind nnd dadurch in rieler Hinsicht aberrant spezialisiert sind. Diese Divergenz läßt eine präzise Definition nur für die Tuterordnungen geben.

Unterordunng Ichthyornithes (Odontotormae Marsh).

Bezahnte carinate Flugvögel mit diplocoelen Wirbeln, einer Incisura ischiatica, und selır kleinem Gehirn. Zälıne in getrennten Gruben. Fossil in der oberen Kreide von Nordamerika.

Unterordnung Procellarii oder Tnrbinares, Albatrosse.

Pelagische Flugvögel, Nesthocker mit rïckgebildeter Hinterzehe.

Unterordnnng Colymbif ormes.

schwach fliegende, mit dem Tarsometatarsus anftretende, aufrecht gehende Wasserrögel mit geradem Schnabel, kurzen Schwanzfedern und Schwimmhäuten. Hierhin gelı̈rt Colymbns nnd Podicipes.

Unterordnung Sphenisci, Pinguine.

Flïgel zn Flossen nmgebildet, Federn schuppenartig, Metatarsalien nnvollständig verwachsen, berïhren beim Auftreten den Boden.

\section{Hanptordnung Coraciomorphae Gadow.}

Der artenreiche Formenkreis enthält die Terwandten der Papageien, der Krähen nnd der Sperlinge, die folgende drei Lnterordnungen bilden:

\section{Unterordnung Cnculiformes Gadow.}

Die Cuculi und Psittaci umfassend; sie sind desmognath, zygodactyl oder mit änßerer Wendezehe mit normalen Zehenbengern.

\section{Unterordnmo Colaciformes,}

zn denen anßer den Krähen u. a. auch die Eulen, Spechte nud Kolibris gehören. Es sind Baumbewohner, echte blindgeborene Nesthocker, mit stark rednzierten alten Dunen, mit kleinen Tränen- nnd Nasendrüsen, kurzen Mandibularfortsatz, 13-15 Halswirbeln. Es sind syndactyle oder freizehige Zehenbenger.

Unterordnnng Passeres.

Echte Nesthocker, Zehenbenger mit normaler Zehenstellnng, mit großer Spina auf dem Sternum, kleinem Procoracoid. Hierhin gehı̈ren etwa 60on Arten, deren feinere Gliedernng große schwierigkeit bereitet. 


\section{V1. Klasse Paratheria Jaekel 1910.}

Von den Reptilien im älteren Sinne haben wir eine Anzahl von Formenkreisen abgesondert, die teils primitiv teils aberrant waren und sich dem Typus der Reptilklasse, wie wir sie oben charakterisiert haben, nicht einfügen wollten. Es sind das die alttriadischen Theriodontia und Anomodontia, sowie die von der Trias bis zur Gegenwart verbreiteten Schildkröten und die Monotremata, die bisher innerhalb der Sïugetiere eine sehr fragwürdige Rolle spielten. Für alle diese stellte ich eine neue Klasse (ler Paratheria auf ${ }^{1}$ ), die ich von den Reptilien abrückte und den Sängetieren näher brachte. Daß ihre ältesten Vertreter den alten Reptilien nahe stehen, ist unlengbar und selhstverständlich, da alle T'etrapoden und namentlich die holospondylen 'Tetrapoden von einem Organisationstypus ausgegangen sind. Die Eigenschaften, die aber jene ältesten Paratheria mit den Reptilien verbinden, sind nicht eigentlich Reptilmerkmale, sondern primitive Eigenschaften aller Tetrapoden. In den ältesten Vertretorn der Paratheria prägen sich aus den gleichen entwicklungsgeschichtlichen Prinzipien die Charakterzinge der Klasse noch nicht scharf aus. Diese Therocephatia sind eine Übergangsgruppe, in denen, wie das gewöhnlich in solchen geschah, einzelne Mitglieder die noch wenig gefestigten Eigenheiten teilweise abstreifen oder in aberranter W'eise selbständig modifizieren. Diese naturgemäßen Unstände können uns nicht abhalten, diese Außengruppe der Klasse zuzuziihlen, in deren weiterer Entwickhung ihre Selbständigkeit und ihre Konvergenz zu den Säugetieren im allgemeinen immer klarer hervortritt. Nur die Schildkröten machen hiervon in mancher Beziehung eine Ausnahme, sie bleiben bei ihrer eigenartigen Organisation in vielen Verhältnissen auf einer niederen Stufe stehen, die man bisher als Reptilstnfe auffaßte, weil man unbewußt geneigt war, die systematische Reihenfolge der alten Klassen als Ausdruck einer stufenweisen Entwicklung derselben anzusehen.

Paratheria sind kurz gedrungene, soweit bekannt Eier legende Vierfüßler mit kurzem wohl abgesetzten Rumpf, kurzem oder mäBig langem Hals und Schwanz. Thre Füße sind dick und schwerfällig, ihr Kopf niedrig, ihr Gehirn klein, ihre Nasenlöcher vorn gelegen, meist vereinigt. Ihre Haut ist

1) Über die Paratheria, eine neue Klasse von Wirbeltieren. Zoolog. Anzeiger XXXVI. Nr. 6/7. Sept. 1910. In dieser Arbeit hatte ich die Cotylosaurier teilweise bei den Paratherien eingereiht, während ich sie hier aus systematischen Gesichtspunkten vorzog, noch den Miosauriern zuzuzählen. 
durch hornige, seltener durch kalkige Bildungen geschützt, die hornigen zu Schnppen oder Haaren modifiziert. Ihr skelett ist dick und schwerfaillig bis zu den Gelenken verknöchert und stark mit Leisten und Fortsätzen als kräftigen Muskelansätzen modelliert. Thr Schädel, der bei den Ausgangsformen noch stegal gebaut war, weist einen Durchbruch in ler Schläfenregion auf und wird damit synapsid, d. h. mit einem einzigen kräftigen Jochbogen versehen und dem entsprechend mit einem einzigen weiten oberen Schläfendurchbruch. Die Gaumenfläche ist im ersten Stadium ihrer Entwicklung (Therapsida) noch einfach, wird damn aber mehr oder weniger diplopalatin, d. h. die Maxillen und meist auch die Palatina bilden in rorderen T'eil der Schnauze einen doppelten Gaumen, hinter dem die imneren Nasenlöcher (Choanen) münden. Demgemäß ist auch del hintere 'Teil des Gaumens säugetierartig gebant mit reduzierten Pterygoiden und Parasphenoid. Ohrkapseln (Bullae osseae) sind erst in Ausbildung begriffen und fellen älteren Typen noch gänzlich. Das Hinterhauptsgelenk ist ursprünglich dreiteilig, wird aber dann dicondyl, mit zwei exoccipitalen Gelenken. Der Unterkiefer zeigt in verschieden hohem Maße eine Vergrößerung des Dentale auf Kosten der ïbrigen primären Unterkieferknochen. Das Gebiß ist primitiv isodont, säugetierartig heterodont, oder rïckgebildet und teilweise oder ganz durch Hornscheiden ersetzt.

Im Schnlterguirtel sind Scapula und Coracoid deutlich gesondert, meist auch ein Praecoracoid, sowie eine Clavicula und Interclavicula vorhanden. Das Becken umfaßt mehrere Wirbel, und zeigt im Ilium, Ischium und Pubis normale reptilartige Ausbildung.

Das Gliedmaßenskelett ist schwerfällig geformt, mit Endkrallen versehen. Die Phalangenformel ist normal säugetierartig 2.3.3.3.3 oder nähert sich doch bei den ältesten Vertretern diesem Typus. Ein vortretender Ellenbogen (Olecranon) ist vielfach ausgebildet.

Die Wirbel sind in allgeneinen kräftig gebant, besonders auch ihre oberen Bögen, nilt denen der Wirbelkörper gewölınlich fest verwachsen ist. Die Rippen sind kräftig in der Regel zweiköpfig und über den ganzen Rumpf ausgedehnt. Untere Bögen an Schwanz sind schwach entwickelt. Zwischenwirbelstïcke fehlen.

Die Formenkreise ordnen sich in folgender Weise an, wobei ich als Hauptordnungen die Stufen normaler Entwicklung in die erste Reihe stellte.

Hauptordnungen:

I Therapsidi

II Theriodonti
Nebenordnungen:

I $\alpha$ Dinocephali

I $\beta$ Testndinati

II a Anomodonti

? Monotremati 


\section{Hauptordmng † Therapsidi Broom.}

Die fast nur aus der Karrooformation Sïdafrikas bekannten Yertreter dieses Formenkreises sind noch wenig genan bekannt, und fast nur Schädel-bestimmbar. Broom rechnet hierher Formen mit großen synapsiden Schädeln von Säugetierhabitns, aber mit einfachem Gaunen, meist bezahnten Pterygoiden, sängetierartig differenziertem Gebiß, in dem aber meist etwa fünf Schneidezähne vorhanden, die Eckzähne nicht lokalisiert und die Backzähne spitz sind. In Schädel sind die Postorbitalia noch vorhanden, aber Supratemporalia nnd Quadratojugalia verschwunden.

Broom unterscheidet drei Formenkreise, die ich als Unterordnungen anffïlnre:

1. Unterordmmg Dromaeosanri Broom mit Galechirus Scholtzi als Typus.

2. Unterordnnng Dinocephali Broom mit Delphinognathms, Titanosuchns, Arehaeosnchns und seapanodon.

3. Unterordnung Therocephahi Broom mit Alopecodon, Scylaeosanrus Pristerognathus, Pardosuchms, Scymnosaurus und Glanosuchus.

Ferner könnte hierher gehören anch die Gattung Denterosaurıs aus dem russischen Perm, von der anßer schädelfragmenten anch einzelne Skeletteile gefmnden sind.

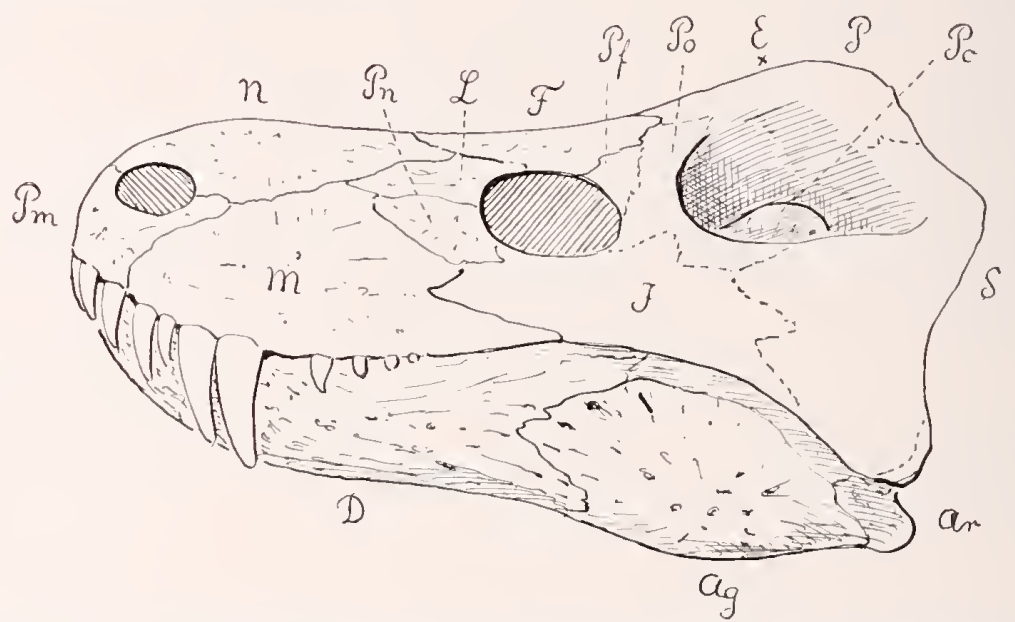

Fig. 197. Lycosuchus vanderrieti Broom. Neue Rekonstruktion des Schädels auf Grund der Figuren von Broom. Unt. Trias. Südafrika.

In einem sehr bemerkenswerten Formenkreis siidafrikanischer Paratherier, ïber die Broom erst vorlänfig berichtet hat, zeigt das Gebiß den Übergang von der isodonten znr heterodonten Bezahnung, in dem die vordersten Zähne des Maxillare größer werden, damit den Charakter 
von Eckzähnen annehmen und nun die Gebißreihe gliedern. Hier sind num bei einigen dieser Formen mehrere Eckzähne vorhanden (Fig. 197).

In eine Nebenordnung I i werden verschiedene Typen zu stellen sein. die noch näherer Aufklärung bediirfen. so namentlich die oben genannten Dinocephali, während die Iromasauri und Therocephali in die Hauptreihe zu stellen sind. Das britische Musem besitzt außerdem noch ein großes Material derartiger Funde aus dem oberen Perm und der 'Trias Südafrikas, das rielleicht anch zur Aufstellung' weiterer' Nebenordnungen Teranlassumg geben wird.

Es scheint mir auch nicht ganz ausgeschlossen, daß sich die Ichthyosaurier hier durch Übergang zur schwimmenden Lebensweise abgezweigt haben könnten. Thr schädelban mit seiner geschlossenen Wangenregion, die als einfacher Jochbogen erscheint, wïrde im Anschluß an Therapsiden seine nächste Erklärung finden. So lange wir aber noch so wenig Sicheres über die Torfahren der Ichthyosaurier wissen, läßt sich solrhen Möglichkeiten kaum nachgehen.

\section{I $\beta$ Nebenordnung 'Testudinata, Schildkröten.}

Die schildkröten sind sehr einseitig spezialisierte Formen, die ihren alten noch reptilartigen Paratheriertypus bis zur Gegenwart bewaht haben, und deshalh auch bisher zu den Reptilien gestellt wurden. In der Tereinigung ihrer Nasenlücher, der Bildung eines doppelten Gaumens, eines einfachen Jochbogens und eines dreiteiligen Hinterhauptgelenks, sowie in ihrer primären Zehenformel 2.3.3.3.3 sind sie echte Paratherier. In der Zahnlosigkeit und Hornschmabelbildung stehen sie den Anomodontiern nahe und auch den Monotremen. Thre wesentliche spezialisierung beruht anf ihrer Rumpfpanzerung. Dieselbe beschuänlit sich nicht wie bei anderen auf epidermale Hornbildungen. (schildpatt), sondern wird in tieferen Lagen der Haut rerstärkt durch Ausbreitung der oberen Bögen (Neuralia) ron 8 Rumpfwirbeln und der diesen angeschlossenen Rippen (Costalia). Zur Tervollständigung dieses Panzers werden Randplatten herangezogen (sog. Marginalia). Alle diese bilden den Rïckenpanzer oder den Carapax. Im seitlichen AnschluB an diesen wird ein Bauchpanzer (Plastron) gebildet, teils aus den Elementen des Schultergïrtels, Claviculae (Epiplastra), Interclavicula (Entoplastron) und Terschmelzungskomplexen ron Bauchrippen, die sich in mehreren Paaren anordnen (Hyoplastra, Mesoplastra, Hypoplastra und Xiphiplastra hinten). Durch die 4 Beine wird das Plastron eingeengt, so daß die Mesoplastra gewöhnlich verschwinden.

Die Lrformen sind schwerfällige plumpe Landtiere mit hoch gewölbtem Panzer und zahlreichen Marginalien. Dieser Typus hat sich etwas vereinfacht in den Landschildkröten bis jetzt erhalten. Andere 
gingen ins Wasser, lernten schwimmen und platteten dazu ihren Panzer $\mathrm{ab}$, den die beweglichen Seeschildkröten (Cheloniden) mehr und mehr reduzierten (Fig. 203). Bei diesen Schwimmformen tritt, wie auch sonst bei solchen, eine Vermehrung der Fingerglieder ein. Ihr Kopf wird nicht mehr wie bei den Landschildkröten unter den Panzer zurückgezogen, sonderm bleibt beim schwimmen vorgestreckt und schafft sich ein nenes Schutzdach durch Ausdehnung der Parietalia über ihre primäre Schläfengrube (tegaler Schädeltypus Jaekels). Bei dem Endglied der Seeschildkröten Dermochelys (Fig. 204) ist der eigentliche Schildkrötenpanzer ganz rednziert und ein Buckelpanzer wieder an seine Stelle getreten. Die Morphologie und historische Entwickhnng der Schildkröten läßt an diesen Vorgängen wohl kamm mehr zweifehn.

Ihre bisherige Einteihmo danach, ob ihre Beckenknochen mit dem Panzer fest oder lose verbunden sind, in Plenrodira und Cryptodira läßt sich an fossilen Formen und namentlich den primitivsten dieser Typen schwer durchfïhren. Wir müssen ihnen noch einen primitiven Typus voransetzen, für den Boulenger den Namen Amphichelydia einführte. Von diesem lassen sich dann nach O. P. Hay die Cryptodira und Plenrodira in verschiedenen Richtungen ahleiten. Es scheint mir nun aber zweckmäßig, die Chelonii und Trionychii, die beide in engerer Beziehung zu deu Cryptodiren als zn den Pleurodiren stehen, als selbständige Nebenreihen der ersteren anzusehen und demnach die Unter-

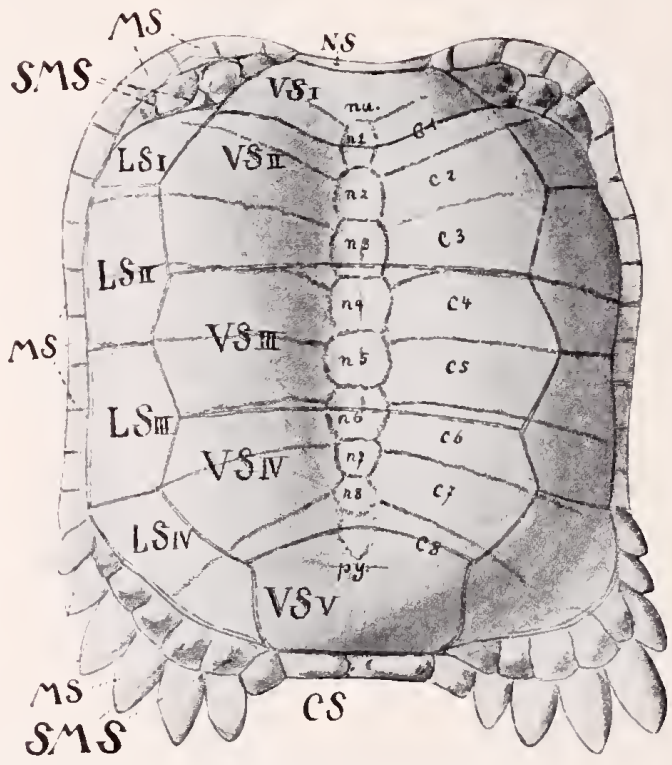

Fig. 198. Rückenpanzer von Proganochelys Quenstedti Baur. Keuper Württembergs. Etwa 1/z• (Nach E. Fraas.) 
ordnnng der Cryptodira auf deren Land- und Sumpftỵpen zu beschränken. Wir erhalten dann folgendes system.

\section{Tnterordnnng Amphichelydii Lyddeker 1889.}

Landschildkröten, deren Becken noch nicht fest mit dem Panzer rerwachsen ist, deren Bauchpanzer (Plastron) noch ein mittleres Paar sogenannter Mesoplastra enthält, deren Kopf und Hals noch nicht die scharfe Spezialisierung der jüngeren Typen aufweist, und deren schädel noch Tasalia aufweist, die später rerschwinden bezw. ron der Oberseite des Schädels verdrängt werden. Hierhin gehören anßer einigen noch fraglichen Resten aus dem Mnschelkalke die Proganochelys aus dem Keuper Wïrttembergs, ferner die Mehrzahl der jurassischen und ein Teil der cretaceischen Formen u. a. Platychelys, Baena, Compsemys.

\section{Unterordnung Pleurodiri.}

Land- nnd Sumpfschildkröten mit voll rerknöchertem Panzer, deren Becken fest mit dem Panzer rerwachsen ist, deren Kopf unter horizontaler Biegung des Halses unter den Panzer gezogen, wird und deren

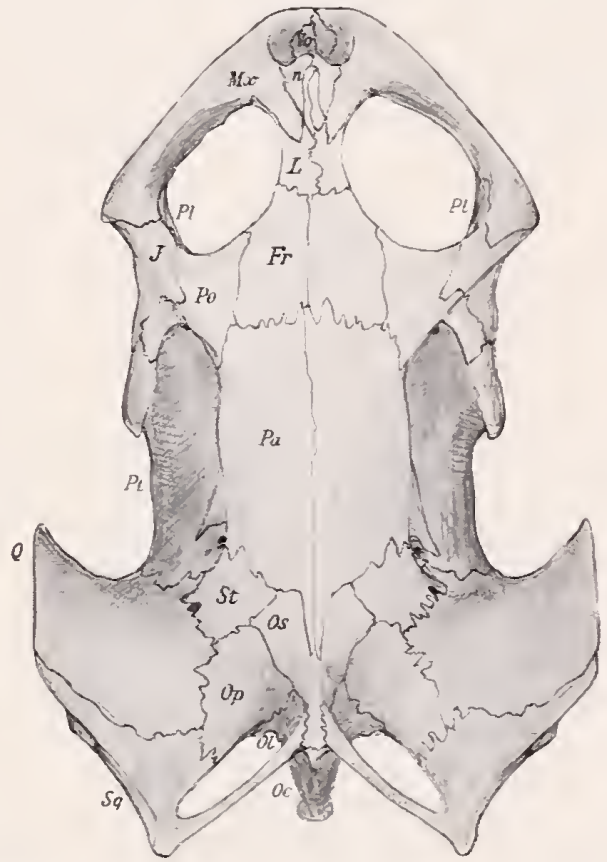

Fig. 199. Hydromedusa sp. mit posttemporalem Bogen, mit kleinen Nasalien vor den Lacrymalia (L), Mx Maxillaria, Pt Palatina, J Jugalia, Po Postorbitalia, Er Frontalia, Pa Parietalia, Pt Pterygoidea, Q Quadrata, St vermutlich die Prootica anderer Autoren, Os Supra-occipitalia, Op Opisthotica, Ol Occipitalia lateralia, Oc Condylus occipitalis, $S q$ Squamosum. 
Plastron in der Regel der Mesoplastra enthehrt. Der schädel zeigt z. T. noch eine posttemporale Brïlke (Fig. 199).

Hierhin gehören außer einer Anzahl weit verbreiteter fossiler Formen die gegenwïrtig in den australischen Landgebieten heimischen Pelomedusen (Fig. 199) und Chelyidae.

\section{Unterordumng Cryptodiri.}

Land- und Sumpfschildkröten mit stark gewölbtem, normal verknöcherndem Panzer, deren Becken nicht oder nur teilweise mit dem Panzer verwachsen ist, deren Kopf unter vertikaler Biegnng des Halses zurückgezogen wird. Mesopolastra fehlen dem Plastron.

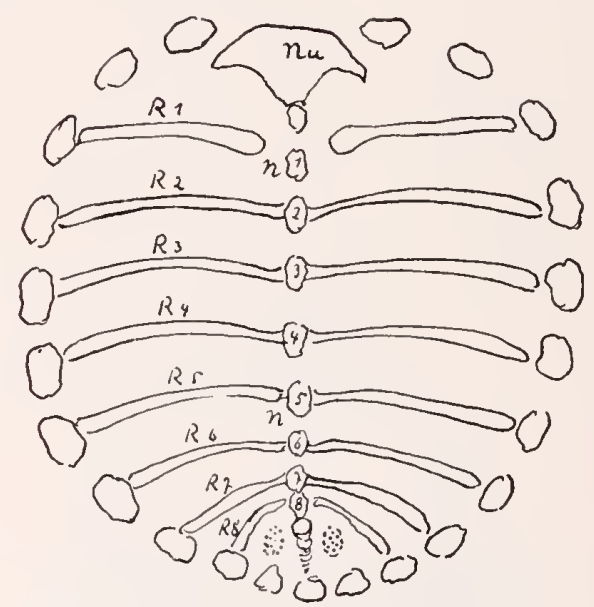

Fig. 200. Anlage des Riickenpanzers bei einer Jugendform von Testudo. 2/2. (Nach Jaekel.)

Diese formenreichste Abteilıng der Schildkröten umfaßt die Chelydridae, Cinosternidae, Testudinidae, Enydidae, die Anosternidae, Dernatemydidae, die Platysternidae und die Tritosternidae. Viele dieser Familien haben seit der Kreide fossile Vertreter.

\section{L'nterordunng T'rionychii, Weichschildkröten.}

Sumpfbewohner mit flachem, grubig sknlpturiertem Knoclenpanzer, der echten Schildpattes und der Randplatten entbeht und anch weiche, überwachsene Kiefer aufweist.

Hierhin gehören die Trionychiden und Plastomeniden.

\section{Unterordnung Chelonii, Seeschildkröten.}

Seeschildkröten mit teilweise aufgelïstem oder ganz reduziertem flachem Panzer, deren Füße zu Paddehn nmgewandelt sind, deren Zehen 


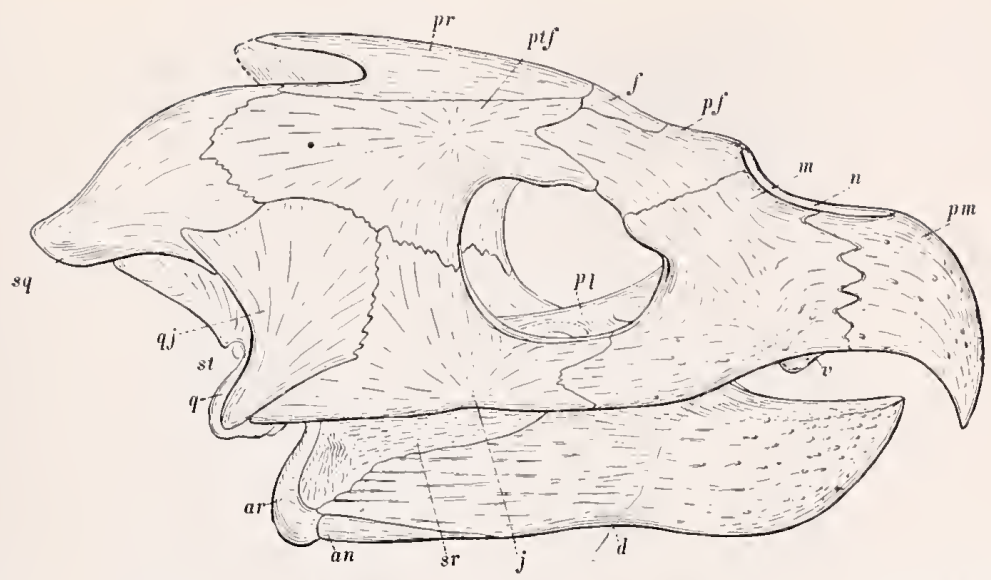

Fig. 201. Chelon ischyros Wieland. Ohere Kreide, Dakotah. 1/8. (Nach Wieland.)

ïberzälllige Glieder aufweisen, und deren Krallen bis auf die letzte reduziert sind. Der Kopf zeigt eine große, rïckwärtige Ausdehnung der Parietalia als Schntz der hinteren Schädelregion, die herausgestreckt bleibt und deshalb eines Schutzes bedarf. Hierher stelle ich außer den jurassischen Acichelyden die Cheloniden (Fig. 202), die cretaceischen Toxocheliden, Protostegiden (Fig. 201), trotz Hays und anderer gegenteiliger Auffassung auch die Familie der Dermochelydidae (Fig. 204),

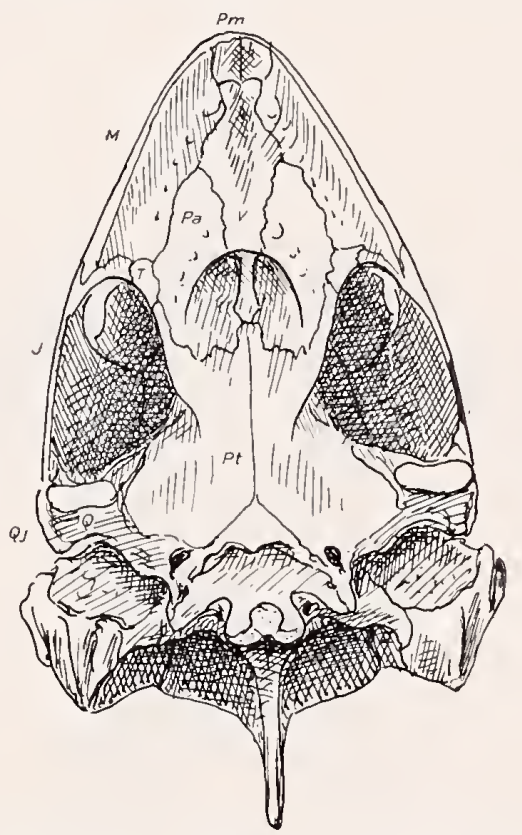

Fig. 202. Gaumenfläche des Schädels von Chelone viridis Schneider, der Suppenschildkröte. 1/2. (Nach Jaekel.) 


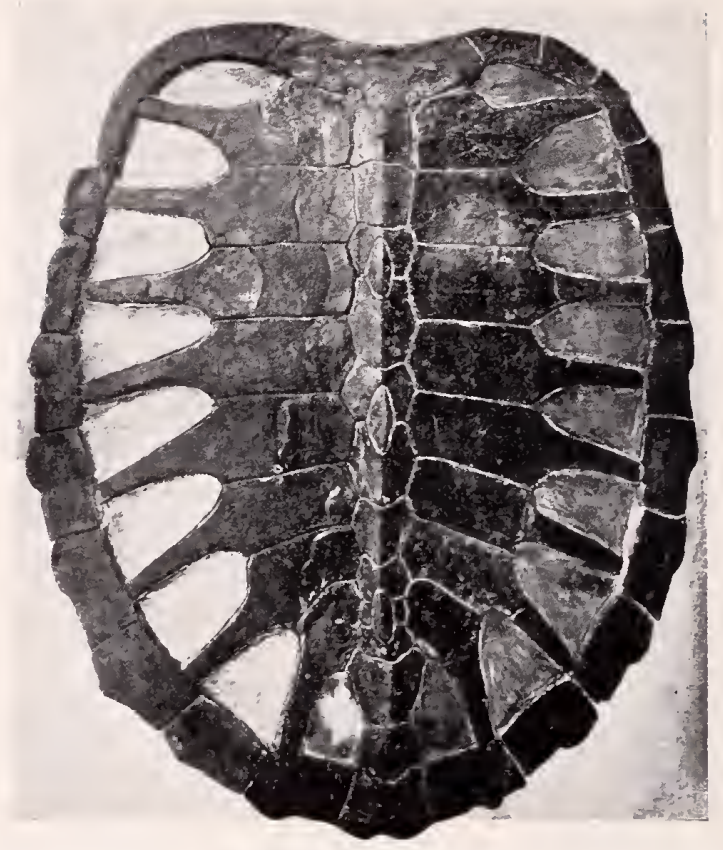

Fig. 203. Toxochelys Bauri Wieland. Rückenpanzer mit den für die Chelonii typischen Unterbrechungen zwischen den Rippenenden. 1/8. (Nach Wieland.)

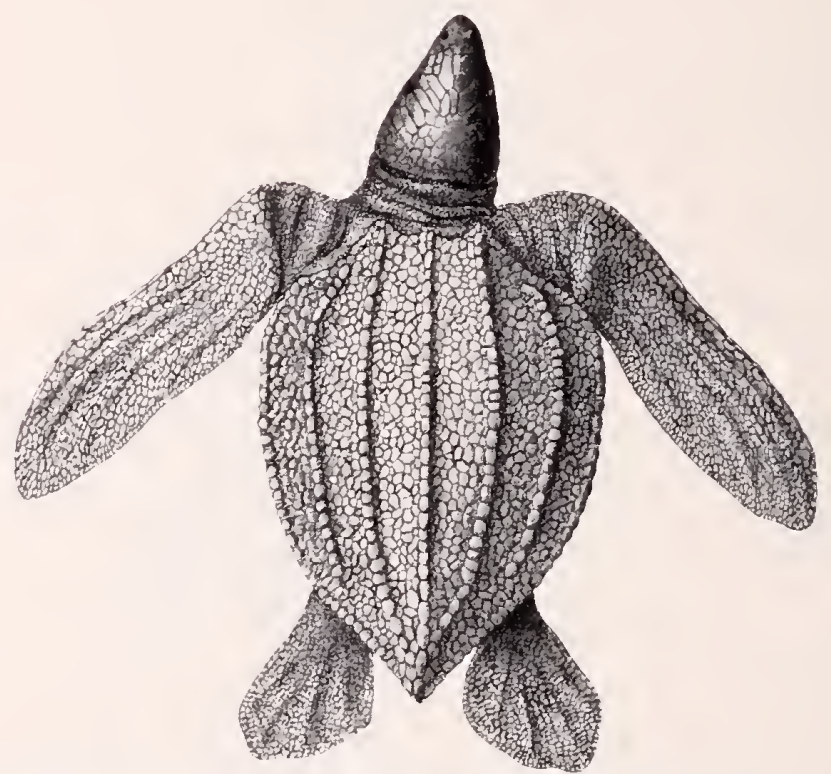

Fig. 204. Dermochelys coriacea. Jugendliches Exemplar. Küste von Kamerun. 1/2, (Nach Jaekel.) 
die sich mit der oberen Freide selbständig zu einem eigenartigen Typus mit einem mosaikartigen Buckelpanzer spezialisiert haben. Auch dieser Typus der Chelonii hat, wie die Trionychii, einen selbständigen Seitenweg eingeschlagen.

\section{$1 \gamma$ Nebenordnung $\div$ Anomodontii Owen.}

Indem wir den oft unzweckmäBig ansgedehnten Begriff der Anomodontier wieder auf seinen Typus, die Formen um Dicynodon, beschränken, verstehen wil darunter sehr spezialisierte Paratherier, die sich offenbar einer eigenartigen Nahrungsaufmahme anpaßten und ihre Bezahnung rückbildeten zugunsten einer hornigen Schnabelbildung, wie sie Schildkröten besitzen. Ihr Gaumen ist diplopalatin, aber so, daß nur die Maxillen an der Überwölbung der Choanen Anteil nehmen. Ihr Hinterhauptsgelenk noch dreiteilig zusammengesetzt. Ihr Unterkiefer ist sehr dick und schwerfällig, seine hinteren Elemente zwar klein, aber aber anscheinend noch vollzählig entwickelt. Thr Extremitätenskelett schwerfällig, die Phalangenformel 2.3.3.3.3.

Man kann die Anomodontier zerlegen in drei Familien:

1. die Endothiodontidae (Fig. 205) mit Caninen und schwachen Zähnen dahinter. Endothiodon Owen, Opisthoctenodon Broom, Esoterodon Broom, Prodicynodon Broom.

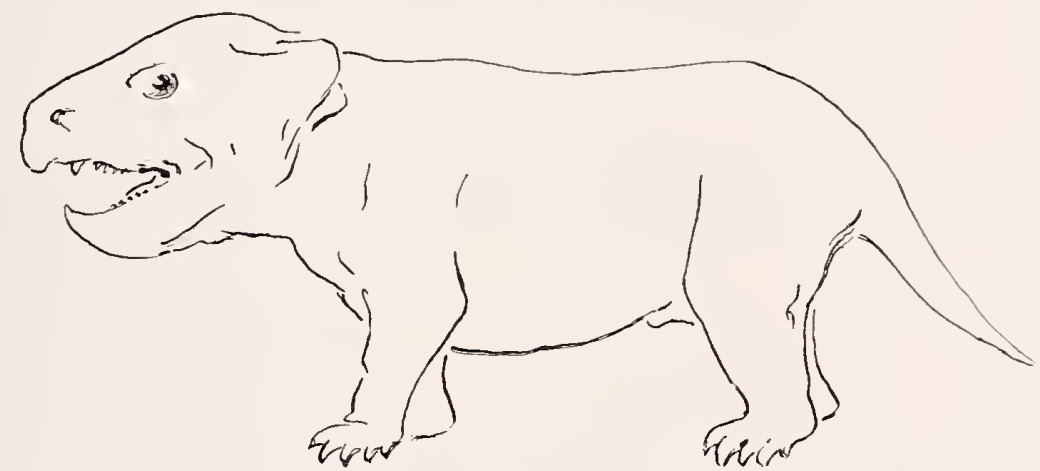

Fig. 205̃. Endothiodon bathystoma Owen (Restauration auf Grund der Darstellungen von Broom). Trias, Karrooformation Südafrikas.

2. Dicynodontidae mit einem Paar großer Eckzähne im Oberkiefer und einer dicken Verknöcherung der Schnauze. Dicynodon mit flach gewölbtem Schädel, Lystrosaurus mit einem starken Knick in der vorderen Frontalregion und Sagecephalus mit einer tiefen Einsattelung (Sage $=$ Suttel) in der Parietalregion und stärkster Verdickung der Schnauze (Fig. 206-209). 


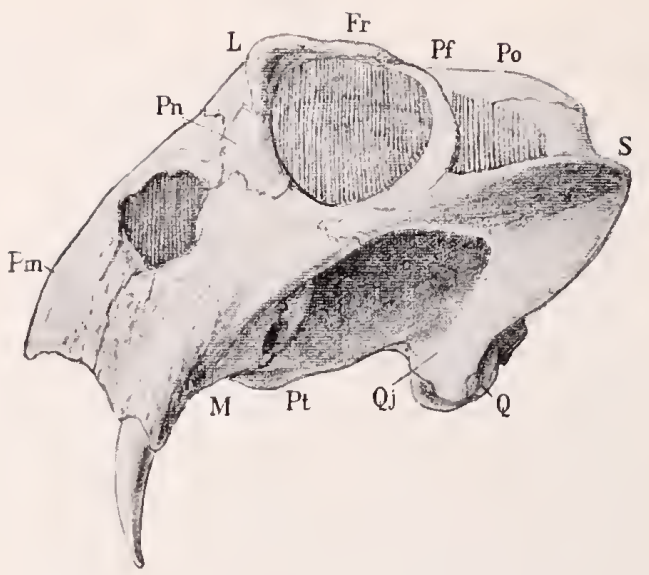

$A$
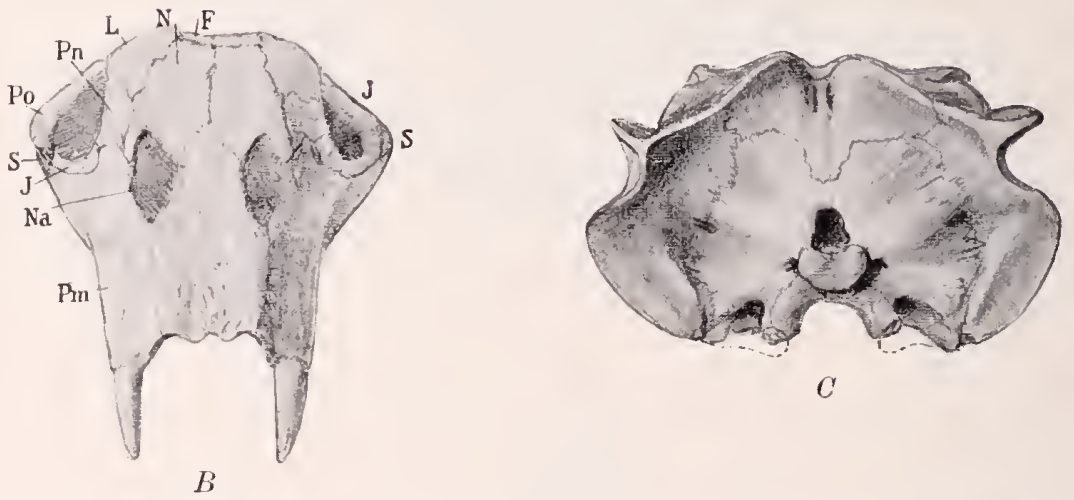

Fig. 206. Dicynodon sp. Scliädel $A$ von der Seite, $B$ von vorn, $C$ von hinten. Untere Trias, Karrooformation Südafrikas. (Nach einem Exemplar des Brit. Mus.) 1/4.

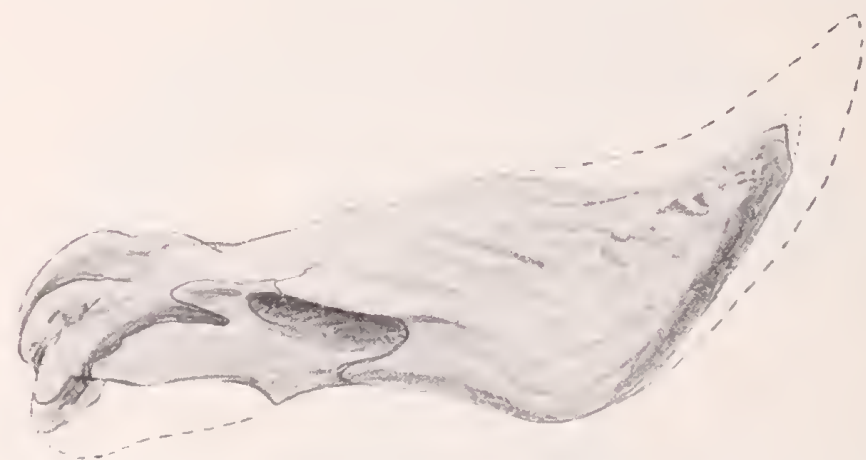

Fig. 207. Unterkieferast eines Dicynodonten, mit großem Dentale, die einen punktiert umrandeten Hornschnabel trug, dahinter das Spleniale und Complementare, dahinter links das Quadratum mit der Gelenkrolle für das Quadratum; die Lage des Angulare ist durch einen unterbrochenen Strich augezeigt. 1/3. (Nach einem Exemplar des Brit. Mus.) 
C. Tetrapoda. Paratheria
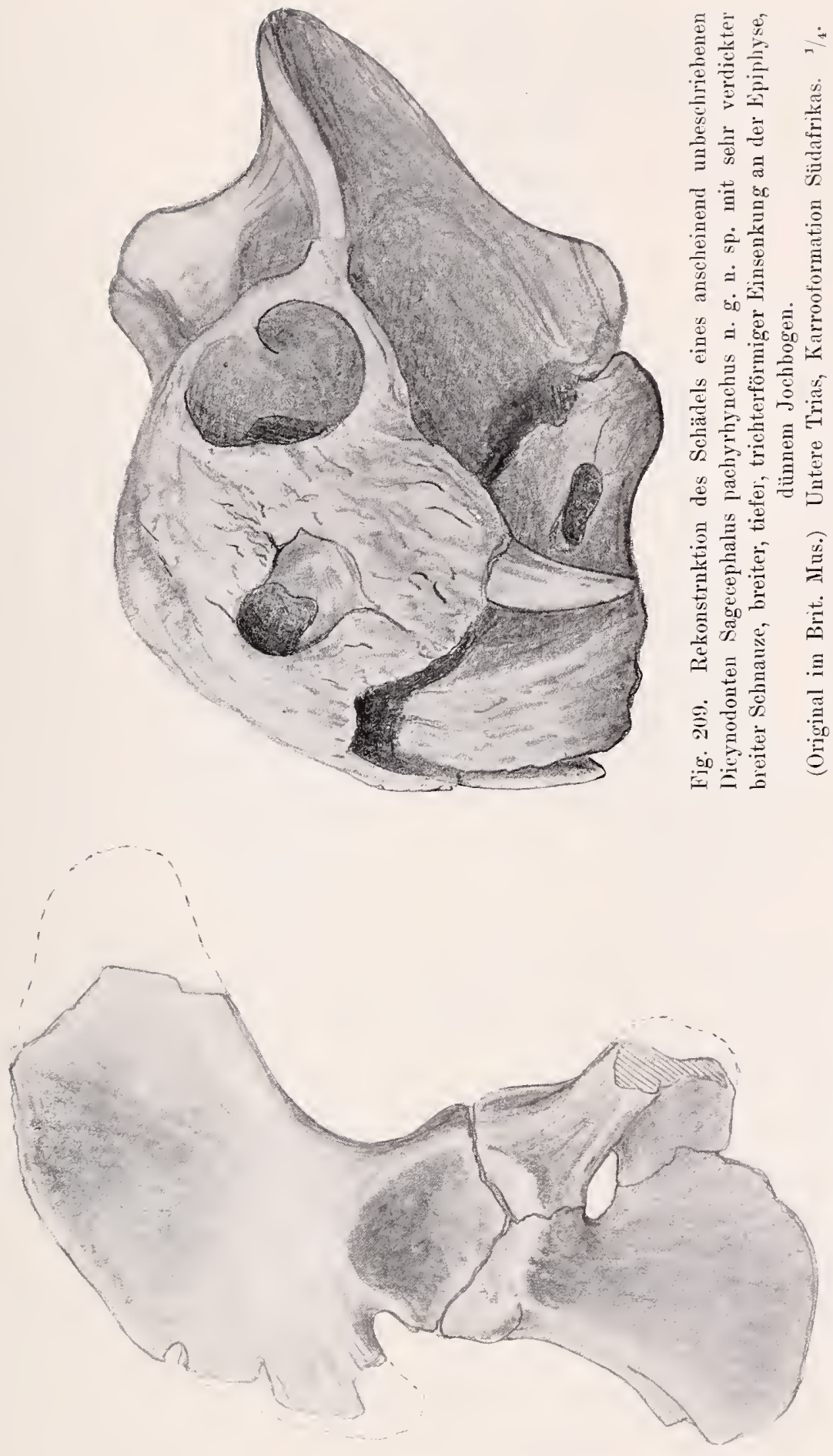

悉急 苛总 这茎 巨) 章

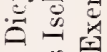
胥 .

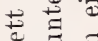

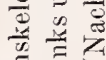
$\Xi \Xi$

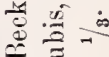
i

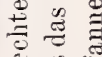

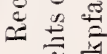
$\dot{0}=\frac{\overline{0}}{0}$ ज) 红 焉 
3. Udenodontidae, zahnlose Formen mit einer rorspringenden Ecke an Stelle der Eckzähne des Oberkiefers, schwacher Ausbildung der Schnauzenregion, und flacher Oberseite des Schädels (Fig. 110—212).

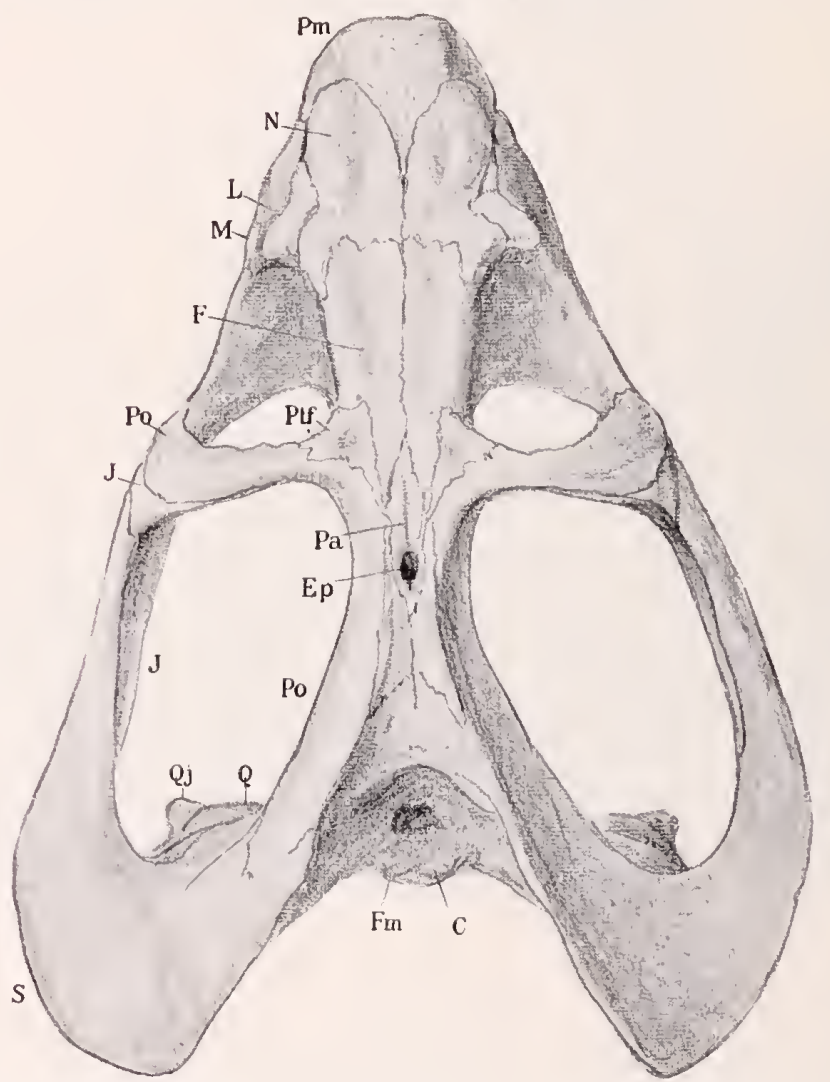

Fig. 210. Udenodou sp. Oberseite des Schädels nach einem Exemplar des Brit. Mus. (nat.-hist.). Trias, Karrooformatiou Südafrikas. Pm Praemaxillae, $N$ Nasalia, L Lacrymalia, $I$ Maxillaria, $F$ Frontalia, Ptf Postfrontalia, Po Postorbitalia, J Jugalia, Pa Parietalia mit der Epidyse (EP), Qj Quadratojugale, $Q$ Quadratum, $S$ Squamosum, $F m$ Foramen magnum, $C$ Condylus, Tr Transversa, $P t$ Pterygoidea.

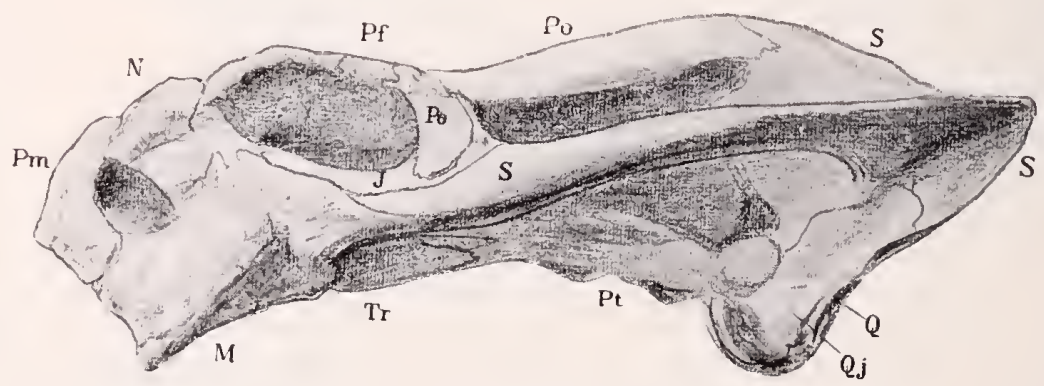

Fig. 211. Udenodon sp. Derselbe Schädel in Seitenansiclit. Bezeichnungen wie in Fig. 206. 


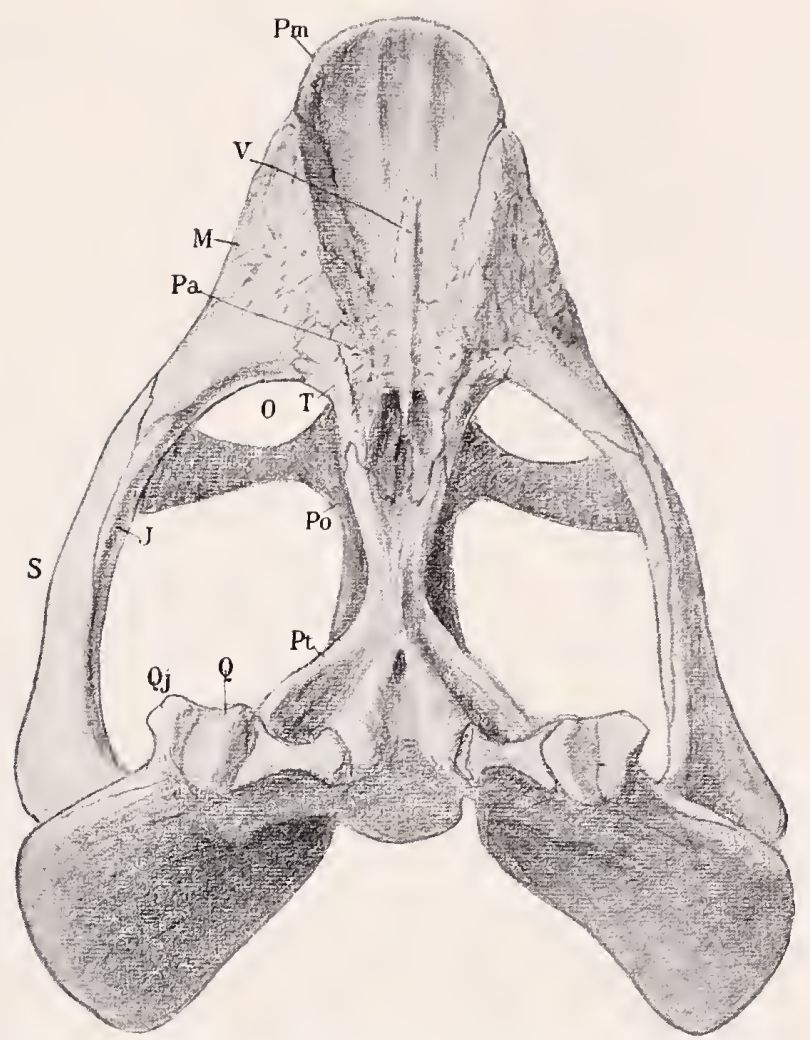

Fig. 212. Udenodon sp. Derselbe Schädel wie Fig. 210. Unterseite. Bezeichnungen wie in Fig. 210 und 211. $V$ Vomer, Pa Palatina, T Transversa, Pt Pterygoidea.

\section{- II. Stufe. Hauptordnung t'Theriodonti.}

Typisch entwickelte Paratheria mit kräftigem Jochbogen, doppeltem (diplopalatinem) Gaumen, mit doppeltem Hinterhaupts-Gelenk, mit sehr vergrößertem Dentale im Unterkiefer, mit einreihiger thecodonter Kieferrandbezahnung, die in 5-3 Schneidezähne, einen Eckzahn und zahlreiche Backzähne gegliedert ist, die eine dominierende Hauptspitze haben und nach hinten zu vordere und hintere Nebenspitzen ausbilden. Postfrontalia, Supratemporalia und Quadratojugalia sind noch vorhanden. Scapula mit Acromion. Zehenformel 2.3.3.3.3.

Eine ununterbrochene Reihe führt von den Therocephali, die z. T'. noch einfachen Gaumen, mehrere Eckzähne und andere indifferente Merkmale aufweisen, in direkter Reihe zu den Theriodonten, in denen wir wohl das Prototyp der Säugetierentwicklung zu erblicken haben. Sie nähern sich diesem Typus in ganz entschiedener Weise, bleiben aber doch in den meisten Verhältnissen noch auf niederer Stufe. Thre 
Bezahmnng ist zwar sängetierartig gegliedert. aher die einzelnen Backzähne sind noch sehr primitiv. Bei dem am besten bekannten Cyno-

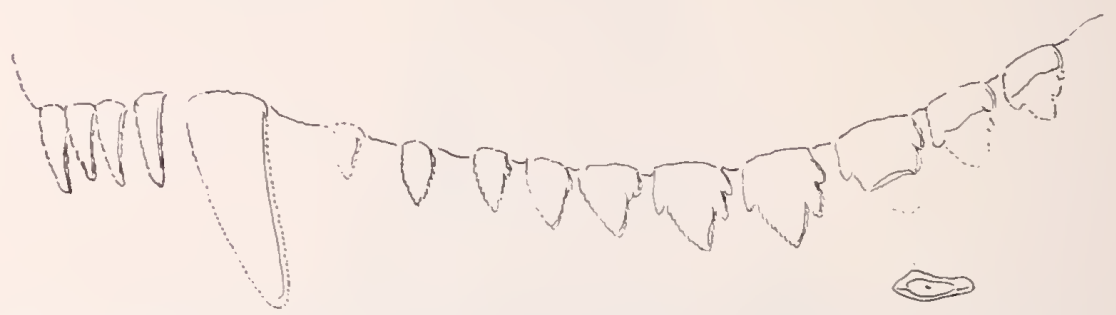

Fig. 213. Zahnreihe des Oberkiefers von Cynognathus crateronotus Ow. Trias, Karrooformation, Südafrika. Der erste Prämolar ist rekonstruiert. 1/1.

gnathus (Fig. 213) sind sie sehr stark komprimiert. vorn mol hinten nicht $n$ r kantig, sondern anch noch wie Reptilzähne fein gekerbt.

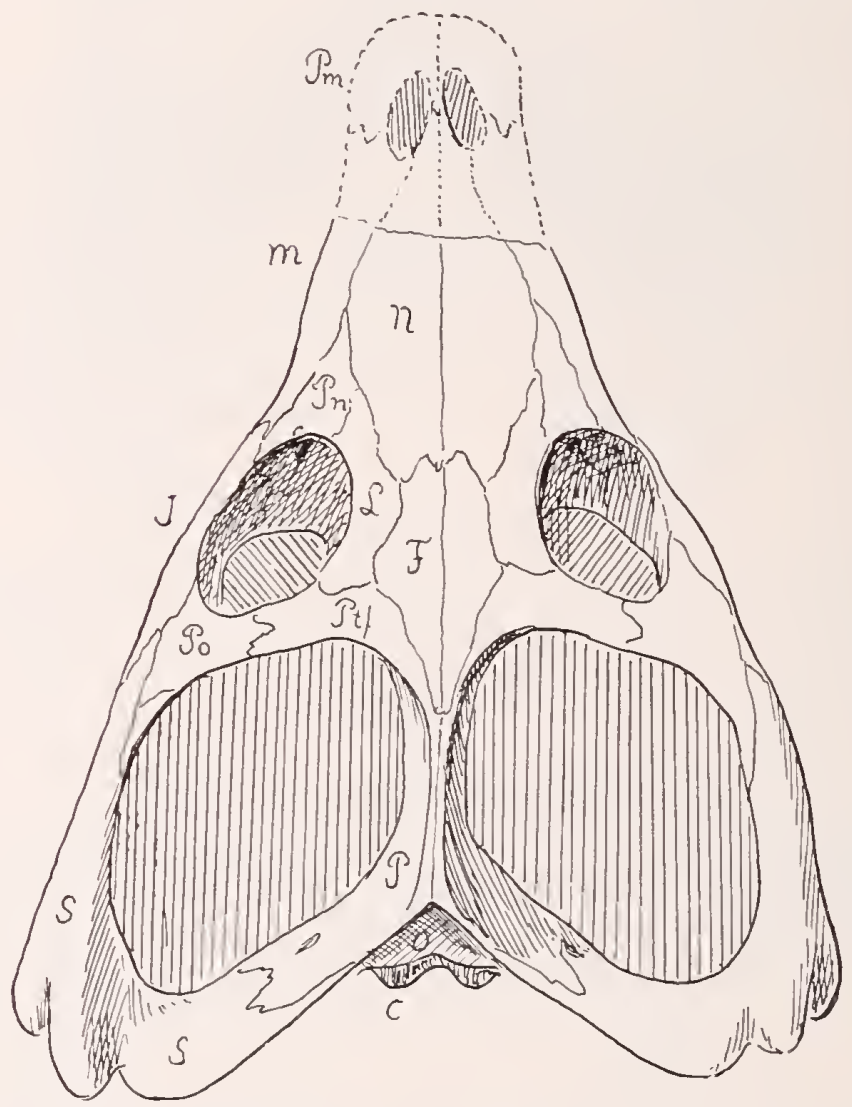

Fig. 214. Oberseite eines Schädels von Gomphognathus aus der oberen Trias der Karroo-Formation Südafrika. 2/3. (Nach einem Exemplar des Brit. Xus. 
Bei einigen sind die Backzähne so nach imnen ausgedehnt, daß sie vermuthich anch innere Höcker aufwiesen.

Fan. Galesauridae mit spitzen Backzähnen und eigentümlich ausgebreiteten hinteren Rumpfrippen. Cynognathus (Fig. 213) Galesaurus. Fam. Lycosanridae mit einfach abgestumpften Molaren, Lycosaurus, Cynodraco; Fam. Gomphognathidae mit breiten Backzähnen. Gomphognathus (Fig. 213, 214) Microgomphodon, Trirachodon, Diademodon.

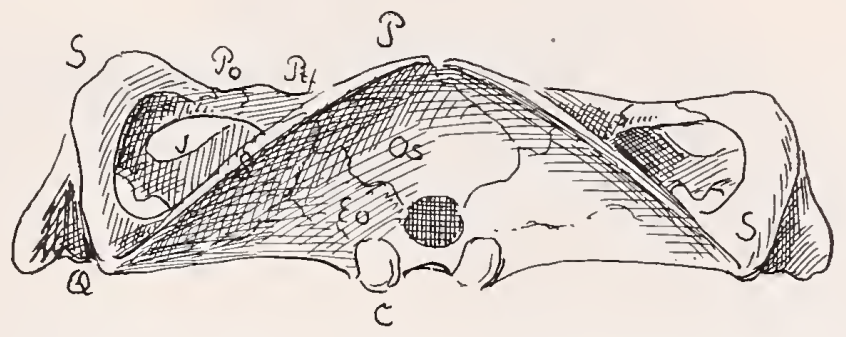

Fig. 215. Hinterseite desselben Schädels von Gomphognathus (Original Brit. Mus.).

Es zeigt besonders deutlich die eigentümliche Bogenbildung des Squamosum.

\section{II $a$ Nebenordnung Monotremati.}

Die Monotremen wurden den Säugetieren angereiht, da man die Paratherien noch nicht kannte, sonst würde man wohl kaum Bedenken getragen haben, sie bei diesen einzureihen. Nicht nur durch ihre Fortpflanzung mit Eieru, und dem Mangel einer echten Säugung der Jungen entfernen sie sich von den Sängetieren, sondern auch durch viele anatomische Merkmale. Ihr Schultergürtel zeigt die primitive Gliederung in die vier Stiicke Suprascapulare, Scapulare, Coracoid und Praecoracoid. Thre Schnabelbildnng findet kein Analogon bei den Mammalia, wohl aber bei den Schildkröten und Ticrnodonten unter den Paratherjern. Auch die Ausdehnung ihrer Pterygoiden und die Erhaltung ihres Articulare in Unterkiefer paßt zu den Paratherien. Ihre Halsrippen bleiben von den Wirbeln gesondert. Die ganze skelettbildung ihrer Gliedmaßen stimmt mit Paratheriern iiberein. Ihre Embryonen scheinen noch in größerer Ausdehnung am Körper rudimentäre Schuppen statt Haare zu besitzen, im erwachsenen Zustand sind erstere auf den Schwanz beschränkt. Wenn man andererseits die große Menge von Säugetiercharakteren der Monotremen in Betracht zieht, muß man erwägen, daß ihnen ein sehr langer Zeitramm zm Verfügung stand, die bei den Theriodontiern schon stark pointierten Sängetiereigenschaften weiter auszubilden. Innerhalb der direkten Nachkommen der Theriodontier in der Hauptreihe sind die Säugetiercharaktere ja noch schneller entwickelt worden, und viele Wege standen wohl der Entwickelung auf so kompli- 
zierter Grundlage wie der dritten stufe der Paratherien-organisation nicht mehr offen. Ob mancherlei organisatorische Beziehnugen der Nonotremen zu den Marsupialiern in obigem Simne als Konvergenz-Lrscheinung abgesondert haben, als die Paratheria sich schon zu haplodonten säuge-

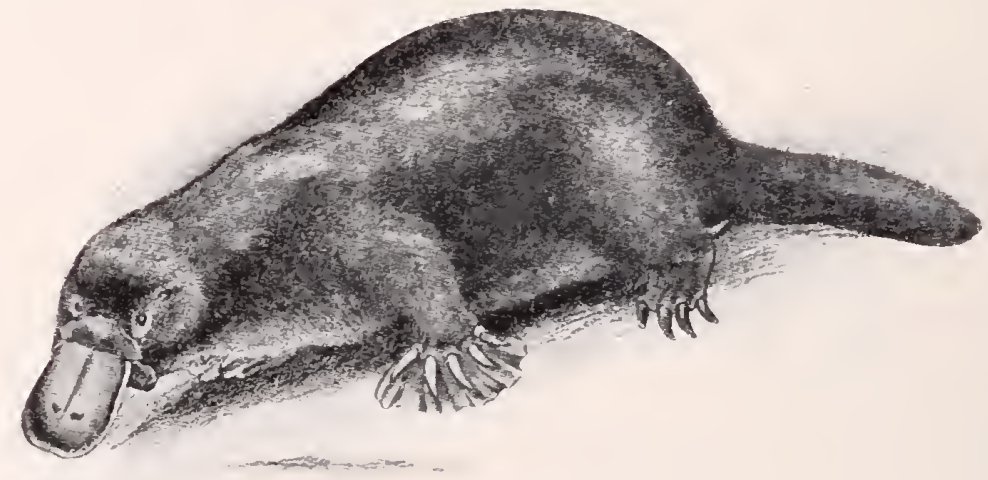

Fig. 216. Oruithorhynchus paradoxus Blumenbach. I) Schnabeltier australischer Flußgebiete.

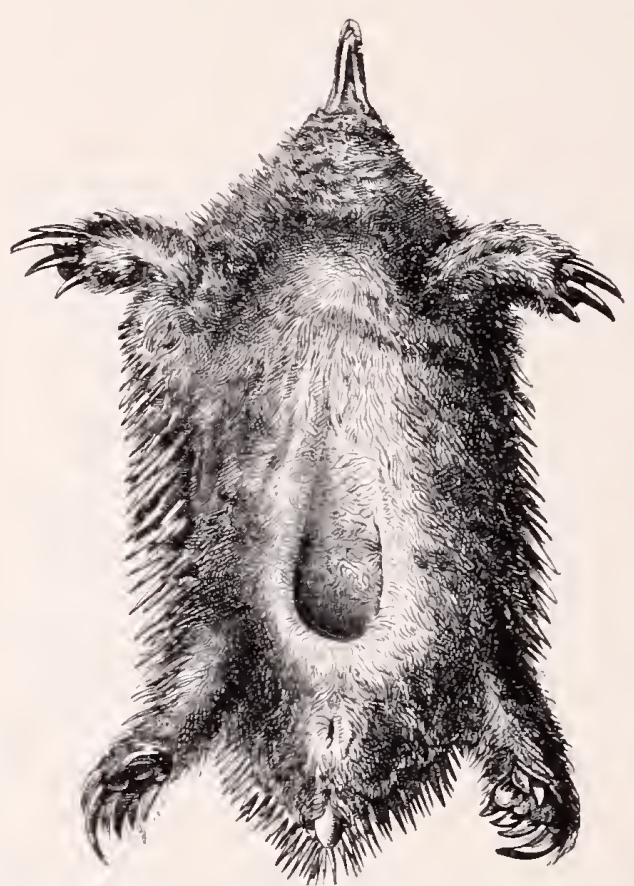

Fig. 217. Echidna hystix Cuv. Neuholland. Bauchfläche eines Weibchens mit der Bauchtasche zur Aufnahme der Jungen. (Nach Haacke.) 
tieren entwickelt hatten. wird wohl immer fraglich bleiben. Mir scheint es namentlich in praktischen srstem richtiger, sie als jüngsten aberranten Seitenzweig der Paratherier anfzufassen. Ihre beiden Vertreter Ornithorhynchns nnd Echidna sind in sehr rerschiedenen Richtmngen spezialisiert und als Vertreter ron Enterordmnnoen aufznfassen.

\section{Hauptklasse Mammalia Aristoteles.}

Durch die Ansscheidnng der Paratheria wird die Klasse der säugetiere wieder zu einem eng geschlossenen Formenkreise, der dmrch eine Menge charakteristischer Kennzeichen systematisch zusammengehalten wird. Fast alle erfuhren bisher durch die Eimreilmng der Honotremata eine bedenkliche Lockermng. Tummehr ergibt sich nnter rollem EinschlnB aller fossilen Formen folgende

Definition: Iammalia sind lungenatmende. Wamblütige. in der Regel beharte Tetrapoden mit grobem Gehirn, einfacher Yase: doppeltem (diplopalatinem) Gaumen mnd doppeltem Condylus, bei deren lebenden Tertretern das Herz mit doppelter Kammer und Torkammer versehen ist, die Ontogenie mit Amnion und Allantois meist ganz im Cterms erfolgt und nach der Geburt durch säugng gefördert wird.

Ihr Skelett ist kräfig verknöchert nnd jeder Knochen energisch geformt. Enterkiefer. Wirbel. selunter und Beckengerüst in sich fest verwachsen. schädel mit grober Gehirnregion. Weiten einfachen Durchbrichen, ohne Epidyse, mit doppelten Condylen, diplopalatinem Gaumen. kleinen Pterygoiden, ohne Transtersa nnd Parasphenoid, ohne Postnasalia, Postorbitaria, Posttemporalia; Lnterkiefer ohne selbständioe splenialia, Angnlaria, Supraangularia und Complementaria. Zähne thecodont befestigt, anf den äuBeren Kieferrand beschränkt; die Backzähne kompliziert geformt. die hinteren mehrwrzelig. Wirbelkörper mit flachen Eyiphysen, mit den oberen Bögen fest verwachsen. Scapulare nnd Coracoid zu einer scapnla rerwachsen, Interclavicula fehlt. ebenso fehlen die Cleithra. Rippen im hinteren Teil des Rnmpfes rïckgebildet. Becken mit geschlossener Pfanne. distal rerbreiterten Pnbis und Ischia. Im sacrmm bei normaler Fnnktion 3 und mehr Wirbel verwachsen. In den GliedmaBen praeralieren Radius und Tibia vor Clna und Fibula. Clna normal mit Olekranon. 
Die Motapodien ofters verwachsen, die Zehenformel 2.3.3.3.3 nur bei marinen Truen übersehriten.

Trias bis jetzt, häufig elst seit tlem Tertiär.

Die Mammalia stammen ron Paratherien ab mud wohl ron deren typisehen Tertretern, den Theriodontiern, die vornehmlich in der oberen Trias Südafrikas rerbreitet sind. Die Süugetiere haben erst im Tertiär die anderen Klassen der Tetrapoden rerhä̈nt und sich namentlich anf dem Festlande heimisch gemacht. Ali Lauf-, Sprung-, Kletter-, Grabund schwimmtiere haben sie fast alle guten Nährplätze erobert; nur ihne fliegenden Vertreter haben gegenüber den Vögeh zuriickstehen mïssen. Del rielseitigen Anpassung entspricht eine große Mannigfaltigkeit der Formen, deren stammesgeschichtliche Zusammenhänge wenigstens bei den niederen Vertretern noch nicht aufgcklärt sind.

Ilne systematische Finteilung auf Grund der Embryonal'ntwicklung ist gegenüber den älteren Formen nndurchführbar, nnd die systematische Terwertung des Bentels erscheint ebenfalls bedenklich, da anch andere als die Beuteltiere Beutelanlagen besitzen, und der Besitz des Bentels wohl eine allgemeine Entwicklnngsphase der Mammalität bedentet.

Die Ausscheidung der Monotremata ermöglicht ihre sehr divergenten Vertreter anf einige orobe Formenkreise zu rerteilen. Klar hebt sich jetzt allmählich der Zusammenlıang der höher entwickelten Typen heraus, die hier als Holotheria zusammengefaßt sind.

Die ststematische Gliederung der säugetiere ist seit den letzten Jahrehnten nicht mehr zur Ruhe gekommen. Inmer neue Formen der Torzeit wurden bekannt; sie wiesen Beziehungen oft zu rerschiedenen Abteilungen der lebenden auf, und wrolen oft allzneilig als stanmformen der letzteren ansgegeben. Fine ansgezeichnete Darstellung dieser Wandlungen und des Entwicklungsganges des Säugetiersystens lat soehen IT. K. (r rogor gegeben. Inden ich anf diesen gründlichen Bericht vermeise, möchte ich mu folgende bedentsamen Etappen der neueren Geschichte unserer Forschung herrorheben. Von den Einteilnngen, die nn' die lehenten Formen herücksichtigen, sehe ich ah. dagegen ließen sich die auf die Monotremen bezogenen Abteilungen hiel nicht ganz beiste stellen. R. Owen hielt die Einteilung in Placentalia und Implacentalia aufrecht. Während letztere auBer den Nonotremen nur die Mansupialia enthalten, teilt (' die Placentalia nach der Ausbildung ihres Gehins in Archencephala (Homo). Gyrencephala (Lnguiculata, Ungulata, Mutelata (Sirenia, Cetacea) und Lissencephala (Bruta, Chiroptera, Insectivora, Rodentia) ein.

1) The Orders of Mammals (Bull. Am. Ins. Nat. Hist. Tol. XXVII. NewYork 1910). 
Gill') suchte 1870 die hier noch ganz unsicheren genetischen Beziehungen klarer zum Ausdrnck zu bringen und nuterschied drei Unterklassen Monodelphia: I .,primate series“ (Anthropoidea, Lemuroidea). II .,feral series" (Fissipedia, Pinnipedia, Cetacea). III .. Insectivore series". IV "Ungulate series", T ., Rodent series". VI .. Edentate series“. Dann folgte die Unterklasse der Didelphia, die alle Marsupialia umfaßte. und die Unterklasse der Ornithodelphia (Monotremata).

Huxley²) unterschied 1880 znnächst folgende stadien der Entwicklung des Säugetierastes: Hypotheria, deren Tertreter wir noch nicht kennen, Prototheria (die durch die Monotremen repräsentiert werden), Metatheria (zn denen div Marsmpialia gehören) und Eutheria, die sich also mit den Placentalia der älteren Antoren im Lnfang deckten. Diese Eutheria werden nun gegliedert in Edentata, Chiroptera, Carnirora. Cetacea, Insectivora, Hrracoidea, Ungulata, virenia, Proboscidea. Rodentia, Lemuroidea, Primates.

Flower") ïbernahm 1883 die drei Lnterklassen der Ornithodelphia oder Prototheria, der Didelphia oder Metatheria und der Monodelphia oder Eutheria, und zerlegte die letztereu in 9 Ordnungen: I. Edentata. II. Sirenia, III. Cetacea, IV. Ungulata, V. Rodentia, TI. Chiroptera. TII. Insectirola, VII. Carnirora, IX. Primates.

Zitte ${ }^{+}$) unterschied wieder als Unterklasse A Eplacentalia mit den Monotremata, Allotheria, Marsupialia, B-Lnterklasse Placentalia mit den Edentata, Cetacea, Sirenia, Ungulata, Tillodontia, Rodentia, Insectivora, Chiroptera, Carnivora, Primates.

$\left({ }^{\prime} o e^{5}\right)$ ïbernalm Gill's Unterklassen der Prototheria und Eutheria und unterschied in den letzteren I. Didelphia, II. Monodelphia. Die letzteren wurden eingeteilt in Cetacea. Sirenia, Edentata, Chiroptera, Bunotheria (Pantotheria, Creodonta, Insectivora, Tillodontia, Tamiodonta), Carnirora. Ancylopoda, Taxeopoda, Taxodontia, Proboscidea, Diplarthra.

Die große Menge nener auf mangelhaft bekannte Formen begüundeten Ordnungen fossiler Tiere. die hier ron Cope eingeführt wurden, mußte rorerst die Lust zn reiteren systematischen Gliederungsversuchen der gesamten säugetiere mnterdrücken.

1) On the Relations of the Orders of Mammals (Proc. Am. Assoc. Adv. Sc. 1870).

$\left.{ }^{2}\right)$ Th. Huxley: On the application of the Laws of Evolution to the Arrangement of the Vertebrata and more particularly of the Mammalia (Proc. Zool. Soc. 1880).

3) Flower: On the Arrangement of the Orders and Families of existing Yammalia. (Proc. Zool. Soc. London 1883.)

4) Zittel: Handbuch der Paläontologie. Band IT, S. 61. München 1891.

5) Cope: Syllabus of lectures on Geology and Paleontology. (Univ. Pensylvania) $1891-98$. 
TTeber ${ }^{1}$ ) bemühte sich 1904 in seinem system der lebenden Sängetiere, die fossilen an der richtigen stelle einzmordnen, nnd klärte das system dadurch, daß er einige, einander durch Konvergenz genäherte Formenkreise wie die Edentata in natürliche Terwandtschaftskreise zn zerlegen suchte. Dieses Bestreben ergab I. Unterlilasse Monotremata, II. Tnterklasse Marsmpialia, III. Tnterklasse Monodelphia. Diese enthalten nun die Insectirora, Chiroptera, Galeopithecidae. Tubnlidentata (Opyeteropms), Pholidota (Manis), Nenarthra (amerik. Edentata), Rodentia, Tillodontia, Camirora, Cetacea. Perissodactyla. Artiodactyla, Condylarthra, Ancylopoda, Litopterna, Amblypoda, Toxodontia, Hyracoidea, Proboscidea, sirenia, Prosimiae, simiae, zu denen anch die Anthroponorphen gerechnet sind. Diese (Ordmugen ergeben die grobe Zahl ron 24 mod haben damit an Öhersichtlichkeit viel verloren.

Der genannte William K. Gregory, dem ich den größten Teil dieser Angaben rntnommen habe, kam nun anf Grund eingeliender studien, namentlich del fossilen Formen Amerikas. 1910 zu folgendem System: A-Tnterklasse Promammalia Haeckel (Protodonta Osborn), B-Lnterklasse Prototheria Critl, Huxley (Monotremata). C-Lnterklasse 'Theria Parker n. Hasmell = Eutheria Gill. Die letzteren werden zerlegt in zwei .Infraclasses", für die uns ein deutscher Anstluck znm Unterschied ron Lnterklasse fehlen wïrde, I. Metatheria Huxley (Triconodonta, ?'Tritnberenlata, Marsupialia), Il. Eutheria Huxley [= Monodelphia Blains, Placentalia ant.] nit folgenden .. C̈berordnungen": 1. Therictoidea (lnsectivora, Ferae = ('arnivora), 2. Alclonta (Menotylula, Dermoptera, (himoptera. Primates), 3. Rodentia (Glires), 4. ? Edentata (?'Tamiodonta, ?Tubulidentata, Plolidota, Xenartha), 5. Paraxonia Mash (Artiodactyla), 6. Ungulata (Protnngulata, Amblyoodis. Barrtheria, Sirenia, Proboscidea, Hyraces, Embrithopota, Notomgulata. Mesaxonia), 7. Cetacea. Abgosehen ron den rielerlei Klärungen, die dieses system in der Benrteilung einzelner fossiler Ordnungen bringt, liegt ein wesentlicher Fortschritt desselben darin. dab in flen dentsch nicht zu ïbersetzenden Begriffen der Infraorders neue phyletische Zusammenhänge der alten Ordnumgen zum Ausdruck gebracht werden. Im besonderen sind dann namentlich die Formenkreise der Ungulata in ihre phyletischen Bestandteile zerlegt.

Da ums ans dem ganzen Mesozoicum fast mur Zälnne mol Kieferteile iiberliefert sind, mnd in ältesten 'Tertiär, wo günstige Chancen paläontologischer [̈berliefernng einsetzen. schon die meisten ordnungen der Mammalia differenzient sind, so kann die Stammesgeschichte dieser

1) Weber: Die Sängetiere. G. Fischer, 1904. 
Klasse nur sehr lïckenhaft nud unbefriedigend sein. Ton den Ahnenreihen der Grnppen fehlt meist jede spmr.

Inmerhin haben sich einige entwicklungsgeschichtliche Tatsachen und einige Formenreihen schon jetzt klar herausgehoben. Die Stellung der Insectiroren vorwärts zn den Chiropteren, Lemuren und Carniroren, rückwärts zn den Didelphiden bietet nns einen sicheren Pfad durch das Labyrinth ron Formenkreisen. Wir haben:

Ninrzel: Theriodonte Paratheria.

\section{Yammalia.}

Stammreihe: Polyprotodonte Marsupialia. Hauptreihe:

Insectivori

\section{Chiropteri}

Lemmini

\section{Carnivori Pitheci \\ Ungmlati Artiodactyli Cetacei Bimani}

Trenig Formenkreise werden in dem Sinne monophyletisch sein, daß sie aus eimem Elternpaare hervorgingen. Möglich ist das allenfalls bei Typen, die durch Jetakinese ${ }^{1}$ ) entstanden sind, wo ein, bestehende Dissonanzen der imneren Organisation anslösender indiridueller Umschlag als zweckmäßig nud bequem sofort erbliche Konstanz erlangte. Auf allen übrigen Tegen der Entwicklung werden mehr oder weniger große Formenkreise als Ansgangspunkt nener in Betracht kommen. Findet die C'mbildnng auf epistatischem, also "miogenetischem" Wege statt. so wïrde ein mreifes Ingendstadium den Ansgangspmnkt bilden. Die Ursache zur Entwicklungshemmung, die wohl meist in änßeren Umständen zn suchen ist. kamı aber verschiedene Arten oder noch breitere Formenkreise betroffen mnd anf das gleiche Jugendstadium zurückgeführt haben. IJie aus solchen dann weiter entwickelten Formenreihen werden die rerschiedene Herkunft mun schwerlich erkennen lassen, ihre Ahnen werden aber immerhin in engem Kreise zn suchen sein.

Noch weniger monophyletisch werden solche Abteilungen sein, die aus einer orthogenetischen Weiterentwicklnng älterer Phasen mehr oder weniger langsam entstanden sind, wo aber der Organisationsänderung nur ein Weg der Fortbildung offen stand.

$\left.{ }^{1}\right)$ O. Jaekel: Uber verschiedene Wege der phylogenetischen Entwicklung. G. Fischer, Jena 1910. 
Wenn sich also normal gehante kleine Sängeticre ciunstio weiter entwickelten. d. h. wenn sie sich gut arn̈ihten und kräftiger wurden und sich dennach an immer gröbere Bentetice heranwagten, so konnten ans rerschiedenen der leistungsfïhigsten ..Insectivoren" die gröBeren und kräftiger oroanisierten "Carnivoren" hervorgehen. Die Einheit solcher Abteilungen wird von der Organisationshreite ihrer Torfahren abhängen. sie können monophyletisch in weiteren sinne sein. aber sie liönnen auch polyphyletischen Znwachs ans anderen Formenreihen erlatten liahen.

Ein solcher Fall trifft anscheinend zu für die hisher für eimheitlich gehaltene Grupve der Huftiere oder Lnoulata. Ziemlich lneit ist offenbar die plyssiologische Bisis für den Übergang von der carniroren zur herbivoren Lebensweise. Während die Zähne hierbei eine Anzahl gleicher Jerkmale annehnen, kann die Bewegmng nnd damit die ciestaltung der Füße trotz gewisser Anpassungen sehr verschiedene Bahnen der Entwicklung einsthlagen. Wïhrend die Huftiere bisher eine systematische Finheit bildeten, ist durch die neneren Lntersuchungen amerikanisther Paläontologen, die IV. K. Gregory jetzt einheitlich remubeitet hat, höchst wahrscheinlich genacht, daß die Artiokactylen, zu denen die Anthracotheridae, Hippopotamidae, Suidae und dis Wioderkäner gohören, sich selbständig von altertiären oder cretaceischen Torfalmen abgezweigt haben nnd mit den ibrigen ..Huftieren“" in keinen phyletischen Konnex stehen. In solchem Falle ist ein polyuhyletischer 'Typus noch zerleghar, wenn er wengstens in gewissen ()rganisationsrerhältniscen die hereditären Eigenarten nngestört behalten lionnte. Wenn dagogen Raubticre ihre Jagdgriunde rom Land in das Wasser rerlegten nul sich in diesem heinisch machen mußten, so wind mit dre Möglichkeit zn rechnen suin, daß rerschiedene Formenkreise durch die Anpassung an die alles umgestaltenden Lebensbedingungen so beeinfluBt wurden, daß sie sehr hald einen eng geschlossenen Hahitus annahnen. Cetaceen und andere Wassertiere, wie zum Beispiel die Phoken. erscheinen als enge Einheiten, und wir werden sehwerlich in tie Lage kommen, jenals eine eventuelle Polyphylie bei ihnen nachweisen zu können. Denn wenn uns auch winklich aus ihren ältesten Formenkreisen eine relativ große Zahl ron Resten bekannt werden sollte - solche Übergangstypen sind ja immer individuenarm gewesen nud schon deshalb änBerst selten — so wird iiber die Beurteilung soleher Fund schwerlich Einigkeit zu erzielen sein. Die einen werden sie noch gar nicht zu den neu werdenden Formenkreisen rechnen wollen, andere werden sie für aberrante Einzelformen erklären. Solche vielleicht sehr polyphyletische Typen werden also für unser System monophyletisch bleiben. 
Monophyletisch und polyphyletisch sind also keine festen Begriffe nnd praktisch nicht zu trennen. Wir sind anch hier iuberall zu Kompromissen gezwngen, nicht nur zu Kompromissen zwischen der sistematischen Klarstellung einer Form und der Tnsicherheit ihrer Phylogenie, soudern selbst zu Kompromissen zwischen systematischer Anordnung mod klargestellten Tegen der phyletischen Entwicklnng.

Die Hauptschwieriokeit einer Konormenz der srstematischen mit der phyletischen Aneinanderreihung der Formen liegt darin, daß jene - wenigstens in der bisher üblichen Art - die Formenkreise in eine Reihe hintereinander schob, während die natiurliche historische Entwicklung in rerschiedenen Reihen dirergierend erfolgte. Wir mïssen also, wenn wir System und Phylogenie in hessere Übereinstimmung bringen wolleu, vor allem, wie dies hier geschehen ist, die einreihige Anordnung im System aufoeben.

Der mehrfach in Einzelgebieten gemachte Versuch, diesem Zweck durch alternierende Buchstaben und Xummerbezeichnungen gerecht zil werden, hat sich deshalb wenig bewälut, weil solche Zahlen keine Begriffe sind und keine konkreten Erinnerungsbilder hinterlassen. Sie sind nützlich im einzelnen, um eine Henge in richtiger Folge zu orduen, aber als begriffliche Erinnerungsbilder sind Bezeichnungen rorznziehen wie Stammast, Hauptast, Yebenast, Hauptreihe, erste, zreite Nebenreihe usw. deren Folge dann mit rerschiedenen Buchstaben- und Zahlenreihen geklärt werden kann. Wir würden nun die phyletisch sicher gestellten Beziehungen innerhalb der Säugetiere nach Ansscheiden der Jonotremata in folgender Teise zum Ansdruck bringen könuen:

\section{Klasse Mammalii.}

1. Stufe. C'nterklasse Miotheria. Hauptordnungen: Yebenordnungen:

I. Haplodonti I c Nultituberculati

$I_{i} ;$ Diprotodonti

2. Nitufe. Tnterklasse Mesotheria.

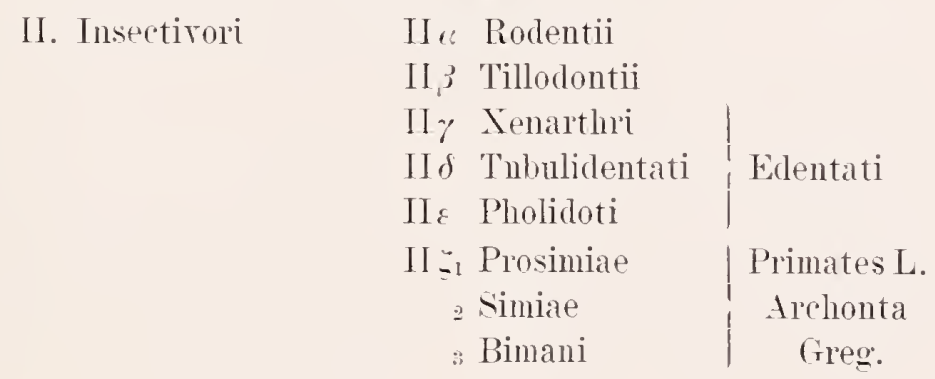


3. Stufe. Unterklasse Holotheria.

III. Carnivori III cetacei

III, Artiodactyli

III $\gamma_{1}$ Cngulati

$\gamma=$ sirenii

Wie anderwärts so liegen anch hier nur wenige 'Typen in der Hamptrichtung der Fntwicklung, die meisten Formenkreise sind von der Hauptrichtung abgewichen nud in Seitemichtungen gedrängt. Die römischen Zahlen mit den Znsatz der grieehischen Buclistaben verweisen dabei auf die vermutliche Ausgangsgnuple, der Nechsel der griechischen Buchstaben $\iota, \beta, \gamma$ anf die Selbständigkeit, inre Gleichheit z. B. II $\gamma_{1}$, II $\gamma_{2}$ auf den phylogenetischen Zusammenhang der Nebenordnungen.

\section{Stufe. Unterklasse Miotheria m.}

Niedrig organisierte kleine Landtiere, mit kleinem nm in jünster \%eit angewachsenem Gehirn, schmalè Schädelkapsel, flachem Schädeldach, mit wenig spezialisiorten Gebiß, das bei normaler Ausbildung zahlreiche einfach gebaute Backzihnne aufweist. Vermutlich waren alle Beuteltiere, deren Entwicklung ohne Allantois erfolgte.

Dadurch, daß sich anscheinend auch hier schon in früher Zeit ron den normalen Insekten und Fleischfressern frugivore 'Typen absonderten nnd frendartig spezialisierten (Multituberculata, Diprotodonta) und ron den fossilen Formen fast nur Kioferfragmente bekannt sind, läßt sich eine umfassende Definition dieses Formenkreises zurzeit noch nicht geben.

\section{Hauptordnung Haplodonti n.}

Tnter diesem Namen möchte ich in erster Linie Osborns Protodonta und T'rieonodonta zusammenfassen, d. h. ans ersteren nur den normal gerichteten Teil der Formen, nicht den aberranten, der nach Osborns Einteihng zn den Honotremen iiberleiten sollte. Ich konnte in dieser Terquickung des ITnnsches, die Monotremen als niederste an die Spitze der Nammalia zn hringen, mit dem nuverkembar richtigen Hauptprozeß der Zahnentwicklung der siugetiere keinen Nntzen erblicken, und habe deshalb dio Monotremen lieber zn den Paratherien als zu den echten Mammalia gestellt. Als l'rotodonta kämen damn zunächst nur die beiden triassischen Kiefereste in Betracht, die als Dromatherium nnd Microconodon beschnieben sind. Sie stehen an der Grenze zwischen Cynodontiern und 'Triconodontiern, und wenn wir ihnen als Stammtypen der sängetiere einen höheren Wert beilggen als den Cynodontiern, so 
können wir uns dabei nur auf ihr Gebiß und ihre geringe Größe stützen, sondern auch darauf, daß Crnognathus u. a. durch ihre sonderbare Rippenbildung und einige andere Merkmale nicht umittelbar als Stammformen der jüngeren in Betracht kommen.

Haplodonti sind primitive mesozoische Mammalia mit heterodontem Gebiß.4-3 Incisiren, einem Canin, zallueiclen Backzähnen, die vor und hinter einen Hautkegel Tebenkegel und deren hintere z. T. schon die Bildung eines Innenkegels aufweisen. Die Reihe der Incisiren ist nicht abgeknickt. Die Backzahnspitzen sind komprimiert oder gerundet im Querschnitt. die hinteren Unterkieferknochen rudimentär. Der Coronoidfortsatz ist breit. Tahrscleinlich waren alle Beuteltiere.

\section{Cnterordnung †Protodonti Osborn.}

Backzähne sehr zahlreich, komprimiert, ohne Imnenkegel. Nur Reste des Unterkiefers erhalten. Microcondon und Dromatherium, Trias.

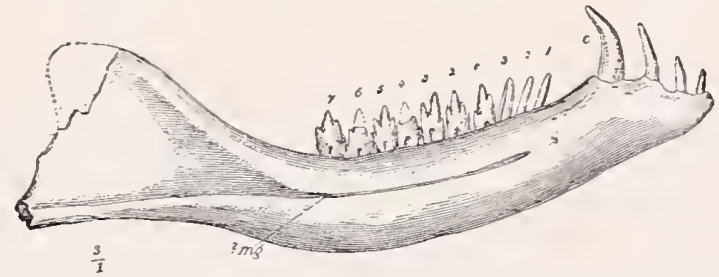

Fig. 218. Dromatherium sylvestre Osb. Ob. Trias. Nord-Carolina. 2/1. (Nach Osborn.)

\section{Unterordnung †Triconodouti Osborn.}

Zahnbau mehr kompliziert. Backzähne mit gerundeten spitzen und die hinteren mit Innenkegel. Amplitestes, Phascolotllerim und Triconodon im Jura.

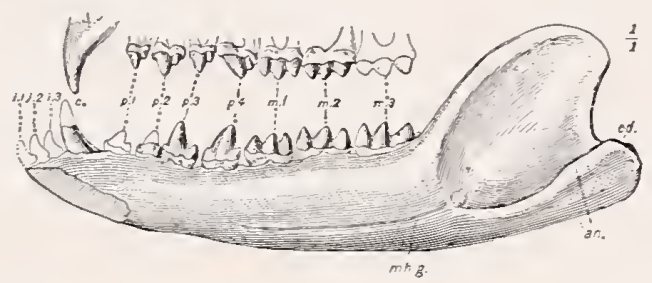

Fig. 219. Tricomodon mordax Owen. Oberster Jura. Purbeck, England. 2/1 (Nach Osborn.)

Anscheinend führte die Entwicklung ron den Protodonten in diesem sinne durch die Triconodonten und Trituberculaten Osborns direkt zu den polyprotodonten Marsupialieru über. die wir hier kürzer als Didelphii bezeichnet haben. ob jene älteren mesozoischen Typen Benteltiere 
waren. läbt sich nicht feststellen, aber seln wohl annehmen, da die Telequickung der . Inngen mit der Bauchfläche der Mutter nnd damit also die Mammalitit am leichtesten verständlich wird, nnter der Ammahme ciner Bentelbihlung. Jiese scheint allerdings bei den Benteltieren stärker spezialisiert zu sein, als wir dies fiir Vorfahren aller Mammalia anzunchmen brauchen. Leider ist bei den älteren Haplodonten das hinterste Ende des Lnterkiefers nicht erhalten, so dab anch hisher nicht festzustellen war. ob dasselbe die fü die lebenden Benteltiere charakteristische Einhiegung des unteren Fortsatzes hesaß.

\section{Conteroldnmo Tritubereulati (Osborn.}

Der Unterkiefer anscheinend einheitlich ossifiziert. 8-6 Molaren, 5-4 Pramolaren vorhanden. Die oheren Backzähne in der Kieferachse velüngert, ihre suitzen dmeh bildnng winkliger Falten zu Kanzähnen, tubereulo-sectorialen 'fypen, modifiziert. Hierhin gohören jnrassische Formen wie Amphitherium. Amblotherium, Dryolestes, und einige cretaceische Reste.

t. Unterordnung Didelphii. Opossmms.

Polypotodontia Owen in eng. Simne.

Kleine ursprïnglich wohl baumbewohnende bekrallte Vierfiißler mit Bentel und kleinem Gehirn, meist ohne Placentabildnng (Eplacentalia) mit eingebogenen hinteren Kieferwinkeln, mit nolmal gegliedertem Gebiß mit zahloeichen einfach gefalteten Molaren.

Frühry weit rerbreitet, sind sie gegenwärtig anf Anstralien beschänkt mit Ansnahme der Jilelphiden oder Beutelatten, die in siddamerika lehen und fliber auch in Europa heimisch waren.
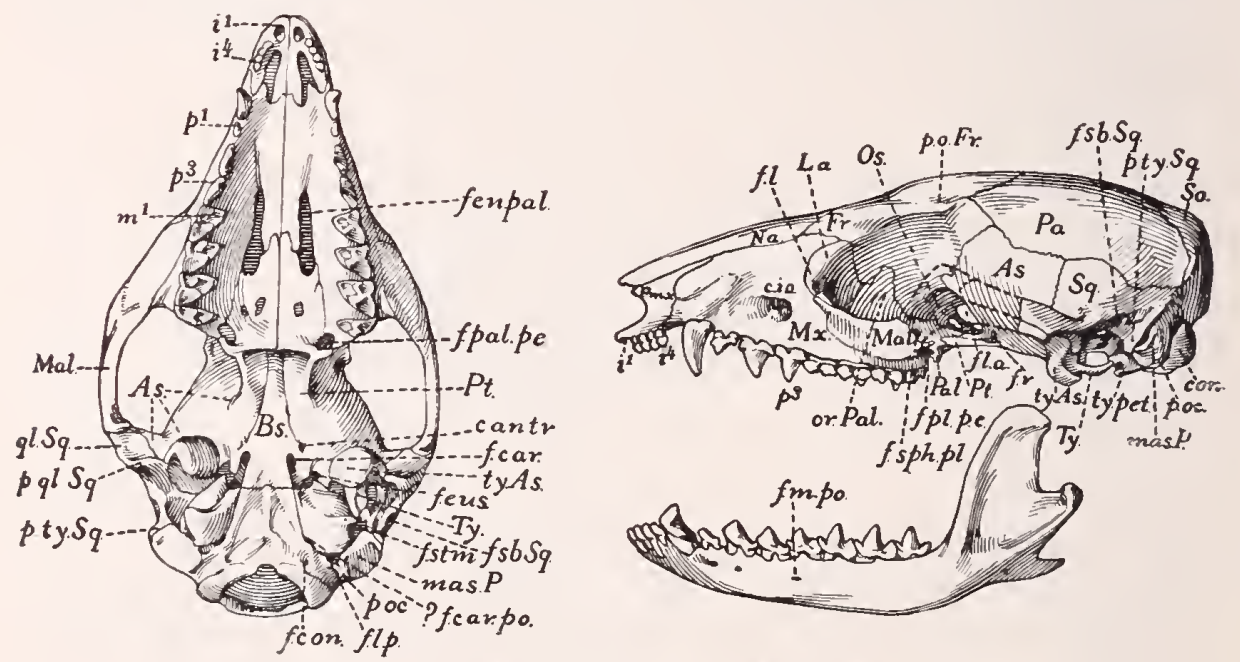

Fig. 2.20. Sichädel von Marmosa simonsi. (Nach W. K. Gregory.) 
Hierher gehören wahlscheinlich einige Reste aus der oberen Kreide Nordanerikas, wie Didelphops und Pedionys nnd die z. T'. schon tertiären Didelphiden mit Marmosa als einfachster Form, Dasyuriden, Myrmecobiiden, Thylaciniden, Notoryctiden und Perameliden.

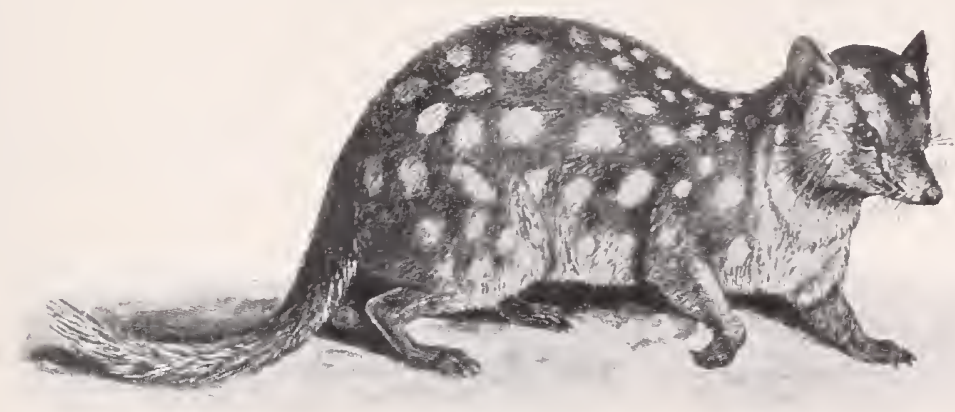

Fig. 221. Dasyurus viverrinus Geoffr. Lebend. Australien, Vandiemensland. (Nach Vogt u. Specht.)

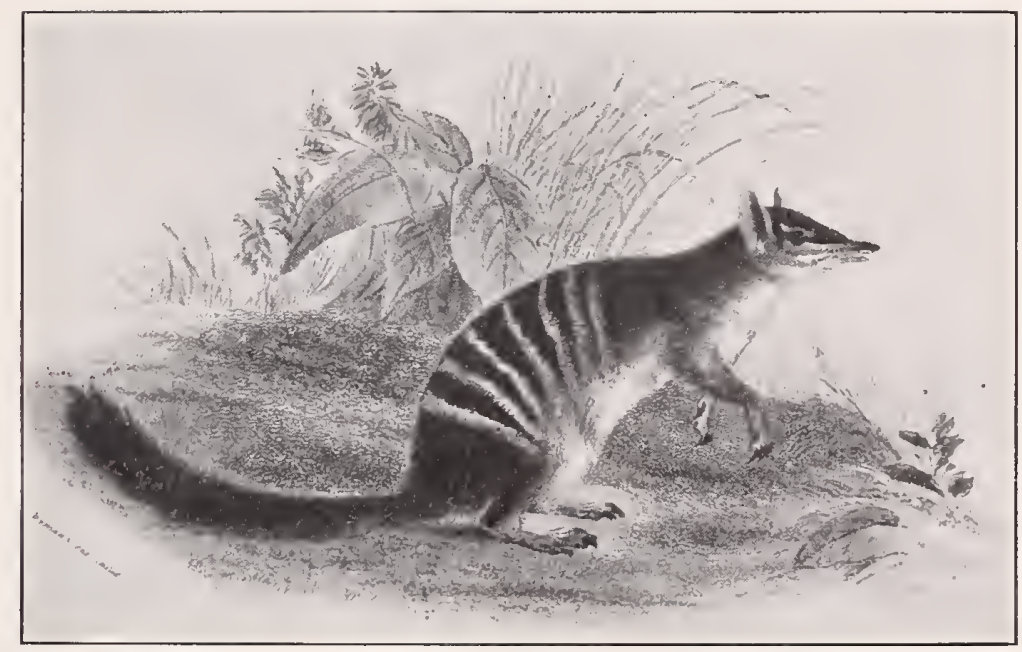

Fig. 222. Myrmecobius fasciatus Waterh. Lebend im südwestlichen Australien. (Nach Lydekker.)

\section{I $\beta$ Nebenordunng Multituberculata Cope.}

Die Stellung dieser Ordnung erscheint mir insofern fraglich, als sie sich möglicherweise nicht erst von den haplodonten, sondern schon früher selbständig von Theriodontiern mit breiten mehrhöckerigen Zähnen abgeleitet haben könnte, bevor noch deren Gebißtypus dnrch 
Aushildnng der Caninen präzisiert war. T) aber andererseits die uns bisher bekannt gewordenen Reste den Typus echter Sängetiere zn haben scheinen, so scheint es mir richtig sie hier anzureihen. So wenig bedentsam diese Frage in phylogenetischer Hinsicht ist, so wichtig ist sie für das system. Wem wir die Mnltituberenlata zwar als sängetiere aher als selbständige Nachkommen der gomphodonten 'Theriodontier ansehen müßten, so wïrden sie systematisch dem ganzen übrigen Säugetierstamm gegenübergestellt werden miissen. I ie damn gegenübergestellten beiden Alsteilnngen mïbten im Range von Unterklassen besondere Bezeichnungen erhalten. Dann wiuden die des Haultastes wohl zweck-

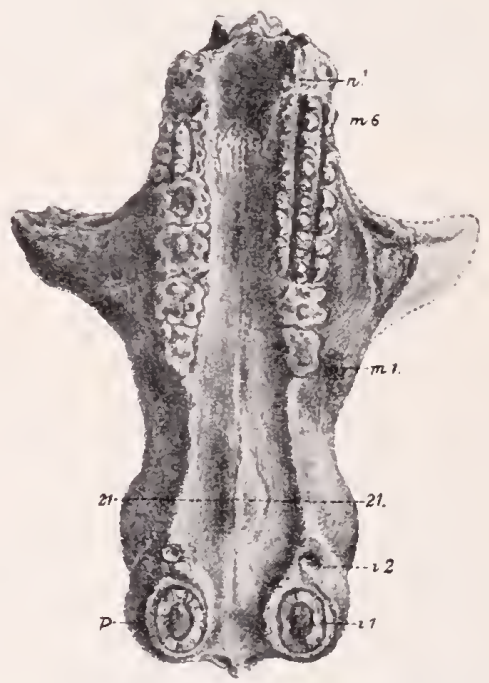

Fig. 223. Tritylodon longaevus 0 w. Obere Trias. Basuto-Land, Südafrika. $\% / 3$ nat. Größe. (Nach Owen.)

mäBig als Eutheria, die Multituberculaten und ihre Nathkommen als Allotheria Cope bezeichnet werden können. Fraglich ist forner, wie anch Gregory soeben in seinen Orders of mammals hervorgehoben hat, ob sie zn den diprotodonten Marsupialiern in ancestralem Konnex stehen, oder ob hier nur gleichgerichtete Anpassnngen rorliegen. Es schien richtig in dieser Beziehnng noch Vorsicht walten zu lassen. Hierhin gehören Trias-Formen wie Tritylodon nud Triglyphis, jüngere Typen wie Bolodon mol Plagianlax, (tenacodon, Meniscoessms, Neoplagianlax und Polymastodon, ilue letzten Tertreter in mutersten 'Tertiair.

Jie Mnltituberenlati sind kleine wahrscheinlich frngivore Singer, deren Molaren mit Höckern in mehreren Reihen versehen sind, Eckzähne fehlen, ein Paar Schneidezähne, vermutlich $\mathrm{J}_{2}$ eckzahnartig vergrößert. 


\section{3 Nebenordumng Diprotodonti (Owen.}

Herbirore rierfüßige z. T. hüpfende Marsupialier mit einem rergrößerten schneidezahn, keinem Eckzahn, persistenten Prämolaren, Iolaren mit 4 Höckern oder zwei Querjochen. Hierhin gehören die anstralischen Känguruhs oder Iacropodidae, Plalangeriden, Tarsipediden, Phaseolomyiden, Diprotodontiden, Thylacoleoniden, sowie deren unmittelbare Torfahren, die sich in China, Europa und Amerika gefunden haben, ferner eine Anzahl älterer ausgestorbener 'Typen, die einen Übergang von den Didelphii zu den Diprotodonten zu begrïnden scheinen, wie namentlich Perameles in der Kreide und Propolymastodon im Tertiär Amerikas, und als typische Diprotodonten die Epanorthiden und Garzoniiden im Tertiär Amerikas.

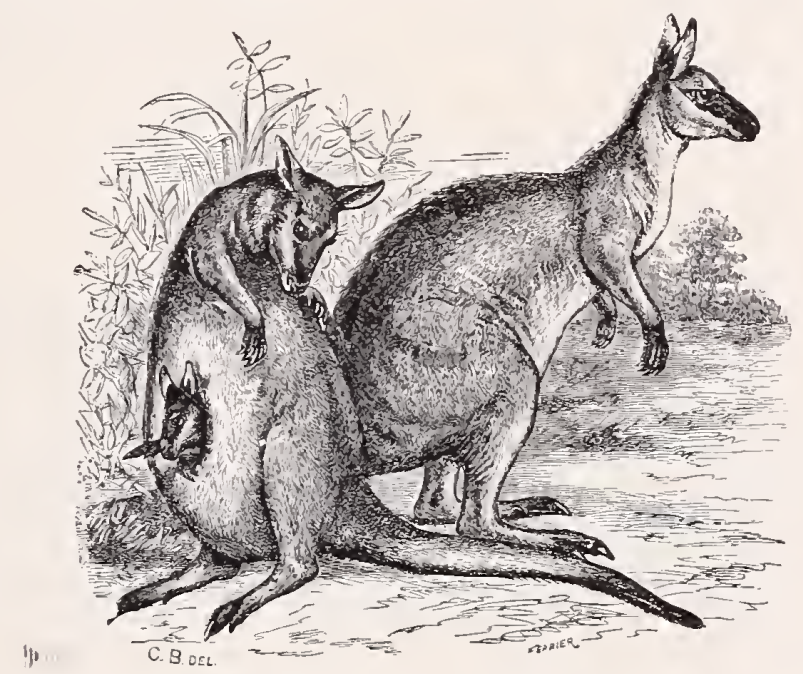

Fig. 224. Halmaturus Parryi, ein Känguruh von New-Süd-Wales, Australien. (Führer d. Brit. Mus. Nat. Hist.)

\section{Stufe. Unterklasse Mesotheria m.}

Ḱlejne, selten große, insectivore, omnivore oder lerbivore Landbewohner mit mäBig kräftigem Gebiß, das in einzelnen Zähnen sehr spezialisiert sein kann, aber im ganzen auf keiner großen Höhe steht. Gliedmaßen mäßig spezialisiert, Metapodien selbständig, die 5 Zehen in der Regel normal entwickelt, mit festen Krallen oder Plattnägeln versehen. Haut behaart, bisweilen gepanzert. Gehirn sehr verschieden hoch entrickelt, Ontogenie mit Allantois nnd normaler Säugnng.

\section{Hauptordnmmg Insectirori, Insektenfresser.}

Die Insektenfresser schließen sich eng an die Triconodonten (I2) und die Didelphiden (I4) an. Thr engenetischer Fortschritt gegeniiber 
den genamnten liegt in der stärkeren Ausbildung des tehirns in der Reduktion der Zahnzahl. in der Komplikation der Backzähne nud in der Rednktion der marsupialen Inrchgangscharaktere des sängetierstammes. Thre besonderen Kennzeichen sind folgende:

Kleine meist pentadactyle und plantigrade Krallenträger mit normalem Gebib $\frac{2 \cdot 1 \cdot 4 \cdot 4-3}{3 \cdot 1 \cdot 4 \cdot 4-3}$. Eckzähne klein. Backzähne meist vieroder fünfspitzig. Milchgebiß normal. Gehirn klein Meist Clavi`ulae und Foramen radiale am Humerns rorhanden. Pollex und Hallux nicht opponicrbar. Meist rersteckt z. T. im Wasser lebend. Bei den lebenden ist der Lterus zweihornig, die 'Testikel präipenial gelegen.

Fossil erst seit dem Tertiär sichergestellt; jetzt in Nordamerika, Eurasien nnd Afrika verbreitet. Hierhin gehören die Lnterordnungen

\section{Unterordnung Menotyphla Haeckel}

mit den anch fossil gefnndenen Cladobatidae (Fig. 225) Asiens und den Lacroseelidae Afrikas.

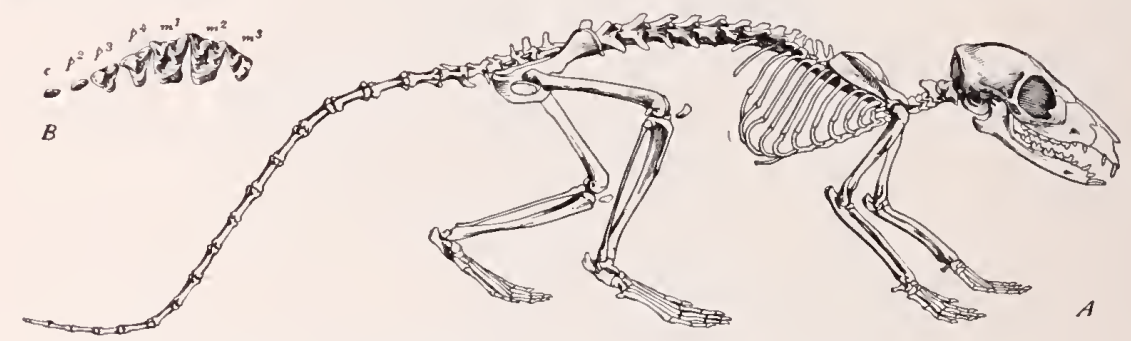

Fig. 22.5. Cladobates (Tupaja)tana Wagn. Skelett aus Gregory. Lebend. 1/2. Sumatra. (Nach Blainville.)

Unterordnung Lipotyphla Haeckel

mit den tertiären Pantolestidae, den Talpidae (Maulwürfe), Soricidae (Spitznäuse), den †Leptictidae, Erinaceidae (Igel), Potamogalidae, tApternshntidae, Centetidae, Chysochloriden und +Necrolestiden.

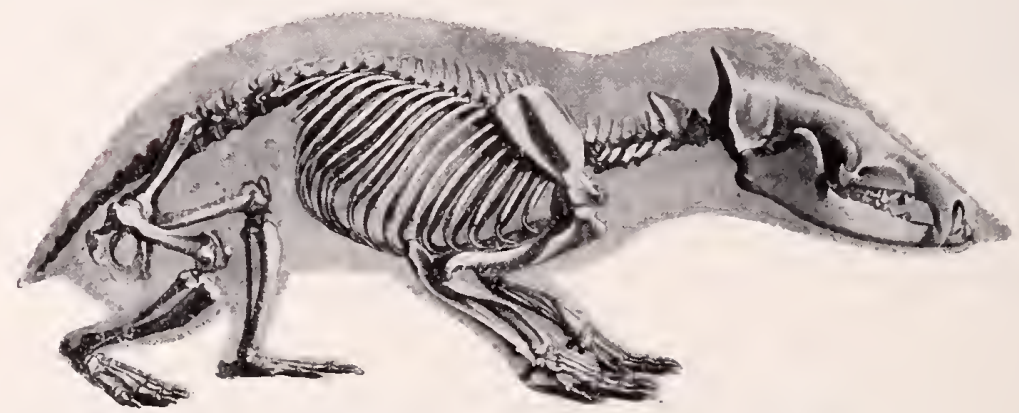

Fig. 226. Centetes ecaudatus Wagn. Lebend in Madagaskar. 1/3. (Nach Pander nnd d'Alton.) 


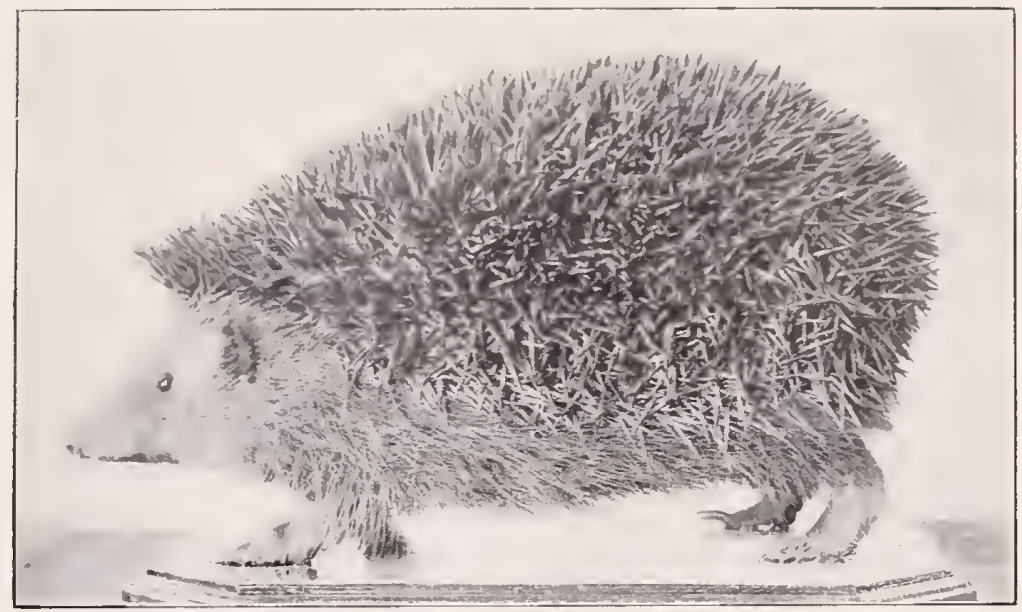

Fig. 227. Erinacens europaeus L., der gemeine Igel Enropas. (Nach einem Exemplar des Brüsseler Mnseums.)

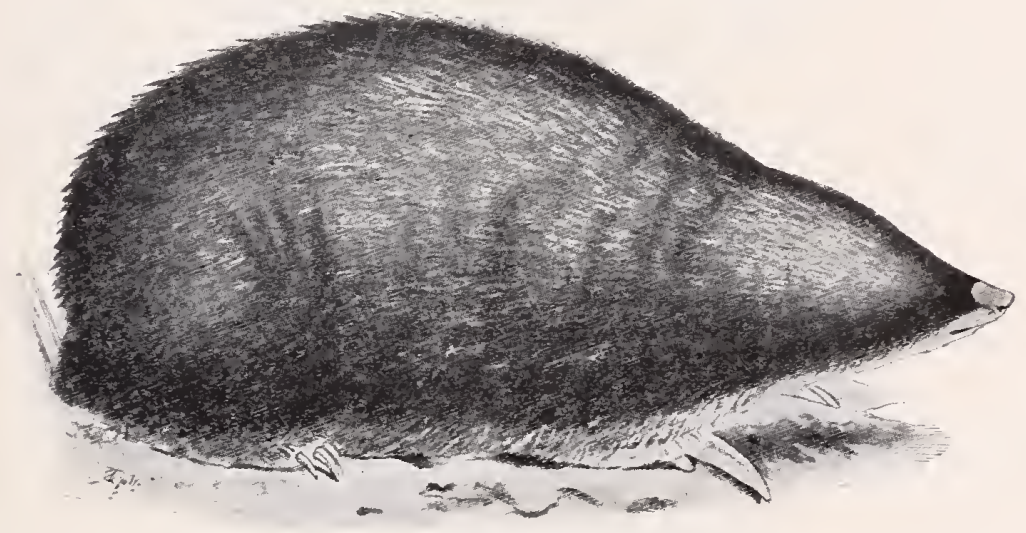

Fig. 228. Chrysochloris trevelyani (Goldmull). Lebend Südafrika. (Nach Günther.)

Als weitere Unterordnungen gehören hierher, wie ich dem eben erschienen Buche H. F. Osborns: "The age of mammals" entnehme, die alttertiären † Hyopsodonti mit Hyopsodus und die †Proghires. die an Diprotodonten und Rodentier erinnern, mit den Familien der Apatemyidae (Apatemiys, Lintasorex, Trogolemur) und die $\div$ Mixodectidae (Mixodectes, Olbodotes, Indrodon, Cynodontomys, Microryops).

II « Nebenordnung Chiropteri, Fledermäuse.

Carnivore oder frugivore Nachkommen der Insectiroren, deren Arme durch Terlängerung der 2--5 Finger und zwischengespannte Flughäute zu Flügeln umgebildet sind. Gehirn ziemlich groß. Ciebiß normal, Back- 
zähne trituberculäı oder bogig gefaltet, Prämaxillen und deren Incisiven bisweilen in Rückbildung. Uterus mehr oder weniger zweiteilig.

Die fast 600 lebenden Arten rerteilen sich auf die beiden L'nterordnumgen der

a) Megachiroptera, zu denen die Pteropodidae oder fliegenden Hunde gehören und

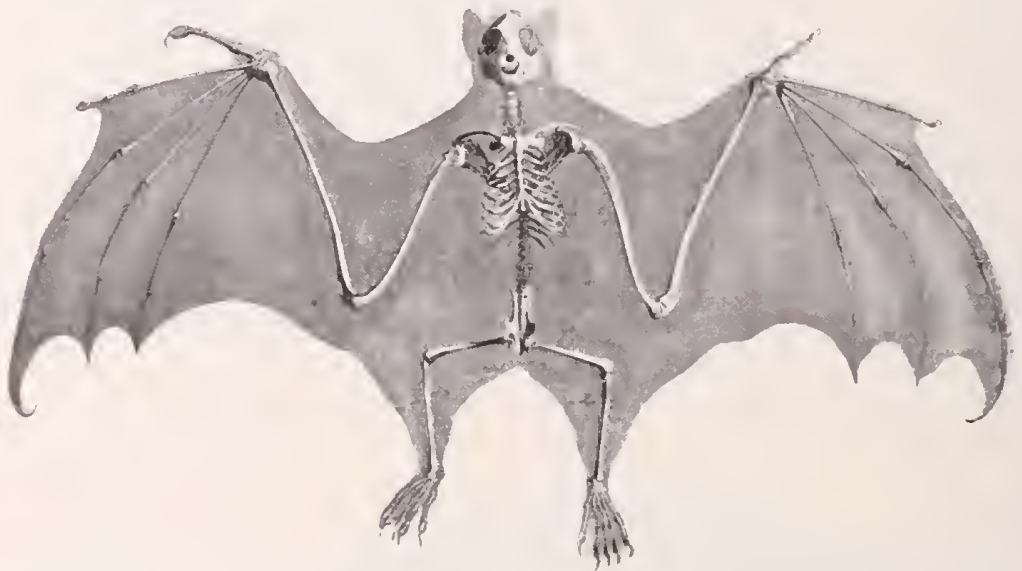

Fig. 209. Pteropus -p. Skelet. (Nach Pauder und d'Alton.) Sunda-Inseln.

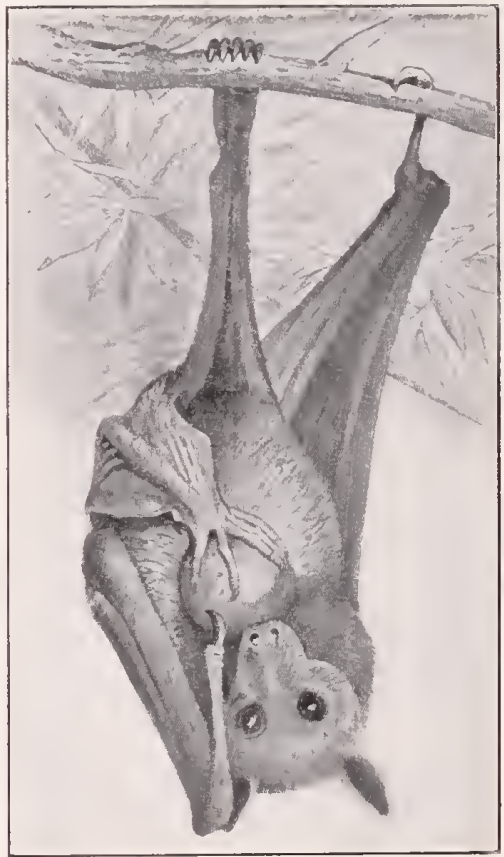

Fig. 230. Pteropus, der fliegende Hund, in Hängelage fressend.

(Nach J. Wolf.) 
b) Microchioptera die Kleinfledermäuse mit den z. T. schon tertiären Familien der Rhinolophiden, Phyllostomidae, Emballonuridae. Natalidae nud Tespertilionidae.

\section{II ${ }^{3}$ Tebenordnmng Galeopitheci,}

die anf den lebenden Galeopithecus basiert ist, der fribler zu den Lemuren gerechnet wmrle, aber uach neneren Forschungen einen eigenen Typus repräsentiert, da er sich nirht nm durch die sonderbare Flughant sonder'n anch durch andere Ierkmale wie eigene Zahnformel $\frac{2 \cdot 0.3 .3}{2.1 .3 .3}$ unterscheidet, die allerdings in ihrer Benteilung schwankungen mutrrliegt.

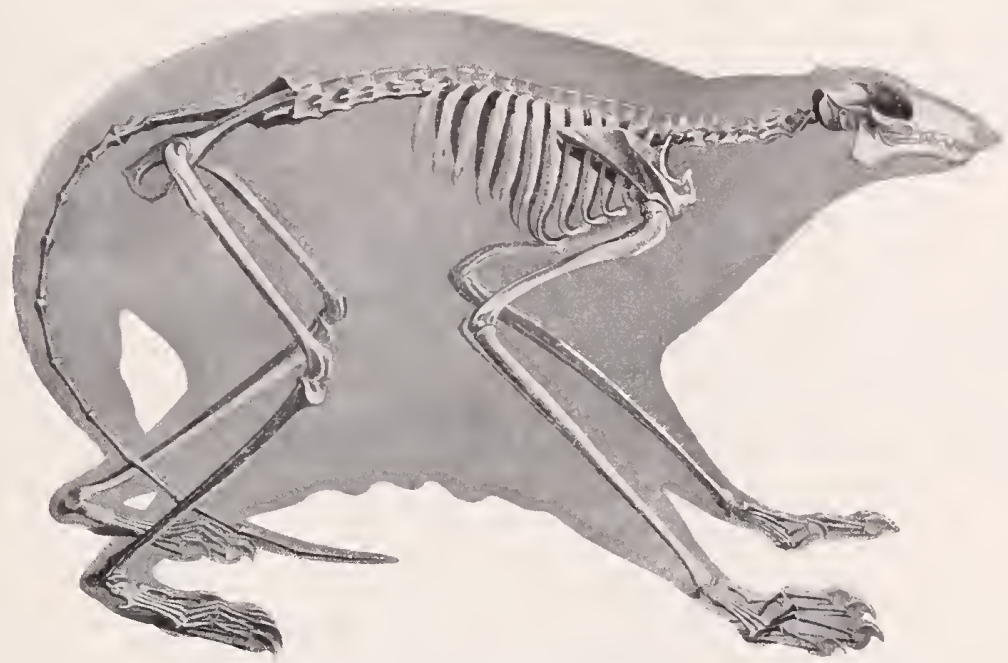

Fig. 2:31. Galeopithecus volaus L., der Flattermaki. Lebend. Sundaarchipel und Philippinen. 1/4. (Nach Pander und d'Alton.)

\section{Nebenordnung Prosimiae.}

Die an die Insectivoren angeschlossene Nebenordnung der Halbaffen steht in engem verwandtschaftlichem Komnex mit den Simiae, und weil sie damit die bedentsamste Entwicklungsreihe des Tierreiches einleitet, die schließlich zum Menschen führte, so hat man diese Seitenreihe zusammenfassen wollen und sie als Primates oder Archonten bezeichnet. Wir konnten derartige geschlossene Seitenäste des Stammes systematisch als eigene Abteilung zusammenfassen, aber eine besondere Veranlassung zu ihrer Begründung war eigentlich nur darin gegeben, daß wir in diesem Falle die Ahnenreihe der Anthropoiden frühel nur bis zn den Halbaffen oder Lemuren zurückverfolgen komnten. Nachden wir diesen Stammbanm jetzt rückwärts mindestens bis zn den Insectivoren fest- 
stellen kümmen, und rerschiedene primitive Lenmuen noch kaum höher als Insectivoren intwickelt sind, ist die untere Grenze einer so begrenzten Üherordnmeg rein willkiirlich. Bedentsam hleibt aber die Tendenz dieses Seitenastes, das Gehirn sehr zu vergrößern mud dabei den Schwerpunkt der Entwicklnng rom Körpor anf den Geist zn verlegen. Aber anch hierin bilden die Lemuren keine scharfe Grenze. Wir betrachten also die Ordnumgen der Lemnen, Simiae und der Bimani als selhständige Ordnungen und bringen ihren genetischen Znsammenhang durch ihre Buchstabenbezeichmugen II $\gamma$ l-3 zmm Austruck.

Die Prosimiae sind vierfïBige herbivore Bambewohner mit langem, nicht znm Greifen dienendem schwanz, grobem Gehirn, der Zahnformel meist $\begin{aligned} & 2.1 .3 .3 \\ & 2.1 .3 .3\end{aligned}$. Die Endzehen meist mit Plattnägelu hesetyt. Hallnx und Pollex opponierbar. Orbita hinten geschlossen.

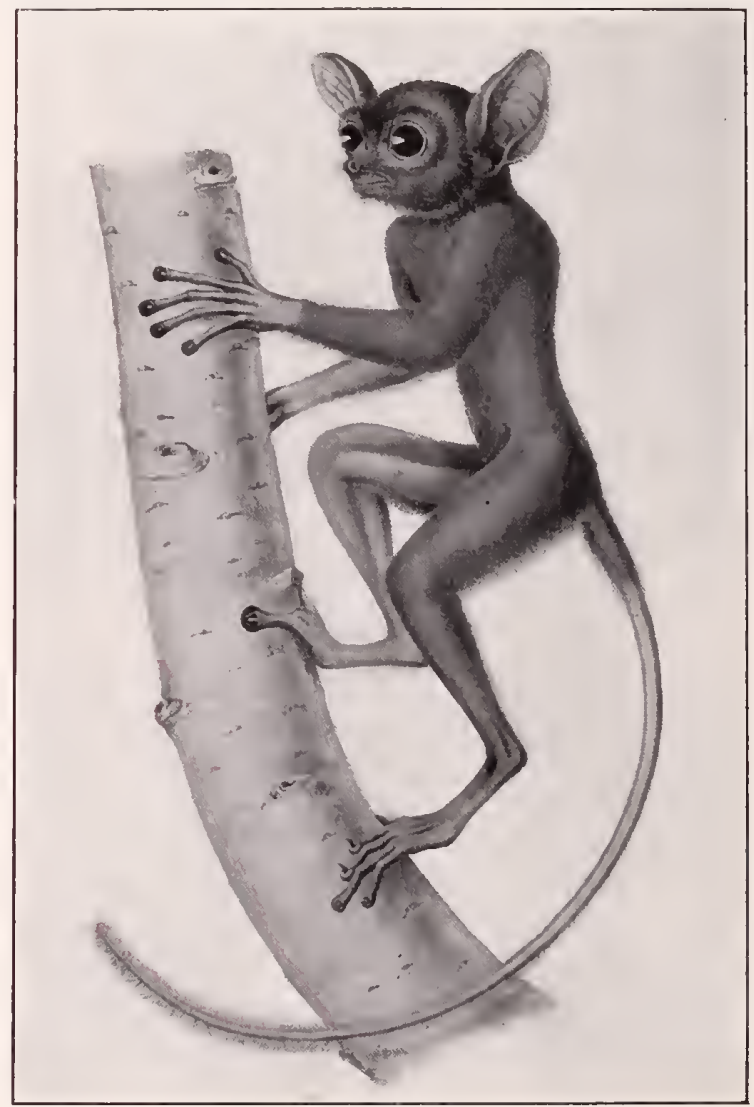

Fig. 232. Tarsius tarsius Erxl, Lebend. Ostindien. (Nach Burmeister.) 
Die gegenwärtig in der Lmoebung des Indischen Ozeans besonders in Madagaskar verbreiteten Tiere sind dicht behaart und meist Nachtsclıwärmel.

M. Wreher teilt die Prosimiae in zwei Lnterordnumgen, von denen die

$$
\text { Unterordumug 'Tarsii Weber }
$$

die primitivste Form unfaßt (Fig. 232).

Augen riesig vergrößert, Gehirmmasse nach hinten gedrängt. Untere Incisiren aufrecht. Tibia und Fibula im Unterschenkel verschmolzen. Calcanens (Fersenbein) und Naviculare verlängert. Tarsius bildete vielleicht den Ausgangspunkt für die Simiae, als fossile Vertreter dieses Typus kommen in Betracht die Anaptomorphidae mit Anaptomorphus, Necrolemur u. a. im Eozän ron Nordamerika. Eine sehr primitive Stellung auch gegenüber den Lemuren nehmen die Notharctidae mit Notharctus und Polycodus im unteren Eozän Nordamerikas ein.

\section{Lnterordnung Lemuri, Lemuren}

mit niederliegenden Schneidezähnen und Eckzahn im Unterkiefer. Orbita mit weitem hinterem Durchbruch. Tibia und Fibula getrennt. Hierher gehören rerschiedene fossile Formen seit dem Tertiär; auBer den g*enannten Notharctidae die Adapidae mit Adapis und Plesiadapis, ferner die lebenden Familien der Lemuriden und Nycticebiden sowie die etwas abseits stehenden Chiromyiden.

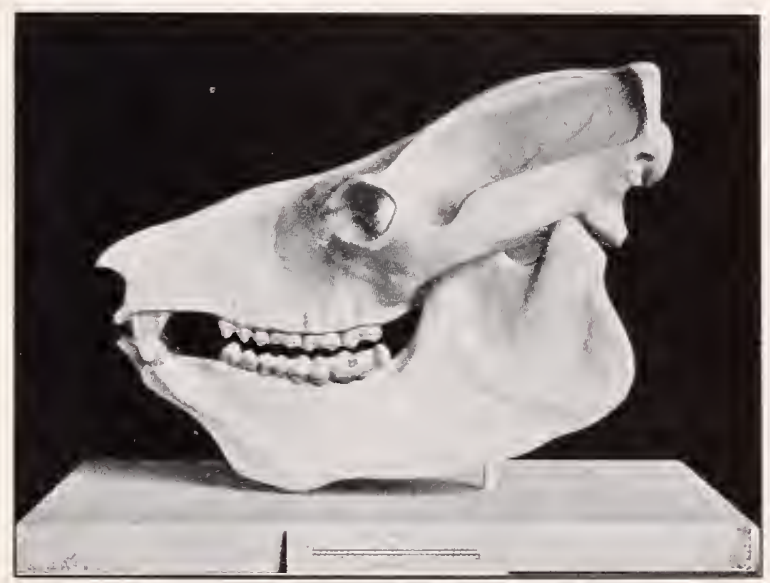

Fig. 233. Schädel ron Megaladapis madagascariensis Forsyth Mayor, ein Adapide des Quartärs von Madagaskar. 1/4. (Nach einem Modell des Brit. Mus. (Nat. Hist.).) 


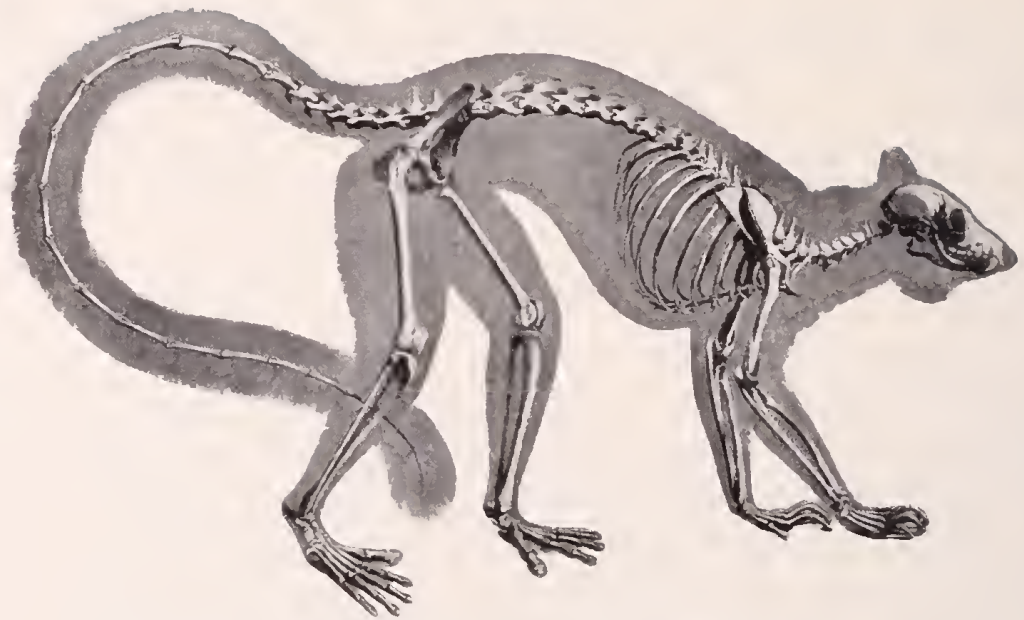

Fig. 234. Lemur mongoz L. Lebend, Madaga-kar. 1/i. (Nach Pander und d'Alton.)

II $\gamma_{2}$ Nebenordnnng Simiae, Affen.

Stark behaarte, banmbewohnende, geschwänzte VierfüBler mit großem Gelirm, opponierbarem Hallux, mit separatem Zwischenkiefer. Die Arme kiirzer als die Hinterbeine. 5 Finger und 5 Zehen, die in der Regel mit Plattnägeh an den Endoliedern hesetzt sind. Zahnformel $2.1 .3-2.3-2$

$2.1 .3-2.3-\overline{2}$

I)ie Affen zerfallen in

a) Unterordmmg Platyrhini, Breitnasen, Affen von sind-Amerika, mit hreitem Nasenseptum. Hapalidae, Cebidae.

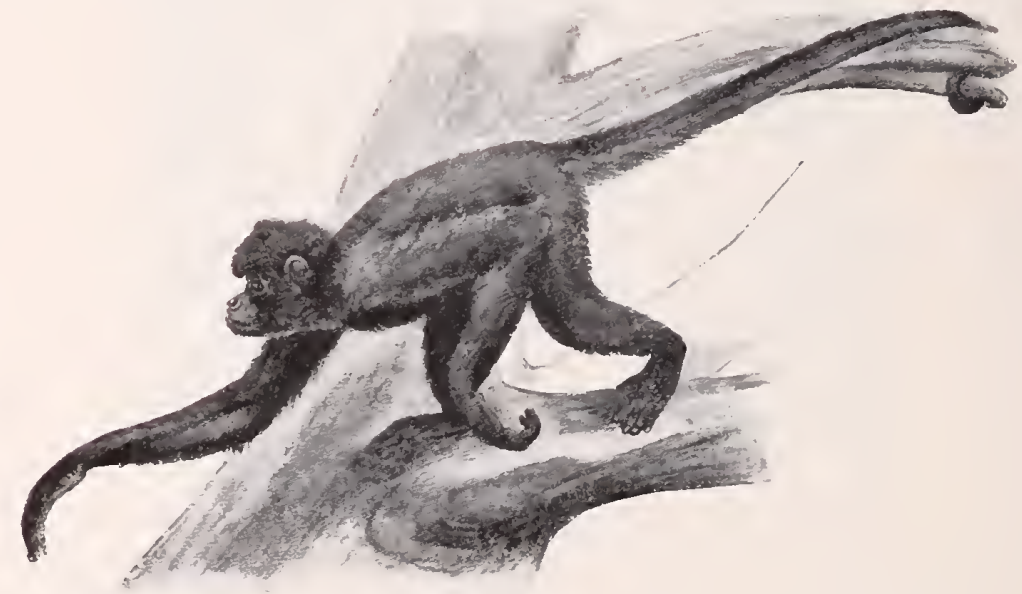

Fig. 235. Ateles ater Cuv. Ecuador und Peru. (Nach Beddard.) 


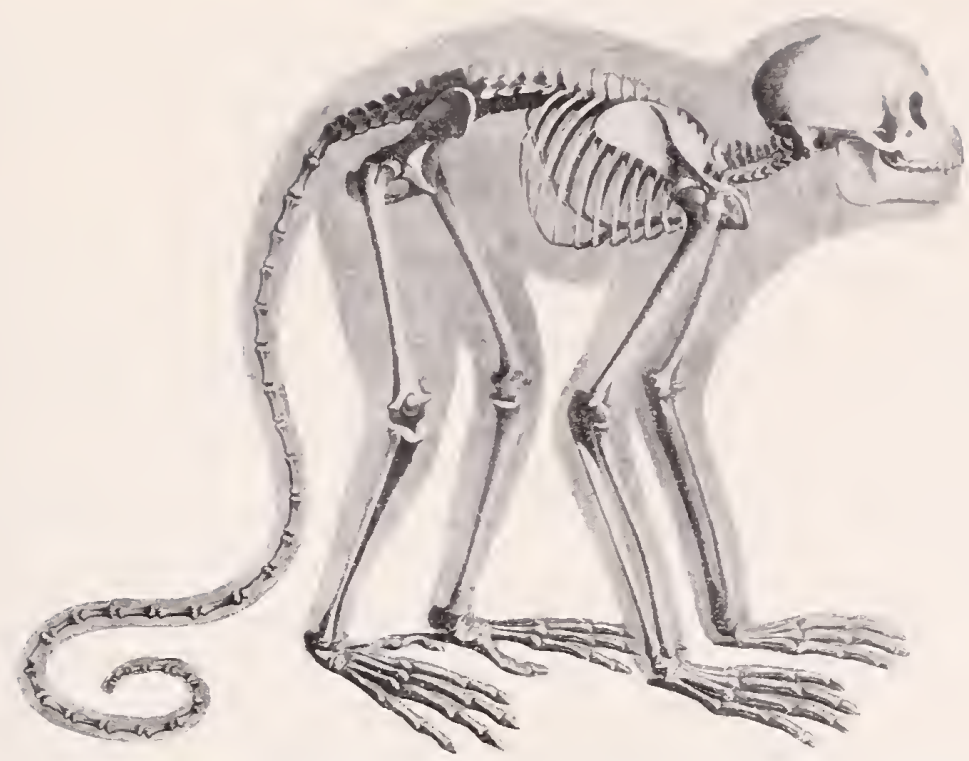

Fig. 236. Skelett von Ateles beelzebuth Geoffr. Im nördlichen Südamerika. (Nach Pander und d'Alton.)

b) Cnterordnung (atarhini. Schmalnasen.

Affen der alten Welt, mit schmalem Nasenseptum und der Zahnformel $\frac{2.1 .2 .3}{2}$. Arme kürzer als Beine. Schwanz meist lang. Gesäßschwielen vorhanden.

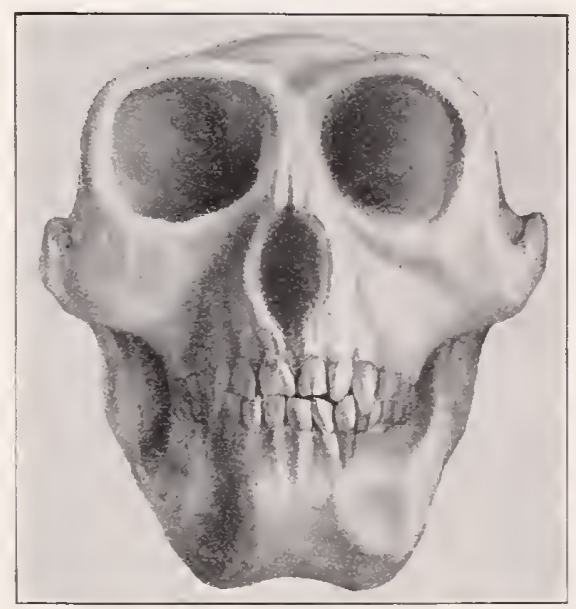

Fig. 237. Vorderansicht eines Schädels von Mesopithecus pentelici Beyrich. Yrocän. Pikermi b. Marathon. 3' ${ }^{\prime}$. (Nach Beyrich.) 
Hierhin gehören ron lebenden die Meerkatzen, Pariane, Makake, Stummelaffen mnd Schlankaffen der alten Welt, von ausgestorbenen Formen des jingeren Tertiärs Oreopithecus, Mesopitlecus, Dryopithecus.

\section{II $\gamma$ : Nebenordnung Bimani.}

Schwanzlose, teilweise aufrecht gehende Affen und der Mensch. Die extreme Vergroßerung des Gehirms als Sitz unseres Denkrermögens unterscheidet den Menschen nur graduell von seinen unmittelbaren Verwandten. unter denen die schwanzlosen Affen dem Menschen anatomisch viel näher stehen als den geschwïnzten Affen.

Die Bimani sind durch aufrechten Gang, Einlagerung des rudimentären schwanzes in das Becken, knrzes Brustbein, gerundeten nicht

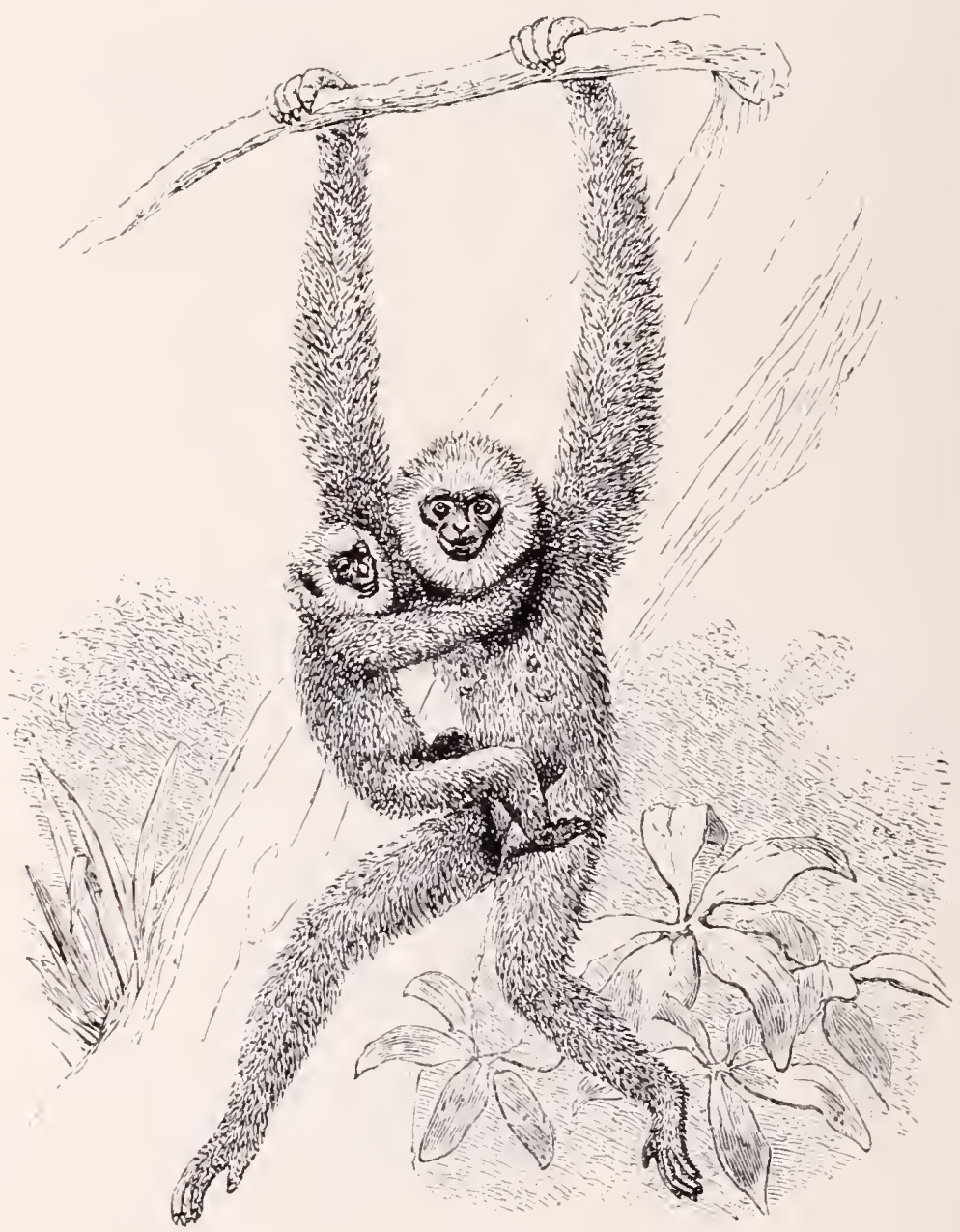

Fig. 238. Hylobates syndactylus Wagn., der Gibbon von Sumatra. 
kompimierten 'T'horax, 16-18' Rumpfwirbel und die z. 'T. sehr lange Aushildung der vorderen Gliedmaben als Arme ausgezeichnet. Gesäßschwielen fehlen. Die Hare sind an Arm dem Ellbogen zugewendet. Coecum mit Wurmfortsatz. Oben 5, unten 4 getrennte Höcker anf den Backzähnen.

Hierhin gehören als

a) Unterordumg Hylobati :

für den Hylobates syndactylus, den cibbon Südost-Asiens und der henachbarten Inseln (Fig, 238).

b) Unterordnung Paranthropi m.

Diese als Anthopomorphen in engeren Sinne bezeichneten Menschenaffen haben sich in anderen Richtungen entwickelt als das Menschengeschlecht, das vielleicht von Hylobatiden seinen Ansgang genommen hat. Es dürte daher zweckmäBig sein, sie auch in der Kollektir-Benennmg aus der ummittelbaren Stammeihe des Menschen

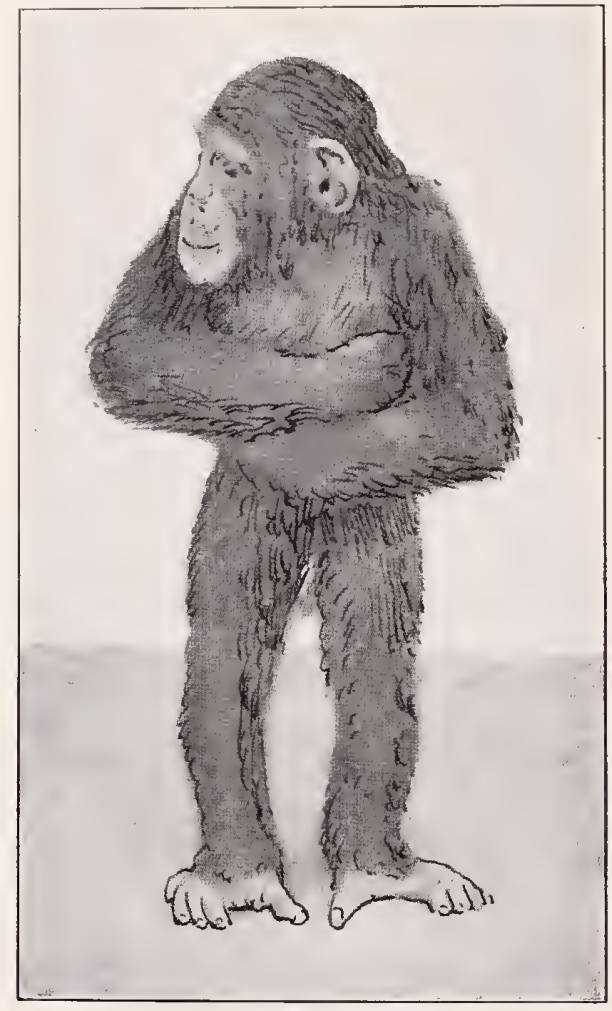

Fig. 239. Anthropithecus (Simia L.) troglodytes Blumeubach sp., der Schimpanse (nach einer Photographie). 1/6 
ansznschlieBen. Daher gab ich ihnen den Nanen Paranthropi. Sie sind abgesellen ron rerschiedenen mimitiven Affenmerkmalen, wie klemerem Gehirn, totaler Belaamung. rortretemdem Schnauzenteil und Erhaltung des Zwischenkiefers und Opponierbarkeit der groben Zehe, besonders durch starke Verlängerung der Arme. den Gang anf dem änBeren Rande der FuBsolile, starke Augeuwiilste und z. T. durell Ausbildung einer Mittelkante auf dem Schädel selbständig entrickelt.

Hierler gehör'n der Orang-Ltang. der .. Waldnann" ron Borneo und Sumatra (Sinia sațrus L.). zweitens der Schimpanse (Anthopopithecus troglodytes L.). drittens der Gorilla (Gorilla gorilla Wrom.). die beide in Afrika leben. Alle drei stellen ..sammelarten* ror, die wohl in rasschiedene Lokalformen zerlegt werden können.

Tou fossilen Formen rechnet man hierles Lryopithecus nnd Pliopitheeus. die dnrch L'nterkiefer im Miozän von Sülfrankreich bekannt

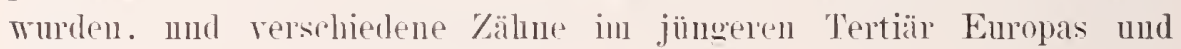
siidasiens.

\section{(c) Enterondnung Antlupopi m.}

Sie nnfassen nur den Menschen nnd seine unnittrolhare Vorfaluenreihe, in der Pithecauthropus erectus Dub. aus dem unteren Diluvium ron Trinil in .Tava molphologisch betrathet die erste stolle einnimmt. Ebenso alt erscheint der . Teandertaler.", dessen erste Reste in einer Höhle des Neandertales bei Disseldorf gefunden nud lange in ilner Bedeutume durch Virchow diskreditiert wurde. der sie fiir Reste eines

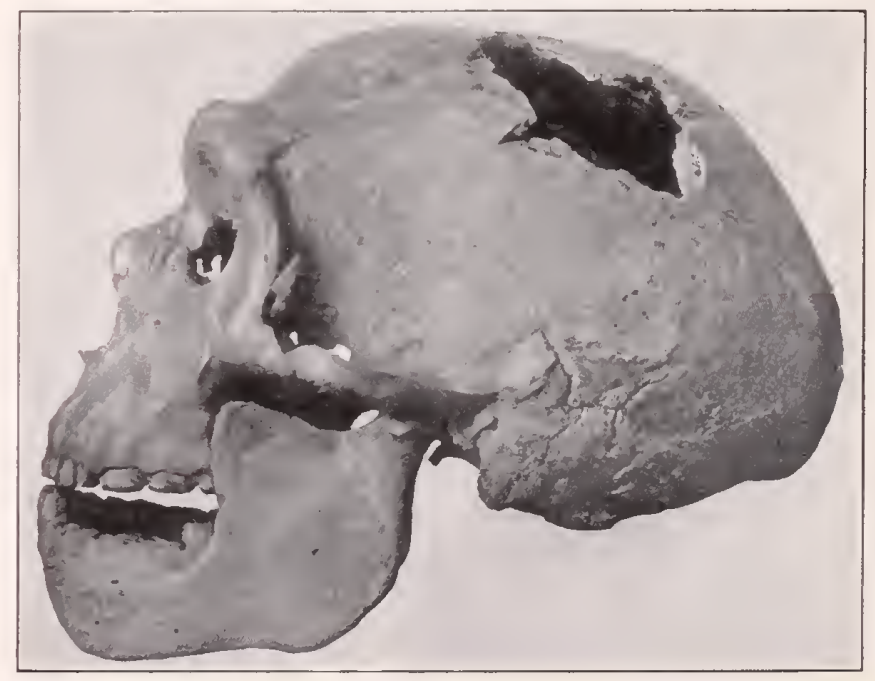

Fig. 240. Schädel des Homo Heidelbergensis Schötensack, in der Rekonstruktion des Schädels von Aix la Chapelle mit dem Lnterkiefer von Heidelberg. (Nach Boule.) 
pathologischen Individums erkärte. Jetzt kennen wir derartige Reste auch ron anderen orten. namentlich durch Klaatsch aus Mähren genauer und wissen, daß der Neandertaler eine primitive Rasse bildete, für die schwallie den Namen Homo neanderthalensis rorschlug. Den nachweislich ältesten Rest im Ininvinm bildet del Enterkiefer ron Maner bei Heidelberg. der in den sanden mit Elephas antiqums gefunden wurde. Thm scheint der kürzlich bei tix la Chapelle gefundene schädel nahezustehen, den Marc. Boule in Paris mit dem Heidelberger Enterkiefer kombiniert hat (Fig. 240). Je älter die Menschenreste sind, 1 m so mehr nähern sie sich dem Typus der Affen. Pithecanthropus scheint den Hỵlobatiden am nächsten zu stehen.

\section{Anhang der zweiten stufe.}

\section{IId Nebenordnung Rodentii, Nagetiere.}

Kleine, meist herbirore, krallentragende Sohlengänger mit je 2 sehr verlängerten hỵpselodonten schneidezähnen (Nagezähne) mit oblitevierenden Eckzähnen. langem Diastema. 'Tympanicum nrsprïnglich lingförmig, dann eine Bulla ossea bildend.

Die sehr formenreiche und ïber die anze Erde verbreitete ordnumg zerfällt in zwei Conterordnungen, die anscheinend schon rom Eozän an. wo sich ihre ersten Tertreter finden, getrennt sind. T'eniger spezialisiert sind die sogenannten

\section{Lnterordnung Duplicidentati.}

die nur die Grupre der Hasen $1 \mathrm{mfaBt}$, die hinter den großen Schneidezähnen noch ein zweites Paar kleiner Incisiven tragen. konstant oben 3. unten 2 Prämolaren. Obere Zahnreihen breiter als die unteren. Kiefergelenk breit. Leporidae. Ochotonidae (Lagomyidae), heide seit dem Oligozä11.

\section{C'nterordnung simplicidentati}

mit beweglichen und rorshiebbaren Lnterkieferhälften, schmalem Kiefergelenk, engerer stellung der oberen Zahmreihen. die großen Abteihungen

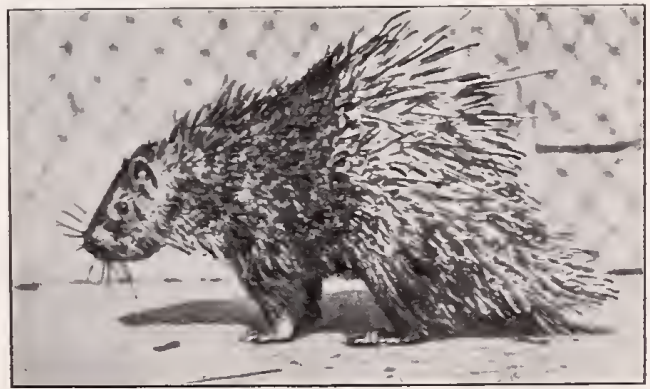

Fig. 241. Hystrix jaranica Cuv. Ein Stachelschwein Südasiens und der Sundainseln. 
der Hystricognathen und der Sciurogmathen umfassend, deren erstere die †'Theridomyidae und die z. 'T'. schon tertiären Octodontidae, Hystricidae (Stachelschweine), Chinchillidae nud Caviidate (Meerschweine), letztere wieder mach T. T'ullberg die sciuriden, Anomahmiden, Ctenodactyliden, Castoriden, Geomyiden, Myiden und nach M. Schlosser auch die Myoxiden enthält.

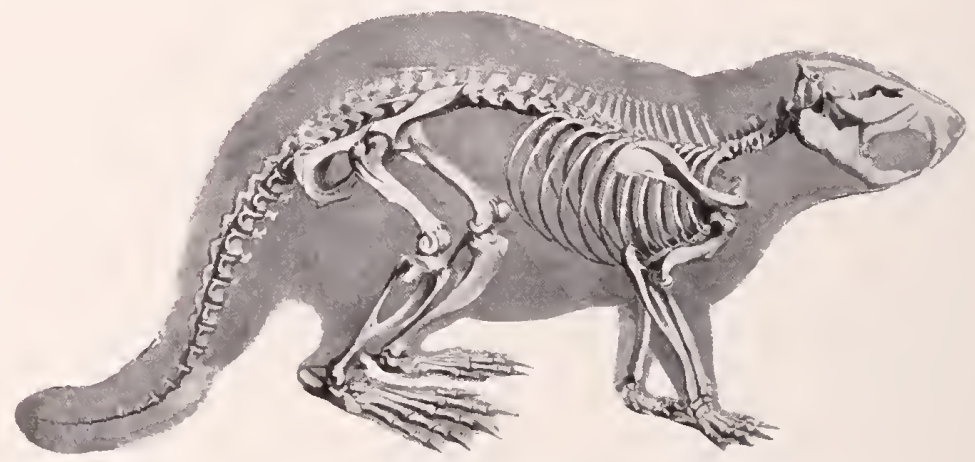

Fig. 242. Skelett des Bibers, Castor fiber L. Nordeuropa und Asien. (Nach Pander und d'Alton.)

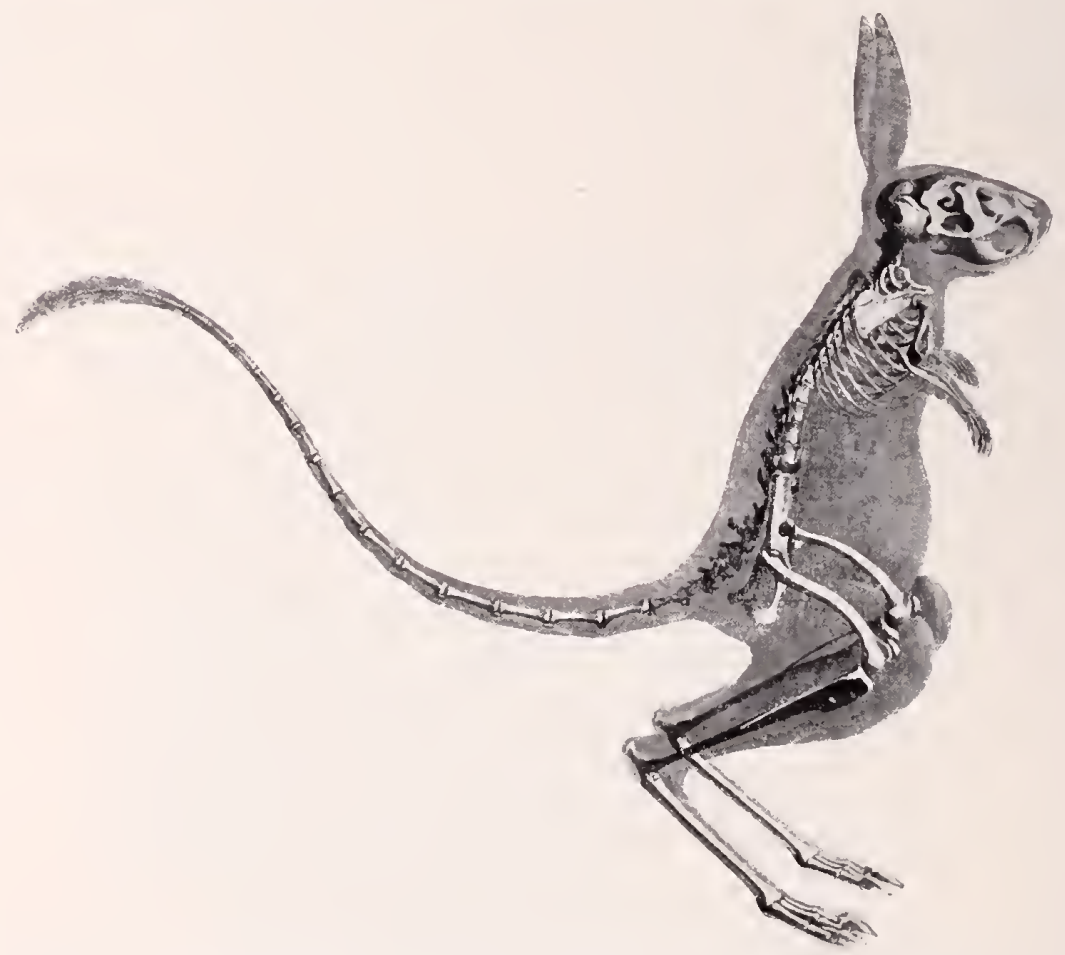

Fig. 243. Dipus aegyptins Hempr. \& Ehrenb. Ägyptische Springmaus. 1/3. (Nach Pander und d'Alton.) 


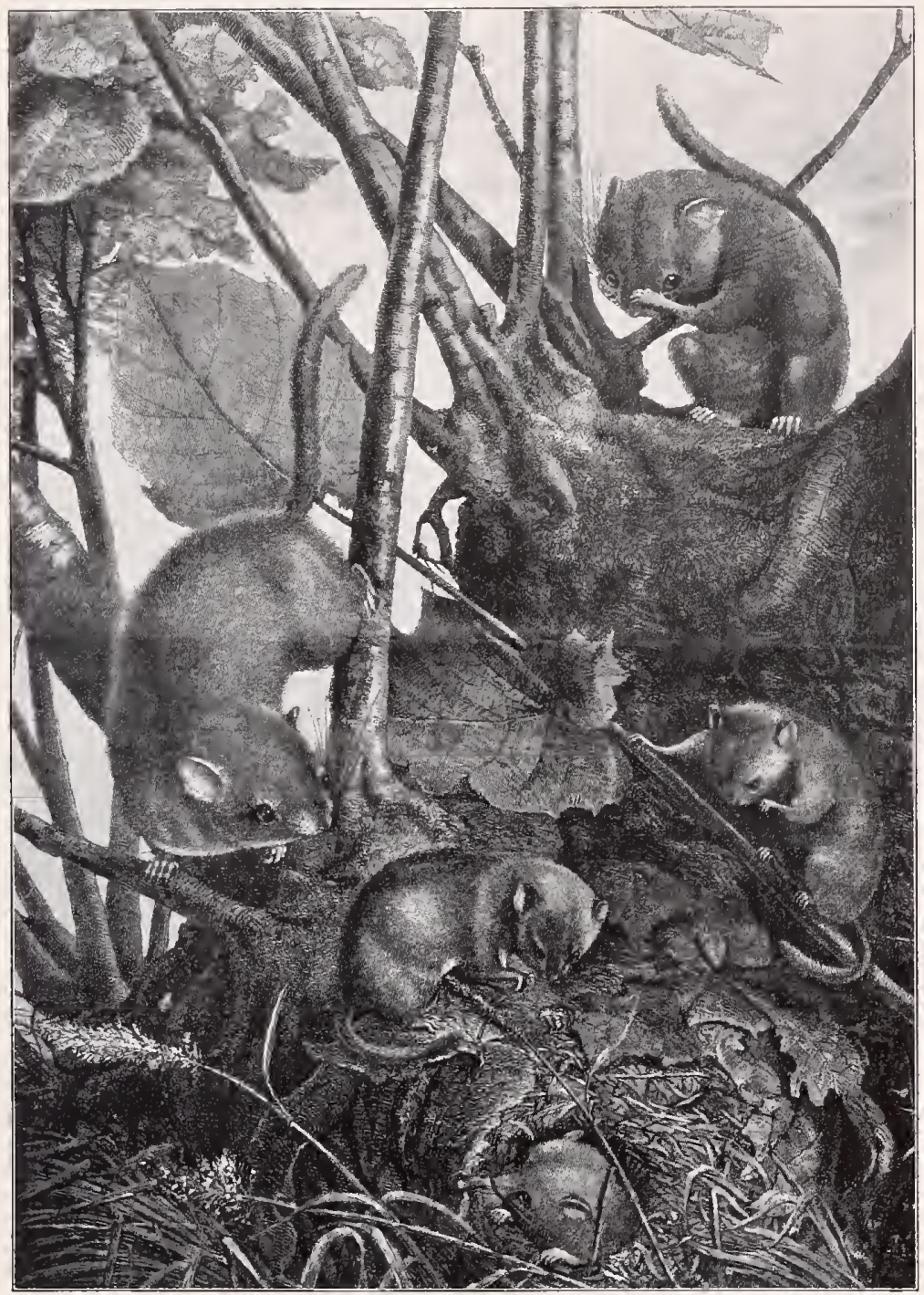

Fig. 24. Muscardinus avellanarius L. Die Haselmaus des nördliclien Mitteleuropa. (Nach einer älteren Ablillung von A. Müller in der Gartenlaube.)

\section{II $\varepsilon$ Nebenordnung Tillodonti.}

Ein in der Kreide und dem ältesten Tertiäı Nordamerikas seltener Typus großer Formen mit nagetierähnlichem Gebiß, großen Incisiven, rudimentären Caninen und einer größeren Zahl relativ einfach gebauter hnftierartiger Backzähne, scheint nach neueren Untersuchnngen keine Beziehungen zu den Nagetieren zu haben, wohl aber nach Wortmann solche zu den Xenarthra und rückwärts mit primitiven Insectivoren in 
Fonnex gestanden zu hahen. Ein leidlich rollständiges skelett ist nur von Tillotherium fodiens Marsh aus dem Eozän von Wyoming bekannt. (O) ihm die stylinodonten und einige isolierte Zahnformen, die hier eingereiht werden, wirklich zugehören, erscheint anch noch fraglich. Nach Osborn nehmen diese letzteren als T'aeniodonten oder Ganodonten eine Ühergangsstellung zu den Xenarthra ein.

\section{Sebenordumo Xenarthri.}

'Trüge behairte, beschuppte oder gepanzerte, krallentragende, insectivore oder herbivore sollengänger nit degeneriertem frebiß nnd obliterierten Vorderzähnen. Tympanicmu ringförmig. Rmmpf- und Beckenwirbel mit akzessorischen Gelenkfortsätzen (Xenarthra). Uterus einfach. Vagina nicht ansgehildet. T'estikel inmerhalh der Bauchhöhle. Penis ohne Eichel.

Diese meist norh als Edentata mit den Homarthra zusammengefaßten Formen sind nach Flower. Theher u. a. so scharf von diesen geschieden, daß man zweckmäBig die Edentata als konvergente Gruppe anfheht und ihre heiden Ordumngen selhständig macht. Über ihre Herkunft ist noch nichts (ienaneres bekannt. Cope leitete sie von Tillodontien ab. Die Xenarthra unfassen folgende gegenwärtig ganz auf Siidamerika beschränkte, früher anch in Nordamerika vertretene Familien:

\section{Interordnume Tardigradi, Faultiere.}

I) ichthehaarte herbivore Baumbewohner mit rundlichem Kopf, sehr langen Arnen und kurzen schwanz. 2--3 Zehen vorhanden, durch Haut verbunden (stundactyl). Alle Wirbel getremnt, Schädel mit nuvollständigen ,Jochbogen, rudimentaren Prämaxillen, mit Schliisselbeinen

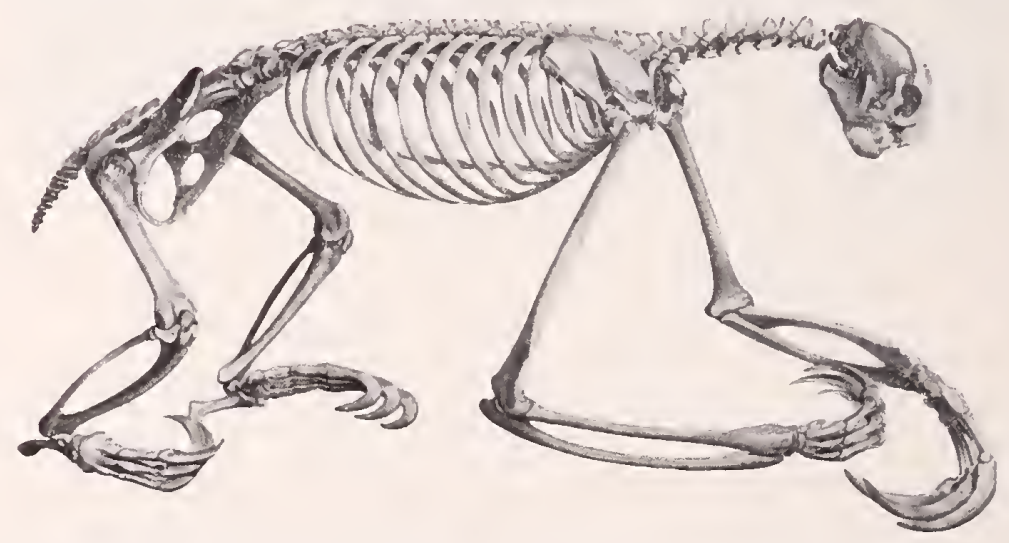

Fig. 245. Bradypus tridactylus L. Skelett des dreizehigen Faultieres des tropischen Südamerika. (Nach Pander und d'Alton.) 
(Clariculis). Höchstens $\frac{5}{4}$ stiftörnnge Zähne rorhanden. Hierher die Bradypodide Siid- und Zentralamerikas (Fig. 245).

Unterordnung †Gravigradi, Megatherien, Riesenfaultiere.

Plumpe, große Pflanzenfresser, mit langen, phmpen Beinen, deren Sohlen nach innen gekehrt, deren Zehen meist nit großen Krallen vorsehen sind. Haut behaart, ohne größere Knochenbildungen. Schädel niedrig, meist absteigender Jochfortsatz, Postorbitalbrücke unterbrochen, Ţmpanikum ringfömig, Zähne schmelzlos, danernd nachwachsend (hyselodont), ohen $5-4$, unten $4-3$, meist in geschlossener Reihe, bisweilen der vorderste eckzahnartig. Hierhin gehören von den fossilen Formen Sïdamerikas das riesige Megatherinm, dam Scelidotherimm, Mylodon, das mit Haut und Haaren erhaltene Grypotherium und Megalonyx.

Unterordnung Placophori, Gürteltiere (Loricata, Hicanodonta).

Schwach heharte, mosaikartig gepanzerte, schwerfällige Bodenbewohner, mit geschlossener Postorbitalbrücke, mit teilweise verwachsenen Hals- und Rumpfwirbeln, mit zahlreichen (wenigstens $\frac{7}{7}$ ) Backzähnen. Tibia und Fibula an den Enden verwachsen. Hierher die Chlamydophoridae, Dasypodidae, Glyptodontidae, die eozänen Metachiromyidae; jiingere fossile Repräsentanten sind die am stärksten spezialisierten Glyptodonten mit ungegliedertem Panzer, während die kleinen, lebenden Dasypodiden, mit Dasypus (Fig. 246) und Tatusia, ihren Riickenpanzer beweglich erhielten und sich in ihm einrollen könuen.

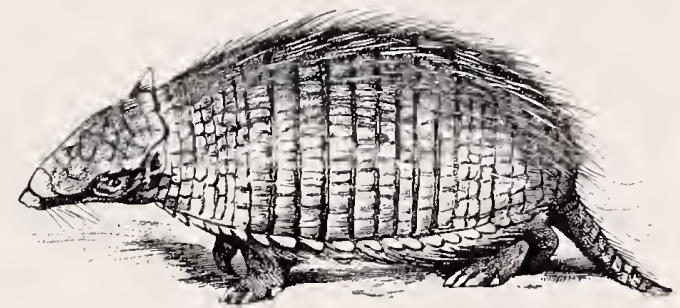

Fig. 246. Tatusia novemcincta L. Das bekannteste der lebenden Gürteltiere. 1/8. Südamerika bis Texas. (Nach Haacke.)

Unterordnung Myrmecophagi, Ameisenfresser (Vemilingua).

Mäßig große, dicht behaarte, zahnlose Insectivoren, mit sehr langem Kopf, kleinen Augen, Ohren nnd Mnnd, mit langer, wnrmförmiger Zunge, mit großer Klane an der dritten Zehe. Hierher Myrmecophaga (Fig. 247), Tamandua nnd Cycloturus, sämtlich in tropischen Gebieten Amerikas. 


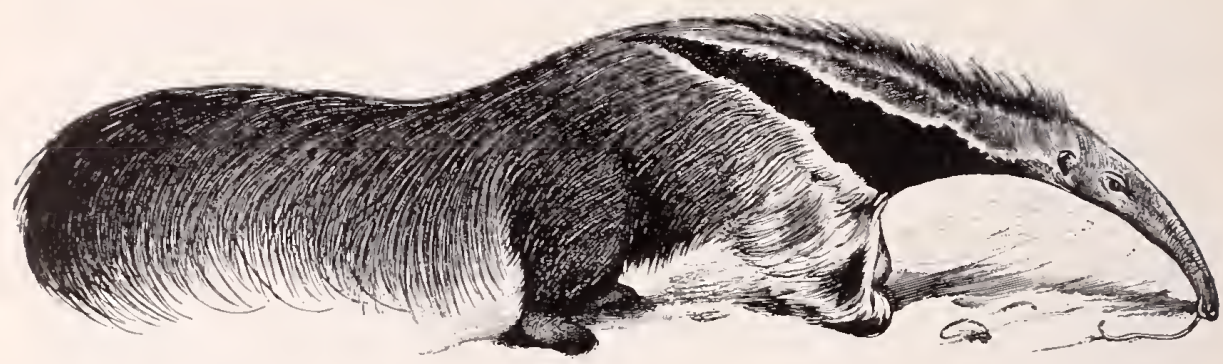

Fig. 247. Myrmecophaga jubata L. Tropische Gebiete Amerikas. 1/16. (Nach Haacke.)

\section{II $\lambda$ Nebenordnung Pholidota M. Weber,}

allein auf das in sïdafrikit und Indien lebende, dort anch fossile Schuppentier Manis beschränkt. Fs sind langsrhwänzige, krallentragende, insektenfressende, fünfzehige sohlengänger mit rollstïndigem Panzer, großen, dachziegelartig iibergreifenden Hornschuppen. Mund zahnlos mit langer, rorstreckharel Znnoe.

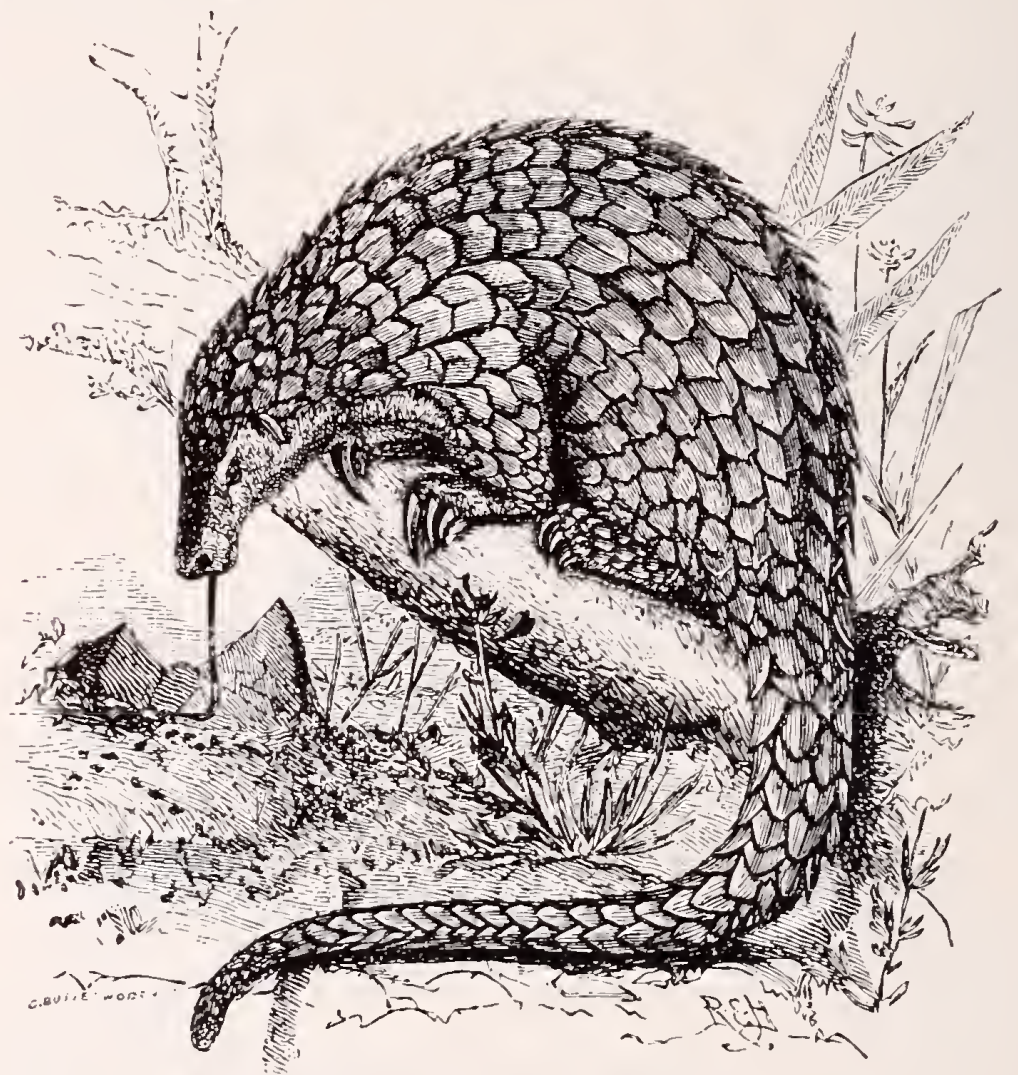

Fig. 248. Manis tricuspis hafinesque, ein westafrikanisches soluppentier. 1/4. (Nach Flower.) 


\section{Unterklasse Holotheria 111.}

I) dritte Stufe der Mammalia bezeichnet den Höhepunkt der Klasse nicht in der Spezialisierung eines einzelnen Organes wie die Primates in der Vervollkommnung des Gehirns, sondern in der gesamten, nnd ich möchte sagen, normalen Entwicklung des Klassentypus. In dieser Beziehung stehen die Raubtiere offenbar an der Spitze, der Löwe ist anch im Volksbewnßtsein der König der Tiere. Die Cetaceen nnd Huftiere sind aberrante Seitenreilen dieses Typus.

\section{Hauptordnung Carnivori, Raubtiere.}

Die Raubtiere sind eine fest geschlossene Abteilung kräftig entwickelter Vierfiißler mit krallenbesetzten Zehen, normal gegliedertem Gebiß mit stark entwickelten Eckzähnen. Clavicula riückgebildet. 1 Zehe nicht opponierbar. Thre gesamte Organisation weist unzweideutig auf Insectivoren als ihre Stammformen hin.

Sie umfassen alttertiäre Urformen, die sogenannten Creodonta, danach zwei Haupttypen, die landbewohnenden Fissipedier und meerbewohnenden Seehunde oder Pinnipedier. Es erscheint nicht zweckmäßig, die älteren Vertreter als Creodonta ihren jüngeren Nachkommen als systematische Einheit gegenuiberzustellen, aber die Formenreihen, die von jenen zu den lebenden Formenreihen überleiten, sind noch nicht in allen Teilen aufgeklärt. Ein Vergleich der älteren und jüngeren Formen lehrt eine Verkürzung der Gebißreihe, die hei den älteren noch 4 Prämolaren nnd 3 Molaren anfweist, während die letzteren bei lebenden Formen fast ganz verkümmern können, eine Vereinfachmo in der Fnßwurzel und stärkere Furchnng des Großhirms.

1. Unterordnung †Protoferi $11 .$.

entspricht den Carnivora primitiva Winges und umfaßt die alttertiären Formen wie Hyaenodon mit 4 Prämolaren und 3 Molaren, keinem be-

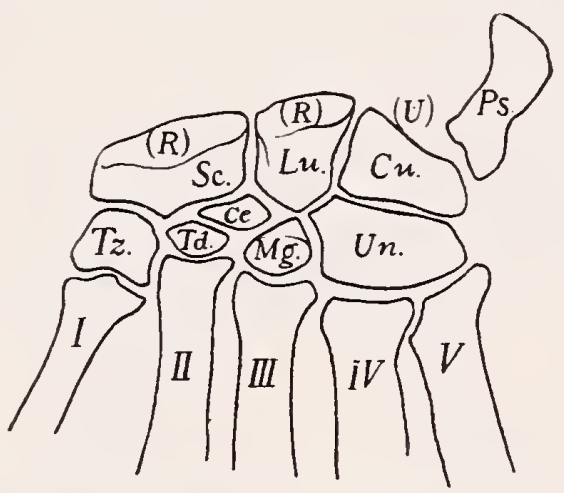

Fig. 249. Schematischer Durchschnitt der Handwurzelknorhen (Carpus) eines primitiven "creodonten" Raubtiers. (Nach Gregory.) 
sonders ausgebildeten Reißzahn, mimitiver Fußwurzel und Foramen ulnare im Humerus.

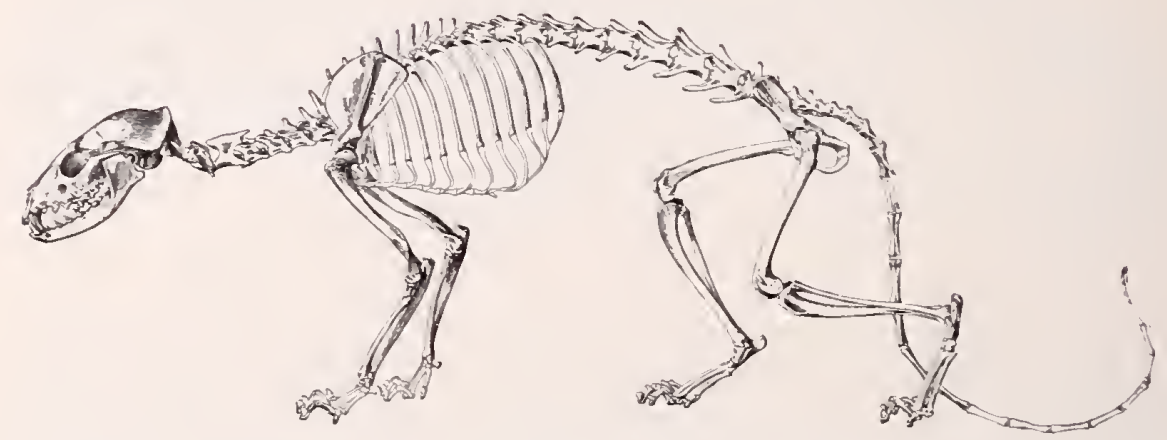

Fig. 250. Cynodictis gregarius. Oligozän, Cedar Creek, Colorado U.S. A. 1/4. (Nach Natthew.)

\section{Unterordnung Protelidi,}

die nur den lebenden Proteles cristatus (Lalandii) Sparman von Siidund Ostafrika umfaßt, der gewöhnlich zu den Hyänen gestellt wird, aber schon durch den Mangel eines Reißzahnes eine Sonderstellung einnimnt.

\section{Lnterordnung Felidi}

im sinne der Aeluroidea Flower, Epimycteri Cope, und der Herpestoidea Winge. Die Unterordnung soll also umfassen die Katzen, die Viverriden, die Herpestiden und die Hyaeniden. Ton diesen sind die Katzen die weitaus bekanntesten Vertreter, sodaß ich den Namen der Unterordnung nach ihnen bilden zu sollen glaubte.

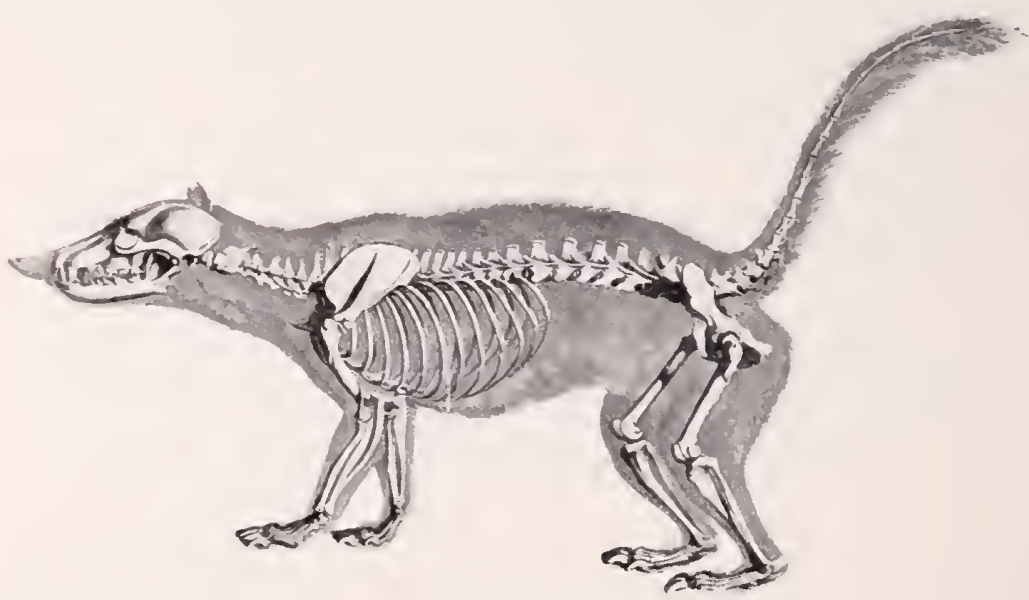

Fig. 251. Nasua narica. Skelett und Körperform. (Nach Pauder und d'Alton., 
4. Enterordnung Urso-Canidi m.

die die Bären nnd Hunde umfassen nund also den Areto-Cyonidae Flower, den Hypomycteri Cope nud den Arctoidea Winge entsprechen würden. Den Namen Lrso wollte ich ihrer Sammelbezeichnnmg Canidi nicht missen. Sie enthalten die Familien der Musteliden, der Caniden, der Ursiden.

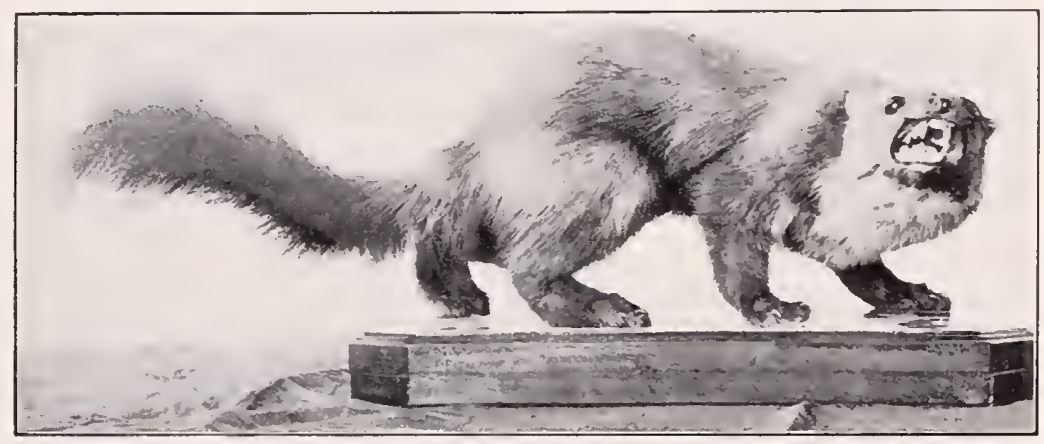

Fig. 252. Mustela martes L., der Baummarder Europas. (Nach einer Photographie des Brüsseler Museums.)

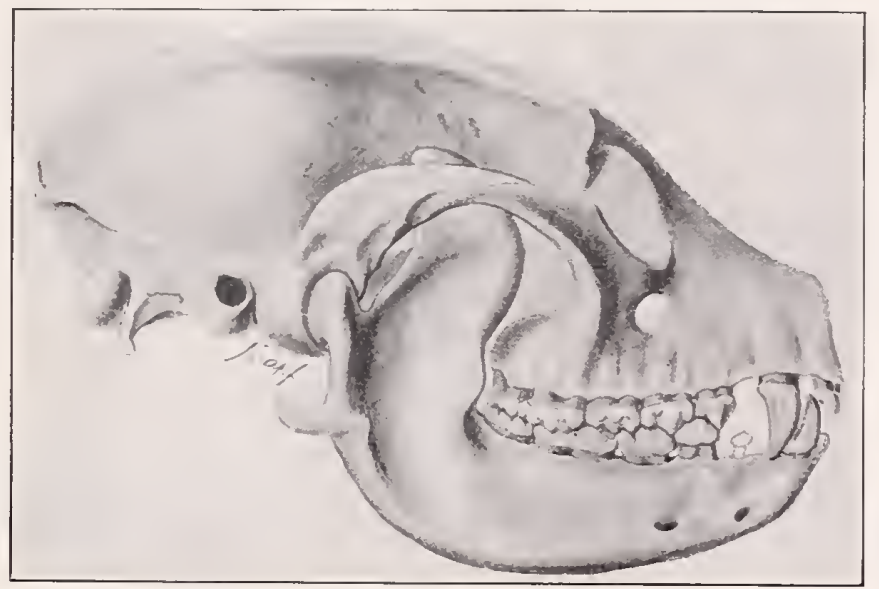

Fig. 253. Parailurus anglicus B. Dawkins sp., Ober-Miozän.

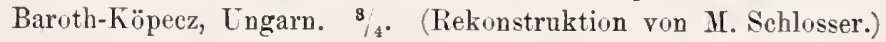

5. Unterordnung Phocidi, Seehmnde.

Die seehunde, die Pinnipedia des alten systems, die rermutlich von den terrestrischen Vorfahren der Ursiden abstanmen. Sie enthalten die Otariiden, die Trichechiden nnd die Phociden. 


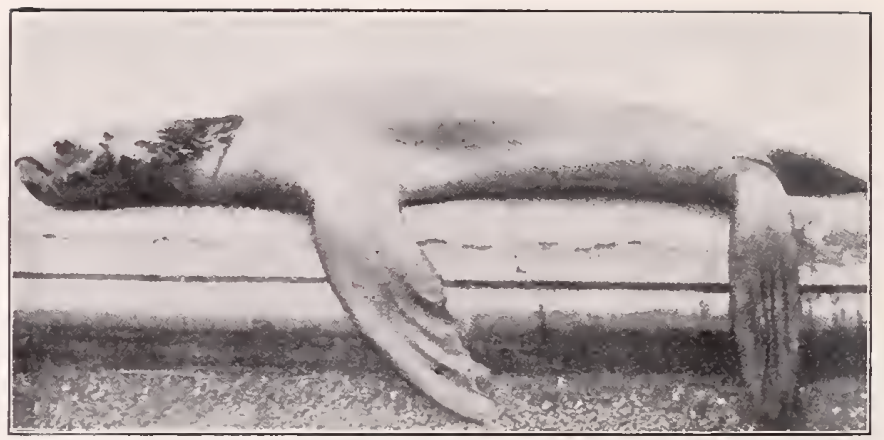

Fig. 254. Otaria sp. nach einer Photographie.

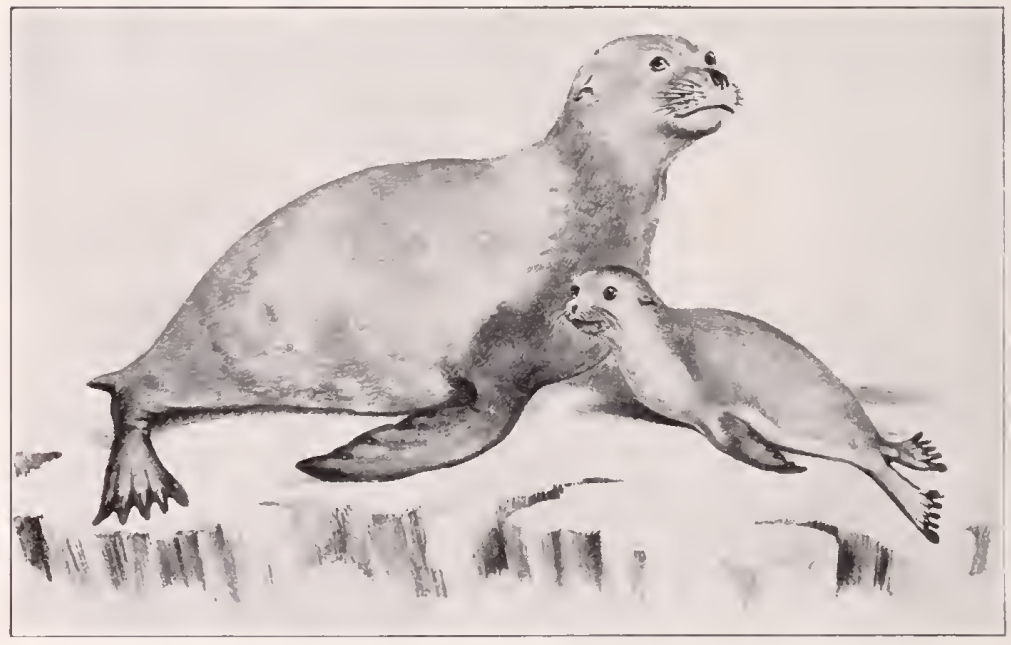

Fig. 25. Arctocephalus lobatus Gray, der australische Seebär. (Nach Gray.)

\section{IIJ" Tebenordnung Cetacei, Wale.}

Die Cetaceen, die die zahntragenden Delphine nnd die zalnulosen Bartenwale unfassen, sind sehr spezialisierte Nachkommen terrestrischer Carniroren. In ältesten Tertiär Ägyptens liegen die Übergangsformen ron diesen zu den primitiven Delphinen. Lnklar bleibt zunächst noch die Torfahrenreihe der zahnlosen Tale. Man teilt die ganze ()rdnung in die

1. Unterordmug +Arcliaeoreti Flower, Lrwale.

Zahnwale mit mohrspitzigen, mehrwurzeligen Barkzähnen, normalen Schärlelhau nit mäßig zurücligeschohenen Nasenlöchern. kurzen Nasalien 
und freien Frontalien. Hierher die Protoceten, die eine Zwischenstellung zwisehen primitiven Garnivoren und Cetaceen einnehmen, im unteren Tertiär Ägyptens, und die weit rerbreiteten, erhehlich größeren Zenglodonten (Fig. 256) Nordafrikas und Nordamerikas.

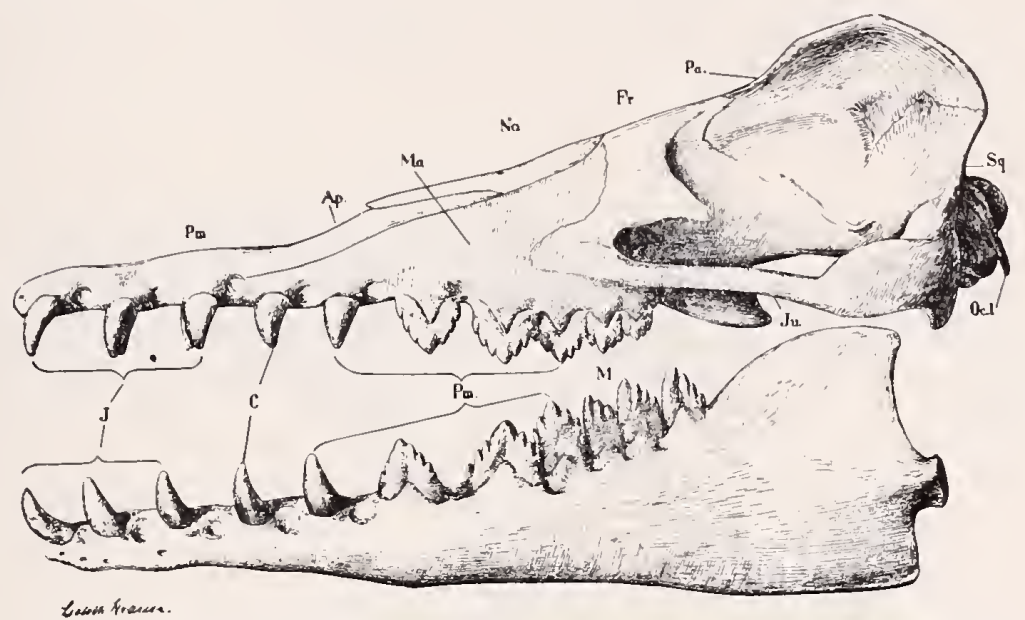

Fig. ‥si. Schädel von Zeuglodon osiris Dam. Eozän. Ägypten. 1/5. (Rekonstruktion ron E. v. Stromer.)

2. L'nterordnung Odontoceti, Zahnwale oder Delphine.

Zahmwale mit einspitzigen, meist sehı zahheichen, kegelförmigen Zähnen, riickwärts geschobenen und vereingoten Nasenlöcher. reduzierten Tasalien, teilweise rerdeckten Frontalien.

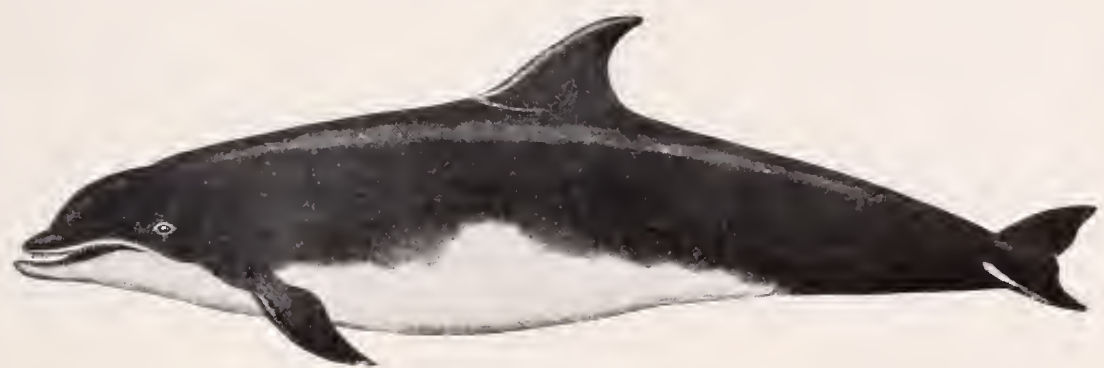

Fig. 257. Tursiops tursio Fabr. Ein Delphin der europäischen Meere.

(Nach Flower.)

Hierhiu gehören die tertiären †Sqmalodonten mit mehrwurzeligen, komprimierten, randlich gekerbten Backzähnen; ferner die Physeteriden. †Eurhinodelphidae, †Acrodelphidae, Delphinidae (Fig. 257) und Platanistiden. 
3. Cnterordmug Mystacoceti, Bartenwale.

Zahnlose Wale mit Fischbein-.Barten" in dem sehr großen Maul mit sehr kleinem Schlund. Schädel sehr groß mit getrennten, spangenförmigen, dünnen Unterkieferästen. Kopf mit getrennten Nasenlächern (Spritzlöchern), kleinen Nasahen und Lacrymalien, freien Frontalien.

Hierher die seit dem jüngeren 'Tertiär vorhandenen Balaenopteriden und Balaeniden (Fig. 258.)

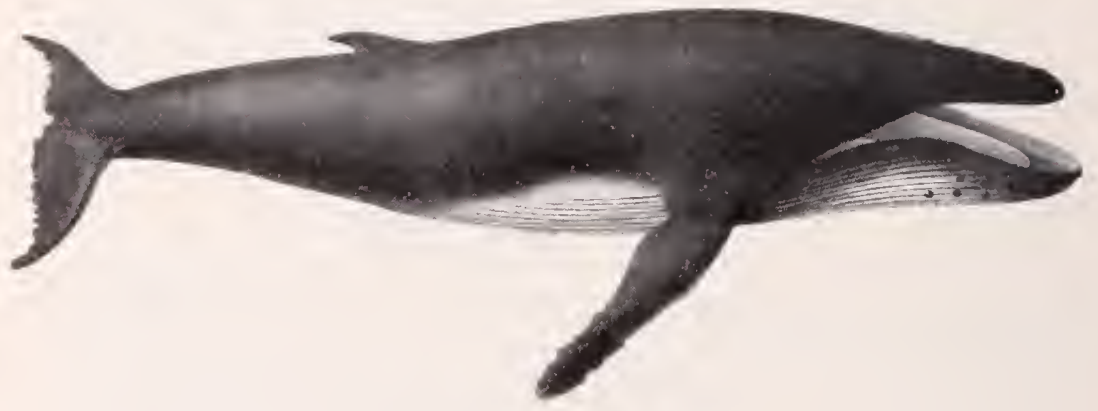

Fig. 258. Balaenoptera antarctica. Südsee. (Aus Siebold-Temminck Fauna Japonica.)

IIf S Nebenordnumg IDiungulati nom. nor. (Artiodactyli Owen).

Die bisherige Gruppe der Hnftiere nmfabte Lanftiere, die sich der Pflanzemahrung und der schmellen Bewegnng anf dem Boden anpaßten. Dabei verkiimmern ihre Eckzälne und die Höcker ihrer Backzïlme, die bei starker Abreibung flach und durch schmelzeinfaltung gehärtet werden, und inre mittleren Zehen richten sich anf ten Zehenspitzen anf, die mit breiten Hufen verstinkt werden. Ihe ältesten bisher bekannten fünfzehigen Vertreter stehen noch den ältesten Carnivoren so nahe, daß über ihre Abstammung von diesen kamm /Wwifel obwalten kömen. Aber es ist jetzt namentlich durch die klaren Darlegungen Gregorys höehst walıscheinlich, daß die Artiodactylen mit den ïbrigen Huftieren nicht eines Stammes sind, sondern sich selbstïndig von primitiven Ranbtieren abgezweigt habell.

Die Diungulati sind behaarte, pflanzenfressende, vierfüßige, parzehige Huftiere, doren dritte und vierte Zohe besonders mol grleichartig gekräftigt sind, währenct die zweite nud fünfte schwächer entwickelt sind und die erste in der Regel fentt. Der Calcaneus artikuliert mit der Fibula, der Astragalus artikuliert distal mit Naviculare nnd cuboid. Femmr ohne dritten Trochantor. 19 Rumpfwirhel. Von den msprünglich vorhandenen 3 Schneidezähnen könn’n die oberen nnd ebenso die Eck- 
zähne rerschwinden. Backzähne herbivor mit Höckern (hmodont) oder bogigen schmelzfalten (selenodont).

Jie "Paraxonia“ Marsh, die seit Owen gewöhnlich mit dem wenig klaren Namen "Artiodactyla" bezeichnet werden, sind vor allem ausgezeichnet durch die Kräftigung ihrer III. nnd IV. Zehen, die Ansprägnng der Gabelung ihrer Fußbildung, die schwache Ausbildung ihrer Praemolaren nnd was ihre Benennnng betrifft, so gibt wedel "artiodactyl" noch "paraxonial" einen klaren Begriff von der zweispaltigen Ausbildung ihrer FïBe. Dinugulati bringt das viel dentlicher zum Ausdruck und da wir erst in der Bildung von Systemen begriffen sind, so scheint es richtig praktische Torschläge auch da zur Geltung zu bringen, wo andere bereits gemacht sind und teilweise Eingang gefunden haben. Die Diungulati zerfallen in die natürlichen Gruppen der Wiederkäner und "Nichtwiederkäner". Tha der letztere Name auch in der lateinischen Form "Non ruminantii" als Negation wenig angebracht erscheint, so wollen wir ihn ersetzen dnrch

\section{Unterordnung Suiformes (Non Ruminantii).}

Normal kanende, meist bunodont bezahnte Dimngulaten mit freien Metapodien, hinterer Orbitallücke und mittlerem Scheitelkamm. Sit ent-

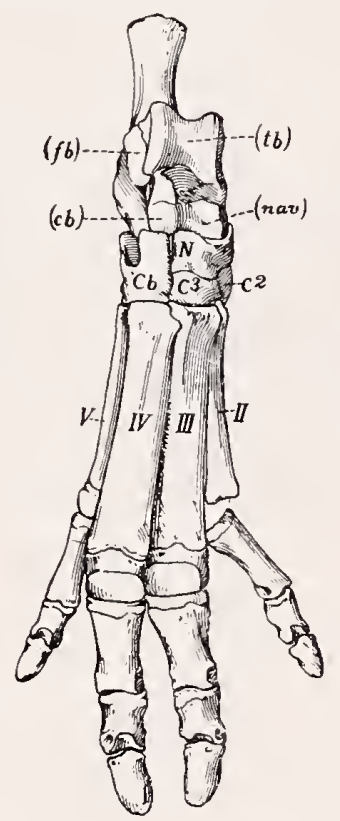

Fig. 259. Die Zehengliederung eines normalen und primitiven Diungulaten (Promerycochoerus) aus dem nordamerikanischen Tertiär. 
halten nach Gregory die Familien der tTrigonolestidae, †Dichobunidae, †Anthracotheridae, Hippopotanidae, †Achaenodontidae, †Entelodontidae, Dicotylidae, Suidar.

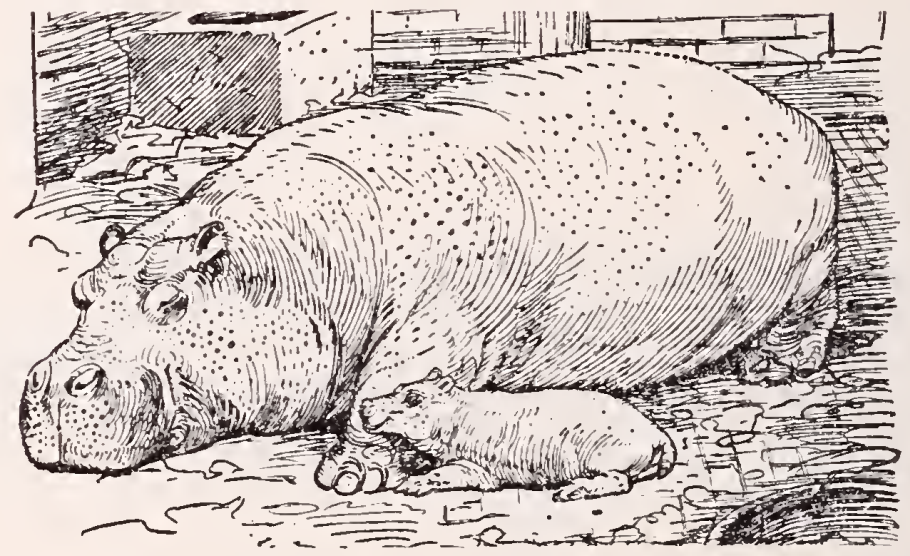

Fig. 260. Hippopotamus amphibius L., das Nilpferd. (Nach einer Zeichnung von Neumann.)

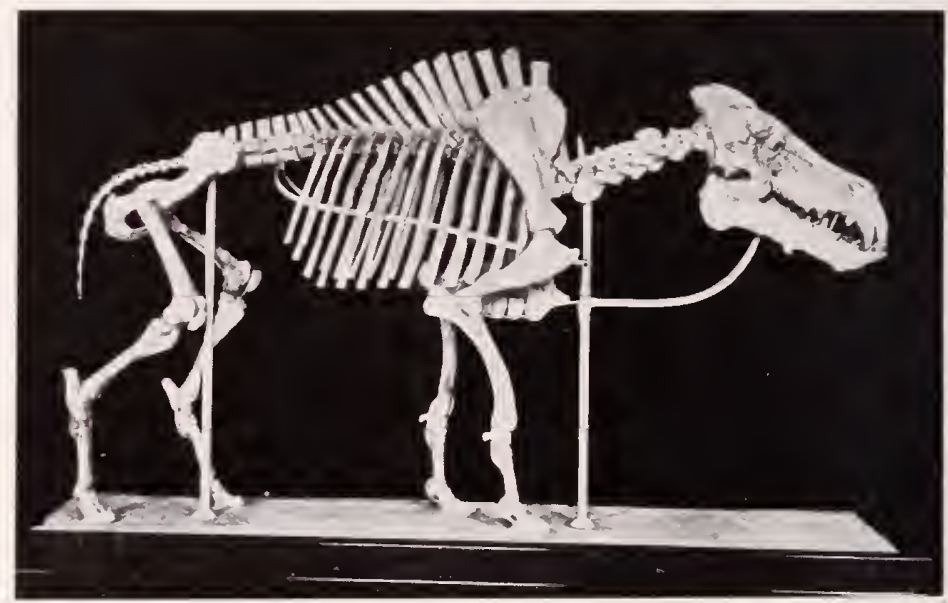

Fig. 261. Dinohyus Hollandi. Nach einem Skelett des Carnegie muscum. Ober-Oligozän. Nebraski.

2. Unterordnung Ruminantii, Wiederkäuer.

Wiederkäner mit rerschmolzenen Metapodien III und IV, selenodonten Zühnen, geschlossenem Orhitalkranz. Sie umfasseu die Familien der Camelidae, †Oreodontidae, †Anoplotheridae, †Hyertragulidae, Tragulidae, Cervidae, Merrcodontidae, Antilocapridae, Giraffidae, Bovidae. 


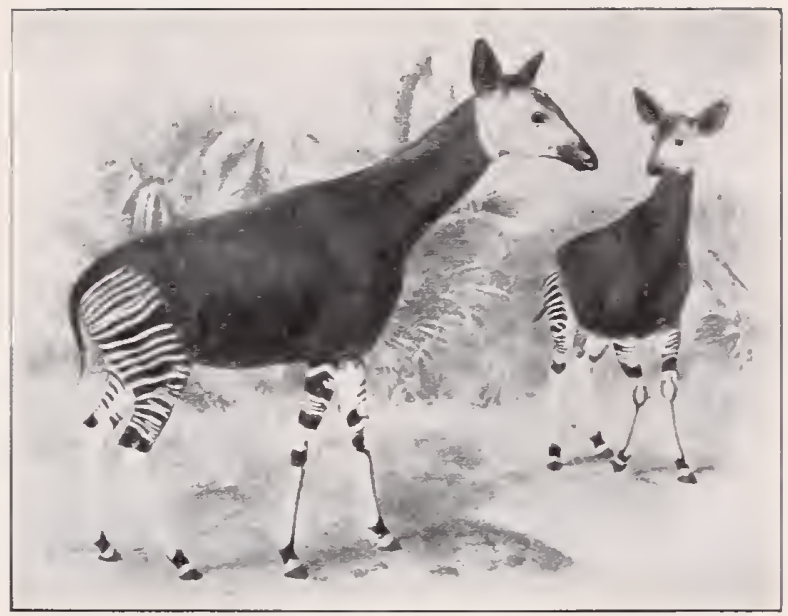

Fig. 262. Okapia Johnstoni Sclater. Lebend. Kongostaat. (Yach Lankester.)

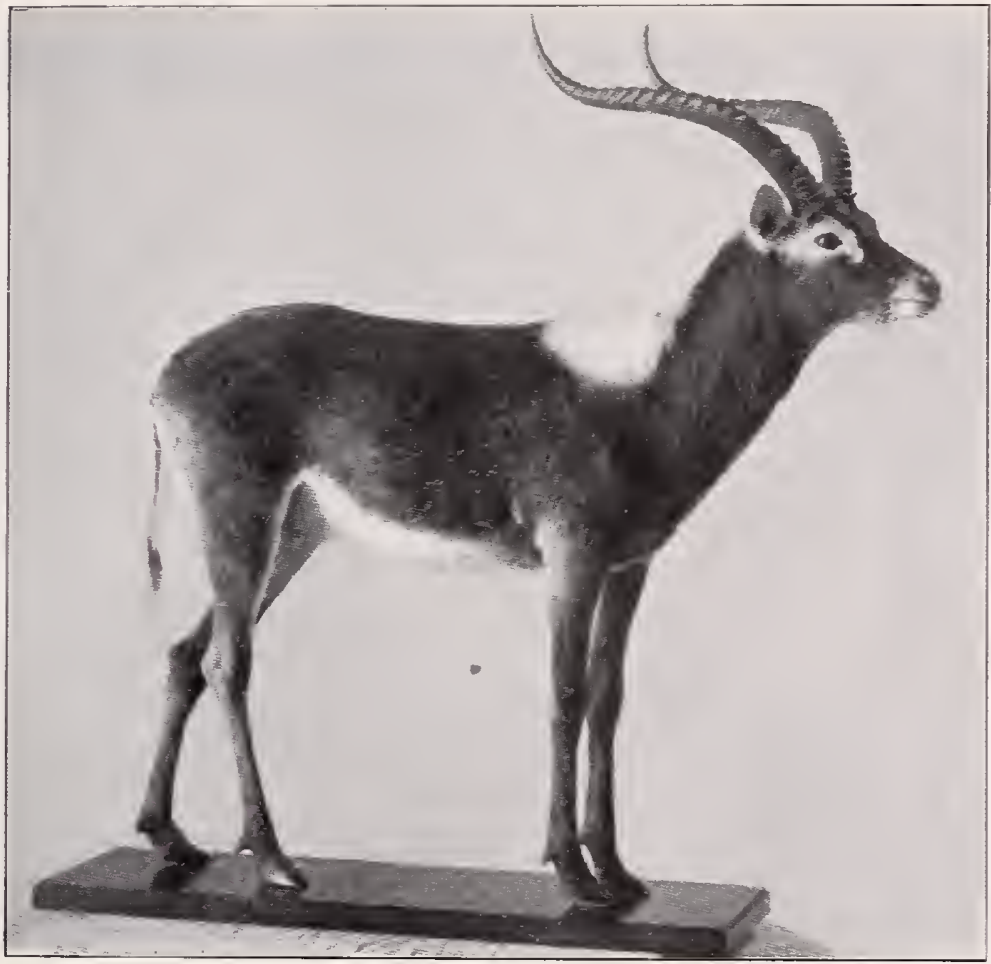

Fig. 263. Cobus Мaria Gray. Lebend am weißen Nil. (Nach einem Exemplar des Field Columbian Yuseum.) 


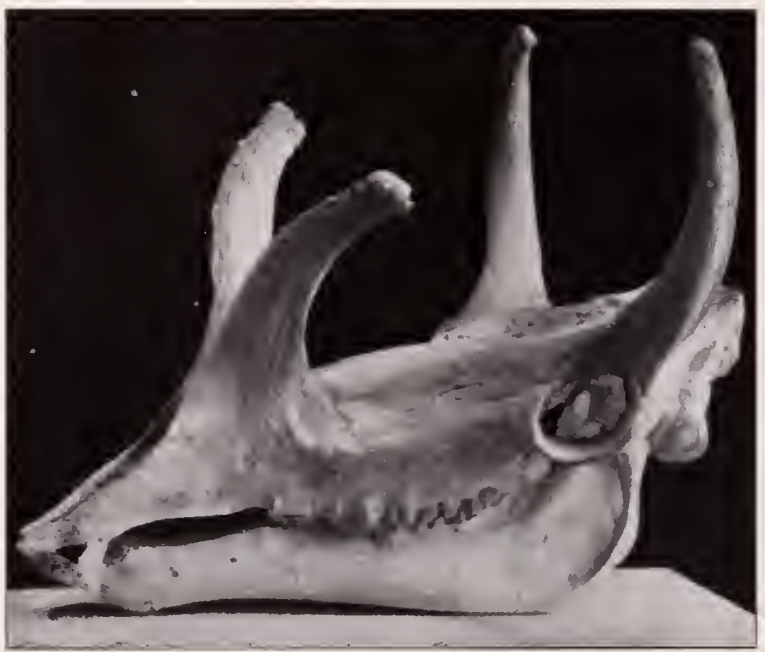

Fig. 26.t. Schädel ron Syndyoceras eines vierhörnigen Traguliden aus den oligozäuen Daemonelix-Schichten von Sioux County, Nebraska. U.S.A. (Nach Osborn.)

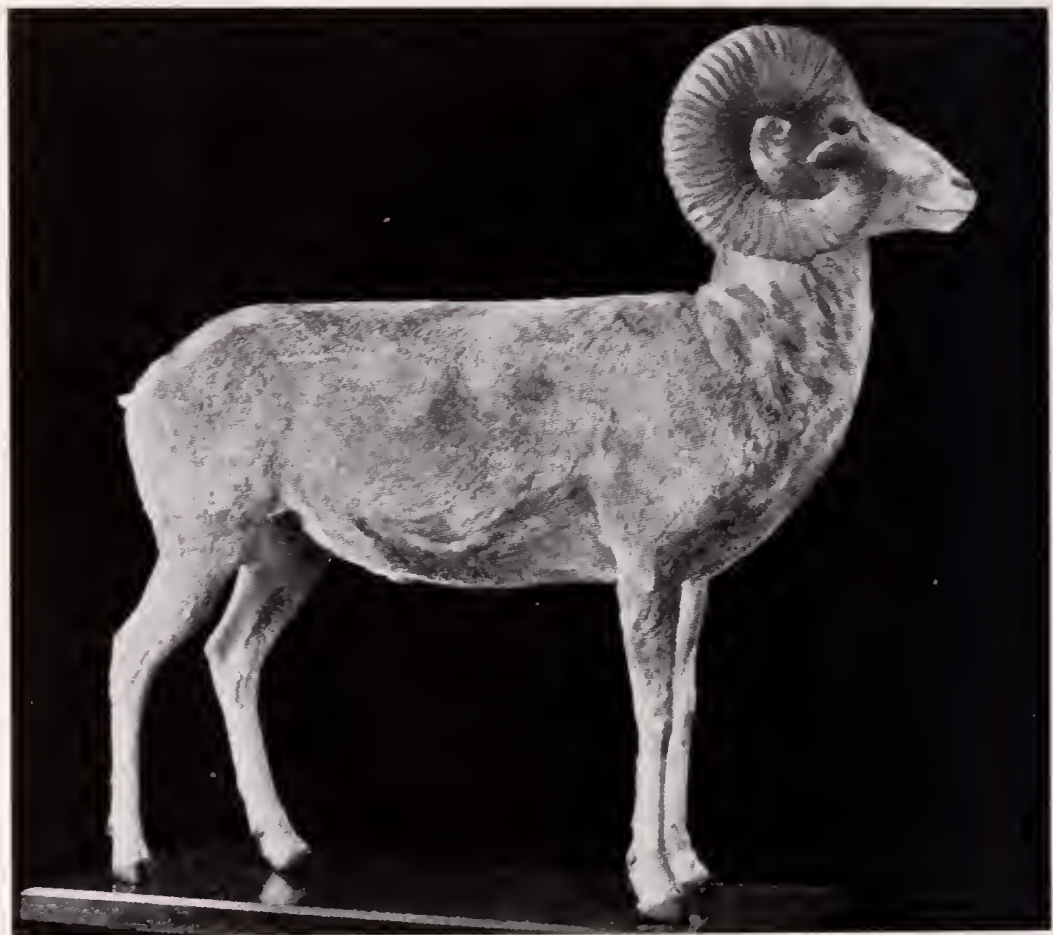

Fig. 26.5. Oris Ammon. Siidsibirien, Pallas. (Nach einem Exemplar des Field Columbian Yuseum. 
III $\gamma$ Vebenordnung 'Tubulidentata M. ITeber,

die im sinne M. Webers phyletisch ganz isoliert nnd auf die lebende und jungtertiäre Gattung Orycteropus (Erdferkel) beschränkt sind. Inre primatische Zahnstruktur hat zur Benemmng der Ordnmo Veranlassung gegeben nnd ist wohl mur als eine sekundäre Zerlegung einzelner Zühne in isolierte Höcker zu rerstehen, die ihre Schmelzkappe rerloren und bei hypselodontem Wachstmm nach unten verlängert wurden. Verhältnisse. wie sie in den Backzälnnen ron Phacochoerus nnter den Schweinen vorliegen, könnten den Ansgangspunkt dieses aberranten Zahntypen gebildet haben.

Unförmliche, schwach behaarte, insektenfressende, fünfehige sohlengänger mit langer Schnanze, großen Ohren. Ihre $4-5$ prismatischen Backzähne ans Irasodentin.

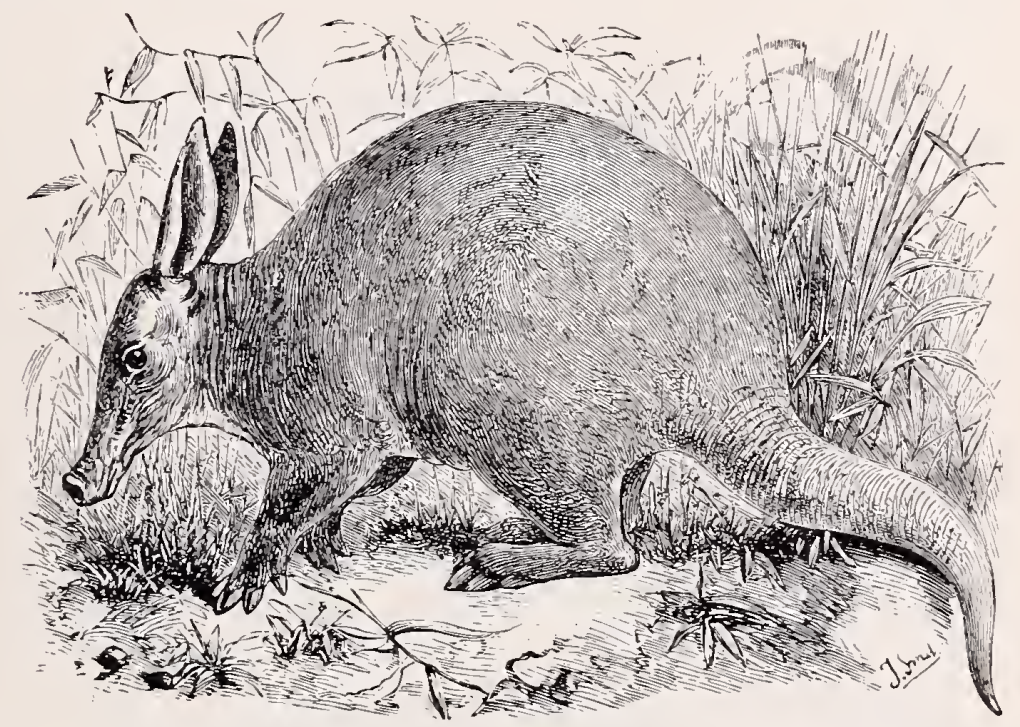

Fig. 266. Orycteropus aethiopius Sunday, das äthiopische Erdferkel. (Nach Sunday.)

\section{III $\delta_{1}$ Nebenordnung: Ungulati, Huftiere.}

Vierfüßige, pflanzenfressende Huftiere, deren Zehenban vielfach vereinfacht nnd deren Backzähne durch Einfaltnng der Schmelzkappe kompliziert werden.

Bei schmellem Lanfen kräftigen sich die mittleren Zehen und machen die seitlichen funktionslos, so daß sie vielfach rerkümmern.

Nach Ausscheidung der Artiodactyla als "Diungulati" (rergl. oben S. 232) umfassen die Ungulaten in diesem engeren sinne folgende Gruppen als Unterordnungen: 
1. Condylarthi.

2. Amblypodi.

3. Polydactyli (Hyracidae, Arsinotherikae, Proboscidiae).

4. Mesolactyli (Perissodartyli).

5. Notoungulati.

6. Litopterni.

\section{Unterordunne †Condylarthri Cope.}

Alttertiäre, plantigade Huftiere mit j Zehen, einfachen, zweireihigen Carnus, flachem schädel, vollständigem Gebib $\frac{3.1 .4 .3}{3.1 .4 .3}$. Humerns mit Foramen ulnare, Femur mit drittem Trochanter.

Ältestes Tertiäl vou Nordamerika nud Europa. Hierhin gehören die + Mioclaneidae. Phenacodontidae. Meniscotheridae. Pleuraspidotheridae.

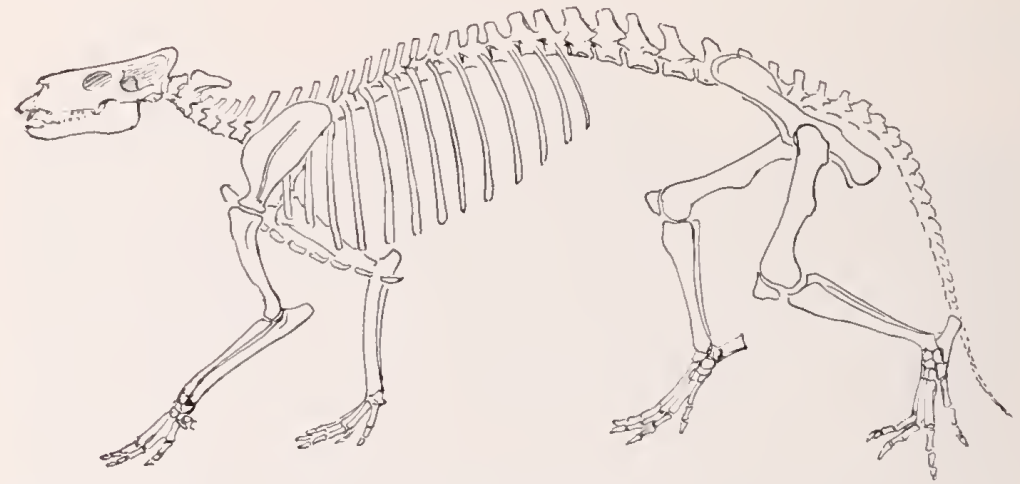

Fig. 267. Phenacodus primaevus Cope. Unteres Eozän. Bighorn Fluß Wyoming U.S. A.

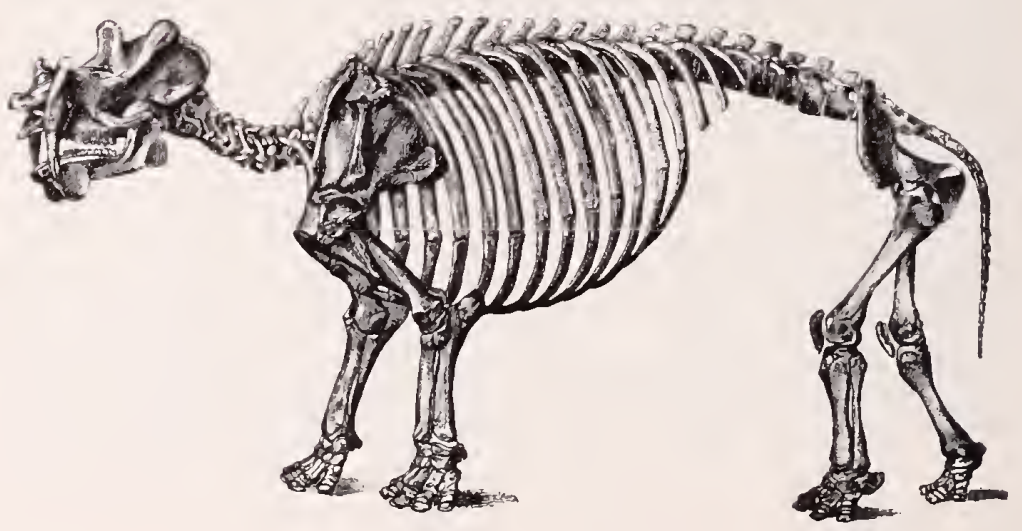

Fig. 268. Dinoceras mirabile Marsh. Eozïn. Colorado. (Nach Marsh.) 


\section{Unterordnung †Amblypodi Cope.}

Große, alttertiäre, nordamerikanische, plantigrade, fünfzehige Huftiere mit kleinem Gehirn, vollständigem, normal gegliedertem Gebiß mit mäßig gefalteten Zähnen. Die Carpalreihen alternieren, der Astragalus ist sehr breit, mit Tibia und Fibula artikulierend.

Hierhin gehören die Familien der Periptychidae, Pantolambdidae (Taligrada Osborn) und die großen Coryphodontidae und Dinoceratidae.

\section{Unterorduung Polydactyli m.}

Diese sollen enthalten die Elefanten, Klippschliefer und Arsinotherien, und entsprecheu damit der Ordnung der Subungulati Schlossers, aber mit Ausschluß der Sirenen. Die Gruppe der Proboscidier oder Rüsseltiere zerfällt ihrerseits in die sehr primitiven Moeritherien, die Badytherien, Dinotherien mit relatis kleinen und zahllreichen Barkzähnen

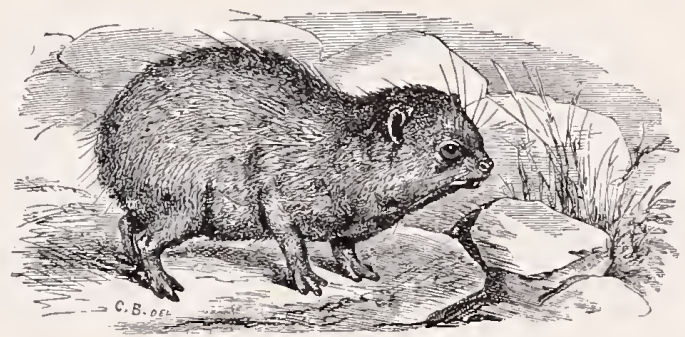

Fig. 269. Hyrax sinaiticus, der Klippschliefer. Lebend. Sinai.

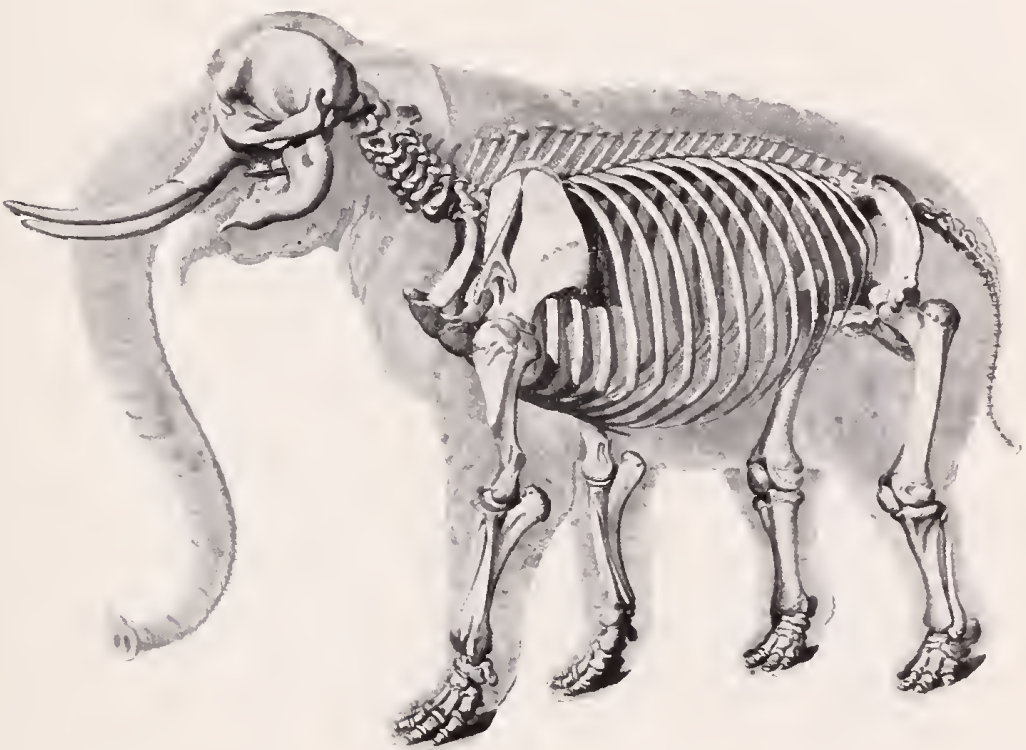

Fig. 270. Skelett und Umriß des indischen Elefanten, Elephas asiaticns Blumenbach (indicus Cuv.). (Nach Pander und d'Alton.) 
nnd groben Incisiven im Unterkiefer nnd die Elefanten im engeren simne (Fig. 271) mit ihren riesigen Incisiven und ihren an Zahl sehr reduzierten in sich mehr und mehr vergröBerten Backzähnen.
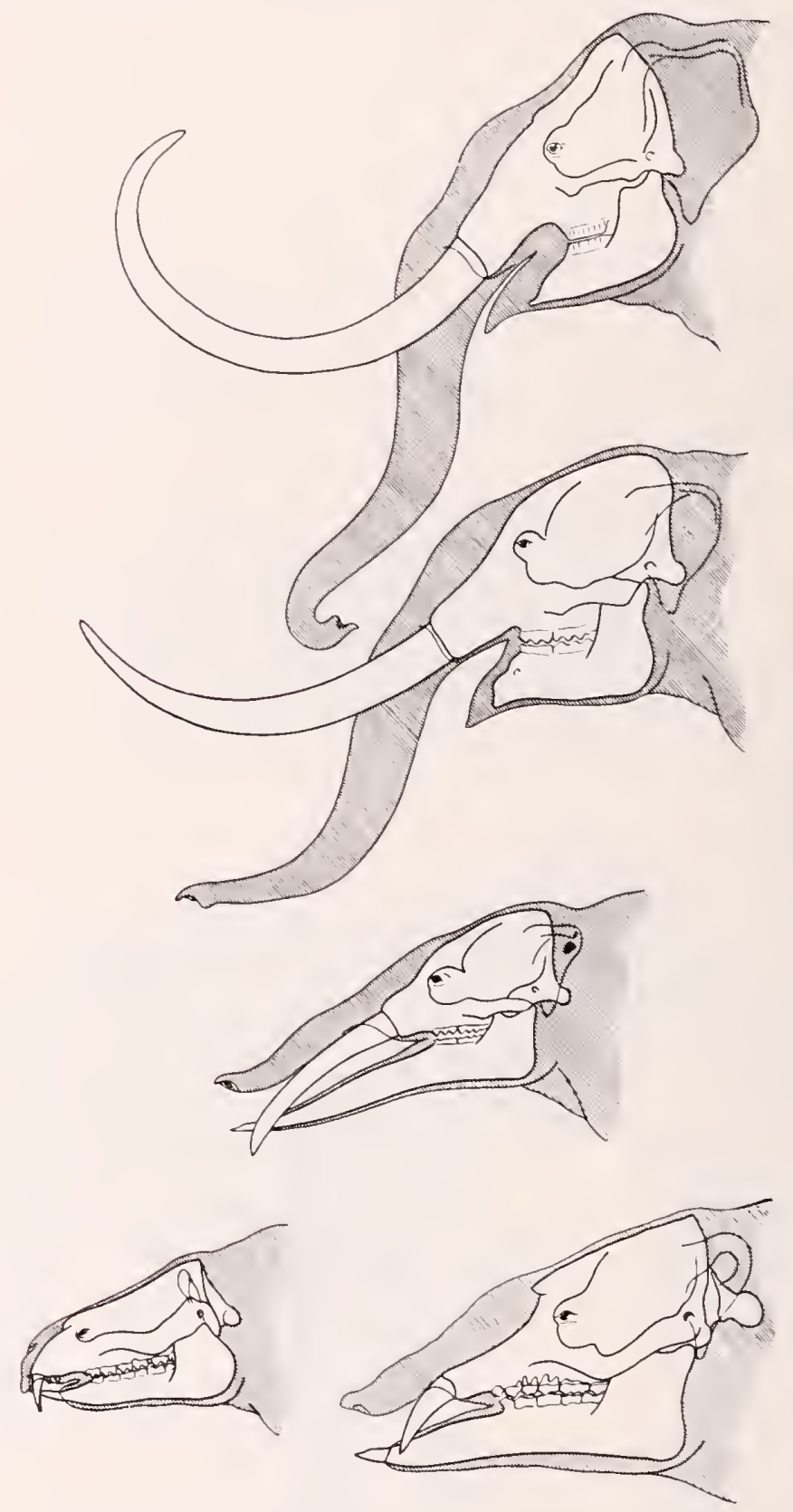

Fig. 271. Die Schädelformen der Elefanten nach Lull.

Unten links Moeritherium; unten rechts Palaeomastodon; dariiber Tetrabelodon: darüber Mastodon; oben Elephas. 


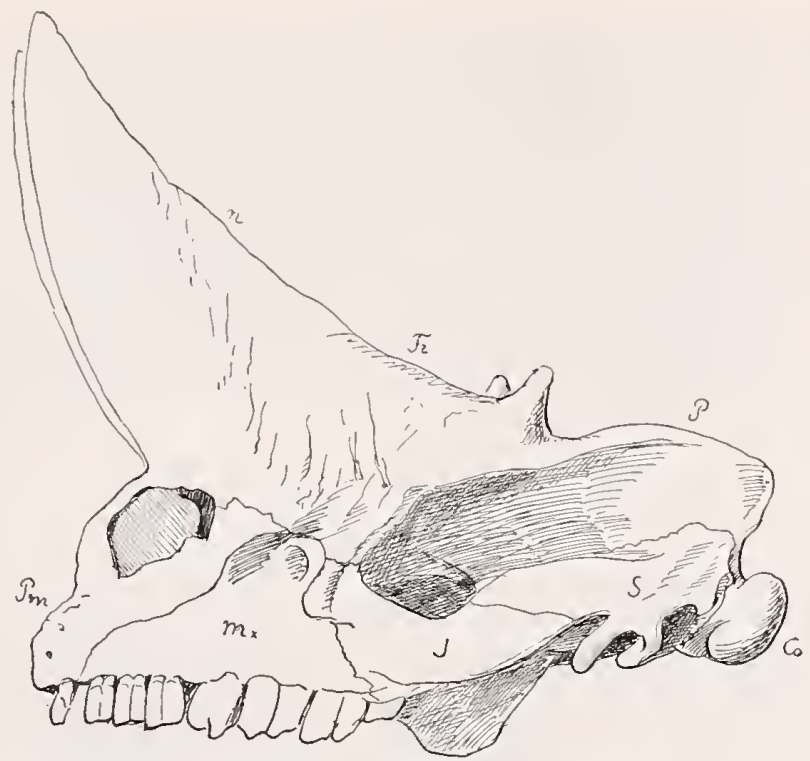

Fig. 272. Arsinotherium Zitteli Andrews, Schädel. Oberes Eozän. Fajum, Ägypten.

4. Unterordnung Mesodactyli (Perissodactyli Owen).

Zehengänger mit stark vergrößerter, zum Teil allein restierender Mittelzehe (III), mit zahlreichen, mäBig großen, stark gefalteten Zühnen.

Hierher gehören die vorn vier-, hinten dreizelıigen Tapiriden (Fig.273), die im Alttertiär durch Lophiodon vertreten sind, dann die Rhinoceronten mit +-3 Vorder- und 3 Hinterzehen (Fig. 27t, 275), die schlieBlich einzehigen Equiden mit den mehrzehigen Torfahren der Hyıcotherien, der Palaeotherien, Anchitherien und Equinen (Fig. 276, 277) nnd der den Rhinoceronten ähnlichen Titanotherien (Fig. 278).

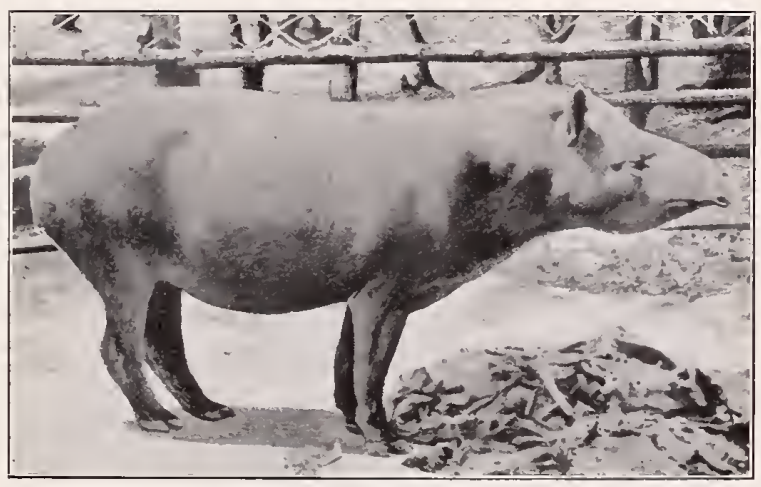

Fig. 273. Tapirus americanus Briss. Südamerika. (Nach eiuer Photographie ans dem zoologischeu Garten in Lissabon.) 


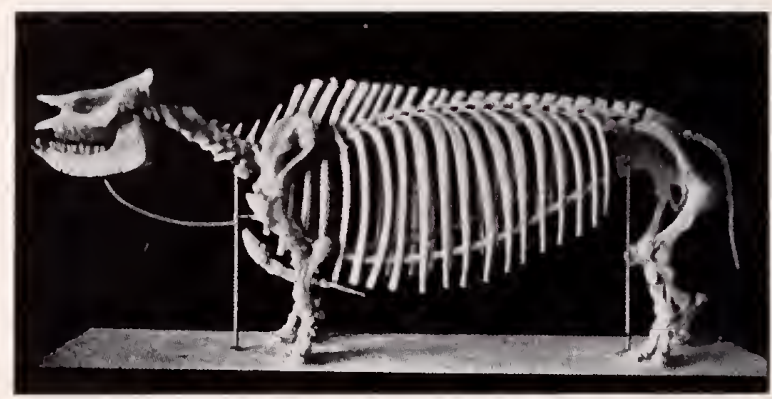

Fig. 274 .

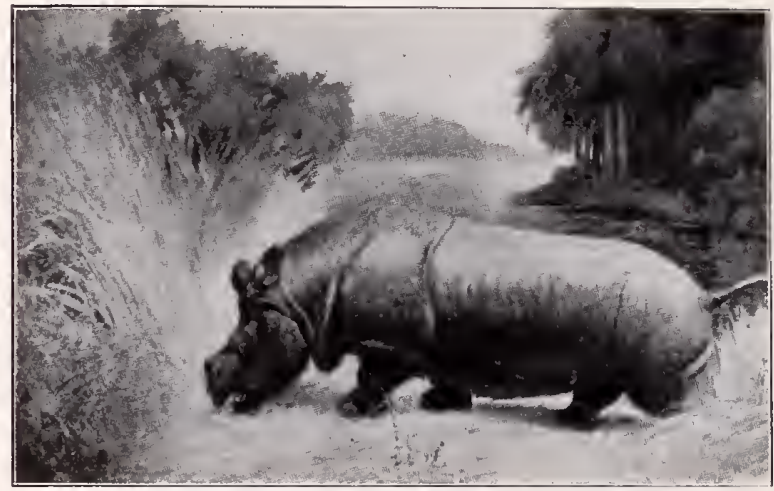

Fig. 275. Teleoceras fossiger, ein Rhinoceront aus dem Miozän von Kansas L.S. A. Oben Fig. 27t, das Skelett derselben Form, nach dem die untere Rekonstrnktion gegezeichnet ist. (Nach Osborn.)

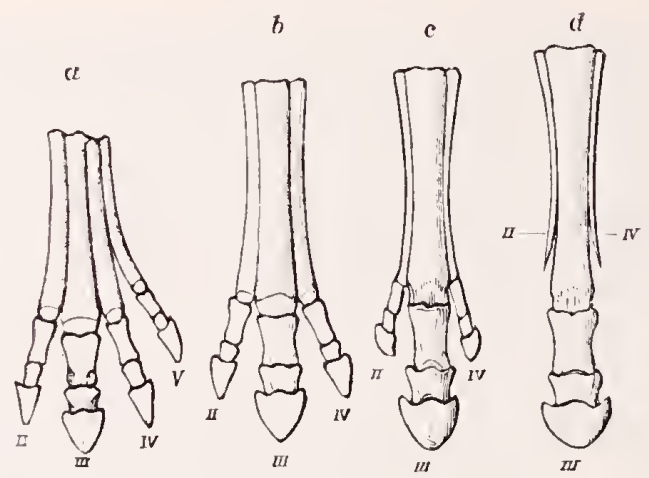

Fig. 276. Die Zehen der tertiären und lebender Pferde, die tertiären restanriert. a Orohippus, $b$ Miohippus, $c$ Hipparion, $d$ Equus. $I I-V$ die zweite bis fünfte vordere Zehe. 


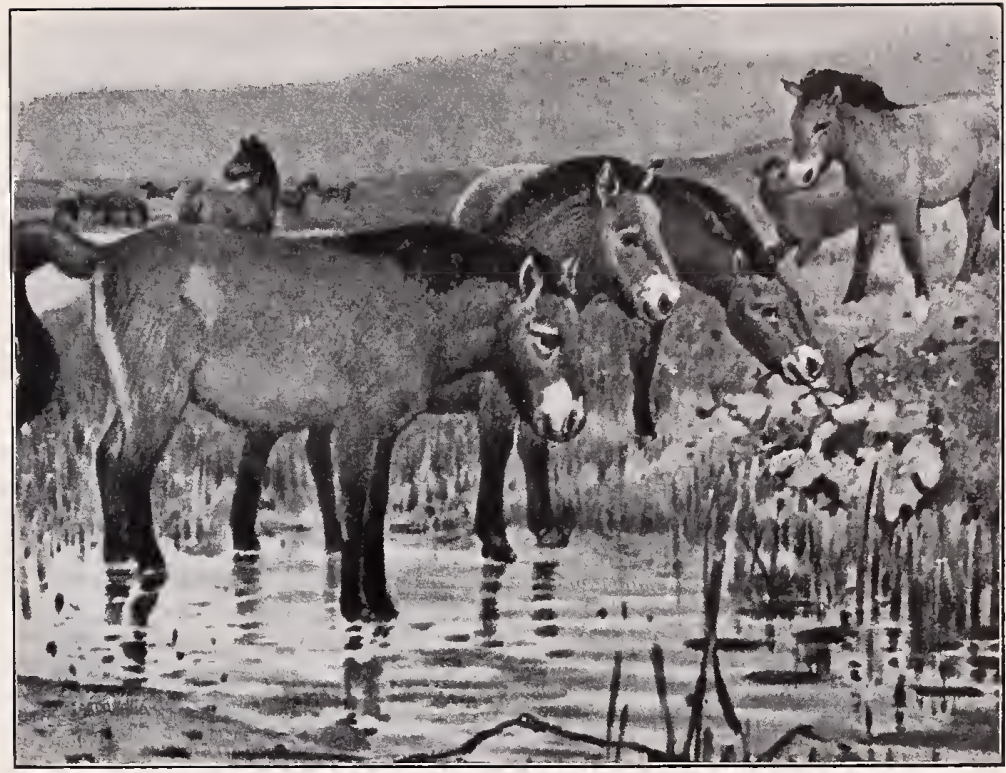

Fig. 277. Gruppe des mongolischen Wildpferdes, Equus Przewalskyi Poljakow, das mit unseren nordischen Ponys verwandt ist und dessen Kopfumriß Pferde-Zeichnungen der diluvialen Menschen entspricht. (Gez. von P. Neumann in Westermanns Monatsheften.)

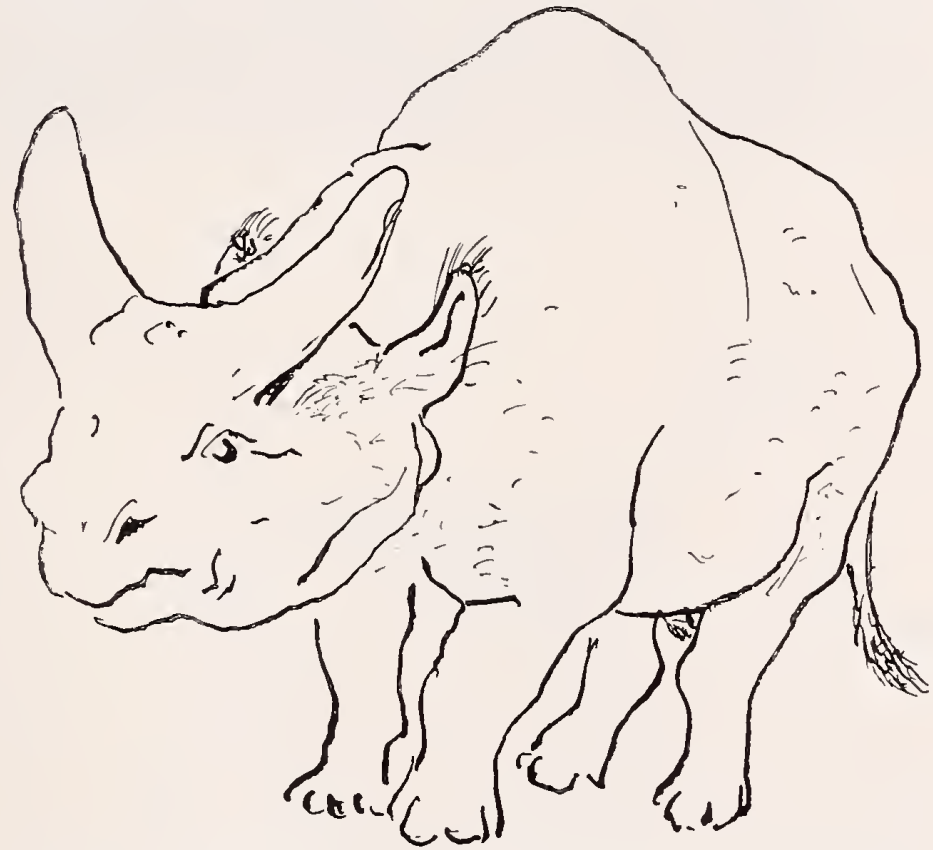

Fig. 278. Brontotherium gigas, ein Titanotherier aus dem Miozän von Süd-Dakotah U.S. A. (Nach Osborn.) 


\section{Unterordnung +Notoungulati Santj. Rotlı.}

Sïdamerikanische tertiäre plantigrade oder semiplantigrade Pflanzenfresser mit 5-3 \%ehen, mit Klanen, K’allen oder Hufen, flachen Schädeln mit dicker Mastoidregion, hohem Unterkiefer. Zahnreihe lang geschlossen, meist mit großen ersten Incisiven und prismatischen, mäBig gefalteten Backzähnen.

Hierunter werden ron dem argentinischen Paläontologen santiago Roth zusammengefaßt die Typotherii Zittel, Toxodontii Owen, Astrapotherii Ameghino und die Protherii Schlosser.

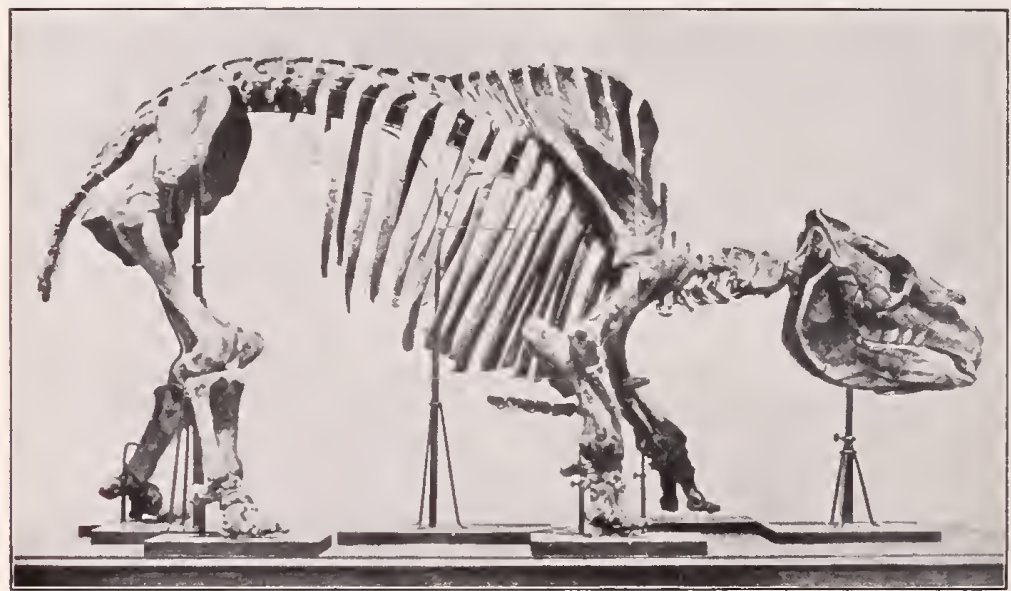

Fig. 27\%. Toxodon Burmeisteri. Pampasformation. Rio Arrecifes bei Buenos Aires. (Nach Sintiago Roth.)

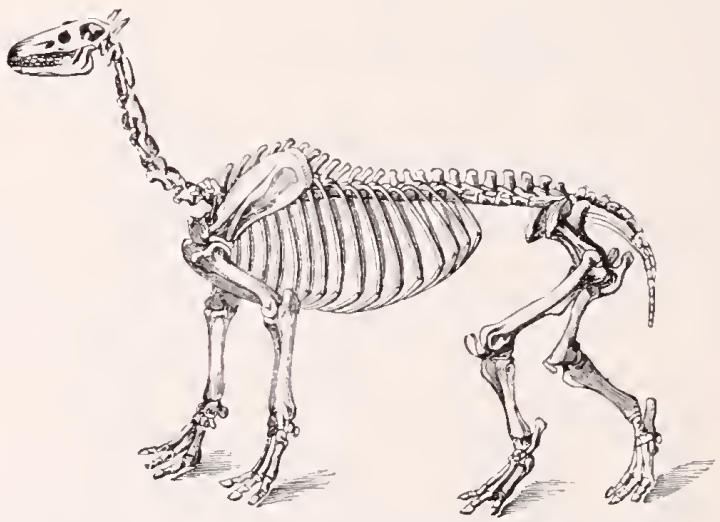

Fig. 2§o. Macranchenia patachonica Owen. Diluvium. Südamerika. (Aus Zittel, Paläontologie.) 
6. Unterordnnng tLitopterni Ameghino.

sindamerikanische tertiäre Huftiere nit zweireihigem Carpns und Tarsıs, meist mit rednzierter Zehenzahl. Schneidezähne rednziert. Backzähne meist vollzählig, mäßig gefaltet.

Hierhin gehören die Bmolitopternidae, die bis in das Diluvium erhaltenen Macranchenidae (Fig. 280), die Proterotheridae und Adiantidae.

III $\delta_{2}$ Nebenordnung Sirenii, Seekühe.

Ije Seekühe mit ilıren rerkïmmerten Hinterbeinen nnd ihrer breit gestellten Schwanzflosse sind, nach den fossilen Tertretern und rielen Organisationsverhältnissen der lebenden zn nrteilen, Nachkonmen prinitiver terrestrischer Ungnlaten, vermutlich aus der Terwandtschaft alttertiärer Condylarthra. Ihre vorderen GliedmaBen sind flossenförmig ihren hinteren rüickgebildet, desgleichen ilne Behaarung. Der Schwanz ist wie bei den Walen mit einer horizontal gestellten Flosse versehen. Sie enthalten die Manatidae (Schuppentiere), die Halicoridae und die alsogestorbenen Rhytinidae. 


\section{Alphabetisches Sachregister}

A canthaspidi 38

Acantholi 71, 72

Acanthordopsidae 72

Acanthopterygii 95

Acanthostoma 113, 114

Acanthuridie 95

Accipitres 178

Acichelydae 187

Acipenseridi i0, 51

Achaeuodontilae 2:34

Acrorlelphidae 231

Acrodoutidae 58

Adapidae 215

Adiantilae 245

Aepyornis 17i

Aetobatis 58, 59

Aetosauri 164

Affen 216;

Aistopodi 118

Albulidae 89

A'actromorphae 175

Alepidosauridae 92

Alepocephalidae 90

Alopecodon 182

Amblotherium 206

Amblyopsidae 92

Amblypodi 239

Amblypterus 81

Ameiseufresser 225

Amii 84, 85

Ammodytidae 95

Amphibamu 109

Amplibia 126;

Amphichelydii 185

Amphioxus +1

Amphipnoidae 91

Amphisilidae 93
Amphistiidae 97

Amphitherium 206

Amphimua 129

Anabantidae 95

Anableps 92

Anacanthini 95

Anaptomorphus 215

Anarosauridae 148

Auaspidi 37

Anchitheridae 241

A uguillidae 91

Anomaluridae 222

Anomodontii 189

Anoplotheridae 234

Anostenidae 186

Anseriformes 178

Antemnariidae 98

Authracosaurus 111

Authracotheridae 234

Authropi 220

Anthropithecus 219

Authropomorphi 219

Autilocapridae $\mathbf{2 3 4}$

Anura 130

A patemyidae 211

A pateon 109

Apodes 91

Appenticularia 20

Apternodontidae $\mathbf{2 1 0}$

Apteryx 175, $17 \overline{6}$

Archaeoceti $\mathbf{2} 30$

Archaeomeuidae 89

Arrhaeornithes 170

Archaeosauria 136

Archaeosuchus 182

Arehegosaurus $107,108,111$,

112
Archeucephala 198

Archonta 213

Aretocephalu, $\mathbf{2 3 0}$

Aretocyonidae 229

Arctoidea 229

Aristodesmus 123

Arsinotherili 2:39

Arsiuotherium 241

Artiodactyli 232

Ascidia 19, 21

Ascilii 20

Aspidorhynchi 83

Aspredinitlae 90

Asterolepidi 38

Asterolepis 38

Astrapotheridae 244

Asymmetrou 41

Ateles 216, 217

Atheriniidae 9.5

Atlantosauridae 159

Atoposauridae 164

Auchemosteidae 48

Anlorlynehidae 93

Aulostomatidae 93

Aves 167

Badytheridae 239

Baena 18.5

Balaenidae 232

Balaenopteridae 232

Balistidae 99

Bartenwale 2:32

Bdellodus 58

Bdellostoma 40

Cestracionti 57

Cetacei 2:30

Cetominidae 92 
Chaetodontidae 9.5

Champsosauri 147

Characinidae 90

Charadriiforues 175

Cheirolepis 81

Cheloue 187

Chelonii 1s6

Chelydridae 186

Chelyidae 186

Chelrosoma 21

Chiasmodontidae 9.5

Chilomys 123

Chimaeri 5ั4, วั

Chimaeropsis 5̆

Chinchillidae 2.2.

Chiracanthus 72

Chiroceutridae 90

Chiromy: 215

Chiropteri 211

Chirothricidae 2

Chlamylophoridae 205

Chlamvdoselachidae 60,61

Choudrostei 49, 50, 51

Chrysochloridae 210

Chrosochloris 211

Ciconiiformes 178

Cinosternidae 187

Cladacanthus òt

Cladobatidae 210

Cladodus 60

Clavellina 21

Clupeidae 90

Cobus 2:35

Coccostei 47

Coccosteus 47

Cochliodus 53

Coelolepis 36

Colymbiformes 179

Colymbomorphae 178

Compsemys 185

Condylarthri 2:38

Conchopoma 78

Copiula 130

Coraciformes 179

Coraciomorphae 179

Coryphaenirlae 95

Coryphodontidae 239

Cottidae 97

Cotylosauria 121

Creodonti $2 \cdot 27$
Belemobatis 65

Belodonti 16:3

Belonorhynehi sif

Belouostomi \&4

Beryciden 9:

Beutehatten 206

Bimani 218

Birkenia $3-$

Blemuiidae 4

Bolotun 207

Bothriolepis 38

Botryllus 21

Bovidae 234

Bradypus, Faultier 224

Branchiosauri 109

Branchiostoma 41

Brontosaurilae 159

Brontotherium 2+3

Bruta 198

Bunodontia 199

Bunolitopterni $2+5$

Calamoichthys 79

Callorhynchus 54

Camarosauridae 159

Camelidae 234

Canidae 229

Capitosauridae 112

Carangidae 95

Carcharidae 63,64

Carnivori 22:

Castor 2202

Castoridar 22.2

Casuarii $17 \overline{5}$

Catarhini 217

Catopteridae 83

Catosteomi 93

Caturus 86;

Caudata 129

Caviidae 222

Cebidae 216

Centetes 210

Centetidae 210

Centrascidii 22

Centriscidae $9:$

Centrobati 58

Cephalaspidi 34

Cephalaspis 30

Ceratiidae 98

Ceratodus 78
Ceratodontidae

Ceratopsidae 161

Ceratrpteridae is

Cervirlae 2:34

Crocodili 164

Cromeriidae 90

Crussopteryoii 75

Cryptobranchia 129

Cryptodiri 186;

Crypturi 175

Ctenacorlon 208

Ctenodactylidae $\mathbf{2} 22$

Ctenodontirlae 78

Cteuothorissidae 89

Cuculiformes 179

Cyamodus 151, 152

Cyathaspis :32

Cyclobatidae 64

Cyclopteridae 97

Cyclostomata 38

Cycloturus 225

Cynodictys 220

Cynodontornys 211

Cynodraco 195

Cynognathus 194

Cyprinidae 90

Cyprinorlontidae 92

Dactylopteridae 97

Dalliidae 92

Dasyceps $11 t$

Dasypodirlae $\mathbf{2 2 5}$

Dasyurus 207

Datheosanrus 122, 124, 125

Delphine 231

Delphinognathus 182

Dercetidae 93

Dermatemydidae 187

Dermochelydidae 187,188

Derotlemen 129

Deuterosaurus 182

Diadectidae 128

Diademorlon 195

Diceratosaurus 118,120

Dichobunidae $\mathbf{2} 34$

Dicotylidae 234

Dicynodontidae 189, 190, 191

Didelphii 206

Didelphops 207

Dimetrodon 144 
Dinichthyidae 48

Dinocephali 181

Dinoceras 238

Dinoceratidae 239

Dinohyus 234

Diuomis 175

Dinosauri 157

Dinotheridae 239

Diodontidae 99

Diplacanthi 72

Diplocaulus 118, 121

Diplodocidae 159

Diplosoma 22

Diplosomoides 19

Dipnoa 77

Diprotodonti 209

Dipteri 77

Dipus 222

Discocephali 97

Distaplia 1!

Diungulati 232

Dolichosauridae 118

Doliolum 23

Drepanaspidi 35

Drepanaspis 36

Dromasanri $1 \& 2$

Dromatherium 205

Dryolestes 206 ;

Dryopithee'us 220

Duplicidentati 221

Fcheneidae 97

Echidna 196, 197

Echinorhinidae 62

Edentata 224

Eleplas 240

Elginia 124

Elopidae 89

Emlallouuridae 213

Empedias 123

Emylidae 187

Enchodontidae 92

Endothiodoutidae 189

Entelodoutidae 234

Eotetrapoda 102

Epanorthidae 209

Eplacentalia 198

Equidae 242

Erinaccus 211

Eryopidae 111
Erythrosuehus 156, 157

Esocidae 92

Esoterodou 189

Euguathi 85, 86

Eurlinodelphidae 231

Eurypholis 92

Eusteuoptherou 76

Eutheria 199

Exocetus 94

Falconiformes 178

Faultiere 224

Felidi 228

Fierasfer 93

Fissiperlii 2027

Fistulariidae 93,94

Fledermäuse 211

Garlidae 95

Galechirus 182

Galeopithecus 213

Galesauridae 195

Galli 175

Ganoceplaali 101

Ganodonti 22-4

Garzoniidae 209

Gastrosteidae 93

Gavial 164

Geomyidae 2029

Geosauridae 164

Gephyrostegi 137, 138

Giblon 218

Gigantactinidae 98

Ginglymustoma 63

Giraffidae $\mathbf{2} 34$

Glanosuchus 182

Glyptorlontidae 225

Glyptolepis 76

Glyptopumus 80

Goliiilae 17

Gorilla 220

Gomploguathus 194, 195

Goniaspidi 33

Gouiopholidae 164

Gonorhynchidae 90

Goodsiria 21

Gravigradi 225

Gresslyosaurus 158

Gruiformes 175

Grypotherium 225
Gürteltiere 225

Gymnodoutes 99

Gymnotidae 90

Gyrencephala 198

Gyrodus 83

Gyproptychidae 75

ILall,affen 213

Halicoridae 245

Halmaturus 209

Halosauridae 93

Hapalidae 216

Haplochitonidae 92

Haplodouti 204

Haplomi 92

Haplosauri 118, 119

Haptodus 142

Hasen 221

Hemiloranchii 93

Hemimyarii 24

Hemispoudyla 106

Herpestoidea 228

Hesperoruis 174

Heteroceres 79

Heterodontus 57

Heteromi 20

Heterostraci 32

Heterostei 48

Hexanclius 61

Hicranodonta 225

Hippopotanidae 234

Holocephalia 52

Holoptychii 75

Holosauria 141

Holospoudyli 117

Holostea 73

Holotheria 227

Homea 40

Homo 220

Homosteus 47

Hoplopteryx 96

Huftiere 227

Hyacuidae 228

Hylodontidae 58

Hydromedusa 18.5

Hylaeolatraclus 126

Hylobates 218

Hylonomidae 118

Hyodoutidae 89

Hyopsodontidae 211 
Hyperoartia 39

Hyperorlapedon 147

Hyperosauria 155

Hyperotreta 39

Hypertragulirlae $2: 34$

Hypobythius 21

Hypomycteri 229

Hypospondyli 39

Hypospondylus 40

Hypostomata 45

Hypotheria 199

Hyrax 239

Hystrix 221

Hystricognathi 222

Janassa 56

Ichthyormithes 178,179

Ichthyosauri $140,1+1$

Icosteidae 95

Iguanodontidae 159,160

Indrodon 211

Insektenfresser 209

Insectivori 209

Ischnacanthidae 72

Jugulares 97

Kadaliosaurus $142,14 t$

Katzen 228

Kneridae 92

Koiloskiosaurus 139

Kurtidae 97

Labidosaurus 125

Labridae 95

Labyrinthorlonti 112

Lacerti $15 \mathrm{t}$

Lagomyidae $\mathbf{2 2 1}$

Lammidae 6:3

Lamprididae 93

Lanarkia 36

Lasanius 37

Lellur 216

Lemuri 215

Lepidosirenidae 78

Lepidostei 8., 8.3

Lepidotus 82

Leporidae 221

Lepospondyli 101, 117

Leptictidae 210

Leptocardia $f 1$
Leptolepidae 89

Leptosteidae 48

Limnerpeton 118

Lipogenyidae 93

Lipotyphla 210

Lissencephala 198

Litopterni 245

Lophiodon $2+1$

Lophius 98

Lophobranchii 93

Lophotidae 98

Loricariidae 90

Loricata 225

Loricati 162

Lrcosamrus 195

Lycosuchus 182

Lyognathi 152

Lysorophus 128

Lystrosaurus 189

Vacaken 218

Macrauchenia 244

Macropetalichthys 46

Macrophthalmia 40

Macropodidae 209

Macroscelidae 210

Malacopteri 88

Malacopterygii 88

Malacostomata 29

Malthidae 98

Iammalia 197

Manatidae 245

Manis 226

Marmosa 206

Marsipobranchii 38

Nartes 229

Mastarembelidae 98

Mastodon 240

Maulwürfe 210

Meerkatzen 218

Meerschweine $2 \cdot 2 \cdot 2$

Megachiroptera 212

Megalichthyidae 79

Megalonyx 2.25

Megalosauri 1.58

Megahnus 85

Megatherii 225

Menaspis .53

Mene 96

Meniscothericlae 238
Meniscoessus 20s

Menotyphla 210

Merycodontidae $\mathbf{2 3 4}$

Mesodactyli 241

Mesolippus 242

Mesopetalichthys 46

Mesopithecus 217

Iesorhinus 163

Mesosauli 139

Mesotheria 209

Metachiromyidae 2.25

Metatheria 199

Metopiadae 112

Metriorhynchidae 164

Microbrachidae 118

Microbrachium 38

Microchiroptera 213

Microconodon 205

Microgomphodon 195

Jicrolepidoti 81

Microloplidae 111

Microsauria 117

Mioclaenidae $2: 38$

Miosauria 115

Miotheria 204

Mixodectidae 211

Mola 99

Molge 129

Molgophidae 118

Moeritheridae 239

IIonascirlii 20

Monodelphia 199

Monorhina 38

Ionotremati 195

Mormyridae 89

Mosasauri 154

Mugil 94, 95

Multitubereulati 207

Inrapnidae 91

Muraenolepidae 95

Mfuscardinus 223

Mnstelidae 63, 229

Mutelata 198

Myilae 222

Myliobatis 58, 59

Mrlodon 225

Mylostonia 48,49

Myoxidae 222

Mrriacanthiden jt

Mrrmecolius 207 
Myrmecophaga 226

Myrmecophagi 2:5

Mystacoceti 232

Mystriosuchus 164

Myxine 40

Mrxini 40

Nagetiere 221

Naosauri 144, 145

Natalidae 213

Nerrolemur 21.5

Necrolestidae 210

Nectridei 11s

Nemichthyidae 91

Neoceratodus 78

Neoplagiaulax 208

Neornithes 170

Neoseopelus 92

Notacanthi 93

Notharetus 215

Notoryetiden 207

Nothosauri 147,148

Notidani 61

Notopterilae 89

Notorhynchus 62

Notoungulati $24+4$

Nürschania 111

Nycticebidae 215

Ocapia 235

Ochotonidae 221

Octorlontilae 2:22

Odontoceti 231

Odontoleae 1it

Olbodotes 211

Oligopleuridae 86

Onychodonti 76

Ophiderpetondidae 118

Ophidii 15.5

Ophidiidae 97

Ophiocephatidae 95

Opisthoctenorlon 189

Opisthomi 98

Opossums 206

Orang 220

Oreodontidae 234

Oreopithecus 218

Orohippus 242

Ornithodelphia 199

Ornithorhynchus 196, 197
Orodontidae is

Orycteropus $\mathbf{2 3 7}$

Ostariophysi 90

Osteoglossidae 89

Usteolepidi 79, 80

Ostracionidae 99

Otaria 230

Otariilae $\mathbf{2} 29$

Oris 236 i

Oxyglossus 130

Oxyosteus 49

Pachycormidae 86

Pacliyosteus to

Palaeaspis 32

Palaeohatteria 142,143

Palaeomastodon 240

Palaeoniscillae 79

Palaeoniscus 81

Palaeospondylus 39

Palaeosqualidi 59

Palaeostraci 31

Palaeotherien 241

Pantorlontilae 89

Pantolambdidae 239

Pantolestidae 210

Paraeturus 229

Paranthropi 219

Parasuchia 163

Paratheria 180

Paraxonii 233

Pardonuchus 182

Pareiasauri 122, 137

Pariotychus 124

Passeres 179

Paviane 21s

Pediculati 98

Perliomys 207

Pegasilae 94

Pelargomorphae 177

Pelomerlusa 187

Pelomedusen 186

Pelosaurus 109

Pelycosauria 14

Perameles 209

Peramelidae 207

Percesores 94

Percidae 95

Perciformes 95

Percopsidae 92
Perennibranchiata 129

Periptychidae 2:38

Perissorlactyli 240

Petromyzon 40

Petromyzontes 40

Phalangeridae 209

Phaneropleuridae it

Pliascolomyidae 209

Phenacodontidae 238

Phlyctaenaspis 46

Phocidi 229

Pholidophoridae 83

Pholidosauridae 164

Pholidosteus 45

Pholidoti 226

Phororhacos 175

Phractolaemidae 90

Phrynixalus 130

Phyllosomatilae 213

Physeteridae 231

Pinnepedii 227, 229

Pistosauridae 148

Pithecanthropus 220

Placentalia 198

Placorhelys 151, 153

Placodermata $4+4$

Placollonti 150

Placoidea i1

Placophori 225

Plagiosterni 109, 110

Plagiaulax 208

Plastomenilae $18 \overline{7}$

Platanistidae 2:31

Platychelys 185

Platyosteilae to

Platyrhini 216

Platyomi 81

Platysternidae 187

Plectognathi 98

Plesiadapis 215

Plesiosauri 149

Pleuracantlıus 60

Pleuraspilotheridae 238

Pleurodiri 185

Pleuronectidae 97

Pleuronectiden 97

Pliopithecus 220

Policipes 179

Poliosauridae $1+4$

Polyarrodus 57 
Polycodu. 21.)

Polycotylus 150

Polydactyli 239

Polymastodon 20:

Polynemidae 9.5

Polyodonti 50, ¿1

Polyprotodontia ?06

Polypteri 79

Polyrhizodus 5-

Polysphenodon 146

Porthens 90

Postpubici 15:9

Potamogalidae 210

Praepubici 15s

Pristerognathus 182

Pristidae 64

Pristiophoridae 62, 63

Proboscidii 239

Procellarii 179

Procolophonii 138

Prodicynodon 189

Ploganochelys 184, 185

Proganosauri 139

Proglires 211

Promammalia உ00

Proostea 70

Propolynustodon 209

Prosimiae 213

Proteles 20s

Protelidae 228

Proterotheridae 245

Protodonti 205

Protoferi 227

Protopteri 78

Protorosauri 142

Protostegidae 93

Protosyngnathidae 93

Prototheria 199

Protriton 109

Psammodus 54

Psephurus 51

Psephoulus 56

Pteranorlon 166

Pteraspidi 3:3

Pteraspis 33

Pterichthyi 37

Pterichthys 38

Pterodactylus 165. 166

Pteropodidae 212

Pterosami 165
Ptychodontidae

Ptychostei 46

Pycnodonti 84

Pyrosoma 22

Pyrotherii 24t

Python 15.5

Pythonomorpha 154

Rajidae 64, 66;

Ratitae 175

Raubtiere 207

Reptilia 131

Rhamphodus 50

Rhamphorhynchus 165, 166

Rheae 175

Rlinidae 61

Rhinobatidae 64

Phinolophidae 213

Rhinoorontidae 241

Rhinoptera òs

Rhinoraji 64

Phinosteus to

Rhizodontidae

Rhombodus 58

Rhynchodonten 50. 51

Rhynchosauri 146

Phytinidae 245

Rodentii 221

Puminantii 234

Saccopharyngidae 91

Sagecephalus 189

Sagenodontidae $7 \mathrm{~s}$

Salmonidae 90

Salpa 23

Salpi ․ㅡㄹ

Saurischia 158

Saurodontilae 90

Sauropoda 159

Sauropterygii $14 i$

Scapanodon 182

Scaridae 95

Scelidosauridae 159

Scelidotherium 225

Schildkröten 183

Schimpanse 219

Schlankaffen 218

Schuppentier $\mathbf{2} \mathbf{2} 6$

Sciaenidae 95

Scincosaurilae 118, 119
Sriurugnatli ?2:2

Sciuridae $2 \cdot 2 \cdot 2$

Sclerocephali 110, 111

Srlerodermi 99

srleroparei 97

Sclerosamrus 123,124

Scombresocidae 95

Scombridae 95

Scombriformes 95

Scopeliılae 92

Scorpaenilae 97

Seylaeosaurus 182

Scyllidae 63

Scylliolamnidae 63

scymnosaurus 182

Seehunde 20.9

Seekühe 24

Selache 63

Selachii 5.5

Semionotidae 83

Serranidae 95

Silurilae 90

simia 220

Simiae 216

simoerlosaurus 147

Simosauridae 1 t8

Simplicidentati 221

Sirenii 245

Solenostomidae 94

Soricidae 210

Sparidae 95

Sphenisci 179

Sphenodonti 145, 146

Sphyraenidae 95

Spinacidi 62

Spitzmäuse 210

Sprinemau, 222

Squalodontilae 231

Squalus 62

Squatina 61

Stachelschwein 222

Statorlonti 56

Stegurephala 101

Stegosamidae 1fil

Stephanoberycidae 92

stereornithes 175

Stereospondyli 101

Stereosternum 139

Stomiatidae 90

Stromateidae 95 
Struthiones 175

Stummelaffen 218

Sturii 51

Subungulati 239

Suidae 234

suiformes 233

symbranchii 91

Synaptobranchidae 91

Synascillii 21

Syndyoceras 236

Syngnathiclae 94

Taeniodonti 224

Taeniosomi 98

Taligrada 239

Talpidae 210

Tamandua 2.2;

Tamiodontia 199

Tapiridae 241

Tardigradi 224

Tarsii 215

Tarsius 214

Tarsipedidae 209

Tatusia 225

Taxeopoda 199

Teleoceras 241

Teleosaurilae 164

Teleostea 87

Teleostomata 66

Temnospondyli 101

Testudinata 183

Testudinilae 187

Tetrabelorlon 240

Tetragonurilae 95

Tetraporła 100

Tetrodontidae 99

Thaliaceae 22

Thaumatosaurus 150

Thelodonti $36 \mathrm{j}$

Thelorlus 36

Therapsidi $18 \underline{2}$

Theridomyidae 222
Therictoidea 200

Theriodontii 193

Therocephali 182

Theropleura $1+4$

Thyestes 35

Thylaciniden 207

Thylacoleonirlae 209

Tillodonti 2.23

Tillotherium 224

Titanosuchus 182

Tolypaspis 32

Tomistomidae 164

Torpedinidae 64,65

Toxochelydae 187,188

Toxodontii 244

Trachinidae 97

Trachyacanthi 52

Trachypteridae 98

Tragulidae 934

Tremataspidi 34

Trematocephali 114

Trematosaurus 112

Triacanthidae 99

Triceratops 161

Tricheclidae 229

Trichiuridae 95

Triconodon 205

Triconodonti 204

Triglidae 97

Triglyphis 208

Trigonolestilne 234

Triodontidae 99

Triouveliii 187

Trirachodon 195

Trirostri 63

Trissopidae 83

Tritosternidae 187

Trituberculati 206

Tritylodon 208

Trogolemur 211

Trygonidae 59

Tubulilentati $2: 37$
Turbinares 179

Turnices 170

Tursiops 231

Tylosaurus 1 กิ

Typhlomolge 129

Typotherii 244

Udenodontidae 192, 193

Uintasorex 211

Undina 76

Unguiculata 198

Ungulati $2: 37$

Uranoscopidae 97

Urocordylidae 118

Urodela 129

Uronemi 77

Urosauri 118

Urislae 229

Ursocanidi 229

Urwale 230

Vermilingua 225

Vespertilionilae 213

Vipera 155

Viverra 228

Viverridae 228

Vultur 177

Wale $\mathbf{2 3 0}$

Wiederkäuer $23+$

Xenarthri 224

Xiphactinus 89

Xiphiidae 95

Zahnwale 231

Zeatermes 96

Zeuglodon 231

Zeus 96

Zoarcidae 97

Zygaena 64

Zygobatis 58 


\section{Arten und Varietäten}

und ihre Entstehung durch Mutation. An der Ĺniversität ron Kalifornieu gehaltene Torlesungen ron Hugo de Vries. Ins Deutsche übertragen ron Professor Dr. H. Klebahn. Mit 53 Textabbildungen. Geheftet 16 Mlk., gebunden 18 Mlk.

\section{Das Problem der Befruchtungsvorgänge}

und andere cytologische Fragen ron Prof. Dr. B. Némec. Vorstand des pflanzenphỵsiologischen Institutes der k. k. böhnıischen Unirersität Prag. Mit 119 Abbildungen in Text und ๖ lithographischen Doppeltafeln. Geheftet 20 Mrk., gebunden 23 ㅍk. 50 Pfo.

\section{Leitfossilien.}

Ein Hilfsbuch zum Bestimmen ron Tersteinerungen bei geologischen Arbeiten in der sammlnng und im Felde ron Professor Dr. G. Gürich.

Erste Lieferung: Kambrium und Silur. 'Text: Bogen 1 bis 6 und Tafel 1 bis 28 . subskriptionspreis 14 Mk. 80 Pfg.

Zweite Lieferming: Devon. Bogen 7 bis 12 und Tafel 29 bis 52. Sulskriptionspreis $1+\mathrm{Mk}$.

\section{Kulturpflanzen und Haustiere}

in ihrem C̈hergange aus Asien nach Griechenland und Italien sowie in das übrige Europa. Historisch-linguistische skizzen rou Victor Hehn. Achte wesentlich umgearbeitete Auflage, herausgegehen ron Prof. Dr. 0. Schrader, mit botanischen Beiträgen ron A. Engler und Ferd. Pax. Geheftet ca. $14 \mathrm{Mk}$. in Halbfranz gebunden ca. 16 Yk. 75 Pfo.

\section{Kleinasiens Naturschätze,}

seine wichtigsten Tiere, Kulturpflanzen und Mineralschätze von Karl Kannenberg. Mit 31 Vollbildern und 2 Plänen. GroßOktav. In Leinen gebunden $14 \mathrm{Ml}$. 


\section{Beiträge zur Naturdenkmalpflege.}

Heransgegeben von Geh. Regierungsrat Prof. Dr. Conwentz. Band I mit 36 Textablildungen und 1 Tafel. In Halbleder gehunden $13 \mathrm{Mk}$. $50 \mathrm{l}$ I'fg.

Band 1l. Heft 1: Die erratischen Blöcke im Regierungs-Bezirk Danzig von Dr. R. Hermann mit botanischen Beiträgen von Prof. Dr. G. Lindau. Nlit 30 Textabbildungen und einer lithographischen Karte. Geheftet 3 Mk. 50 Pfg.

Band III: Die Monographie des Plagefenn-Reservates enthaltend, befindet sich im Druck.

\section{Die Gefährdung der Naturdenkmäler und Vorschläge zu ihrer Erhaltung.}

Denkschrift. dem Herrn Minister der geistlichen, Unterrichtsund Medizinalangelegenheiten überreicht vom Geh. Regierungsrat Prof. Dr. H. Conwentz. Vierte Auflage. In Leinen gebunden 2 Nlk. $20 \mathrm{Pfg}$.

\section{Die Heimatkunde in der Schule.}

Grmollagen nud Vorschläge zur Fördernng der natmoreschichtlichen und geographischen Heimatkunde in der sichule von H. Conwentz. Zweite vermehte Anflage. In Leinen gehmulen 3 Mk. 50 Pfo.

Schutz der natürlichen Landschaft, vornehmlich in Bayern. Sach einen Vortrag in der zn Miinchen am 1. Oktoher 1906 alıgraltenen .Jahresversammlung des Bumdes Heimatschutz von H. Conwentz. Steif broschiert $75 \mathrm{Pfg}$.

Gedanken und Vorschläge zur Naturdenkmalpflege in Hohenzollern

ron Fürst Wilhelm von Hohenzollern. Geheftet $811 \mathrm{Pf} g$. 


\section{Bibliothek für naturwissenschaftliche Praxis}

hermsgegeben von Dr. W. Wächter.

Bd. I: Praxis der Linsenoptik in einfachen Versuchen zur Èläntermog nnd Prïfung optischer Instrmmente ron Dr. Wilhelm Volkmann. Vit 36 Textabbildungen und 4 T'ifeln. Taschenbuchformat. Gebmuden 3 Mk. 50 Plg.

Bd. II: Anleitung zum praktischen Studium niederer Tiere (Protozoa, Coelenterata, Vermes, Echinodermata) von Dr. W. Schleip, Privatdozenten an der Universität Freiburg i. Br. Mit 56 T'extabbildmngen. Gehunden 3 Mk. 50 Pfg.

Bd. III: Die praktische Bodenuntersuchung. Eine Anleitung zmr Untersuchung, Benrteilnng und Verbesserung der Böden mit besonderer Rïcksicht auf die Bodenarten Norddentschlands ron Prof. E. Heine. Mit 25 Textabb. n. einer geolog.-agronomischen Karte. Gebunden 3 Mlk. 50 Pfg.

Bd. IV: Praktikum der experimentellen Mineralogie mit Berïcksichtigung der kristallographischen und chemischen Grenzgebiete von Dr. Ernst Sommerfeldt, Professor an der Technischen Hochschnle zu Aachen. Mit 61 Textahbildungen und einer Tafel. Gebunden 4 Mk. 8n Pfg.

Die Bücher der "B. f. n. Pr." sollen dem, Anfänger eine Anleitung zu praktischen Arbeiten auf allen Gebieten der Naturwissenschaft geben. Wenn auch die Elemente der einzelnen Disziplinen als beliannt vorausgesetzt werden, so wird doch das Bestreben der Mitarbeiter dahin gehen, durch Einfachheit der Darstellung und instruktive Abbildungen ihre Praktika für weitere Kreise nulzbar zu machen.

Im Interesse eines gründlichen Studiums werden in der "Bibliothek für naturwissenschaflliche Praxis" vielfach nur Spezialgebiete der einzelnen Disziplinen bchandelt, da bei dem geringen Unfang der Bände eine Anhäufung des Lehrstoffes nur auf Kosten der Klarheit möglich wäre, wodurch die Praktilia für den Selbsiunterricht unbrauchbar wïrden. 


\section{Einführung in die experimentelle Vererbungslehre}

ron Professor Dr. phil. et med. El'win Baur. Mit 80 Textfiguren nud 9 farbigen Tafeln. In Ganzleinen gebunden $10 \mathrm{Mk}$.

\section{Zeitschrift für induktive Abstammungs- und Ver- erbungslehre}

heransgegeben von C. Correns (Münster), V. Haecker (Stuttgart), G. Steinmann (Bonn), R. v. Wettstein (Wien), redigiert ron E. Baur (Berlin).

I He Zeitschrift rscheint in zwanglosen Heften, ron denen fünf einen Band bilden. Der Preis des Bandes beträgt 20 Mk. Bamd I- $\mathrm{V}^{r}$ liegen abgeschlossen vor. Band VI befindet sich in Erscheinen.

Die auBerordentliche Entwickehno der Abstammungs- und Tererbungslehre hat in den letzten Jahrzehnten die einschlägige Literatur gewaltig anwachsen lassen, und es ist heute bereits sehr schwierig, einigermaben einen Iberblick über diese Literatur zu behalten. Die Publikationen erscheinen zndem zersplittert in geologischen. zoologischen und botanischen Fachzeitschriften, in periodischen Schriften zahlreicher natmwissenschaftlicher Vereine und in den Berichten von Akakemien und lnstituten. Lebhaft machte sich daher das Fulen eines Zentralorganes fïhlbar. - Diesem [̈belstande begegnet die .Zeitschrift für induktive Alstammungs- und Vererbungslehre", deren sechster Band zu erscheinen begonnen hat. - Die Zeitschrift hringt unter Nitwirkung hervorragender Forscher

1. Abhandlungen. welche nenes, für die Abstammungsund Tererbungslehre withtiges 'Tatsachenmaterial enthalterl,

2. kleinere Mitteilungen ans denselben Gebieten, besonders vorläufige Wittcilungen über noch unveroffentlichte Untersuchnngen, ferner Rundfragen und wissenschaftiche Diskussionen,

3. Referate und Autoreferate iiber allgemein wichtige Arbeiten.

4. Bibliographie. 




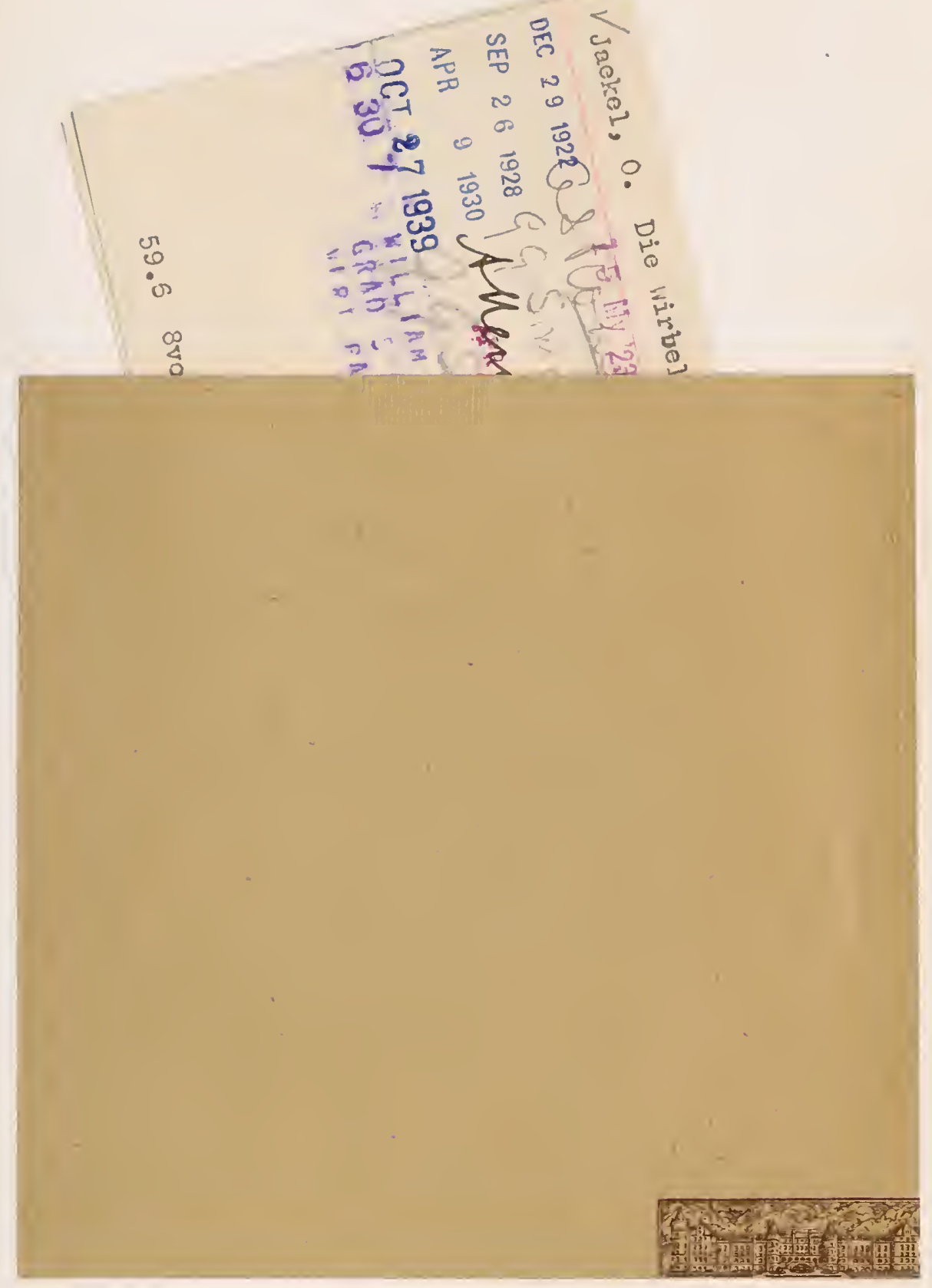


